\title{
Bearing Capacity of Multilayer-deposited In-line Flocculated Oil Sands Tailings
}

\author{
by \\ Elizaveta Rozina \\ B.Eng., Carleton University, 2013
}

A thesis submitted to the Faculty of Graduate and Postdoctoral Affairs in partial fulfillment of the requirements for the degree of

Master of Applied Science

in

Civil Engineering

Department of Civil and Environmental Engineering

Carleton University

Ottawa-Carleton Institute of Civil and Environmental Engineering

Ottawa, Ontario

(C) 2015, Elizaveta Rozina 


\section{Abstract}

Oil sands tailings exhibit poor consolidation and settling behavior when conventional deposition techniques are used; therefore tailings management is a great challenge in the oil sands mining industry. The objectives of this research were to gain an in-depth understanding of the dewatering behavior of polymer-amended mature fine tailings (MFT) deposits, and to study the bearing capacity of these tailings. Polymeramendment is one of many technologies being investigated in the oil sands industry.

Polymer-amended MFT that imitates field samples was generated and both, thin $(0.30 \mathrm{~m})$ and thick $(0.50 \mathrm{~m})$ multi-layer deposition dry box tests were performed. The dry box testing to studied how dewatering behaviors progress as layers are dried and more layers are added, and how cracking influences the evaporation rates. Core samples were extracted before the addition of each layer in each dry box experiment to investigate the history of dewatering with respect to gravimetric water content, total suction, osmotic suction, and total organic content. Shear strength and plate load tests were performed to determine undrained shear strength; and bearing capacity respectively between the additions of each new layer for each dry box test.

Results with respect to dewatering suggest that thin lifts may be more beneficial for quicker land reclamation. Matric suction was found to have a strong influence on the bearing capacity of polymer-amended MFT. 


\section{Dedication}

To my wonderful parents, Maria and Serguei Rozin, who have always given me the best of everything.

To my dear fiancé, David Kolkman, who always believes in me. 


\section{Acknowledgements}

The completion of my Master's studies would not have been possible without the support and encouragement of many individuals. I would like to acknowledge everyone who has been a part of this journey.

The opportunity to pursue my studies would not have been possible without the guidance, continued support, and endless patience of my supervisor, Professor Paul Simms. Thank you very much for giving me such an incredible opportunity to be a part of this project, and all the time and effort you have invested in my studies.

I would have been completely lost without the technical support provided by the laboratory staff of the Civil and Environmental Engineering Department. Thank you, Stan, Marie, Jason, Pierre, Ben and Ken, for going above and beyond whenever the "pair of trouble-making girls" asked you for any assistance.

Thank you to Shabnam, my "partner in crime", for the endless hours you have spent in the laboratory with me, setting experiments up, and showing me the ropes. I am very lucky to have had the opportunity to work with, and to be inspired by you.

A special thank you to Professor Rayhani, for encouragement and steering me towards graduate studies, and the support during my studies as well.

I would also like to acknowledge all of the professors that I have taken courses with during my studies, especially Professors Vanapalli, Rennie, Sivathayalan, and Mamadou. I have learned so much from you, and applied a lot of that knowledge into the execution of this project.

Momin, you have my sincerest gratitude for lending an extra hand, whenever I needed it, and for looking after the dry box whenever I couldn't. Thank you also for being part of the "dry box deposition crew", and the days you dedicated to getting the experiements started. 
Thank you, Manuel, for also being part of the "dry box deposition crew".

I would also like to thank a few friends for their contributions to my studies. Sebastian, thank you for your technical and photographic support. Alex, thank you for coming into the laboratory with me during your visit.

Johanne Trickey, thank you for instilling a passion for learning in me, ever since I was little, and being there all these years.

Alla Makarova, thank you for your support and care.

To my XCOttawa, and Carleton Nordic Ski Team teammates, thank you for keeping me sane, with our insane workouts, during all of my time at Carleton.

Thank you to my family for your love and support, for being so accommodating all these years.

To my fiancé, David, thank you for being a constant source of love, support and encouragement. 


\section{Table of Contents}

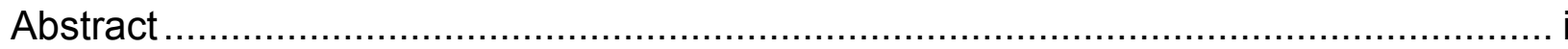

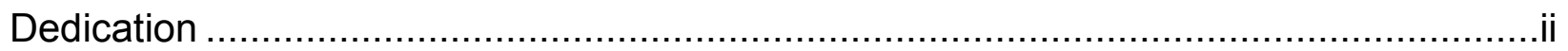

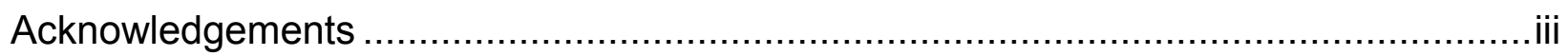

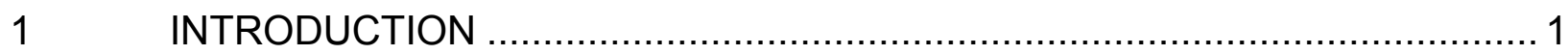

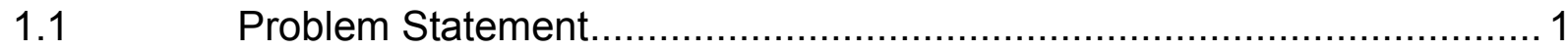

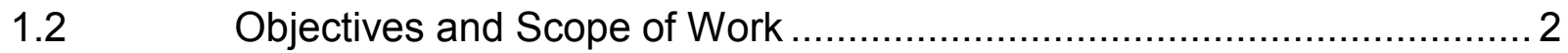

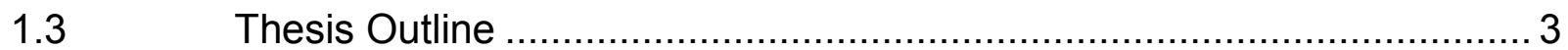

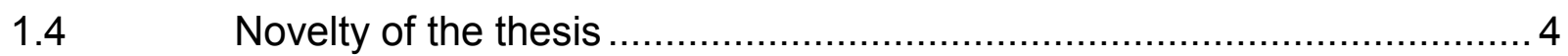

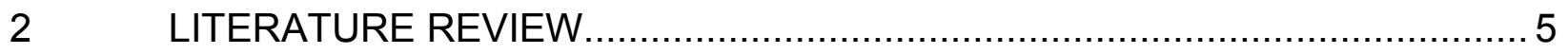

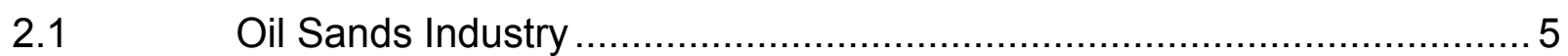

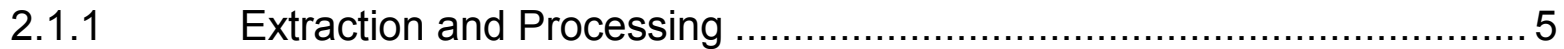

2.1.2 Oil Sands Tailings and Properties ..................................................... 9

2.1.3 Conventional Oil Sands Tailings Management ............................... 10

2.2 Mature Fine Tailings and Properties............................................. 11

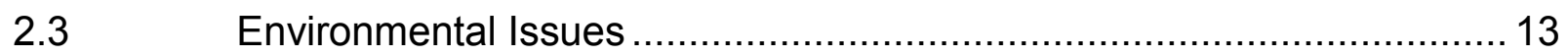

$2.4 \quad$ Oil Sands Tailings Management Regulations..................................... 13

$2.5 \quad$ Tailings Dewatering Technologies................................................... 14

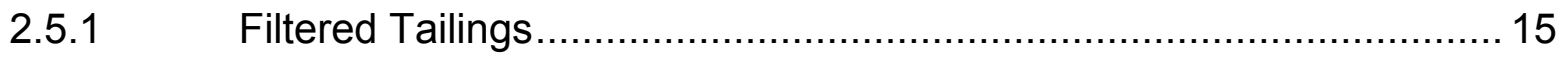

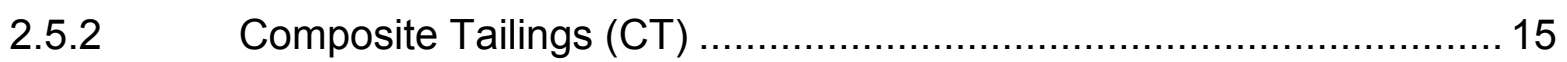

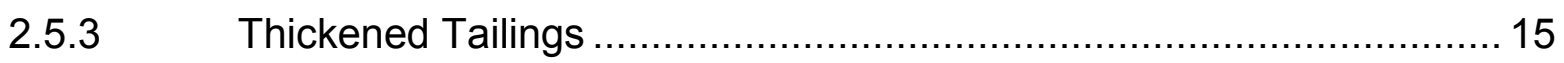

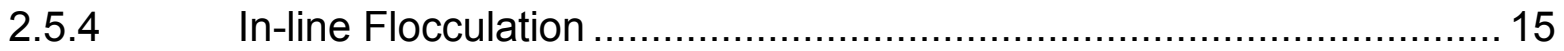

2.5.4.1 Atmospheric Fines Drying (AFD) ……................................ 16

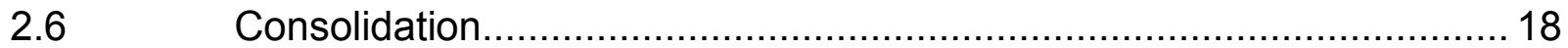

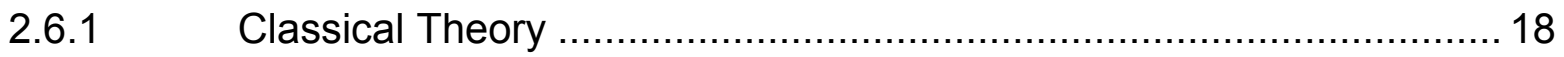

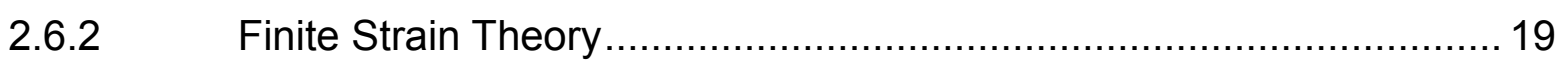

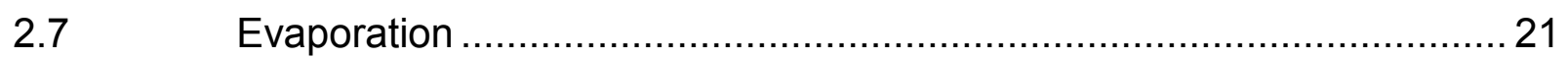

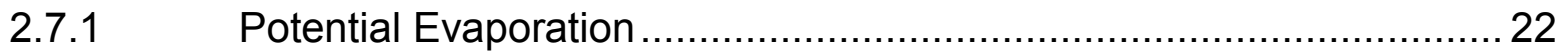

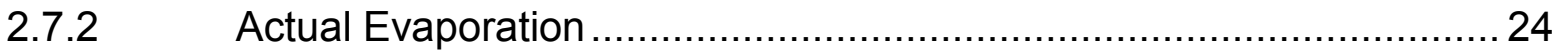

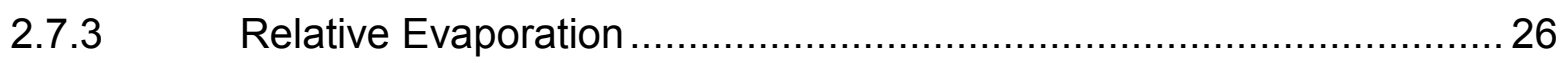

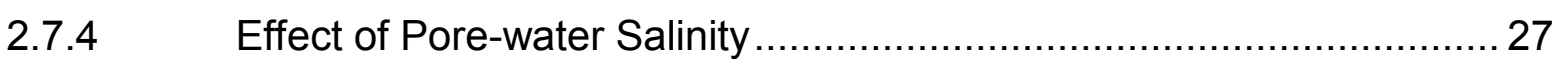




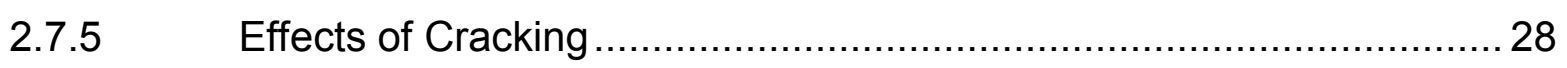

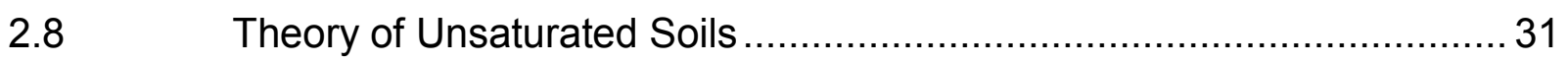

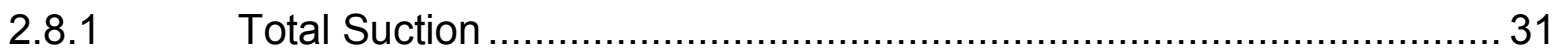

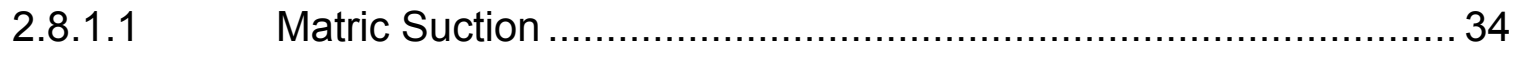

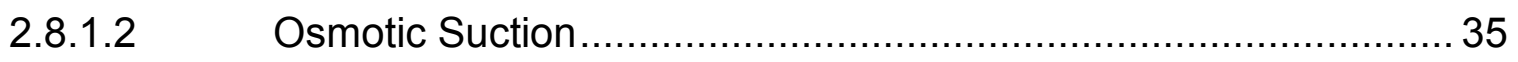

2.8.1.3 Soil Water Characteristic Curve (SWCC) ................................. 37

2.8.1.4 SWCC for Oil Sands Tailings (TWCC) …................................. 39

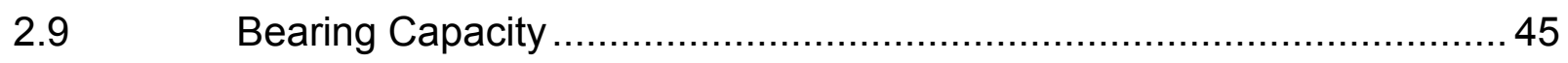

2.9.1 Bearing Capacity of Unsaturated Soils............................................. 46

2.9.2 Modified Total Stress Analysis (MTSA) ......................................... 48

2.9.3 Modified Effective Stress Analysis (MESA) …................................ 50

2.9.3.1 Matric Suction Profile ................................................................ 51

2.9.3.2 Bearing Capacity Fitting Factor ................................................ 55

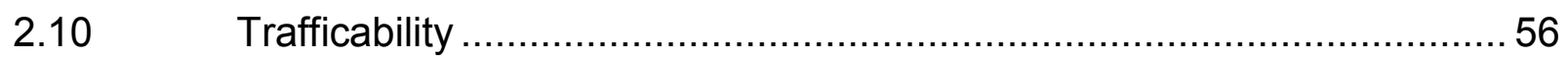

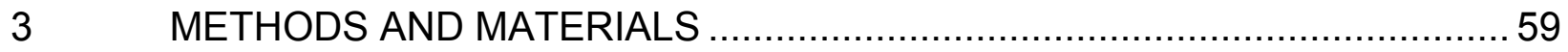

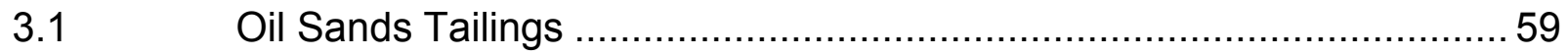

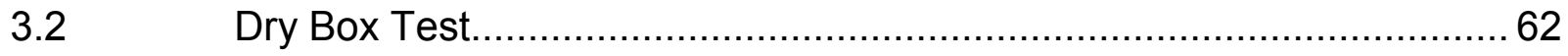

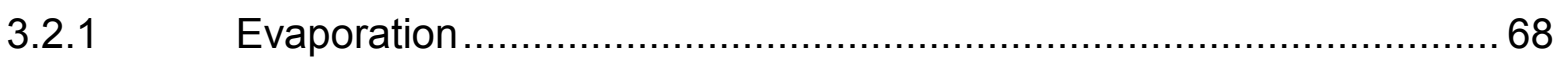

3.2.1.1 Water (Potential Evaporation) Test .......................................... 68

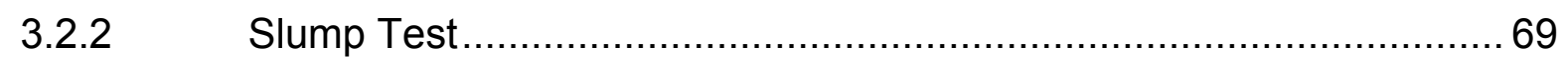

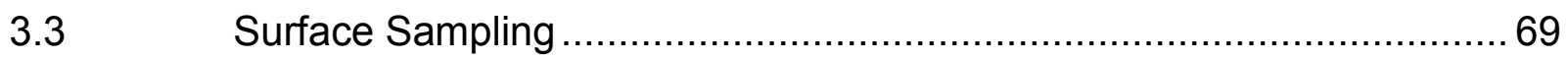

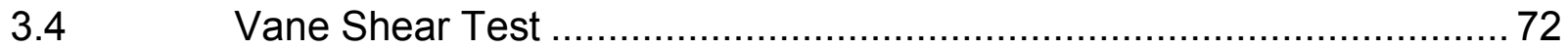

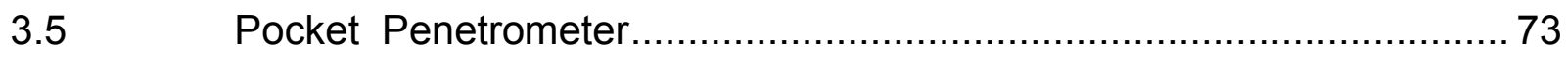

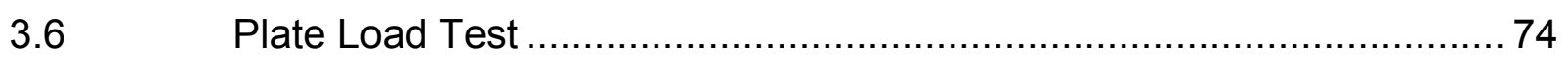

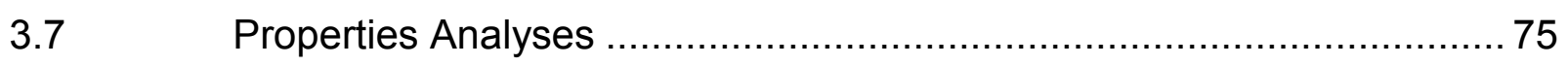

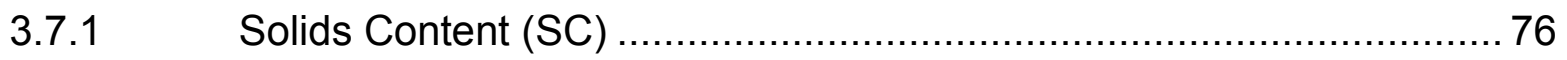

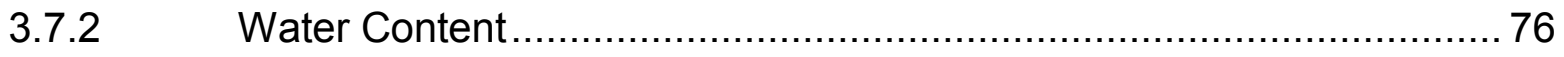

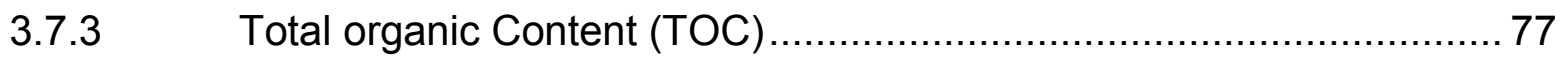

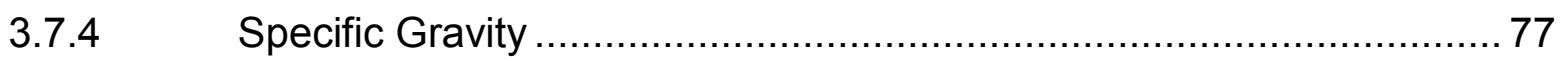

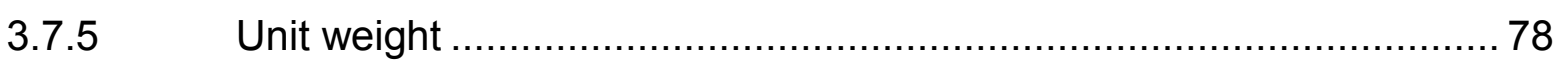




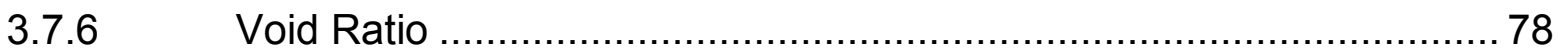

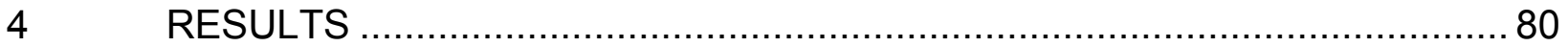

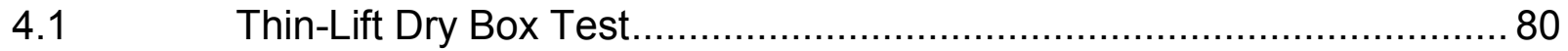

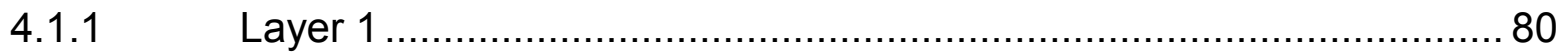

4.1.1.1 Mass Loss, Evaporation and Drainage .................................... 80

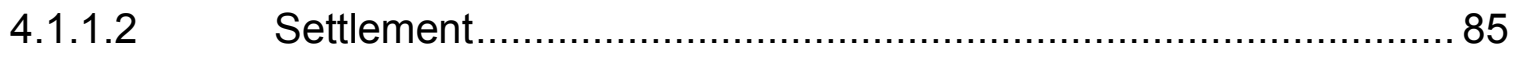

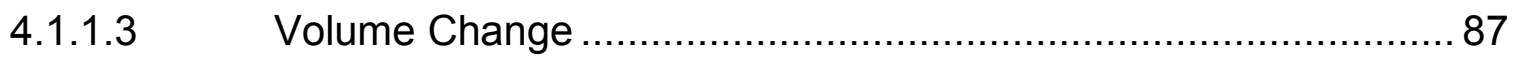

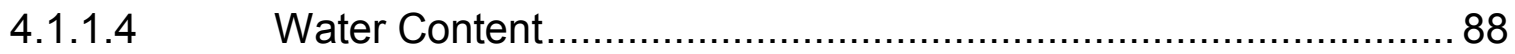

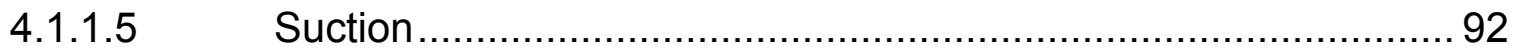

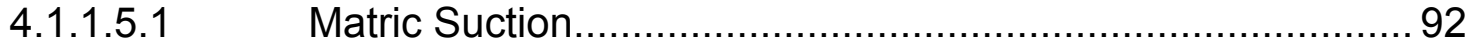

4.1.1.5.2 Osmotic Suction .......................................................... 93

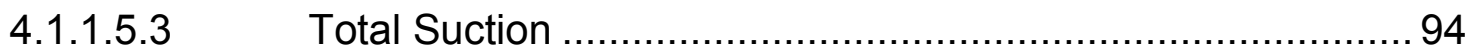

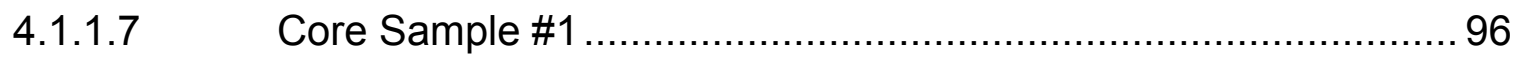

4.1.1.8 Core Sample \#2 …..................................................... 98

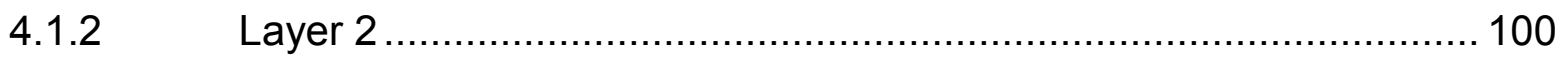

4.1.2.1 Mass Loss, Evaporation and Drainage .................................. 100

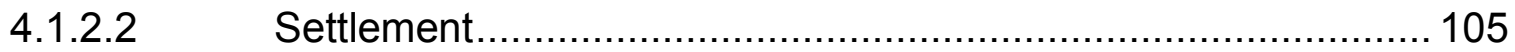

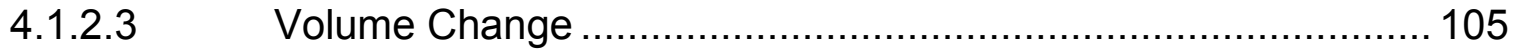

4.1.2.4 Water Content................................................................ 107

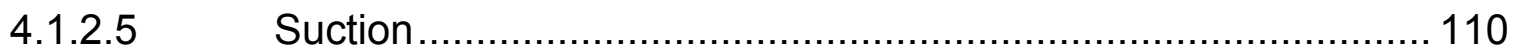

4.1.2.5.1 Matric Suction......................................................... 110

4.1.2.5.2 Osmotic Suction ......................................................... 111

4.1.2.5.3 Total Suction ......................................................... 112

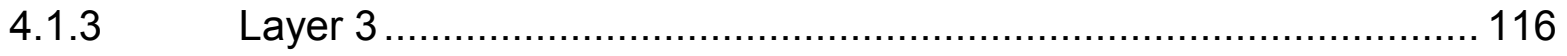

4.1.3.1 Mass Loss, Evaporation and Drainage ................................. 117

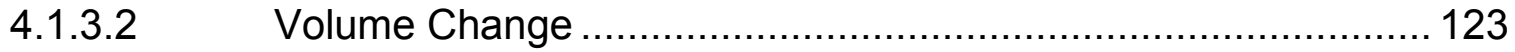

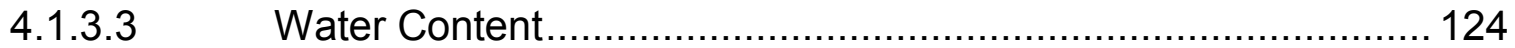




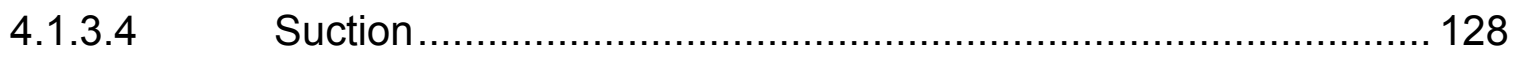

4.1.3.4.1 Matric Suction............................................................ 128

3.7.6.1.1 Osmotic Suction ............................................................ 129

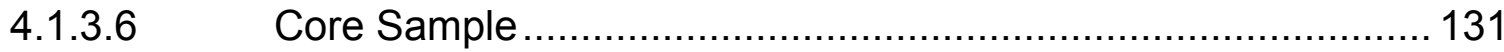

4.1.3.7 Undrained Shear Strength .................................................. 134

4.1.4 Thin-Lift Dry Box Overall Results ................................................... 135

4.1.4.1 Mass Loss, Evaporation and Drainage .................................. 135

4.1.4.2 Settlement.................................................................. 139

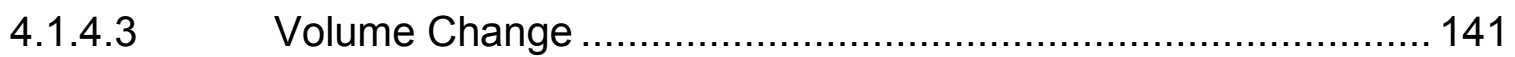

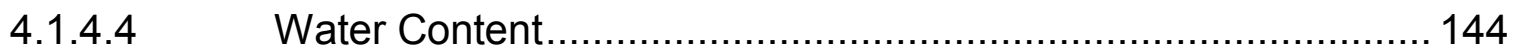

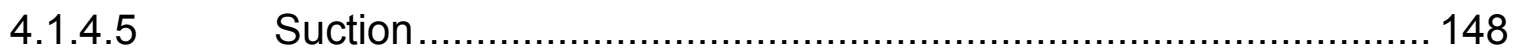

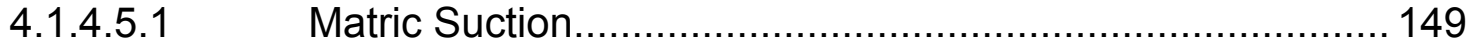

4.1.4.5.2 Osmotic Suction ............................................................ 150

4.1.4.5.3 Total Suction ......................................................... 151

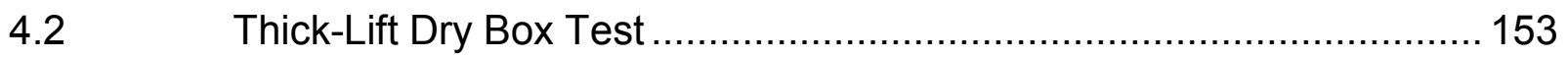

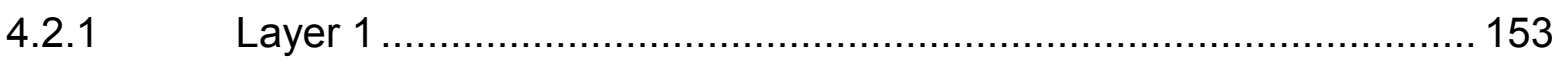

4.2.1.1 Mass Loss, Evaporation and Drainage ................................. 153

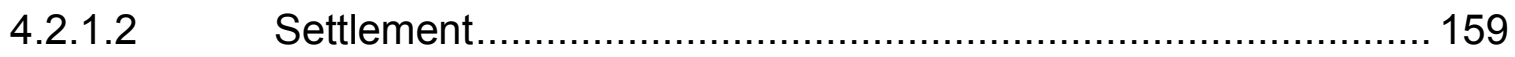

4.2.1.3 Volume Change .............................................................. 161

4.2.1.4 Water Content............................................................... 162

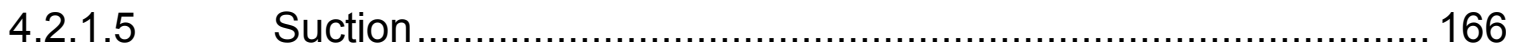

4.2.1.5.1 Matric Suction........................................................... 166

4.2.1.5.2 Osmotic Suction ........................................................ 167

4.2.1.5.3 Total Suction ......................................................... 168

4.2.1.6 Core Sample Results …................................................... 170

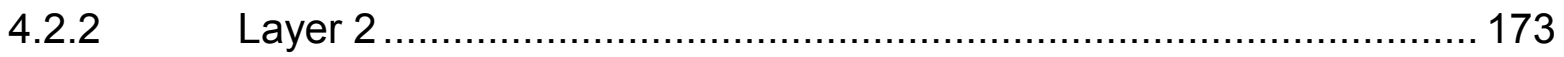


4.2.2.1 Mass Loss, Evaporation and Drainage ................................ 174

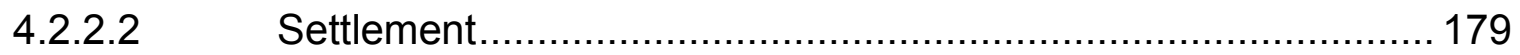

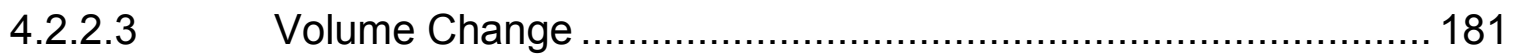

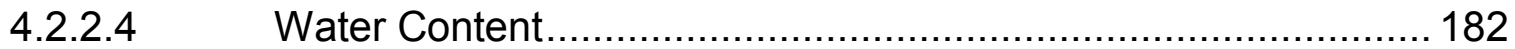

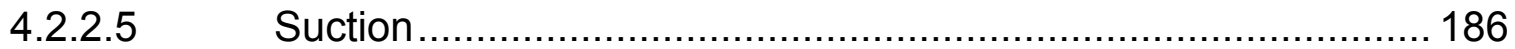

4.2.2.5.1 Matric Suction................................................................... 186

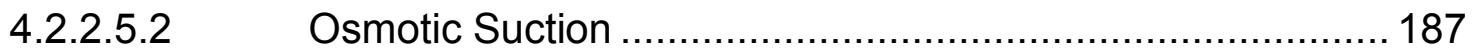

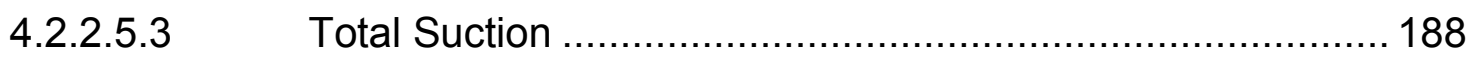

4.2.2.6 Undrained Shear Strength ................................................ 192

4.2.3 Thick-Lift Dry Box Overall Results .................................................. 196

4.2.3.1 Mass Loss, Evaporation and Drainage .................................. 196

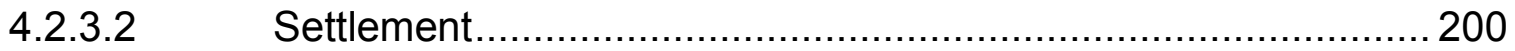

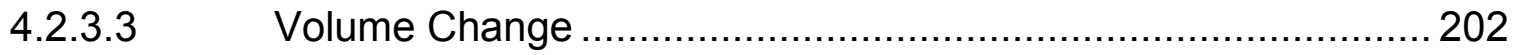

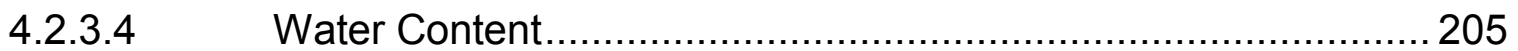

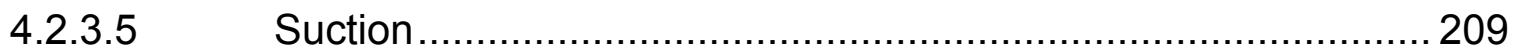

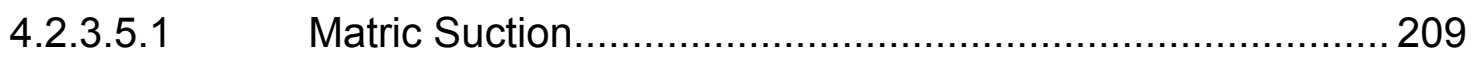

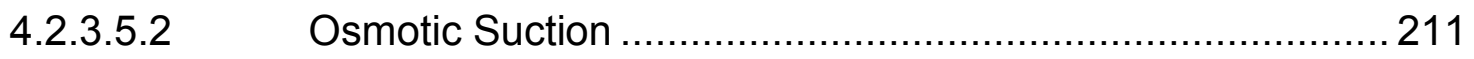

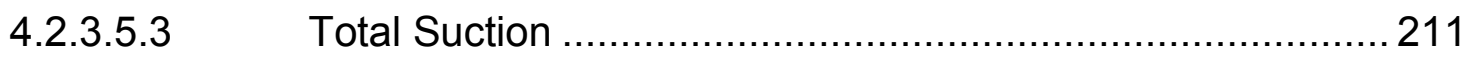

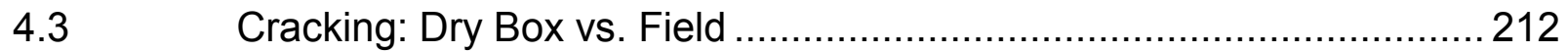

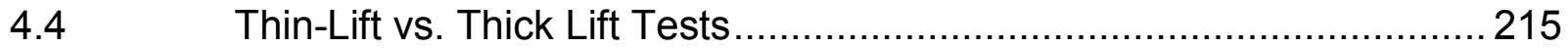

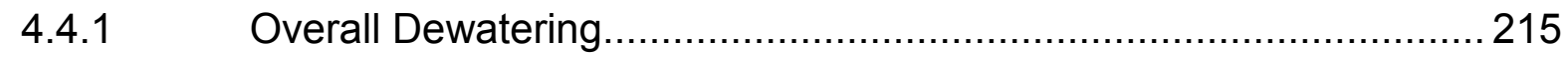

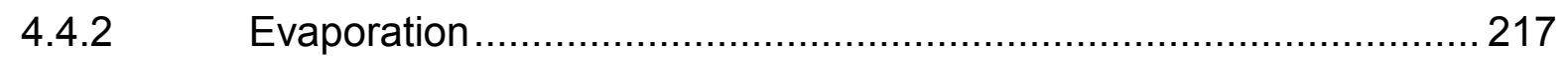

4.3.1 Implications for the Industry …............................................. 218

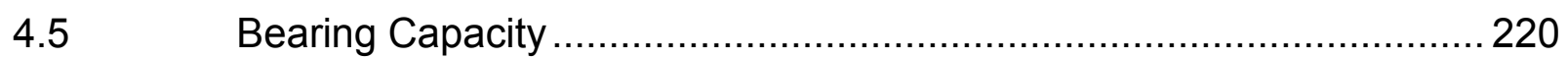

4.5.1 Shrinkage Curves and SWCCs inferred from dry box measurements 220

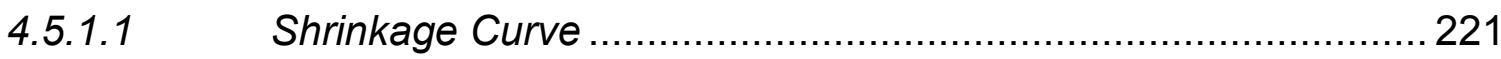


4.5.1.1 SWCC - GWC versus Total Suction.................................... 221

4.5.1.2 SWCC - GWC versus Matric Suction ..................................... 223

4.5.1.3 SWCC - Degree of Saturation versus Suction ........................ 227

4.5.2 Estimation of Bearing Capacity ……............................................ 229

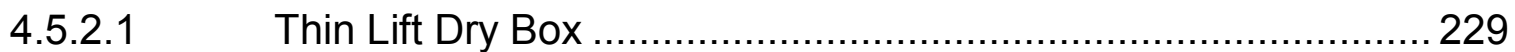

4.5.1.4 Thick Lift Dry Box........................................................ 230

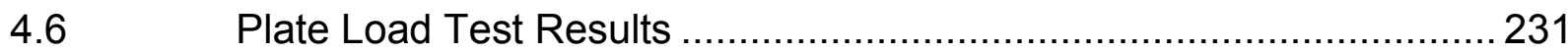

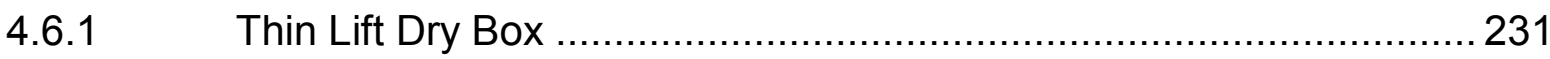

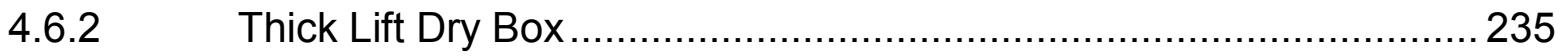

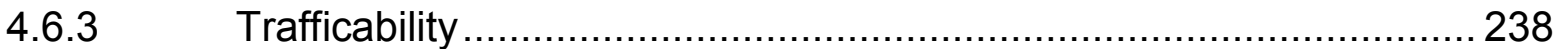

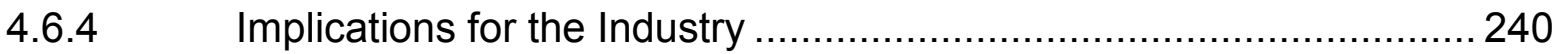

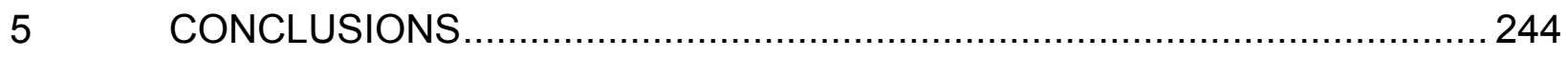

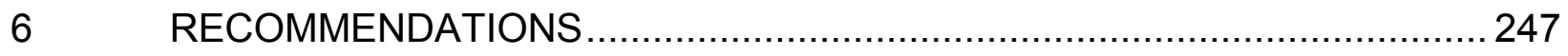

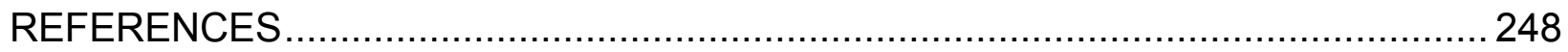

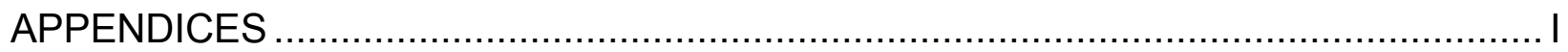

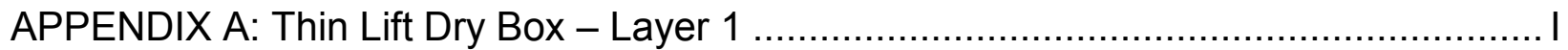

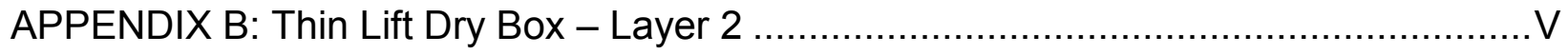

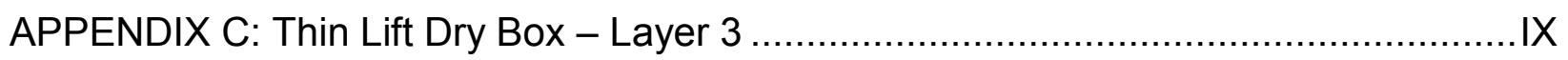

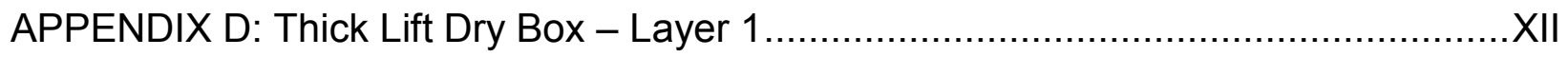

APPENDIX E: Thick Lift Dry Box - Layer 2 ......................................................... XV

APPENDIX F: Overall Dry Box Results ............................................................... XVIII

APPENDIX G: Crack Island Analysis for Thick Lift Dry Box .....................................XX

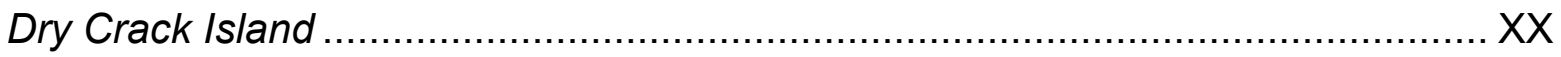

Rewetted Crack Island....................................................................................... 


\section{List of Tables}

Table 2.1-1. Typical whole oil sands tailings properties (Beier et al., 2013) ..................9

Table 2.2-1. Oil sands tailings properties (modified from BGC Engineering, 2010) ...... 11

Table 2.7-1. Summary of studies on the influence of cracking on evaporation rates .... 30 Table 2.8-1. Devices for measuring soil suction and its components (Fredlund and

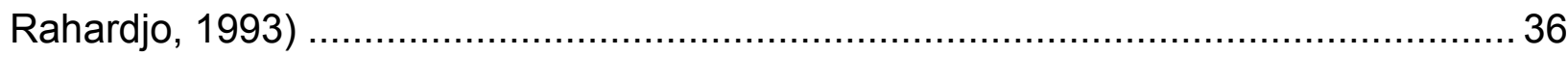

Table 2.10-1. Operating weights of various earthmoving equipment (adapted from

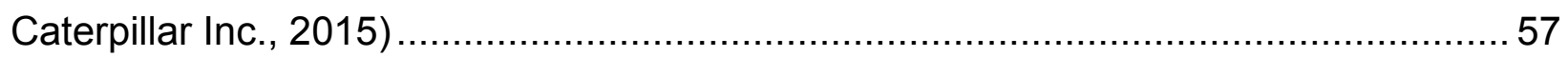

Table 3.1-1. Geotechnical properties of raw and flocculated MFT used in the study ....59

Table 3.2-1. Potential evaporation measurements for thick lift dry box ........................69

Table 4.4-1. Estimated drying times for various lift thicknesses ............................... 219

Table 4.5-1. Bearing capacity estimates - Thin lift dry box .................................. 230

Table 4.5-2. Bearing capacity estimates - Thick lift dry box.................................... 231

Table 4.6-1. Summary of experimental bearing capacity values for Thin Lift Dry Box 234 Table 4.6-2. Summary of experimental bearing capacity values for Thick Lift Dry Box237

Table 4.6-3. Comparison of plate load tests to 824K........................................... 240

Table 4.6-4. Bearing capacity estimates for dozer wheel .................................... 241 


\section{List of Figures}

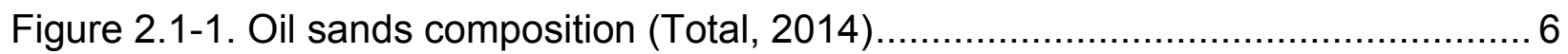

Figure 2.1-2. Orientation of bitumen, water and sand in the ore body (Alberta Energy, 2015) 7

Figure 2.1-3. Generalized scheme of Clark Hot Water Extraction Process (Chalaturnyk et al., 2004; Jeeravipoolvarn, 2010) .8

Figure 2.1-4. Cross section of an oil sands tailings storage facility (FTFC, 1995;

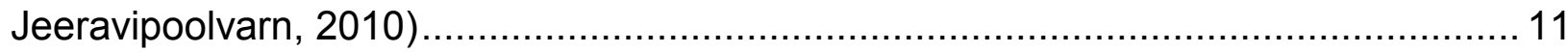

Figure 2.2-1. Hydraulic conductivity vs. void ratio of oil sands MFT (Jeeravipoolvarn,

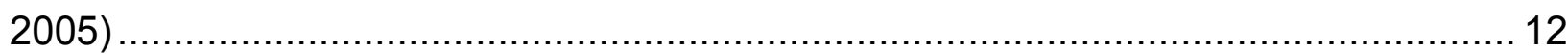

Figure 2.5-1. Generalized AFD process (Barr Engineering, 2012) …...................... 17

Figure 2.6-1. Compressibility of mature fine tailings (Jeeravipoolvarn, 2010) .............. 21

Figure 2.6-2. Hydraulic conductivity of mature fine tailings (Jeeravipoolvarn, 2010)..... 21

Figure 2.7-1. Stages of evaporation (Wilson et al, 1994) ..................................... 25

Figure 2.8-1. Relative humidity versus total suction relationship (Fredlund and Rahardjo, 1993) 33

Figure 2.8-2. Typical soil-water characteristic curve features for the drying and wetting

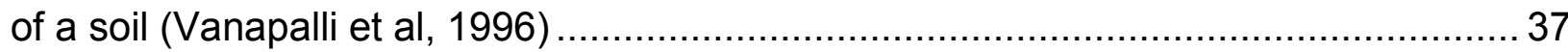

Figure 2.8-3. Stages of de-saturation (Vanapalli et al, 1996) ................................... 39

Figure 2.8-4. Average laboratory shrinkage curves for oil sands tailings samples (SFR = 0.1) (Fredlund and Houston, 2013). 40

Figure 2.8-5. Gravimetric water content SWCC's measured on oil sands tailings (SFR = 0.1) (Fredlund and Houston, 2013). 41

Figure 2.8-6. SWCC's plotted as the degree as saturation versus suction for oil sands tailings (SFR $=0.1$ ) (Fredlund and Houston, 2013). 42

Figure 2.8-7. Volumetric water content versus suction for oil sands tailings ( $S F R=0.1$ ) (Fredlund and Houston, 2013).

Figure 2.8-8. Void ratio versus suction plot for oil sands tailings (SFR $=0.1$ ) (Fredlund

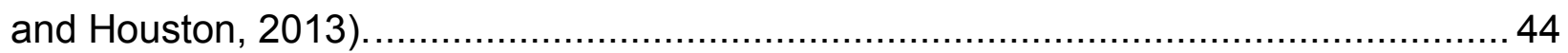

Figure 2.8-9. SWCC for oil sands tailings (Soleimani et al., 2014) ............................ 45 
Figure 2.9-1. Bearing capacity failure modes of tailings deposits (Jakubick et al., 2003)

Figure 2.9-2. Punching shear-failure mechanism in UFG soils below a footing (Oh and Vanapalli 2013) 49

Figure 2.9-3. Estimation of the average matric suction value based on the matric suction distribution diagram (Oh and Vanapalli 2013) 52

Figure 2.9-4. Average matric suction values for different footing sizes under an idealized nonuniform matric suction distribution profile (Oh and Vanapalli 2013) 52 Figure 2.9-5: Matric suction profile for hydrostatic and evaporative conditions, water table depth $=1.5$ and $2.5 \mathrm{~m}$ (Rassam and Williams 1999). 53

Figure 2.9-6. Matric suction contribution to shear strength at steady-state conditions for gold tailings (Rassam and Williams 1999). 54

Figure 2.9-7: Typical strength profiles from T-bar test $\left(\boldsymbol{N}_{T-4}=10 * 5\right)$ (Hossain and Fourie, 2013) 55

Figure 2.10-1. Tailings bearing capacity issues (Williams, 2013). 56 Figure 2.10-2. Remediation methods as functions of shear strength and critical

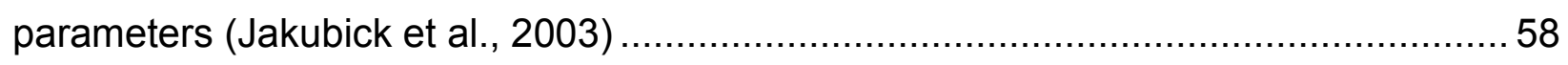

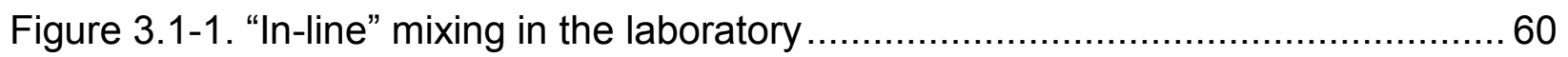
Figure 3.1-2. Comparison of un-flocculated (left) and flocculated (right) oil sands tailings. 61

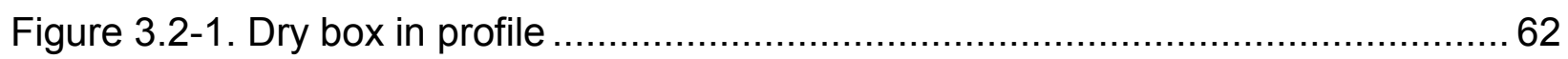

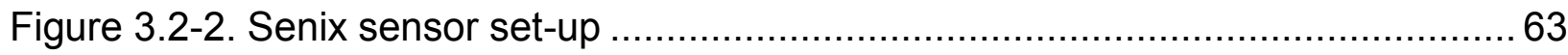

Figure 3.2-3. Dry box dimensions and sensor ports (Daliri, 2013) .............................. 64

Figure 3.2-4. Decagon 5TE sensor (Decagon, 2015) ............................................... 65

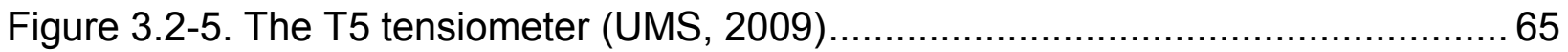

Figure 3.2-6. Placement of Easy Log USB Sensors in the Thick lift dry box. ............... 67

Figure 3.3-1. WP4-C potentiometer (Hoskin Scientific Ltd, 2015) ............................. 70

Figure 3.3-2. View inside the WP4C (Decagon, 2007) ....................................... 71

Figure 3.3-4. Crack geometries and measured dimensions (Innocent-Bernard, 2013) . 72

Figure 3.3-3. Crack measurement techniques .................................................. 72

Figure 3.4-1. H-60 Shear vane tester (ESS Earth Sciences, 2015) ........................... 73 
Figure 3.5-1. Pocket penetrometer (Vanapalli, 2015) ............................................... 74

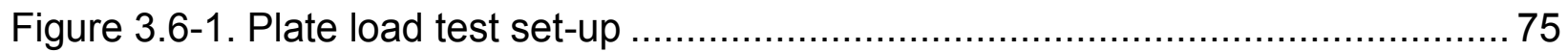

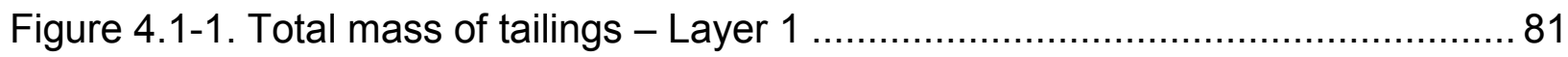

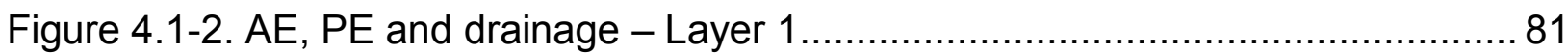

Figure 4.1-3. Temperature, $\mathrm{RH}$ and dewpoint profiles above the tailings - Layer $1 \ldots \ldots 82$

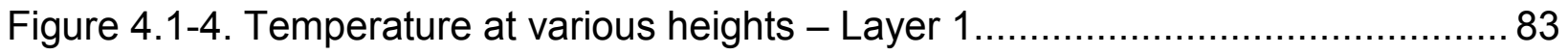

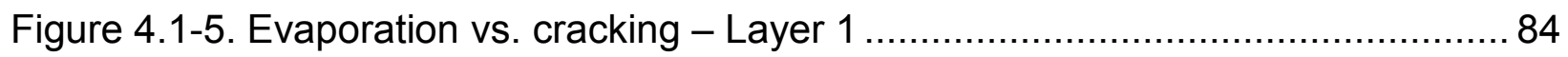

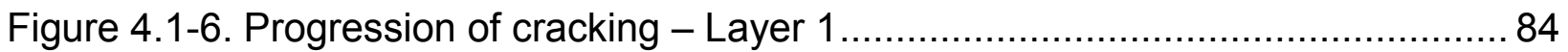

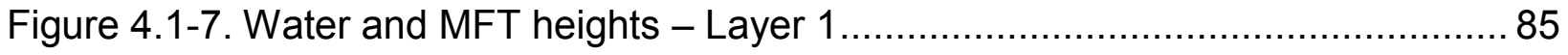

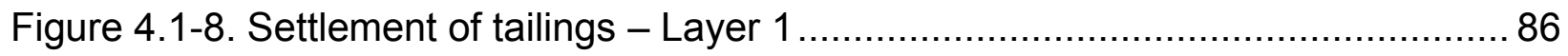

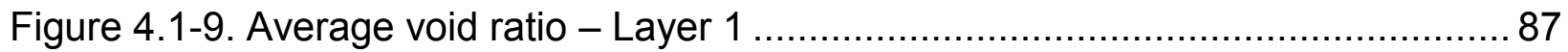

Figure 4.1-10. Volumetric water content at various heights- Layer $1 \ldots \ldots \ldots \ldots \ldots \ldots \ldots \ldots . . . . . . . . . . . .88$

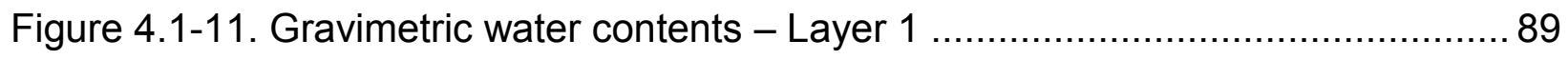

Figure 4.1-12. Surface sample gravimetric water contents - Layer 1 ......................... 89

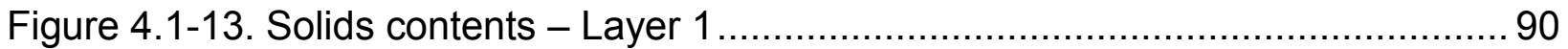

Figure 4.1-14. Surface sample solids contents - Layer 1 ...................................... 91

Figure 4.1-15. Overall degree of saturation - Layer 1 ............................................ 91

Figure 4.1-16. Matric suction at various heights - Layer 1 ...................................... 92

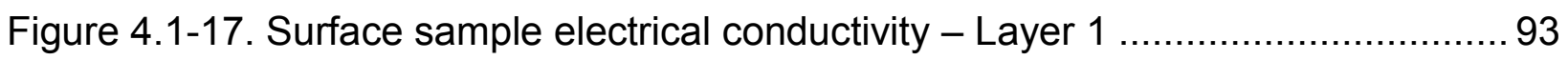

Figure 4.1-18. Surface sample total and osmotic suction - Layer 1 ........................... 94

Figure 4.1-19. Surface sample total suction - Layer 1 ............................................ 95

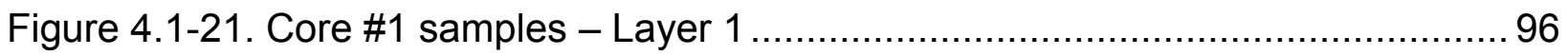

Figure 4.1-20. Core sample locations - Layer 1 ..................................................... 96

Figure 4.1-22. Core \#1 GWC, TOC and SC profiles - Layer 1 ................................. 97

Figure 4.1-23. Core \#1 EC, and osmotic and total suction profiles - Layer 1 ................ 97

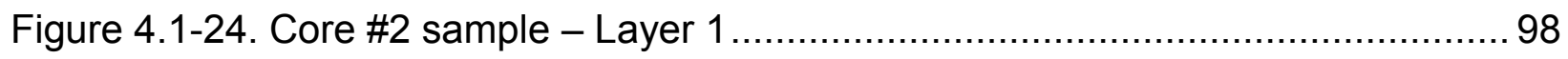

Figure 4.1-25. Core \#2 GWC, TOC and SC profiles - Layer 1 ................................ 98

Figure 4.1-26. Core \#2 EC and osmotic and total suction profiles - Layer 1................ 99

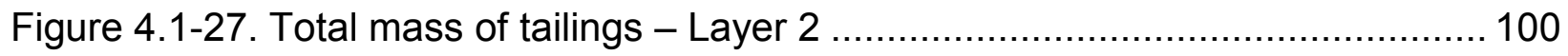

Figure 4.1-28. AE, PE and drainage - Layer 2 .............................................. 101

Figure 4.1-29. Temperature at various heights - Layer 2 ...................................... 102 
Figure 4.1-30. Temperature, $\mathrm{RH}$ and dewpoint profiles above the tailings - Layer 2.. 103

Figure 4.1-31. Evaporation vs. cracking - Layer 2 ….......................................... 104

Figure 4.1-32. Progression of cracking - Layer 2 .............................................. 104

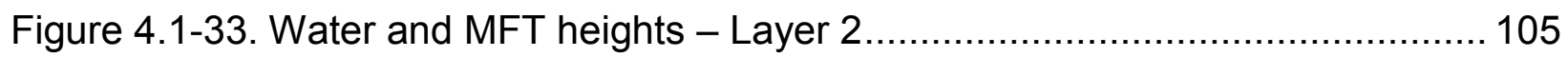

Figure 4.1-34. Volumetric water contents at various heights in bottom layer - Layer 2 106

Figure 4.1-35. Volumetric water contents at various heights in top layer - Layer 2 .... 106

Figure 4.1-36. Gravimetric water contents - Layer 2 .......................................... 107

Figure 4.1-37. Surface sample gravimetric water contents - Layer $2 \ldots \ldots \ldots \ldots \ldots \ldots \ldots \ldots . . . . . . . .108$

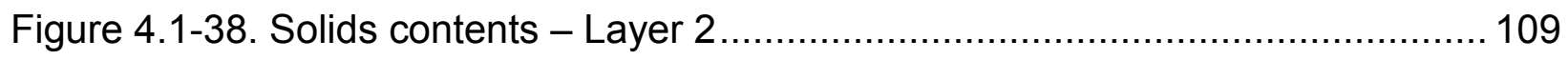

Figure 4.1-39. Surface sample gravimetric water contents - Layer 2 ....................... 109

Figure 4.1-40. Overall degree of saturation - Layer 2 ........................................ 110

Figure 4.1-41. Matric suction at various heights - Layer 2 …................................. 111

Figure 4.1-42. Surface sample electrical conductivity - Layer 2 ........................... 111

Figure 4.1-43. Surface sample total and osmotic suctions - Layer 2 ….................... 112

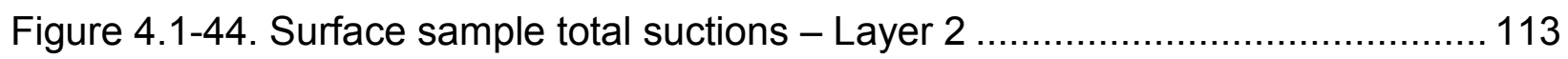

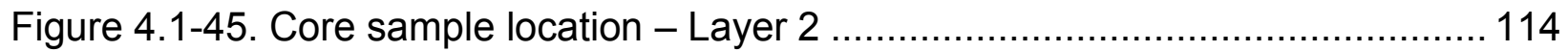

Figure 4.1-46. Core sample - Layer 2 ....................................................... 114

Figure 4.1-47. Core GWC, TOC and SC profiles - Layer 2 ….............................. 115

Figure 4.1-48. Core EC and osmotic and total suction profiles - Layer 2.................. 115

Figure 4.1-49. Undrained shear strength profile - Layer 2 …............................... 116

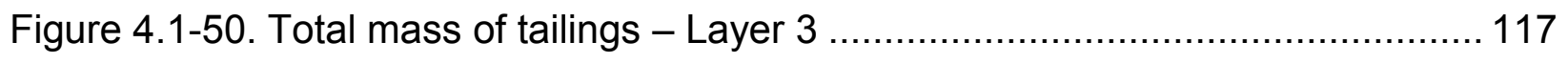

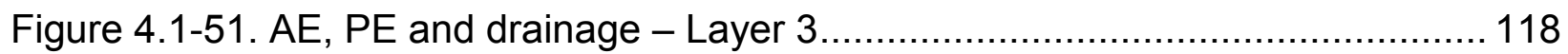

Figure 4.1-52. Temperature at various heights - Layer 3..................................... 119

Figure 4.1-53. Temperature, $\mathrm{RH}$ and dewpoint profiles above the tailings - Layer 3.. 120

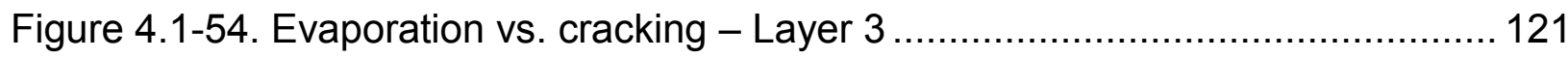

Figure 4.1-55. Progression of cracking - Layer 3 ……........................................ 121

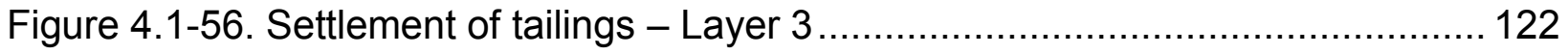

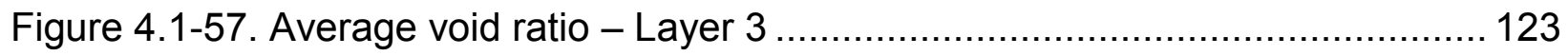

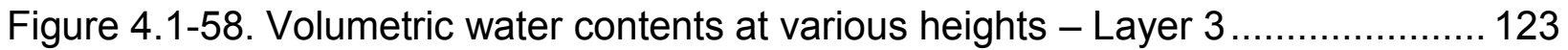

Figure 4.1-59. Volumetric water contents at various heights in top layer - Layer 3 .... 124 


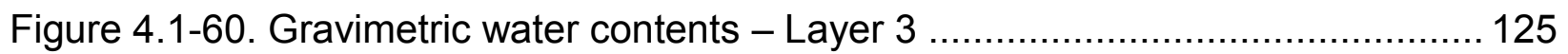

Figure 4.1-61. Surface sample gravimetric water contents - Layer 3 ...................... 125

Figure 4.1-62. Solids contents - Layer 3 ….................................................. 126

Figure 4.1-63. Surface sample solids contents - Layer 3..................................... 127

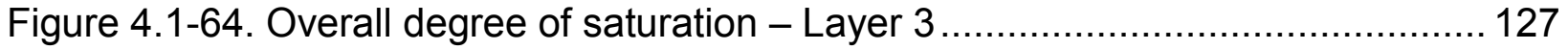

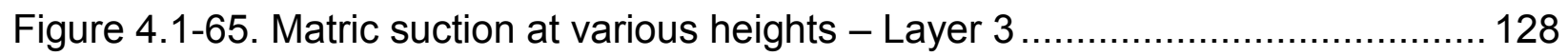

Figure 4.1-66. Surface sample electrical conductivity - Layer 3 ............................ 129

Figure 4.1-67. Surface sample total and osmotic suctions - Layer 3 ........................ 130

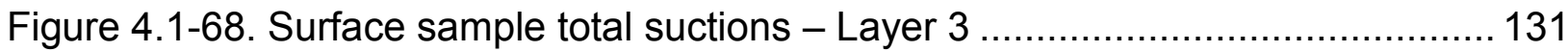

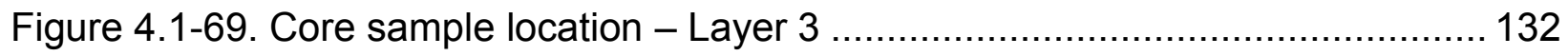

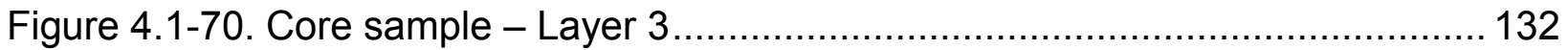

Figure 4.1-71. Core GWC, TOC and SC profiles - Layer 3 ................................. 133

Figure 4.1-72. Core EC, and total and osmotic suction profiles - layer 3 .................. 133

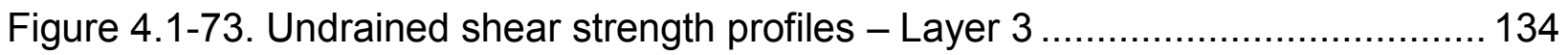

Figure 4.1-74. Volumetric water contents at various heights - Overall ....................... 135

Figure 4.1-75. Thin lift dry box temperature profiles ............................................ 136

Figure 4.1-76. Thin lift dry box temperature profiles over time - Layer 1 ................... 136

Figure 4.1-77. Temperature, $\mathrm{RH}$ and dewpoint profiles above the tailings - Overall .. 137

Figure 4.1-78. AE, PE and drainage - Overall ..................................................... 138

Figure 4.1-79. Evaporation vs. cracking - Overall .................................................... 139

Figure 4.1-80. Settlement of the tailings - Overall ............................................. 140

Figure 4.1-81. Average void ratio - Overall....................................................... 141

Figure 4.1-82. Volumetric water contents at various heights - Overall ...................... 142

Figure 4.1-83. Volumetric water contents at various heights in top layers - Overall ... 143

Figure 4.1-84. Thin lift dry box shrinkage curve ................................................... 144

Figure 4.1-85. Gravimetric water contents - Overall ........................................... 145

Figure 4.1-86. Surface sample gravimetric water contents - Overall ........................ 146

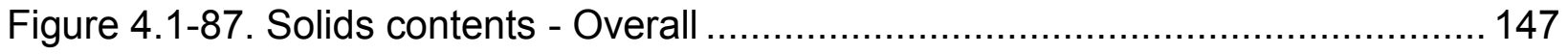

Figure 4.1-88. Surface sample solids contents - Overall ..................................... 147

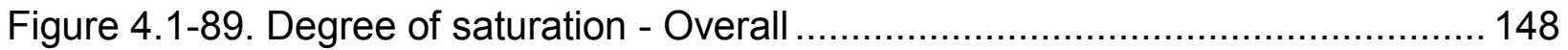

Figure 4.1-90. Matric Suction at various heights - Overall....................................... 149 
Figure 4.1-91. Thin lift dry box matric suction profiles ............................................. 150

Figure 4.1-92. Surface sample total and osmotic suctions - Overall ........................ 151

Figure 4.1-93. Surface sample total suctions (Log scale)- Overall ............................ 152

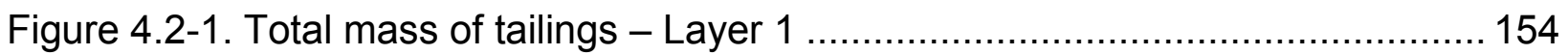

Figure 4.2-2. AE, PE and drainage - Layer 1 ................................................... 154

Figure 4.2-3. Surface temperatures - Layer 1 .................................................... 155

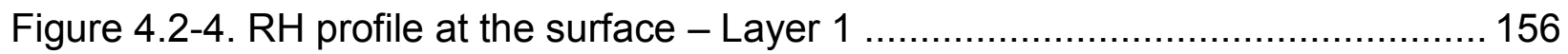

Figure 4.2-5. Temperatures at various heights - Layer 1 ....................................... 157

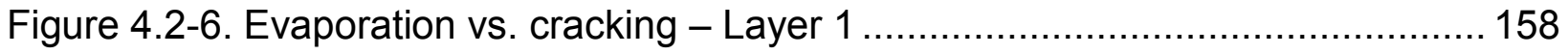

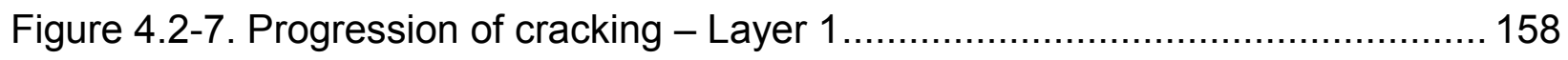

Figure 4.2-8. Water and MFT heights - Layer 1 ................................................ 159

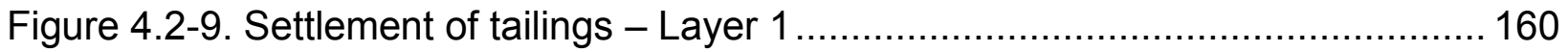

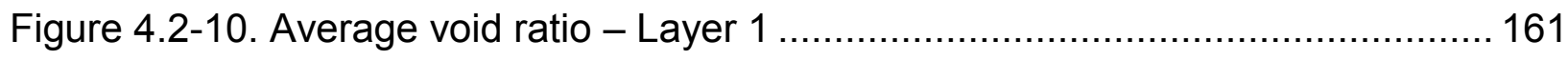

Figure 4.2-11. Volumetric water contents at various heights - Layer 1 ...................... 162

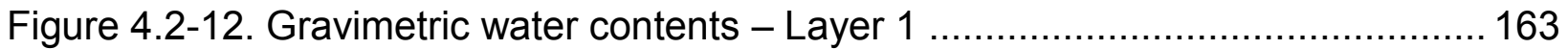

Figure 4.2-13. Surface sample gravimetric water contents - Layer 1 ...................... 163

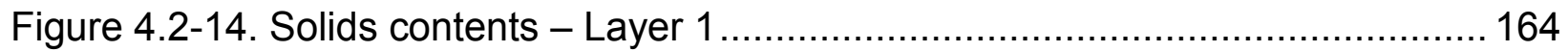

Figure 4.2-15. Surface sample solids contents - Layer 1 ..................................... 165

Figure 4.2-16. Overall degree of saturation - Layer 1 ......................................... 165

Figure 4.2-17. Matric suction at various heights - Layer 1 ....................................... 166

Figure 4.2-18. Surface sample electrical conductivity - Layer 1 ............................. 167

Figure 4.2-19. Surface sample total and osmotic suctions - Layer 1 ........................ 168

Figure 4.2-20. Surface sample total suctions - Layer 1 ........................................... 169

Figure 4.2-21. Surface samples total suctions on log scale - Layer 1 ....................... 169

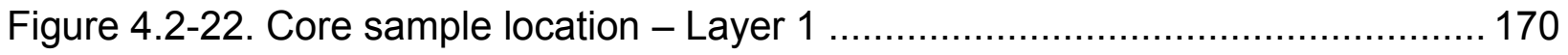

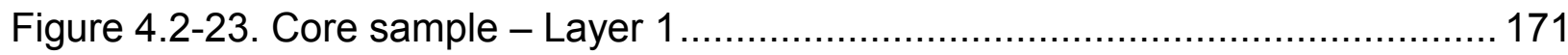

Figure 4.2-24. Core GWC, and SC profile - Layer 1 ......................................... 172

Figure 4.2-25. Core EC, osmotic and total suction profiles - Layer $1 \ldots \ldots \ldots \ldots \ldots \ldots \ldots \ldots . . .172$

Figure 4.2-26. Undrained shear strength profiles - Layer 1 .................................. 173

Figure 4.2-27. Total mass of tailings - Layer 2 ............................................... 174

Figure 4.2-28. AE, PE and drainage - Layer 2 .................................................. 175 


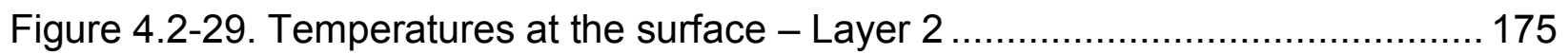

Figure 4.2-30. Temperatures at various heights in bottom layer - Layer 2 ................ 176

Figure 4.2-31. Temperatures at various heights in top layer - Layer 2 .................... 177

Figure 4.2-32. RH profiles at the surface - Layer 2 .............................................. 178

Figure 4.2-33. Evaporation vs. cracking - Layer 2 ............................................ 179

Figure 4.2-34. Progression of cracking - Layer 2 .............................................. 179

Figure 4.2-35. Water and MFT heights - Layer 2 ............................................ 180

Figure 4.2-36. Settlement of tailings - Layer 2 ……......................................... 181

Figure 4.2-37. Volumetric water contents at various heights - Layer 2 ................... 181

Figure 4.2-38. Volumetric water contents at various heights in top layer - Layer 2 .... 182

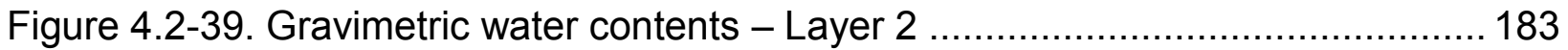

Figure 4.2-40. Surface sample gravimetric water contents - Layer $2 \ldots \ldots \ldots \ldots \ldots \ldots \ldots \ldots . . .183$

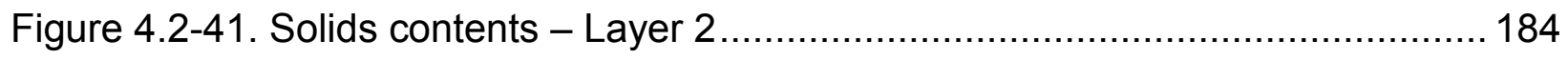

Figure 4.2-42. Surface sample solids contents - Layer 2 ..................................... 185

Figure 4.2-43. Overall degree of saturation - Layer 2 ….................................... 185

Figure 4.2-44. Matric suction at various heights - Layer 2 .................................. 186

Figure 4.2-45. Surface sample electrical conductivity - Layer 2 ............................ 187

Figure 4.2-46. Surface sample total and osmotic suctions - Layer 2 ….................... 187

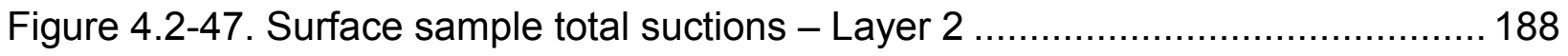

Figure 4.2-48. Surface samples total suctions on log scale - Layer 2 ...................... 188

Figure 4.2-49. Core sample \#1 location - Layer 2 ............................................ 189

Figure 4.2-50. Core \#1 sample - Layer 2 ……............................................... 190

Figure 4.2-51. Core \#1 GWC and SC profiles - Layer 2 …................................. 191

Figure 4.2-52. Core \#1 EC and total and osmotic suction profiles - Layer 2.............. 191

Figure 4.2-53. Core \#1 undrained shear strength profiles - Layer 2 ......................... 192

Figure 4.2-54. Core \#2 sample location - Layer 2 .............................................. 193

Figure 4.2-55. Core \#2 sample - Layer 2 ……................................................... 193

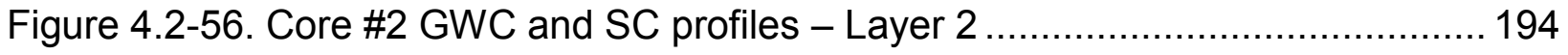

Figure 4.2-57. Core \#2 EC, and total and osmotic suction profiles - Layer 2.............. 195

Figure 4.2-58. Core \#2 undrained shear strength profiles - Layer $2 \ldots \ldots \ldots \ldots \ldots \ldots \ldots \ldots \ldots . . .196$

Figure 4.2-59. Temperature profiles at the surface - Overall ................................... 197 


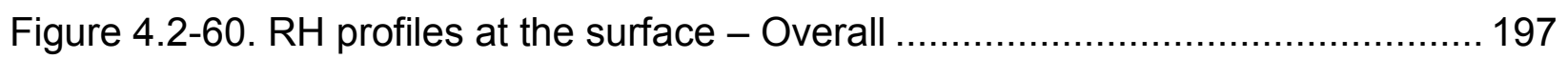

Figure 4.2-61. Thick lift dry box temperature profiles ............................................ 198

Figure 4.2-62. Thick lift dry box temperature profiles over time - Layer 1 .................. 198

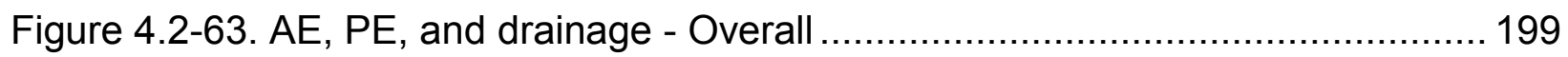

Figure 4.2-64. Evaporation vs. cracking - Overall.............................................. 200

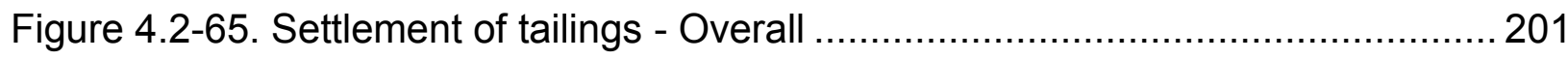

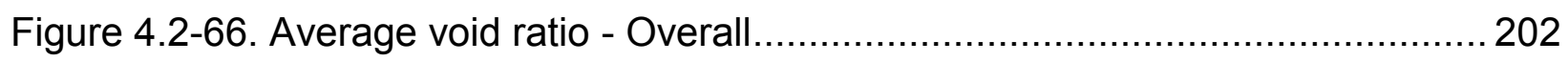

Figure 4.2-67. Volumetric water contents at various heights in bottom layer - Overall 203

Figure 4.2-68. Volumetric water contents at various heights in top layer - Overall ...... 204

Figure 4.2-69. Shrinkage curve for thick lift dry box .................................................. 205

Figure 4.2-70. Gravimetric water contents - Overall ............................................ 206

Figure 4.2-71. Surface sample gravimetric water contents - Overall ........................ 206

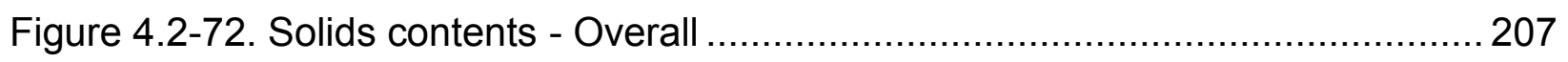

Figure 4.2-73. Surface sample solids contents - Overall ...................................... 208

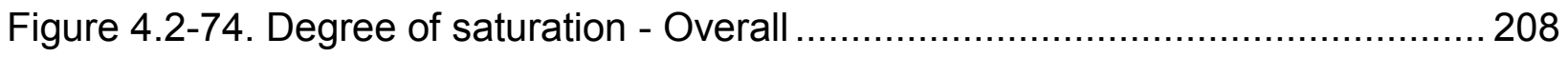

Figure 4.2-75. Matric suction at various heights - Overall...................................... 209

Figure 4.2-76. Thick Lift dry box matric suction profiles ........................................ 210

Figure 4.2-77. Surface sample total and osmotic suctions - Layer $2 \ldots \ldots \ldots \ldots \ldots \ldots \ldots \ldots . . . .211$

Figure 4.2-78. Surface sample total suctions - Overall ........................................ 212

Figure 4.3-1. Dry box thin and lift tailings and AFD tailings dried to approximately $60 \%$

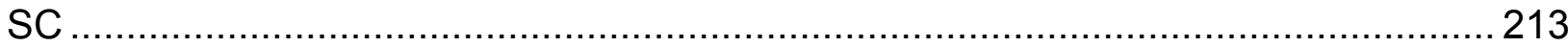

Figure 4.3-2. Dry box thin lift tailings (left) and AFD tailings (right), both dried to

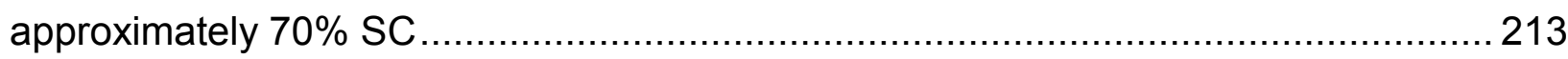

Figure 4.3-3. Dry box thin lift tailings (left) and AFD tailings (right), with dry box tailings

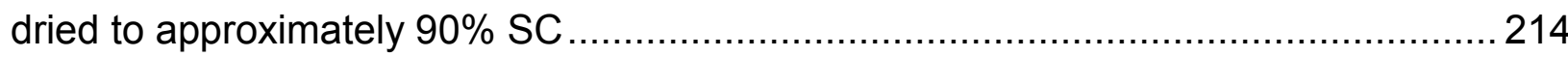

Figure 4.3-4. Transect of total suctions (MPa) across a multi-layer thick lift crack from the field (left), and thick lift layer 1 crack (right) .................................................. 214

Figure 4.4-1. Comparison of solids content in thin and thick lift tests ....................... 215

Figure 4.4-2. Comparison of solids content to modeling results - Thin lift dry box...... 216

Figure 4.4-3. Comparison of solids content to modeling results - Thick lift dry box .... 217

Figure 4.4-4. Evaporation for thin and thick lift dry box experiments ......................... 217 
Figure 4.4-5. RE for thin and thick lift dry box experiments 218

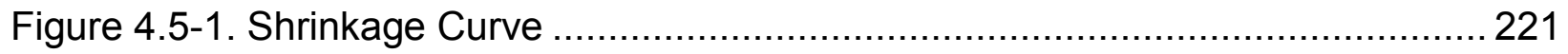

Figure 4.5-2. SWCC in terms of GWC and total suction from surface samples ......... 222

Figure 4.5-3. SWCC in terms of GWC and total suction from core samples .............. 223

Figure 4.5-4. SWCC in terms of GWC and matric suction for thin lift dry box ............. 224

Figure 4.5-5. SWCC in terms of GWC and matric suction for thick lift dry box ............ 224

Figure 4.5-6. Comparison of SWCC from thin lift dry box experiment to field data ..... 225

Figure 4.5-7. Comparison of SWCC from thick lift dry box experiment to field data .... 226

Figure 4.5-8. SWCC for oil sands tailings (Soleimani and Simms, 2014) ................... 227

Figure 4.5-9. SWCC in terms of degree of saturation for thin lift dry box ................... 228

Figure 4.5-10. SWCC in terms of degree of saturation for thick lift dry box................. 228

Figure 4.6-1 "Punching Shear" failure mechanism after the $60 \%$ SC bearing capacity

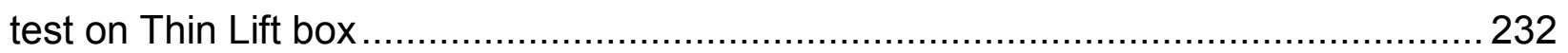

Figure 4.6-2. Failure after the $70 \%$ SC bearing capacity test on Thin Lift box............. 232

Figure 4.6-3. Plate load test results for thin lift dry box............................................ 233

Figure 4.6-4 Failure after the 60\% SC bearing capacity test on Thick Lift box Layer 1235

Figure 4.6-5. Plate load test results for thick lift dry box ......................................... 236

Figure 4.6-6. Comparison of estimated and measured bearing capacity values ......... 238

Figure 4.6-7. Caterpillar 824K medium wheel dozer ............................................ 239

Figure 4.6-8. Cracking and bearing capacity failures (Lozada et al., 2015)................ 242 


\section{List of Abbreviations}

AE- Actual Evaporation

AER- Alberta Energy Regulator

AEV - Air-entry Value

ASTM - American Society for Testing and Materials

CE-Edge of crack

CT_Composite/consolidated Tailings

EC-Electrical Conductivity

ERCB-Energy Resources Conservation Board

ESA-Effective Stress Analysis

GWC-Gravimetric Water Content

IC_-Inside of crack

LL_Liquid Limit

LVDT_ Linear Variable Differential Transformer

MESA—Modified Effective Stress Analysis

MFT_Mature Fine tailings

MTSA—Modified Effective Stress Analysis

PE-Potential Evaporation

$\mathrm{PI}-$ Plasticity Index

PL_Plastic Limit

PSV_Primary Separation Vessel

RE- Relative Evaporation

$\mathrm{RH}-$ Relative Humidity

SA-Surface Area 
SC-Solids Content

SFR— Sands to Fines Ratio

SL_ Shrinkage Limit

SWCC_- Soil Water Characteristic Curve

TMF_- Tailings Management Framework for Mineable Athabasca Oil Sands

TOC_-Total Organic Content

TSA-Total Stress Analysis

TT-Thickened Tailings

TWCC-Tailings Water Characteristic Curve

UC—Unconfined Compression

USDA—United States Department of Agriculture

VWC-Volumetric Water Content 


\section{INTRODUCTION}

\subsection{Problem Statement}

Alberta contains the third-largest proven crude oil supply in the world. This supply plays a significant role in the Canadian and global economies. However, oil sands mining produces very large quantities of solid and fluid tailings. The mining of Albertan oil sands, and the subsequent production of tailings, has been ongoing for over 40 years and is expected to continue, at increasing rates (Sobkowicz, 2012). Production is forecasted to average approximately 200,000 to 300,000 bpd per year over the next three to four years with total bitumen to up to nearly three million bpd in 2020 (Calgary Herald, 2015).

The management of tailings is one of the most difficult environmental challenges in the oil sands industry. Upon deposition, the fines in the tailings are dispersed and have very poor consolidation and settling behaviour when conventional deposition methods are used. Quite deep deposits show very low strength $(<1 \mathrm{kPa})$ and very high water content $(<180 \%$ gravimetric water content) even after 30 years (Wells 2011). This behaviour presents significant challenges to the end goal of land reclamation. In addition, the Alberta government has recently released a new plan for the management of oil sands tailings, with more penalties for failure to achieve reclaimable deposits (AER, 2015). Previously, regulations (namely Alberta Energy Regulator Directive 74) mandated that oil sands tailings must achieve specific undrained shear strengths within prescribed times post-deposition; however these regulations were suspended in March 2015.

The oil sands industry is investigating a number of dewatering technologies to help reduce the volumes of tailings, including centrifugation, in-line flocculation, thickening, and combing fine tailings with sand particles. Many of these technologies use a polymer to flocculate the fines, which induces faster rates of consolidation and sedimentation. These technologies all rely on post-deposition dewatering mechanisms, including 
consolidation but also evaporation and freeze-thaw to achieve sufficient dewatering and strength for eventual reclamation of tailings deposits.

Reclamation solutions that are considered to be environmentally acceptable for tailings ponds generally involve integrating the tailings deposits into the landscape (Jakubick et al, 2003). In order to do so, however, the tailings must achieve sufficient strength to be able to support earthmoving equipment: in other words, they must be trafficable. Therefore, for remedial purposes and planning, the assessment of the bearing capacity and consolidation behaviour is essential.

This work focuses on one of the dewatering technologies, namely, thin lift deposition of in-line flocculated tailings. This technology is already used at the commercial scale by Suncor (the TRO process), and is being trialed by a number of other oil sands operators at large scales.

\subsection{Objectives and Scope of Work}

The main objectives of this research are two-fold:

1. To gain an in-depth understanding of the dewatering behavior of in-line flocculated multi-layer deposits by:

a. Investigating the difference in dewatering behavior in thin lift versus thick lift deposition; and

b. Investigating the influence of cracking on the evaporation rate.

2. To study the bearing capacity of these tailings, including:

a. The influence of variable density and matric suction with depth on bearing capacity

b. How bearing capacity of tailings relates to undrained shear strength measurements using field vanes. 
In order to meet these general objectives, the following scope of work was pursued:

1. Generate polymer amended MFT in the laboratory that imitates field samples

2. Perform two dry box tests: thin $(0.30 \mathrm{~m})$ and thick $(0.50 \mathrm{~m})$ layer multilayer depositions to study how dewatering behaviors progress as layers are dried and more layers are added, and how cracking influences the evaporation rates in these tests;

3. Extract core samples before the addition of each layer in each dry box experiment to investigate the history of dewatering with respect to gravimetric water content, total suction, osmotic suction, and total organic content. Compare thin lift and thick lift core sample results.

4. Perform shear strength, and plate load tests to determine undrained shear strength; and bearing capacity, respectively, between the additions of each new layer for each dry box test. Compare thin lift and thick lift strength results.

\subsection{Thesis Outline}

This thesis is divided into six chapters as outlined below:

- Chapter 2 - Literature review: a compilation of studies on dewatering of oil sands tailings and bearing capacity of tailings, soft soils, and unsaturated soils

- Chapter 3 - Methods and Materials: a description of the experimental set-up, including: the characteristics and origin of the oil sands tailings used in this work, and the equipment and analytical methods used in the laboratory experiments. 
- Chapter 4-Results: a comprehensive record of the results achieved for the thin lift, and thick lift dry box tests, and plate load tests. Results are presented in chronological order, to provide a history of the conducted tests.

- Chapter 5 - Conclusions: a summary of the experiments, and significant findings.

- Chapter 6-Recommendations: a list of suggestions for future work based on the findings of the thesis.

\subsection{Novelty of the thesis}

No academic work has been performed either on dewatering behaviour of multilayer deposits of in-line flocculated tailings. No academic work has been done on bearing capacity of multilayer deposits of polymer amended tailings. 


\section{LITERATURE REVIEW}

This section provides an overview of the oil sands industry, including extraction and processing, oil sands tailings properties, and management, environmental issues and dewatering technologies. Overviews of unsaturated soil mechanics, bearing capacity and trafficability are then discussed.

\subsection{Oil Sands Industry}

Since 1964, the oil sands in northern Alberta have been mined to produce bitumen, making Alberta a world-leading energy supplier. In 2011, it was estimated that the Albertan oil sands deposits contain about 170 billion barrels of recoverable bitumen (Alberta Energy, 2014). More than 200 million litres of mature fine tailings (MFT) are produced per day. In 2010, tailings ponds occupied 176 square kilometers, and are projected to increase in area by $50 \%$ in area by 2020 (Pembina Institute, n.d.). The large volume of tailings produced by the bitumen extraction process has to be carefully managed, and in time, the lands used by the tailings storage impoundments have to be reclaimed.

\subsubsection{Extraction and Processing}

The oil sands deposits themselves are a stratigraphic unit consisting of approximately $70 \%$ sand, $5 \%$ water, $15 \%$ clay, and $10 \%$ bitumen as shown in Figure 2.1-1. (Total, 2014). 


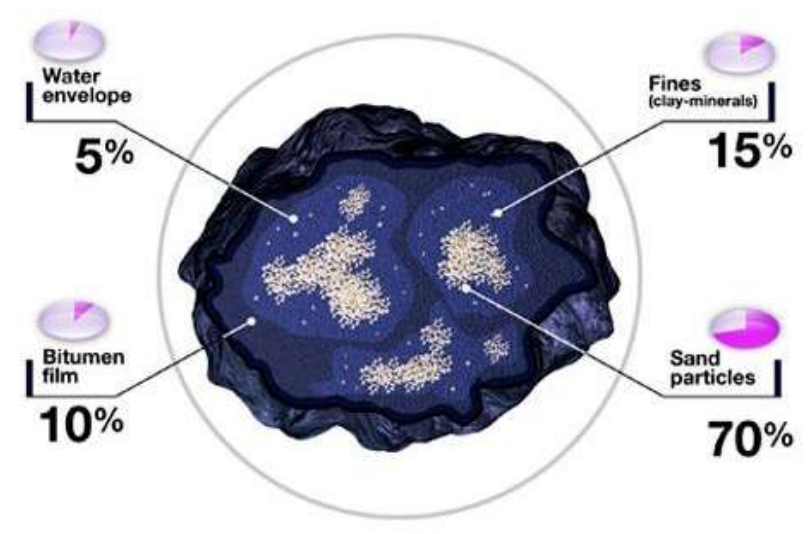

Figure 2.1-1. Oil sands composition (Total, 2014)

Clay particles are either associated with the sands themselves, or are present as seams within the oil sands unit. Oil sands are typically overlain by a $50 \mathrm{~m}$ to $200 \mathrm{~m}$ layer of overburden consisting of rock, soil, vegetation and muskeg of varying depths (NRCan, 2013). The oil sands themselves may be up to $150 \mathrm{~m}$ thick, but it is cost effective for surface mining only to depths of $75 \mathrm{~m}$ below the top of the oil sands deposit. In-situ methods are used for reserves that are found deeper underground.

Open-pit mining and a water-based extraction process are usually used to produce bitumen from the oil sands ore. The application of water-based extraction works on the basis that the sand grains in the oil sands are hydrophilic. Furthermore, Mossop (1980) established that the grains are surrounded by a thin film of water, as shown in Figure 2.1-2, and the oil lies in the centre of the pore. 


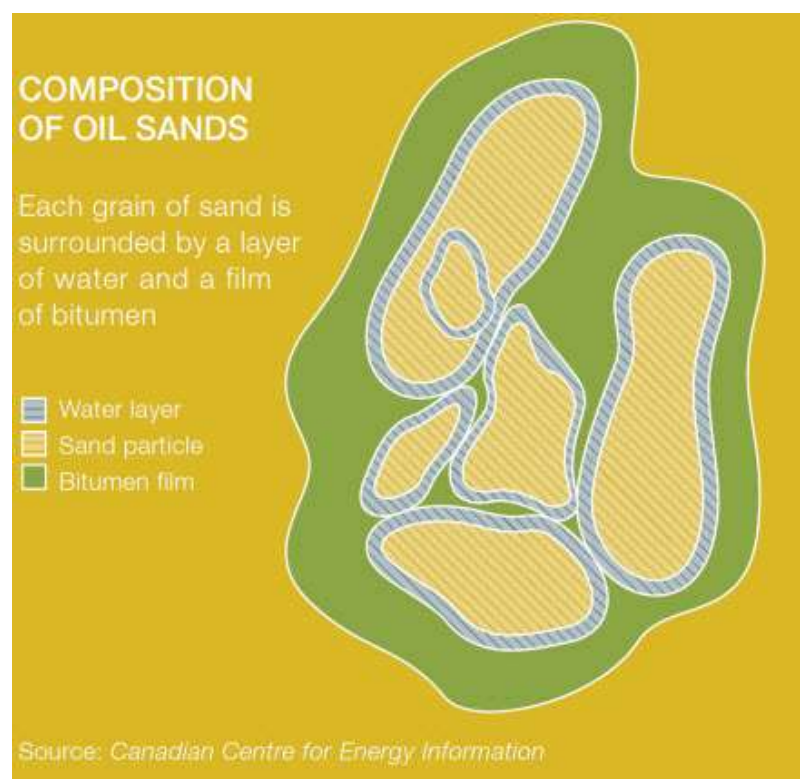

Figure 2.1-2. Orientation of bitumen, water and sand in the ore body (Alberta Energy, 2015)

Electrical double layers at the oil/water and water/sand grain interfaces create electrostatic forces that stabilize the water film. (Takamura, 1982; Hall et al., 1983; Anderson, 1986).

The process of bitumen extraction was developed by Professor Karl Clark in 1926, using a combination of hot water, steam and sodium hydroxide. Known as the Clark Hot Water Extraction Process (CHWE), with details shown in Figure 2.1-3. The bitumen extraction process can be broken down into three main stages: conditioning, separation, and scavenging, as described below (Oil Sands Discovery Centre, 2009): 


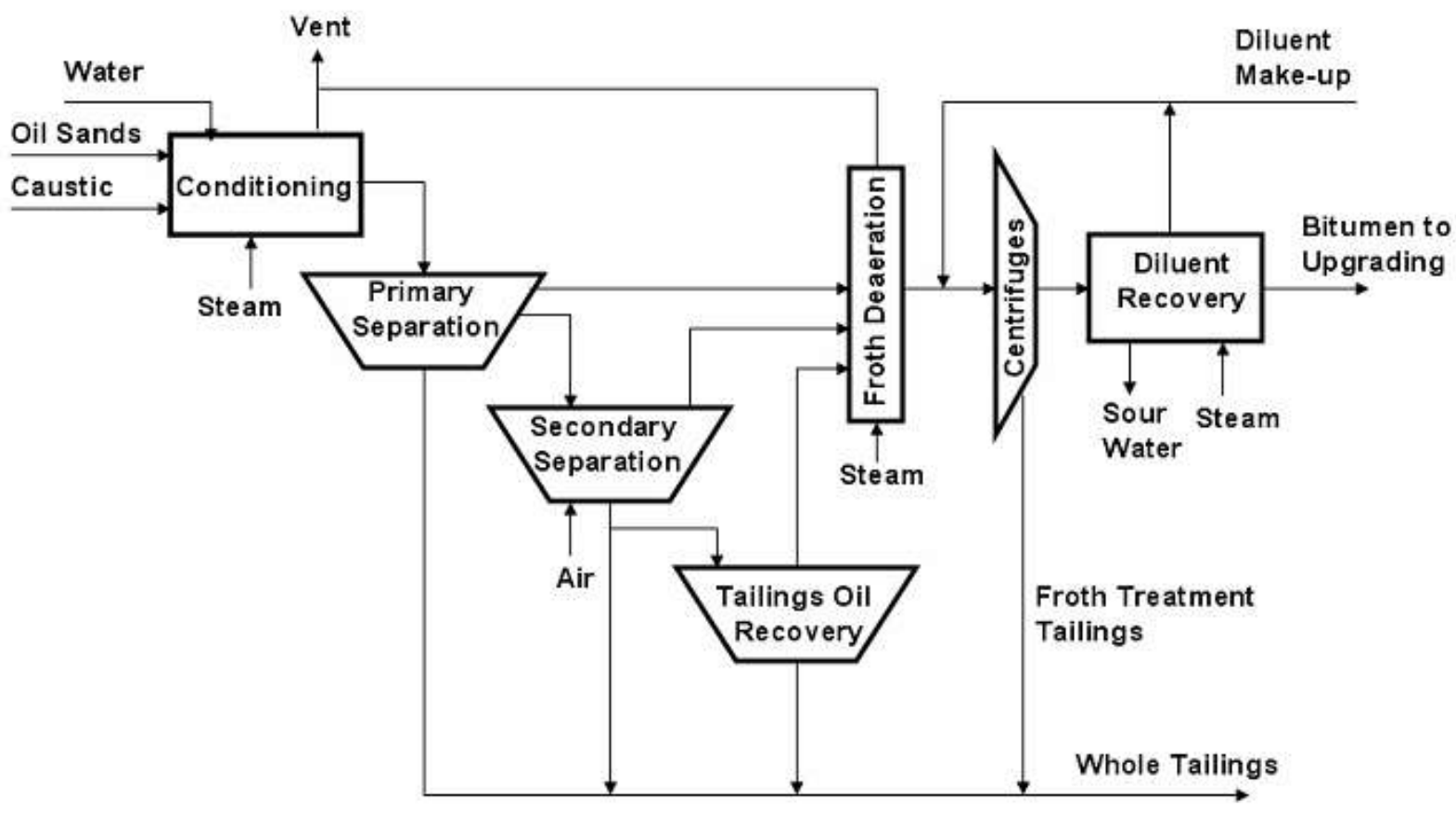

Figure 2.1-3. Generalized scheme of Clark Hot Water Extraction Process (Chalaturnyk et al., 2004; Jeeravipoolvarn, 2010)

1) Conditioning: The oil sands ore is mined by trucks and shovels, large lumps of oil sands are broken up, coarse particles are removed, then the oil sand is partially conditioned in transport pipelines from the truck discharge by mixing it with hot water. Conditioning begins the separation of bitumen from the oil sands by breaking the bonds that hold it together.

2) Seperation: More hot water is added to the slurry in order to ensure better separation of the bitumen from the sands, and the slurry is fed into primary separation vessels (PSVs). The temperature water varies somewhat between the different separation processes used by the operators, but it is generally above 40 degrees $\mathrm{C}$. Primary separation vessels segregate bitumen as a floating froth at the top, sand on the bottom, and a mixture of bitumen, sand clay and water in the middle (middlings slurry). There is a rake at the bottom of the PSVs that pulls the 
sand component down to accelerate the separation. This sand component becomes part of the tailings stream.

3) Scavenging: Middlings undergo a secondary separation, to recover additional bitumen. During secondary separation, air is injected into middlings, in flotation tanks, to create bitumen froth. An additional $2-4 \%$ bitumen recovery is the objective of this step. The additional bitumen recovered is added back to the PSVs. The froth is heated to $80^{\circ} \mathrm{C}$, and a de-aerator is used to remove excess air bubbles to allow efficient operation of pumps.

\subsubsection{Oil Sands Tailings and Properties}

About $90-92 \%$ of the bitumen is recovered from the ore, leaving behind a combination of water, sand, silt, clay and residual bitumen, known as "whole tailings". A typical breakdown of the composition for whole tailings is shown in Table 2.1-1 (Beier et al., 2013).

Table 2.1-1. Typical whole oil sands tailings properties (Beier et al., 2013)

\begin{tabular}{|c|c|c|}
\hline Parameter & $\begin{array}{l}\text { Whole tailings } \\
\text { (typical values) }\end{array}$ & $\begin{array}{l}\text { Mature fine tailings } \\
\text { (typical values) }\end{array}$ \\
\hline Solids content (\%) & 55 & $30-35$ \\
\hline Sand content ( $\%$ by dry mass) & 82 & $<5$ \\
\hline $\begin{array}{l}\text { Fines content (\% by total dry } \\
\text { mass including bitumen) }\end{array}$ & 17 & $>95$ \\
\hline $\begin{array}{l}\text { Clay content (\% by dry mass } \\
\text { of fines) }\end{array}$ & - & $30-50$ \\
\hline
\end{tabular}

In this table, the solids content (SC) is the dry mass of solids (including mineral solids and residual bitumen) divided by the total mass of the tailings (including mineral solids, residual bitumen, and fluid). Sand content is the dry mass of sand divided by the 
dry mass of solids. Fines content is the dry mass of fines (silts and clay particles that pass through a $44 \mu \mathrm{m}$ sieve and residual bitumen) divided by the total dry mass of solids. The clay content is the dry mass of clay divided by the dry mass of fines (Boratynec, 2003).

\subsubsection{Conventional Oil Sands Tailings Management}

Whole tailings are either directly discharged into a storage facility, at $55 \%$ SC (conventional tailings deposition). In the storage facility, whole tailings undergo segregation once they are deposited onto beaches or into constructed cells, as shown

in Figure 2.1-4. The sand fraction resulting from this segregation naturally forms beaches or is recovered and then compacted in the cells to construct a containment dam.

Some of the fines remain in the sand matrix of the beaches during deposition, a fraction greater than $50 \%$ of the total mass of fines, while the remaining fines flow into the settling pond with the water, at a SC of $6-10 \%$. This portion of the fines is known as thin fine tailings. There is overflow from the cyclone classifier that consists mostly of fines and residual bitumen. The overflow is further dewatered in thickeners, and deposited into the impoundment.

Over some time, the fines settle to a SC of about $30-35 \%$, and are called mature fine tailings (MFT). At this stage, additional settlement and consolidation of these tailings is extremely slow, since the clay fraction is dispersed in nature, due to the extraction process (Beier et al., 2013). The low rate of consolidation is both due to the low hydraulic conductivity of the tailings, as well as the development of structure over time that impedes consolidation - this process is termed thixotropy or creep (Scott et al. 2013). For every barrel of bitumen $\left(\sim 0.12 \mathrm{~m}^{3}\right)$ produced, Beier and Sego (2008) have estimated that approximately 1 cubic meter of sand and 0.25 cubic meter of MFT have been deposited. Over the course of mining in Alberta, this has resulted in an accumulation of over 800 million cubic meters of MFT (Hyndman and Sobkowicz, 2010). 


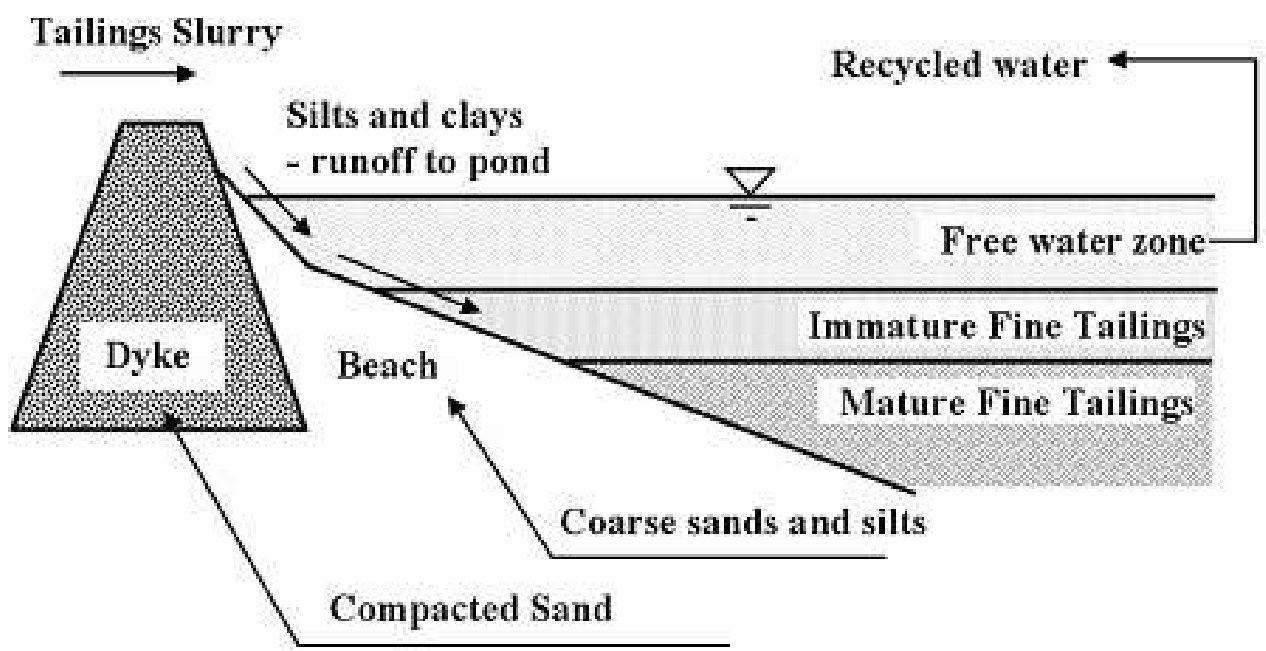

Figure 2.1-4. Cross section of an oil sands tailings storage facility (FTFC, 1995; Jeeravipoolvarn, 2010)

\subsection{Mature Fine Tailings and Properties}

Mature fine tailings are problematic for the oil sands industry due to their poor settlement and consolidation behaviours, arising from a low hydraulic conductivity and thixotropy. Some geotechnical properties of MFT are summarized in Table 2.2-1 (FTFC, 1995; Sobkowicz, 2012). A relationship of hydraulic conductivity to void ratio relationships is shown in Figure 2.2-1.

Table 2.2-1. Oil sands tailings properties (modified from BGC Engineering, 2010)

\begin{tabular}{cc} 
Property & Value \\
\hline Mean particle size $(\mu \mathrm{m})$ & $5-10$ \\
Solids content $(\%)$ & 33 \\
Hydraulic conductivity $(\mathrm{m} / \mathrm{s})$ & $10^{-6}-$ \\
Void ratio (dimensionless) & 5 \\
Liquid limit $(\%)$ & $40-75$ \\
Plastic limit $(\%)$ & $10-20$
\end{tabular}




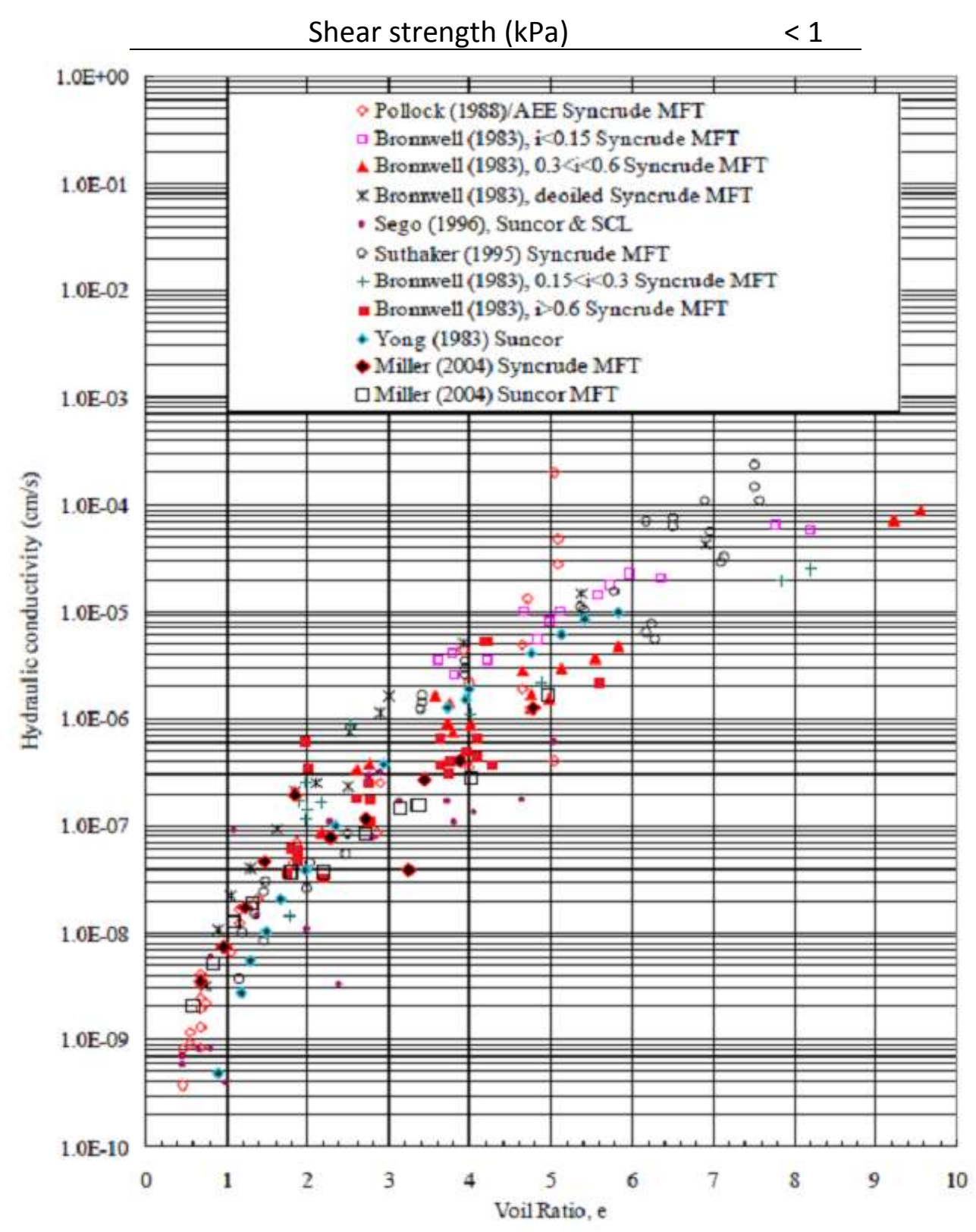

Figure 2.2-1. Hydraulic conductivity vs. void ratio of oil sands MFT (Jeeravipoolvarn, 2005)

Since dewatering of MFT takes an extended period of time, large containment ponds are required for long-term storage, creating environmental and economical concerns. To reduce the long-term storage of MFT in fluid retaining facilities, technological advances in the area of tailings dewatering are ongoing in the oil sands industry. 


\subsection{Environmental Issues}

Tailings ponds are vast and can have significant repercussion on the surrounding environment. There are currently more than 170 square kilometers of tailings ponds in Alberta (Alberta Energy, 2014). These structures pose a number of challenges including (CAPP, 2015):

- Poor consolidation and settling of the MFT layer, which may take several decades to settle;

- Quality of the remaining water, which contains concentrations of chemicals toxic to fish; and

- Residual soil that floats to the top of the pond, which poses a risk to birds.

In order to mitigate these challenges, regulations and policies have been put into place, and are described in the following section.

\subsection{Oil Sands Tailings Management Regulations}

As an initial step in decreasing the fluid fine tailings inventory, the Energy Resource Conservation Board (ERCB), Alberta's governing body that oversees the oil sands industry, released Directive 074: Tailings Performance Criteria and Requirements for Oil Sands Mining Schemes in 2009. This directive outlined performance criteria for the minimization of fluid tailings volumes and establishment of trafficable deposits for reclamation.

The directive specified the following criteria: in order to obtain a trafficable surface, the minimum undrained shear strength, $S_{u}$, of the tailings was required to be $10 \mathrm{kPa}$; and the minimum undrained shear strength of any tailings deposited in the previous year must achieve $5 \mathrm{kPa}$. Any material that did not meet this requirement had to be removed or remediated. In five years, after active deposition had ended, the deposit must have achieved trafficability or an undrained shear strength of $10 \mathrm{kPa}$ (Energy Resources Conservation Board, 2009). Although Directive 074 addressed the conversion of a specified amount of fine tailings to a solid form, it did not address 
existing fine tailings. As of March 13, 2015, this directive was suspended, due to the industry's inability to meet the directive's objectives. The $5 \mathrm{kPa}$ target, however, is retained in new regulations, without a firm timeline as to when this has to be achieved.

With the suspension of Directive 074, the Government of Alberta released the Tailings Management Framework for Mineable Athabasca Oil Sands (TMF), a new policy that provides the Alberta Energy Regulator (AER, former ERCB) with guidance on the regulation of fluid tailings volumes, and the reduction of risks related to the buildup of fine tailings on the environment. Some highlights of the TMF include the following:

- Minimizing the accumulation of fluid tailings (both new and existing);

- Encouraging the investment in technologies that would aid in keeping with those constraints for the oil sands industry;

- Reducing environmental and other risks during mine operation and closure;

- Ensuring that tailings are treated and reclaimed progressively throughout the life-cycle of the mine, and are ready-to-reclaim within 10 years of the end of mine life.

These regulations allow the monitoring and measurement of progress of the deposit towards the reclamation goal. A number of dewatering technologies that the industry is investigating are presented in the next section.

\subsection{Tailings Dewatering Technologies}

The efficient dewatering of oil sands tailings is necessary to minimize the environmental footprint of oil sands operators. Many dewatering technologies are available for dewatering oils sands tailings, including those that depend on physical/mechanical processes, natural processes, chemical/biological amendments, mixtures/co-disposal and permanent storage. A comprehensive review of 34 dewatering technologies is available in a report published by BGC Engineering in 2010. A brief summary of a few of these technologies follows. 


\subsubsection{Filtered Tailings}

Filtered tailings technology involves the mechanical dewatering by filtration, typically under pressure or a vacuum and dry stacking. In this process, filtration is applied either to the unaltered extraction tailings stream, the coarse fraction (cyclone underflow) or the thickener underflow (mostly fines) of the tailings slurry. The unsaturated tailings are then either conveyed or trucked and placed, spread compacted to create an unsaturated, dense and stable tailings pile ("dry stack") in a disposal area.

\subsubsection{Composite Tailings (CT)}

Composite/Consolidated tailings (CT) technology consists of densified extraction tailings (coarse sand from cyclone underflow) and fine particles (MFT) mixed with a chemical additive (typically gypsum). This treatment creates a non-segregated and more homogeneous slurry, which is then discharged into a tailings pond. The CT process creates a cappable soft deposit able to consolidate more quickly.

\subsubsection{Thickened Tailings}

Thickened tailings (TT) technology focuses on the settling and sedimentation of suspended fine particles, using an apparatus known as a thickener. Chemicals are also added to promote flocculation of fines, and extracting water that may be recycled back to the oil extraction process.

\subsubsection{In-line Flocculation}

Previously, the enforcement of Directive 074 prompted the industry to assess current dewatering technologies, and investigate new methods. In-line flocculation is one such technology, where polymer solutions are added to dredged MFT in the transfer pipeline, before the subsequent deposition onto sloped beds. (Beier et al., 
2013) Flocculated MFT may be deposited in thin or thick layers, which emphasize different post-deposition dewatering mechanisms.

In thin-lift deposition, significant instantaneous dewatering is achieved as fines aggregate into flocs, improving the permeability and water release of the tailings. Settlement, seepage, desiccation and freeze-thaw contribute to further dewatering (Beier et al, 2013). Suncor has commercially implemented this technology, as part of their tailings reduction operations. (Wells et al, 2011). Shell has launched a commercialscale demonstration of this technology at their Muskeg River Site, known as atmospheric fines drying (AFD), described in more detail in the next section. (Kolstad et al., 2012).

Alternatively, the flocculated tailings may be discharged in thick lifts of greater than $1 \mathrm{~m}$ thicknesses. In this case, self-weight consolidation and evaporation are relied on for dewatering. Water management must be undertaken through decant structures and perimeter ditching as water is released to the surface, to ensure additional dewatering. Syncrude has piloted this technology, known as "rim-ditching" or "accelerated dewatering" (Beier et al., 2013).

\subsubsection{Atmospheric Fines Drying (AFD)}

As mentioned previously, AFD is a pilot-scale trial of in-line flocculation technology implemented at Shell's Muskeg River Mine. MFT at $35.5 \%$ SC is collected from an existing tailings pond, transferred by pipelines to designated cells while being injected with a polymer solution, and deposited by an 8" pipe. The injection of polymer occurs 17 $\mathrm{ft}$ before the end of the pipe. The process is illustrated in Figure 2.5-1. The tailings are

further conditioned in submerged pipe outlets within the spill box. Immediate floc formation, settling, consolidation, drainage, evaporation and freeze-thaw further dewater the material after deposition. (Barr Engineering, 2012). 


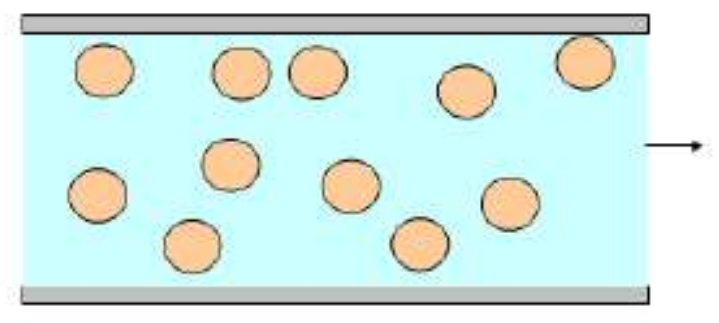

Stage 1: Delivery Piping of MFT

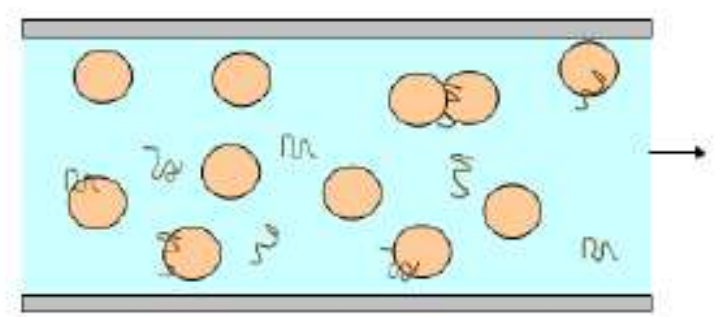

Stage 3: Flocculant Mixing

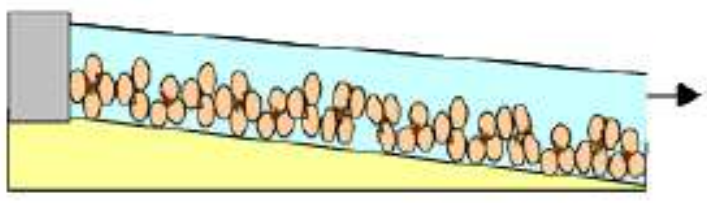

Stage 5: In-situ dewatering of flocs in Disposal Area

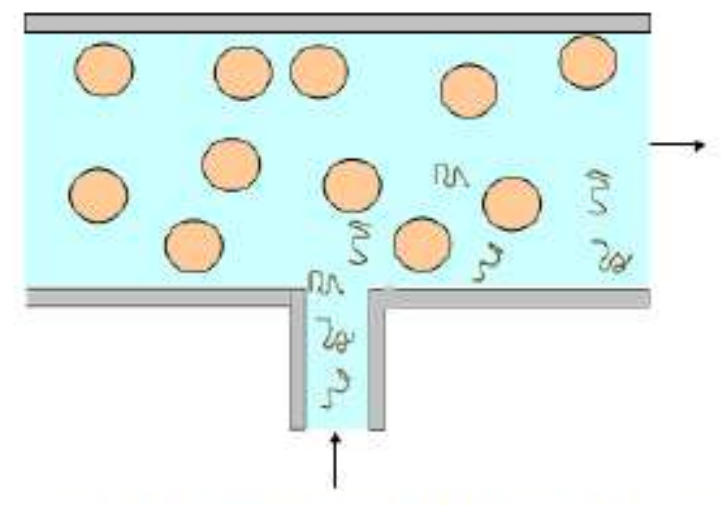

Stage 2: Flocculant Solution Injection

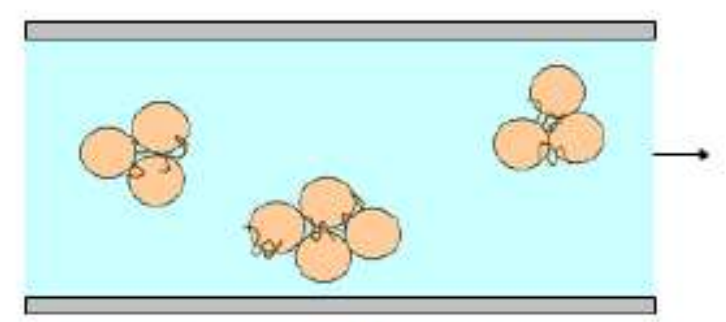

Stage 4: Floc Conditioning

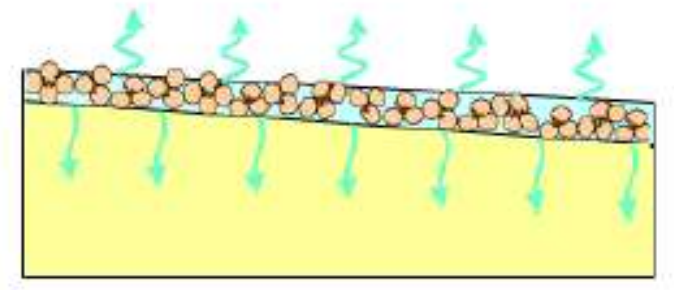

Stage 6: Evaporation and Deep Percolation of Water from MFT Layer

Figure 2.5-1. Generalized AFD process (Barr Engineering, 2012)

An important factor for the optimization of tailings dewatering is lift thickness. Both, thin and thick lift deposition techniques were tested in this trial. Three variations were trialed: multilayer thin lifts of $0.5 \mathrm{~m}$ with a total thickness of $4 \mathrm{~m}$; multilayer thick lifts of 1-2m; and a single thick lift of $5 \mathrm{~m}$ deposited over 11 hours. (Barr Engineering, 2012) 


\subsection{Consolidation}

Consolidation is the time-dependent process in which soils decrease in volume due to applied loads. The soil gains effective stress through the dissipation of excess pore pressures. The soil particles become more tightly packed during the process, reducing the volume. The effective stresses control the deformation of the soil during consolidation. Classical theory and finite strain consolidation theory are discussed below.

\subsubsection{Classical Theory}

Karl Terzaghi derived a one-dimensional consolidation theory in 1923, which has been widely accepted in geotechnical engineering. The theory combines a fluid flow relationship, a continuity equation and the principle of effective stress. Mathematically, it is expressed as equation (1):

$$
c_{v}=\frac{\partial^{2} u}{\partial z^{2}}=\frac{\partial u}{\partial t}
$$

Where,

$$
\begin{array}{ll}
c_{v} & =\text { coefficient of consolidation; } \\
u & =\text { excess pore pressure; } \\
t & =\text { time; } \\
z & =\text { one dimensional vertical coordinate. }
\end{array}
$$

This theory is based on the following assumptions:

- A homogeneous and saturated soil

- Incompressible soil and water particles 
- Vertical water flow

- Darcy's law is valid

- Small strains

In the classical theory, it is assumed that when a stress is applied to the soil, at $t=0$, it is immediately taken up by the pore water. This leads to the development of excess pore water pressure, and initial settlement of the soil. The excess pressure is gradually dissipated over time as drainage progresses, and the load is transferred to the remaining soil particles. At the end of consolidation, at $t=\infty$, the excess pore water pressure is completely dissipated, and the load is completely carried by the soil particles.

In the case of oil sands tailings and other soft soils, the assumptions of consistent material properties and small strains are not applicable. In these types of soils, compressibility and hydraulic conductivity are non-linear, and a small strain solution is not applicable to the large settlements that may occur in soft soils. (Jeeravipoolvarn, 2010). Therefore, the finite strain consolidation theory may provide the necessary solution.

\subsubsection{Finite Strain Theory}

In order to model the consolidation of soft soils, Gibson, England and Hussey developed the finite strain theory in 1967. In geotechnical engineering, the finite strain theory is often used when the application consists of self-weight consolidation such as tailings pond size, strength implications, and pore water pressure in slurries. It has been found that even in relatively thin lifts, significant consolidation occurs (Matthews et al., 2011). 
The finite strain theory is mathematically expressed in terms of void ratio, excess pore pressure and porosity. This theory is based on the following assumptions:

- Darcy's law is valid

- There is no time dependent effect in the soil skeleton

This theory is mathematically expressed as equation (2):

$$
\pm\left(\frac{\rho_{s}}{\rho_{f}}-1\right) \frac{d}{d e}\left[\frac{k(e)}{(1+e)}\right] \frac{\partial e}{\partial z}+\frac{\partial}{\partial z}\left[\frac{k(e)}{\rho_{f}(1+e)} \frac{d \sigma^{\prime}}{d e} \frac{\partial e}{\partial z}\right]+\frac{\partial e}{\partial t}=0
$$

$$
\begin{array}{ll}
\text { Where, } & \\
\rho_{s} & =\text { solids density; } \\
\rho_{f} & =\text { fluid density; } \\
e & =\text { void ratio; } \\
k & =\text { hydraulic conductivity; } \\
\sigma^{\prime} & =\text { effective stress; } \\
t & =\text { time; } \\
z & =\text { reduced or material coordinate. }
\end{array}
$$

Since equation (2) is not dependent on strain, it can be used in cases where thick clay layers are subjected to large settlements.

The most important difference between finite strain consolidation is the variation in hydraulic conductivity and stiffness with void ratio. These relationships are presented for MFT in Figures 2.6-1 and 2.6-2. 


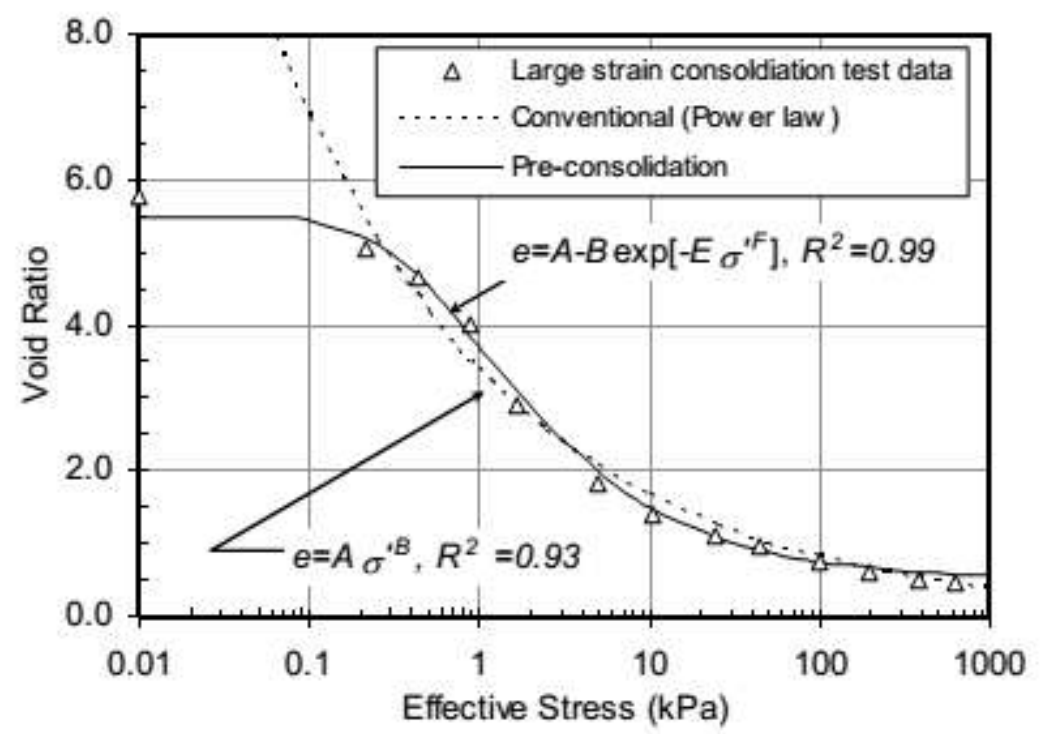

Figure 2.6-1. Compressibility of mature fine tailings (Jeeravipoolvarn, 2010)

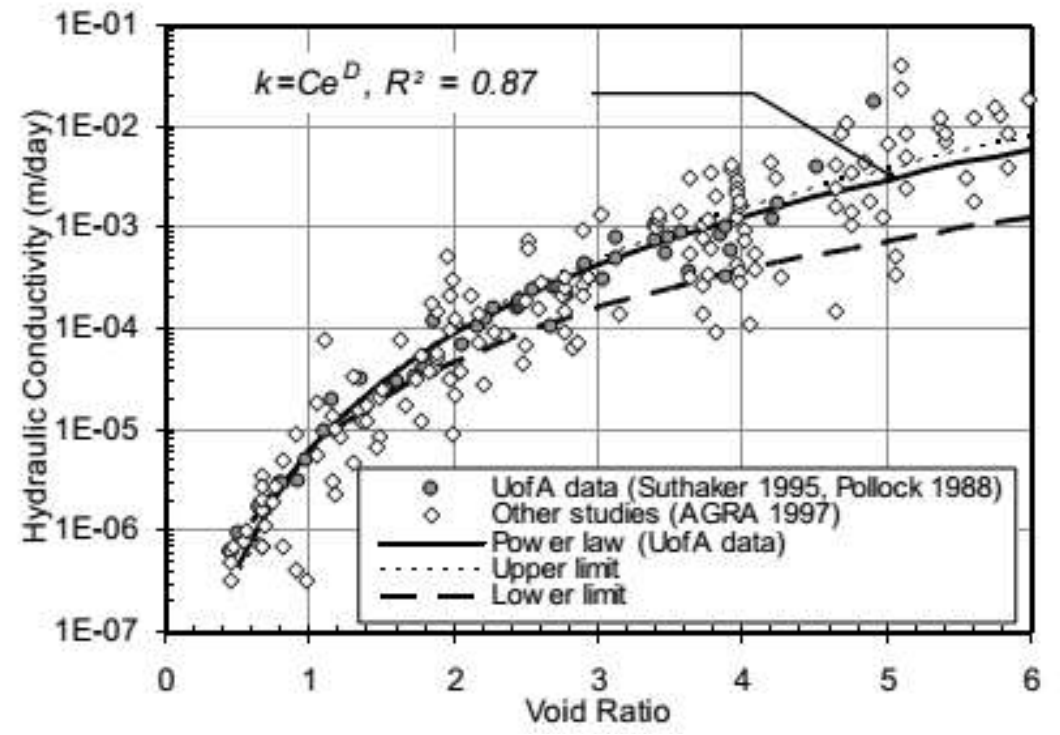

Figure 2.6-2. Hydraulic conductivity of mature fine tailings (Jeeravipoolvarn, 2010)

\subsection{Evaporation}

Evaporation is the escape of water vapour from a soil surface into the atmosphere. It is the process by which water is transferred from the bare soil (without vegetation) into the atmosphere by a state change of water from a liquid to a gas phase (Lal and 
Shukha, 2004). The evaporation process can be broken down into three stages (Innocent-Bernard, 2013):

1) Water is transported to the surface of the soil

2) Water is changed from a liquid to a gaseous state through an interrupted supply of heat (solar energy, microbial activity, etc.)

3) Water vapour escapes from the soil surface to the atmosphere due to a difference in vapour pressure, using convection and diffusion processes.

\subsubsection{Potential Evaporation}

Potential evaporation $(\mathrm{PE})$ is defined as "The quantity of water vapour which could be emitted by a surface of pure water per unit surface area and unit time under the existing atmospheric conditions." (International Glossary of Hydrology, 1974).

The pan evaporation method can be used to measure PE in the laboratory or the field. In the laboratory, a vessel with similar dimensions to the object of interest is placed in the same conditions as the material under study. The weight is recorded at regular time intervals. PE can also be calculated using the Penman-Monteith equation, as a relation between temperature, relative humidity $(\mathrm{RH})$, wind speed, and radiation. This equation assumes that the supply of water to the soil is constant.

$$
P E=\frac{\Delta\left(R_{n}-G\right)+\rho_{a} C_{p}\left(e_{s}-e_{a}\right) / r_{a}}{\Delta+\gamma\left(1+\frac{r_{s}}{r_{a}}\right)}
$$

Where:

$$
\begin{array}{ll}
\mathrm{PE}= & \text { Potential evaporation, }[\mathrm{mm} / \text { day }] ; \\
\mathrm{R}_{\mathrm{n}}= & \text { Net Radiation, }\left[\mathrm{MJ} \mathrm{m} \mathrm{m}^{2} / \text { day }\right] ; \\
\mathrm{G}= & \text { Soil heat flux, }\left[\mathrm{MJ} \mathrm{m} \mathrm{m}^{2} / \mathrm{day}\right] ; \\
V= & \text { Psychometric constant, }\left[\mathrm{kPa} /{ }^{\circ} \mathrm{C}\right] ; \\
\Delta= & \text { Slope of saturation vapour curve, }\left[\mathrm{kPa} /{ }^{\circ} \mathrm{C}\right] ; \\
\mathrm{e}_{\mathrm{s}}= & \text { Mean saturation pressure, }[\mathrm{kPa}] ; \\
\mathrm{e}_{\mathrm{a}}= & \text { Actual vapour pressure derived from relative humidity }(\mathrm{RH}),[\mathrm{kPa}] ;
\end{array}
$$




$$
\begin{array}{ll}
e_{s-} e_{a} & =\text { Saturation vapour pressure deficit, }[\mathrm{kPa}] ; \\
r_{\mathrm{s}}= & \text { Soil surface resistance, }[\mathrm{s} / \mathrm{m}] ; \\
r_{\mathrm{a}}= & \text { Bulk surface aerodynamic resistance to water vapour, }[\mathrm{s} / \mathrm{m}] ; \\
\rho_{\mathrm{a}}= & \text { Density of air, }\left[\mathrm{kg} / \mathrm{m}^{3}\right] ; \\
\mathrm{C}_{\mathrm{p}}= & \text { Specific heat of air, }\left[1.013 \times 10^{-3} \mathrm{MJ} / \mathrm{kg}^{\circ} \mathrm{C}\right] .
\end{array}
$$

Since the current experiment was carried out indoors, away from radiation sources, the radiation component was neglected. The equation can be further simplified for short crops, providing a reasonable estimate for PE on bare soil:

$$
P E=\frac{0.408 \Delta\left(R_{n}-G\right)+\gamma \frac{900}{T+273} u_{2}\left(e_{s}-e_{a}\right)}{\Delta+\gamma\left(1+0.34 u_{2}\right)}
$$

Where:

$$
\begin{array}{ll}
\mathrm{u}_{2} & =\text { Wind speed, }[\mathrm{m} / \mathrm{s}] ; \\
\mathrm{T} & =\text { Temperature }\left[{ }^{\circ} \mathrm{C}\right]
\end{array}
$$

In this case, the following equations are used to solve for $\Delta, \mathrm{Y}$ and $\mathrm{G}$ :

$$
\Delta=\frac{4098\left(0.6108 e^{\left(\frac{17.27 T}{T+273.3}\right)}\right)}{(T+273.3)^{2}}
$$

Where:

$$
\begin{aligned}
\mathrm{T} & =\text { Mean air temperature, }\left[{ }^{\circ} \mathrm{C}\right] \\
\gamma & =0.665 \times 10^{-3} \mathrm{P}
\end{aligned}
$$

Where:

$$
\mathrm{P} \quad=\quad \text { Atmospheric pressure, }[\mathrm{kPa}]
$$




$$
e_{s}=\frac{e^{o}\left(T_{\max }\right)+e^{o}\left(T_{\min }\right)}{2}
$$

Where:

$$
\begin{aligned}
& e^{o}\left(T_{i}\right)=0.6108 e^{\left(\frac{17.27 T}{T+273.3}\right)} . \\
& e_{a}=\frac{e^{o}\left(T_{\max }\right) R H_{\max } / 100+e^{o}\left(T_{\min }\right) R H_{\min } / 100}{2} \\
& G=c_{S} \frac{T_{i}-T_{i-1}}{\Delta t} \Delta z
\end{aligned}
$$

Where:
$\mathrm{C}_{\mathrm{s}}=$ Soil heat capacity, $\left[\mathrm{MJ} / \mathrm{m}^{3}\right.$ day $]$;
$\mathrm{T}_{\mathrm{i}}=$ Mean air temperature at time $\mathrm{i},\left[{ }^{\circ} \mathrm{C}\right] ;$
$\mathrm{T}_{\mathrm{i}-1}=$ Mean air temperature at time $\mathrm{i}-1,\left[{ }^{\circ} \mathrm{C}\right] ;$
$\Delta \mathrm{t}=\quad$ Length of time interval, [d];
$\Delta z=$ Effective soil depth, [m].

\subsubsection{Actual Evaporation}

The International glossary of Hydrology defines the actual evaporation (AE) as "the quantity of water that could be emitted from an unsaturated soil per unit surface area and unit time under current atmospheric conditions" (Int'l glossary of Hydrology WMO 1974). AE in soil is usually a fraction of the PE, the maximum rate of evaporation from a pure water surface at the same climatic conditions (Wilson et al., 1994).

There are three stages of evaporation. Stage I occurs when the soil is saturated at the onset of evaporation and has a significant quantity of water available. At this point, the $\mathrm{AE}$ rate is almost equal to the $\mathrm{PE}$ rate, as long as the $\mathrm{RH}$ of the air above the soil surface stays at $100 \%$ (Monteith, 1981). Stage II occurs when the rate of evaporation 
decreases substantially. At this point, the soil desaturates and the permeability at the surface decreases. The suction gradient increases exponentially in order to meet the evaporative demand. The onset of Stage III occurs when the rate of evaporation eventually falls to a minimum rate. The stages of evaporation are shown in Figure 2.7-1.

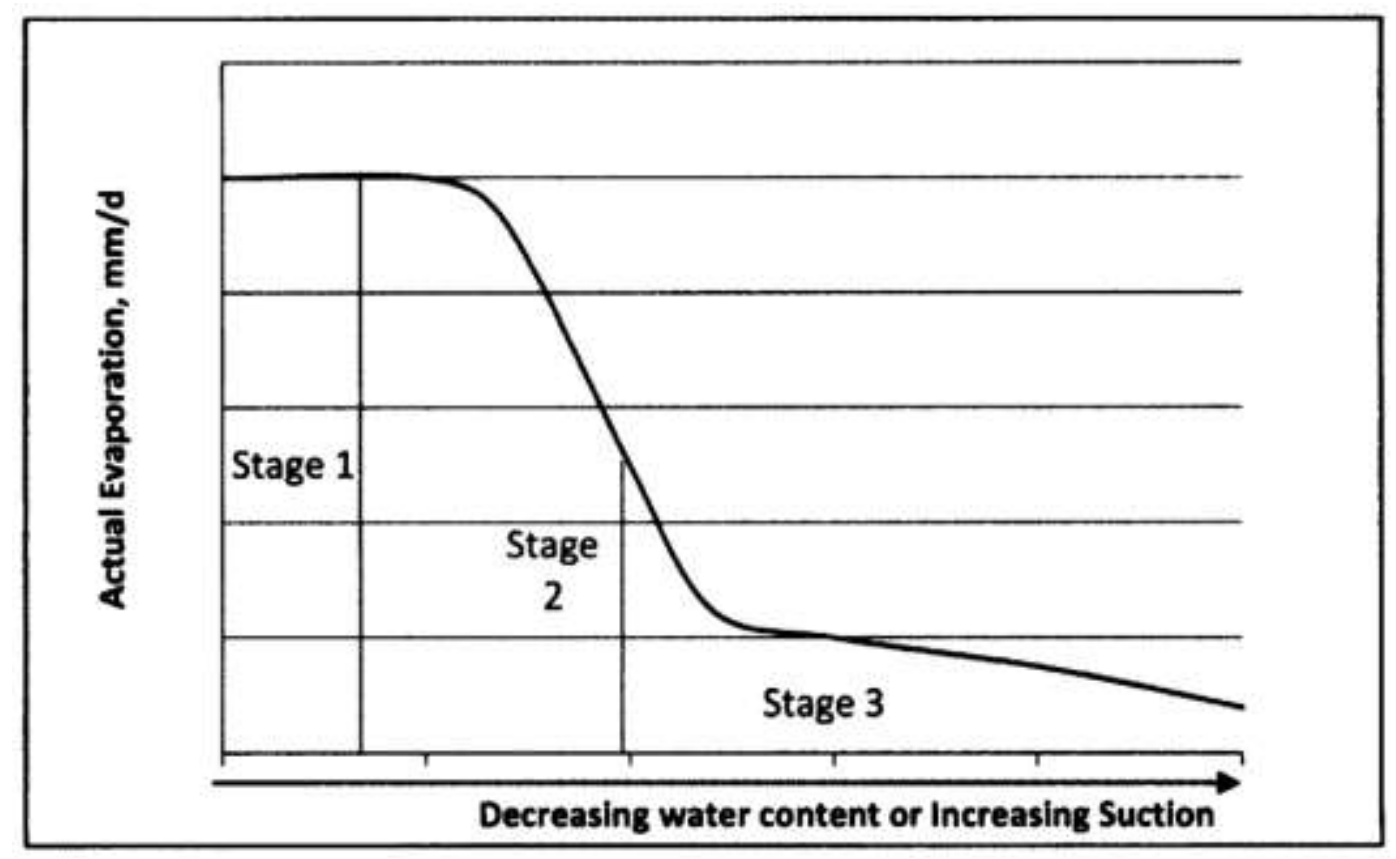

Figure 2.7-1. Stages of evaporation (Wilson et al, 1994)

In the laboratory, AE can be estimated by taking weight measurements at regular time intervals from the soil sample where evaporation is occurring. Drainage must also be taken into account, or suppressed. Lysimeters can also be used to measure AE. 


\subsubsection{Relative Evaporation}

Relative evaporation (RE) is the ratio of $A E$ to $P E$, and usually varies between 0 and 1. This ratio can be calculated from measurements of $A E$ and PE or calculated, using the following equation (Wilson et al., 1997).

$R E=\frac{A E}{P E}=\frac{\left(e_{o}-e_{a}\right)}{\left(e_{s}-e_{a}\right)}$

Where,

$\mathrm{e}_{0} \quad=\quad$ Actual vapour pressure of the soil surface, $[\mathrm{kPa}]$;

$\mathrm{e}_{\mathrm{s}} \quad=\quad$ Saturation vapour pressure at the temperature of the soil, water and air $[\mathrm{kPa}]$;

$\mathrm{e}_{\mathrm{a}} \quad=$ Air vapour pressure $[\mathrm{kPa}]$.

If the water, air and soil are assumed to be at the same temperature, the value of $\mathrm{RE}$ can also be expressed as a function of total suction at the surface, which is discussed in further detail in section 2.6.1 (Wilson et al., 1997):

$$
R E=\frac{A E}{P E}=\left[\frac{\exp \left(\frac{\Psi_{g}-W_{v}}{R T}\right)-h_{a}}{\left(1-h_{a}\right)}\right]
$$

Where,

$\Psi=$ Total suction in the liquid water phase expressed as equivalent matric suction and as a negative value;

$\mathrm{W}_{\mathrm{v}}=$ Molecular weight of water [0.018 kg/mol];

g = acceleration $\left[\mathrm{m} / \mathrm{s}^{2}\right]$;

$\mathrm{h}_{\mathrm{a}} \quad=\mathrm{RH}$ of the air above the evaporating soil and water surfaces. 
Generally, the principle that suction controls the normalized evaporation for a soil has been found to be valid, at least for Regina clay in a study conducted by Wilson et al., 1997. Additionally, properties such as moisture content, texture and mineralogy do not impact this principle.

Studies have shown that predictions of RE based solely on suction tend to over predict cumulative evaporation, and the time of onset for stage II evaporation (Bittelli et al, 2008). Therefore various mechanisms have been proposed to explain this overprediction. Van De Griend and Owe (1994) suggested that an increase in surface resistance as moisture falls below the residual water content may be responsible.

\subsubsection{Effect of Pore-water Salinity}

As evaporation progresses in soils, water is driven up to the surface leaving salts behind. The salts precipitate, forming a salt crust. Studies have shown that the presence of salts can decrease the AE by up to 90\% (Fujiyasu and Fahey, 2000; Fujimaki et al., 2006; Shimojima et al., 1996). There are three mechanisms that may cause this phenomenon presented in Fujiyasu and Fahey (2000):

1. High shortwave radiation reflectivity of the dry salt crust: A high level of shortwave reflectivity significantly reduces the net amount of radiation that reaches a soil surface with a salt crust, which contributes to evaporation reduction.

2. Vapor density depression due to salinity: The evaporation from a salt water surface is lesser than that of a freshwater surface since the number of water molecules per unit volume is decreased by the presence of salt molecules. The thermal energy of water is also impacted by the corresponding interactions of these molecules. As surface salinity increases, the saturation vapour density above a saline surface decreases, decreasing the rate of evaporation from the surface. 
3. High salt crust resistance to moisture transfer: The formation of salt precipitates at the surface may significantly reduce the moisture transfer rate from soil to air. Studies have shown that two mechanisms may be responsible for the induced evaporation reduction, including: salt crusting and the physical blocking of soil pores (Chen 1992; Zawislanski et al. 1992; Thorburn et al., 1992).

In a study conducted by Simms et al (2007), it was found that salt formations began to affect evaporation rates three weeks after the deposition of a single layer of thickened gold tailings. A decrease in albedo was also identified as a contributor to the reduced evaporation.

\subsubsection{Effects of Cracking}

Another factor that affects evaporation rates in soils is the formation of cracks in soils due to shrinkage. Cracking have been correlated with an increase in water loss in previous studies (Adams and Hanks 1964; Hatano et al., 1988; Innocent-Bernard, 2013).

Upon their formation, cracks create new macropores that can act as additional channels for water flow during evaporation. The development of cracks is a function of the soil properties such as the fines content, and mineralogy. Although the contribution of cracking increases densification and improves the strength of tailings deposits, it can lead to the infusion of oxygen into the tailings matrix and the generation of acid mine drainage, which can be environmentally detrimental (Djalal, 2014).

The appearance of cracks also increases the surface area, which means that more liquid will be exposed to the atmosphere. Surface area affects the amount of interchange that can occur with the atmosphere; therefore the quantity of water that can 
evaporate will increase with an increased surface area. Changes to the surface area of the water are proportional to a change in evaporation volume (McJannet et al., 2008)

The progression of cracking can be divided into three phases (Barbour et al. 1997; Tuk-Ki and Nhat 2008; Liu et al. 2008; Djalal, 2014):

4) Initiation and development of primary cracking

5) Secondary cracking (soil zones that are delineated by primary cracking are subdivided by new cracks)

6) Tertiary cracking (zones that are delineated by secondary cracking are subdivided by new cracks)

The following table details some studies on the influence of cracking conducted to date and some of their key findings. 
Table 2.7-1. Summary of studies on the influence of cracking on evaporation rates

\begin{tabular}{|c|c|c|c|}
\hline Authors & Date & Type of study & Key Findings \\
\hline $\begin{array}{l}\text { Adams and } \\
\text { Hank }\end{array}$ & 1964 & $\begin{array}{l}\text { Agricultural field } \\
\text { and laboratory } \\
\text { studies }\end{array}$ & $\begin{array}{l}\text { - Crack surface to top surface ratios of } 2.9 \text { - } \\
\text { - Evaporation from side walls of shallow } \\
\text { shrinkage cracks may vary from } 35 \text { to } 91 \% \\
\text { of that from a comparable area of surface } \\
\text { soil depending on soil moisture content } \\
\text { - Wind tunnel studies with a simulated } \\
\text { shrinkage crack } 20 \text { inches deep showed } \\
\text { that evaporation increased at all depths as } \\
\text { surface wind velocity increased } \\
\text { - Increasing the wind velocity from calm to } \\
25 \text { mph. increased evaporation } 570 \% \text { at } 2 \\
\text { inches below the surface and } 100 \% \text { at } 18 \\
\text { inches } \\
\text { - Evaporation increased as crack width } \\
\text { decreased from } 2.75 \text { inches to } 1.75 \\
\text { inches. }\end{array}$ \\
\hline Adams et al. & 1969 & $\begin{array}{l}\text { Simulated soil } \\
\text { shrinkage crack }\end{array}$ & $\begin{array}{l}\text { - In simulated cracks } 60 \mathrm{~cm} \text { deep and } 30- \\
70 \text { mm wide, } 50-60 \% \text { of the total } \\
\text { evaporation occurred below } 15 \mathrm{~cm} \text { and } \\
30-40 \% \text { occurred below } 30 \mathrm{~cm} \text {. }\end{array}$ \\
\hline $\begin{array}{l}\text { Kirkham and } \\
\text { Selim }\end{array}$ & 1970 & $\begin{array}{l}\text { Artificial soil } \\
\text { shrinkage } \\
\text { cracks ( } 3 \\
\text { containers with } \\
\text { different soils) }\end{array}$ & $\begin{array}{l}\text { shrinkage cracks increased evaporation } \\
\text { from bare soil } 12-16 \% \text { with cracks } 0.64 \\
\text { cm wide and about } 30 \% \text { with cracks } 1.91 \\
\text { cm wide as compared to evaporation from } \\
\text { soils with no cracks. }\end{array}$ \\
\hline $\begin{array}{l}\text { Fujiyasu et } \\
\text { al. }\end{array}$ & 2000 & $\begin{array}{l}\text { Dessicating } \\
\text { mine tailings }\end{array}$ & $\begin{array}{l}\text { - Cracking increased exposed total area by } \\
\text { as much as four times }\end{array}$ \\
\hline $\begin{array}{l}\text { Innocent- } \\
\text { Bernard }\end{array}$ & 2013 & $\begin{array}{l}\text { Thickened oil } \\
\text { sands tailings }\end{array}$ & $\begin{array}{l}\text { - Crack formation was a main contributor to } \\
\text { increased evaporation }\end{array}$ \\
\hline Djalal & 2014 & $\begin{array}{l}\text { Large scale } \\
\text { drying test }\end{array}$ & $\begin{array}{l}\text { - crack surface contributed at most, } 6.6 \% \text { of } \\
\text { total evaporation in saturated stage } \\
\text { - At de-saturation, crack opening contribute } \\
\text { to } 35 \% \text { of total evaporation by } 7.64 \text { days } \\
\text { and } 64 \% \text { by } 7.85 \text { days } \\
\text { - Drying and salt precipitation then lowers } \\
\text { suction, and decreases total evaporation }\end{array}$ \\
\hline
\end{tabular}




\subsection{Theory of Unsaturated Soils}

The desiccation of oil sands tailings is an instance of unsaturated conditions in the mining field, where unsaturated soil mechanics can be applied to analyze the strength of the tailings. This section provides an overview of unsaturated soils theory including: suction, soil water characteristic curves, and bearing capacity analysis for unsaturated conditions.

\subsubsection{Total Suction}

Soil suction is commonly referred to as the free energy state of soil water (Edlefsen and Anderson, 1943). It is one of the three stress state variables that influence the engineering behaviour of unsaturated soils. Total suction is the sum of matric and osmotic suction, as shown in the following equation:

$$
\psi=\left(u_{a}-u_{w}\right)+\pi
$$

Where:

$\psi=$ Soil suction or total suction, $[\mathrm{kPa}]$

$$
\begin{array}{ll}
\left(u_{a}-u_{w}\right) & =\text { Matric Suction [kPa]; } \\
\pi & =\text { Osmotic Suction, [kPa]. }
\end{array}
$$

Suction is a measure of the energy required to remove water from the soil. In other words, the greater the suction, more energy or work is required to remove water from the soil. The free energy can be related to the partial vapour pressure of the soil water (Richards, 1965), this relationship is given below: 


$$
\psi=\frac{R T}{v_{w o} \omega_{v}} \ln \left(\frac{\vec{u}_{v}}{\vec{u}_{v o}}\right)
$$

Where:

$$
\begin{array}{lll}
\mathrm{R} & = & \text { universal (molar) gas constant, [ie., } 8.1432 \mathrm{~J} / \mathrm{mol} \mathrm{K}] ; \\
\mathrm{T} & = & \text { absolute temperature, }[\mathrm{K}] ; \\
\mathrm{V}_{\mathrm{wo}} & = & \text { specific volume of water, }\left[\mathrm{m}^{3} / \mathrm{kg}\right] ; \\
\mathrm{w}_{\mathrm{v}} & = & \text { Molecular mass of water vapor, [ie. } 18.016 \mathrm{~kg} / \mathrm{ml}] ; \\
\mathrm{u}_{\mathrm{v}} & = & \text { Partial pressure of pore-water vapor, }[\mathrm{kPa}] ; \\
\mathrm{u}_{\mathrm{vo}} & = & \text { Saturation pressure of water over a flat surface of pure water at the } \\
& \quad \text { same temperature, [kPa]. }
\end{array}
$$

The term $\left(\frac{\vec{u}_{v}}{\vec{u}_{v o}}\right)$ is referred to as relative humidity $(\mathrm{RH})$. Figure $2.8-1$ shows the relation between $\mathrm{RH}$ and total suction; a value of $\mathrm{RH}$ less than $100 \%$ indicates the presence of suction in the soil. To quantify the components of suction in the equation given above, it is assumed that the reference state is vapour pressure above still pure water (containing no impurities or salt). 


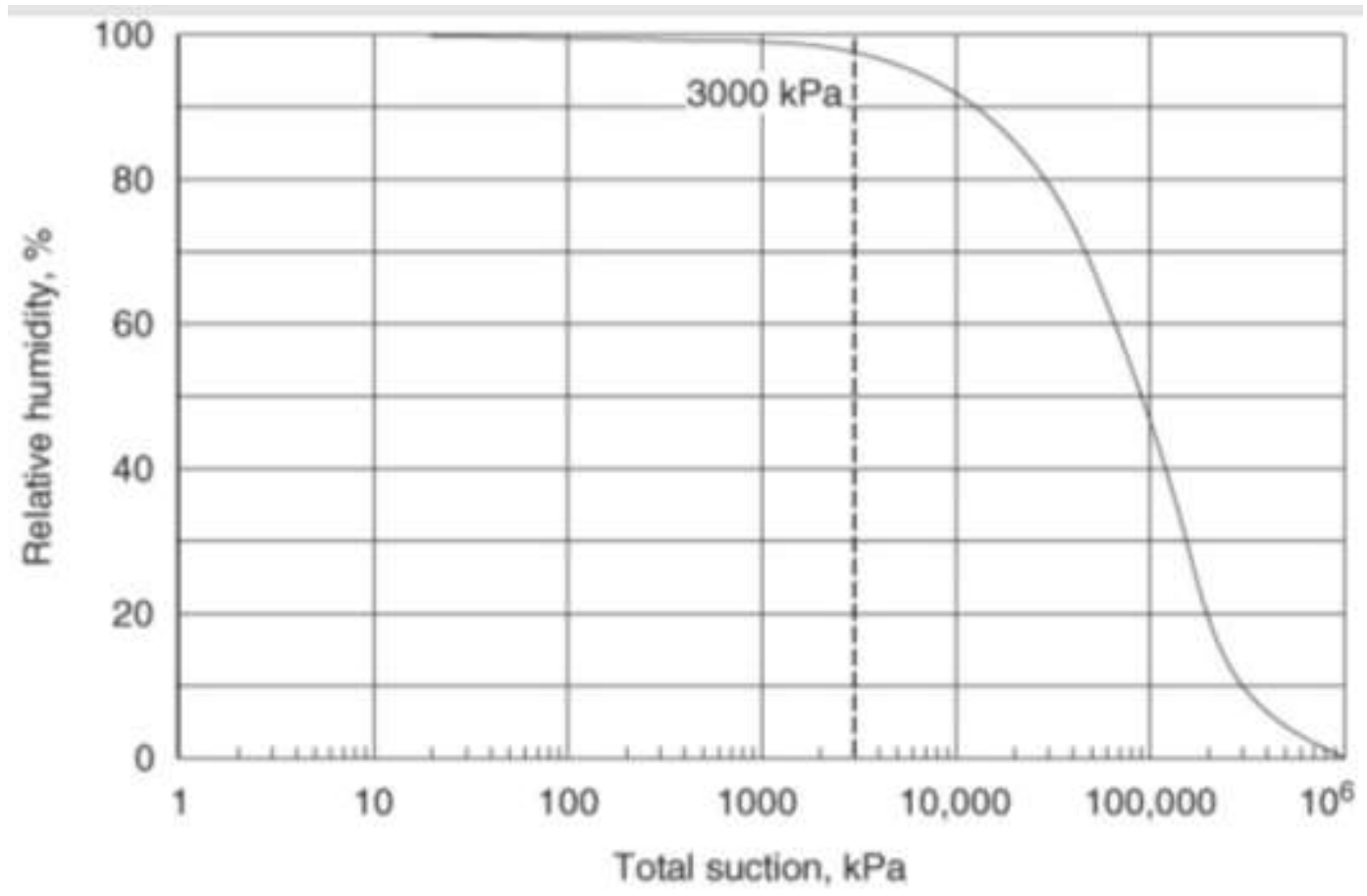

Figure 2.8-1. Relative humidity versus total suction relationship (Fredlund and Rahardjo, 1993)

The soil water characteristic curve (SWCC, discussed in detail later) represents the water holding capacity of the soil (storage capacity). Suction is influenced by the pore geometry and surface. Pore geometry influences the suction in the boundary and transition regions of the SWCC; while surface area affects suction in the residual zone of unsaturation.

Total suction can be measured using direct or indirect methods. Indirect methods measure the $\mathrm{RH}$ of the soil in order to estimate the total suction, such as psychrometers. These devices are useful for high total suction ranges; however a limitation is presented for in-situ measurements due to temperature fluctuations. The most reliable instrument to measure total suction is the WP4-C dewpoint potentiometer. The potentiometer is discussed in more detail in Chapter 3 of this thesis. 


\subsubsection{Matric Suction}

As shown in equation 12, matric suction is a component of total suction. Matric suction is the also referred to as the capillary component of free energy. It is "the equivalent suction derived from the measurement of the partial pressure of the water vapour in equilibrium with the soil water, relative to partial pressure of the water vapour in equilibrium with a solution identical composition with the soil water." (Fredlund and Rahardjo, 1993).

An unsaturated soil structure consists of pores that can be filled with air or water. A meniscus forms at the air-water interface inside the pore structure, similarly to water in a capillary tube. Matric suction is related to the capillary action from water surface tension that is related to the movement of water in the soil pores. Pores with small radii act as capillary tubes that transport water in the pores above the water table. (Fredlund and Rahardjo, 1993). Typically, at high suctions (above 1500kPa) changes in water content due to matric suction can be neglected, since these changes are more associated with total suction at higher suction values (Krahn and Fredlund 1972). It was found that the matric suction component primarily governs the engineering behavior in the lower suction range, in most field situations. (Vanapalli et al., 1996).

Matric suction can be measured by direct or indirect methods. For direct measurements, such as the axis translation technique and tensiometers, high air entry ceramic disks are used. For indirect methods, the electrical and thermal properties of a standard ceramic as a function of water content are measured to estimate matric suction.

A high air entry ceramic disk is generally made from sintered kaolin and has very small uniform pores. Once this disk is saturated, air cannot pass through, since the contractile skin has the ability to resist the air flow.

Tensiometers consist of high air-entry porous ceramic cups, connected to a pressure-measuring apparatus through a small bore tube. They are prepared by filling the tube and cup with de-aired water, and inserting them into the soil, making sure they have good contact. Tensiometers measure the pressure exerted by the soil on the 
device, which is measured by the pressure-measuring apparatus once equilibrium is achieved. Numerically, the negative pore water pressure is equal to the matric suction when pore air pressure is atmospheric. The pore water pressure than can be measured by a tensiometer is limited to $90 \mathrm{kPa}$ due to cavitation of water in the tensiometer (Fredlund and Rahardjo, 1993). The T5 tensiometers, however, are specially made for more reliable measurements, and can measure up to $200 \mathrm{kPa}$ (UMS, 2009).

The osmotic component of suction will not be measured since soluble salts are able to move through the porous cup. The limitation of tensiometers is that the matric suction cannot exceed the air-entry of the ceramic cup, generally measuring up to 90 $\mathrm{kPa}$. However it is common for the readings to be problematic once values of $70 \mathrm{kPa}$ are reached (Vanapalli et al., 2003).

\subsubsection{Osmotic Suction}

Osmotic suction is also referred to as the solute component of free energy. It is the "equivalent suction derived from the measurement of the partial pressure of the water vapour in equilibrium with a solution identical in composition with the soil water, relative to the partial pressure of the water vapour in equilibrium with a solution identical in composition with free pure water" (Fredlund and Rahardjo, 1993).

Osmotic suction is caused by the concentration of salts in the pore water; therefore the osmotic suction can be indirectly estimated from the measurement of the salt concentration. The electrical conductivity $(E C)$ is a property that is related to the solutes that are present. The relationship used is the following (USDA, 1954):

$$
\pi=0.36 \times E C \times 101.35
$$

Where:
$\pi \quad=\quad$ Osmotic Suction, $[\mathrm{kPa}] ;$
$\mathrm{EC}=$ Electrical Conductivity, $[\mathrm{mS} / \mathrm{cm}]$. 
Two methods exist to measure osmotic suction: the saturation and the pore squeezing techniques. In the saturation technique, deionized water is added to the soil, mixed, and the centrifuged to extract the pore water from the sample. The EC is measured, and extrapolated to determine the osmotic suction related to that of the natural water content (USDA, 1954; Krahn and Fredlund, 1972; Fredlund and Rahardjo, 1993).

In the pore squeezing technique, a pore squeezer is used to remove water from the sample. The EC of the pore water is then measured and the osmotic suction is determined from osmotic suction versus concentration curves or equation 14 above. This technique is limited for dry soils.

Table 2.8-1 provides a summary of devices that measure soil suction and their components, range of measurement and limitations.

Table 2.8-1. Devices for measuring soil suction and its components (Fredlund and Rahardjo, 1993)

\begin{tabular}{|c|c|c|c|}
\hline Name of Device & Suction Component Measured & Range $(\mathrm{kPa})$ & Comments \\
\hline Psychrometers & Total & $100^{\circ}-\sim 8000$ & $\begin{array}{l}\text { Constant temperature environment } \\
\text { required }\end{array}$ \\
\hline Filter paper & Total & (Entire range) & $\begin{array}{l}\text { May measure matric suction when } \\
\text { in good contact with moist soil }\end{array}$ \\
\hline Tensiometers & $\begin{array}{l}\text { Negative pore-water pressures or } \\
\text { matric suction when pore-air } \\
\text { pressure is atmospheric }\end{array}$ & $0-90$ & $\begin{array}{l}\text { Difficulties with cavitation and air } \\
\text { diffusion through ceramic cup }\end{array}$ \\
\hline $\begin{array}{l}\text { Null-type pressure plate } \\
\text { (axis translation) }\end{array}$ & Matric & $0-1500$ & $\begin{array}{l}\text { Range of measurement is a function } \\
\text { of the air entry value of the } \\
\text { ceramic disk }\end{array}$ \\
\hline $\begin{array}{l}\text { Thermal conductivity } \\
\text { sensors }\end{array}$ & Matric & $0-\sim 400+$ & $\begin{array}{l}\text { Indirect measurement using a } \\
\text { variable pore size ceramic sensor }\end{array}$ \\
\hline Pore fluid squeezer & Osmotic & (Entire range) & $\begin{array}{l}\text { Used in conjuction with a } \\
\text { psychrometer or electrical } \\
\text { conductivity measurement }\end{array}$ \\
\hline
\end{tabular}

${ }^{a}$ Controlled temperature environment to $\pm 0.001^{\circ} \mathrm{C}$. 


\subsubsection{Soil Water Characteristic Curve (SWCC)}

The soil water characteristic curve (SWCC) or water retention curve (WRC) is the relationship between the amount of water (volumetric or gravimetric) in a soil, or degree of saturation and the matric suction. This relationship can be related to the shear strength, hydraulic conductivity and the volume change in unsaturated soils, making it a valuable tool (Vanapalli et al., 1996). A typical SWCC is shown in Figure 2.8-2.

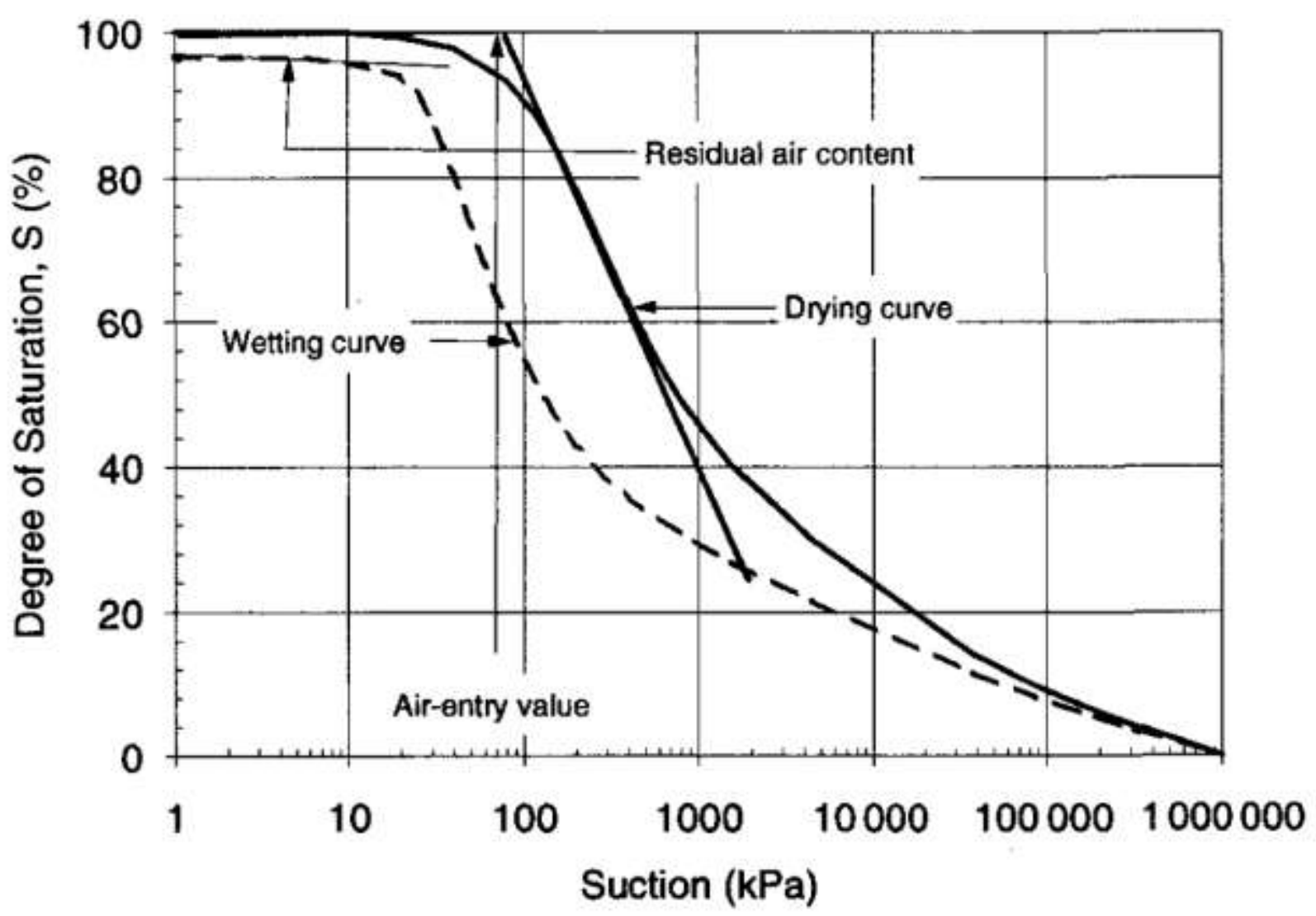

Figure 2.8-2. Typical soil-water characteristic curve features for the drying and wetting of a soil (Vanapalli et al, 1996)

The slope of the curve is the storage capacity of the soil. As soil desaturates, different saturation stages can be identified, shown in Figure 2.8-3, including: the boundary effect stage, the transition stages (primary and secondary transition stages), 
and the residual stage of unsaturation. These stages are described below (Vanapalli et al., 1996):

1) Boundary effect stage: All the soil pores are filled with water, and all the water menisci are continuous. Essentially, the soil is saturated at this point. This stage ends at the air-entry value (AEV).

2) Transition stage: The transition stage begins at the $A E V$, where the value of suction corresponds to the point where air enters the largest pores of the soil. In the transition stage, soil begins to de-saturate, and the water content in the soil reduces significantly as suction values increase. The water menisci area in contact with soil particles is no longer continuous, and is ever decreasing.

3) Residual stage of unsaturation: Begins at the point where large increases in suction correspond to small changes in water content. At the beginning of this stage, the water content is referred to as the residual water content. 

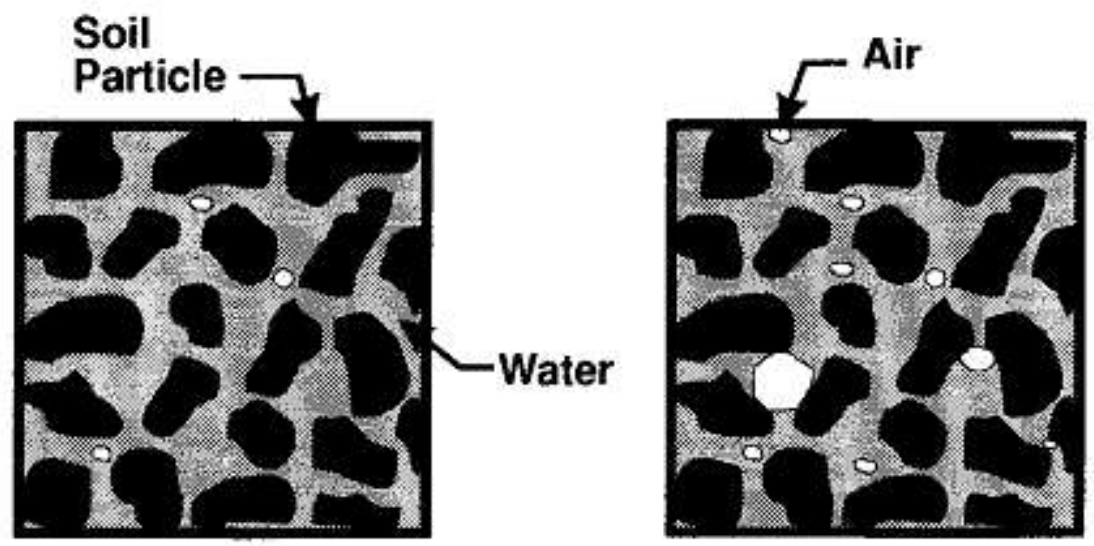

(a) Boundary effect stage

(b) Primary transition stage

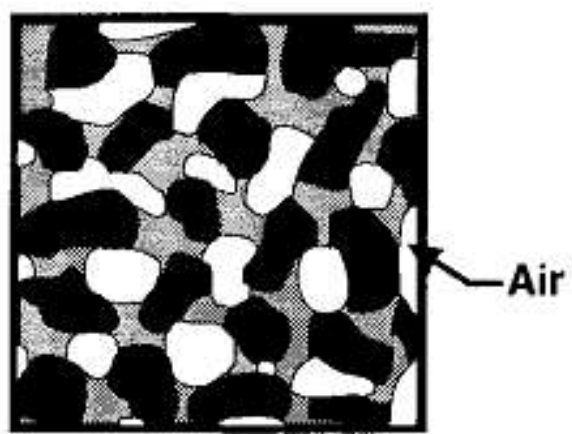

(c) Secondary transition stage

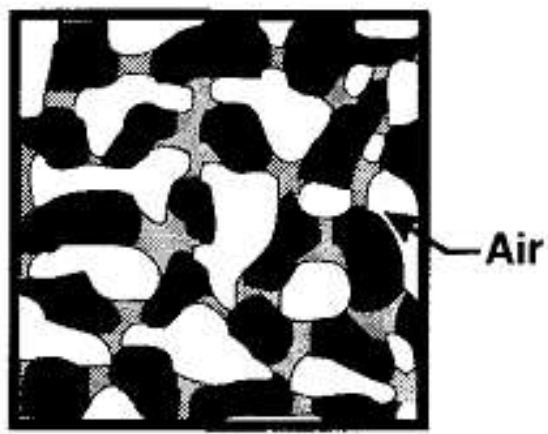

(d) Residual stage of unsaturation

Figure 2.8-3. Stages of de-saturation (Vanapalli et al, 1996)

\subsubsection{SWCC for Oil Sands Tailings (TWCC)}

In soils that undergo significant volume change as suction changes, such as tailings, the estimation of the AEV is more difficult. There have been developments in SWCC equipment that allow the monitoring of overall volume change and water content when estimating the SWCC.

A shrinkage curve, where void ratio is plotted against the gravimetric water content (GWC), provides a graphical representation of volume-mass pathways that can be followed for various geotechnical engineering problems with unsaturated soils. Figure 2.8-4 illustrates shrinkage curves obtained for oil sands tailings samples with $10 \%$ sand 
added by Fredlund and Houston (2013). It is seen that the oil sands tailings decrease in volume as water is removed, and the tailings begin to desaturate once the plastic limit is reached.

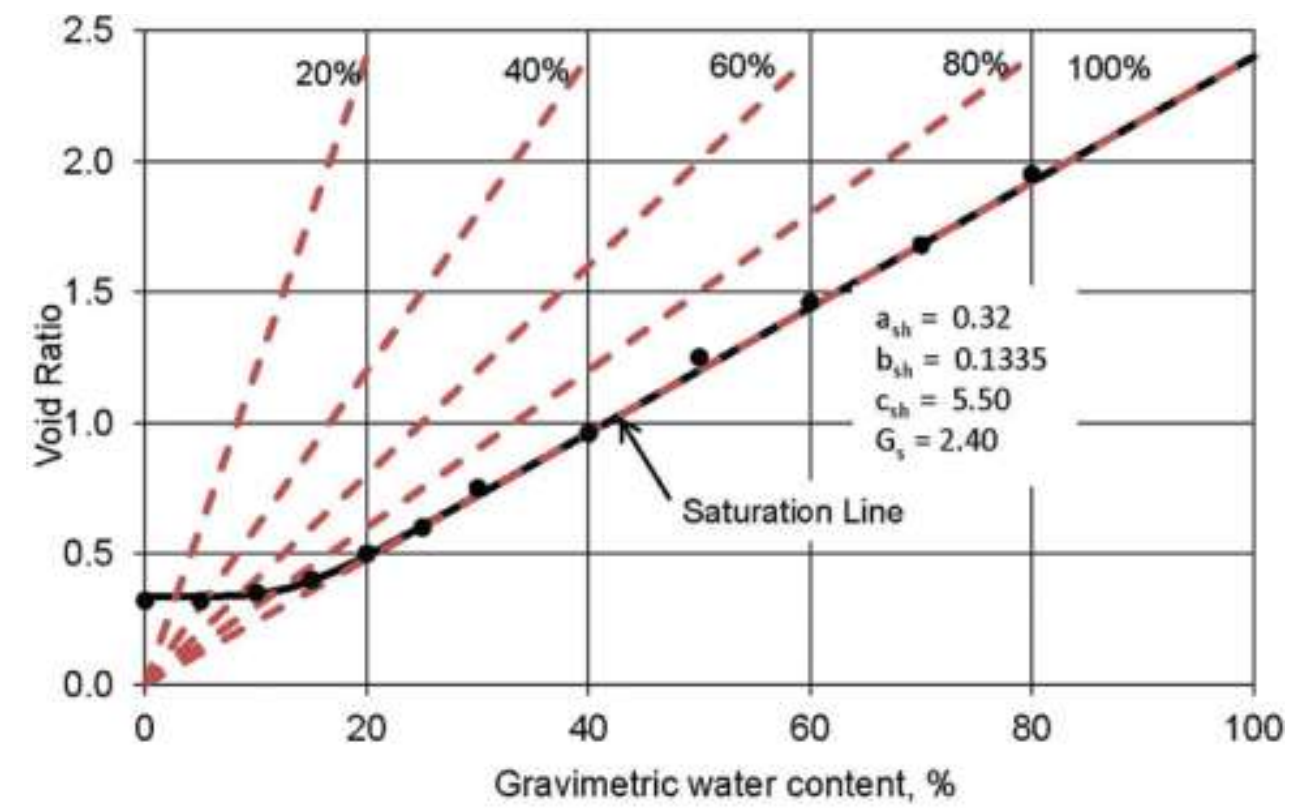

Figure 2.8-4. Average laboratory shrinkage curves for oil sands tailings samples (SFR = 0.1) (Fredlund and Houston, 2013).

Fredlund et al. (2011) developed a procedure to describe how SWCC tests can be conducted on high volume change materials, and used this procedure on independently measured shrinkage curves to provide the required unsaturated soil property functions. This procedure takes into account the considerable volume change that occurs in oils sands tailings as soil suction is increased, when the tailings are left to dry in storage impoundments (Fredlund et al., 2011).

The study was conducted using oil sands tailings samples from Fort McMurray, $A B$, where the climate is semi-arid, and the tailings will dessicate with time. The samples were mixed with $10 \%$ sands, resulting in a sand-fine ratio (SFR) of 0.1 (plastic and liquid limits of 30 , and 55 ) and $45 \%$ sand, with SFR 0.8 respectively (plastic and liquid limits of 15 , and 38 ). Approximately $60 \%$ of the material can be considered as clay size particles. The GWC of the slurry was roughly $100 \%$. As water escapes the tailings, 
the volume of the material decreases, and the shear strength gradually increases. A considerable increase is observed when the material reaches the plastic limit. Fredlund et al. (2011) obtained the tailings-water characteristic curve (TWCC) in terms of GWC, degree of saturation, volumetric water content (VWC) and void ratio, shown in Figures 2.8-5 to 2.8-8 below. In the study, one specimen was tested with an initial GWC of $78 \%$ and the other was dried to a GWC of $47 \%$, and then tested.

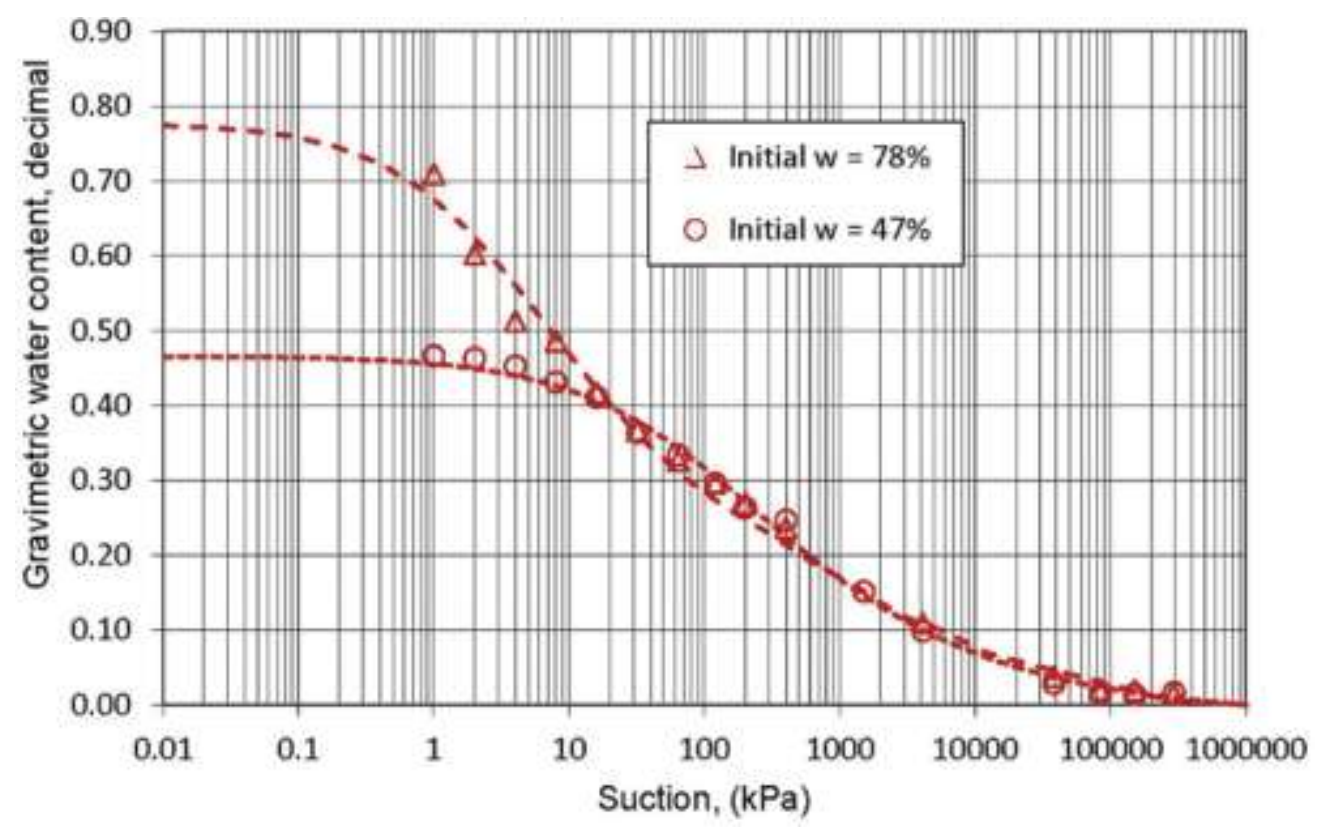

Figure 2.8-5. Gravimetric water content SWCC's measured on oil sands tailings (SFR = 0.1) (Fredlund and Houston, 2013).

The $78 \%$ GWC specimen showed a break in curvature at a suction of approximately $1 \mathrm{kPa}$, while the $47 \%$ GWC specimen had this break at approximately 10 $\mathrm{kPa}$. In this case, the curvature is not defined and does not accurately represent the true AEV of the material. Therefore, the shrinkage curve results must be analyzed to interpret the TWCC (Fredlund and Houston, 2013).

Fredlund and Houston (2013) combined a best-fit shrinkage equation with the Fredlund and Xing (1994) SWCC equation in order to plot the degree of saturation in terms of suction, shown in Figure 2.8-6. The resulting TWCC shows an AEV of 
approximately $1000 \mathrm{kPa}$ for both initial GWCs. From this result, Fredlund and Houston (2013) concluded that it is more accurate to use the SWCC in terms of degree of saturation to estimate the hydraulic conductivity function after desaturation. This figure also indicates a residual suction value of approximately $15000 \mathrm{kPa}$ at $20 \%$ degree of saturation.

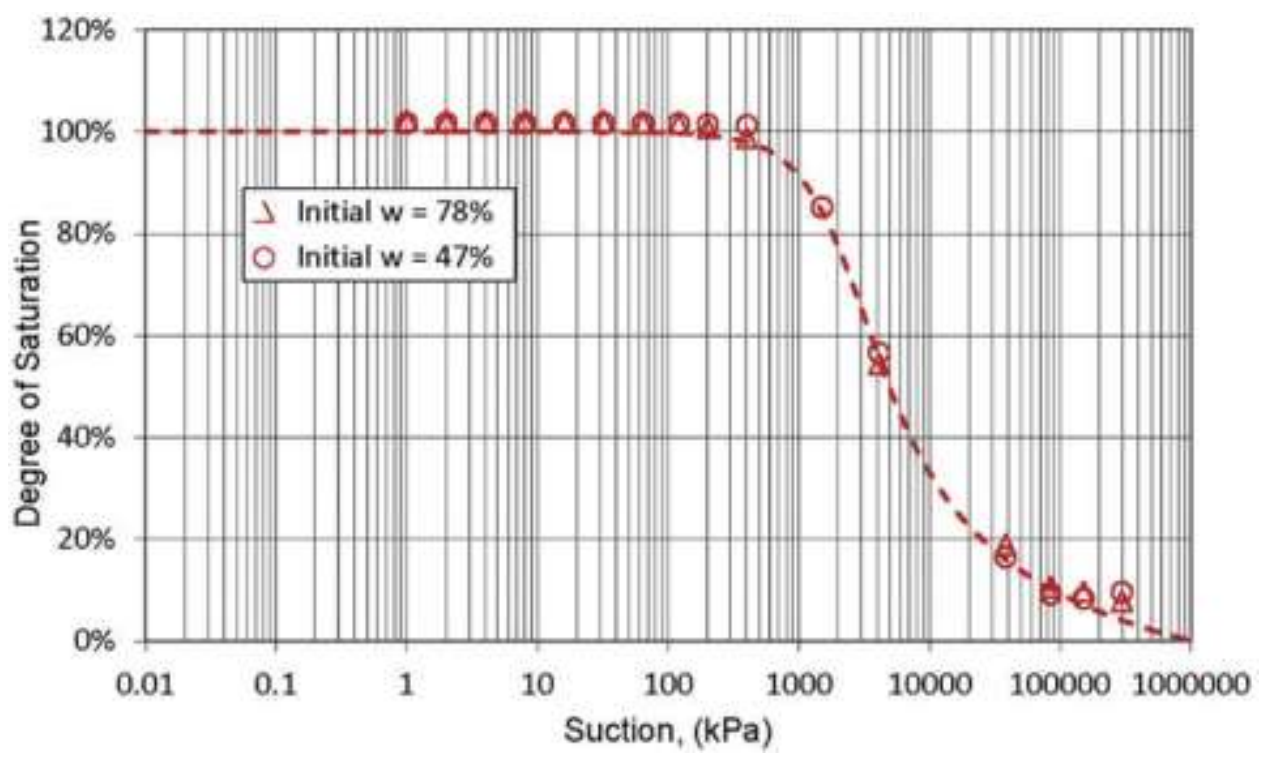

Figure 2.8-6. SWCC's plotted as the degree as saturation versus suction for oil sands tailings (SFR $=0.1$ ) (Fredlund and Houston, 2013).

SWCC in terms of VWC curves are useful to quantify the water storage function for the soil. This relationship is shown in Figure 2.8-7. 


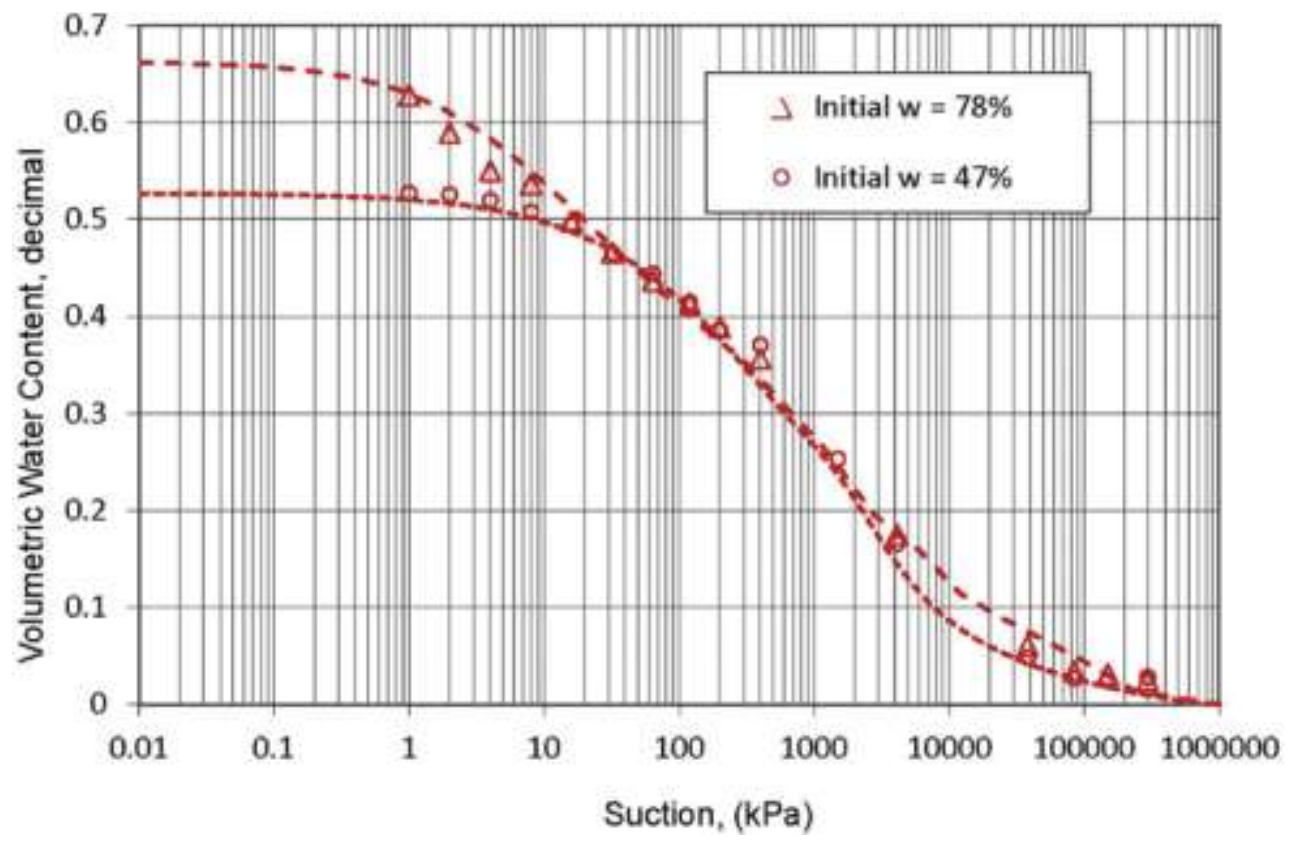

Figure 2.8-7. Volumetric water content versus suction for oil sands tailings (SFR = 0.1) (Fredlund and Houston, 2013).

Fredlund and Houston (2013) also plotted a TWCC in terms of void ratio, using basic volume-mass relationship (i.e., $\mathrm{Se}=w \mathrm{Gs}$ ), shown in Figure 2.8-8. This TWCC shows that the volume change becomes virtually non-existent once soil suctions higher than the residual soil suctions are obtained. 


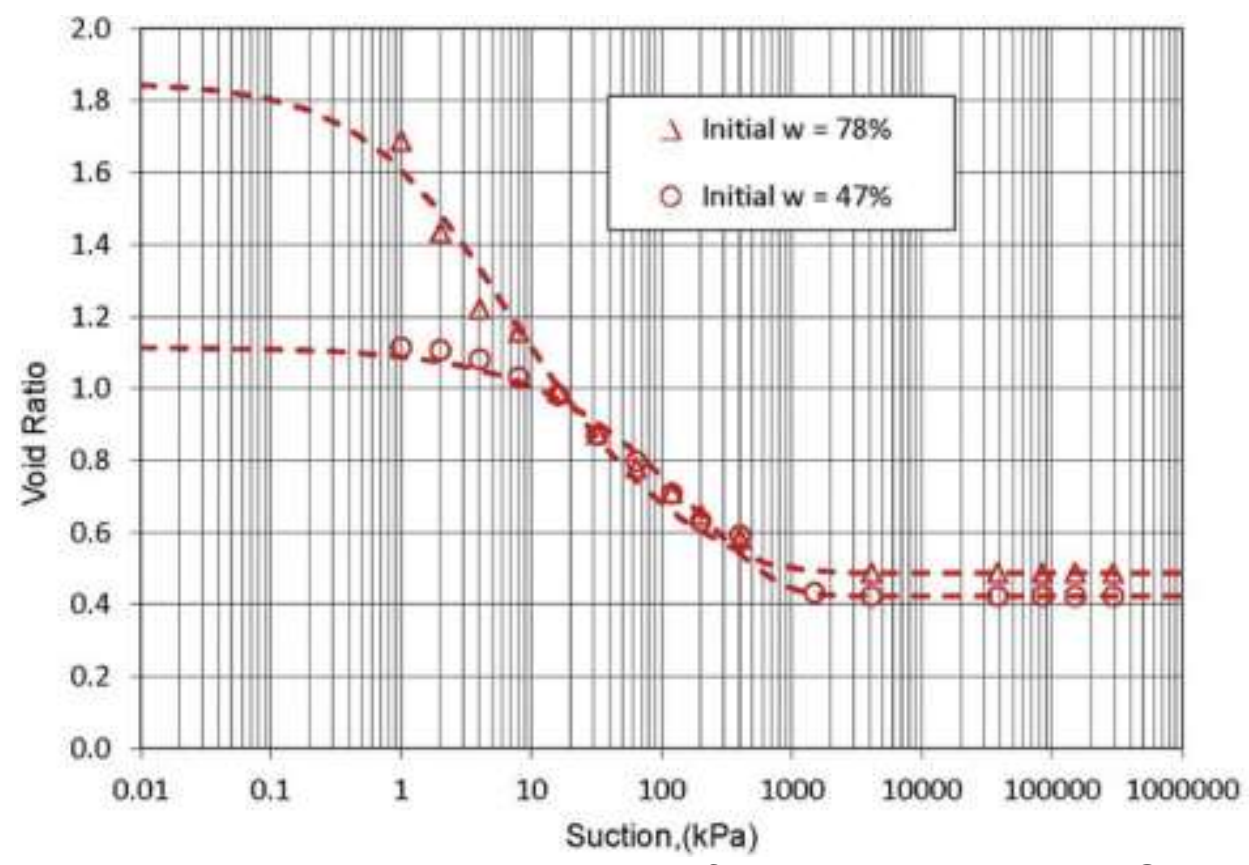

Figure 2.8-8. Void ratio versus suction plot for oil sands tailings $(S F R=0.1)$ (Fredlund and Houston, 2013).

The higher AEV indicates that the gradual decrease of the slurry volumes is a result of increasing suction, and pore compressibility under capillary action. As the average degree of saturation nears $90 \%$, the pore water decreases as drainage occurs, and most of the pore spaces fill with air. After this point, higher suction is required for air to infiltrate the slurry, and further drainage becomes difficult (Owolagba and Azam 2013).

Soleimani et al. (2014) established a TWCC for polymer-amended oil sands tailings obtained from Shell's Muskeg River Mine, shown in Figure 2.8-9, using the axistranslation method with volume change measurement for low suctions, and with the use of a dewpoint hygrometer to measure total suction in the high range. 


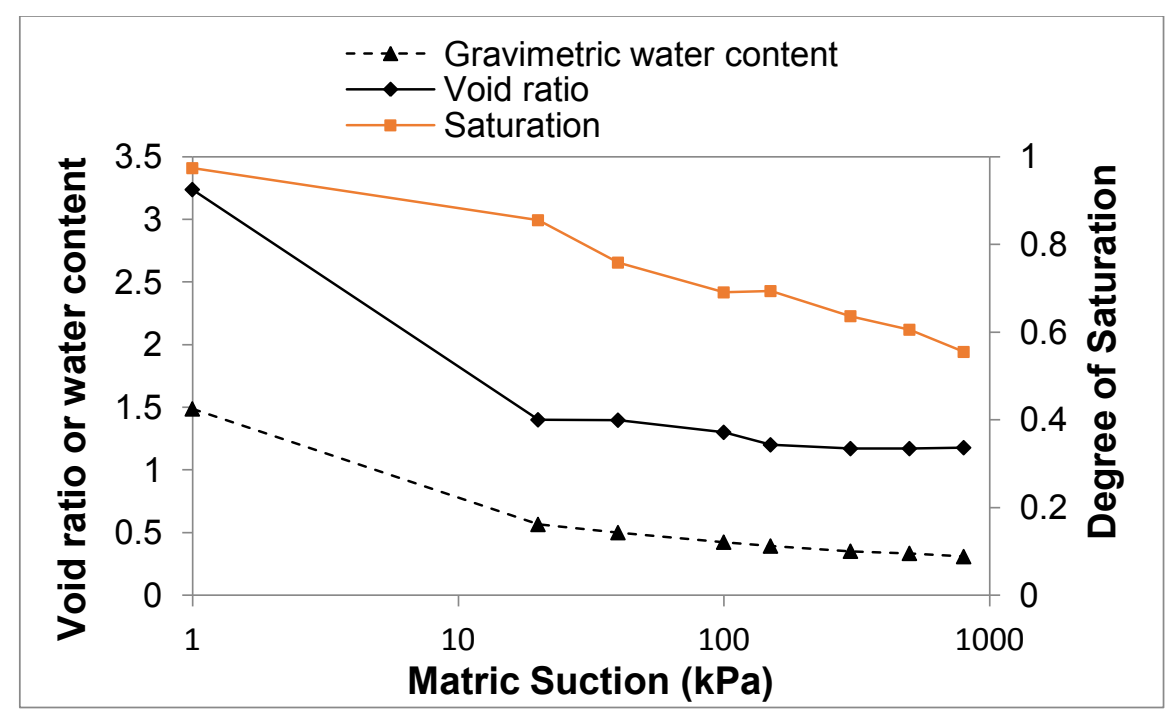

Figure 2.8-9. SWCC for oil sands tailings (Soleimani et al., 2014)

\subsection{Bearing Capacity}

In mine tailings deposit rehabilitation, it is standard practice to place a cover layer over the top of the deposit. The economics of any mining operation dictate that rehabilitation work should be carried out as soon as possible after the closure of the mine. In order for the construction of the cover layer to take place, the tailings deposit must provide a safe and accessible surface for earthmoving equipment. The tailings deposit must achieve a certain level of trafficability in order for construction to take place.

Over time, the soft mine tailings gain strength after their deposition into the storage impoundment. Bearing capacity failures may still result after the placement of a cover layer, indicating the need for a bearing capacity analysis prior to any rehabilitation work (Rassam and Williams, 1999). Figure 2.9-1 shows some of the bearing capacity modes experienced by tailings deposits. 


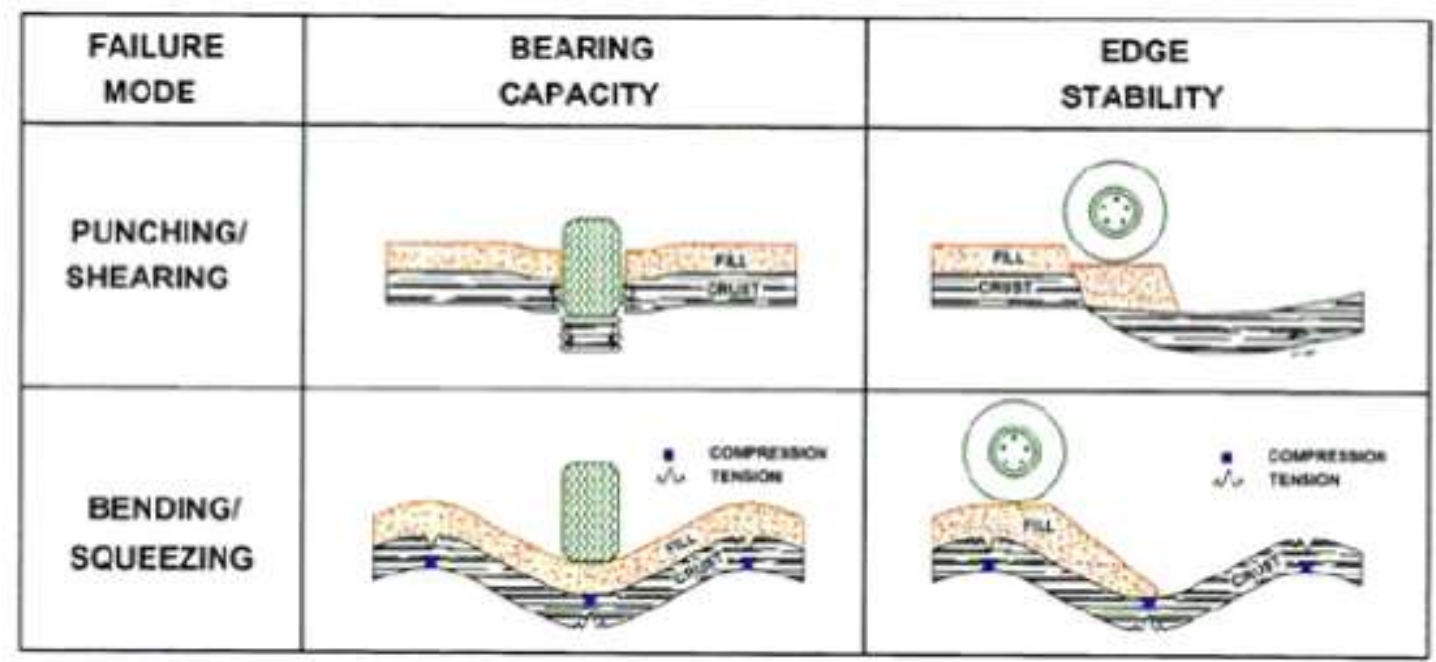

Figure 2.9-1. Bearing capacity failure modes of tailings deposits (Jakubick et al., 2003)

The loads experienced by tailings deposits by earthmoving equipment can be approximated as strip foundations in a bearing capacity analysis (Hossain and Fourie, 2013). The equation proposed by Terzaghi (1943), and discussed in the following section, is the most widely used for determining the bearing capacity of centrally, vertically loaded, shallow strip footings on saturated, homogenous soils.

\subsubsection{Bearing Capacity of Unsaturated Soils}

According to the Canadian Foundation Engineering Manual (2006), the ultimate bearing capacity of a shallow foundation on uniform soil can by calculated as follows (Terzaghi, 1943):

$$
q_{u}=c N_{c} S_{c}+q_{s} N_{q} S_{q}+\frac{1}{2} \gamma B N_{\gamma} S_{\gamma}
$$


Where,

$\begin{array}{ll}q_{u} & =\quad \text { ultimate bearing capacity; } \\ N_{c}, N_{q}, N_{\gamma} & =\quad \text { dimensionless bearing capacity factors; } \\ S_{c}, S, S_{\gamma} & =\quad \text { dimensionless modification factors for foundation shape, } \\ & \text { inclination, depth and tilt, and ground slope; } \\ q_{s} & =\quad \text { vertical stress acting at the elevation of the base of } \\ B & \text { foundation; } \\ & =\quad \text { width of foundation or minimum plan dimension of the } \\ c & =\quad \text { soil cohesion; } \\ \gamma & =\quad \text { soil unit weight; }\end{array}$

The non-dimensionless bearing capacity factors are a function of the friction angle, and were derived based on modified plasticity solutions for uniform ground conditions. Meyerhof (1963), Hansen (1970), and Vesic (1975) developed the following equations:

$$
\begin{aligned}
& N_{c}=\cot \phi\left(N_{q}-1\right) \\
& N_{q}=e^{\pi \tan \phi} \tan ^{2}\left(45+\frac{\phi}{2}\right) \\
& N_{\gamma}=\frac{1}{2}\left(\frac{K_{p \gamma}}{\cos ^{2} \phi}-1\right) \tan \phi
\end{aligned}
$$

Where $K_{p \gamma}$ is the passive pressure coefficient. Equation 15 considers a foundation that is subjected to general shear failure.

The bearing capacity of saturated soils is usually estimated using the total stress analysis (TSA) [ie. short-term stability, undrained conditions, $c=\mathrm{S}_{\mathrm{u}}$ (undrained shear strength) and $\Phi=0$ based on (Skempton, 1948)] or the effective stress analysis (ESA) 
[ie. long-term stability, drained conditions, $c=c^{\prime}$ (effective cohesion intercept) and $\Phi=\Phi^{\prime}$ (effective angle of friction of the soil) based on (Terzaghi, 1943)], based on the type of soil and the drainage state.

Once the influence of suction is considered, the ESA can be extended to apply to both, fine and coarse-grained soils, since unsaturated coarse-grained soils will be under a drained condition for pore-air and pore-water pressures. The application of this approach to unsaturated fine-grained soils is questionable since the drainage conditions of pore-air and pore-water pressures have some uncertainties under plate load tests compared to unsaturated coarse-grained soils. Some work has been done to interpret the in-situ plate load test results in unsaturated soils considering the influence of matric suction by introducing modifications to the conventional ESA (Oloo, 1994; Costa et al., 2003; Vanapalli and Mohamed, 2007).

\subsubsection{Modified Total Stress Analysis (MTSA)}

In an undrained condition, total stress analysis should be conducted for the shortterm evaluation. However, using the conventional Terzaghi equation leads to inconsistencies, since the failure mechanism in uniform fine grained (UFG) soils is not governed by general shear failure. Therefore a modified approach is necessary. (Oh and Vanapalli, 2013)

The failure mechanism in UFG soils under a shallow foundation was found to be governed by a punching shear failure mode. For this failure mode (1) well-defined failure is not observed from the stress versus settlement behavior of model footing tests, (2) no heave is observed on the soils outside the loaded areas, and (3) the vertical displacement of a footing is caused primarily by the compression of the soil directly below the footing and the vertical shearing of the soils around the footing perimeter. (Oh and Vanapalli, 2013) Figure 2.9-2 illustrates this failure mode. 


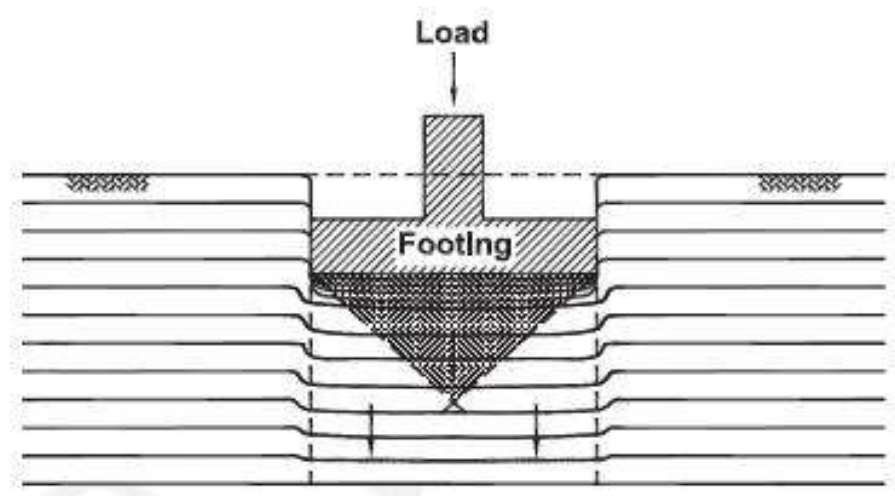

Figure 2.9-2. Punching shear-failure mechanism in UFG soils below a footing (Oh and Vanapalli 2013)

According to Oh and Vanapalli (2013), unconfined compression (UC) tests for unsaturated soils can be used to the estimate the bearing capacity of UFG soils extending the conventional TSA, based on the following justifications and assumptions:

- The drainage conditions for the CW test in UFG soils are similar to that of the UC test; and

- The shear strength obtained from the UC tests typically provides a conservative estimate due to the zero-confining pressure.

Therefore, Skempton's (1948) equation for determining the bearing capacity of saturated fine-grained soils assuming undrained conditions, can be applied, in the following form (Oh and Vanapalli, 2013):

$$
q_{u l t(u n s a t)}=\left(s \times \xi \times N_{c}\right)_{\text {unsat }}
$$

Where,

$$
\begin{aligned}
& s=\text { shear strength of UFG soil based on UC strength; } \\
& \xi=\text { shape factor. }
\end{aligned}
$$




\subsubsection{Modified Effective Stress Analysis (MESA)}

In unsaturated fine-grained soils, numerous studies have observed that bearing capacity values increase with greater matric suction, but eventually reach a maximum value despite increasing suction (Oloo 1994; Costa et al., 2003; Rojas et al. 2007). Unlike the modified total stress approach (MTSA), where the measurement of matric suction is not required, this measurement is important for the modified effective stress analysis (MESA).

One equation that considers bearing the matric suction contribution to bearing capacity was proposed by Oloo et al. (1997), by extending Terzaghi's (1943) ESA, is given by equation 20 :

$$
q_{u l t \text { (unsat) }}=\left\{c^{\prime}+\left(u_{a}-u_{w}\right) \tan \Phi^{\mathrm{b}} N_{c} \xi_{c}+\mathrm{qN}_{\mathrm{q}} \xi_{q}+0.5 B \gamma N_{\gamma} \xi_{\gamma}\right.
$$

Where,

$$
\begin{array}{ll}
\begin{array}{ll}
q_{\text {ult }(\text { unsat })} & =\text { ultimate bearing capacity of unsaturated soils; } \\
c^{\prime} & =\text { effective cohesion; } \\
\left(u_{a}-u_{w}\right) & =\text { matric suction; } \\
\gamma & =\text { soil unit weight; } \\
B & =\text { width of footing; } \\
N_{c} \text { and } N_{\gamma} & =\text { bearing capacity factors from Terzaghi (1943) and Kumbhokjar } \\
(1993) ; & \\
\left.\xi_{c}\left\{=\left[1.0+\left(\frac{N_{q}}{N_{c}}\right)\left(\frac{B}{L}\right)\right]\right\} \text { and } \xi_{g}\left\{=1.0-0.4\left(\frac{B}{L}\right)\right]\right\} \text { are shape factors from Vesić }
\end{array}
\end{array}
$$
(1973).

Equation (20) assumes that the shear-strength envelope of unsaturated soils is bilinear, however, further studies found that this assumption can lead to discrepancies for UFG soils (Oloo, 1994; Costa et al., 2003). Therefore Vanapalli and Mohamed (2007) proposed equation (21) which uses effective shear strength parameters, the SWCC and a bearing capacity fitting parameter. 
$q_{u l t(\text { unsat })}=\left\{c^{\prime}+\left(u_{a}-u_{w}\right)_{b}\left[1-S^{\left(\psi_{B C}\right)} \tan \emptyset^{\prime}\right]+\left(u_{a}-u_{w}\right)_{A V R} S^{\left(\psi_{B C}\right)} \tan \emptyset^{\prime}\right\} N_{c} \xi_{c}+0.5 B \gamma N_{\gamma} \xi_{\gamma}$

Where,

$$
\begin{array}{ll}
\left(u_{a}-u_{w}\right)_{b} & =\text { air-entry value; } \\
\left(u_{a}-u_{w}\right)_{A V R} & =\text { average matric suction; } \\
S & =\text { degree of saturation; } \\
\psi_{B C} & =\text { fitting parameter with respect to bearing capacity; }
\end{array}
$$

This model, MESA, however is not applicable for suction values greater than the residual suction value since the bearing capacity of UFG soils converges to a certain value at the residual state. (Oh and Vanapalli, 2013)

In order to account for punching shear failure in the tailings a reduction-factors approach can be applied. In the reduction-factors approach, the soil cohesion, and the internal angle of friction are reduced as follows (Terzaghi, 1943):

$$
\begin{aligned}
& c^{\prime}=\frac{2}{3} c \\
& \phi^{\prime}=\tan ^{-1}\left(\frac{2}{3} \tan \phi^{\prime}\right)
\end{aligned}
$$

\subsubsection{Matric Suction Profile}

Oh and Vanapalli (2013) found that the matric suction distribution profile with depth is not uniform in a UFG soil. Since the matric suction distribution profile is not uniform with depth, the average matric suction in the MESA equation is taken as a representative value. This representative value is the value at the centroid of the matric suction distribution diagram in the stress-bulb zone from the surface to a depth of $1.5 \mathrm{~B}$ - 
2.0B as described in Oh and Vanapalli (2013). The method for estimating the stressbulb zone is shown in Figures 2.9-3 and 2.9-4 below.

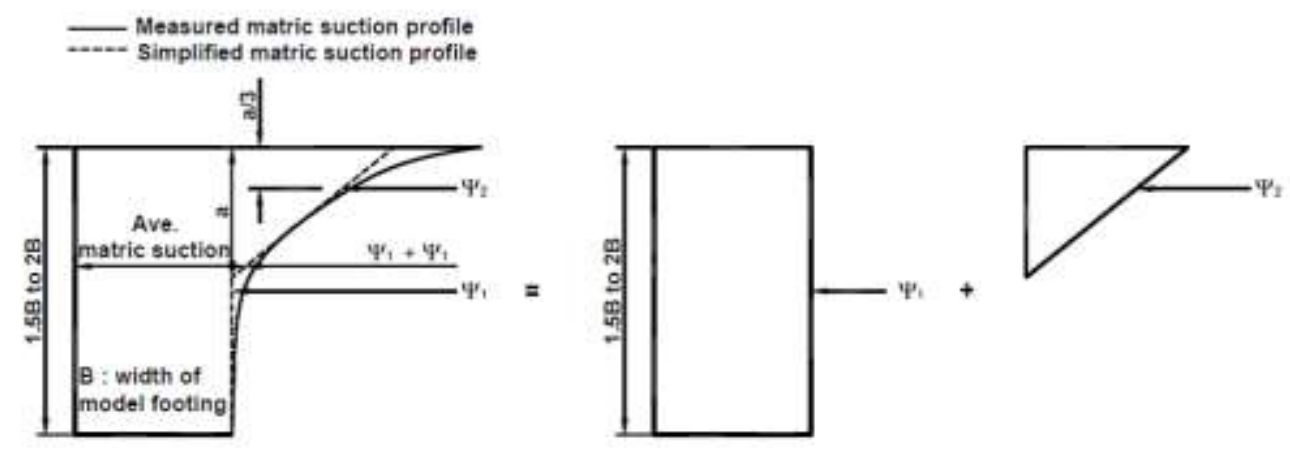

Figure 2.9-3. Estimation of the average matric suction value based on the matric suction distribution diagram (Oh and Vanapalli 2013)

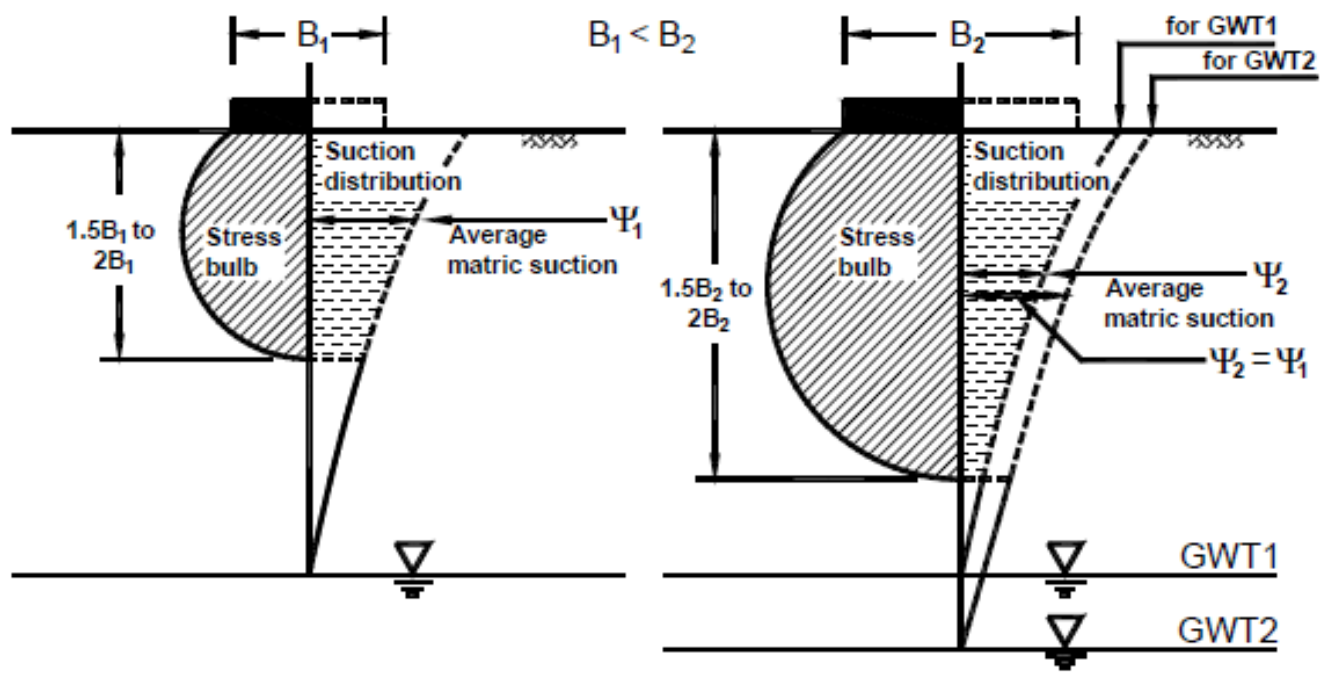

Figure 2.9-4. Average matric suction values for different footing sizes under an idealized nonuniform matric suction distribution profile (Oh and Vanapalli 2013)

Since the matric suction distribution profile is not uniform, the average matric suction depends on the size of the footing. The study conducted by Oh and Vanapalli (2013) determined that the stress bulb sizes are different when loads are applied to 
footings of different sizes, as shown in Figure 2.9-4. Therefore, the average matric suction depends on the size of the footing.

As shown in Figure 2.9-5, Rassam and Williams (1999) obtained a matric suction profile for unsaturated gold tailings using an explicit finite-difference technique. These matric suction profiles were obtained for steady-state evaporative conditions and hydrostatic conditions for water table depths of $1.5 \mathrm{~m}$ and $2.5 \mathrm{~m}$. In both conditions, matric suction increases with a water table that is lower (Rassam and Williams 1999).

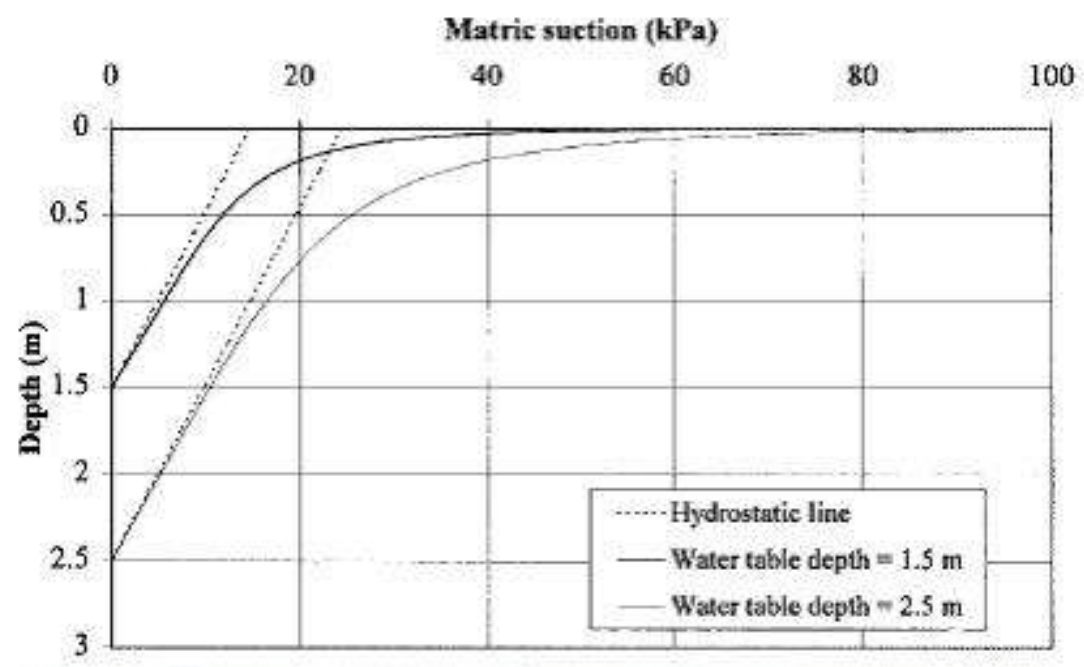

Figure 2.9-5: Matric suction profile for hydrostatic and evaporative conditions, water table depth $=1.5$ and $2.5 \mathrm{~m}$ (Rassam and Williams 1999)

The shear strength profile of dessicating tailings depends on the matric suction profile, as shown in Figure 2.9-6. The contribution of the matric suction to the shear strength is represented as an additional apparent cohesion. 


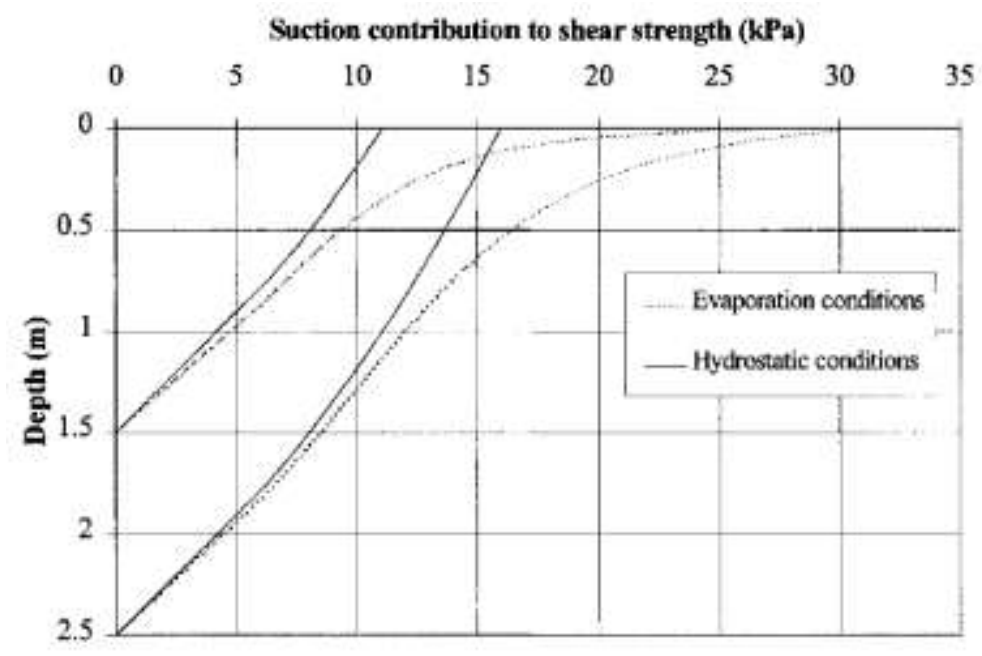

Figure 2.9-6. Matric suction contribution to shear strength at steady-state conditions for gold tailings (Rassam and Williams 1999)

Hossain and Fourie (2013) investigated the bearing capacity of a strip footing on a sand embankment on a weaker clay layer (acts similarly to mine tailings). Typical shear strength profiles are shown in Figure 2.9-7 below, based on a T-bar factor of $N_{T-b a r}=10 \bullet 5$, where $\mathrm{z}$ is the penetration depth of the T-bar mid-diameter. The profiles can be simplified as increasing linearly with depth. 


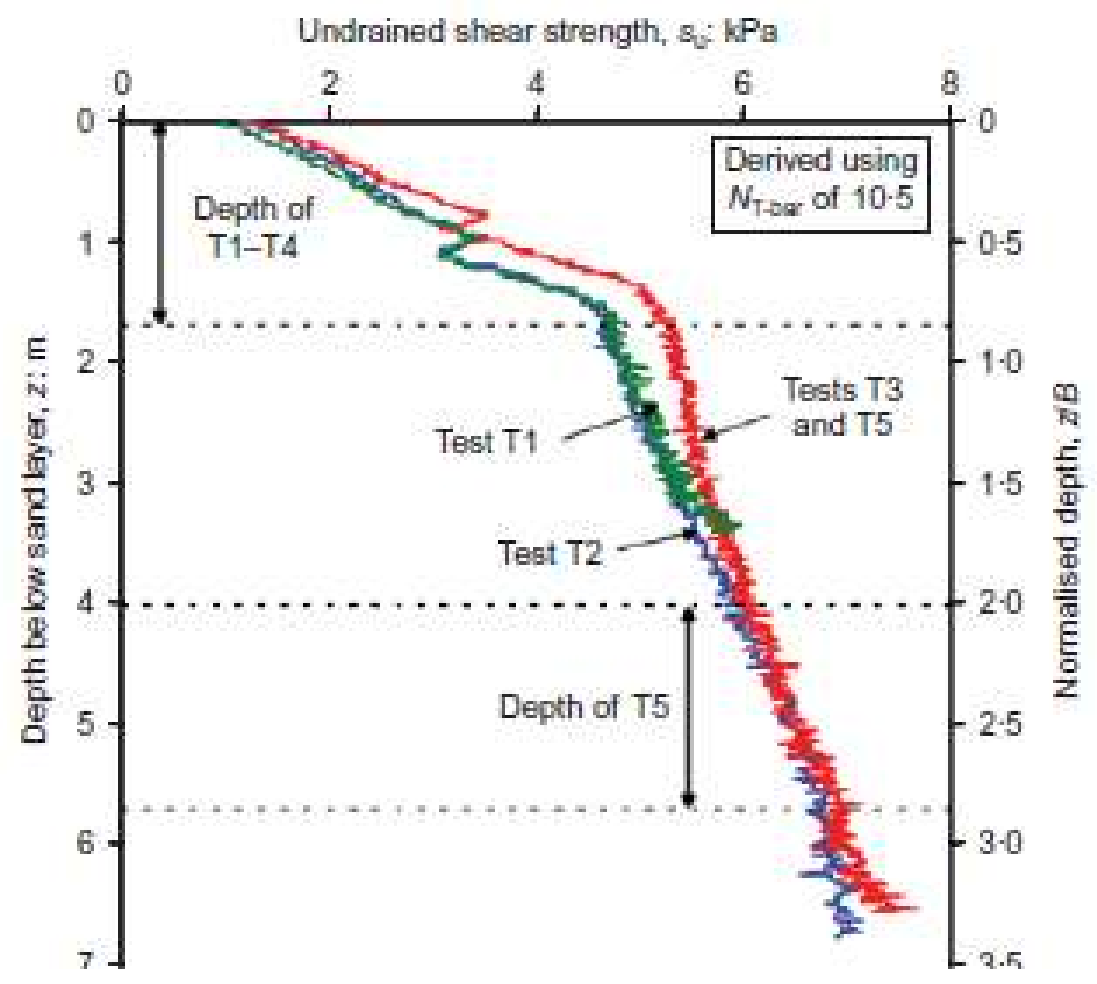

Figure 2.9-7: Typical strength profiles from T-bar test $\left(N_{T-4}=10 * 5\right)$ (Hossain and Fourie, 2013)

In Rassam and Williams (1999) study on the bearing capacity of dessicated mine tailings, it was found that when the contribution of matric suction was considered in the shear strength of the tailings, a greater factor of safety is achieved. The suction contribution to the shear strength of the tailings was determined to be non-linear. In addition, when the suction contribution was considered, the depth of the water table had a significant effect on the bearing capacity results.

\subsubsection{Bearing Capacity Fitting Factor}

In equation 23 , the value of the bearing capacity fitting parameter is equal to 1 for coarse-grained soils, but for fine-grained soils, it is higher, and dependent on the 
plasticity index (Vanapalli and Mohamed, 2007). The factor for the bearing capacity fitting is the following:

$$
\psi_{B C}=1.0+0.34\left(I_{p}\right)-0.0031\left(I_{p}\right)^{2}
$$

Where,

$$
I_{p}=\text { Plasticity Index. }
$$

\subsection{Trafficability}

The rehabilitation of any mined void must be carried out as soon as the stored tailings can provide an accessible surface where earthmoving equipment can travel and work safely, in other words, a trafficable surface. There have been many cases where earthmoving equipment has punched through a progressively placed cover (a cover that is stronger than the underlying tailings). Figure 2.10-1 shows some tailings bearing capacity issues that have occurred in the past.

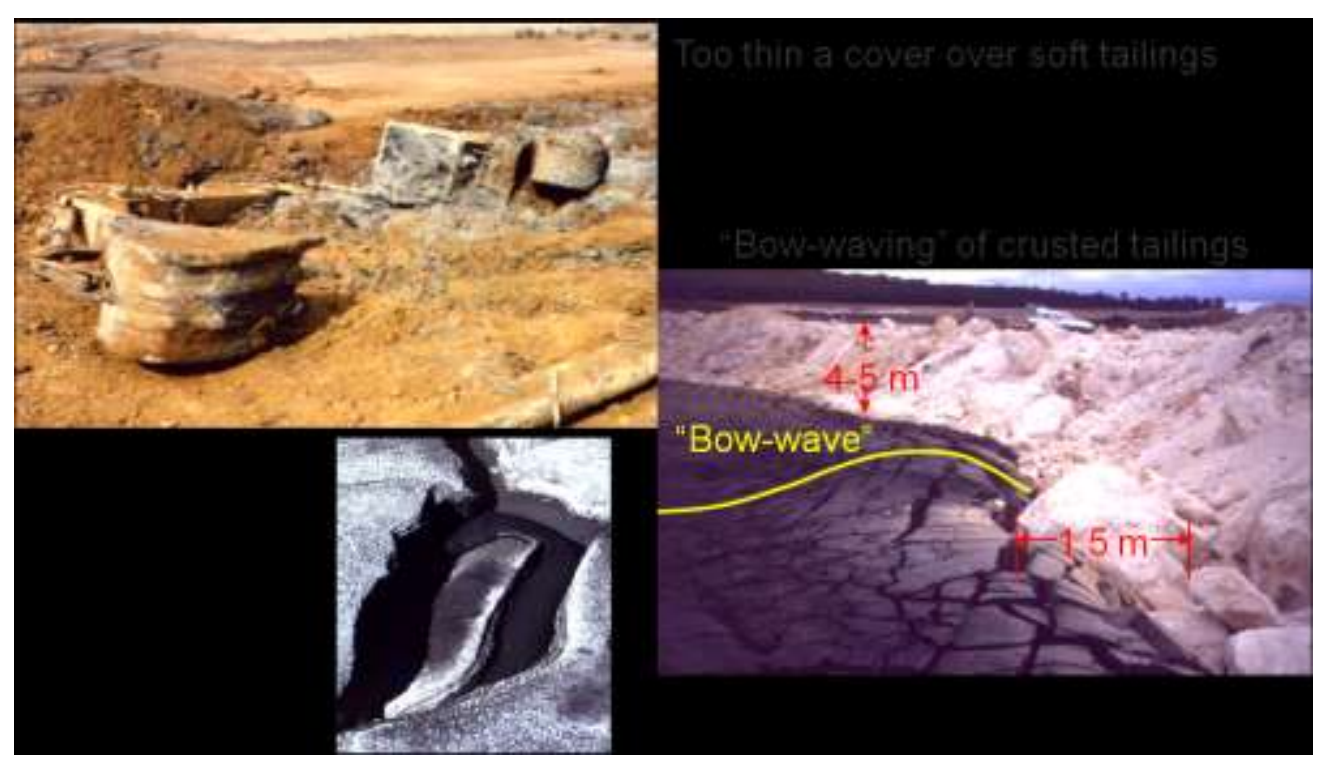

Figure 2.10-1. Tailings bearing capacity issues (Williams, 2013) 
For rehabilitation planning, two basic points are of utmost importance (Jakubick et al., 2003):

1) Sufficient bearing capacity of the tailings surface to hold machinery and advance the cover (trafficability); and

2) The extent of the rate and amount of settlement of the tailings surface due to the load of the cover.

In this thesis, the issue of trafficability is the focus. Trafficability of a soil is often defined as the capability of the soil to support vehicle traffic (Lutton et al, n.d.). Trafficability problems generally consider bearing and traction capacities. Both capacities are functions of soil strength or shearing resistance.

Trafficability bearing capacity is focused on the capability of the soil to support the vehicle without significant settlement. Trafficability traction capacity is the resistance between the wheels of the vehicle and the soil required to develop the forward thrust to overcome the rolling resistance. The combination of these capacities is considered to be adequate trafficability for a given vehicle. (Lutton et al., n.d.).

The loads of some earthmoving machines are presented in Table 2.10-1 below. These operating weights are the ranges obtained from Caterpillar Inc.'s website.

Table 2.10-1. Operating weights of various earthmoving equipment (adapted from Caterpillar Inc., 2015)

\begin{tabular}{cc}
\hline Earthmoving Machine & $\begin{array}{c}\text { Operating Weight } \\
(\mathbf{k g})\end{array}$ \\
\hline Dozers & $10000-100000$ \\
Articulated trucks & $46820-54920$ \\
Excavators & $40000-92020$ \\
Compactors & $24000-56000$ \\
\hline
\end{tabular}

Different types of tailings require differing remediation approaches. For example, in slimes of lower shear strengths $(<5 \mathrm{kPa})$, thinner initial cover layers, and lighter 
equipment and/or long arm hydraulic shovels would be needed. Various techniques for surface drainage and air drying could be used. (Jakubick et al., 2003) Remediation methods used for various tailings types used by Syncrude tailings facilities in Alberta are presented in Figure 2.10-2.

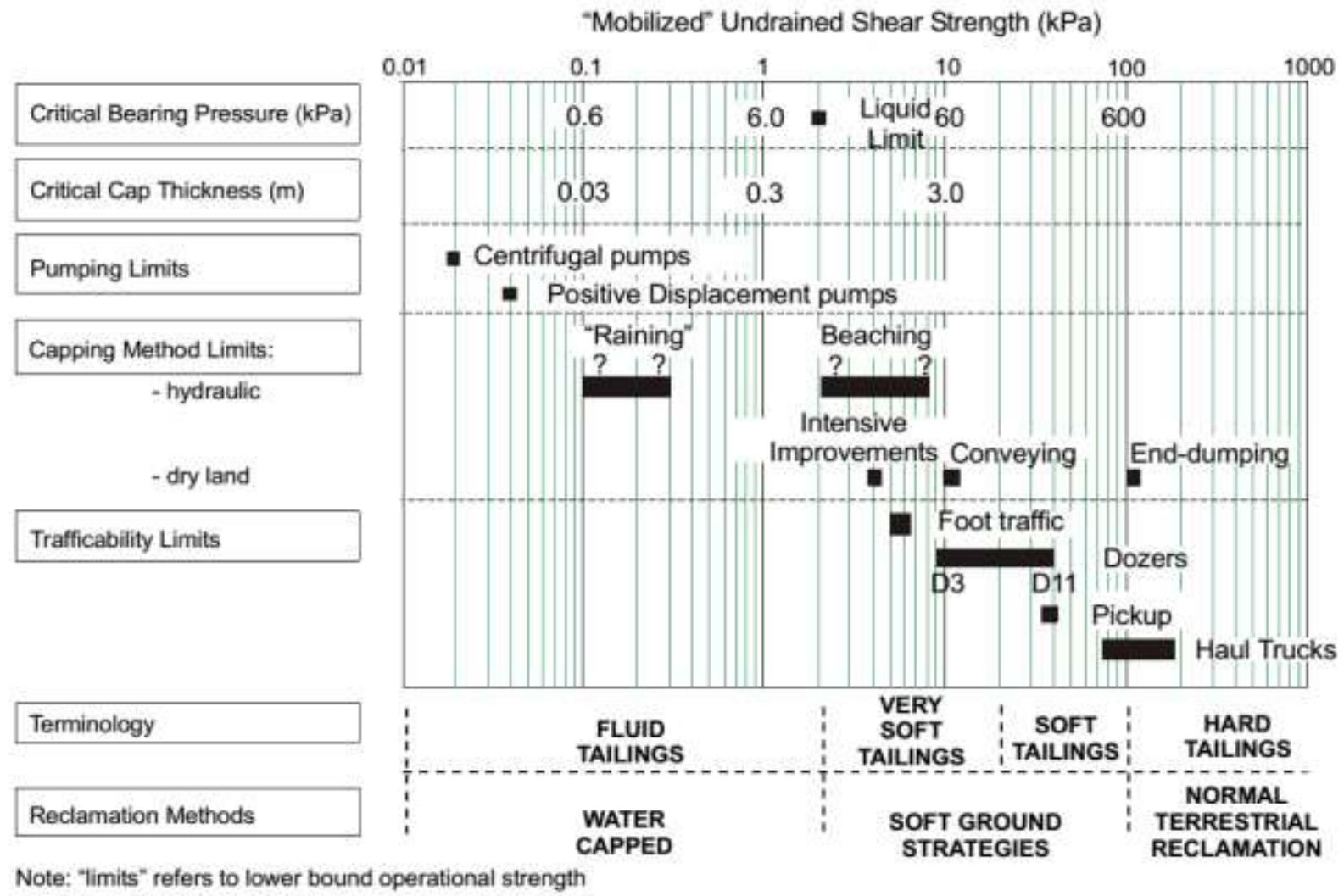

Figure 2.10-2. Remediation methods as functions of shear strength and critical parameters (Jakubick et al., 2003)

For perspective, the 5 year target under the recently suspended Directive 74 was $10 \mathrm{kPa}$. According to this figure, the tailings would only be able to support foot traffic and small D3 dozers. 


\section{METHODS AND MATERIALS}

This chapter provides a detailed description of the experimental set-up, beginning with the characteristics and origin of the oil sands tailings used in this work, and concluding with the equipment and analytical methods used in the laboratory experiments.

\subsection{Oil Sands Tailings}

MFT and a high molecular weight anionic polymer, A3338 were used in this study. The raw MFT had an initial SC of approximately $36 \%$ and a SFR of 0.27 . The geotechnical properties of the MFT can be found in Mizani et al. (2013).

Table 3.1-1. Geotechnical properties of raw and flocculated MFT used in the study

\begin{tabular}{lll} 
& \multicolumn{2}{c}{ Value } \\
\hline Property & Raw MFT & Flocculated MFT \\
\hline Specific gravity (dimensionless) & 2.2 & - \\
$\mathrm{D}_{10}, \mathrm{D}_{50}, \mathrm{D}_{60}$ (microns) & $0.8,6.4,11.1$ & - \\
$\mathrm{Cu}\left(\mathrm{D}_{60} / \mathrm{D}_{10}\right)$ (dimensionless) & 14.1 & - \\
Liquid limit $(\%)$ & 36.3 & 73.5 \\
Plastic limit $(\%)$ & 19.7 & 26.7 \\
Fines content $(<44 \mu \mathrm{m})(\%)$ & 78.7 & - \\
\hline
\end{tabular}

Flocculant solutions of $0.4 \%(\mathrm{w} / \mathrm{w})$ were prepared by adding $4 \mathrm{~g}$ of polymer to $996 \mathrm{~g}$ of mine reclaimed water. A dosage of $650 \mathrm{mg} / \mathrm{kg}$ mass of polymer per dry mass of tailings was employed, based on maximizing water release due to consolidation over a one week period (Soleimani et al., 2014). The procedures followed for preparing flocculant solutions and amended MFT are as outlined in Mizani et al. (2013), where the material was prepared so as to replicate the properties of field generated polymer amended MFT by comparing yield stress values measured by the stress growth technique. Part of the mixing procedure is shown in Figure 3.1-1. 


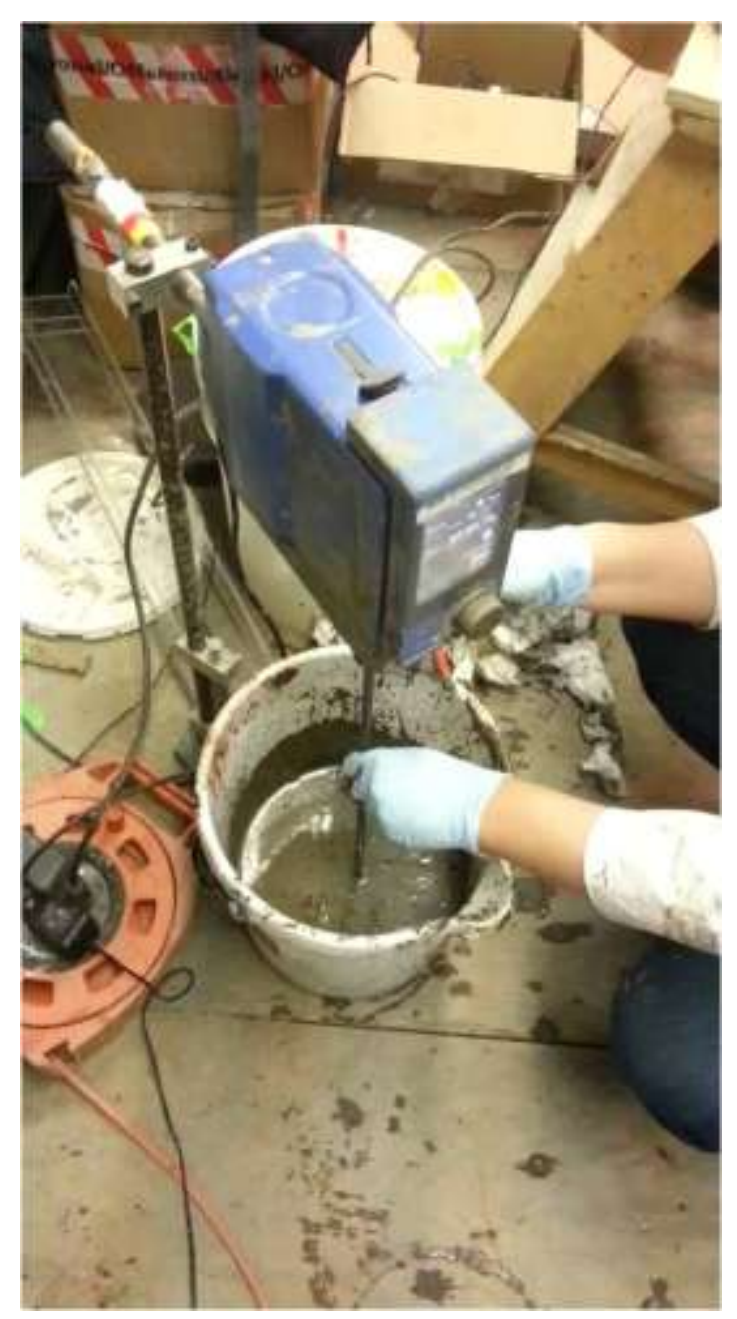

Figure 3.1-1. "In-line" mixing in the laboratory

The step by step method used to replicate conditions representative of field intensity and mixing times is the following (Mizani et al., 2013):

- A four blade impeller with radius $8.5 \mathrm{~cm}$ was immersed in 3,6 $\mathrm{kg}$ of MFT;

- Mixing started at a fixed speed of $250 \mathrm{rpm}$;

- The flocculant solution was added but mainly directed near the impeller during mixing;

- After adding the $0.4 \%$ flocculant solution, mixing continued for another 10 seconds. 
During this process, slump and moisture content measurements were taken after the mixing of every 5 buckets to ensure consistency in the produced material during testing.

For the thin lift dry box test, the tailings were deposited in three layers of a thickness of approximately 31,35 , and $33 \mathrm{~cm}$, at average solids contents of $35 \%, 34 \%$, and $33 \%$ respectively, with a flocculant dosage of approximately $650 \mathrm{mg} / \mathrm{kg}$ into a dry box, described in the following section. The layers were left to consolidate and desiccate to the shrinkage limit of the material, before the deposition of the subsequent layer. A comparison of unflocculated, and flocculated tailings is shown in Figure 3.1-2 below.

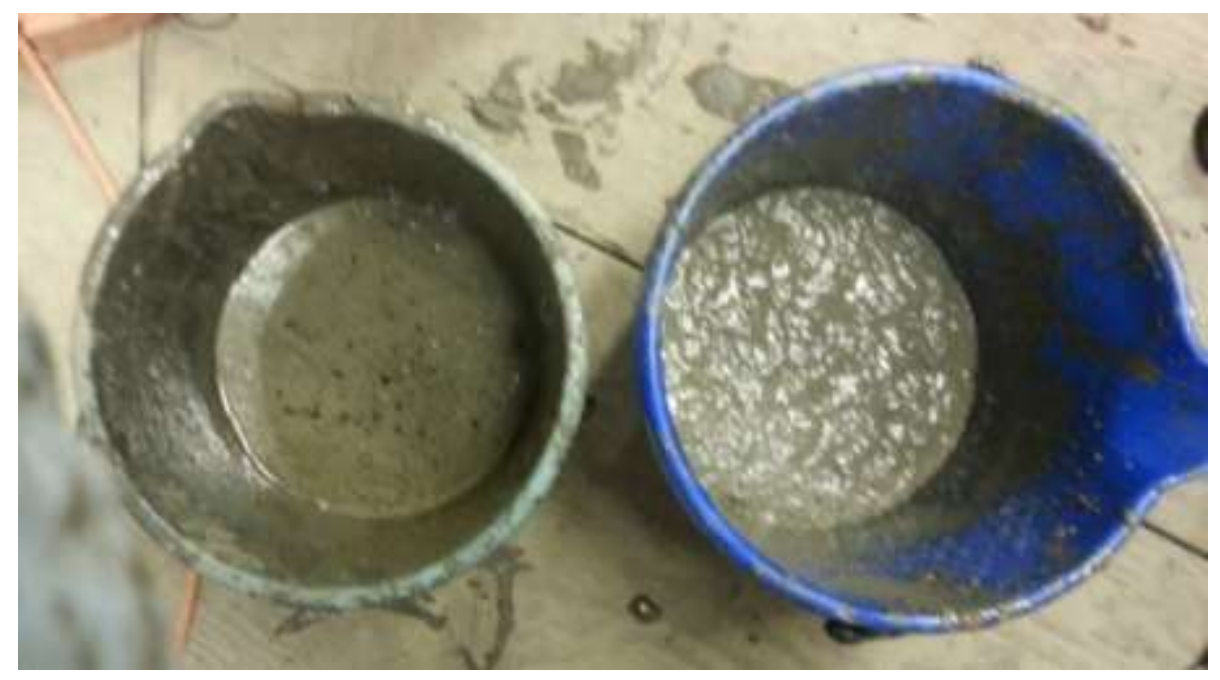

Figure 3.1-2. Comparison of un-flocculated (left) and flocculated (right) oil sands tailings.

For the thick lift dry box test, the tailings were deposited in two layers of 50 and $49.5 \mathrm{~cm}$ thicknesses, at average solids contents of 33 and $34 \%$, with a $650 \mathrm{~m} / \mathrm{kg}$ flocculant dosage. The layers were also left to consolidate and desiccate to the shrinkage limit before deposition and strength tests. 


\subsection{Dry Box Test}

Two dry box tests were conducted for thin lift $(\sim 30 \mathrm{~cm})$ and thick lift $(\sim 50 \mathrm{~cm})$ depositions. For both, the thin lift, and thick lift tests, flocculated oil sands tailings were deposited in three layers into a plexiglass box with steel framing with dimensions of 98.7 $\times 69.7 \times 63.0 \mathrm{~cm}(\mathrm{LxWxH})$ for the thin lift test and $98.7 \times 69.7 \times 100.0 \mathrm{~cm}(\mathrm{LxWxH})$ for the thick lift test, similar to the set-up used by Innocent-Bernard et al. (2013) and Daliri et al. (2012), and shown in Figure 3.2-1. Material was deposited in buckets of $3.6 \mathrm{~kg}$ until the desired lift height was reached.

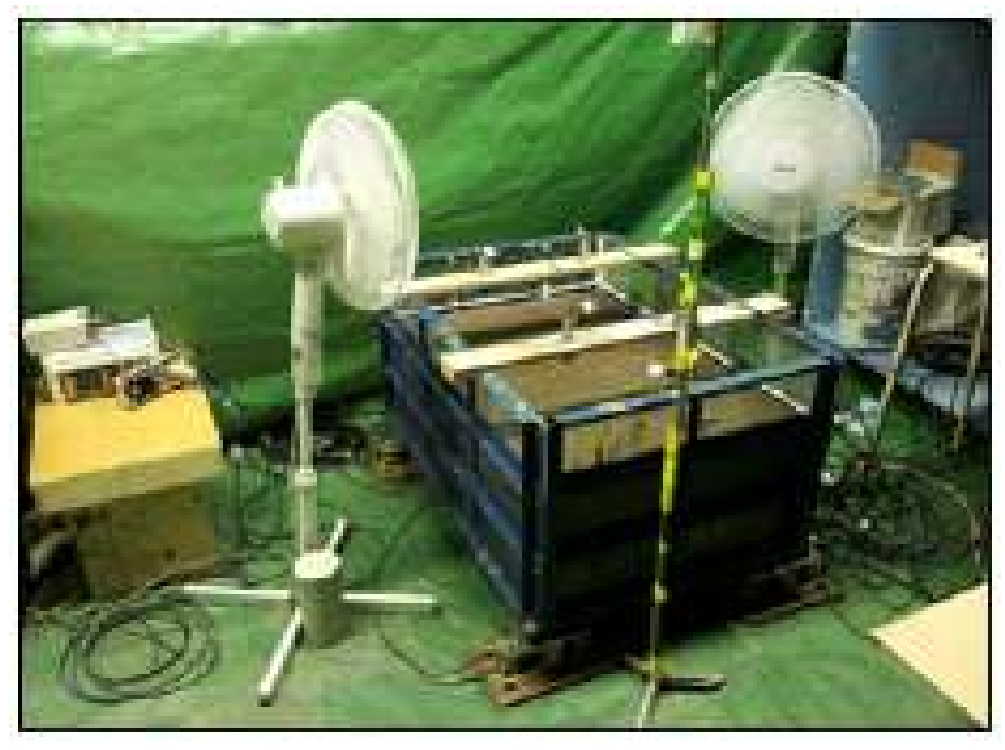

Figure 3.2-1. Dry box in profile

Geotextile material was secured along the base and sides to prevent the loss of solids with drainage. A tipping bucket rain gauge collected the water lost by drainage through a valve in the centre of the bottom of the box. The box was mounted on load cells, which were connected to a data logger that recorded the loss of mass due to evaporation and drainage.

The change in height of the material was recorded by Senix (height) sensors mounted on wooden beams as shown in Figure 3.2-2 for the thin lift test. The wooden 
beams were replaced by beams made of plexi-glass for the thick lift test, to provide a better quality visual from the top of the box. The sensix sensors were calibrated using known heights and connected to a data acquisition system. Senix sensors and load cells recorded the changes in height and weight, respectively, every minute.

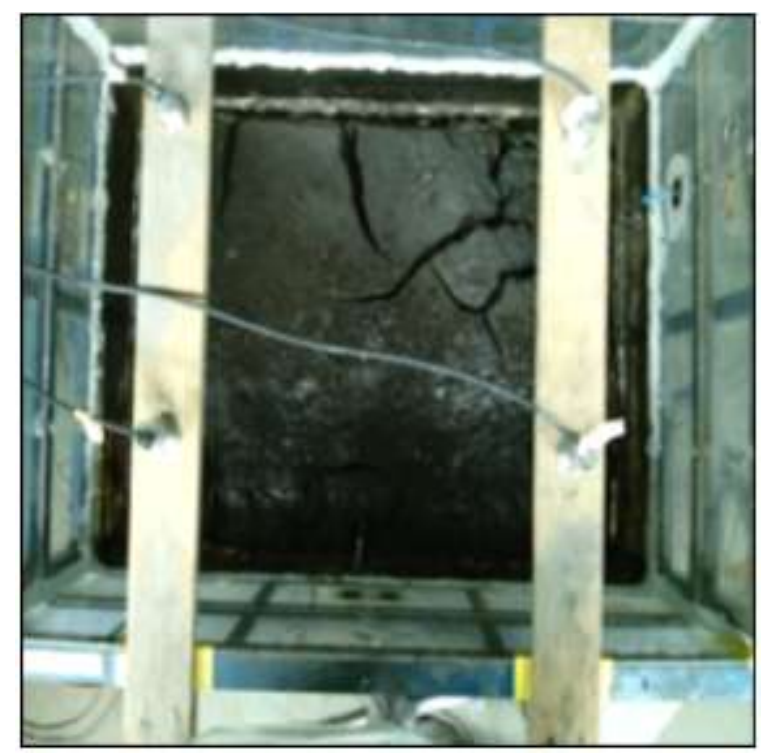

Figure 3.2-2. Senix sensor set-up

The $\mathrm{AE}$ was monitored through the use of load cells. Measurements were taken every minute by the sensors, and the daily water loss was determined from measurements taken every 24 hours. The amount of water lost through drainage, recorded by the tipping bucket at the bottom of the box was subtracted from the total mass loss in order to determine the daily evaporative rate. Midway through Layer 1, it was observed that the tipping bucket has inconsistent with the readings due to the water coming into contact with the wiring. The tipping bucket was replaced, but for the rest of Layer 1, manual measurements were performed by replacing the tipping bucket with a container, and weighing it daily. 


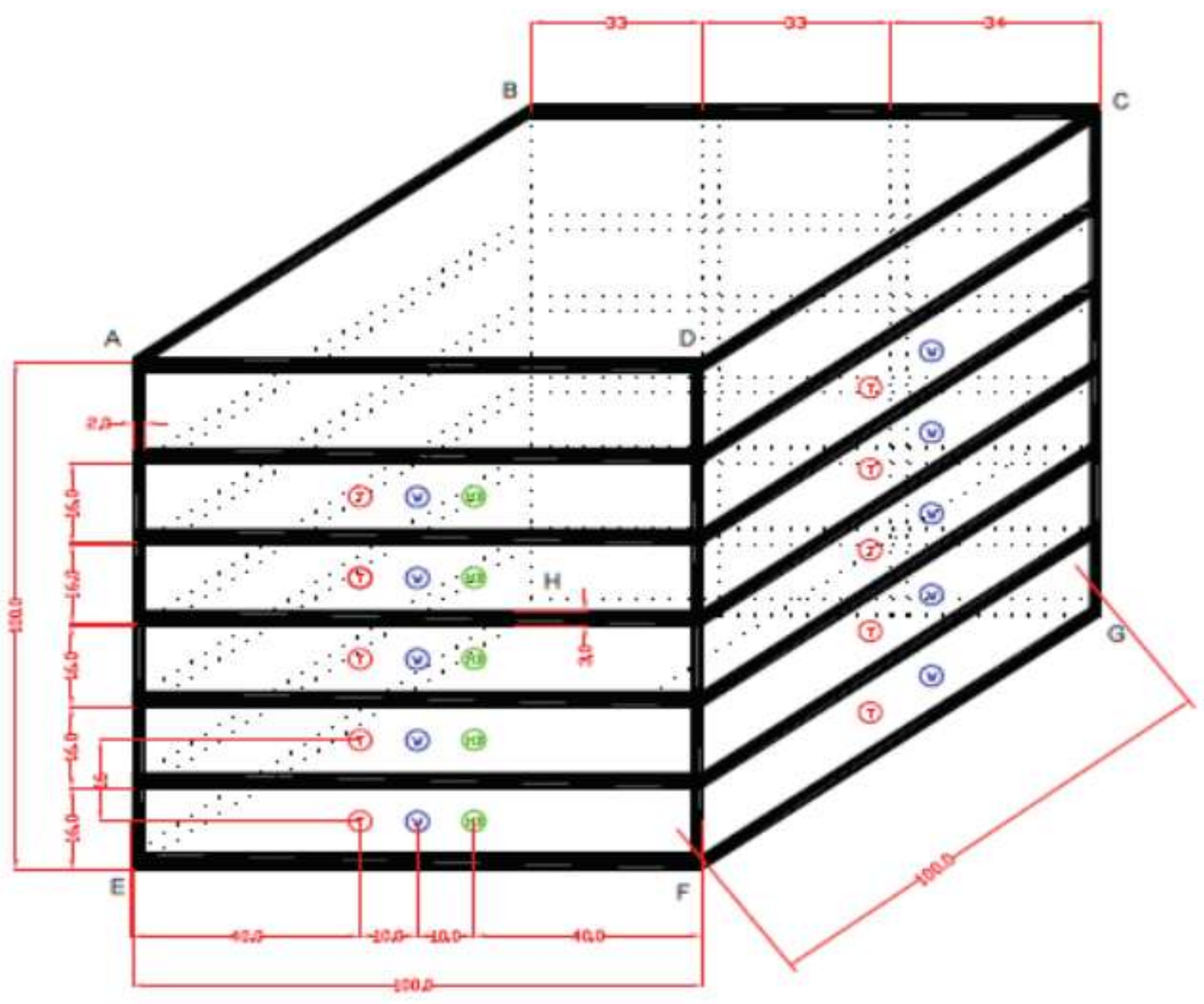

Figure 3.2-3. Dry box dimensions and sensor ports (Daliri, 2013)

Deagon 5TE (VWC, bulk EC and temperature) sensors, and UMS T5 tensiometers (pore-water pressure and matric suction, shown in Figures 3.2-4 and 3.2-5) were placed at every $16 \mathrm{~cm}$ height interval in the box to monitor the variability of consolidation and drying in the soil profile, as shown in Figure 3.2-3. Both of these sets of sensors recorded data every five minutes. 


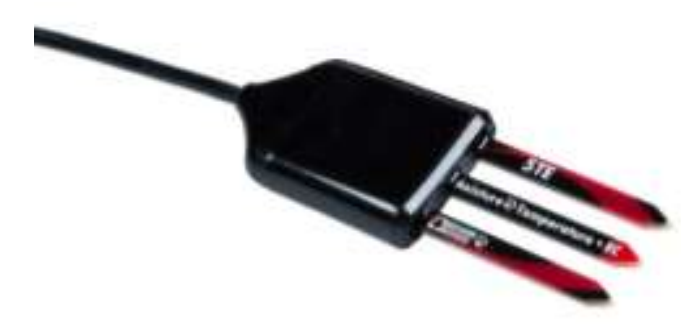

Figure 3.2-4. Decagon 5TE sensor (Decagon, 2015)

The Decagon 5TE measures VWC, EC and temperature with the three prongs pushed that are in contact with the soil. This sensor uses capacitance/frequency domain technology to measure the dielectric constant of the soil to estimate VWC. A frequency of $70 \mathrm{MHz}$ is used by the sensor, since it minimizes the effects of texture and salinity. The Topp equation is applied to calculate the VWC, but in this experiment, calibration curves were developed using WWC calculated by senix sensor readings. EC is measured with a stainless steel electrode array. The temperature is measured using an onboard thermistor. Factory calibrations are applied for both of these properties. (Decagon, 2015)
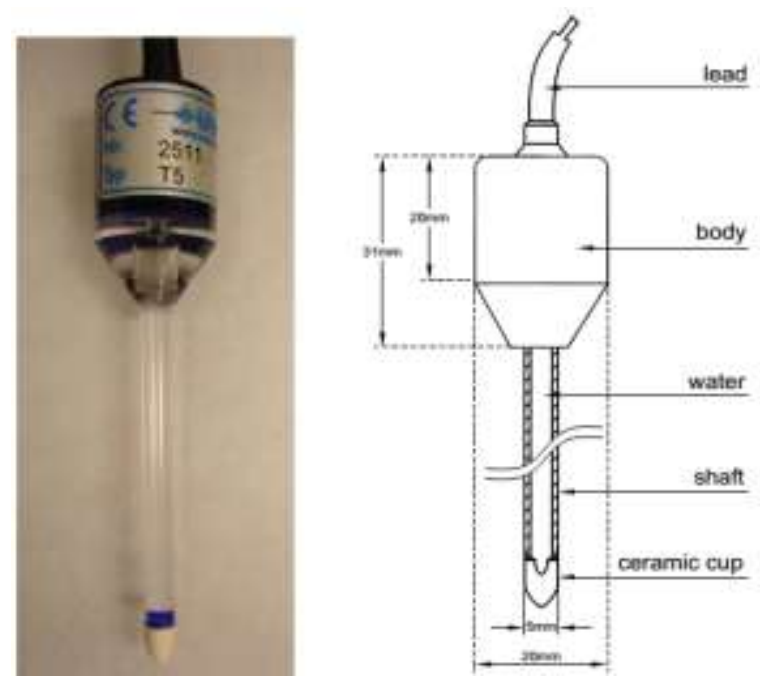

Figure 3.2-5. The T5 tensiometer (UMS, 2009) 
Before installation, tensiometers must be refilled for accurate and rapid measurement of the pore water pressure. Distilled water is de-aired in a vacuum for 15 minutes. The tensiometer tip is left to fully saturate for 30 minutes, preferably in a vertical position. Once the tip is thoroughly saturated, a syringe was used to remove air bubbles from the tip and the body of the tensiometer in the distilled water. Once all visible air bubbles are removed with the syringe, both components are deaired in a vacuum for 15 minutes. The removal of air bubbles by syringe and vacuum are repeated twice more. Before the installation, the plastic bubble caps are placed over the tip, and the tensiometer must always remain under water to avoid cavitation. Before installation, tensiometers were tested at various heights in a water column, and the response was checked by briefly exposing the tip to the air.

Two electrical fans were placed at opposite ends of the box in order to simulate wind. A webcam was mounted over the dry box, and recorded an image every hour to monitor cracking development. The following link provides a time lapse of cracking development in the thin lift dry box: http://youtu.be/ISluXm89g2E.

For the thin lift test, one RH Easy Log USB sensor was placed on one of the beams to monitor temperature change and $\mathrm{RH}$ above the tailings. For the thick lift test, three additional $\mathrm{RH}$ sensors were acquired to compare the measurements at the top of the beams, the surface of the tailings, and in the cracks, once they had formed. The placement of the RH sensors for the thick lift dry box is shown in Figure 3.2-6. 


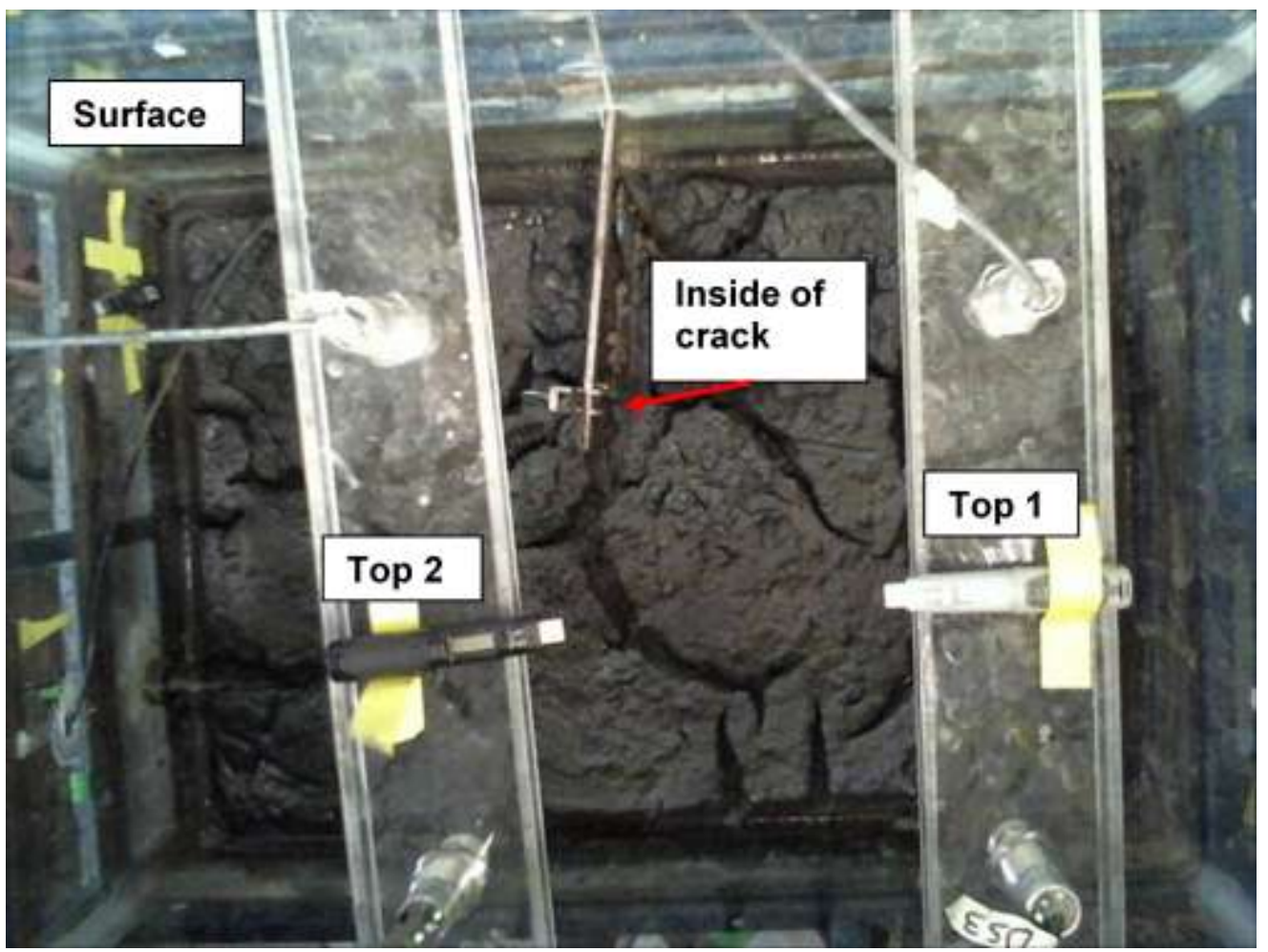

Figure 3.2-6. Placement of Easy Log USB Sensors in the Thick lift dry box.

Once cracking began, a wind speed sensor, shown in Figure 3.2-7 was used to compare the wind speed on the surface of the tailings and inside the same crack where the $\mathrm{RH}$ sensor was placed. This was measured multiple times during the duration of the experiment.

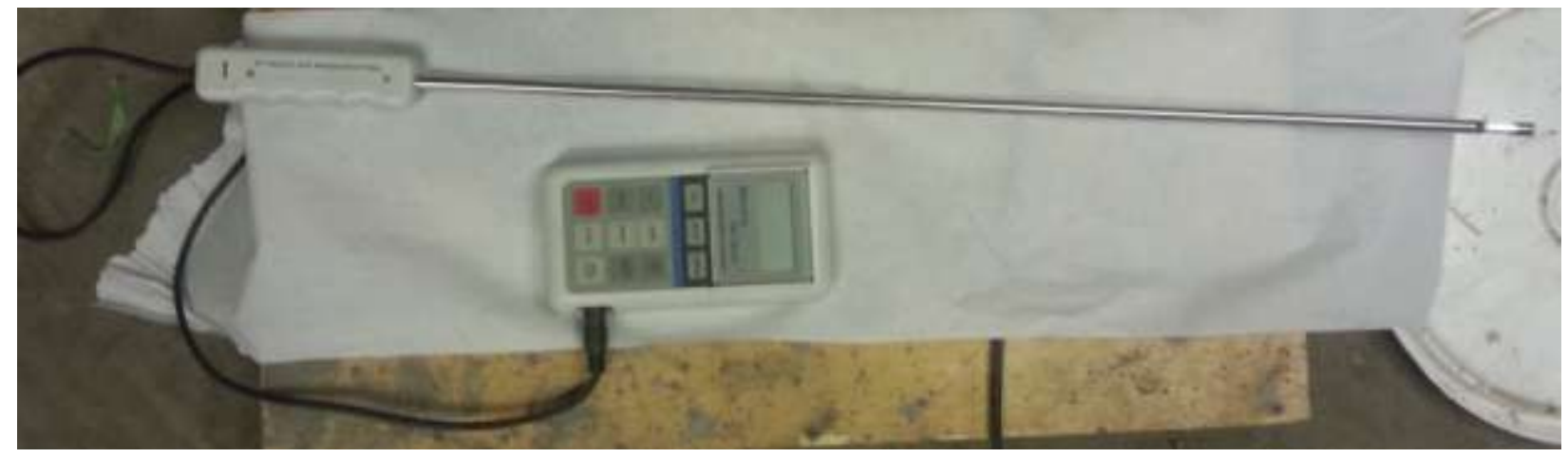

Figure 3.2-7. Wind speed sensor 


\subsubsection{Evaporation}

A rain gauge was used to record the amount of drainage that came out of a valve under the drying box, where every tip was equal to $5 \mathrm{~mL}$ or $10 \mathrm{~mL}$ of water (depending on the test). AE was measured by the weight recorded by the load cells. A daily weight measurement was recorded at the same time every day, and the drainage was subtracted to determine AE. The load $(\mathrm{kg})$ was then converted to a height measurement $(\mathrm{mm})$ considering plane horizontal dimensions of the dry box $(63.0 \times 98.7 \mathrm{~cm})$, resulting in an "apparent actual evaporation" of the dry box. The AE measurements shown in the results sections consider the surface area of the entire box, without the consideration of crack geometry contribution to surface area.

\subsubsection{Water (Potential Evaporation) Test}

In order to determine the potential, or pan evaporation rate, the dry box was filled with water prior to deposition of tailings, and the evaporation was recorded over 24 hours. The effective wind speed was then back-calculated using the Penman-Monteith Equation (equation 4) and employing the measured $\mathrm{RH}$ and temperature values. When tailings were placed, the $\mathrm{PE}$ rate was calculated using measured $\mathrm{RH}$ and temperature values, and knowing that the contribution of wind (generated by fans) remained the same.

The evaporation recorded by the load cells (Figure 4.2-2) once the tailings were deposited was compared to the PE rate from a water test conducted on February $25^{\text {th }}$, 2015 (thick lift). The effective wind speed was back calculated using data from the RH sensors and the Penman-Monteith calculation. These were found to closely match, as expected, shown in Table 4.2-1. 
Table 3.2-1. Potential evaporation measurements for thick lift dry box

\begin{tabular}{ccccc}
\hline Test & $\begin{array}{c}\text { Evaporation } \\
(\mathrm{mm} / \mathrm{d})\end{array}$ & $\begin{array}{c}\text { Average Temperature } \\
\text { (Celsius) }\end{array}$ & $\begin{array}{c}\text { Average RH } \\
(\%)\end{array}$ & $\begin{array}{c}\text { Wind speed, u } \\
(\mathrm{m} / \mathrm{s})\end{array}$ \\
\hline Water & 4.00 & 11.3 & 21.2 & 3.94 \\
Tailings & 4.26 & 15.9 & 20.3 & 3.66 \\
\hline
\end{tabular}

\subsubsection{Slump Test}

Since layers were deposited in buckets of $3.6 \mathrm{~kg}$ until the required height was achieved, in order to ensure uniformity of the mix, slump tests were conducted at regular intervals during the deposition of each layer. A small 12" cylinder and two rulers were used. The material was poured into the cylinder until it was full. The cylinder was then pulled away, and placed next to the material. The height of the material was then measured from the centre. The slump is the difference between the initial and final height of the material. These measurements ensured the consistency of the mix.

\subsection{Surface Sampling}

Samples from the edge of the crack, and the inside of crack (IC) were collected as soon as they appeared. A dew point hygrometer (WP4-C) was used to measure the total suction of the samples. This device is shown in Figure 3.3-1. 


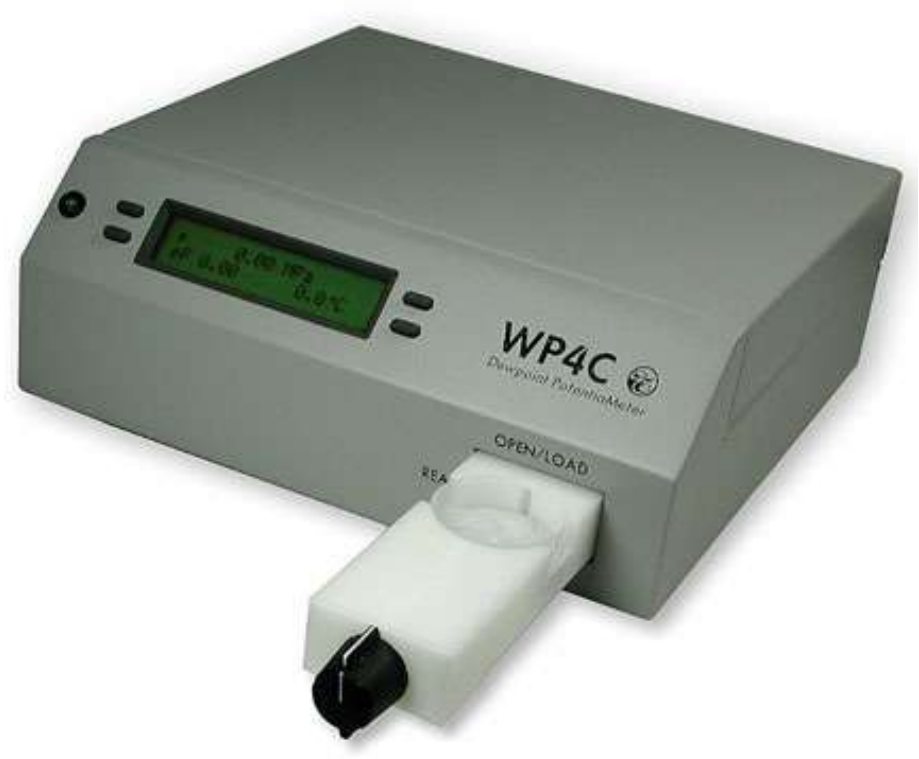

Figure 3.3-1. WP4-C potentiometer (Hoskin Scientific Ltd, 2015)

This device is the most reliable instrument available for measuring water potential and it uses the chilled mirror dewpoint technique, and has a high range from 0 $300 \mathrm{MPa}$. A specimen $40 \mathrm{~mm}$ in diameter and $15 \mathrm{~mm}$ in height is placed in a test container. Then the specimen is placed into a drawer which slides into the WP4C. Once in the sealed chamber, the sample is equilibrated with the air in the chamber. The components of the WP4C are shown in Figure 3.3-2. The chilled mirror dewpoint technique uses a mirror with detects condensation. At equilibrium, the $\mathrm{RH}$ of the air in the chamber is equal to the $\mathrm{RH}$ in the specimen. A thermoelectric cooler controls the temperature on the mirror, and a photoelectric cell measures the change in reflectance of a beam of light directed at the mirror. (Decagon, 2007) 


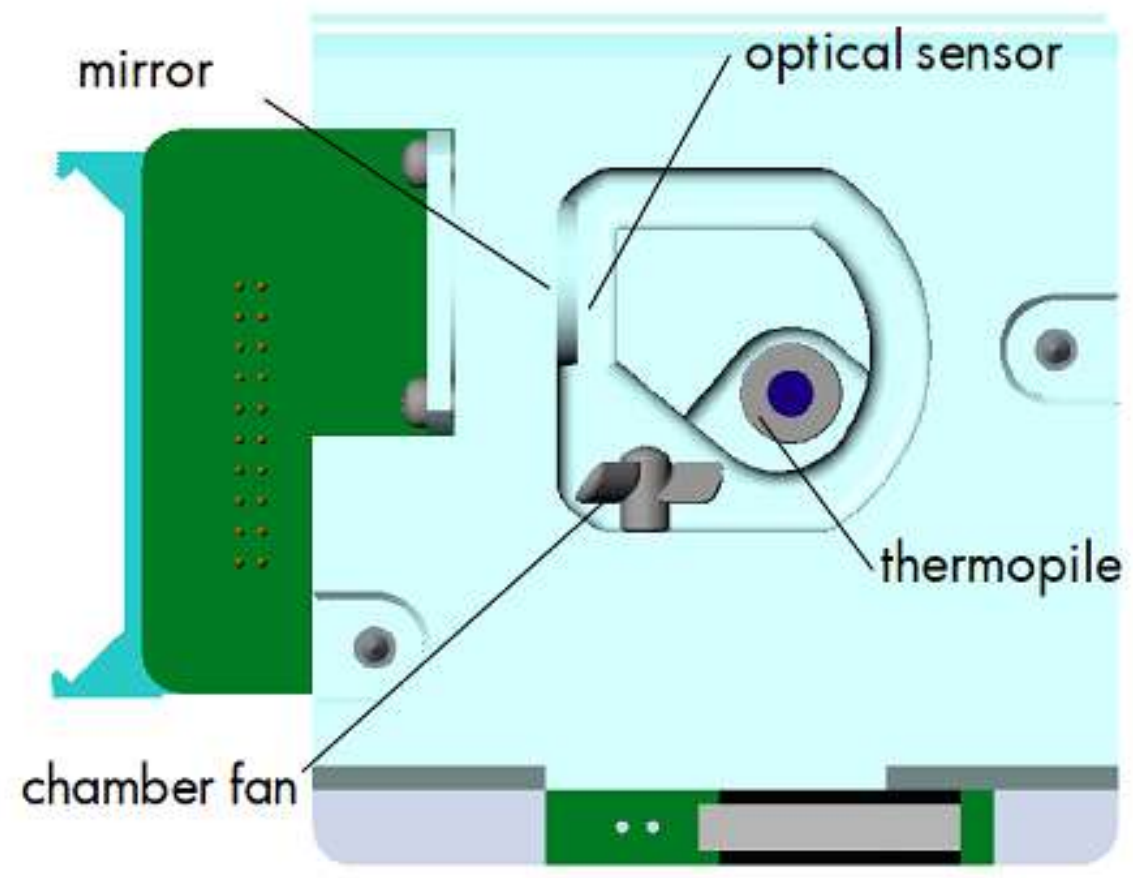

Figure 3.3-2. View inside the WP4C (Decagon, 2007)

The EC of the surface samples was measured using the saturation technique. In this technique, deionized water was added to the soil, mixed, and the centrifuged to extract the pore water from the sample. The conductivity was measured, and extrapolated to determine the osmotic suction related to that of the natural water content (USDA, 1954; Krahn and Fredlund, 1973; Fredlund and Rahardjo, 1993). As with the total suction measurements, samples extracted from the top $1 \mathrm{~cm}$ of the surface were measured.

In addition, once crack formation began, the width, depth, and length of each crack was measured using a caliper and a wooden ruler to calculate the growth of crack surface area and volume, as shown in Figure 3.3-3. These parameters were calculated based on the geometry of every crack as shown in Figure 3.3-4. 

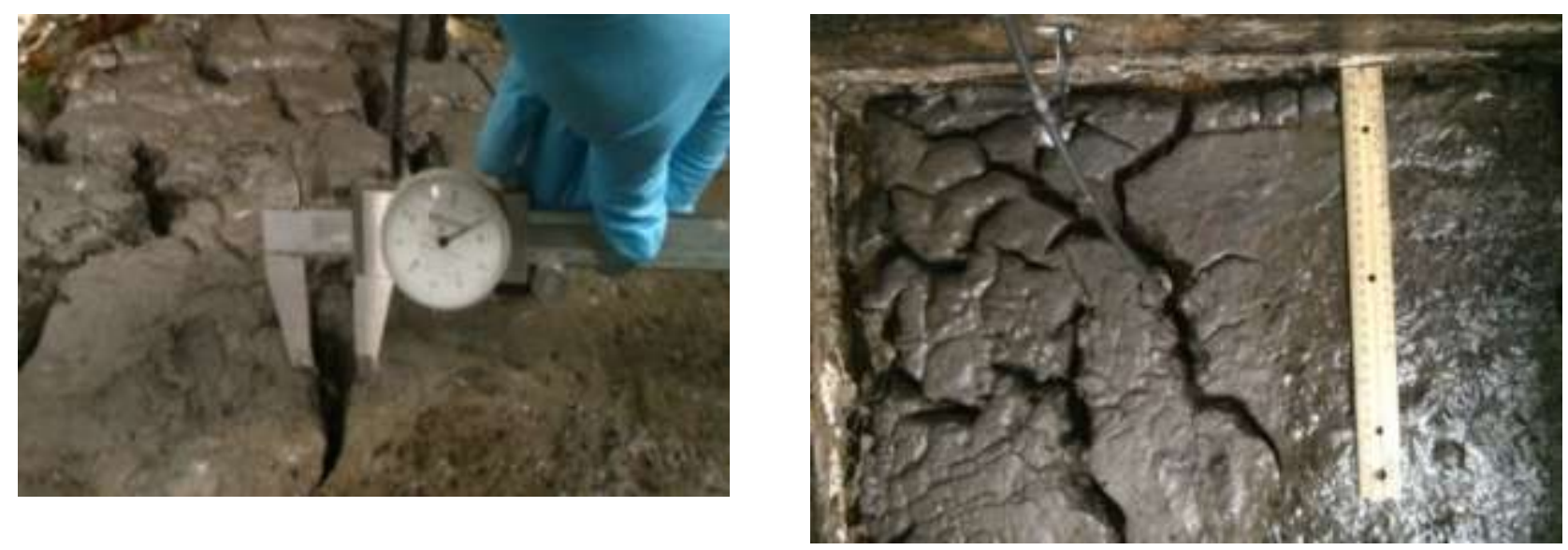

Figure 3.3-3. Crack measurement techniques

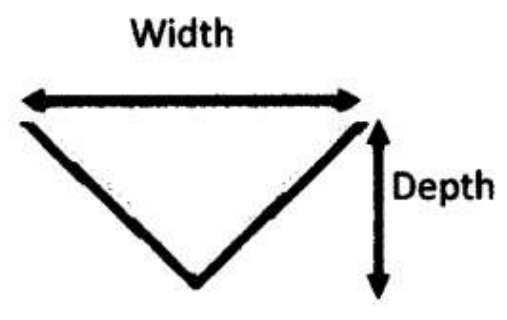

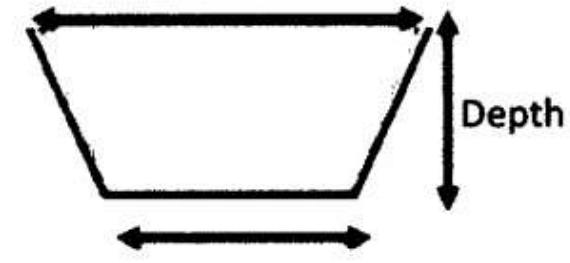

Width

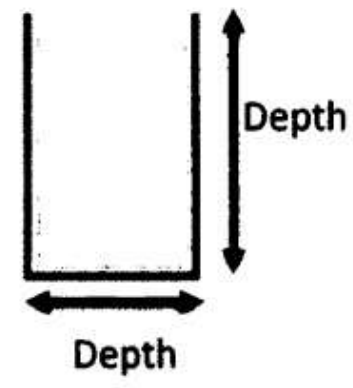

Figure 3.3-4. Crack geometries and measured dimensions (Innocent-Bernard, 2013)

Upon the completion of each layer, core samples were extracted from various locations in order to analyze the GWCs, solid contents, total suction, osmotic suction, and hydrocarbon content with depth, to provide a history of drying in the soil profile.

\subsection{Vane Shear Test}

Upon the completion of each layer, vane shear tests using shear vane tester $\mathrm{H}-60$ (shown in Figure 3.4-1), were conducted to verify for regulatory compliance in terms of in situ undrained shear strength. A vane of various diameters was inserted into the soil 
approximately every $5 \mathrm{~cm}$. Once the vane was at the zero position, it was rotated slowly at a uniform rate. The point where the vane reaches the maximum torque and the soil fails in shear on a cylindrical surface around the vane is the undrained shear strength of the soil. Specific factors were applied for the appropriate correction depending on the size of the vane. The range of the device ranges from 0-260 kPa.

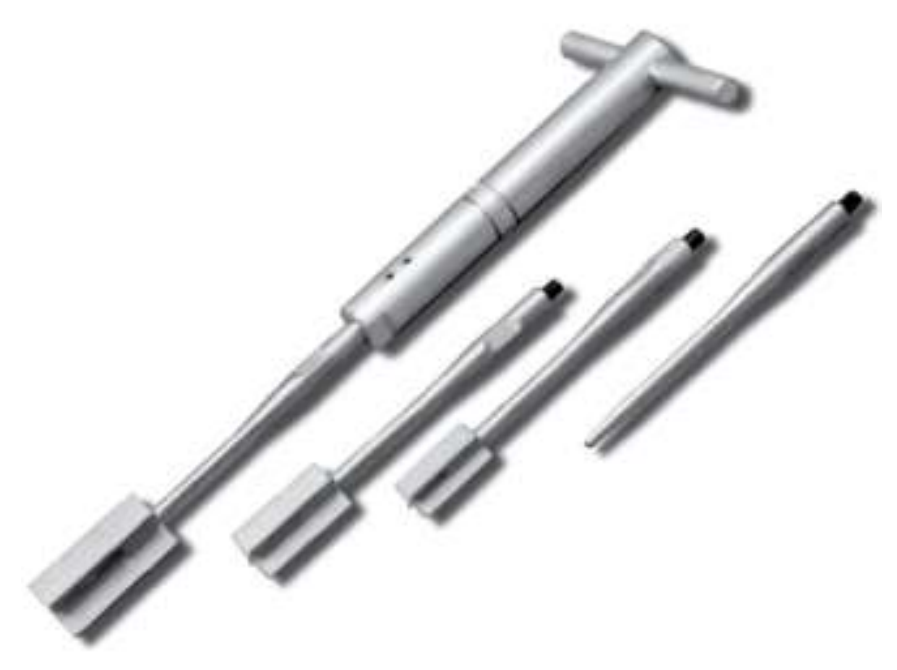

Figure 3.4-1. H-60 Shear vane tester (ESS Earth Sciences, 2015)

\subsection{Pocket Penetrometer}

In addition to the vane shear test, a pocket cone penetrometer (Figure 3.5-1) was used to measure the unconfined compression strength in the top $5 \mathrm{~mm}$ of the dry box after the completion of each layer. The piston end of this device is pushed into the ground, where the pin at the tip of the penetrometer encounters the force of the ground, which compresses the spring in the device. The maximum force encountered is measured by the distance that is shifted by the slip ring. The penetration resistance can be read directly on the compression strength scales using the slide ring. 


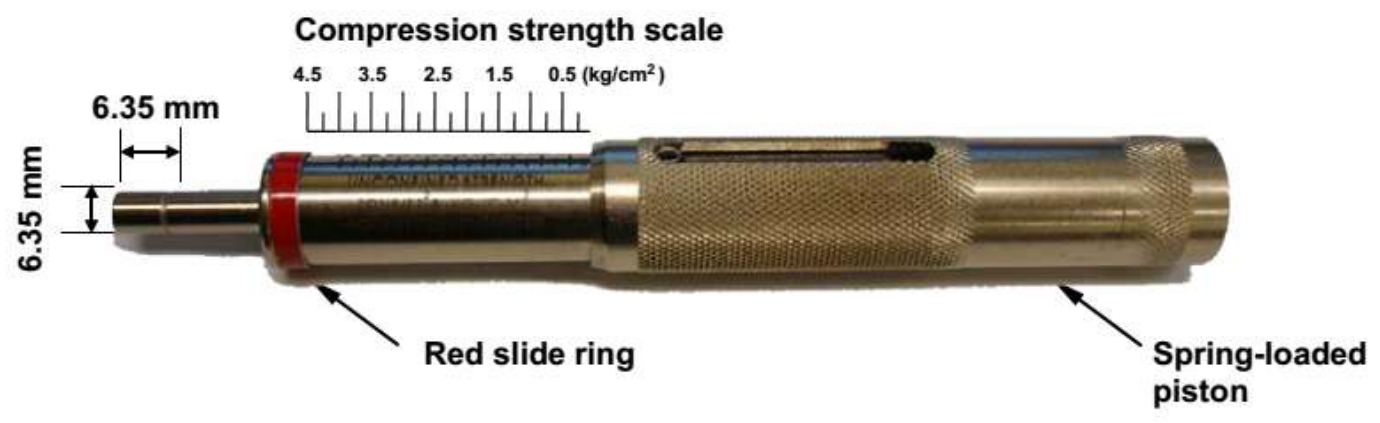

Figure 3.5-1. Pocket penetrometer (Vanapalli, 2015)

\subsection{Plate Load Test}

To determine the bearing capacity of the dried oil sands tailings, once the third and final layer achieved SCs of approximately $60 \%$ and $70 \%$, in-situ plate load tests based on a modified American Society for Testing and Materials (ASTM) 2003 method, were conducted on the tailings in the dry box at both solids contents.

A "screw mechanism", as shown in Figure 3.6-1, was used to apply a uniformly increasing load to the material, while being recorded on a data acquisition system through a load cell. The screw mechanism worked by converting a torque into a linear force to the load cell. , at a uniform rate until failure was observed. For the test at $60 \%$ SC, a dial gauge held by a stand was used to measure the displacement of the load cell at regular time intervals. For the $70 \%$ SC test, linear variable differential transformer (LVDT) position sensors connected to a data acquisition system replaced the dial gauge. This change permitted more readings at smaller time intervals. 


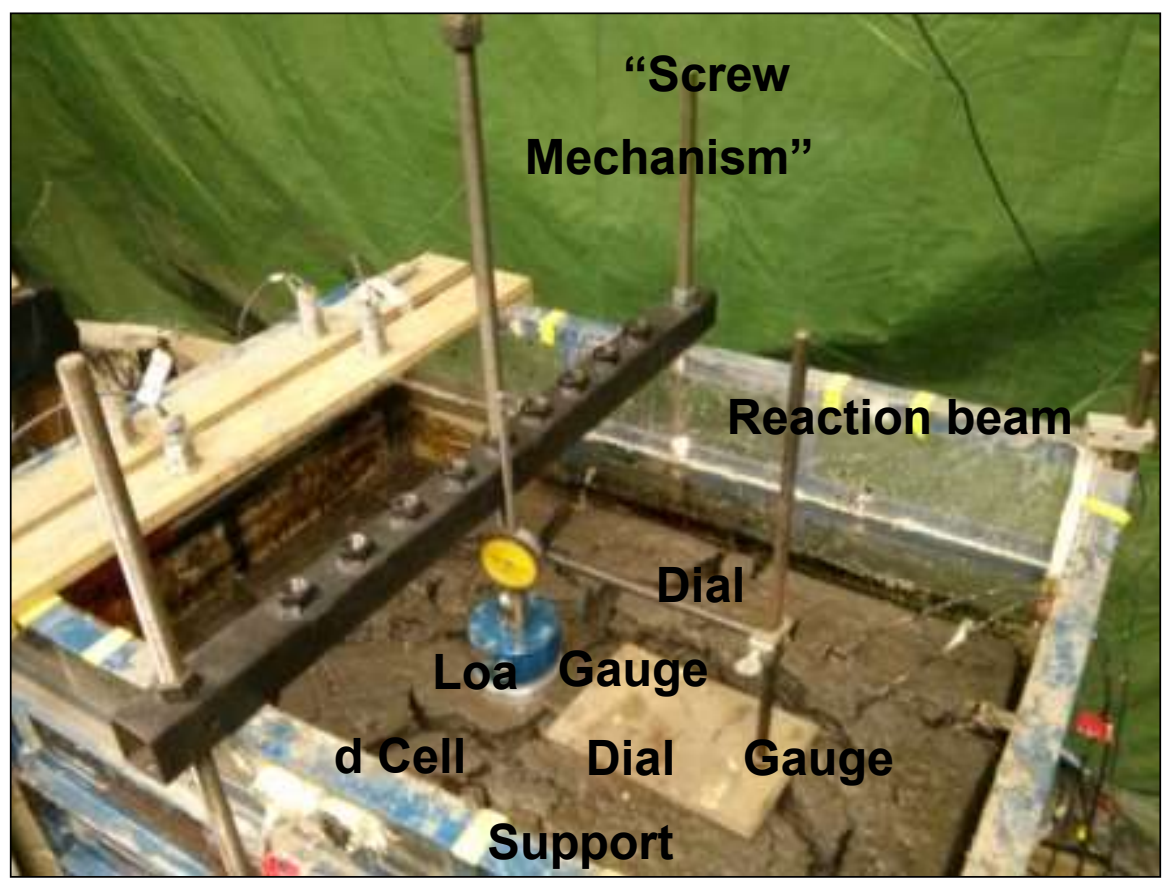

Figure 3.6-1. Plate load test set-up

The model footing was $10.5 \mathrm{~cm}$ in diameter to allow a uniform distribution of the load. The ratio of the width of the dry box (W) to the diameter of the footing (D) was chosen in order to match previous studies as closely as possible (ie. W/D 6) (Adams and Collin, 1997; Hanna and Abdel-Rahnam, 1998; Dash et al,. 2003; Bera et al., 2007; Oh and Vanapalli, 2013).

\subsection{Properties Analyses}

This section provides equations for properties that were measured in the laboratory, including: SC, moisture content, GWC, TOC, specific gravity and void ratio 


\subsubsection{Solids Content (SC)}

In the oil sands industry, the solids content (SC) is ratio of the mass of solids (fines, sands, and bitumen) to the total mass of the tailings. To determine the SC, samples were dried in an oven at $105^{\circ} \mathrm{C}$ for 24 hours.

The equation for SC is shown below:

$$
C_{S}=\frac{M_{S}}{M_{T}} \times 100
$$

Where,

$$
\begin{array}{ll}
C_{s} & =\text { Solids Content }(\%) ; \\
M_{S} & =\text { Mass of solids; } \\
M_{T} & =\text { Total mass. }
\end{array}
$$

\subsubsection{Water Content}

The water content is the ratio of the mass of water to the total mass of the material, shown in equation 26 .

$$
C_{w}=\frac{M_{w}}{M_{T}} \times 100
$$

It can also be expressed as a ratio of the mass of water to the mass of solids (gravimetric water content, GWC), as shown in equation 27.

$$
w=\frac{M_{w}}{M_{s}} \times 100
$$

Both of these properties were determined by placing samples in an oven at $105^{\circ} \mathrm{C}$ for 24 hours. 


\subsubsection{Total organic Content (TOC)}

Total organic content (TOC) is a measure of carbon based contaminants in a soil. Majid and Sparks (1983) and Schumacher (2002) found that the TOC could be determined by the indiscriminate removal of carbon matter from samples heated at high temperatures. Kaminsky (2008) found that inorganic carbon in oil sands tailings samples was not destroyed up to a temperature of $500^{\circ} \mathrm{C}$, using thermogravimetric analysis. It was found that up $2 \%$ of the mass loss that occurred up to that temperature was of organic content based on gas analyses.

To determine the TOC, a high temperature combustion method was used, similar to the method used by Innocent-Bernard (2013). After samples were dried at $105^{\circ} \mathrm{C}$ for 24 hours, they were combusted at $500^{\circ} \mathrm{C}$ for 4 hours. The equation for TOC is as follows:

$$
\text { TOC }(\%)=\frac{(\text { Dried weight }- \text { Ash weight })}{(\text { Total weight of the sample })} \times 100
$$

Where,

Dried weight $=$ Weight of sample after being dried at $105^{\circ} \mathrm{C}$;

Ash weight $=$ Weight of sample after being dried at $500^{\circ} \mathrm{C}$;

\subsubsection{Specific Gravity}

The specific gravity is the ratio of the mass of a volume of soil to the mass of equal volume of water at a specific temperature. From earlier experiments, the specific gravity was determined to be 2.12 . 


\subsubsection{Unit weight}

The unit weight is the weight per unit volume of a material, the equation for unit weight is the following:

$$
\gamma_{m}=\frac{G+S e}{1+e} \gamma_{w}
$$

Where,

$$
\begin{array}{ll}
\gamma_{m} & =\text { bulk unit weight; } \\
G & =\text { specific gravity; } \\
e & =\text { void ratio; and } \\
\gamma_{w} & =\text { unit weight of water. }
\end{array}
$$

\subsubsection{Void Ratio}

The void ratio is the ratio of the volume of voids and the volume of soil particles, as shown in equation 30 . For a saturated soil, the voids consist mostly of water, but in an unsaturated soil, the voids consist of air and water.

$$
e=\frac{V_{v}}{V_{s}}=\frac{V_{w}}{V_{s}}=\frac{M_{w} \times G_{s}}{M_{s}}
$$

Where,

$V_{v} \quad=$ Volume of void space (air and water);

$V_{S} \quad=$ Volume of solids;

$V_{w} \quad=$ Volume of water; 


$\begin{array}{ll}M_{w} & =\text { Mass of water; } \\ M_{S} & =\text { Mass of solids; } \\ G_{S} & =\text { Specific gravity; }\end{array}$




\section{RESULTS}

This chapter presents the results and interpretation of these results for the thin and thick lift dry box tests, and bearing capacity.

\subsection{Thin-Lift Dry Box Test}

The thin-lift dry box test was conducted April $4^{\text {th }}-$ August $16^{\text {th }}, 2014$. Three layers of $30-35 \mathrm{~cm}$ were added approximately one month apart.

\subsubsection{Layer 1}

MFT was remixed with a drum mixer at a speed of $180 \mathrm{rpm}$ for approximately $6 \mathrm{hr}$ in forward and reverse modes. The material was then dosed with a polymer at 650 $\mathrm{mg} / \mathrm{kg}$ using the method described in Mizani et al. (2013). The average initial SC of the tailings was $35 \%$ after the addition of polymer solution. Then the flocculated tailings were deposited in 61 buckets of $3.6 \mathrm{~kg}$ into a drying box on April $4^{\text {th }}$ (Figure 3.2-1, Chapter 3 ) and allowed to dry to a final SC of $90 \%$ overall. Additional details concerning the deposition are available in Appendix A.

Core samples were taken before the deposition of layer \#2, on May $27^{\text {th }}$ to provide a history of the drying process with depth. The data collected for the first layer is presented in this section.

\subsubsection{Mass Loss, Evaporation and Drainage}

Figure 4.1-1 shows the overall mass loss in the dry box in Layer 1, which occurred due to the combination of evaporation and drainage. Figure 4.1-2 presents a breakdown of the mass loss due to the two components. In this layer, overall mass loss occurs gradually, but constantly. 


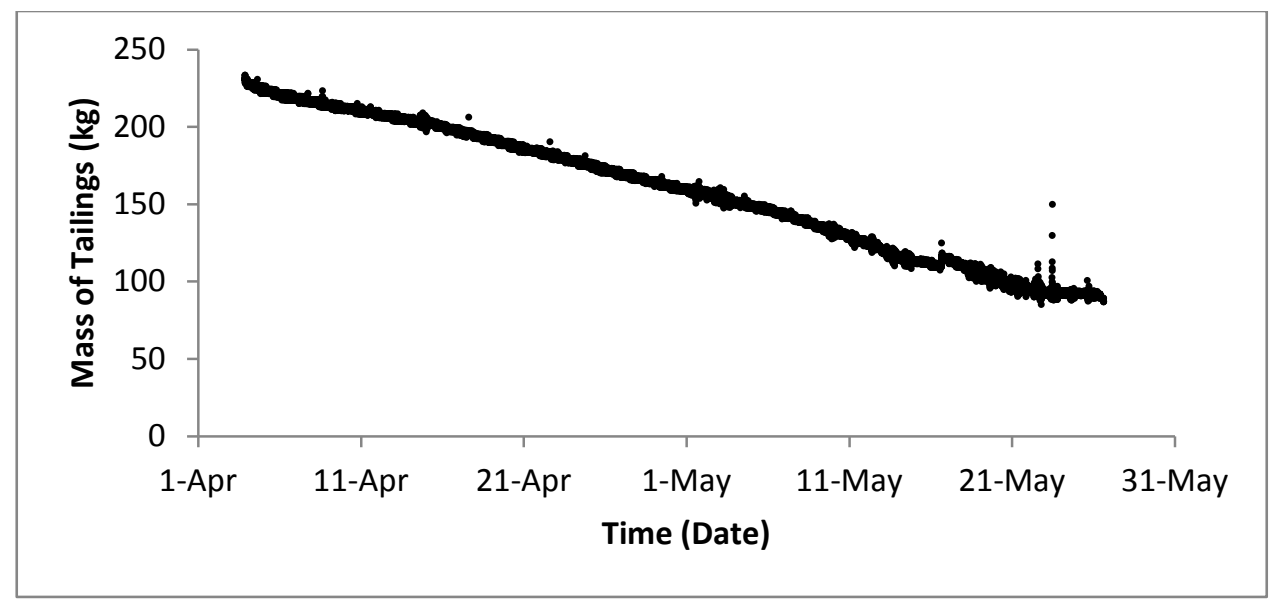

Figure 4.1-1. Total mass of tailings - Layer 1

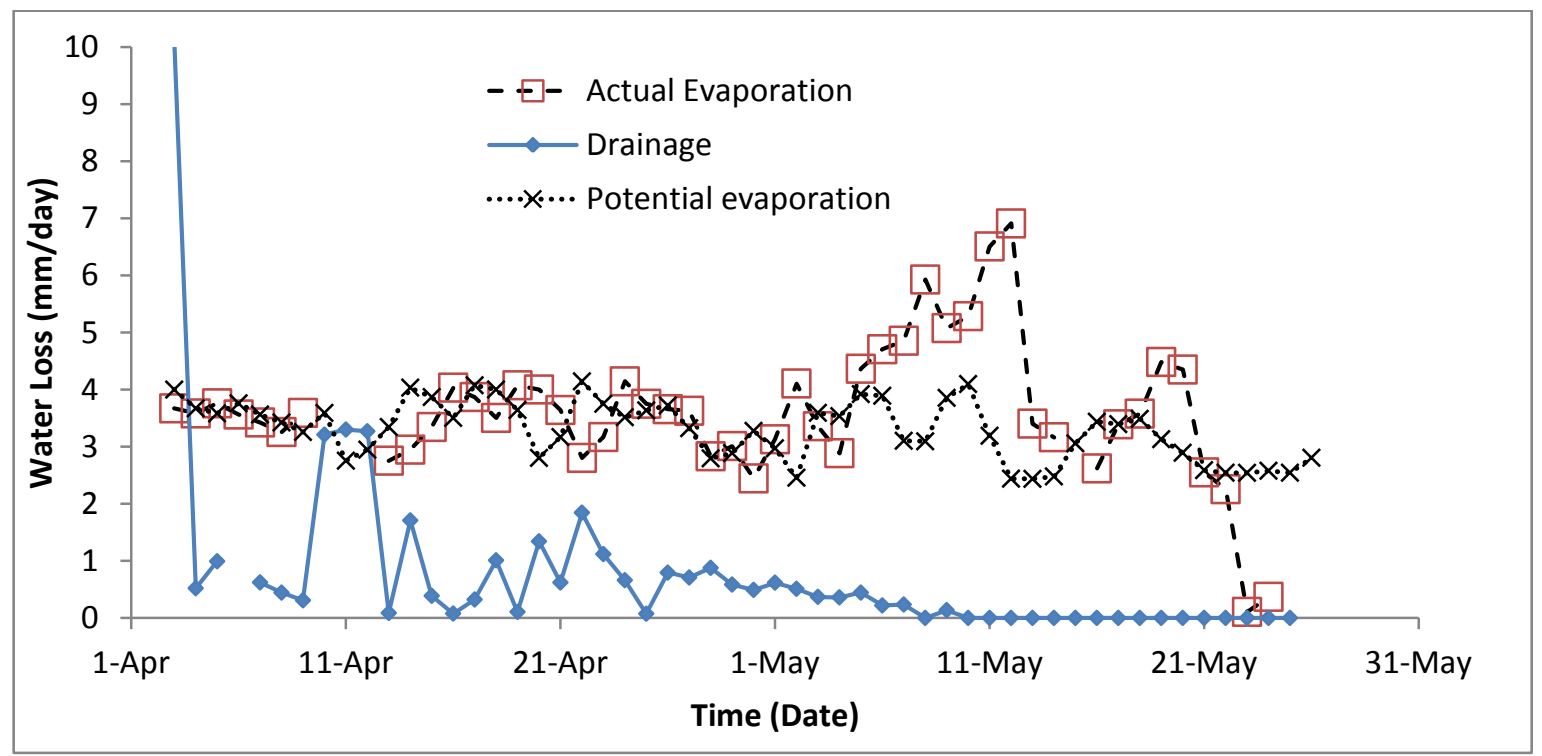

Figure 4.1-2. AE, PE and drainage - Layer 1

The evaporation rate was found to vary from approximately 2 to $7 \mathrm{~mm} /$ day. The measured $\mathrm{RH}$ and temperature values, shown in Figure 4.1-3 were then used in the Penman-Monteith equation to calculate PE upon tailings deposition. 


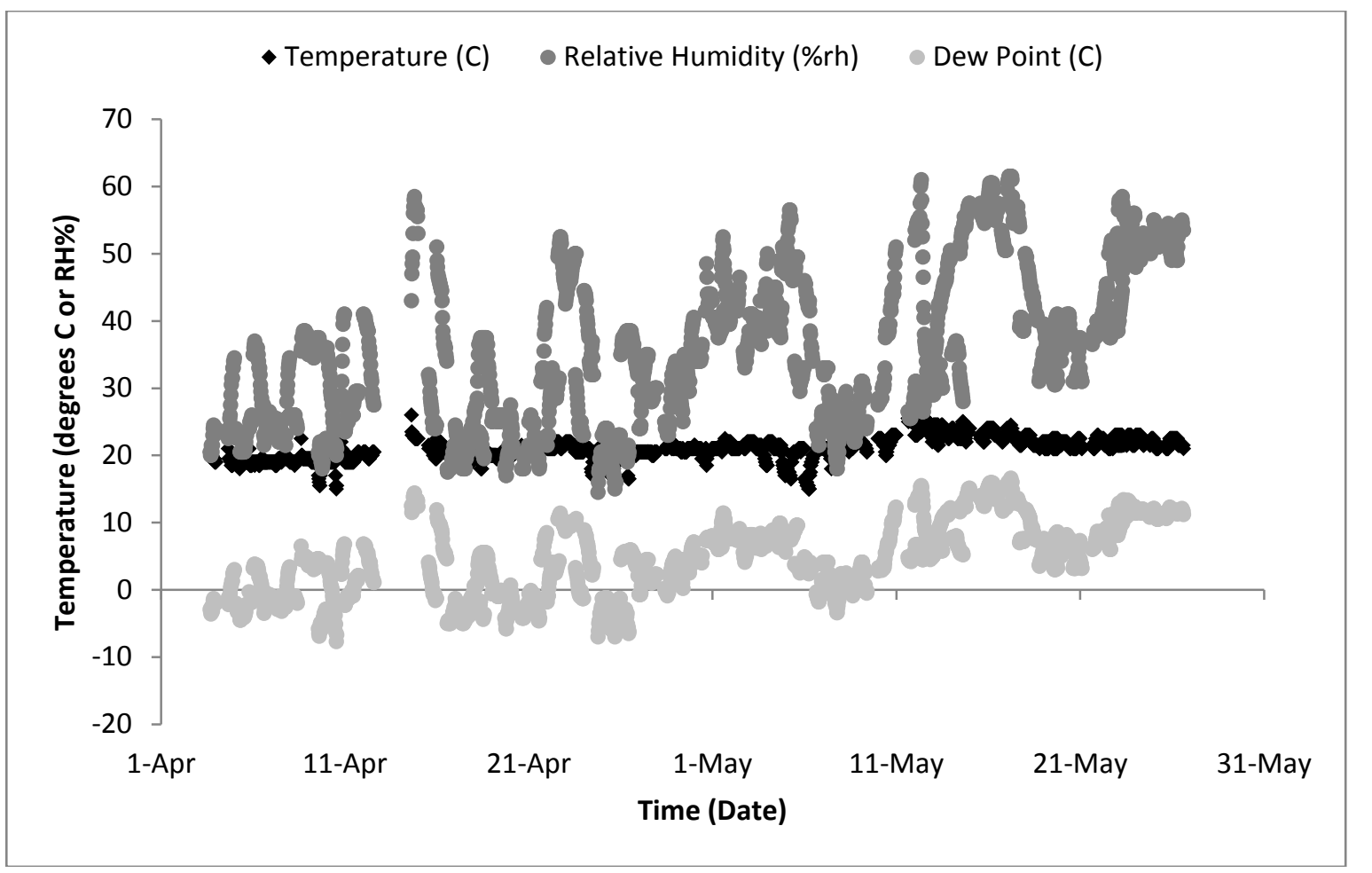

Figure 4.1-3. Temperature, $\mathrm{RH}$ and dewpoint profiles above the tailings - Layer 1

Figure 4.1-4 shows the temperatures recorded by the VWC sensors in the tailings and the temperature recorded by the $\mathrm{RH}$ sensor above the tailings. Generally, temperatures varied from 15-23 degrees Celsius, but were higher at the surface. 


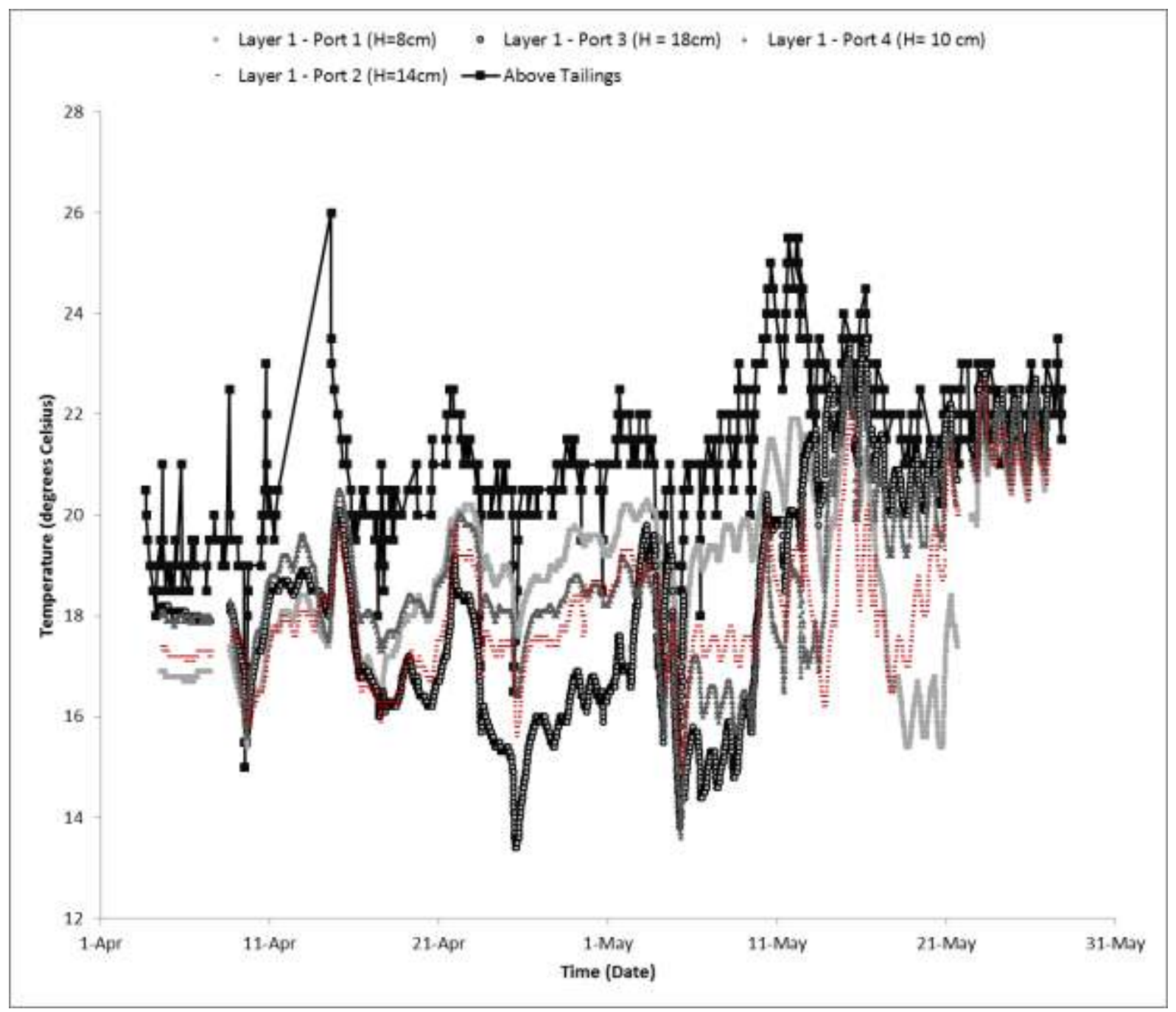

Figure 4.1-4. Temperature at various heights - Layer 1

Temperatures varied from 15-23 degrees Celsius. Based on the conditions shown in Figure 4.1-3, the PE was found to vary from approximately $2.5 \mathrm{~mm}$ to $4.25 \mathrm{~mm}$ per day. In the first layer, the PE closely matches the $A E$ until about April $30^{\text {th }}$, when cracking was first observed. After that date, although the AE should in theory be decreasing with increasing suction values, the $A E$ exceeds the $P E$, and continues to do so until almost the end of drying. This behavior is almost mirroring the progression of cracking in the tailings as shown in Figures 4.1-5 and 4.1-6. 


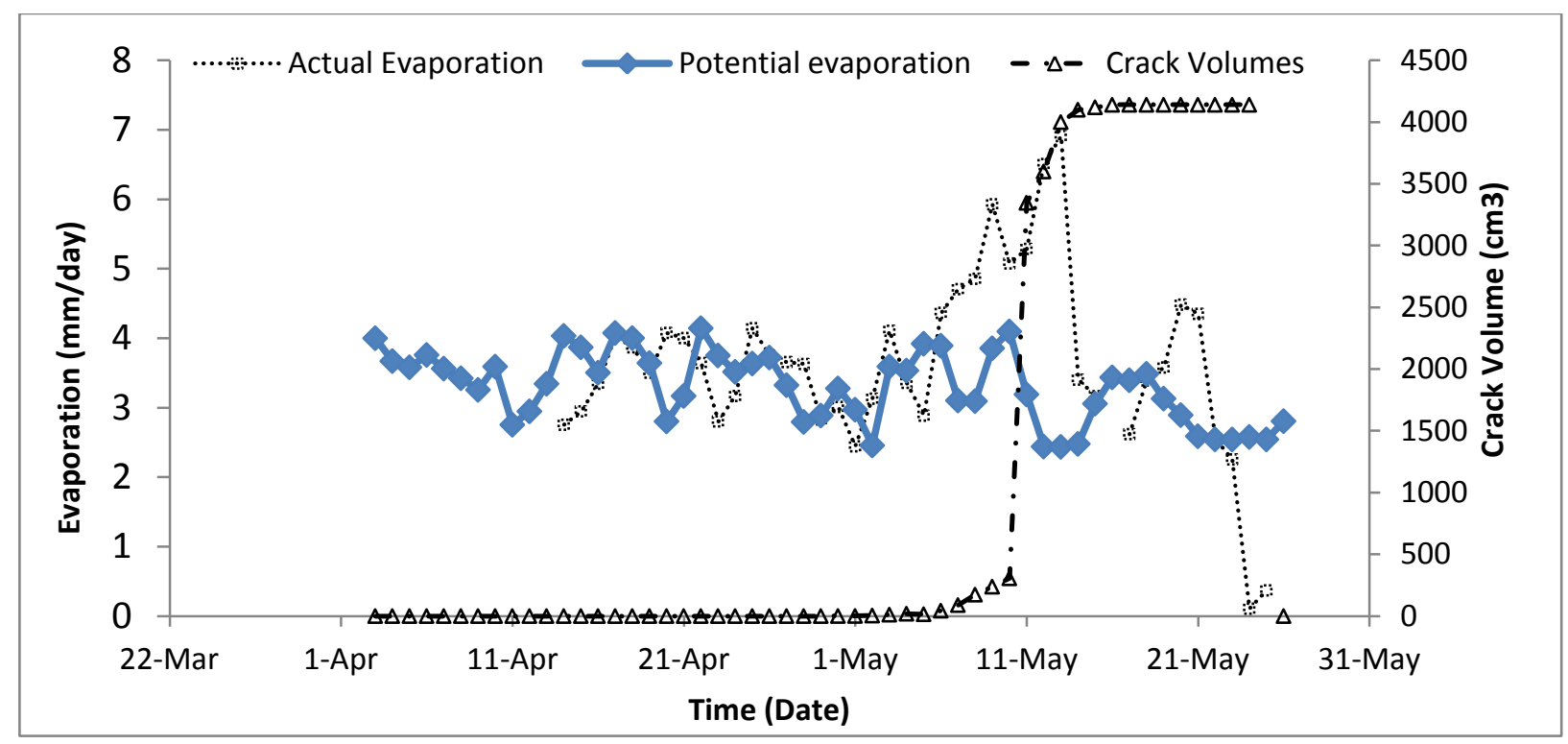

Figure 4.1-5. Evaporation vs. cracking - Layer 1

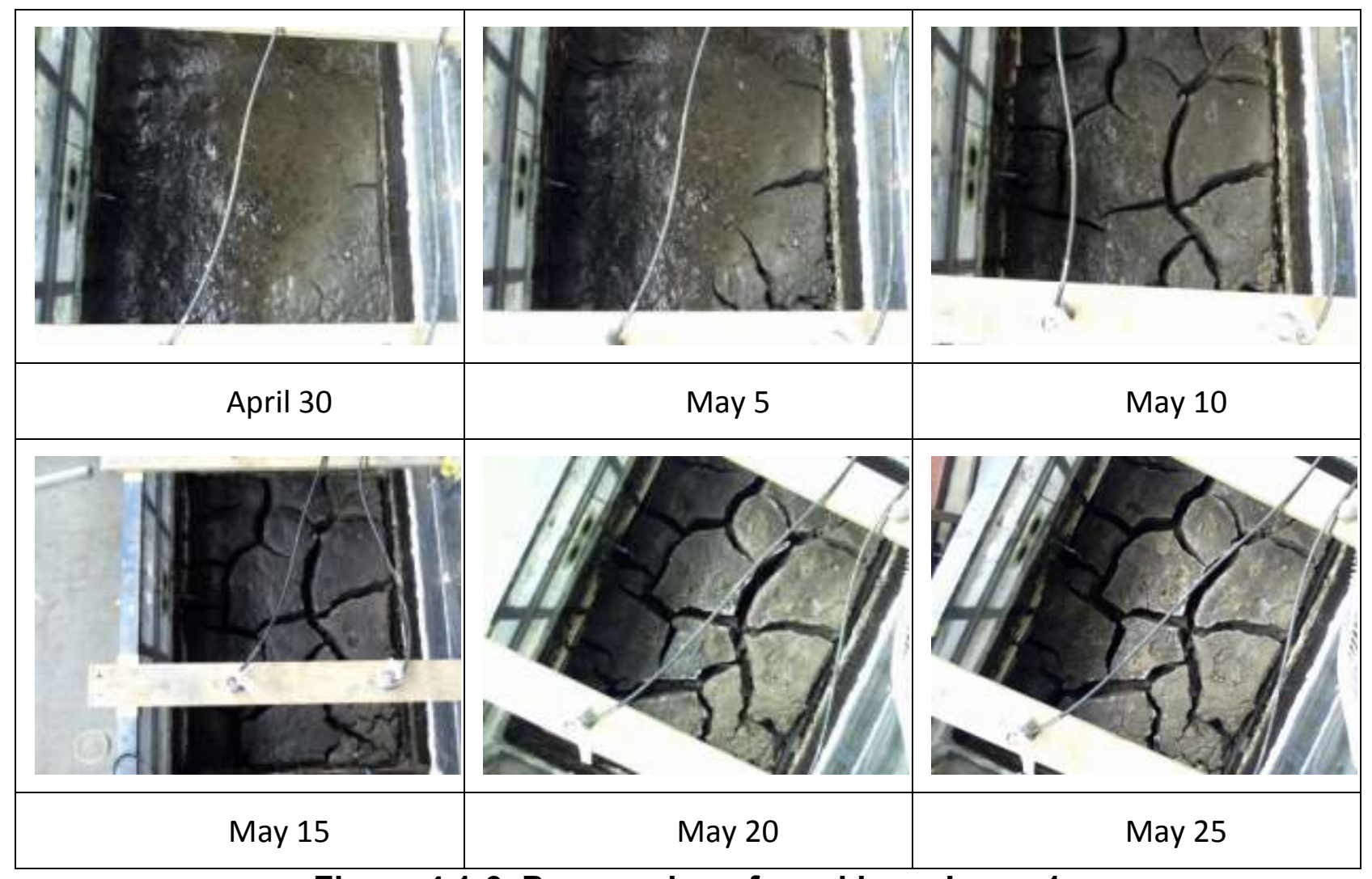

Figure 4.1-6. Progression of cracking - Layer 1 
This trend suggests that the formation of fresh new cracks is exposing wet material to the atmosphere, increasing the surface area of the tailings and therefore the $A E$ rate.

\subsubsection{Settlement}

A few hours after deposition, the tailings separated into two visible layers, the heavier MFT at the bottom and a layer of clear water at the top. The distance between the top of the water and the MFT interface was measured at one point. The MFT settled due to self-weight consolidation, and the water at the top evaporated. Figure 4.1-7 shows the settlement of the MFT and the evaporation of the top water before that point. The increase in height might reflect accumulation of settling solids, but the accuracy of these measurements is somewhat in doubt.

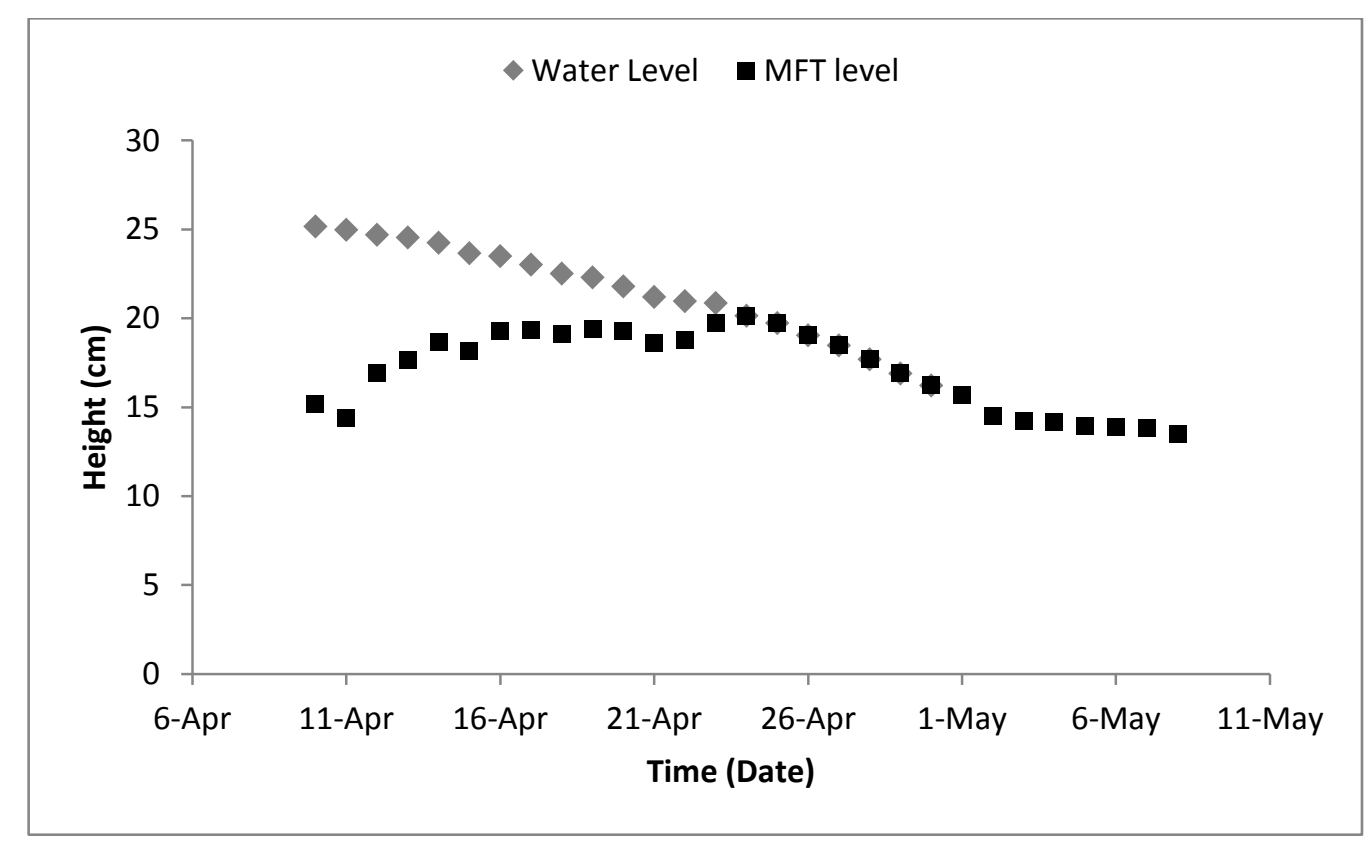

Figure 4.1-7. Water and MFT heights - Layer 1 
Figure 4.1-8 shows the settlement of the tailings. The vertical line represents the height of the tailings if they were deposited instantaneously, but since they were not there is a slight divergence at the beginning.

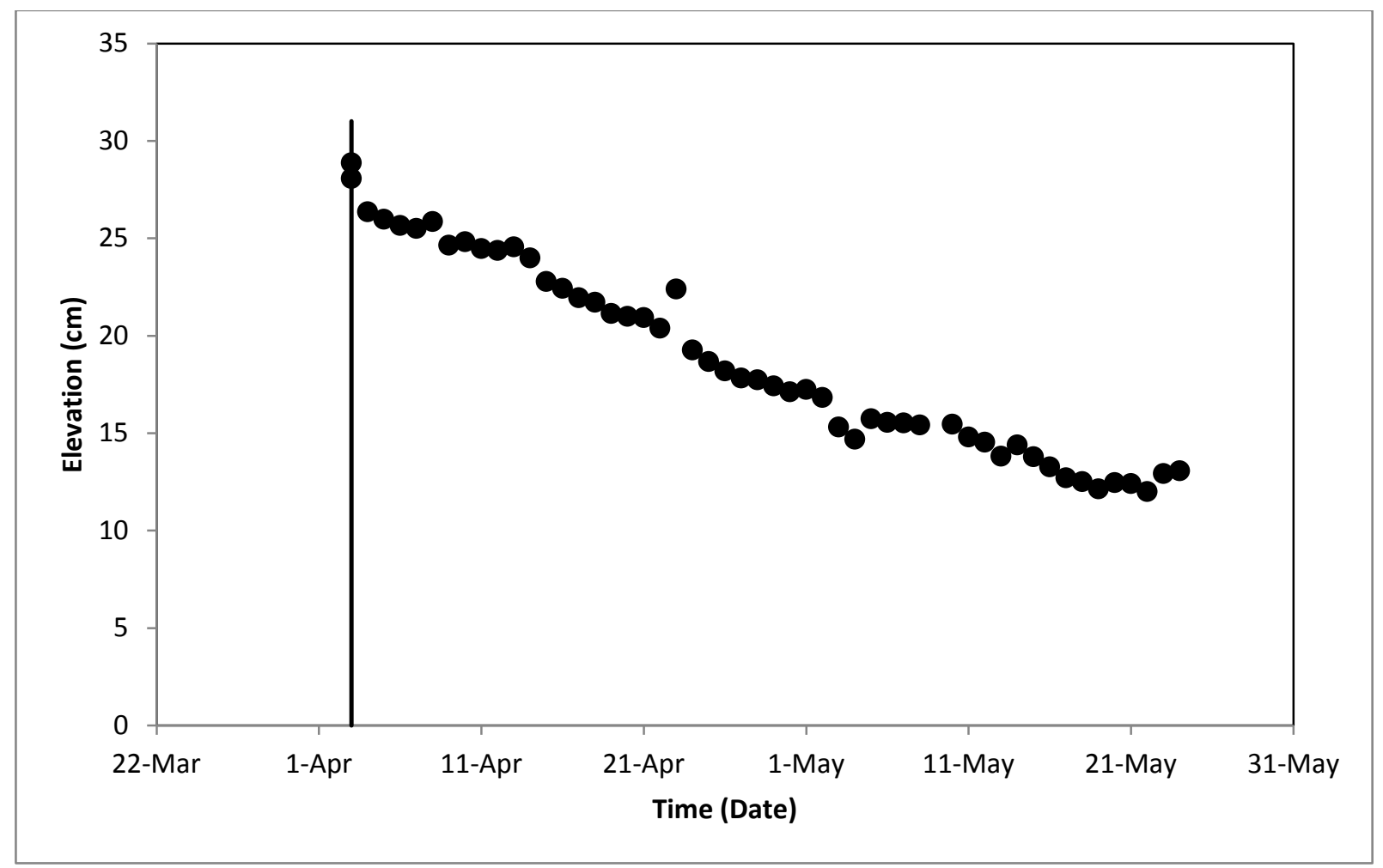

Figure 4.1-8. Settlement of tailings - Layer 1

Based on the settlement and water loss results, the overall void ratio was calculated and plotted in Figure 4.1-9. This figure shows the change in void without considering cracks, and considering the influence of cracks. There is no considerable difference in both sets of data at the beginning, but as cracks began to appear and grow in size, there is a difference of about 0.2 . 


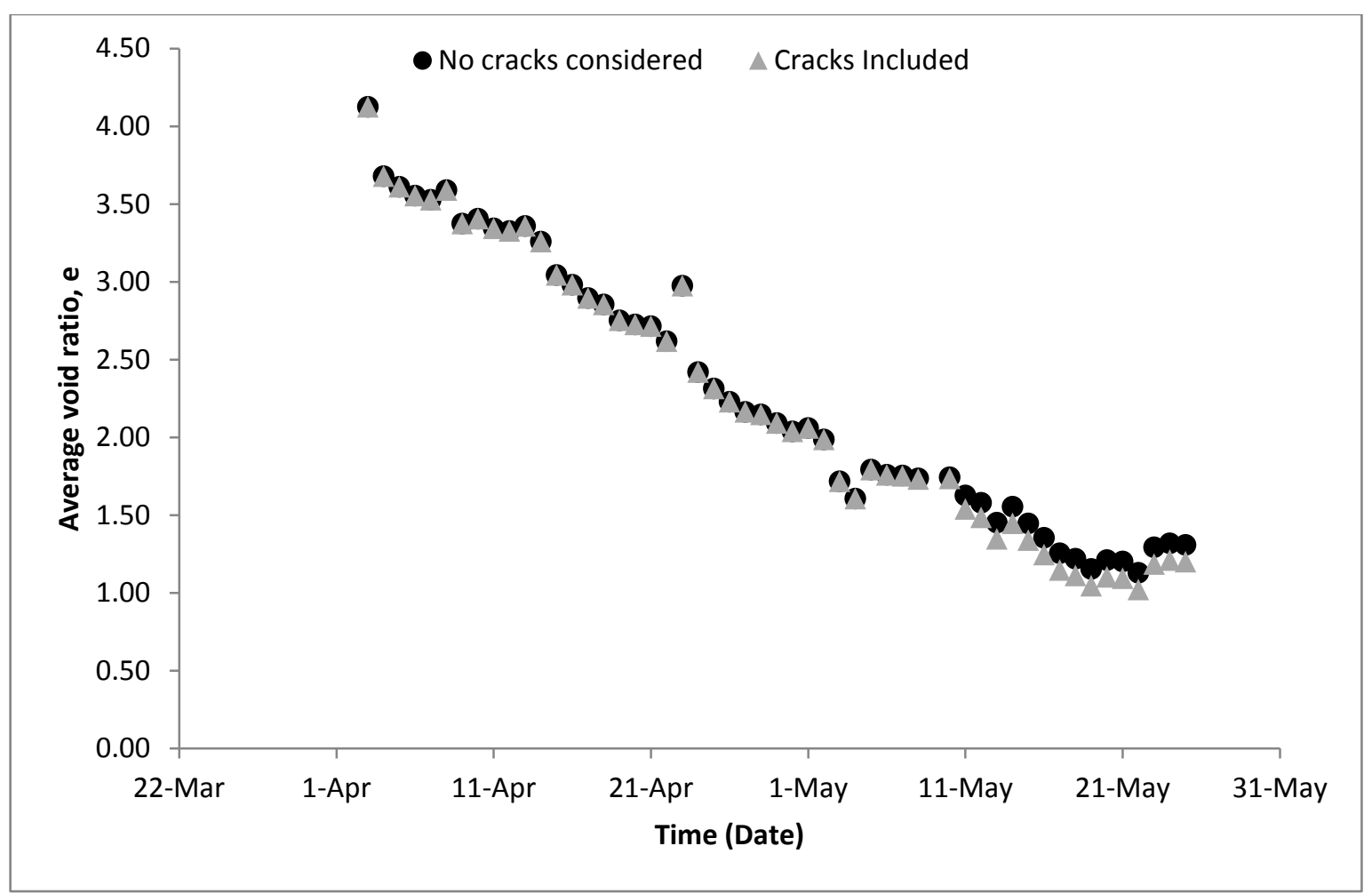

Figure 4.1-9. Average void ratio - Layer 1

\subsubsection{Volume Change}

Volume change was measured by VWC sensors placed at varying heights in each layer in the dry box and processed using calibration curves for each sensor. Uncalibrated VWC data for layer 1 is shown in Figure 4.1-10. On the onset of dewatering, the readings vary with depth. Lower water contents are at the bottom, indicating higher densities, as expected, due to self-weight consolidation. There are drops in the data where top sensors were ratcheted out of the tailings and had to be pushed back in. Once drying sets in, the water contents sensors show lower water contents at higher elevation. 


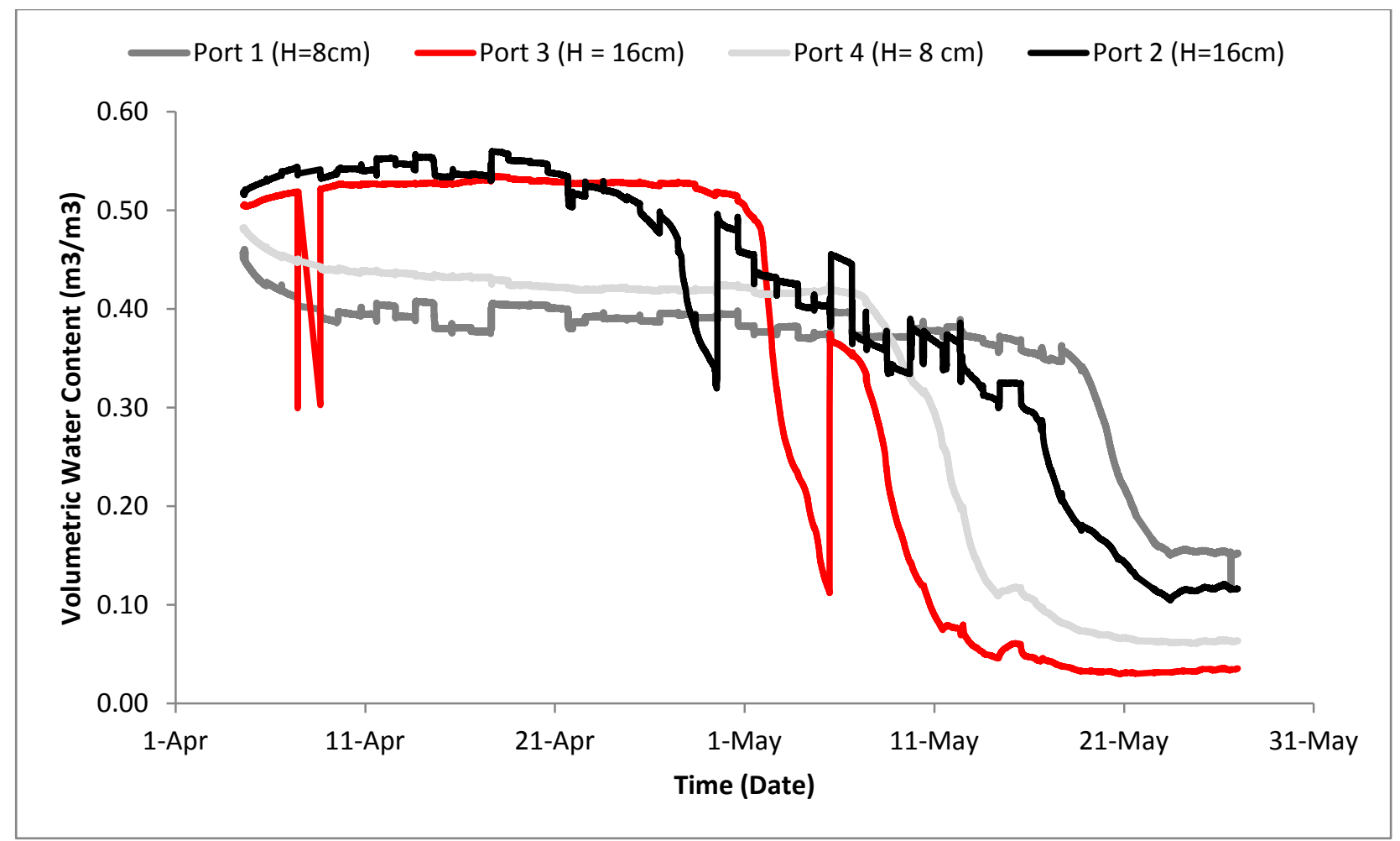

Figure 4.1-10. Volumetric water content at various heights- Layer 1

\subsubsection{Water Content}

The overall GWC (Figure 4.1-11) was calculated based on weight measurements obtained with the load cells and the water loss through evaporation and drainage. Surface measurements within the top centimeter were also taken after the supernatant water that had collected at the top of the tailings had evaporated. The overall GWC takes the supernatant water into account. There is a steady decrease in overall GWC from $180 \%$ to $12 \%$ while the surface GWC decreases from $59 \%$ to $9 \%$. 


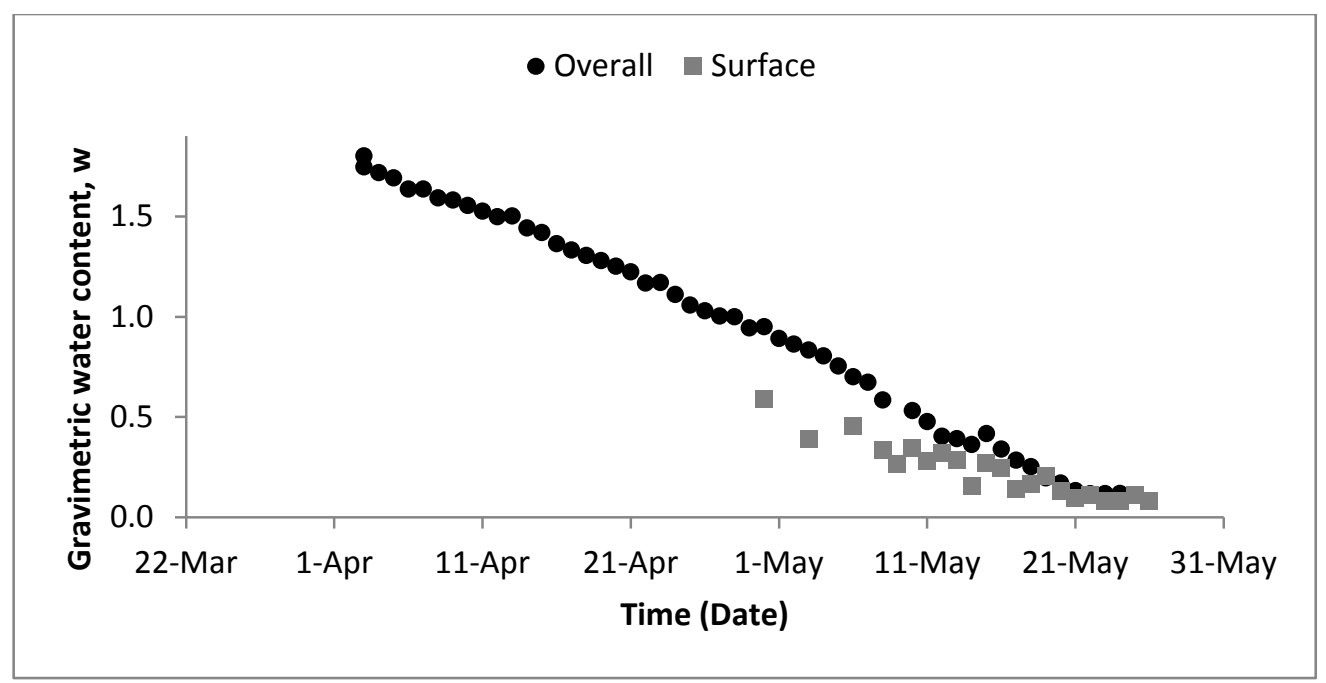

Figure 4.1-11. Gravimetric water contents - Layer 1

Surface samples were also taken at various locations once cracks began to form. They were taken from the surface (between cracks), at the edge of cracks (CE) and inside the cracks. The insides of crack measurements were stopped as soon as the tailings became so dry that extraction of samples would significantly damage the integrity of the crack formations. GWCs are shown in Figure 4.1-12 for these samples.

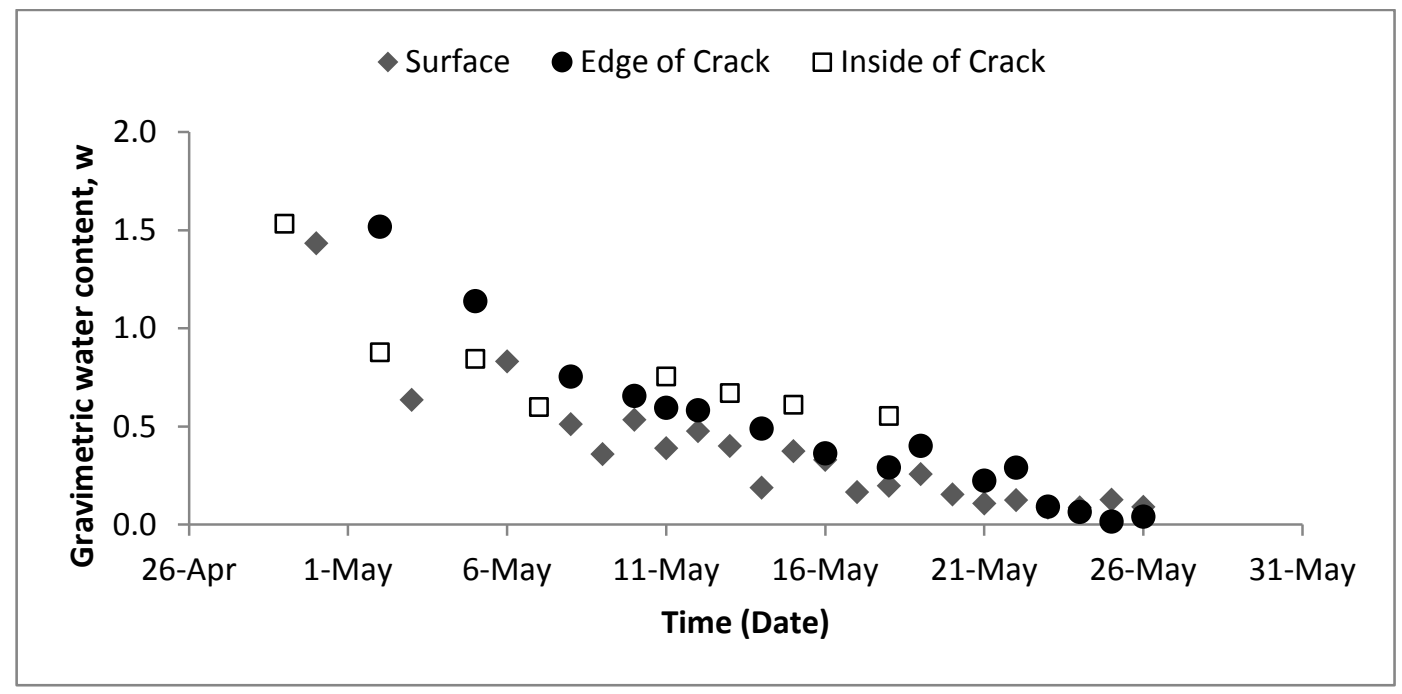

Figure 4.1-12. Surface sample gravimetric water contents - Layer 1 
Generally, the GWC inside the cracks was highest, followed by the surface, and the CEs had the lowest GWC, and were found to be the driest.

SCs were calculated using three different methods. The overall SC was based on the load cell measurements and water loss. The SC of the top layer was based on the readings obtained by the VWC sensors. The surface SC was obtained by measuring SC from samples extracted from the top $1 \mathrm{~cm}$ of the top layer. Results are presented in Figure 4.1-13.

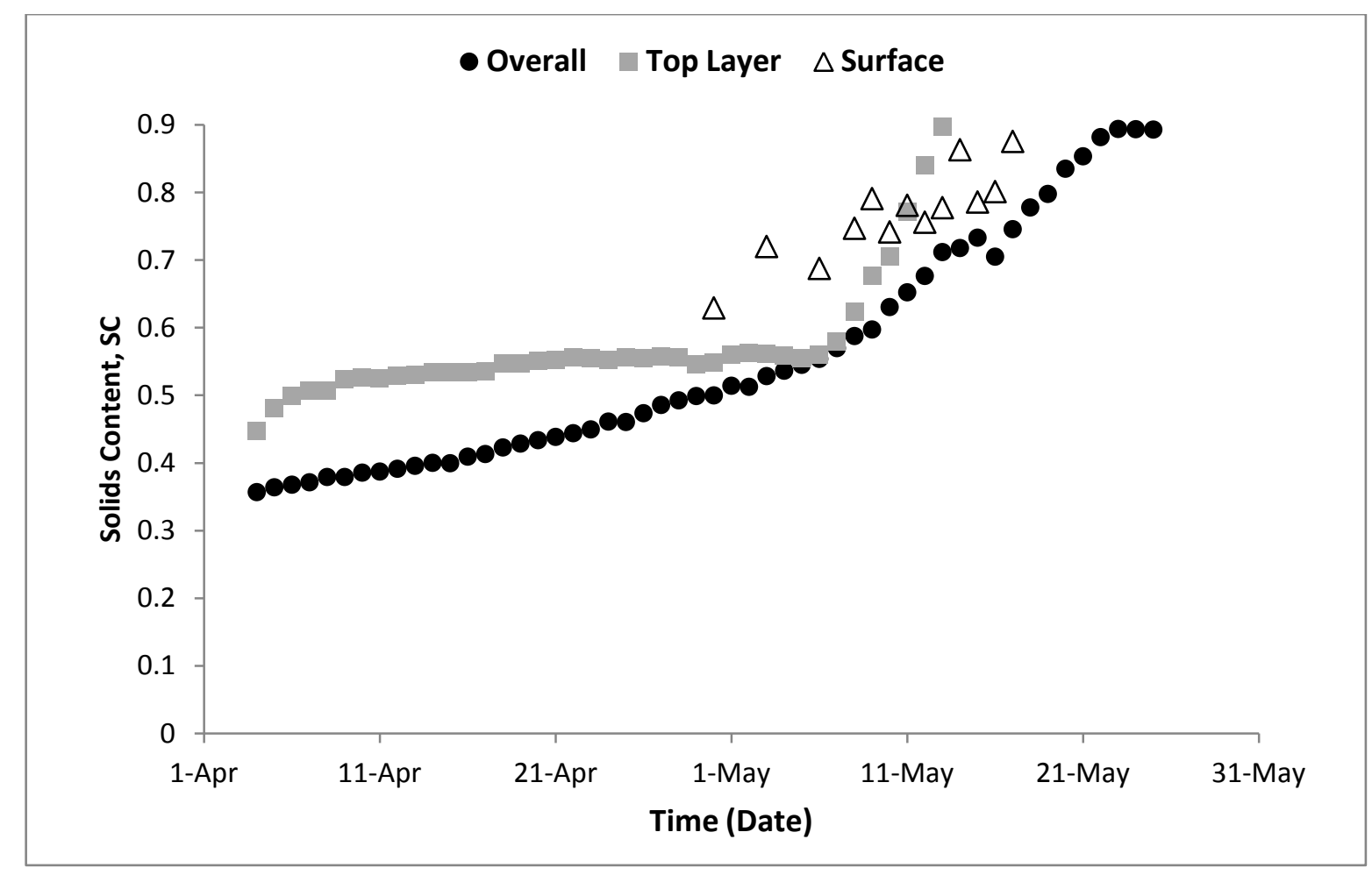

Figure 4.1-13. Solids contents - Layer 1

Figure 4.1-14 provides a breakdown of the SC at the surface, CE and IC surface samples. Here, the SC mirrors the behavior of the surface GWC (Figure 4.1-12). 


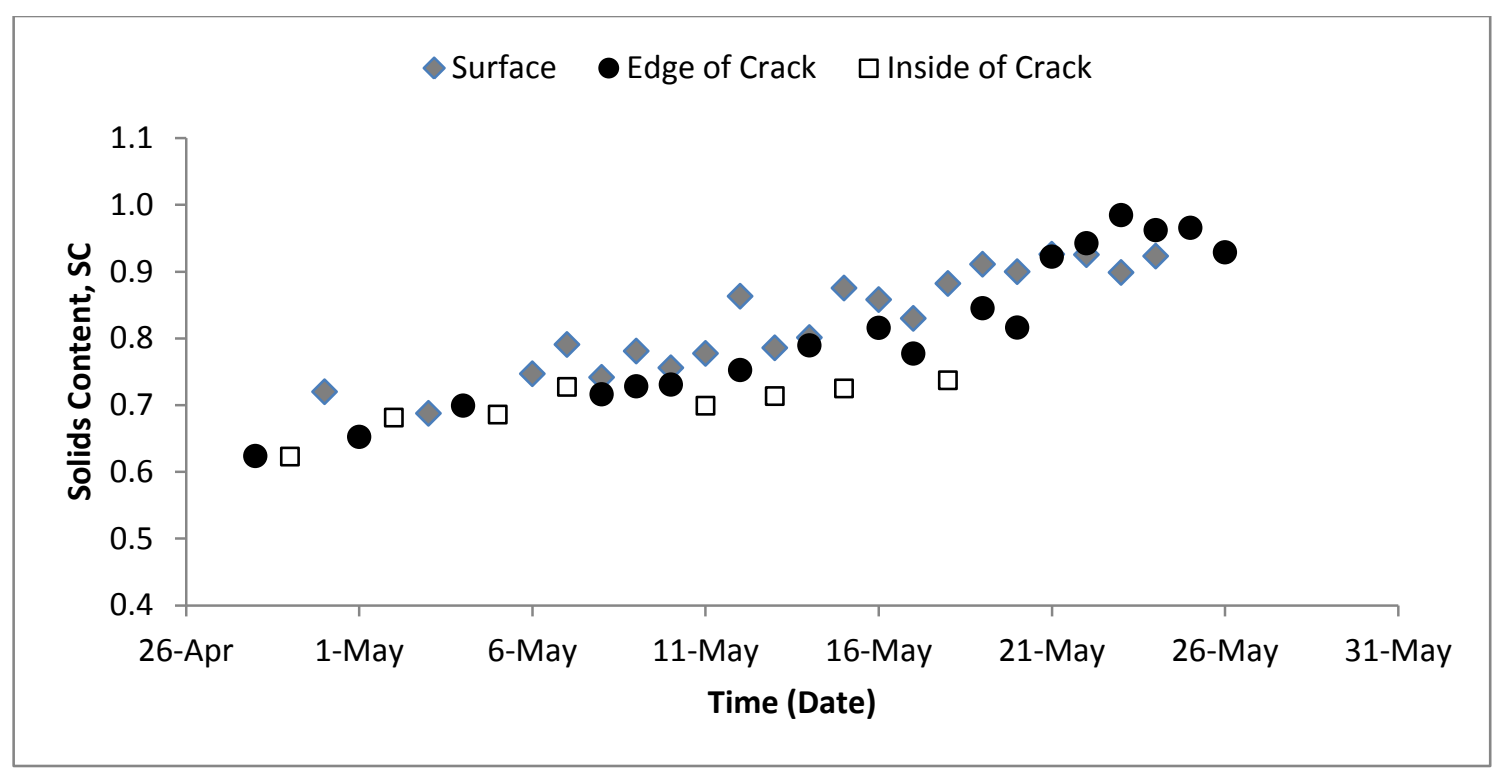

Figure 4.1-14. Surface sample solids contents - Layer 1

Figure 4.1-15 shows the variation in overall degree of saturation in Layer 1 throughout the test.

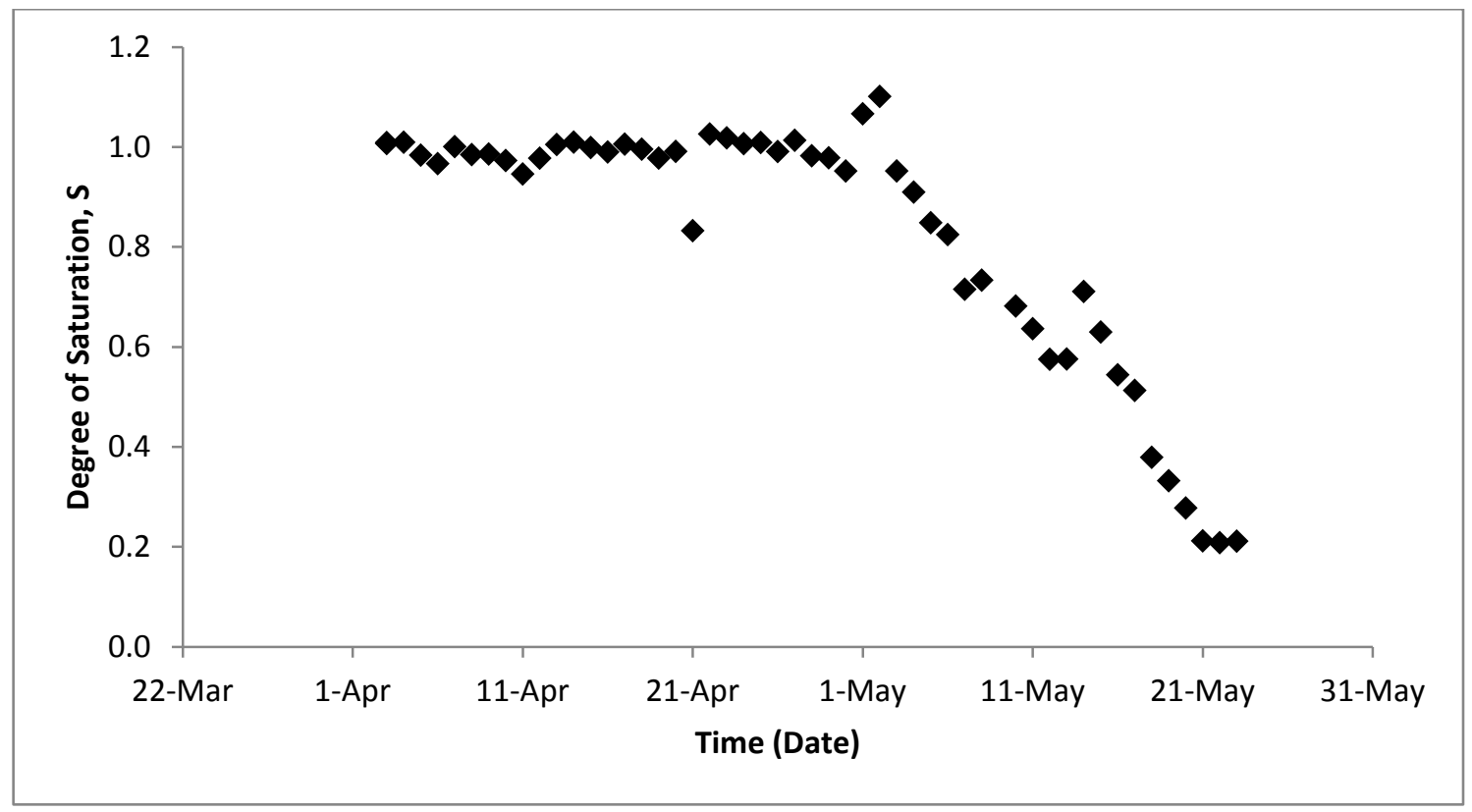

Figure 4.1-15. Overall degree of saturation - Layer 1 


\subsubsection{Suction}

This section provides results for measurements for matric, osmotic, and total suctions in various locations for Layer 1.

\subsection{Matric Suction}

Matric suction was measured with tensiometers placed at varying heights in each layer. The results obtained for layer 1 are shown in Figure 4.1-16. The top tensiometer reached suctions of $10 \mathrm{hPa}$ and cavitated once it was exposed to air. Many of the cracks formed at the edges of the box, where the tensiometers were inserted, and this was a case where the tensiometer was in the middle of the newly formed crack and the tip became exposed to air. The other two tensiometers cavitated later on, but they did not reach very high values of matric suction.

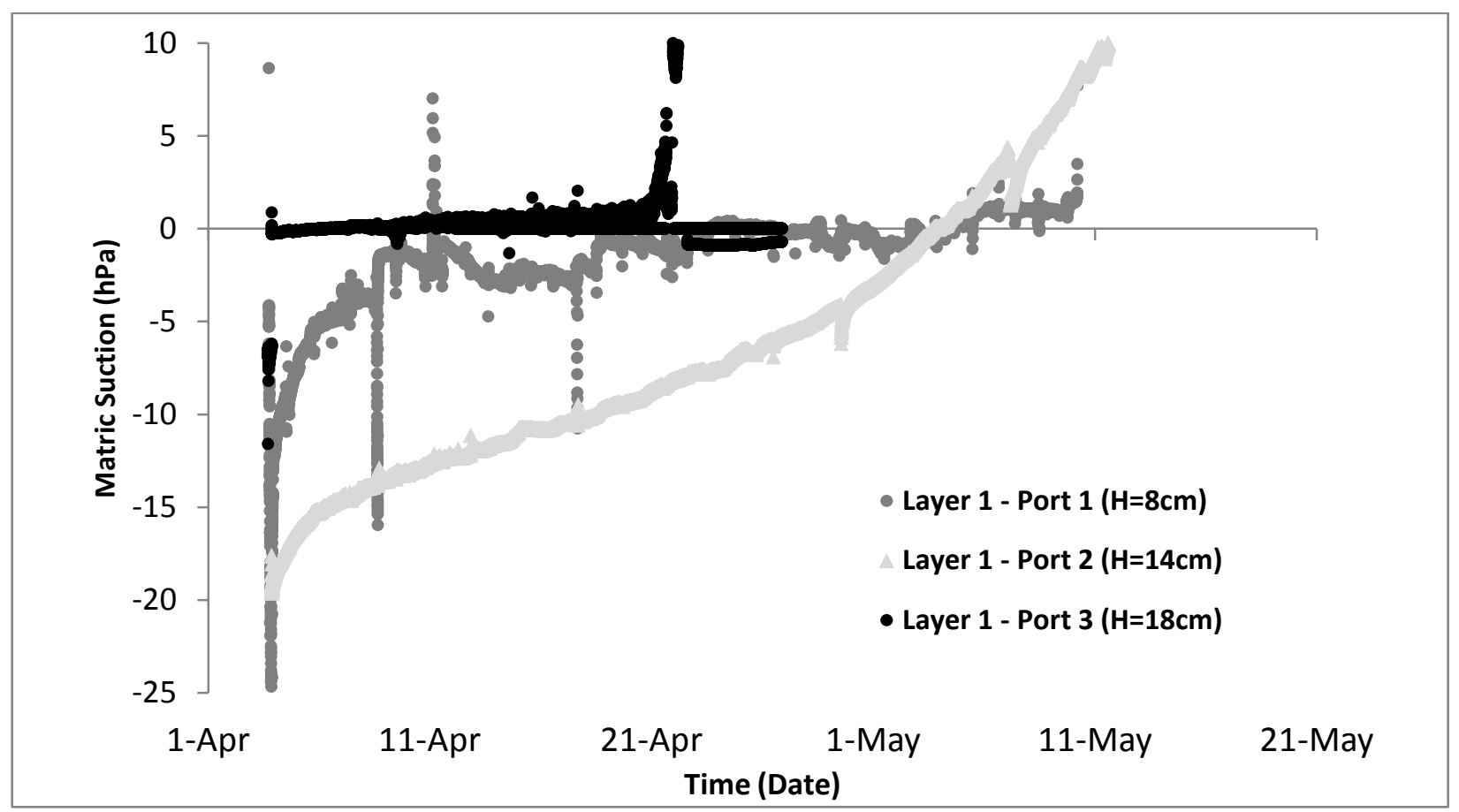

Figure 4.1-16. Matric suction at various heights - Layer 1 


\subsection{Osmotic Suction}

Daily EC measurements at the surface are shown in Figure 4.1-17. These values begin increasing significantly around May $16^{\text {th }}$.

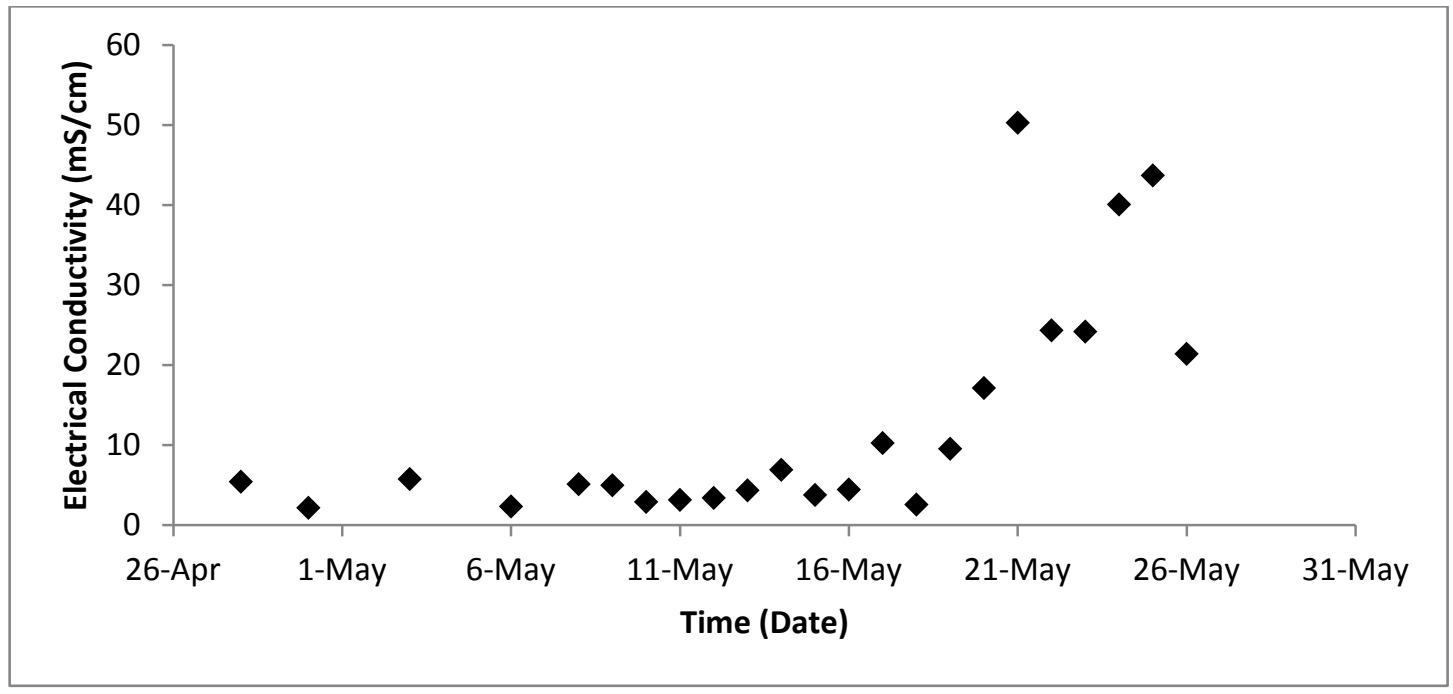

Figure 4.1-17. Surface sample electrical conductivity - Layer 1

A comparison of osmotic suction to total suction is shown in Figure 4.1-18. The total suction is always greater than the osmotic component. The osmotic suction forms a greater part of the suction at the beginning, up to around May $21^{\text {st }}$, when the osmotic suction becomes much smaller than the total suction. 


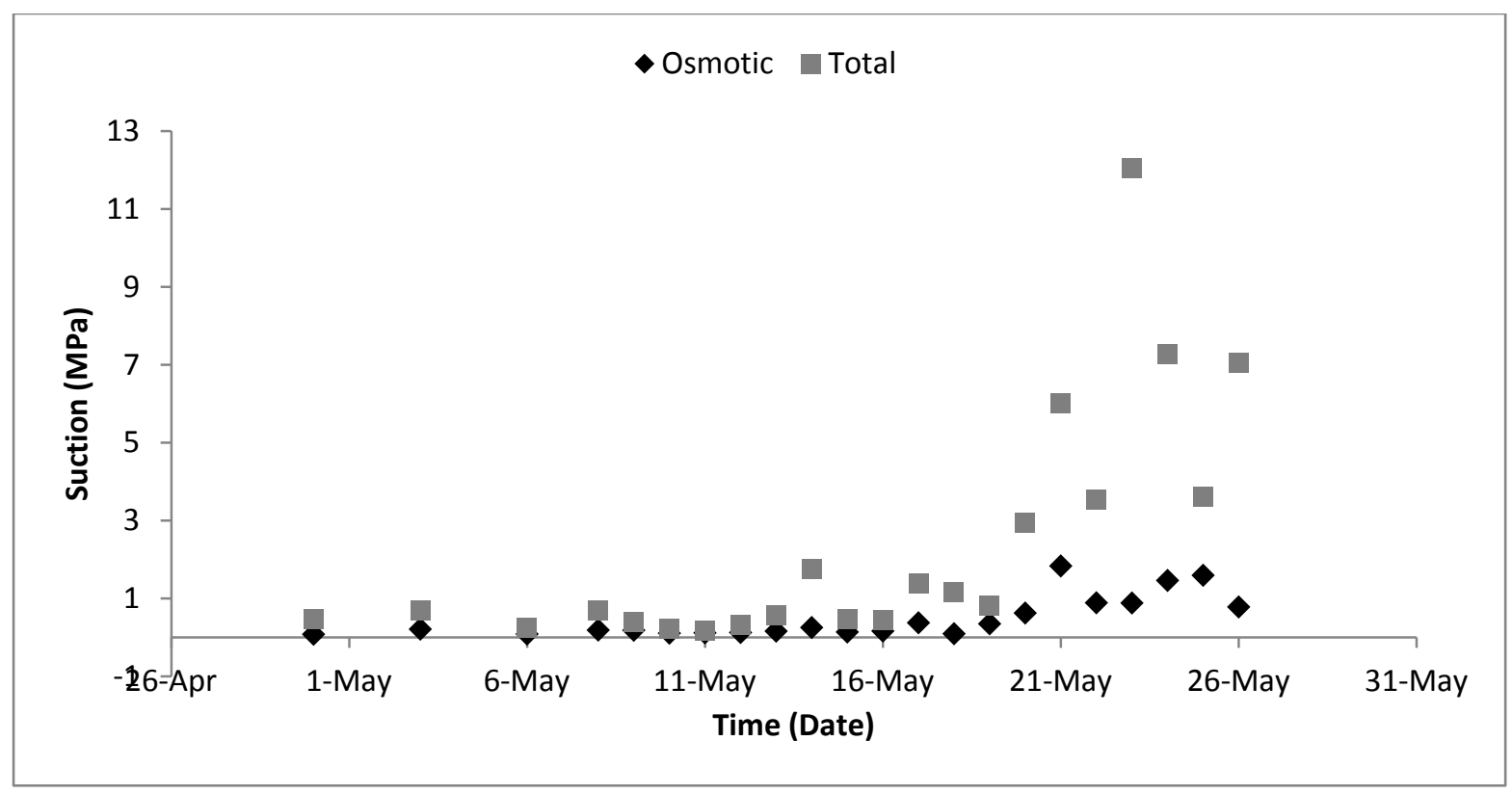

Figure 4.1-18. Surface sample total and osmotic suction - Layer 1

\subsection{Total Suction}

Samples extracted from the top $1 \mathrm{~cm}$ of the surface of the tailings, CEs and the ICs were measured for total suction using a WP4-C potentiometer. These results are shown in Figure 4.1-19.

Overall, suction values at the surface increased as water escaped the tailings. Initially, suction values along the CEs were wetter than those at the surface, but as the tailings dried out and the crack volumes remained constant, the edges also dried out, and in some instances surpassed the values at the surface. The values inside the cracks were always lowest, but measurements were stopped once the tailings got so dry that sample extraction could damage the crack integrity. 


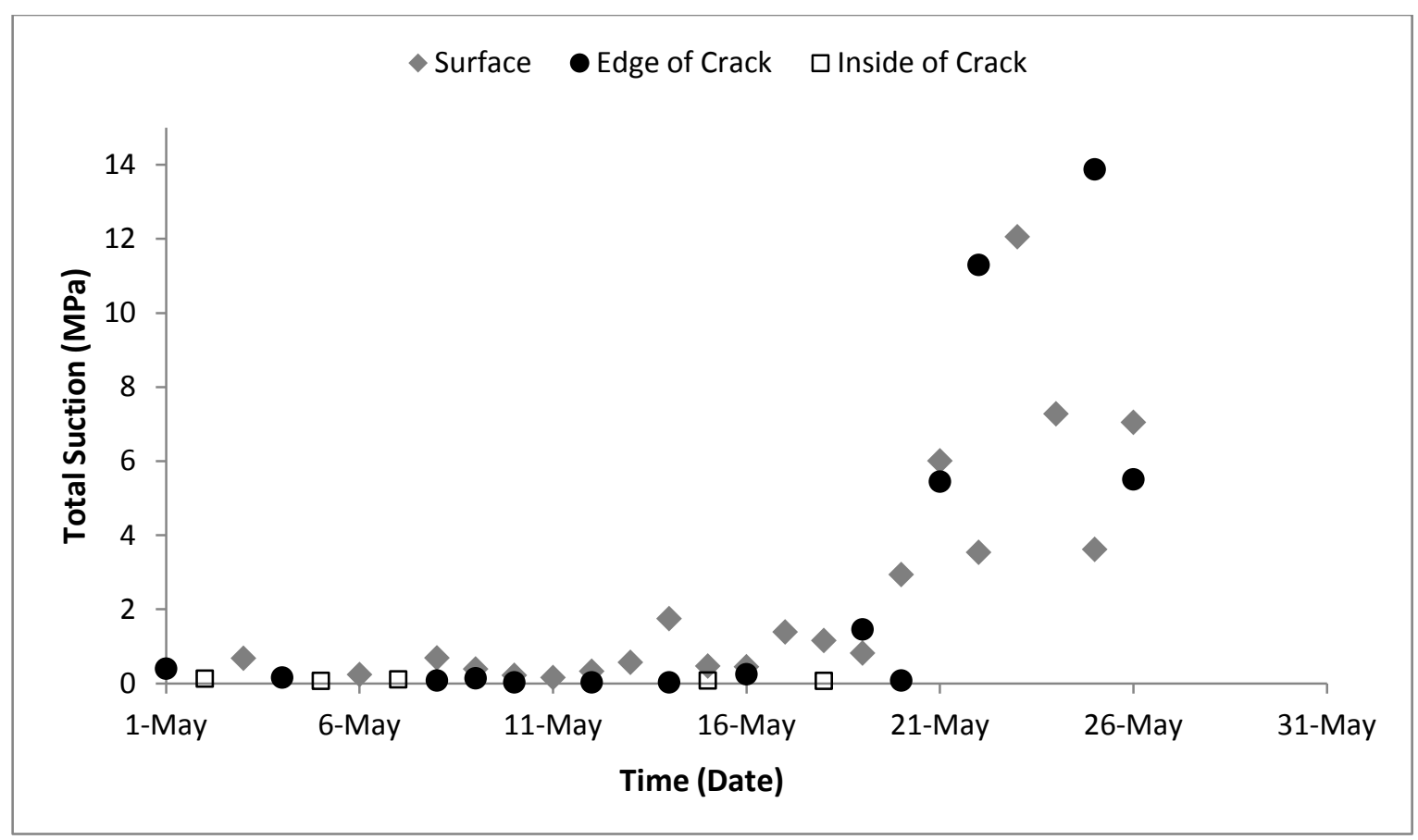

Figure 4.1-19. Surface sample total suction - Layer 1

\subsubsection{Core Samples}

Two core samples were extracted once the layer had reached $90 \%$ SC on May $27^{\text {th }}$. The locations for both core samples are shown in Figure 4.1-20. Core $\# 1$ is on the right, while Core \#2 is on the left. 


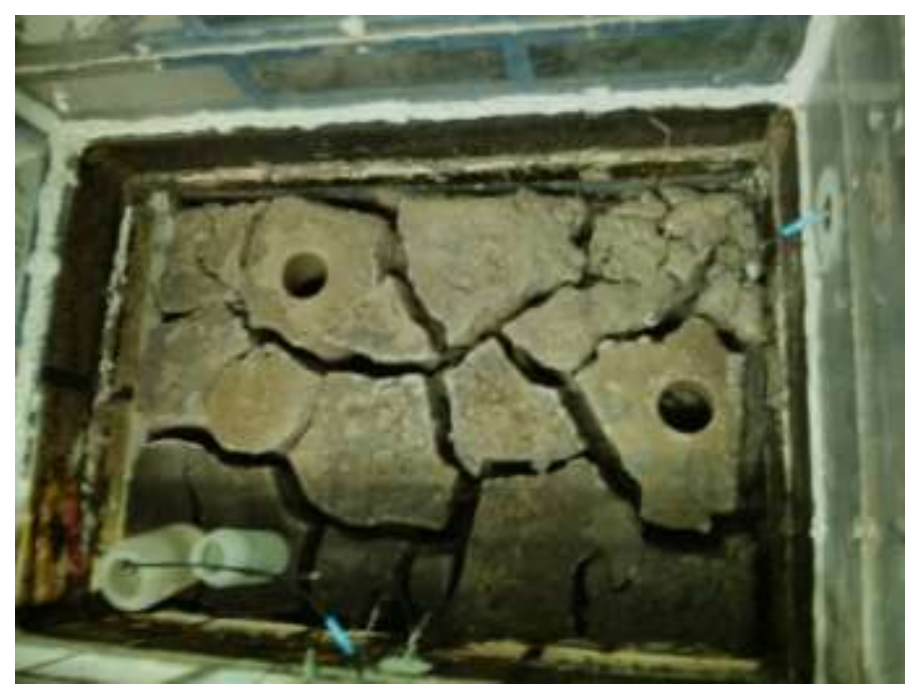

Figure 4.1-20. Core sample locations - Layer 1

Both cores were analyzed for GWC, SC, osmotic suction, total suction and TOC every $1 \mathrm{~cm}$.

\subsubsection{Core Sample \#1}

The first extracted core sample is shown in the following figures, along with the extracted depth.
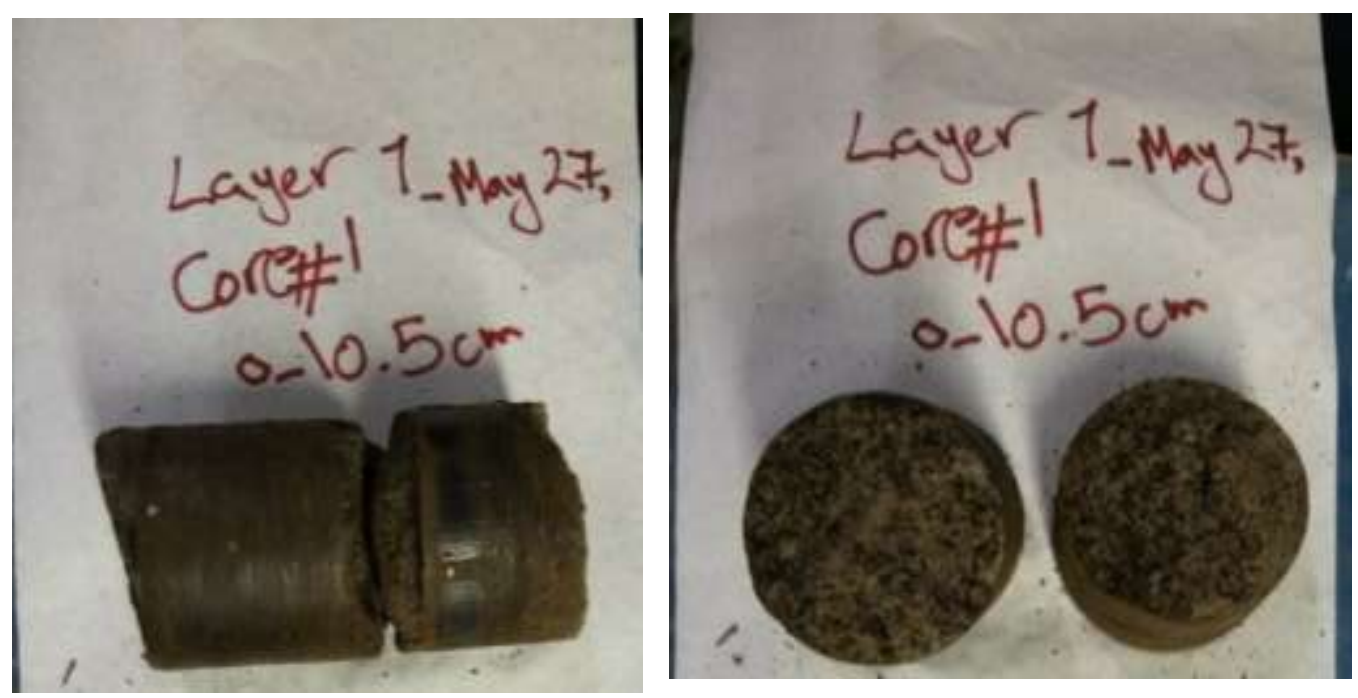

Figure 4.1-21. Core \#1 samples - Layer 1 
The following figures are related to water content with depth, as well as the TOC.
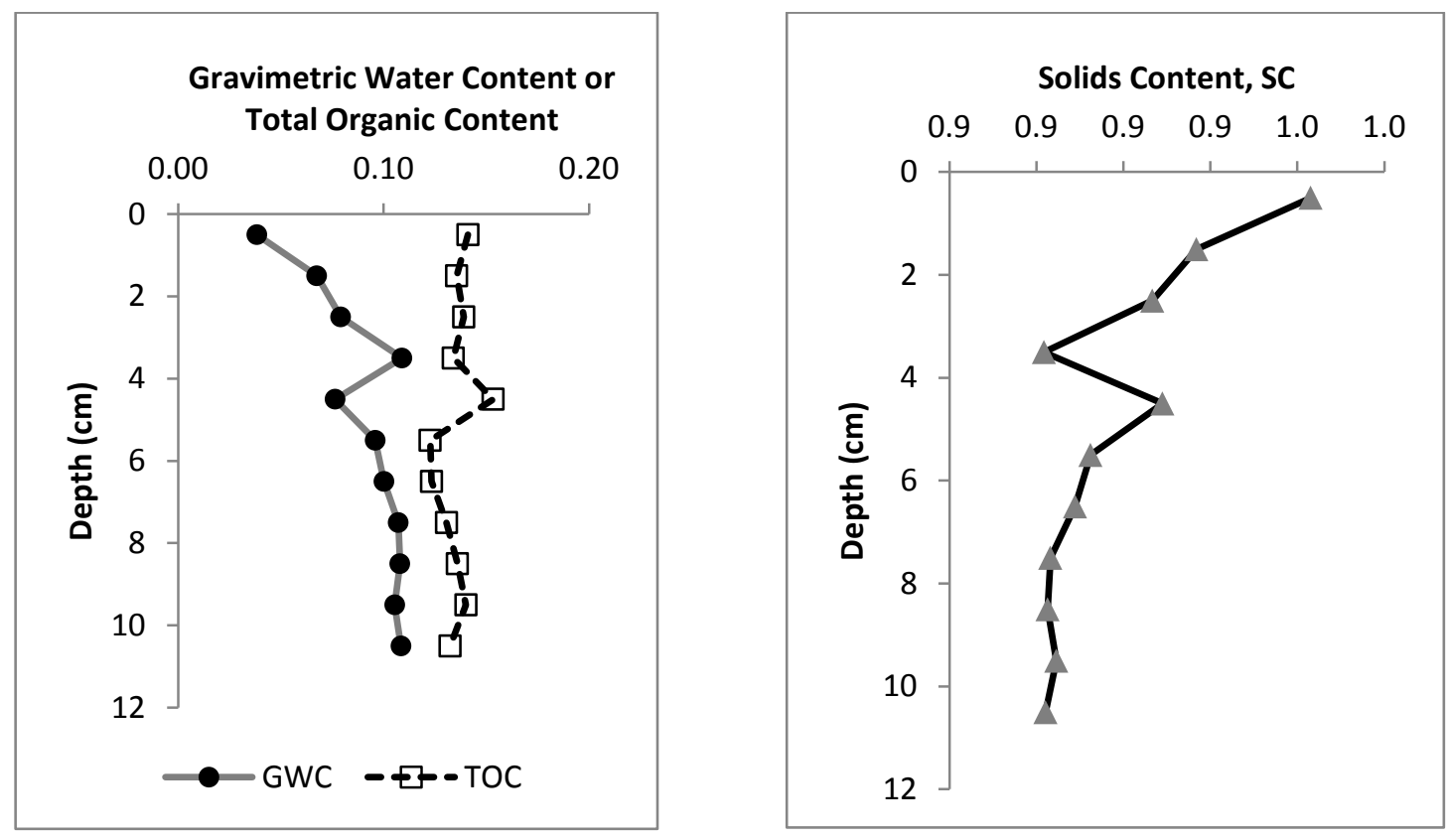

Figure 4.1-22. Core \#1 GWC, TOC and SC profiles - Layer 1

The following figures are related to osmotic and total suction with depth. The osmotic component is significantly smaller than the total suction.
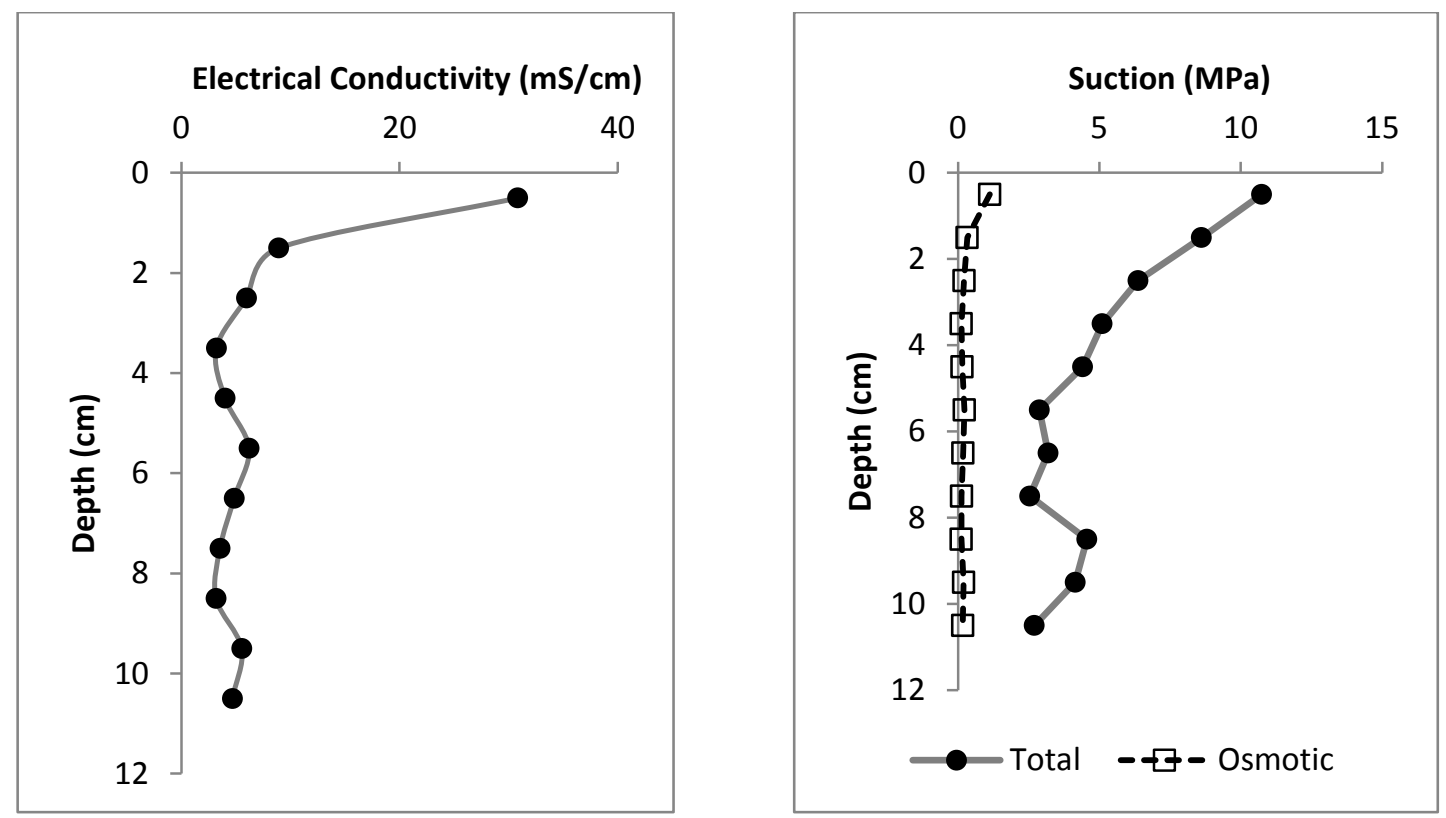

Figure 4.1-23. Core \#1 EC, and osmotic and total suction profiles - Layer 1 


\subsubsection{Core Sample \#2}

The second extracted core sample is shown in the following figures, along with the extracted depth.
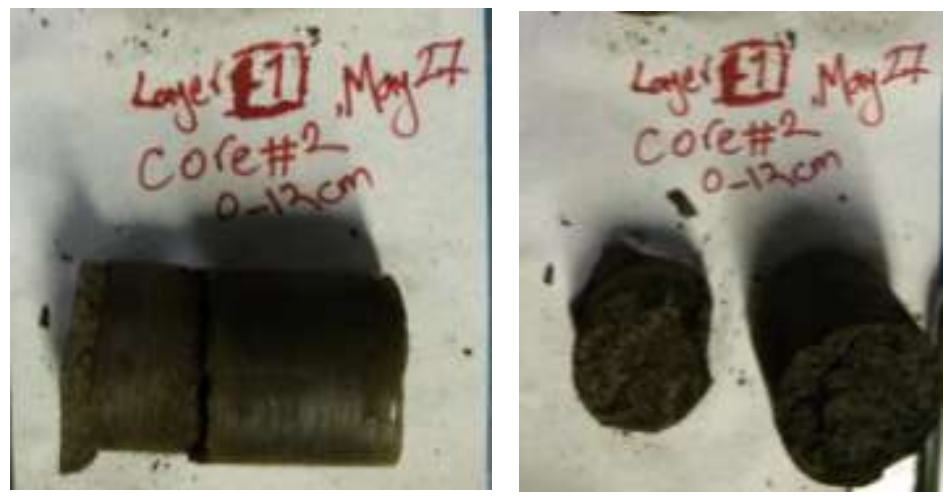

Figure 4.1-24. Core \#2 sample - Layer 1

. The following figures are related to water content, and SC with depth, as well as the TOC.
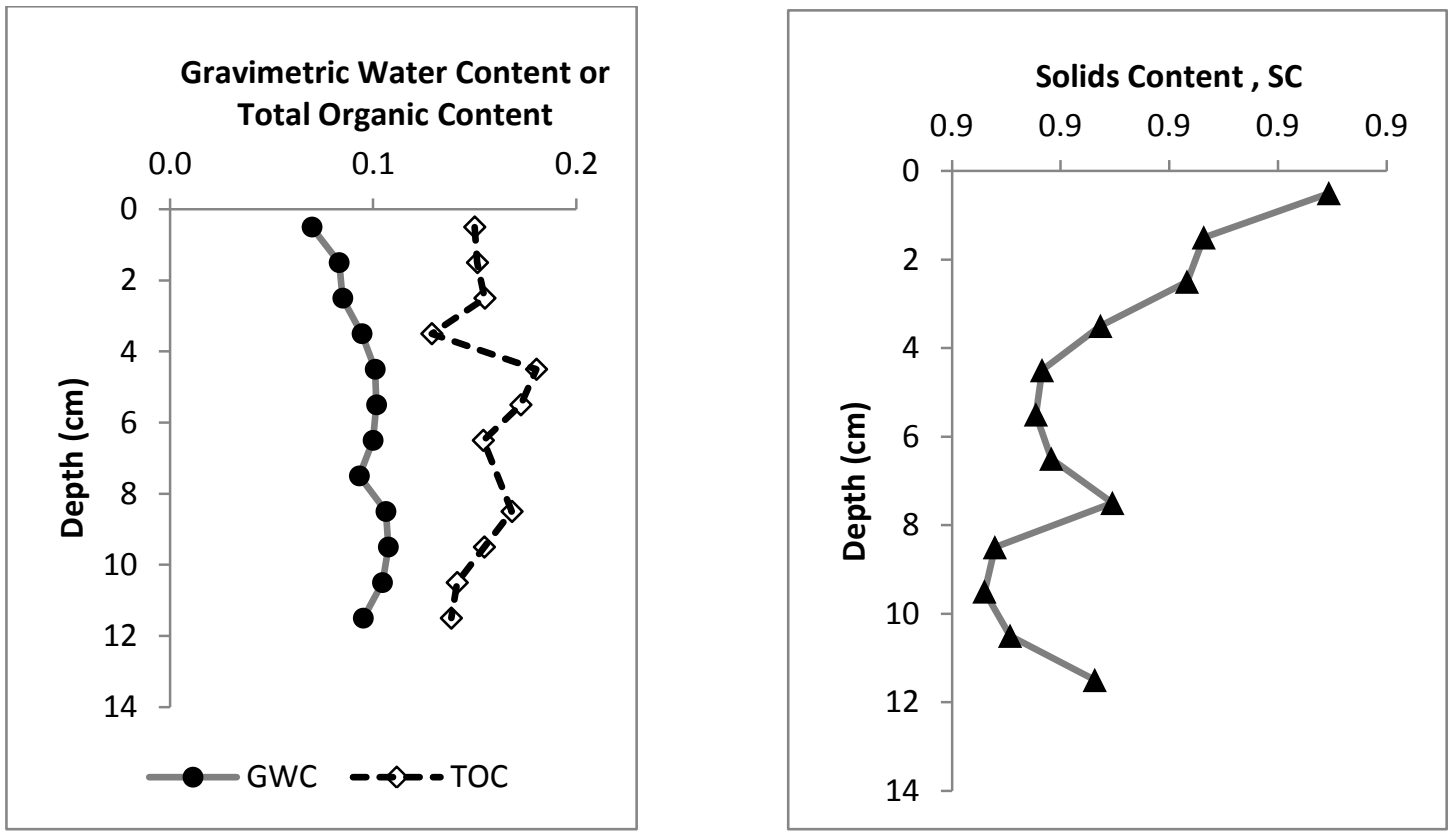

Figure 4.1-25. Core \#2 GWC, TOC and SC profiles - Layer 1 
The following figures are related to osmotic and total suction with depth.
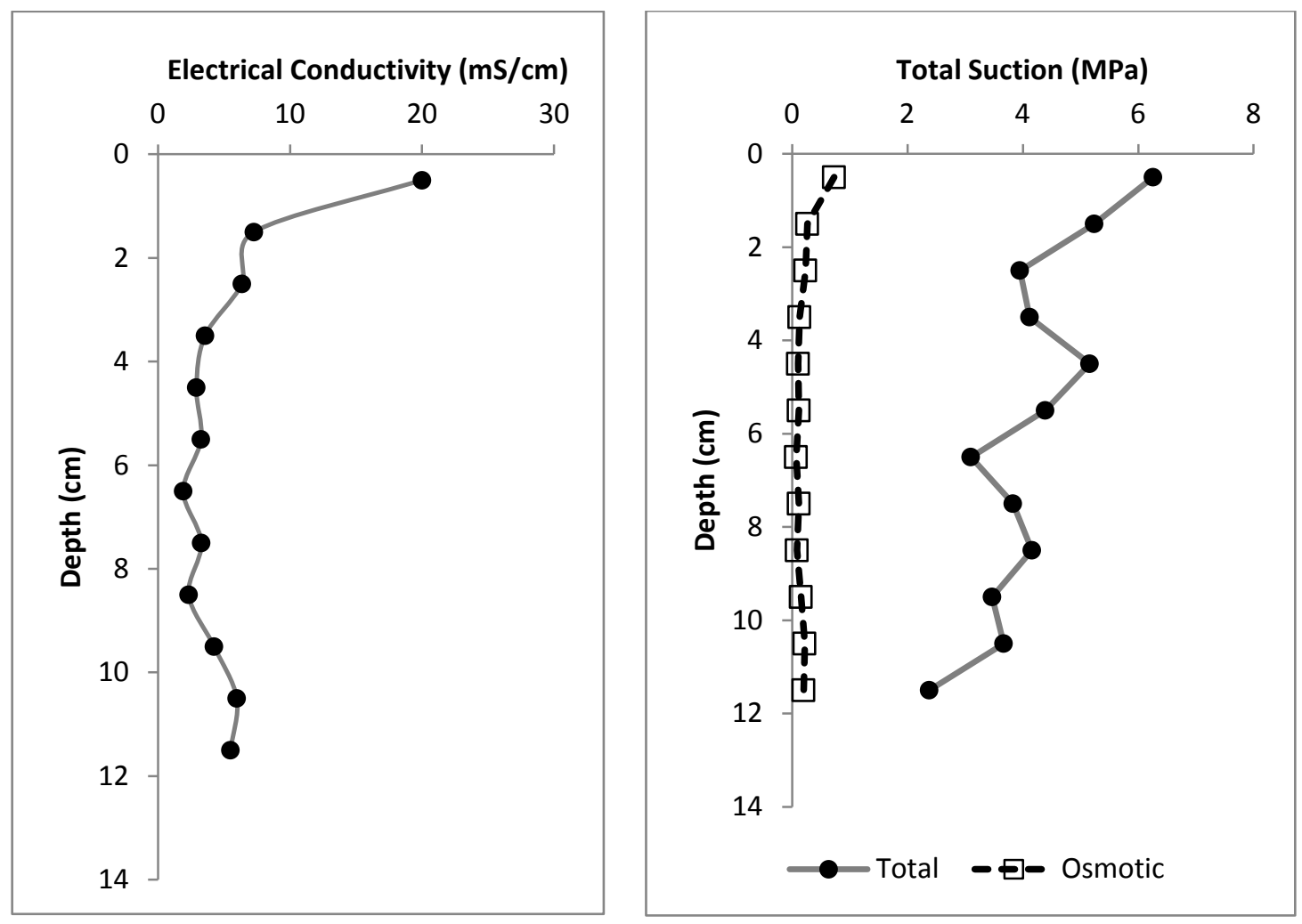

Figure 4.1-26. Core \#2 EC and osmotic and total suction profiles - Layer 1

\subsubsection{Undrained Shear Strength}

Vane shear tests were not conducted for Layer 1 because it had gotten so dry before deposition. 


\subsubsection{Layer 2}

Once layer 1 had attained an overall SC of 90\%, Layer 2 was deposited on May $28^{\text {th }}$. The same process was used as for Layer 1 . The average initial SC of the tailings was $34 \%$. Then the flocculated tailings were deposited in 69 buckets of $3.6 \mathrm{~kg}$ and allowed to dry to overall $68 \% \mathrm{SC}$. Core samples were taken before the deposition of Layer \#3, on July $17^{\text {th }}$. The data collected for the second layer is presented in this section. More details on the deposition are available in Appendix B.

\subsubsection{Mass Loss, Evaporation and Drainage}

Figure 4.1-27 shows the overall mass loss in the dry box after the deposition of Layer 2. Figure 4.1-28 provides a breakdown of the evaporation and drainage. In this layer, the mass loss is very slow, because of the underlying layer 1 , which got so dry that it absorbed most of the moisture from layer 2 , resulting in a greater energy demand to evaporate water from the top of the tailings, but also significantly decreased drainage under the box.

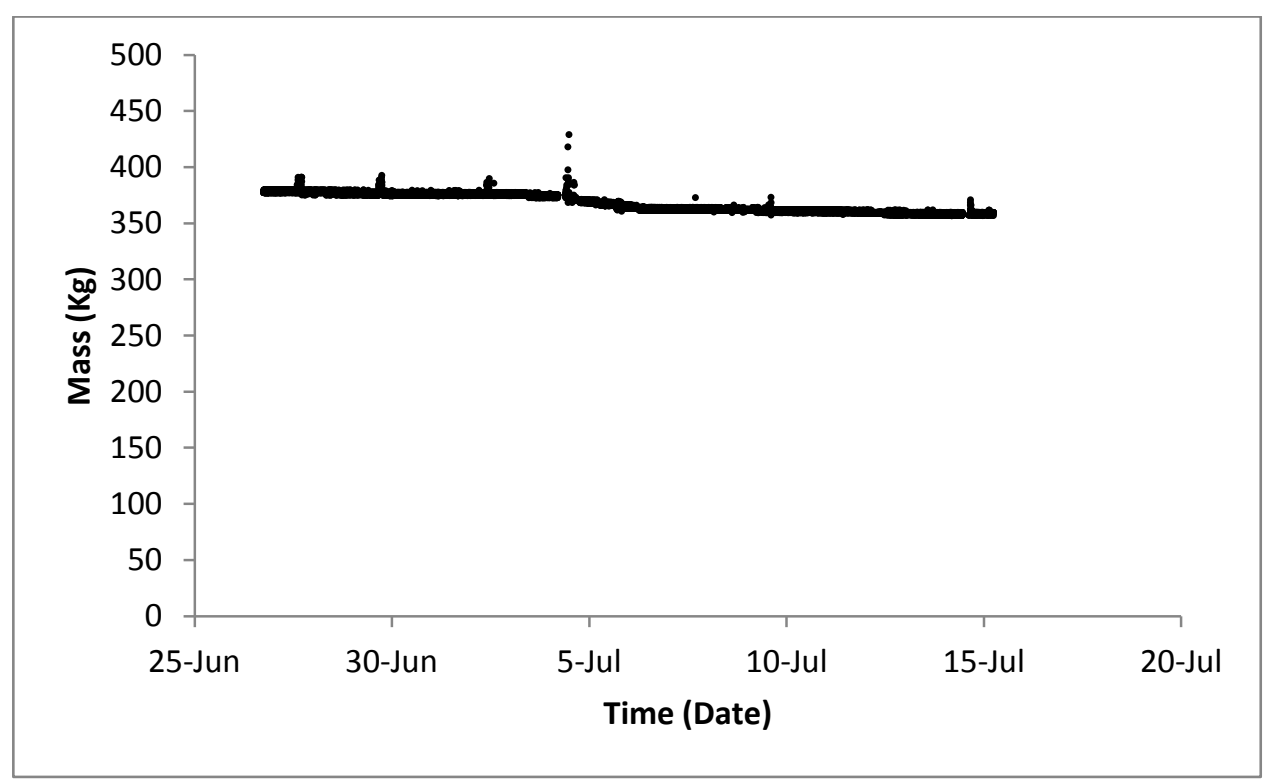

Figure 4.1-27. Total mass of tailings - Layer 2 
The AE rate was found to vary from approximately 3 to $6.5 \mathrm{~mm} /$ day, an overall decrease from the values seen in layer 1.

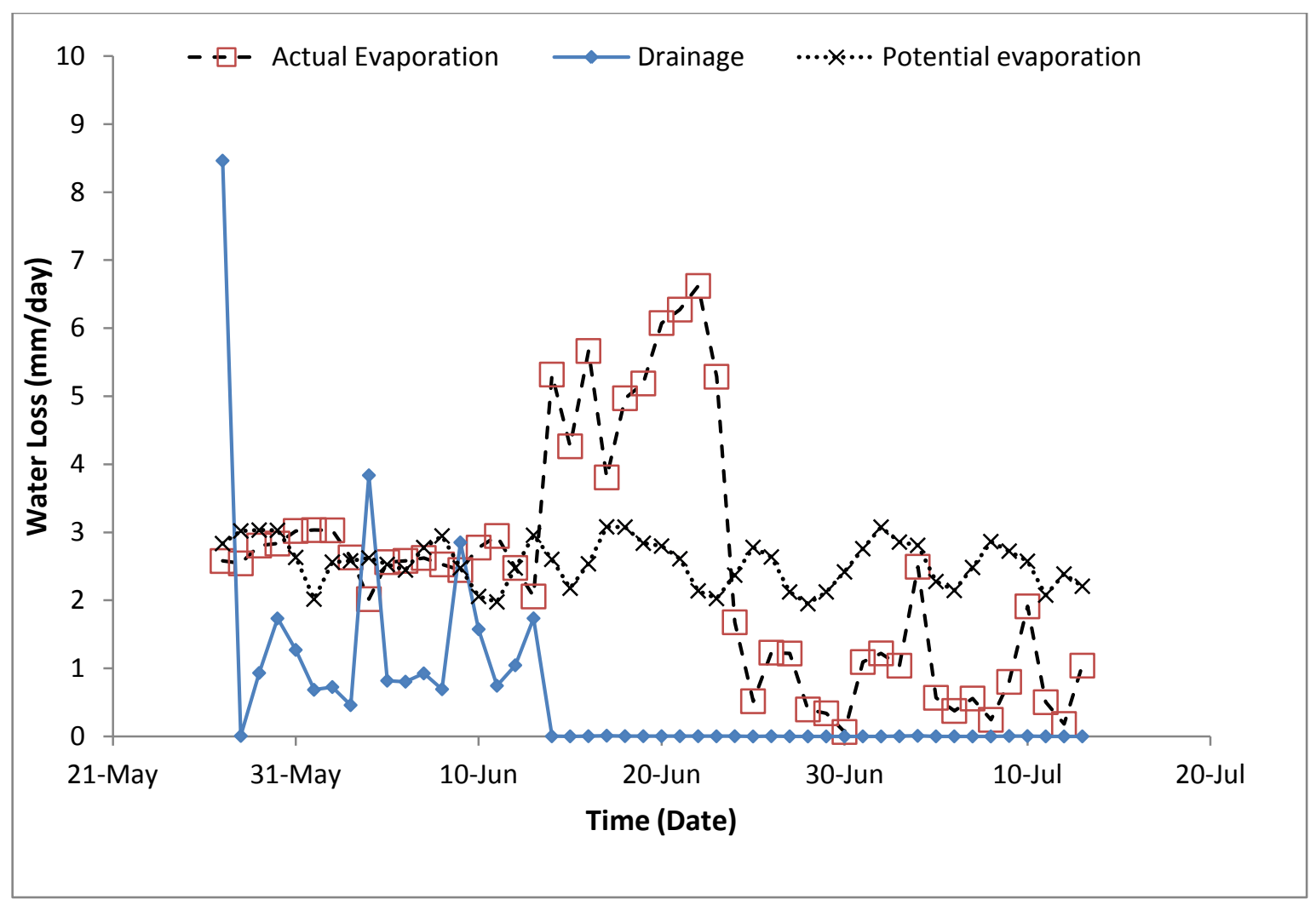

Figure 4.1-28. AE, PE and drainage - Layer 2

Figure 4.1-29 shows the temperatures recorded by the VWC sensors in the tailings and the temperature recorded by the $\mathrm{RH}$ sensor above the tailings. Generally, temperatures varied from 16-28 degrees Celsius, but were higher at the surface most of the time. 


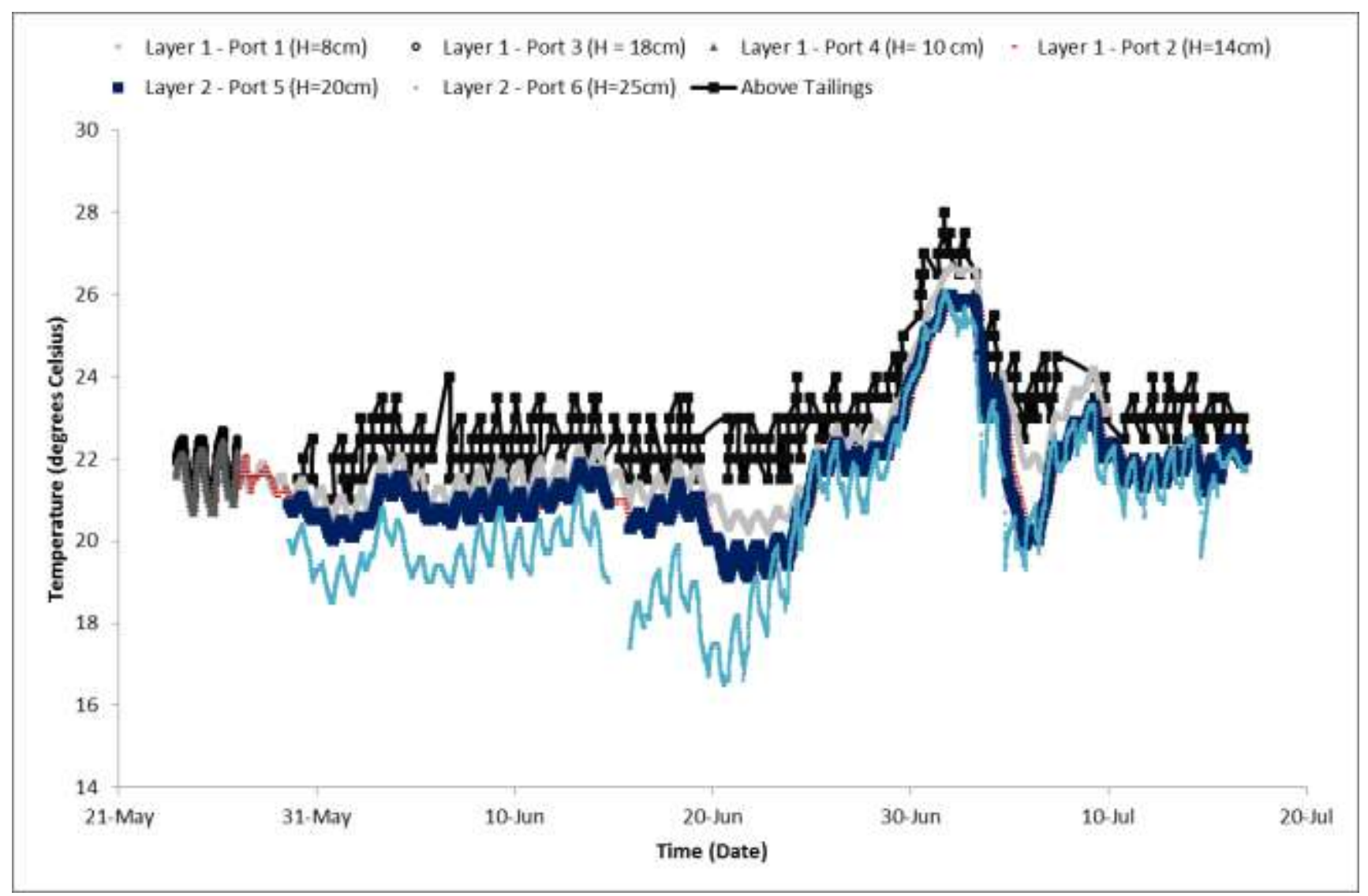

Figure 4.1-29. Temperature at various heights - Layer 2

Figure 4.1-30 shows the temperature, $\mathrm{RH}$ and dewpoint profiles above the tailings. Temperatures varied from 22-24 degrees Celsius, which was more consistent than layer 1 , and there is an overall increasing trend in the $\mathrm{RH}$ values as the seasons changed from spring to summer. Based on the conditions shown in Figure 4.1-30, the PE was found to vary from approximately $2 \mathrm{~mm}$ to $3 \mathrm{~mm}$ per day. 


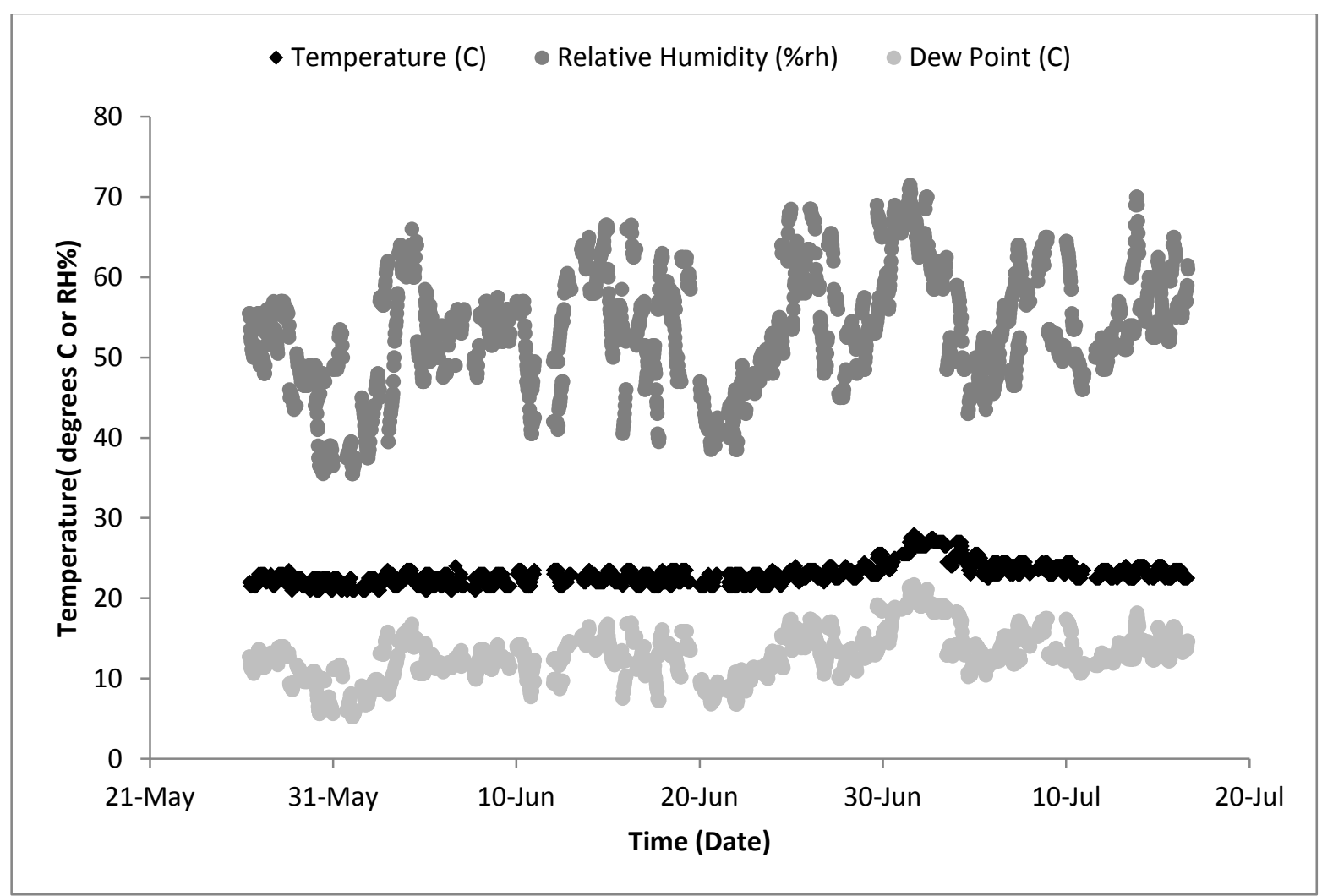

Figure 4.1-30. Temperature, $\mathrm{RH}$ and dewpoint profiles above the tailings - Layer 2

After the deposition of the second layer, the PE closely matches the AE until about June $13^{\text {th }}$, when cracking was first observed. After that date, the $A E$ increased beyond $P E$ values. After the cracks stopped growing, around June $27^{\text {th }}$, as shown in Figures 4.1-31 and 4.1.32 the AE values dropped below PE values. This behavior is further examined in section 4.1.4. 


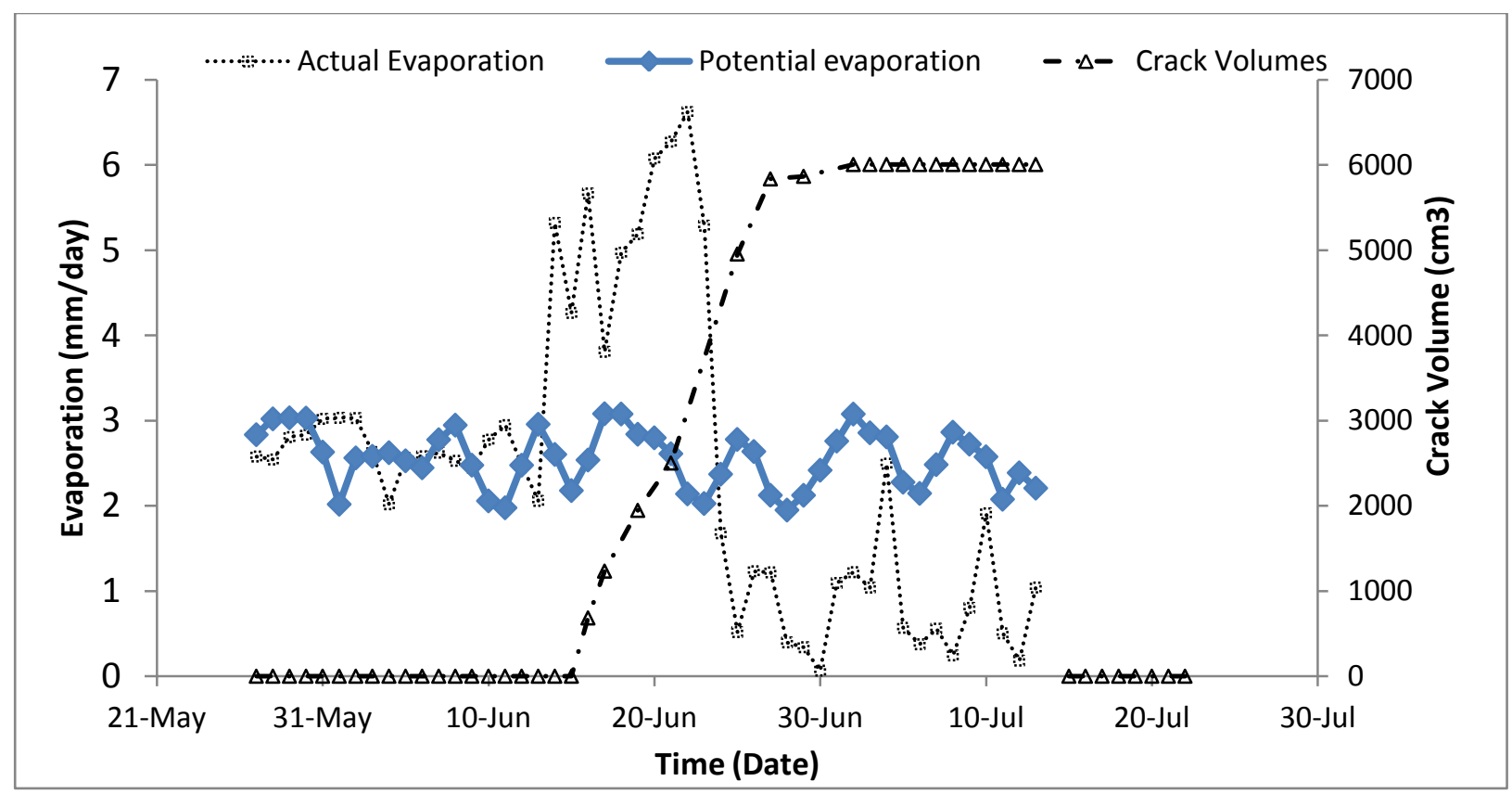

Figure 4.1-31. Evaporation vs. cracking - Layer 2

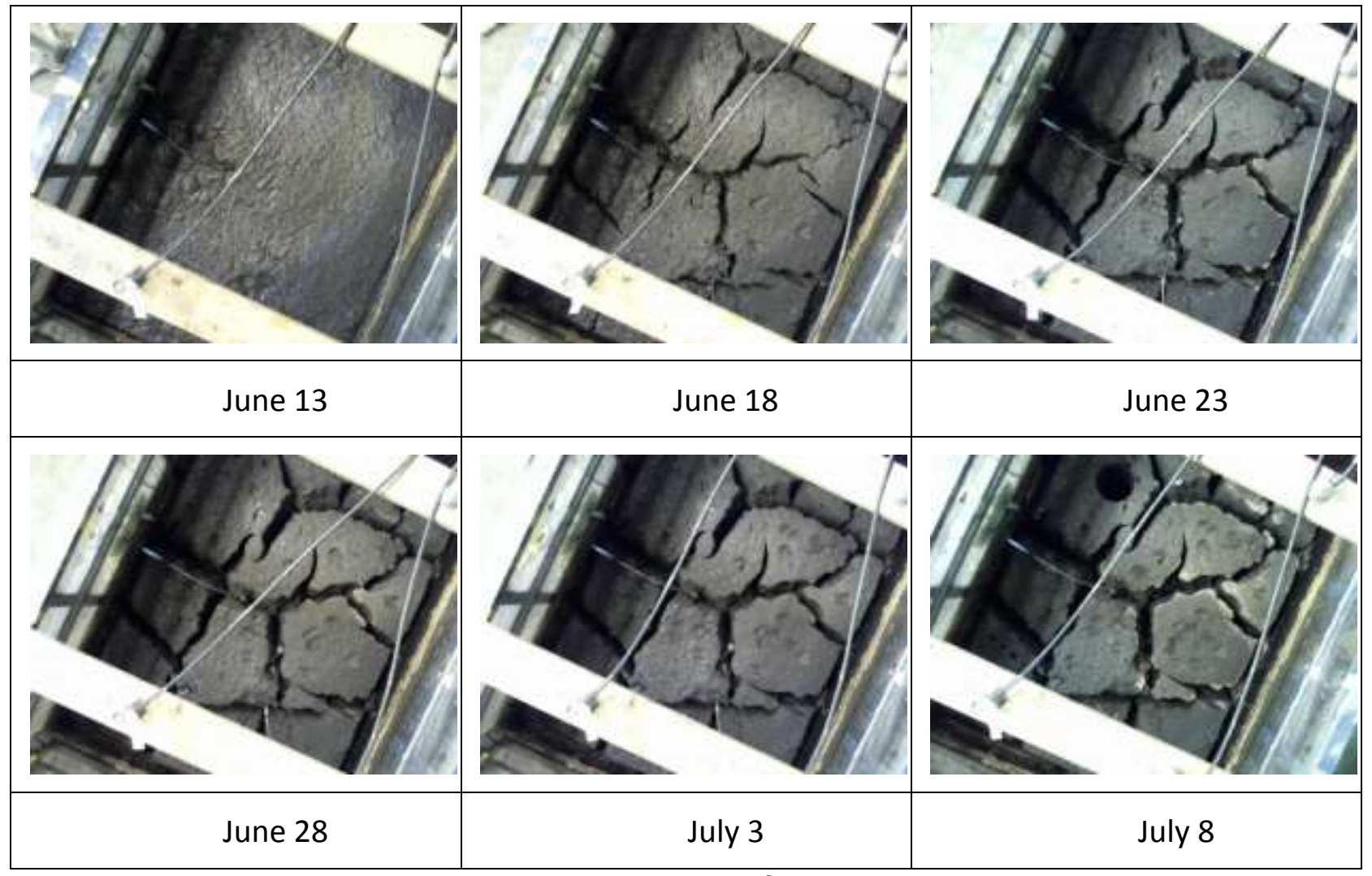

Figure 4.1-32. Progression of cracking - Layer 2 


\subsubsection{Settlement}

A few hours after deposition, the tailings separated into two visible layers, the heavier MFT at the bottom and a layer of clear water at the top. The distance between the top of the water and the MFT interface was measured at 5 different points daily, and averaged. The MFT settled due to self-weight consolidation, and the water at the top evaporated. Figure 4.1-33 shows the settlement of the MFT and the evaporation of the top water before that point.

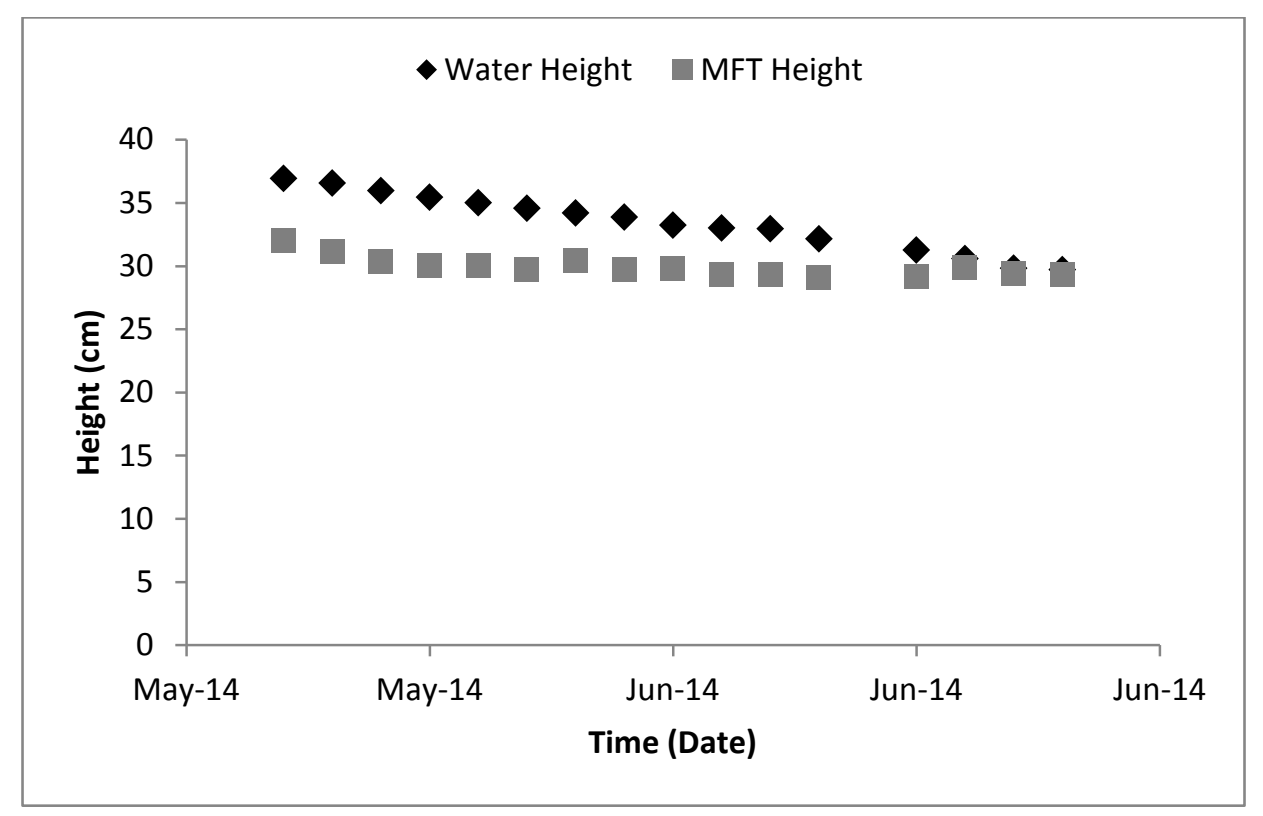

Figure 4.1-33. Water and MFT heights - Layer 2

\subsubsection{Volume Change}

After placement of the second layer, the VWC of layer 1 settled down to about 0.35 (uncalibrated) as seen in Figure 4.1-34, about 0.50 calibrated. One sensor rose in VWC value, since it was in contact with the fresh deposited tailings. 


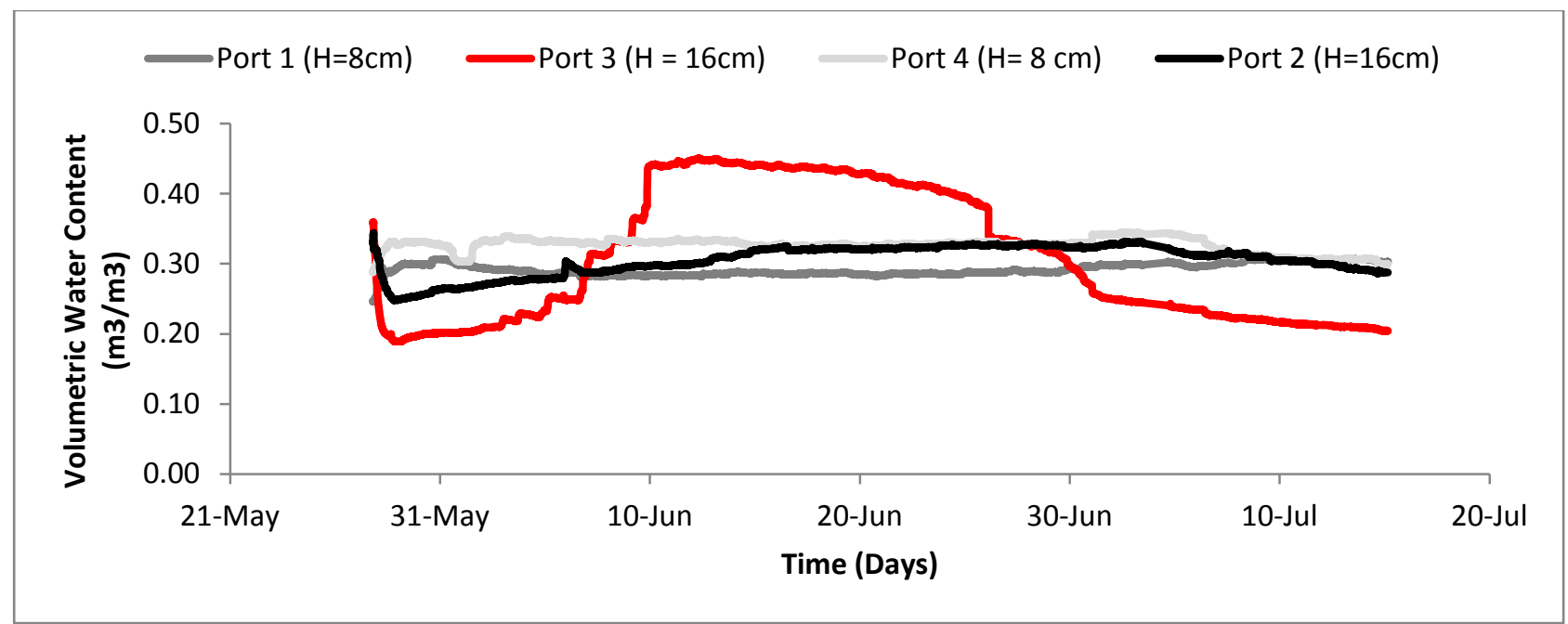

Figure 4.1-34. Volumetric water contents at various heights in bottom layer Layer 2

Upon the addition of layer 2, two more VWC sensors were placed, one at the bottom of the fresh layer, and one at the top. Figure 4.1-35 presents the data collected by these two sensors for the drying time of layer 2 . The trends in the data are similar to those seen on the onset of drying and the end of drying as in layer 1, where there is variance in elevation due to higher densities at the bottom at the beginning and then the lower water contents seen in the top sensor after drying settles in.

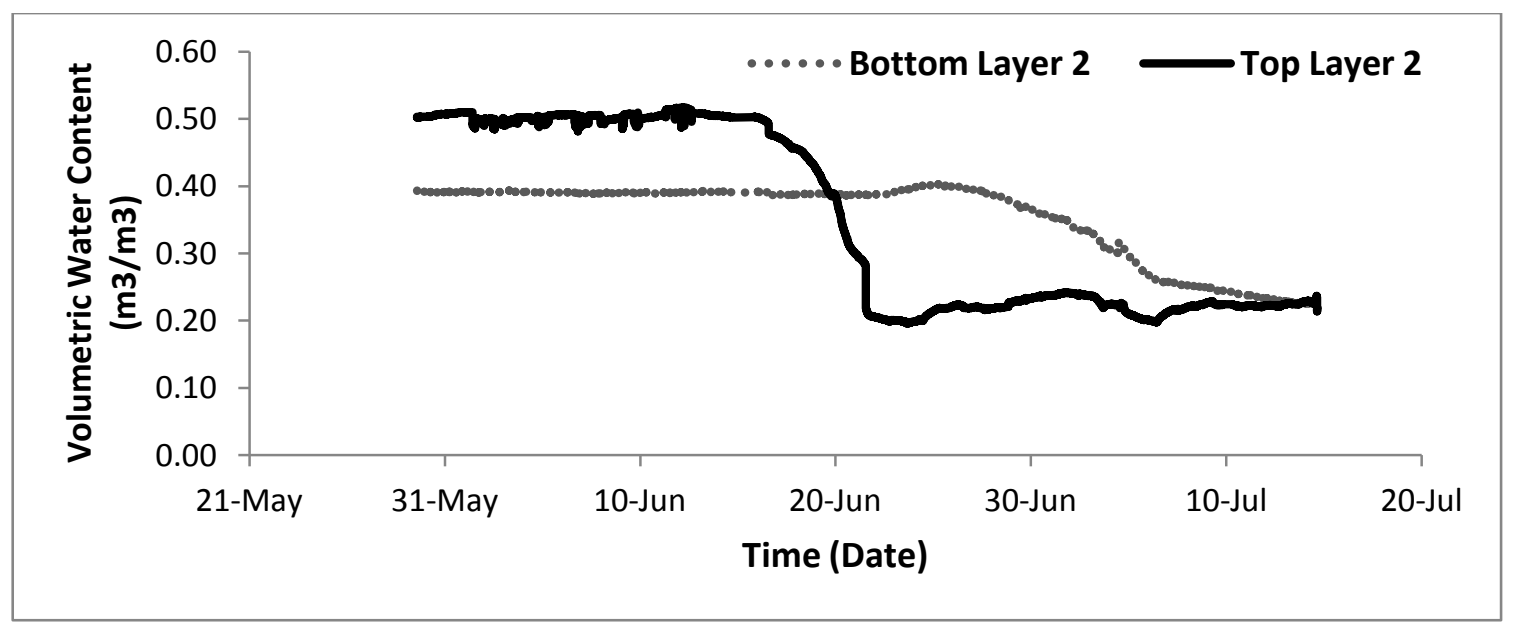

Figure 4.1-35. Volumetric water contents at various heights in top layer - Layer 2 


\subsubsection{Water Content}

The overall GWC in layer 2 is shown in Figure 4.1-36, as well as results for surface measurements within the top $1 \mathrm{~cm}$ after the supernatant water that had collected at the top of the tailings had evaporated. There is a steady decrease in overall GWC from $105 \%$ to $40 \%$ while the surface GWC decreases from $54 \%$ to $16 \%$.

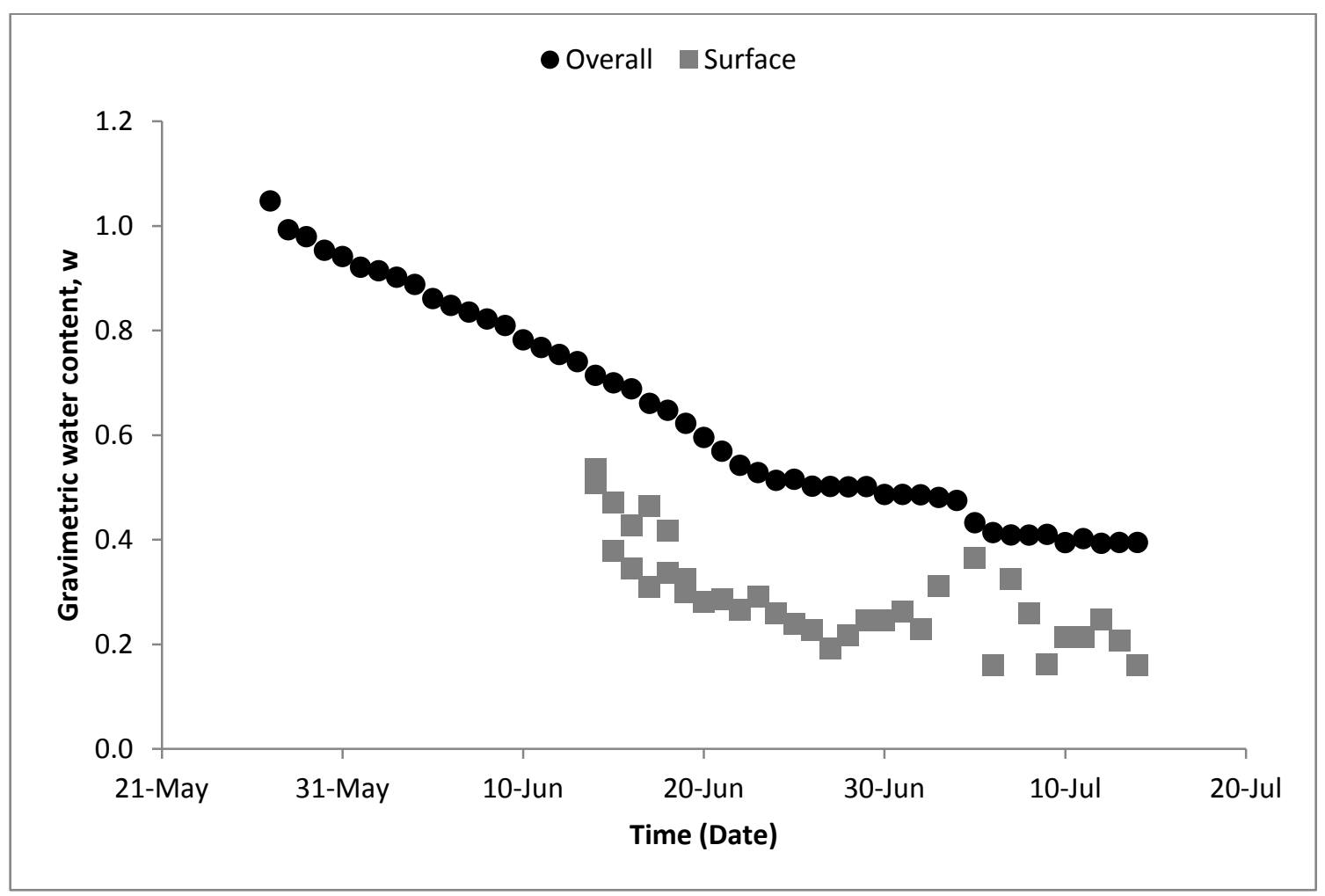

Figure 4.1-36. Gravimetric water contents - Layer 2

Surface samples taken at various locations once cracks began to form are shown in Figure 4.1-37. This time, the tailings did not get so dry as to prevent the collection of samples. 


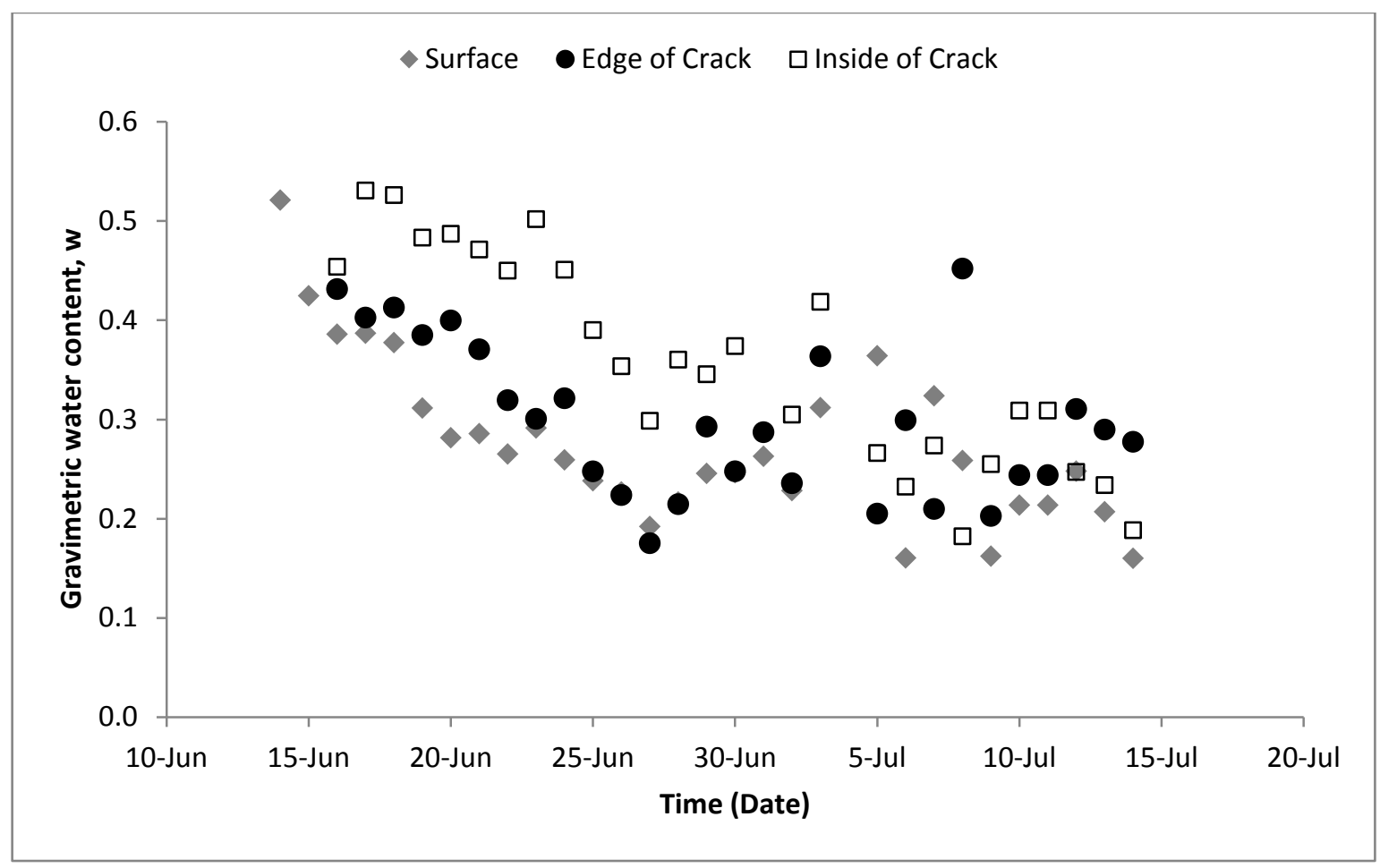

Figure 4.1-37. Surface sample gravimetric water contents - Layer 2

Generally the IC measurements once again show the greatest GWC, but Figure 4.1-37 shows that all three locations are decreasing at the same rate.

SC measurements are shown in Figure 4.1-38. The overall SC increased from $50 \%$ to $67 \%$. The initial SC is greater than that of the added tailings since it takes into account the underlying tailings. The figure shows that the drying rate was greater at the onset of drying and slowed down near the end.

From the data regarding water retention obtained from the sensors in layer 1 , it was possible to determine the SC in the second layer at the top. This information is shown in Figure 4.1-38. 


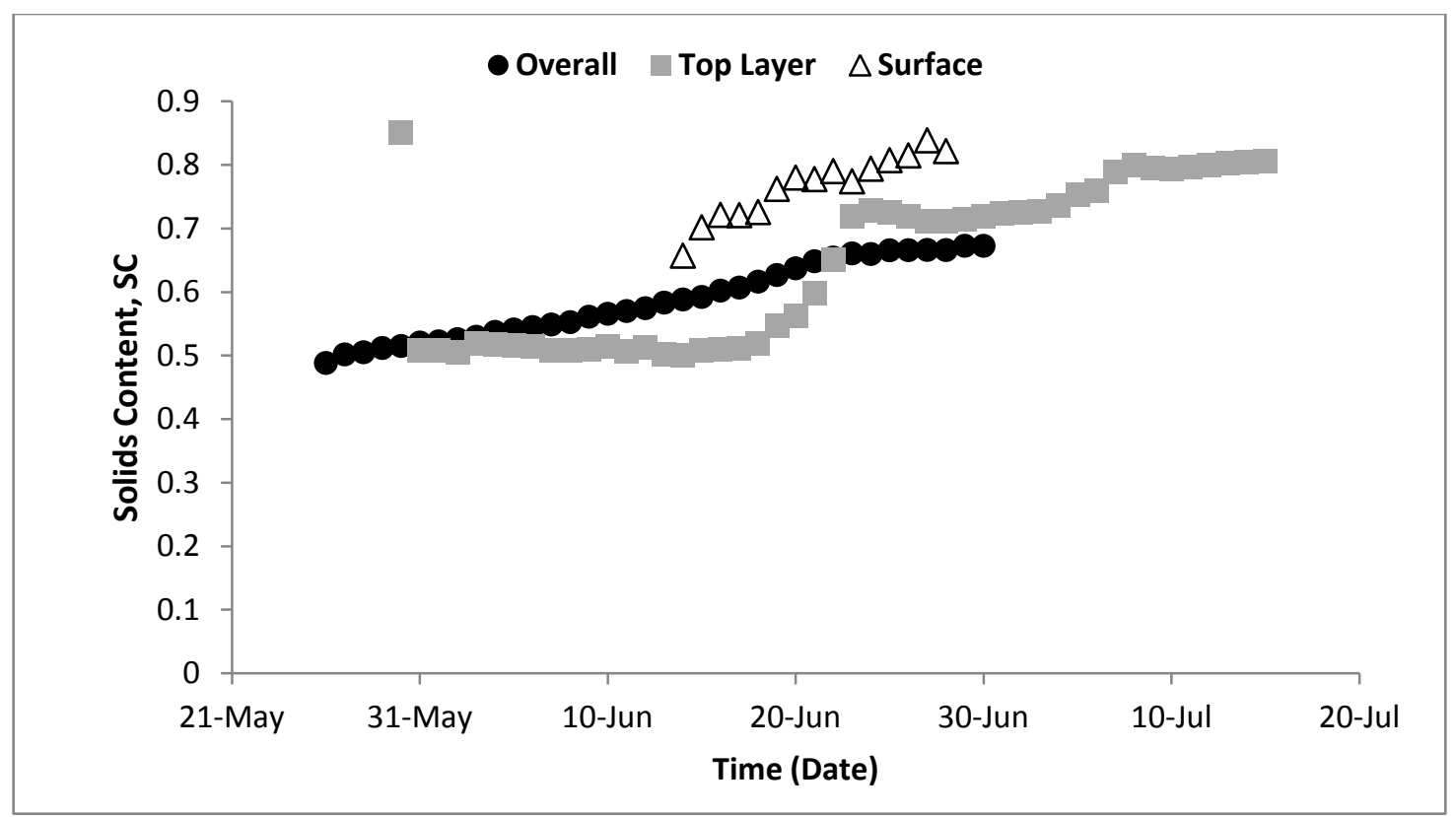

Figure 4.1-38. Solids contents - Layer 2

From this figure, the rate of density increase is quite a bit slower than in the first layer.Figure 4.1-39 provides a breakdown of the SCs at the surface, CE and IC surface samples.

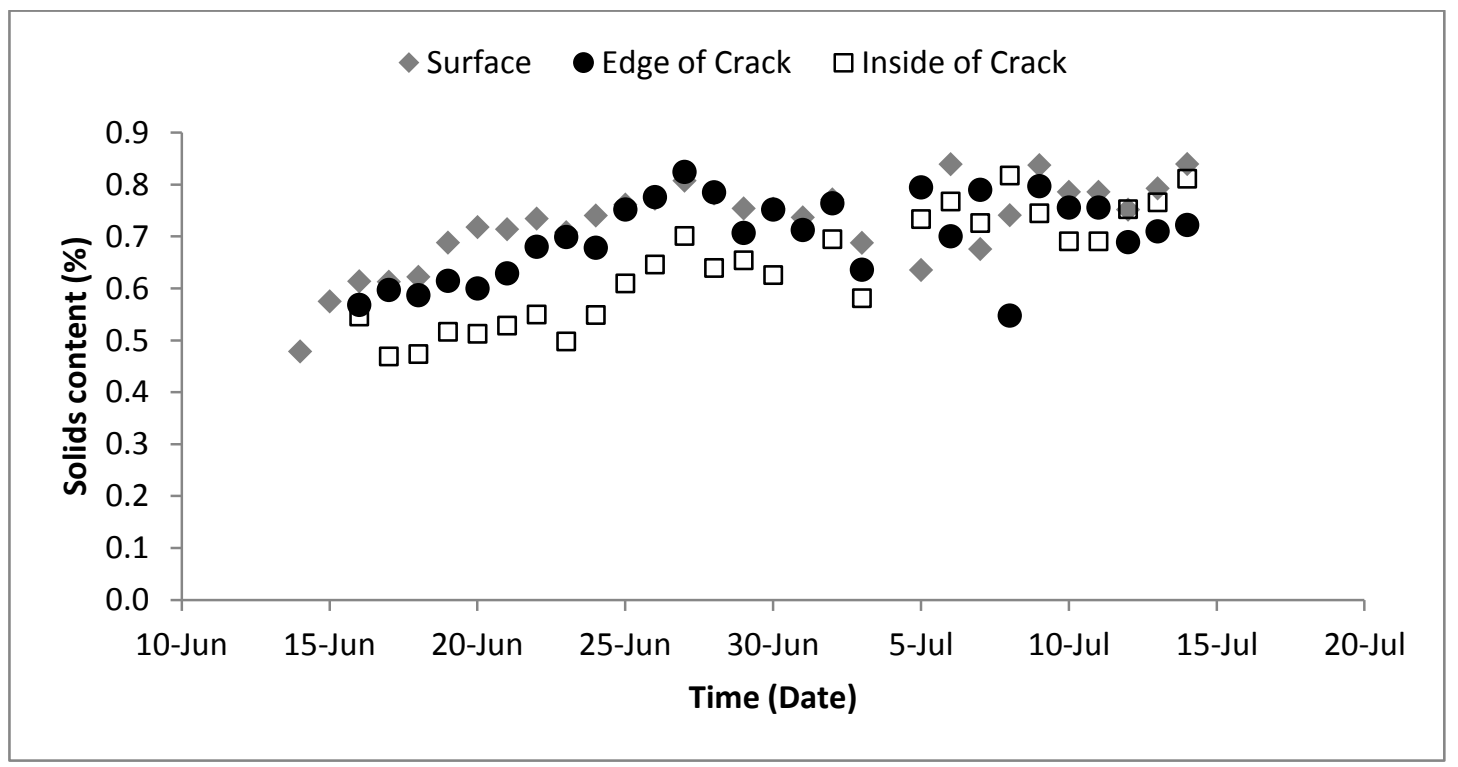

Figure 4.1-39. Surface sample gravimetric water contents - Layer 2 
Figure 4.1-40 shows the variation in overall degree of saturation in Layer 2 throughout the test.

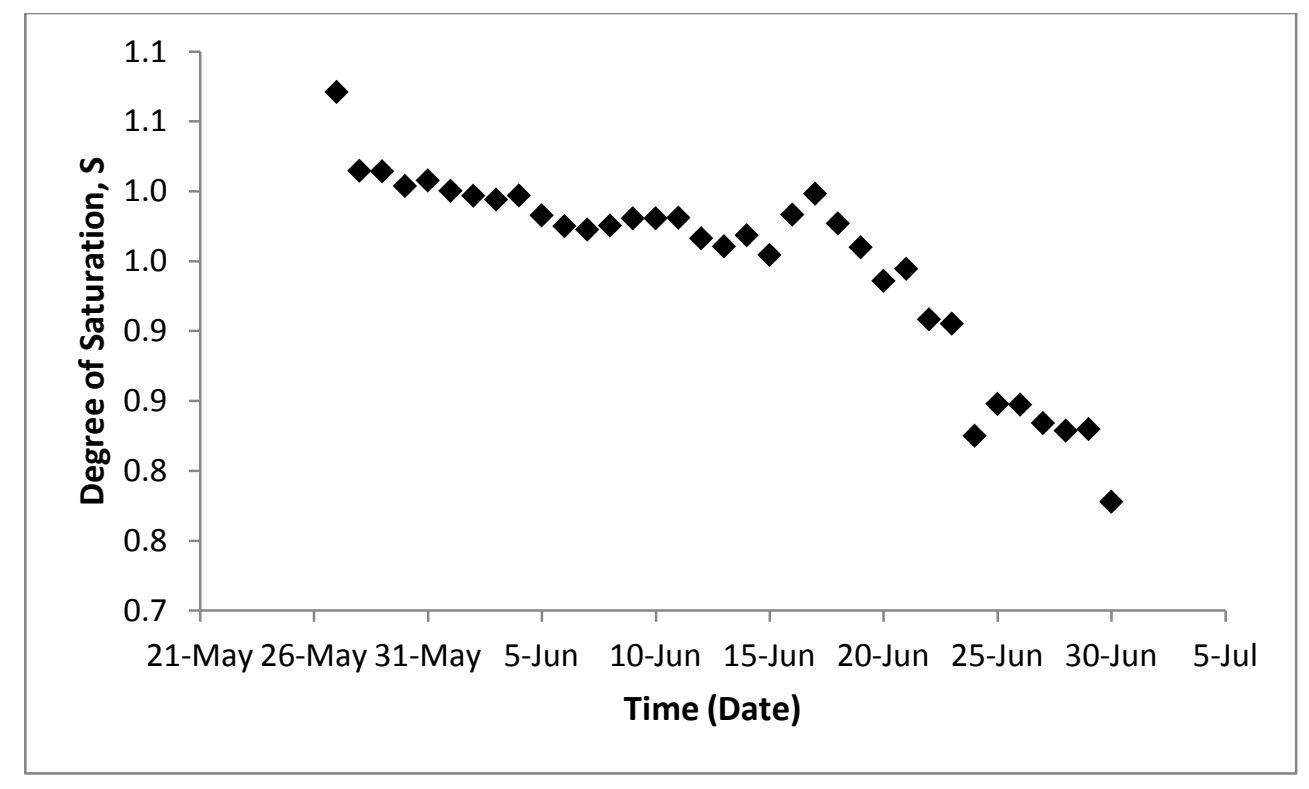

Figure 4.1-40. Overall degree of saturation - Layer 2

\subsubsection{Suction}

This section provides results for measurements for matric, osmotic, and total suctions in various locations for Layer 2.

\subsection{Matric Suction}

Two more tensiometers were added to layer 2 upon deposition, as shown in Figure 4.1-41. Both tensiometers show increasing values of matric suctions, with similar rates of increase. The tensiometers in the first layer cavitated and could not be replaced at this point, since the tailings had dried up and became very hard. 


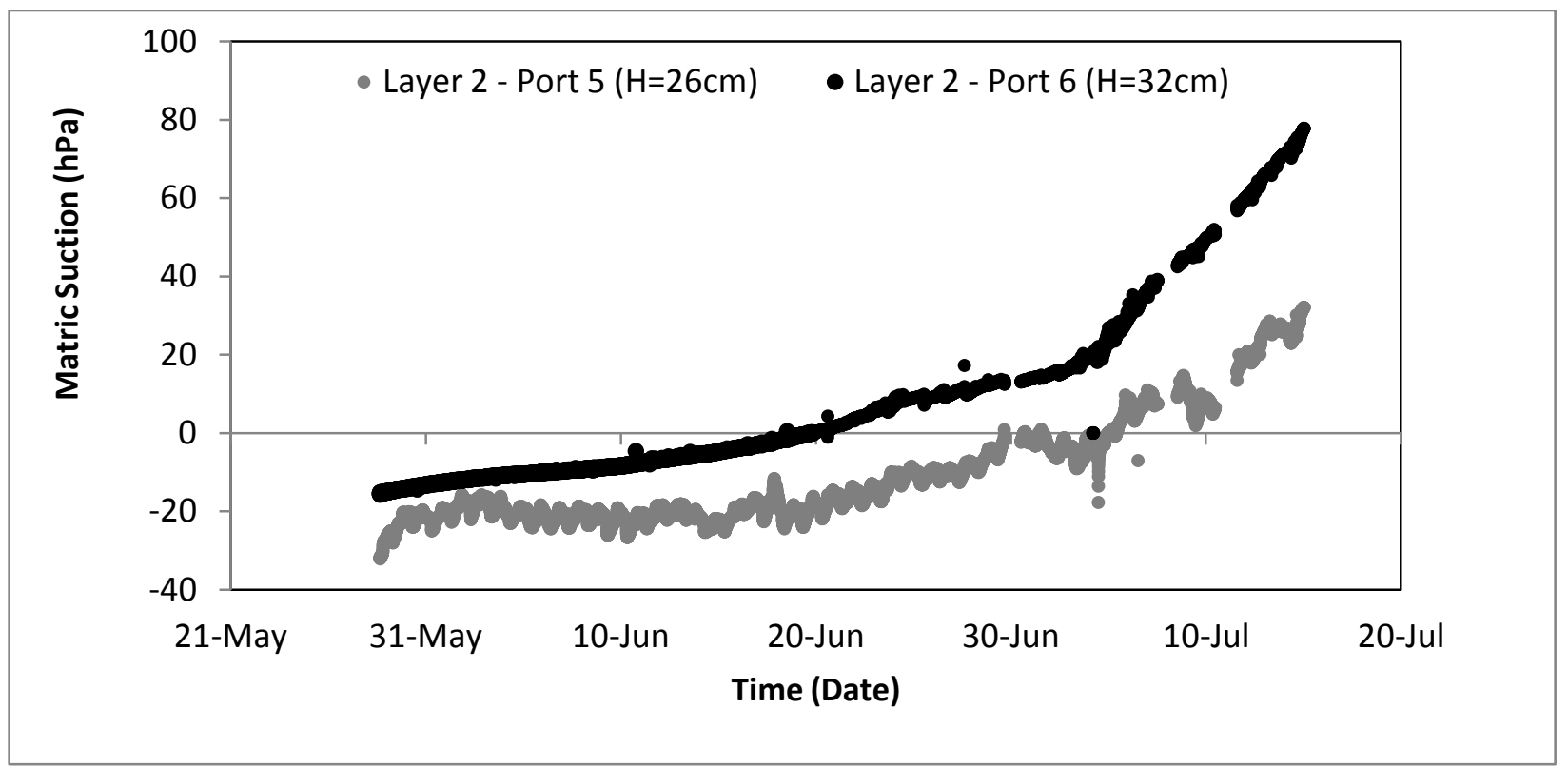

Figure 4.1-41. Matric suction at various heights - Layer 2

\subsection{Osmotic Suction}

Daily EC measurements at the surface, CE and IC are shown in Figure 4.1-42. There is no great variance in the values for CE and IC.

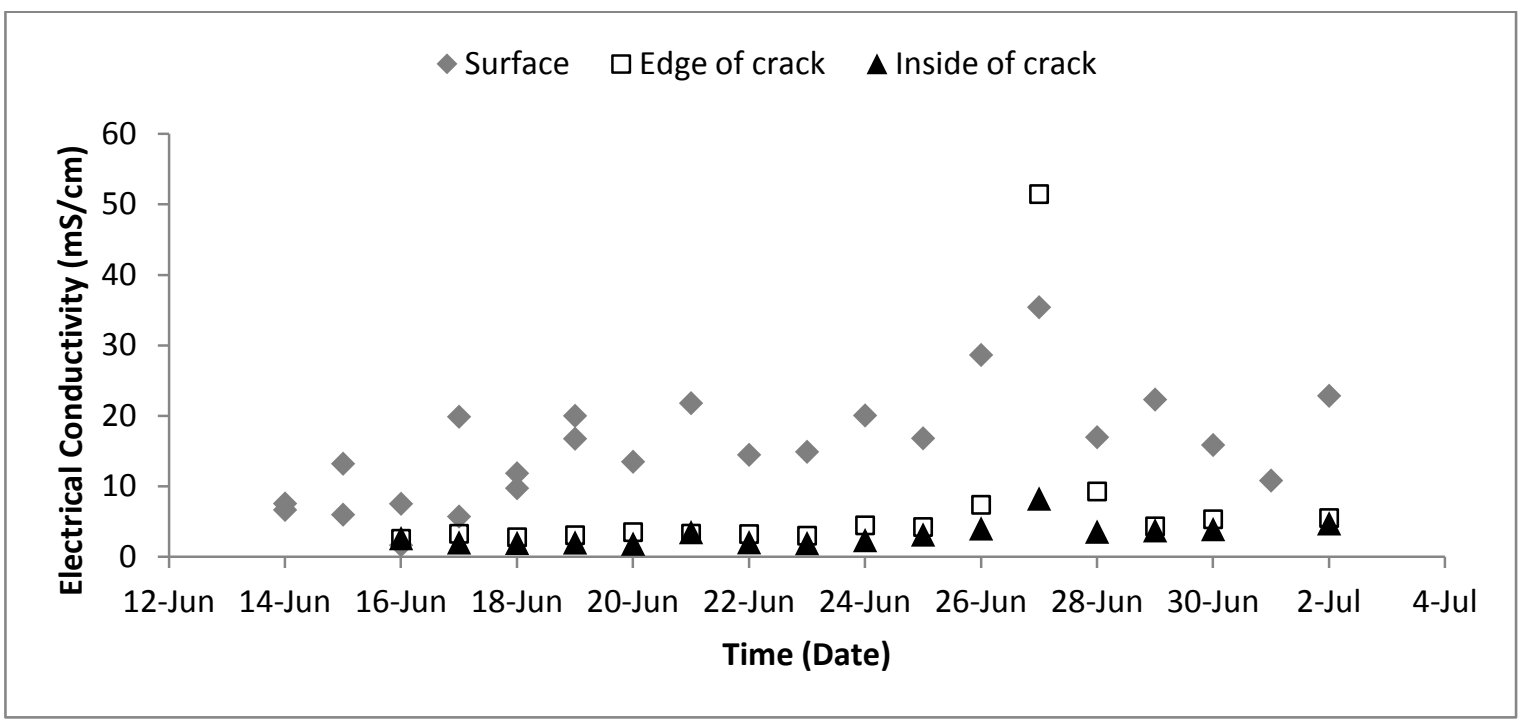

Figure 4.1-42. Surface sample electrical conductivity - Layer 2 
A comparison of osmotic suction to total suction is shown in Figure 4.1-43. The total suction is always greater than the osmotic component. In this layer, the fraction of osmotic suction is found to be much higher than in layer 1 .

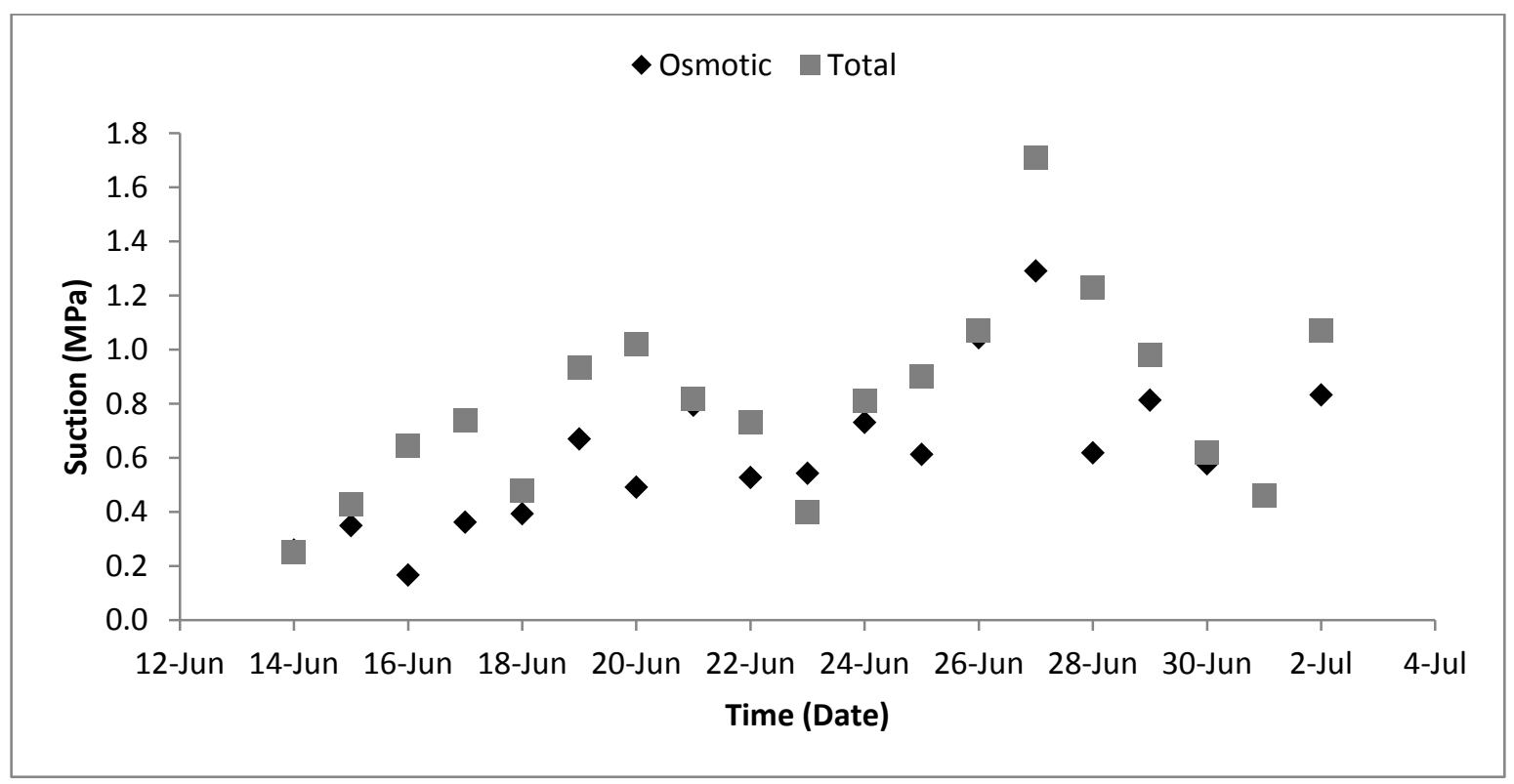

Figure 4.1-43. Surface sample total and osmotic suctions - Layer 2

\subsection{Total Suction}

Samples extracted from the top $1 \mathrm{~cm}$ of the surface of the tailings, CEs and the ICs were measured for total suction using a WP4-C potentiometer. These results are shown in Figure 4.1-44. 


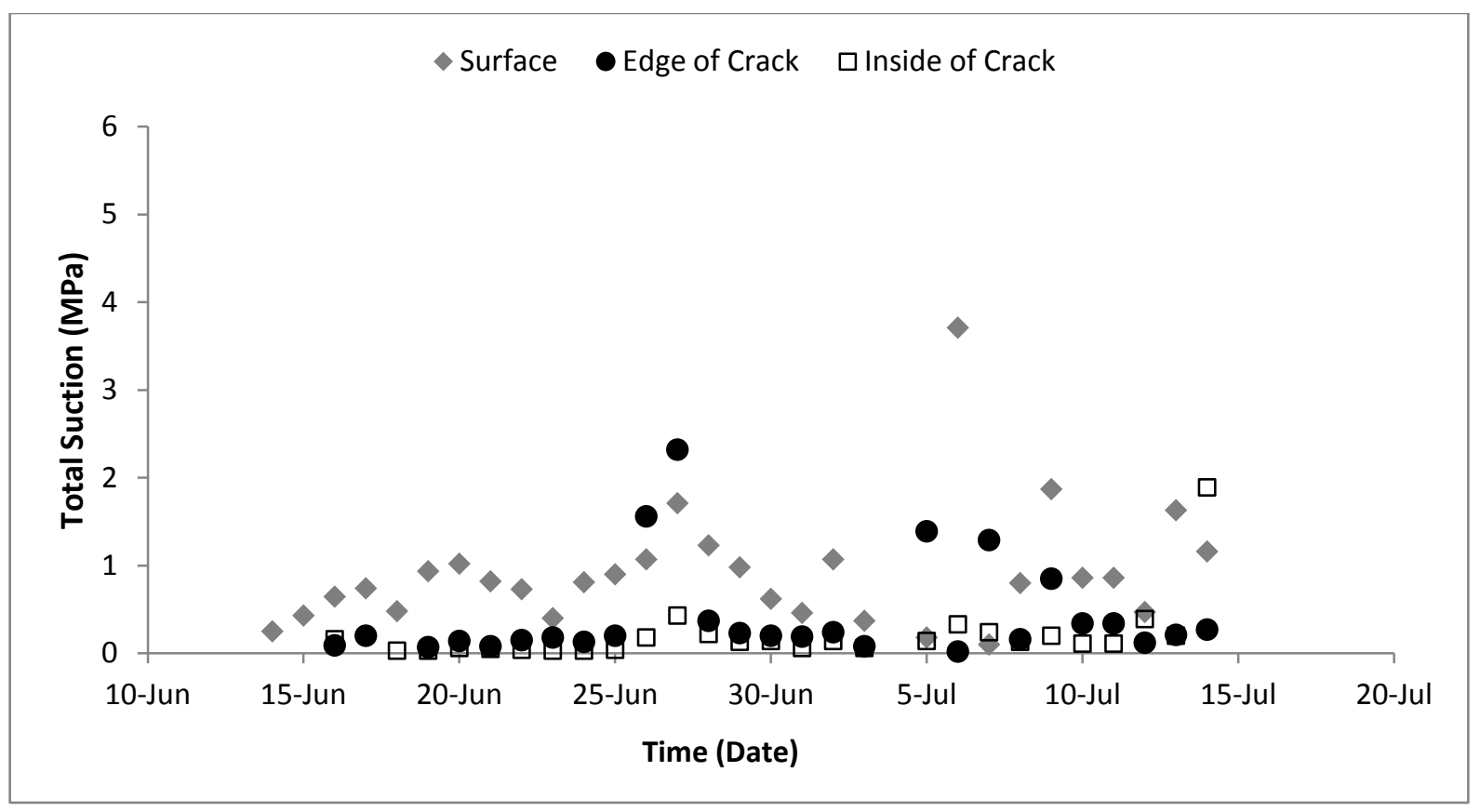

Figure 4.1-44. Surface sample total suctions - Layer 2

Overall, suction values at the surface increased as water escaped the tailings. Initially, suction values along the CEs were wetter than those at the surface, but as the tailings dried out and the crack volumes remained constant, the edges also dried out, and in some instances surpassed the values at the surface. The values inside the cracks were always lowest. The suction values in this layer did not reach the same suction as those of layer 1 , since the layer was not dried out to the same extent.

\subsubsection{Core Sample}

A core sample was extracted once the layer had reached $68 \%$ overall SC on July $4^{\text {th }}$. The location for the core sample is shown in Figure 4.1-45. The extracted sample was taken from the bottom right. 


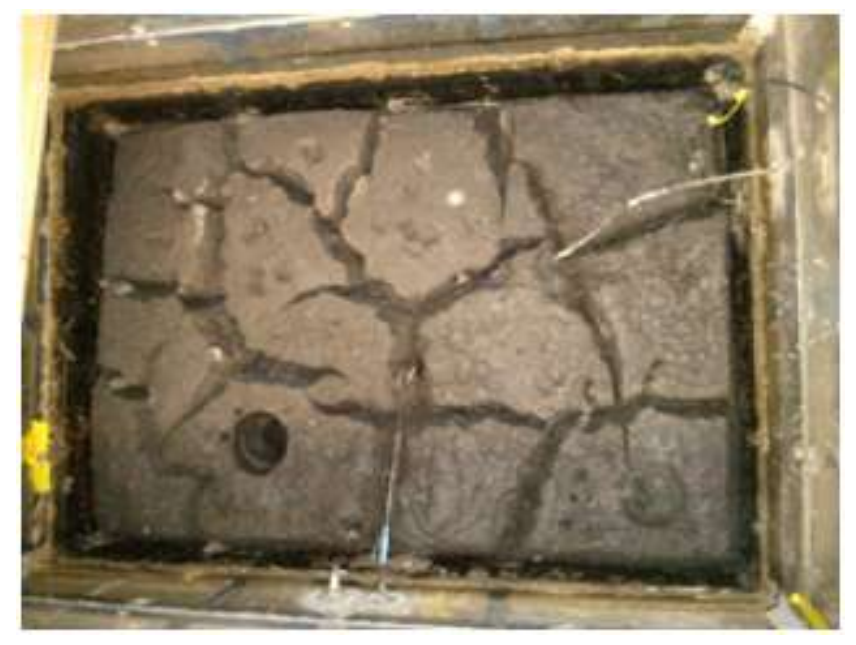

Figure 4.1-45. Core sample location - Layer 2

The core was analysed for GWC, SC, osmotic suction, total suction and TOC every $1 \mathrm{~cm}$. The core sample is shown in the following figure, along with the extracted depth.

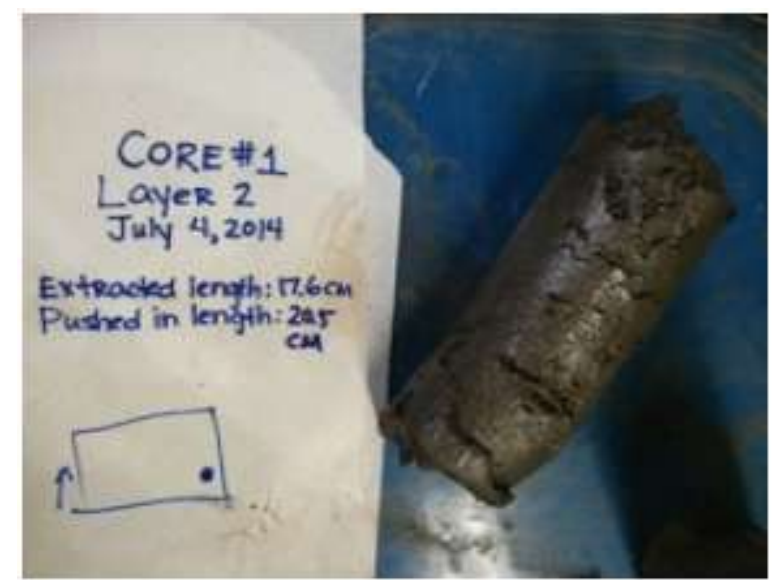

Figure 4.1-46. Core sample - Layer 2

. The following figure is related to water content with depth, as well as the TOC. 


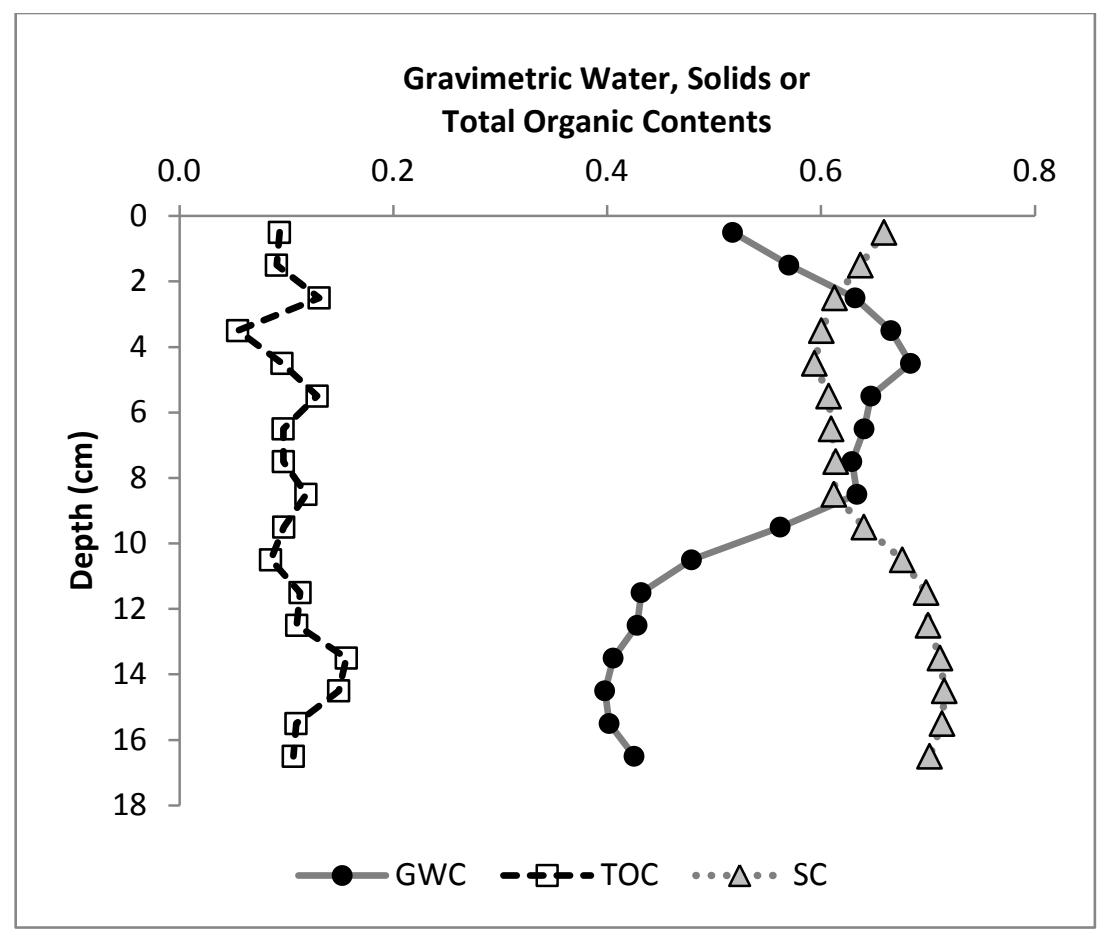

Figure 4.1-47. Core GWC, TOC and SC profiles - Layer 2

The following figures are related to osmotic and total suction with depth.
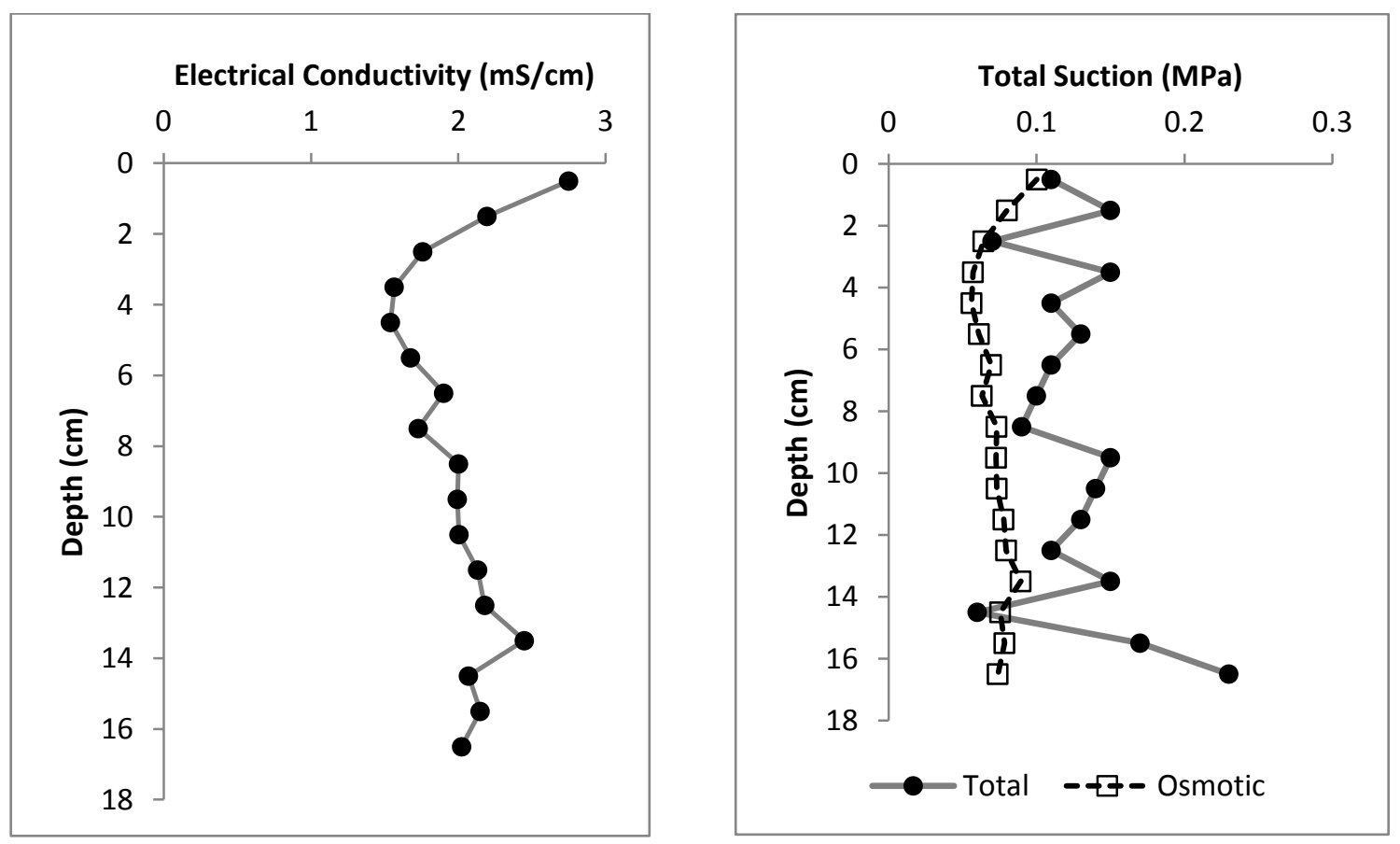

Figure 4.1-48. Core EC and osmotic and total suction profiles - Layer 2 


\subsubsection{Undrained Shear Strength}

Vane shear tests were conducted in conjunction with core extraction. The locations of these tests are right next to the locations of the core extraction. Figure 4.1-49 shows the results from these tests. Generally the undrained shear strength decreases with depth.

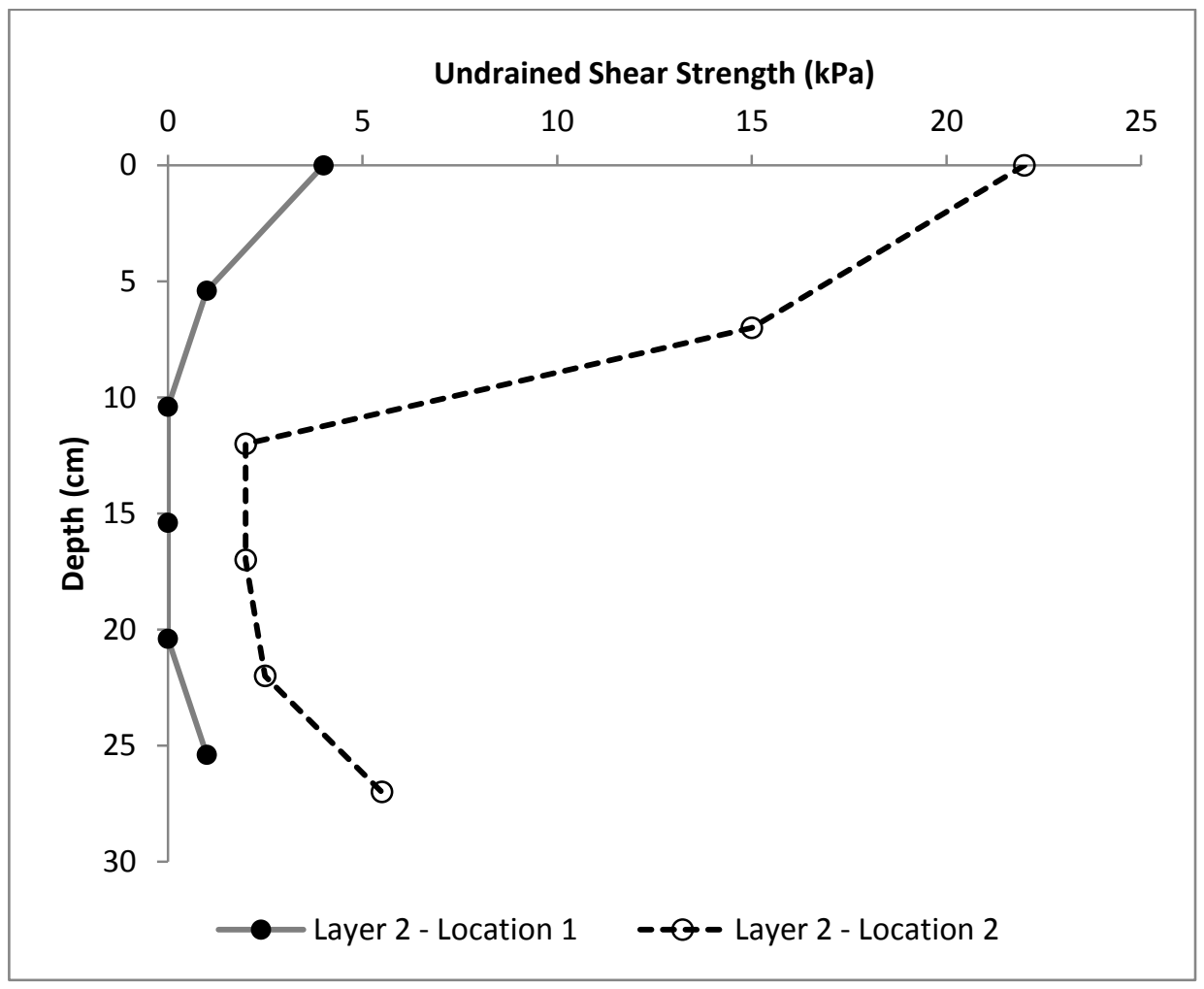

Figure 4.1-49. Undrained shear strength profile - Layer 2

\subsubsection{Layer 3}

Once layer 2 had attained a SC of approximately $60 \%$ at the top, layer 3 was deposited on July $17^{\text {th }}$. The same process was used as for the previous layers. The average initial SC of the tailings was $34 \%$. Then the flocculated tailings were deposited in 65 buckets of $3.6 \mathrm{~kg}$ and allowed to dry to $70 \%$ SC at the top layer. Core samples 
were taken once the top layer had reached $60 \%$ SC on August $26^{\text {th }}$. Plate load tests were also performed at that time. Strength tests are discussed in section 4.4. The data collected for the third layer is presented in this section.

\subsubsection{Mass Loss, Evaporation and Drainage}

Figure 4.1-50 shows the overall mass loss of the dry box after the addition of the third layer. Figure 4.1-51 provides a breakdown of evaporation and drainage. In this layer, the mass loss occurred faster than layer 2 but more slowly than in layer 1 .

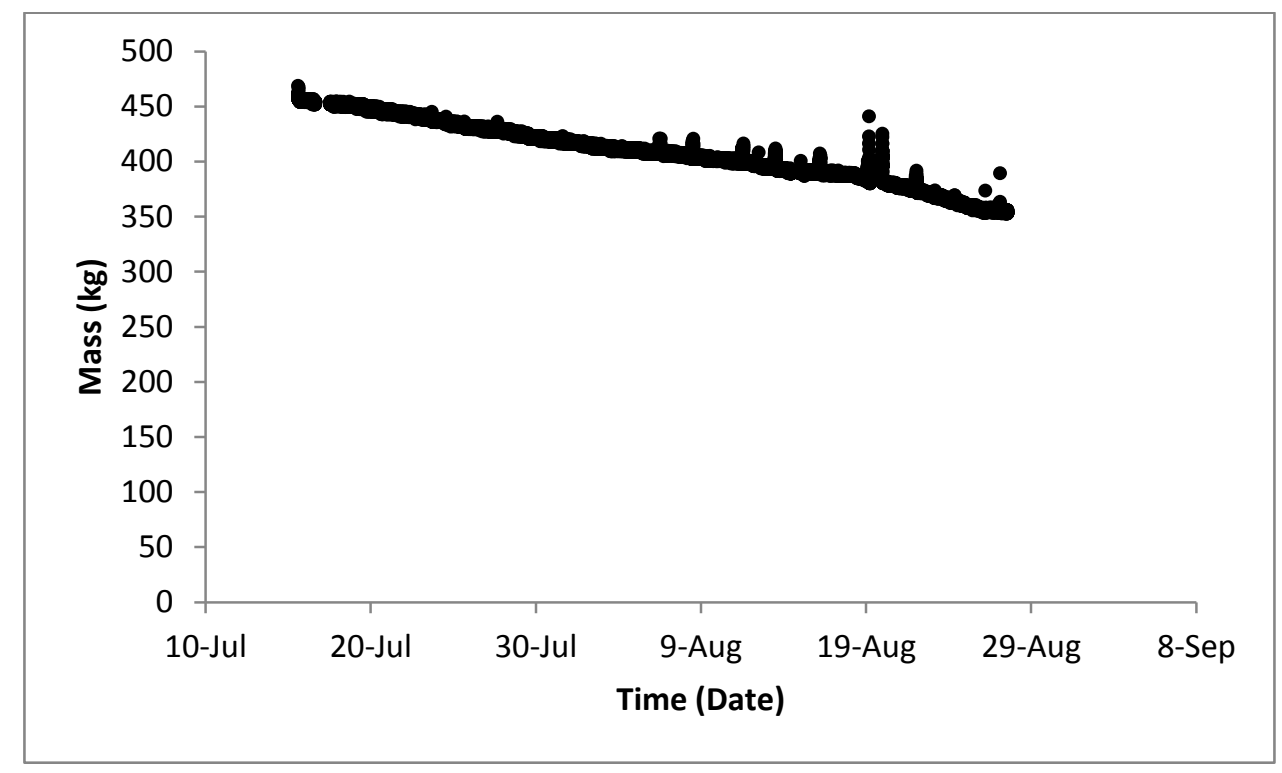

Figure 4.1-50. Total mass of tailings - Layer 3

The $A E$ rate was found to vary from approximately 2 to $7 \mathrm{~mm} /$ day, similarly to layer 1 again. Since the amount of drainage was very minimal at this point due to the underlying dry tailings, the supernatant water that collected at the top was decanted using a syringe and beaker beginning July $19^{\text {th }}$ (when the interface between the water and the MFT was more pronounced) and ending on July $25^{\text {th }}$ (when the use of the syringe would disturb the thin fine tailings that separate the MFT and the water). About 1 litre of water was extracted from the top consistently (or $2 \mathrm{~mm} /$ day) as shown in Figure 
4.1-52. Also after the deposition of this layer, the rain gauge was replaced, providing more reliable drainage measurements.

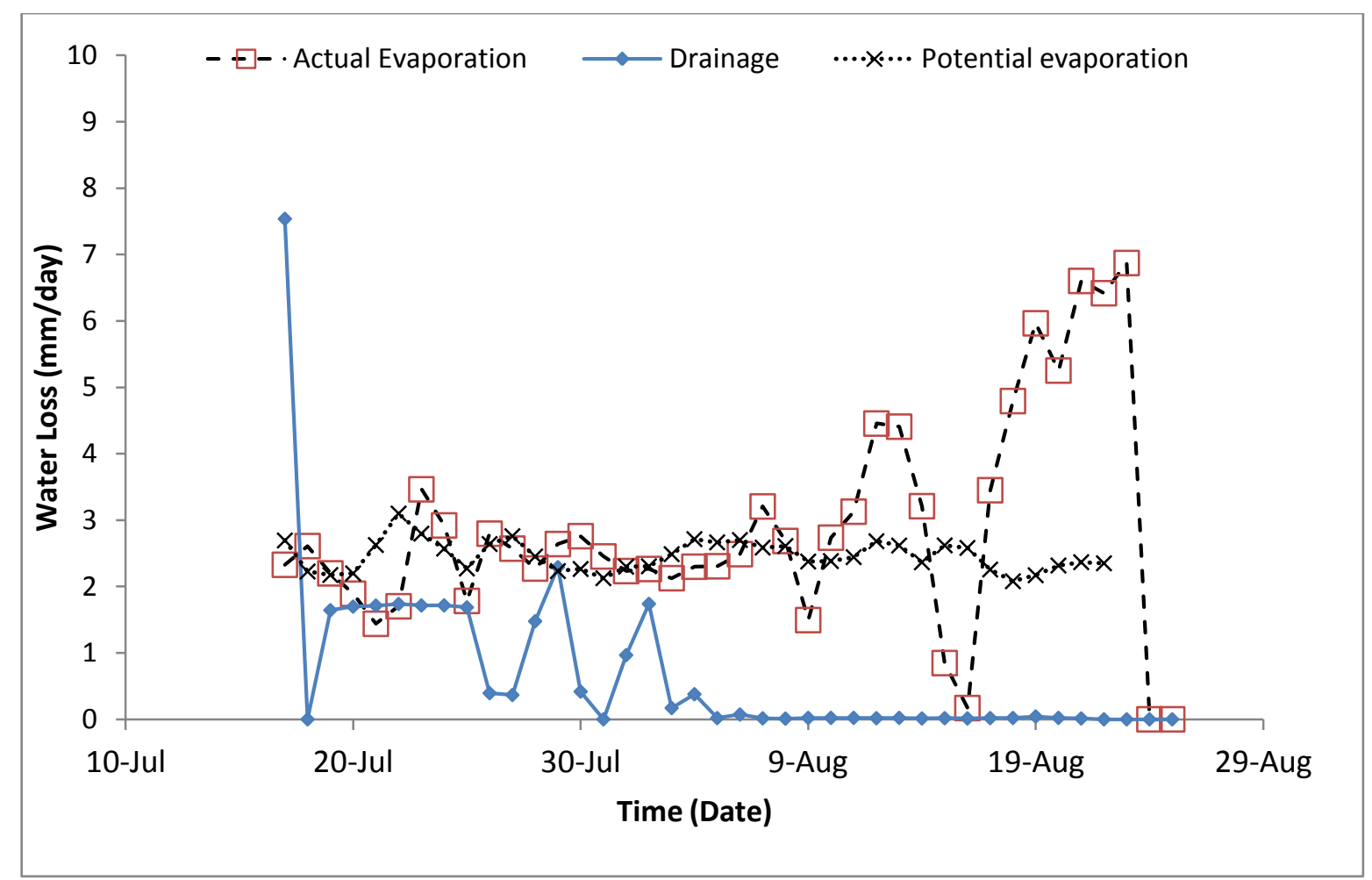

Figure 4.1-51. AE, PE and drainage - Layer 3

Figure 4.1-52 shows the temperatures recorded by the VWC sensors in the tailings and the temperature recorded by the $\mathrm{RH}$ sensor above the tailings. Generally, temperatures varied from 16-26 degrees Celsius, but were higher at the surface most of the time. 


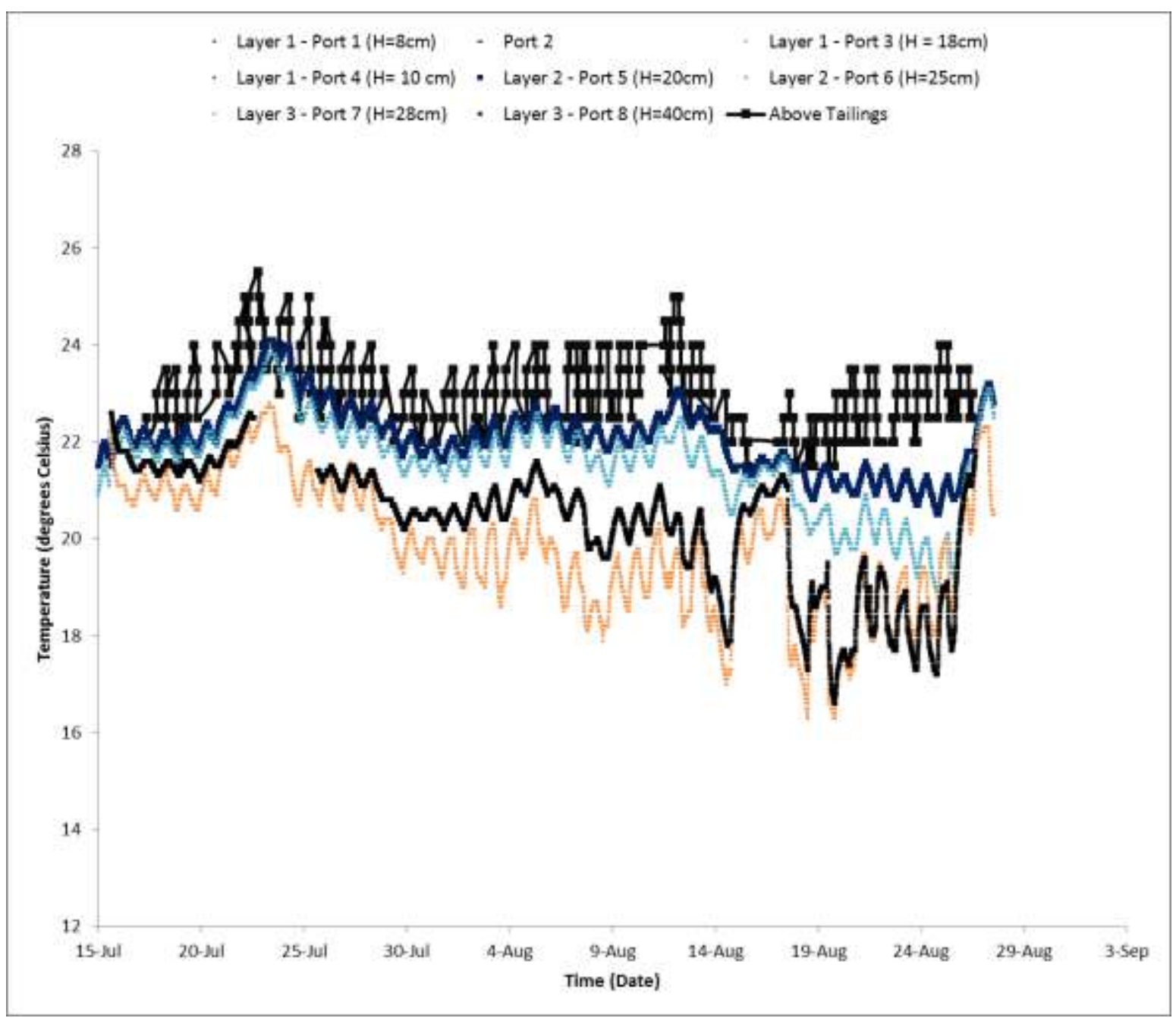

Figure 4.1-52. Temperature at various heights - Layer 3

Figure 4.1-53 shows the temperature, $\mathrm{RH}$ and dewpoint profiles above the tailings for layer 3. Temperatures varied from 22-24 degrees Celsius, which was more consistent with layer 2, and the $\mathrm{RH}$ values were also more consistent. Based on the conditions shown in Figure 4.1-53, the PE was found to vary from approximately $2 \mathrm{~mm}$ to $3 \mathrm{~mm}$ per day, just like layer 2 . 


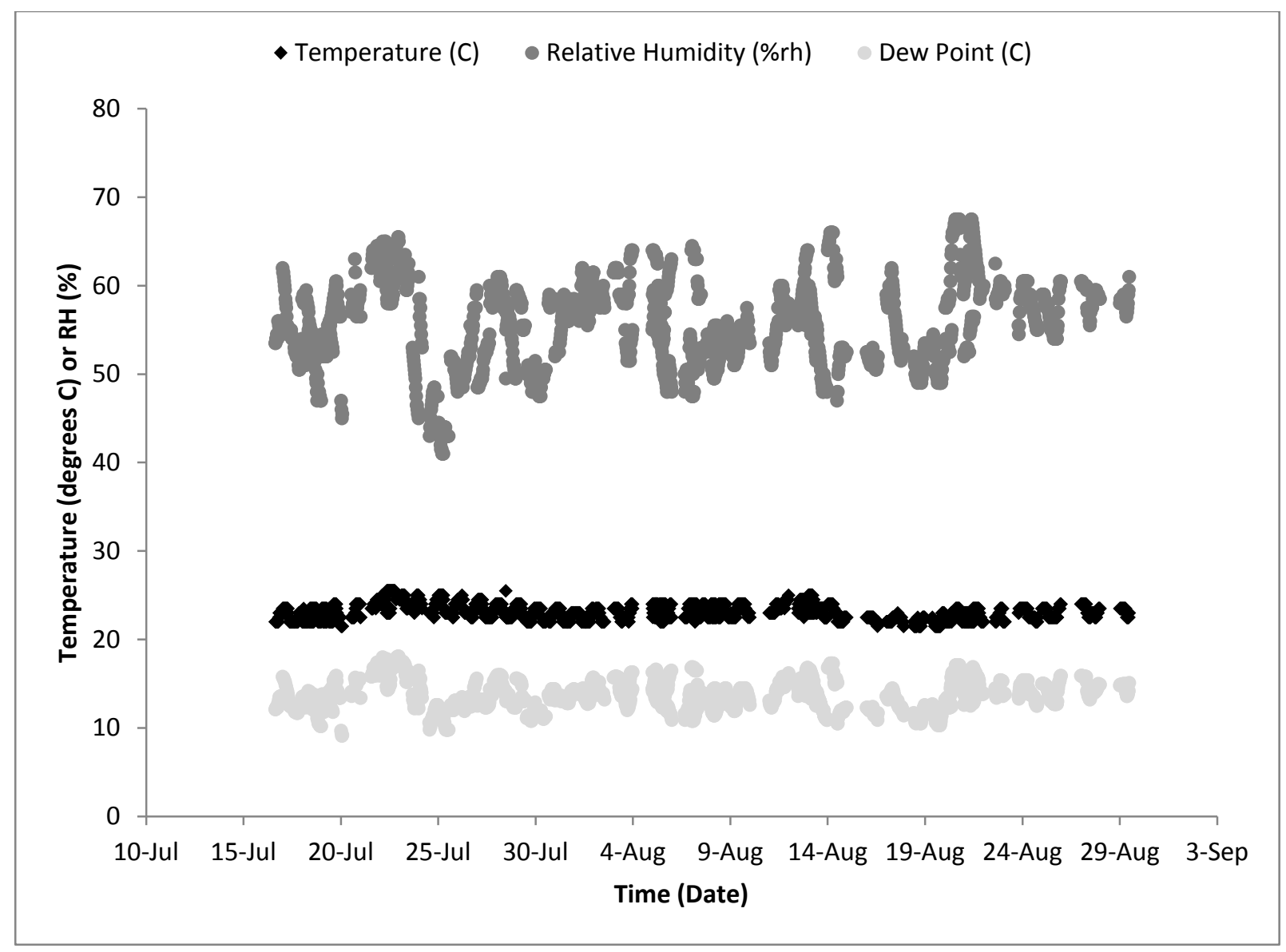

Figure 4.1-53. Temperature, $\mathrm{RH}$ and dewpoint profiles above the tailings - Layer 3

Figures 4.1-54 and 4.1-55 provide the same relationship as previously between evaporation and cracking progression in layer 3. 


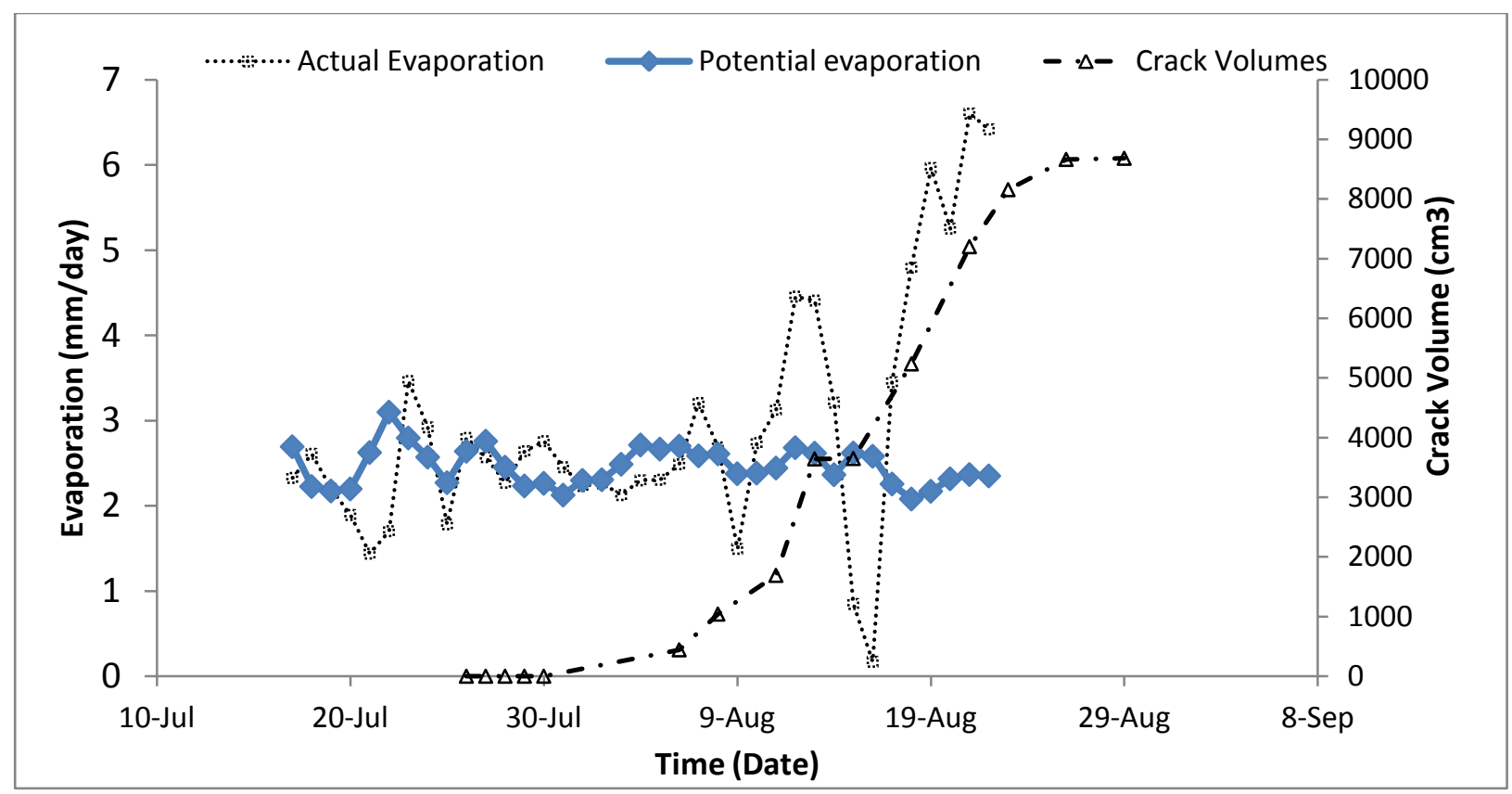

Figure 4.1-54. Evaporation vs. cracking - Layer 3

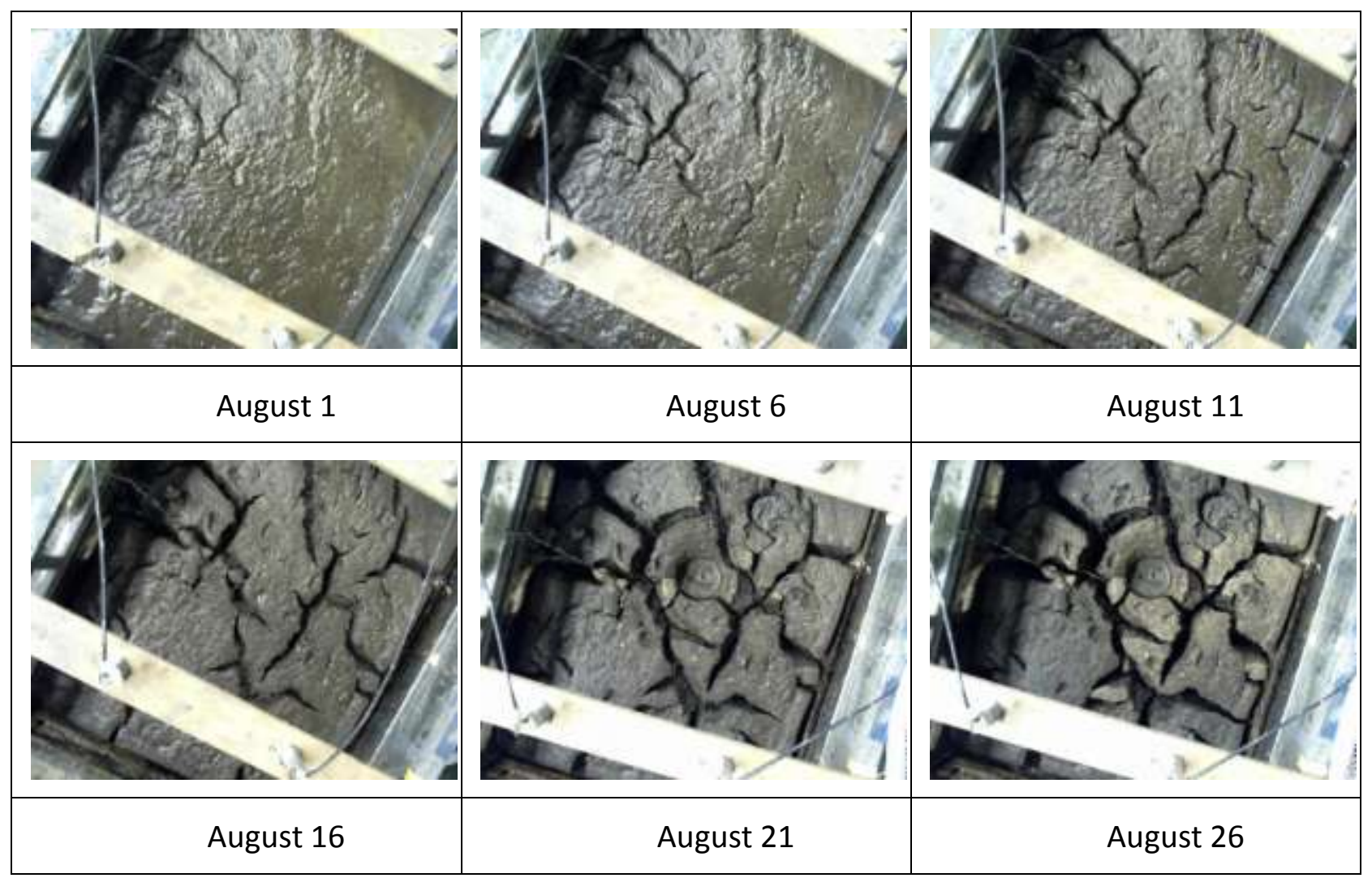

Figure 4.1-55. Progression of cracking - Layer 3 
Figure 4.1-56 shows the settlement of the tailings. The vertical line represents the height of the tailings if they were deposited instantaneous. Since this was not the case, the actual tailings height diverges due to the ability of the dry underlying dry tailings to absorb moisture.

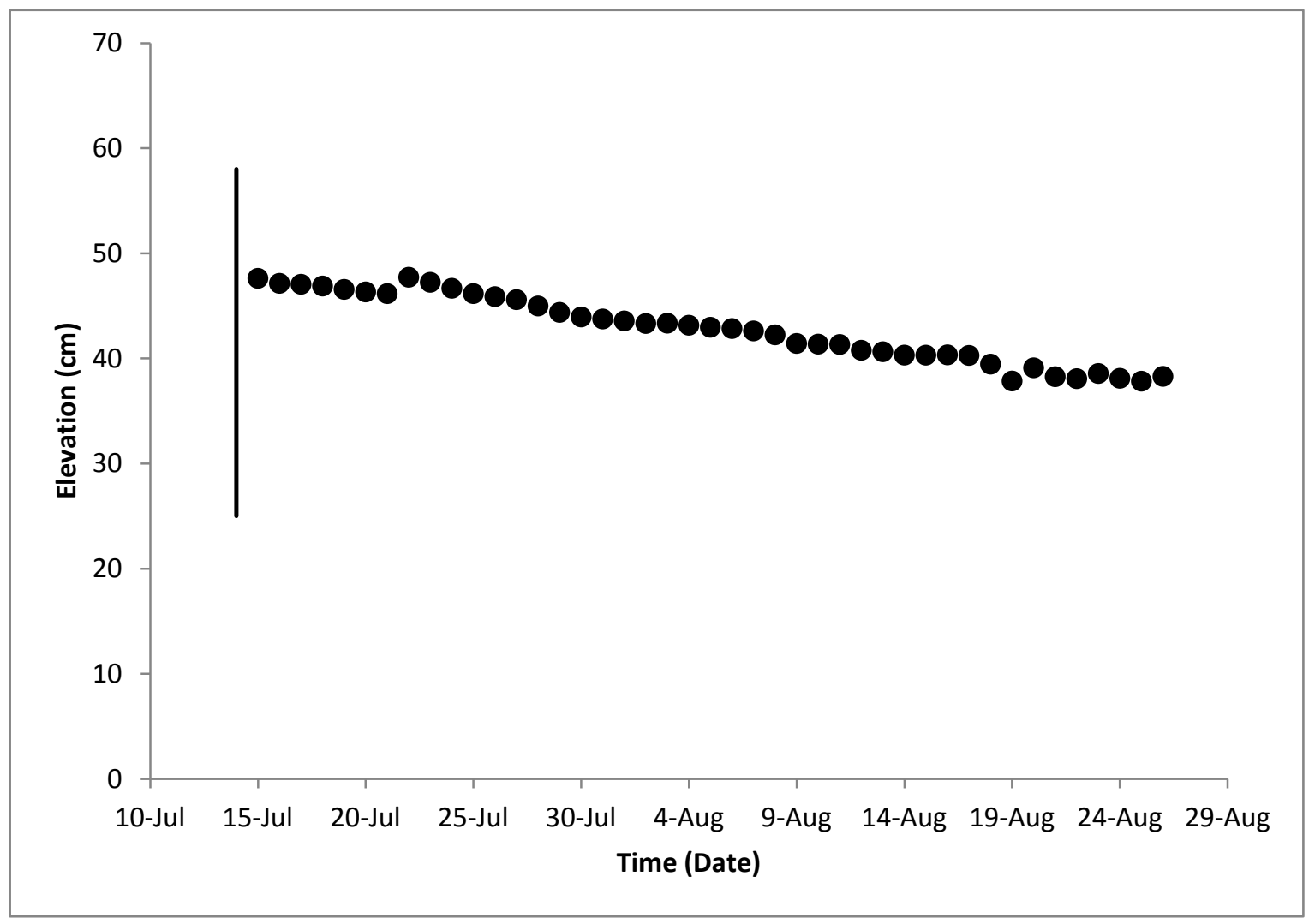

Figure 4.1-56. Settlement of tailings - Layer 3

Based on the settlement and water loss results, the overall void ratio was calculated and plotted in Figure 4.1-57. This figure shows the change in void without considering cracks, and considering the influence of cracks. There is no considerable difference in both sets of data at the beginning, but as cracks began to appear and grow in size, there is a difference of about 0.2 . 


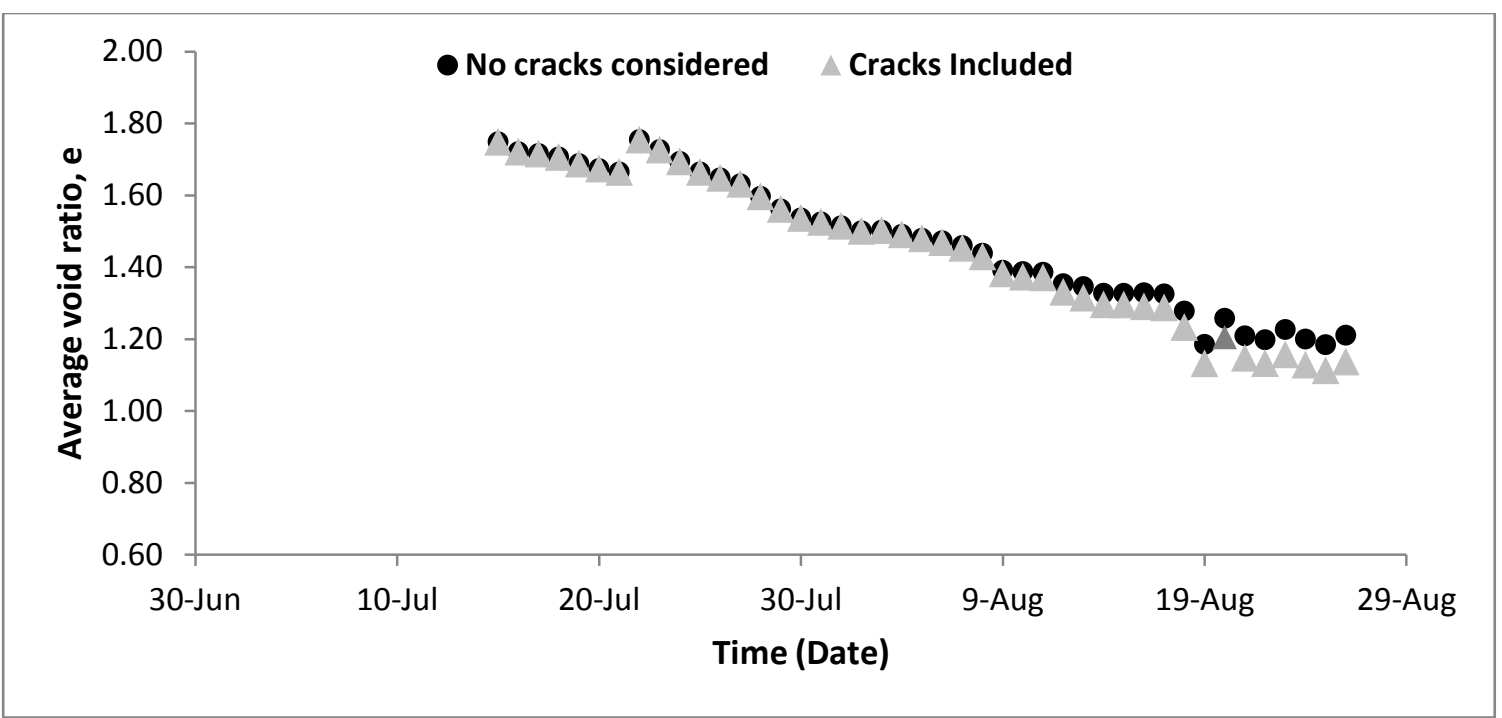

Figure 4.1-57. Average void ratio - Layer 3

\subsubsection{Volume Change}

Upon placement of the third layer, the VWC sensors in the first layer converged to a value of approximately 0.35 (uncalibrated), or 0.5 (calibrated) as shown in Figure 4.158.

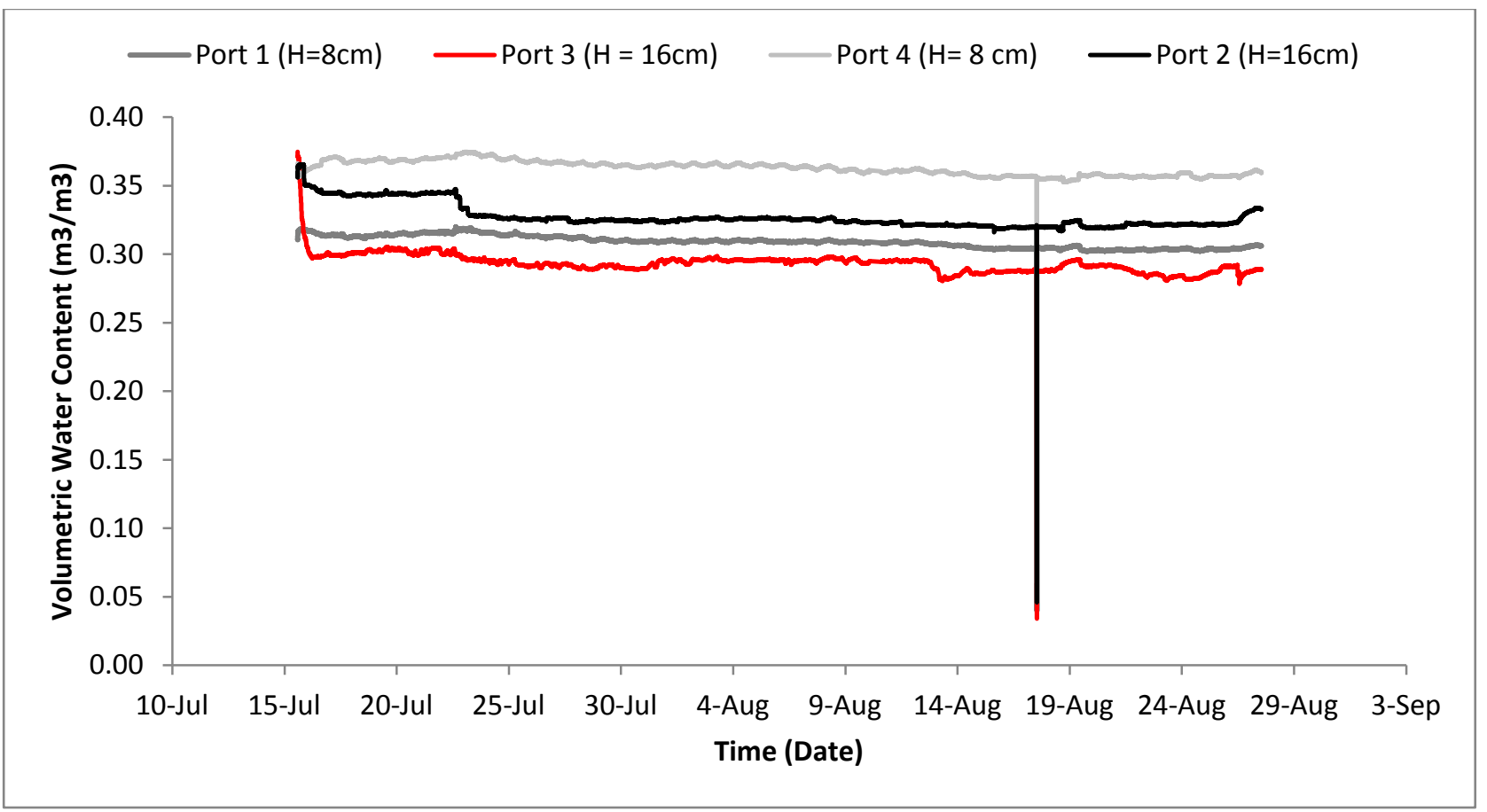

Figure 4.1-58. Volumetric water contents at various heights - Layer 3 
Upon the addition of layer 3, two more VWC sensors were placed, one at the bottom of the fresh layer, and one at the top. Figure 4.1-59 presents the data collected by these two sensors for the drying time of layer 3 and the sensors that remained in layer 2 . The sensors in layer 2 converge to a value of approximately 0.4 , while the new sensors in layer 3 start out at approximately the same value and diverge as the tailings dry out. The trends in these sensors are also very similar to the sensors that were added in layer 1 and 2 upon deposition.

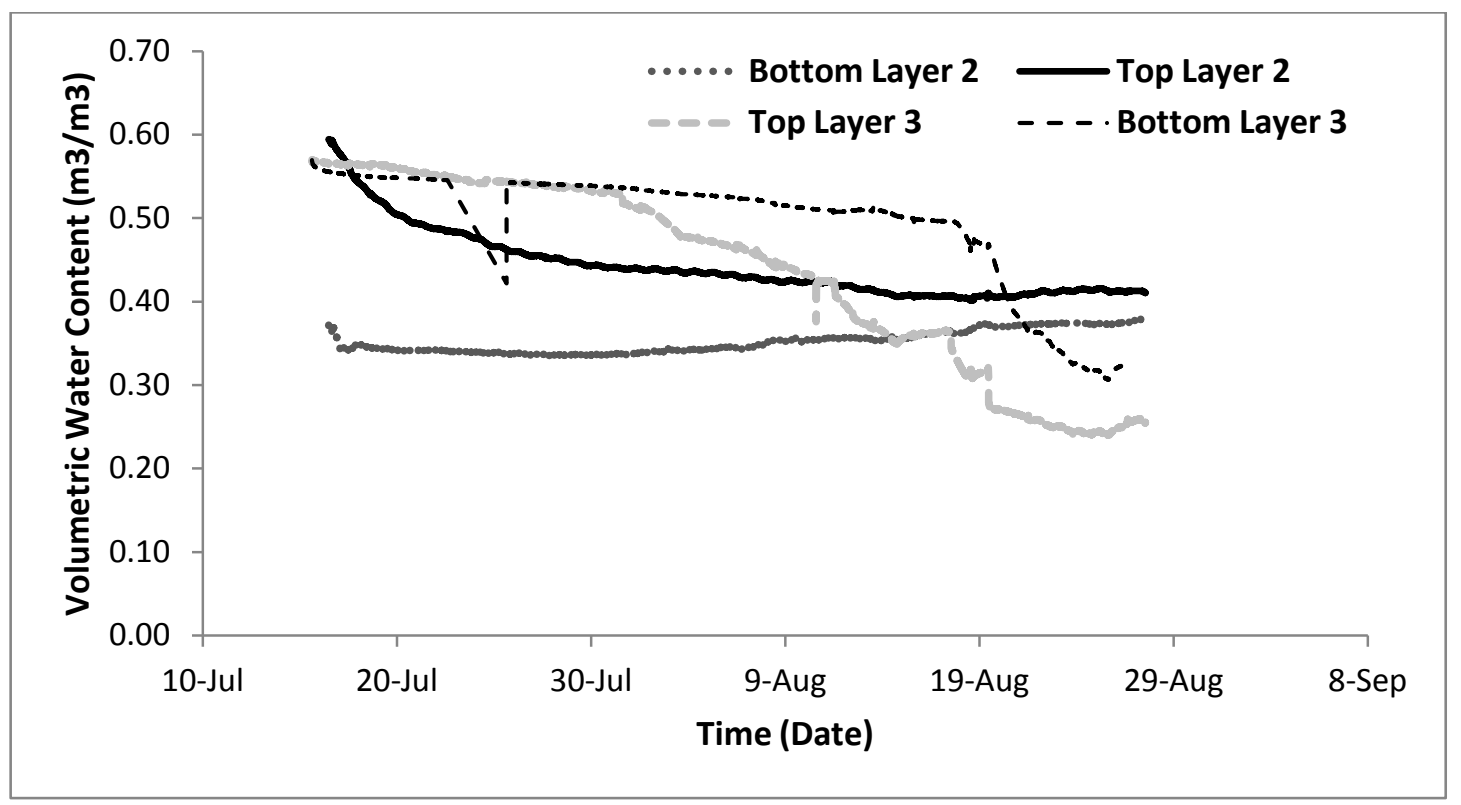

Figure 4.1-59. Volumetric water contents at various heights in top layer - Layer 3

\subsubsection{Water Content}

The overall GWC in layer 3 is shown in Figure 4.1-60, as well as results for surface measurements within the top $1 \mathrm{~cm}$ after the supernatant water that had collected at the top of the tailings had evaporated. There is a steady decrease in overall GWC from $86 \%$ to $46 \%$ while the surface GWC decreases from $63 \%$ to $11 \%$. 


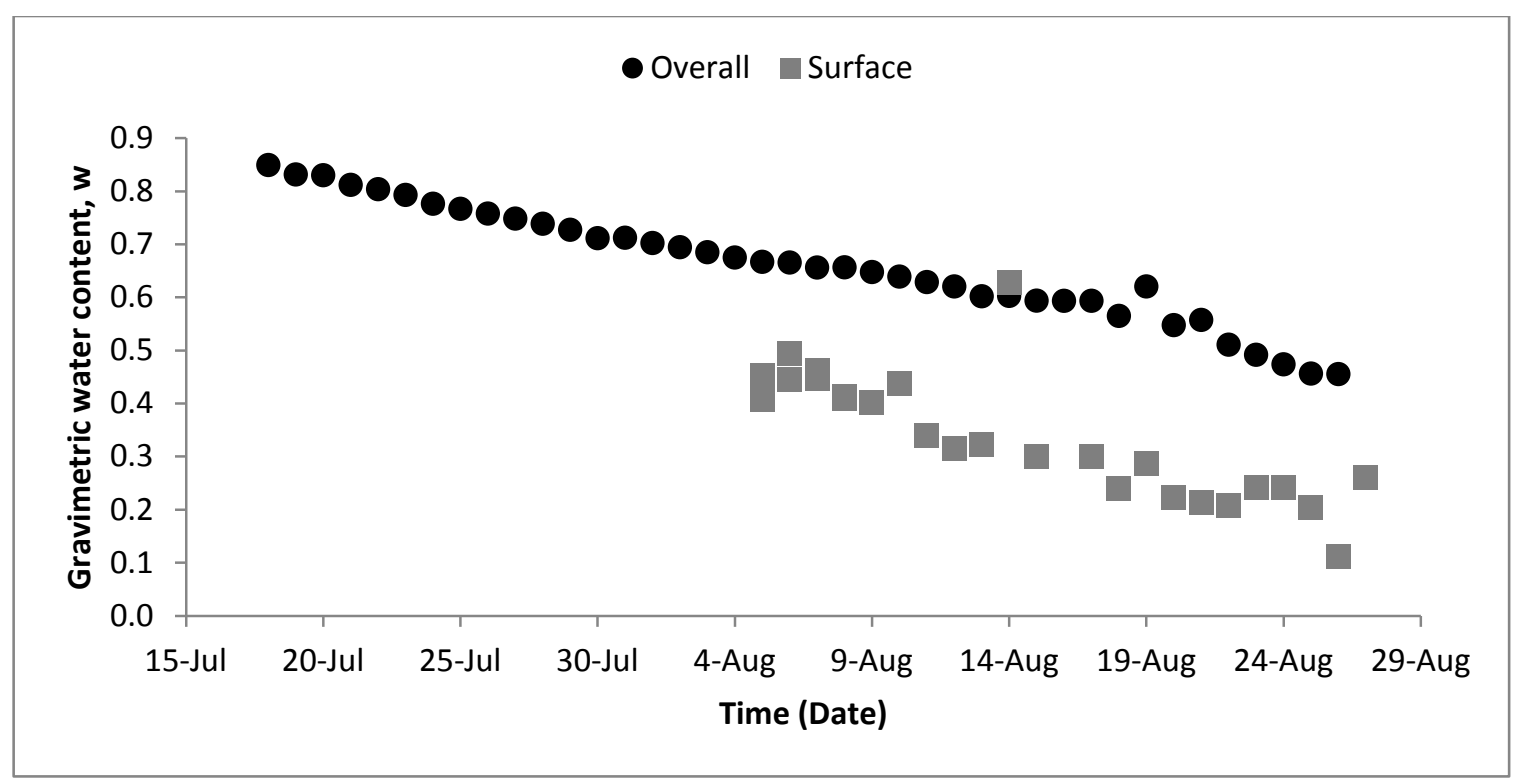

Figure 4.1-60. Gravimetric water contents - Layer 3

Surface samples taken at various locations once cracks began to form are shown in Figure 4.2-61.

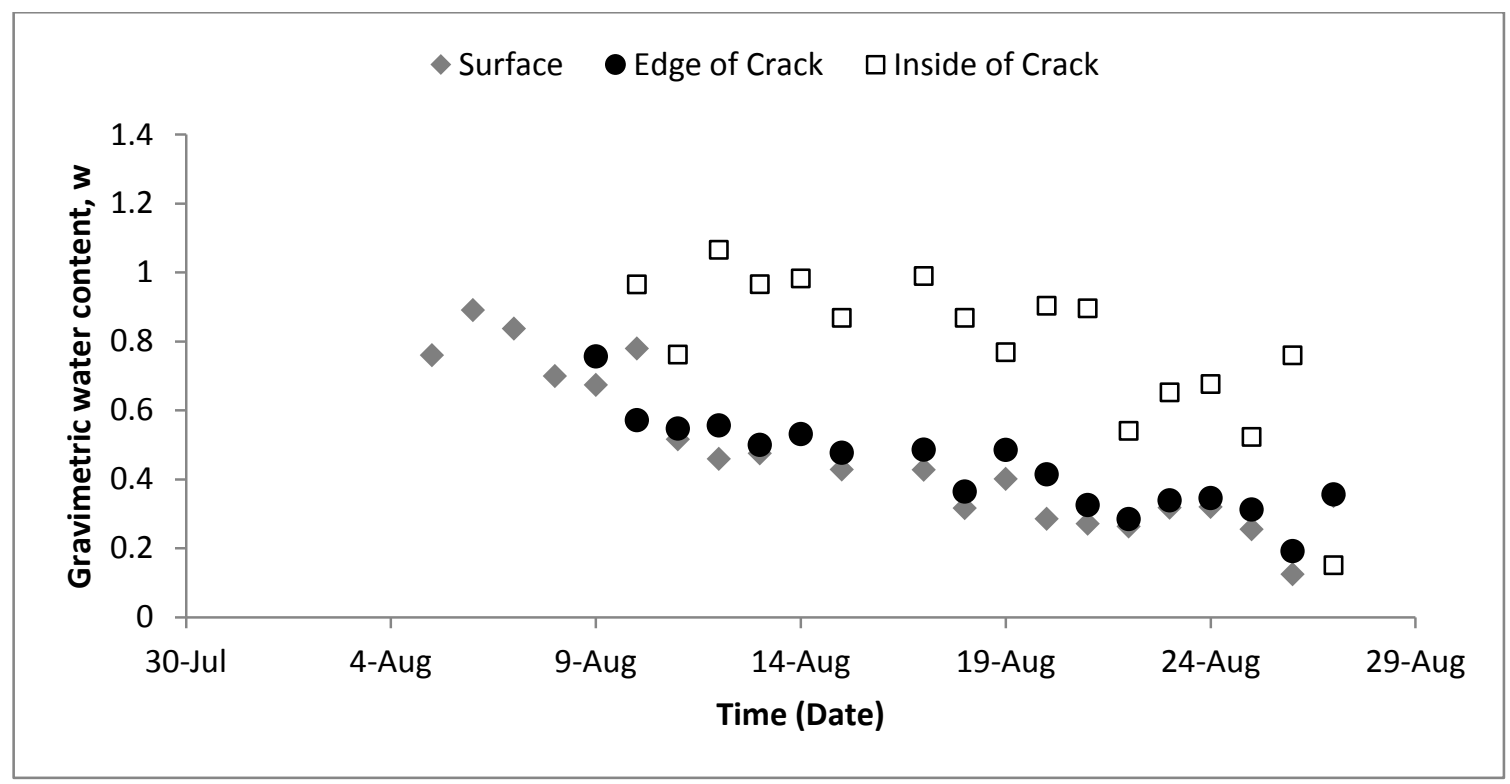

Figure 4.1-61. Surface sample gravimetric water contents - Layer 3 
Generally the IC measurements exhibit the greatest difference in GWC in this layer. The differences in values are higher between IC and the other two locations. The Figure shows that the values for CE and surface measurements are decreasing at the same rate, while for IC the rate is gentler.

From the VWC obtained from the sensors in layers 1 and 2 it was possible to calculate the SC in the third layer only. The overall, top layer and surface SCs are shown in Figure 4.1-62.

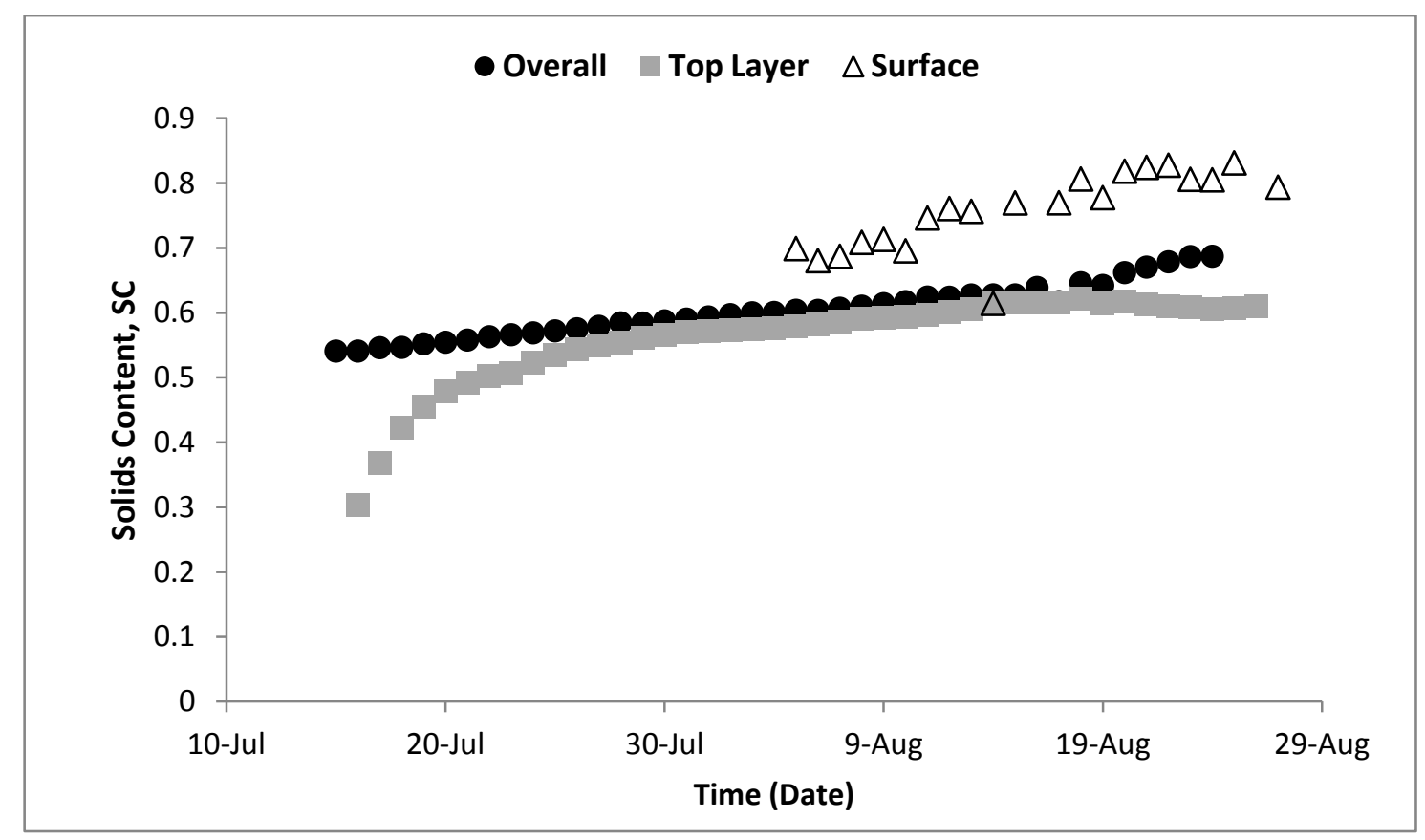

Figure 4.1-62. Solids contents - Layer 3

The overall SC increased from $54 \%$ to $70 \%$. The initial SC is greater than that of the added tailings since it takes into account the underlying tailings from the first two layers. The figure shows that the drying rate is consistent over the entire drying period. From this figure, the rate of increase in density is about the same as in layer 2. However, the SC in the top layer never surpasses the overall SC in this layer. 
Figure 4.1-63 provides a breakdown of the SCs at the surface, CE and IC surface samples.

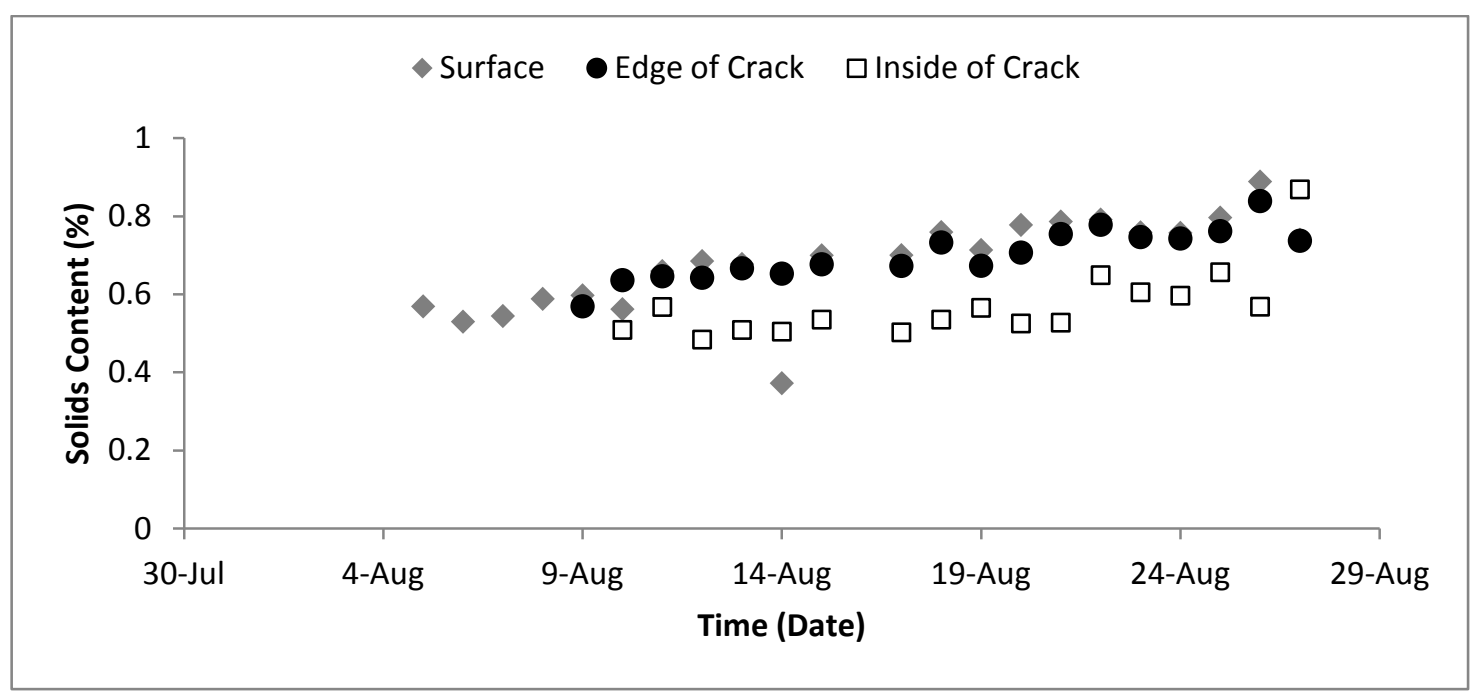

Figure 4.1-63. Surface sample solids contents - Layer 3

Figure 4.1-64 shows the variation in overall degree of saturation in Layer 3 throughout the test.

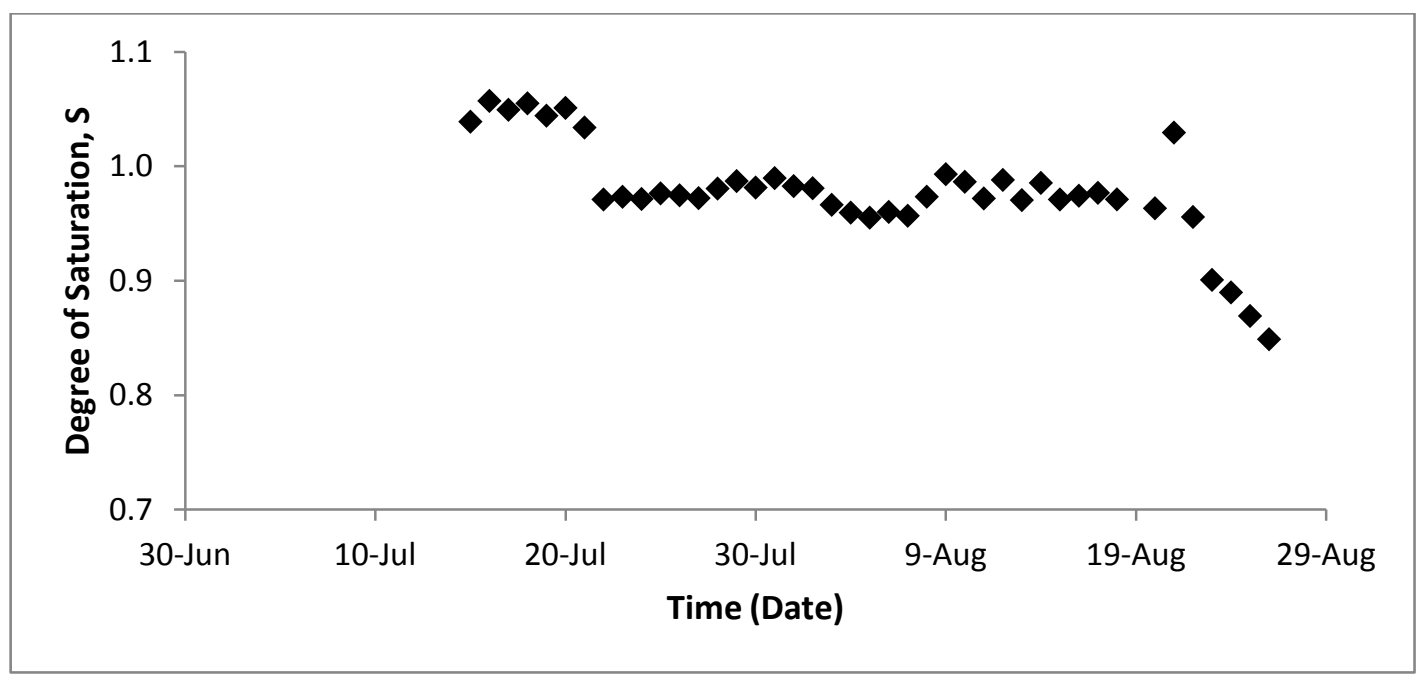

Figure 4.1-64. Overall degree of saturation - Layer 3 


\subsubsection{Suction}

This section provides results for measurements for matric, osmotic, and total suctions in various locations for Layer 3.

\subsection{Matric Suction}

Two more tensiometers were added to layer 3 upon deposition, as shown in figure 4.1-65. The tensiometers in layer 2 were also left to record matric suction values. Both of these tensiometers, however, converged to one single suction value. The top tensiometer in layer 3 did rise up to a maximum suction of almost $200 \mathrm{hPa}$ and then cavitated.

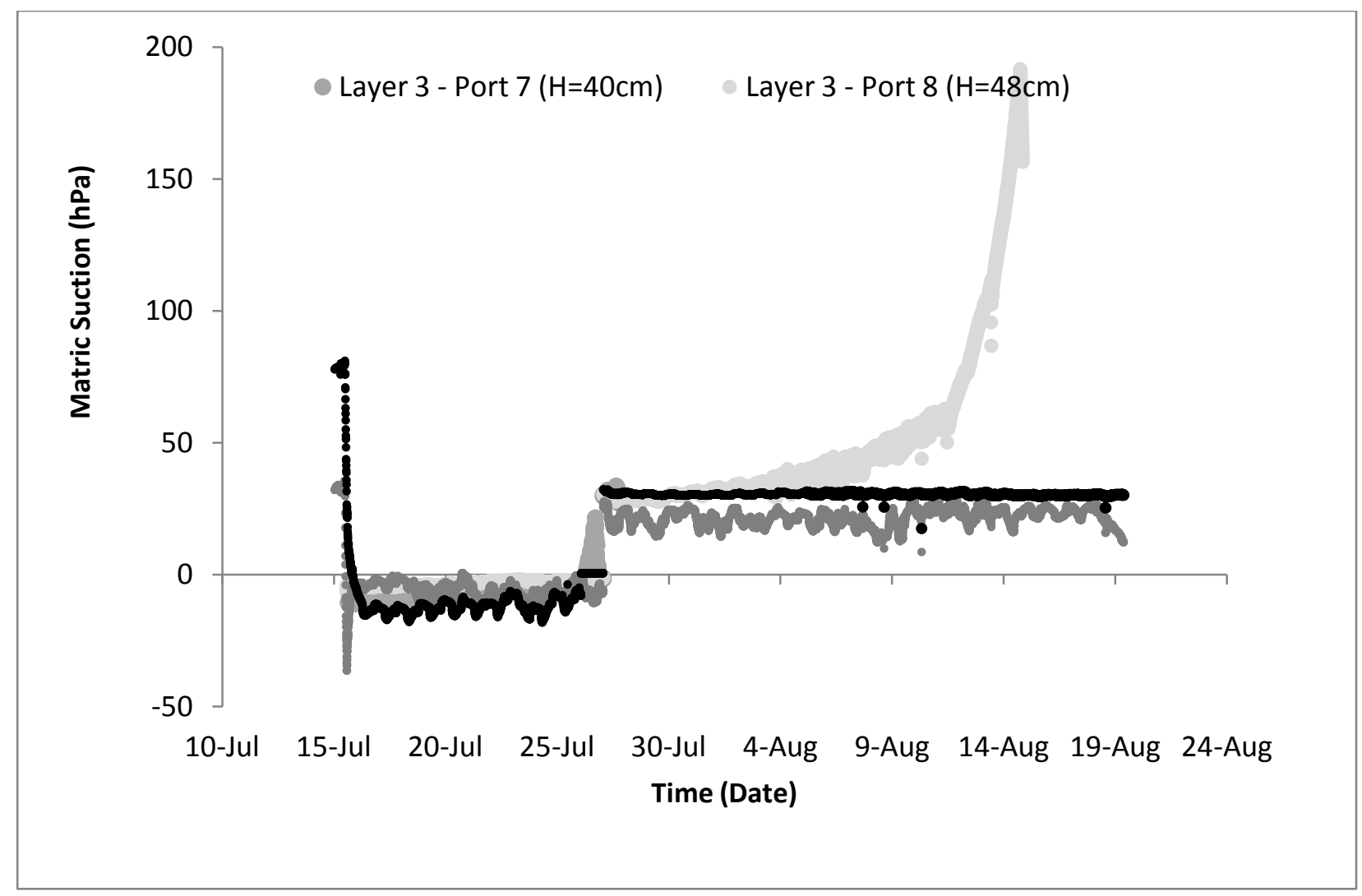

Figure 4.1-65. Matric suction at various heights - Layer 3 


\subsection{Osmotic Suction}

Daily EC measurements at the surface are shown in Figure 4.1-66.

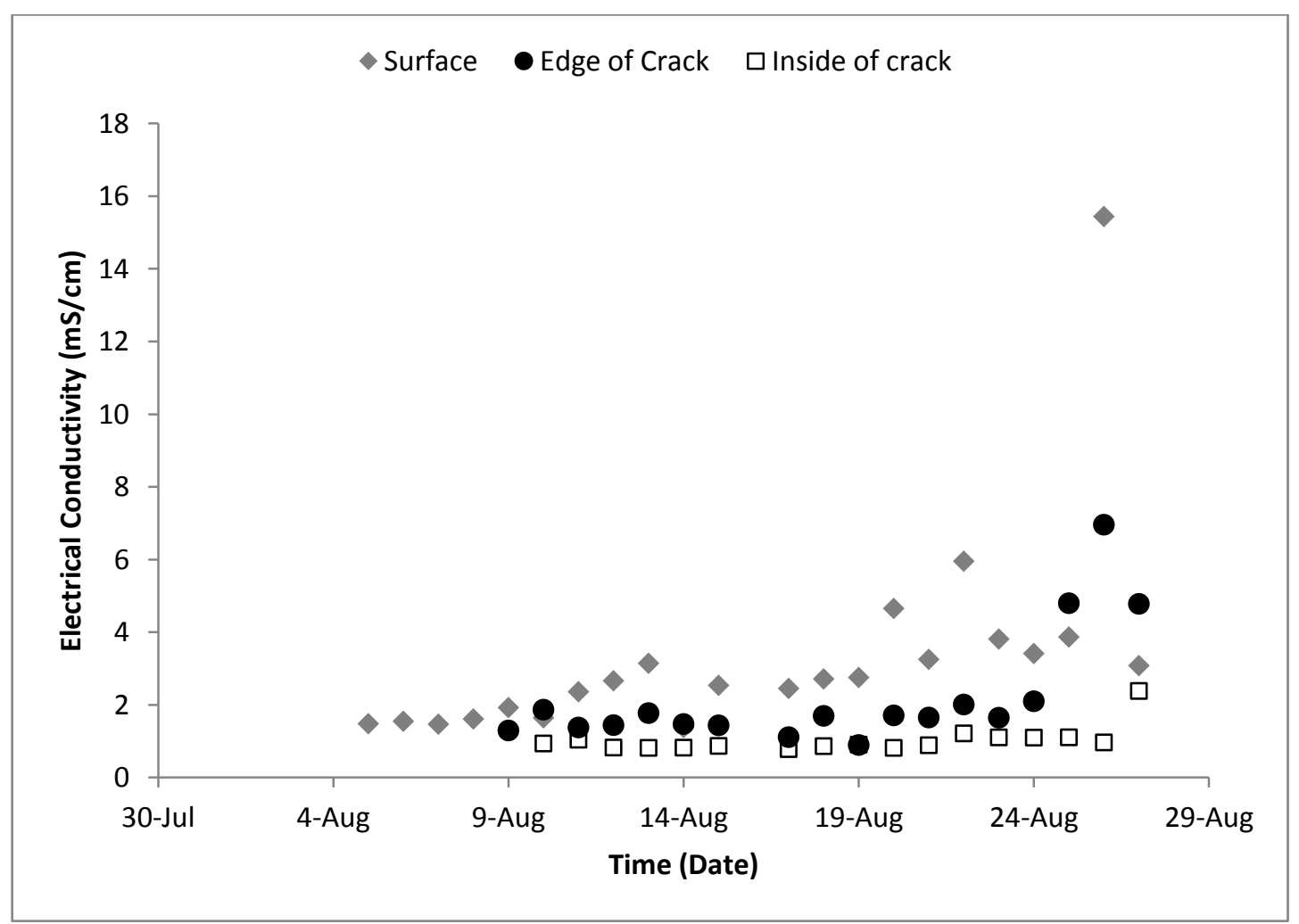

Figure 4.1-66. Surface sample electrical conductivity - Layer 3

A comparison of osmotic suction to total suction is shown in Figure 4.1-67. The total suction is always greater than the osmotic component. The osmotic suction forms a greater part of the suction at the beginning, up to around August $21^{\text {st }}$ when the osmotic suction becomes much smaller than the total suction. 


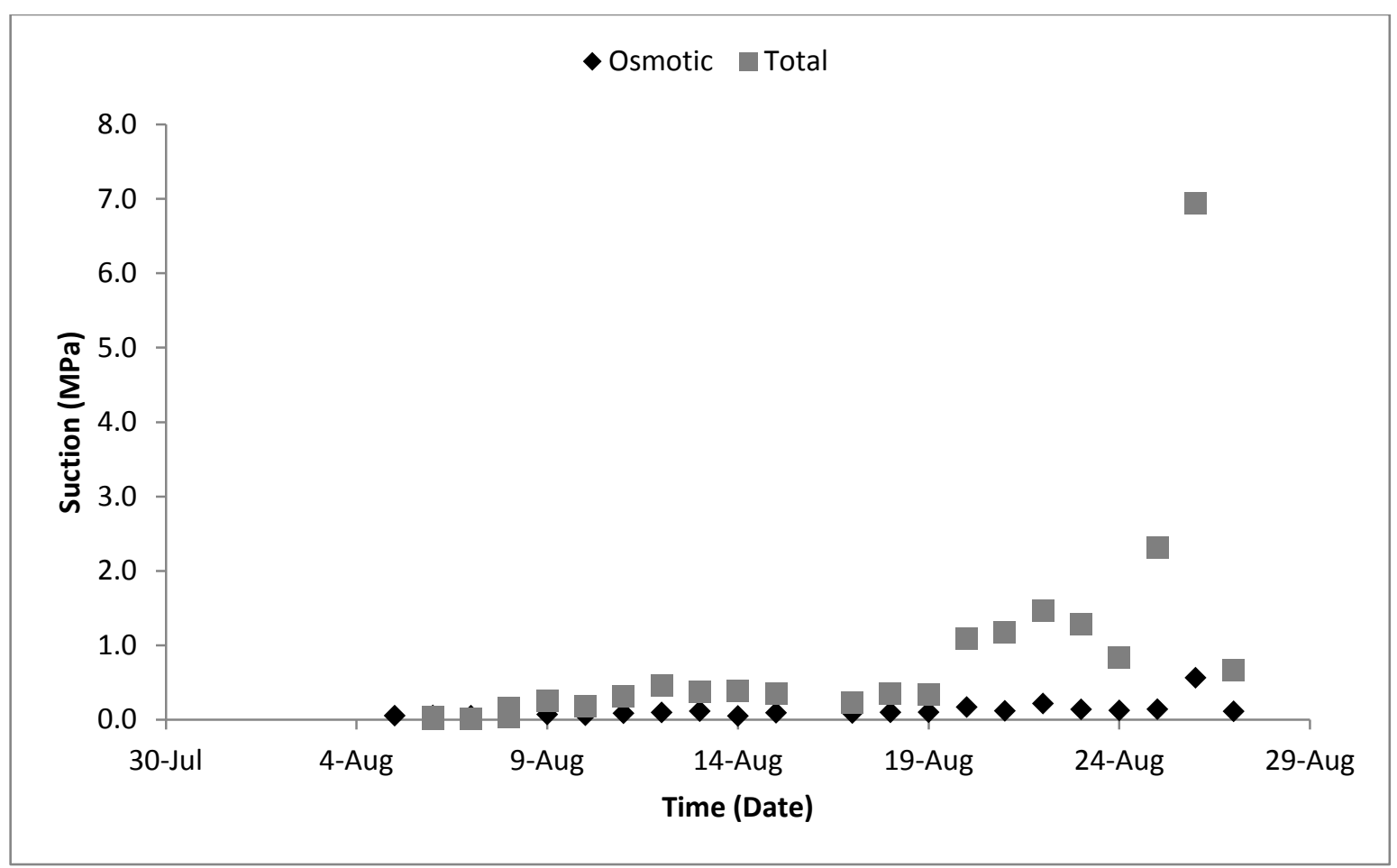

Figure 4.1-67. Surface sample total and osmotic suctions - Layer 3

\subsection{Total Suction}

Samples extracted from the top $1 \mathrm{~cm}$ of the surface of the tailings, crack edges and the ICs were measured for total suction using a WP4-C potentiometer. These results are shown in Figure 4.1-68.

Overall, suction values at the surface increased as water escaped the tailings. The CE measurements never surpassed those of the surface in this layer, unlike the other two layers. The IC values were always lowest. The suction values in this layer did not reach the same suction as those of layer 1 , since the layer was not dried out to the same extent, but they did exceed those of layer 2 . 


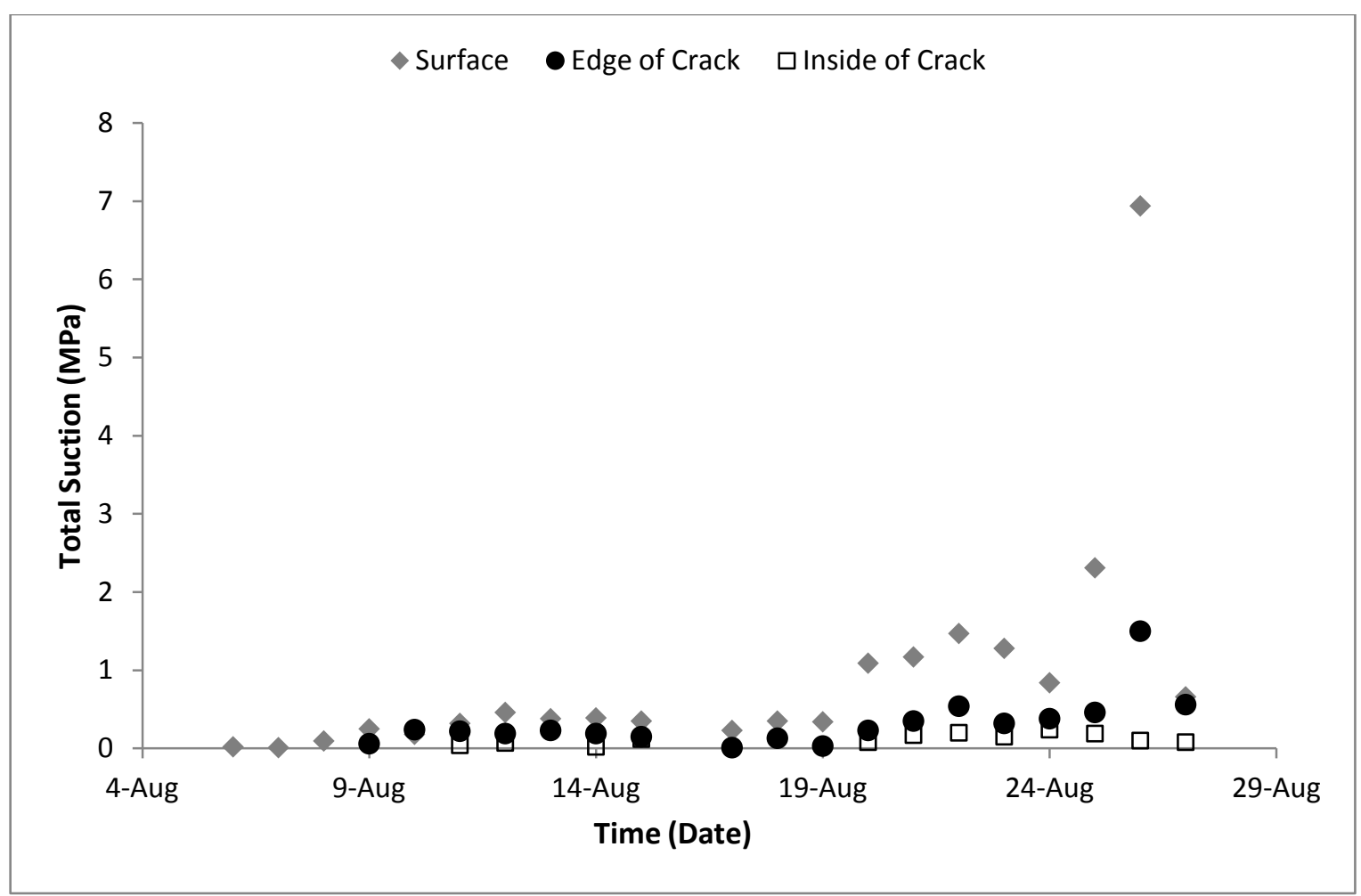

Figure 4.1-68. Surface sample total suctions - Layer 3

\subsubsection{Core Sample}

A core sample was extracted once the layer had reached $70 \%$ overall SC on August $26^{\text {th }}$. The location of the core sample is shown in Figure 4.1-69. 


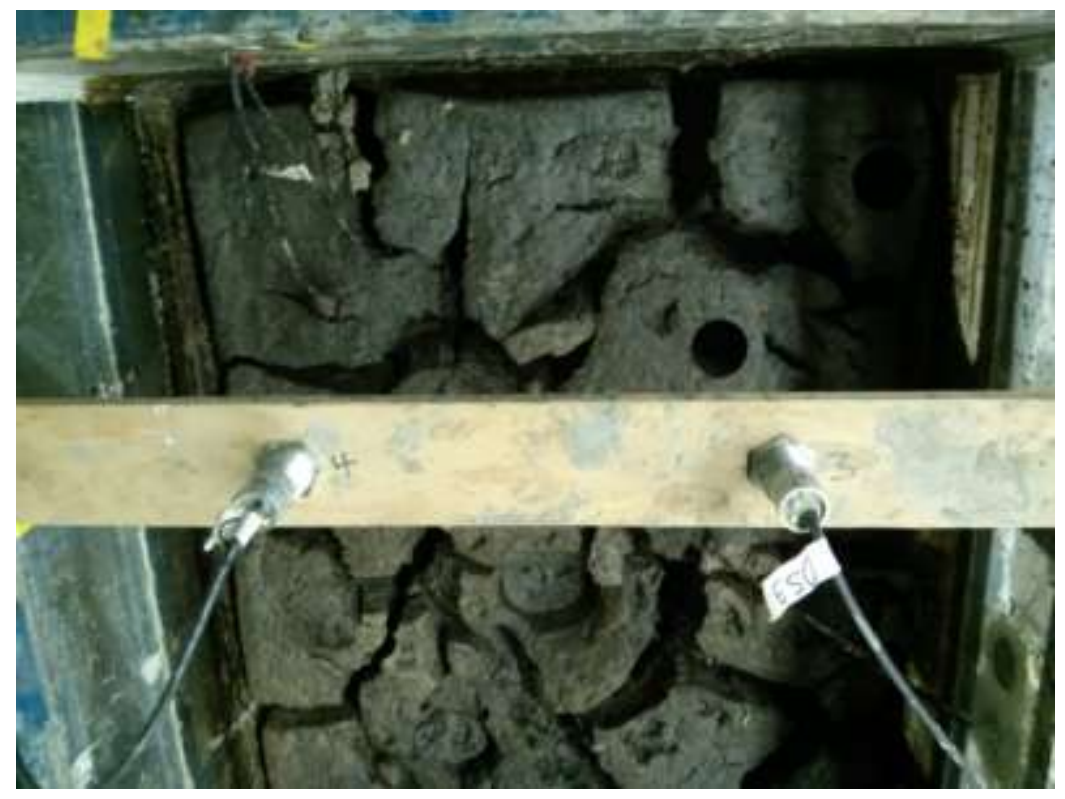

Figure 4.1-69. Core sample location - Layer 3

The core was analysed for GWC, SC, osmotic suction, total suction and TOC every $1 \mathrm{~cm}$. The core sample is shown in the following figures, along with the extracted depth.

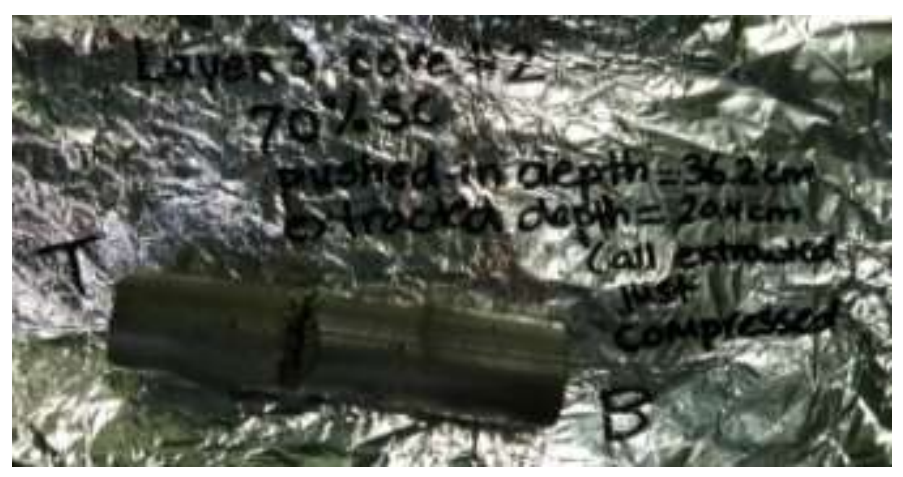

Figure 4.1-70. Core sample - Layer 3

. The following figure is related to water content with depth, as well as the TOC. 


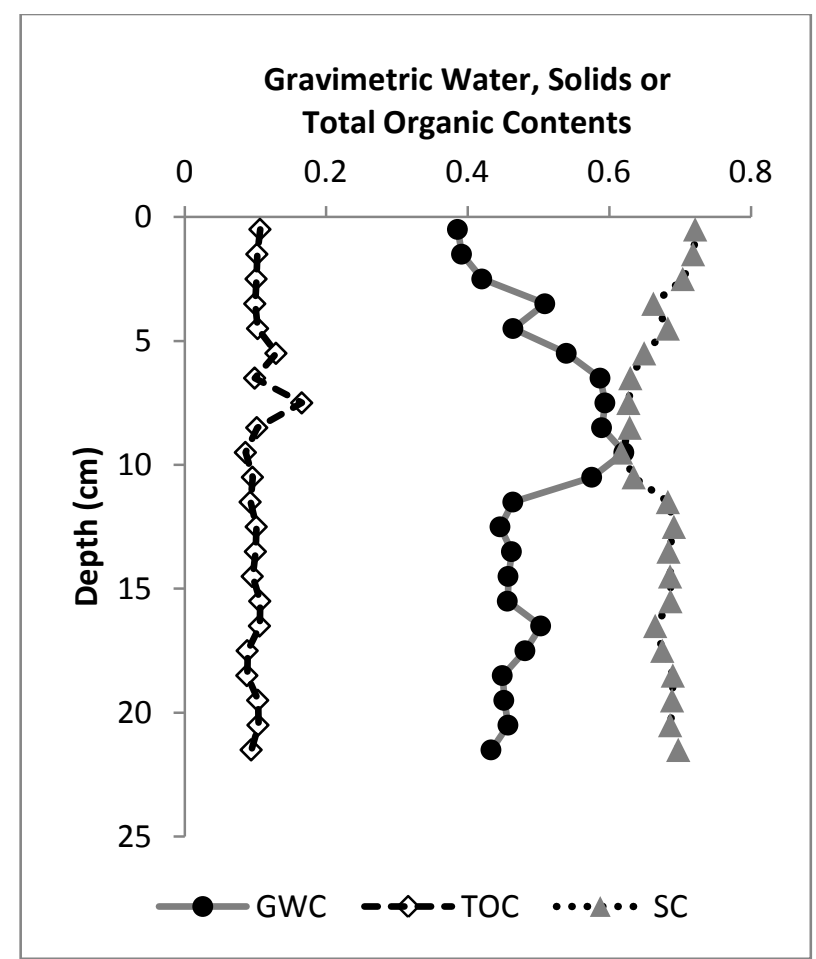

Figure 4.1-71. Core GWC, TOC and SC profiles - Layer 3

The following figures are related to osmotic and total suction with depth.
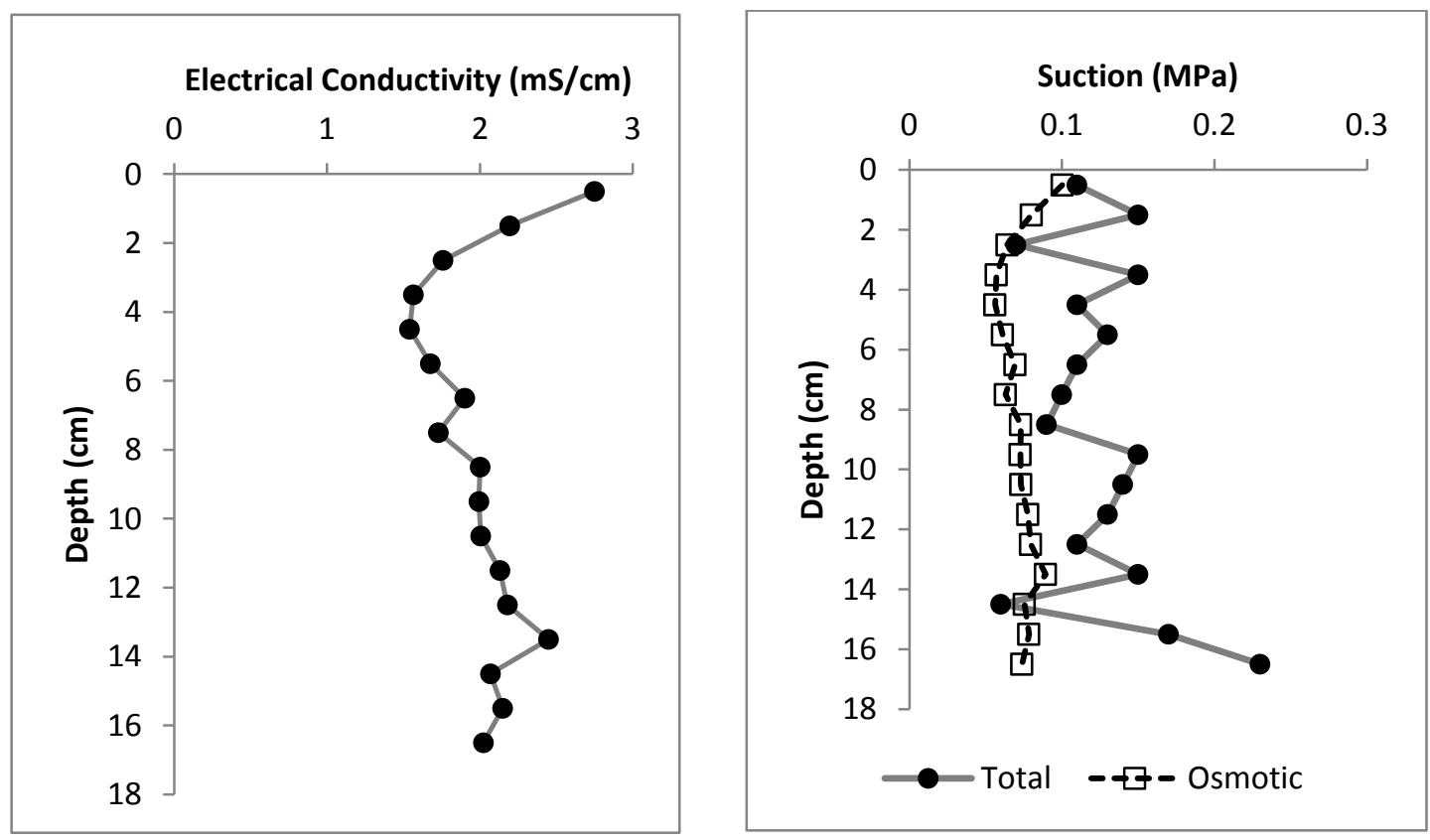

Figure 4.1-72. Core EC, and total and osmotic suction profiles - layer 3 


\subsubsection{Undrained Shear Strength}

Vane shear tests were conducted in conjunction with core extraction. The locations of these tests are right next to the locations of the core extraction. Figure 4.1-73 shows the results from these tests. The undrained shear strength decreases with depth up until the top of the previous layer, where the values increase.

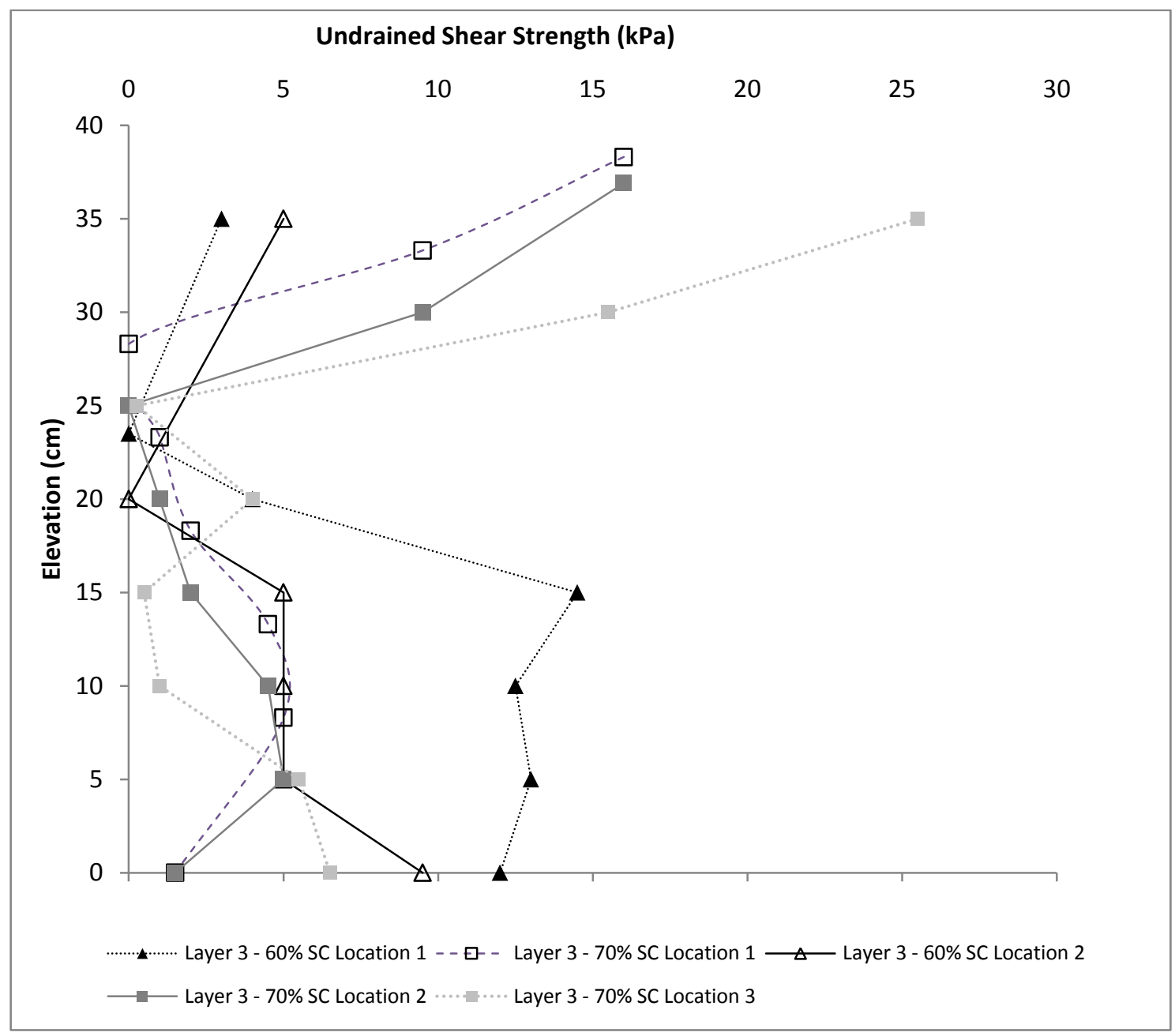

Figure 4.1-73. Undrained shear strength profiles - Layer 3 


\subsubsection{Thin-Lift Dry Box Overall Results}

This section provides a compilation of selected thin lift dry box results for all three layers.

\subsubsection{Mass Loss, Evaporation and Drainage}

Figure 4.1-74 shows the temperatures recorded by the VWC sensors in the tailings and the temperature recorded by the $\mathrm{RH}$ sensor above the tailings. Generally, temperatures varied from 13-28 degrees Celsius, but were higher at the surface most of the time.

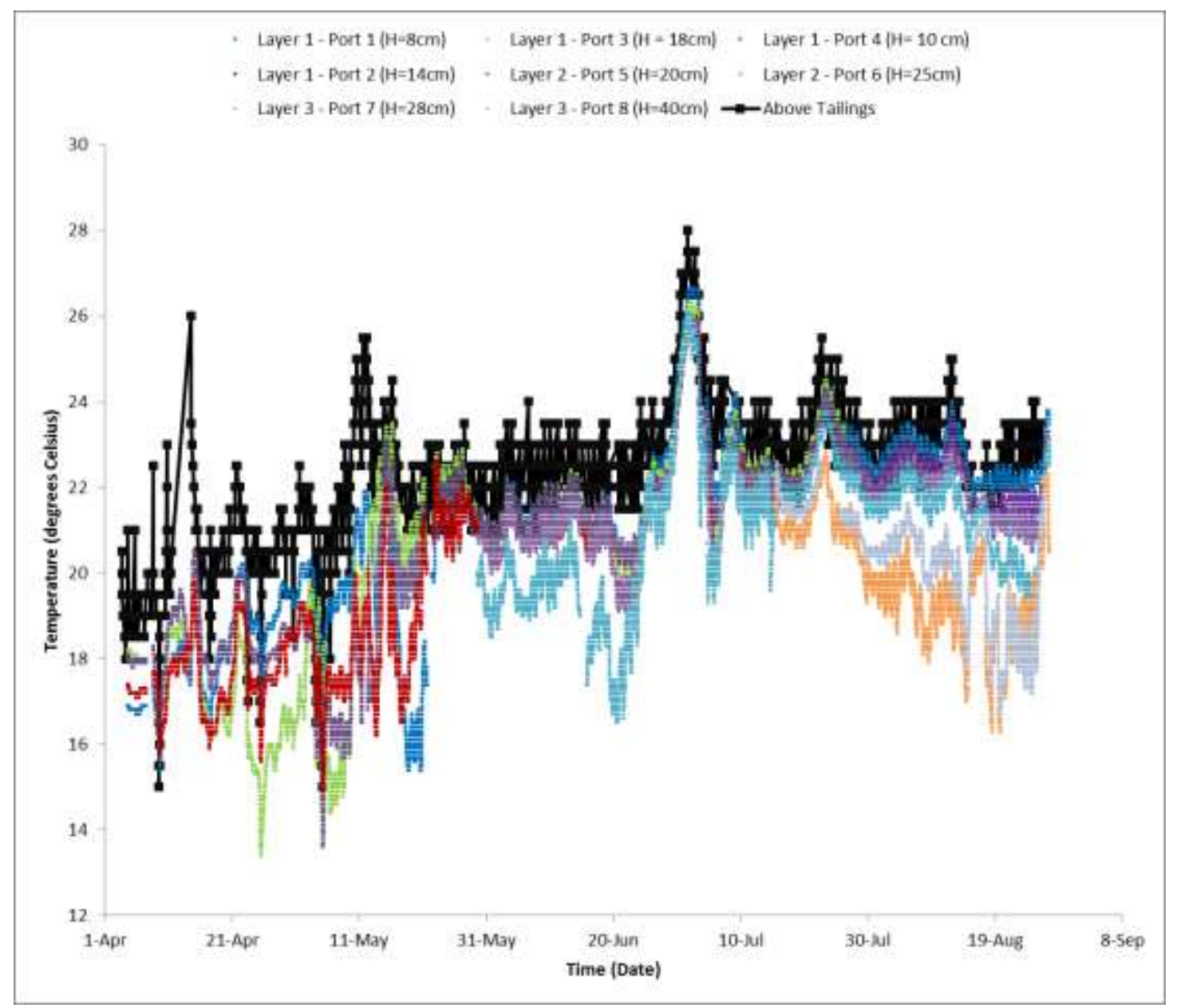

Figure 4.1-74. Volumetric water contents at various heights - Overall 
Figure 4.1-75 provides a distribution of temperature with elevation plotted shortly before the end of drying for all layers. The temperature is always highest at the bottom and decreases with elevation.

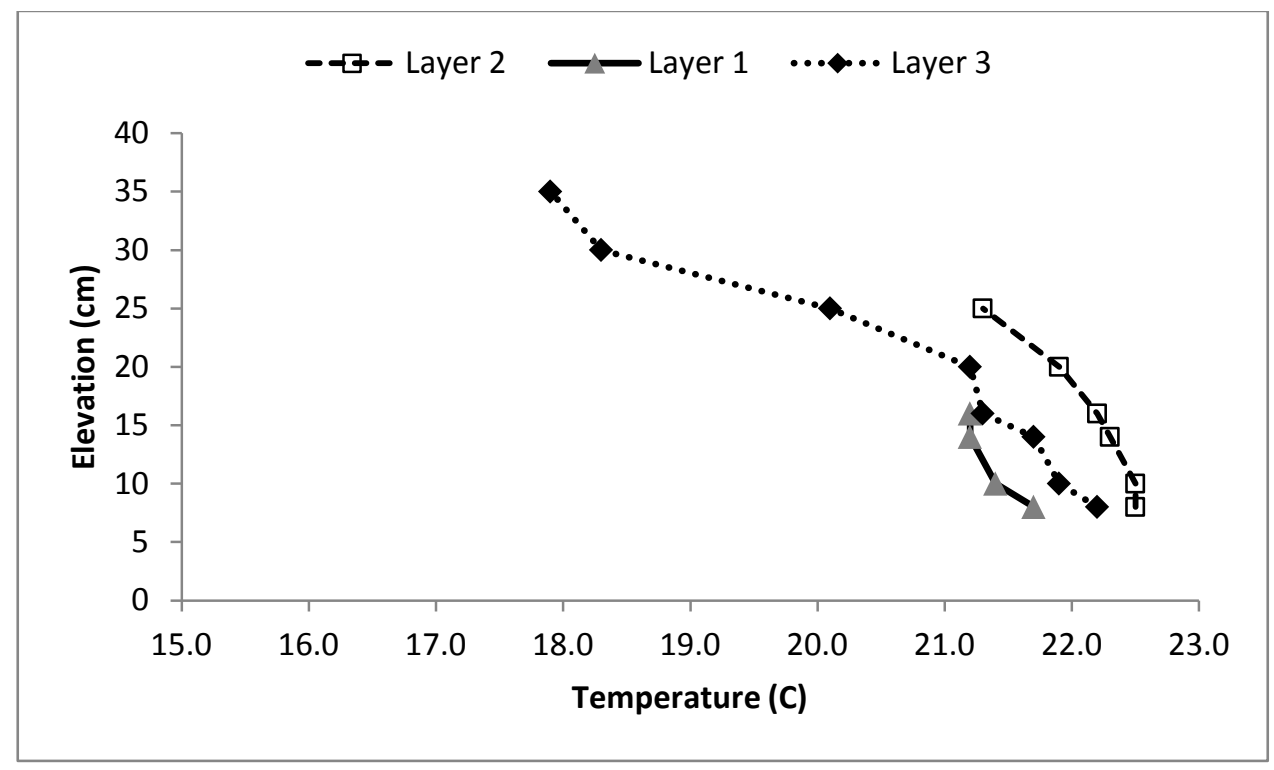

Figure 4.1-75. Thin lift dry box temperature profiles

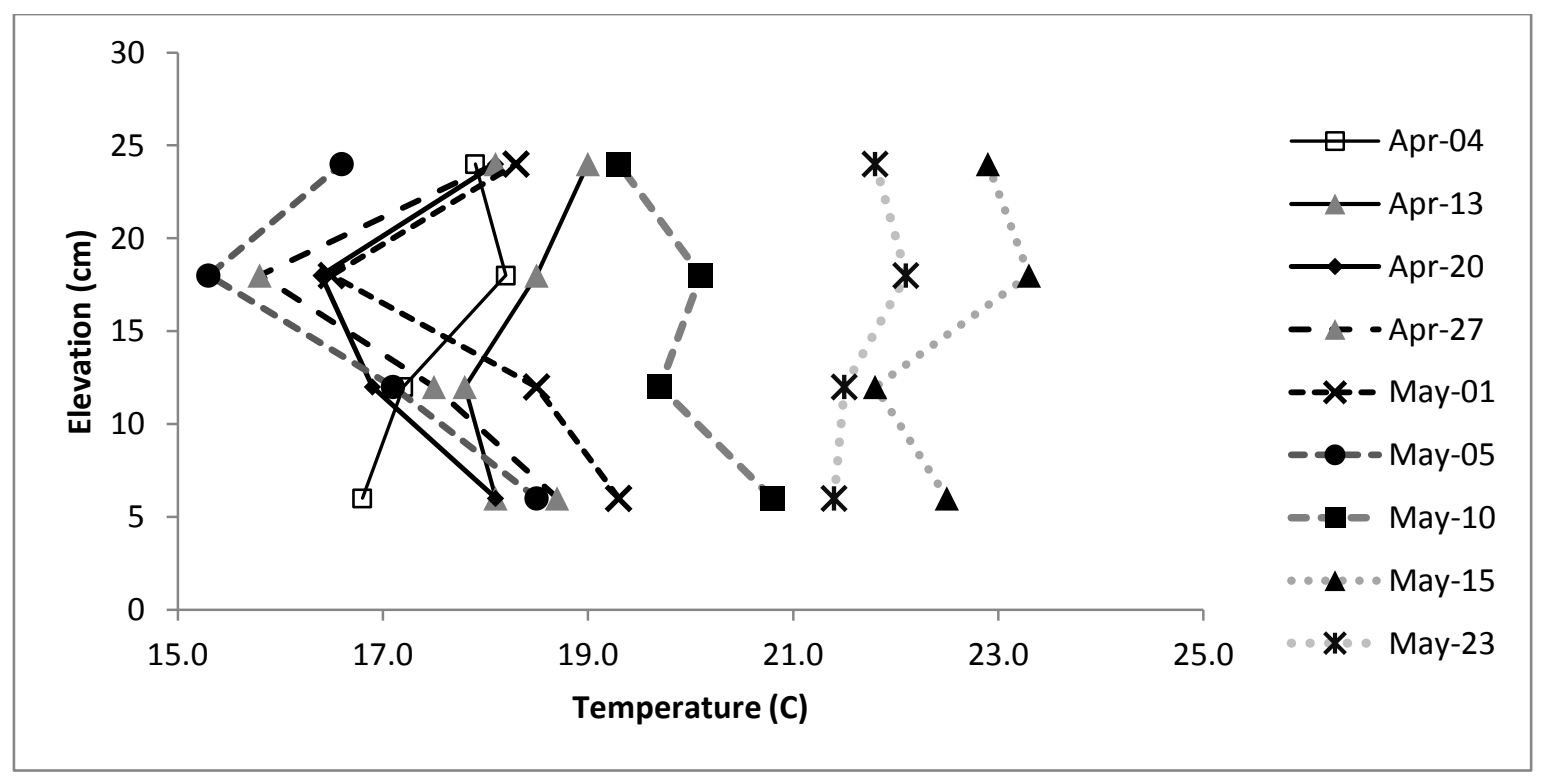

Figure 4.1-76. Thin lift dry box temperature profiles over time - Layer 1 
Figure 4.1-76 provides a distribution of temperature with elevation for layer over time. The tailings start with a higher temperature near the surface and lower at the bottom. As time progresses, lower temperatures are seen near the top and higher at the bottom.

The evolution of $\mathrm{RH}$, temperature and dewpoint is shown in Figure 4.1-76. Temperatures varied from 15-23 degrees Celsius throughout the experiment. The RH shows a gradual but substantial increase from April to mid-June, as the seasons change from spring to summer. The change in the $\mathrm{RH}$ is reflected in the variation of the predicted PE rate, shown in Figure 4.1-77, which gradually decreases from $4 \mathrm{~mm} /$ day to $2.5 \mathrm{~mm} /$ day.

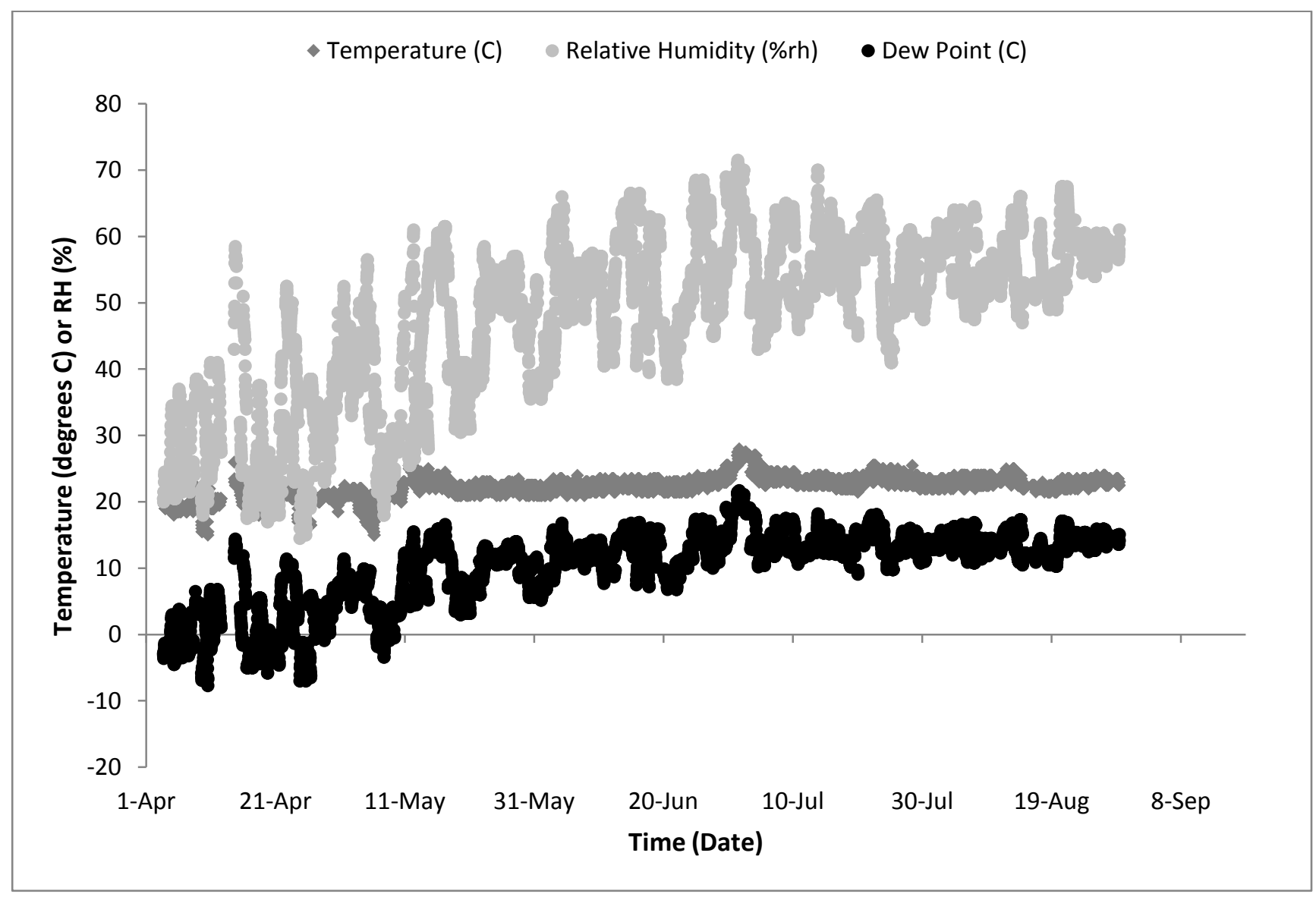

Figure 4.1-77. Temperature, $\mathrm{RH}$ and dewpoint profiles above the tailings - Overall 
Figure 4.1-78 shows $\mathrm{AE}, \mathrm{PE}$ and drainage, where the calculated PE assumes a constant surface area. Deposition of each lift occurred on April $3^{\text {rd }}$, May $26^{\text {th }}$, and July $17^{\text {th }}$. AE matches closely with the predicted PE values from after deposition until May $5^{\text {th }}$, June $13^{\text {th }}$, and August $17^{\text {th }}$ for each layer, after which there is a period where AE substantially exceeds PE.

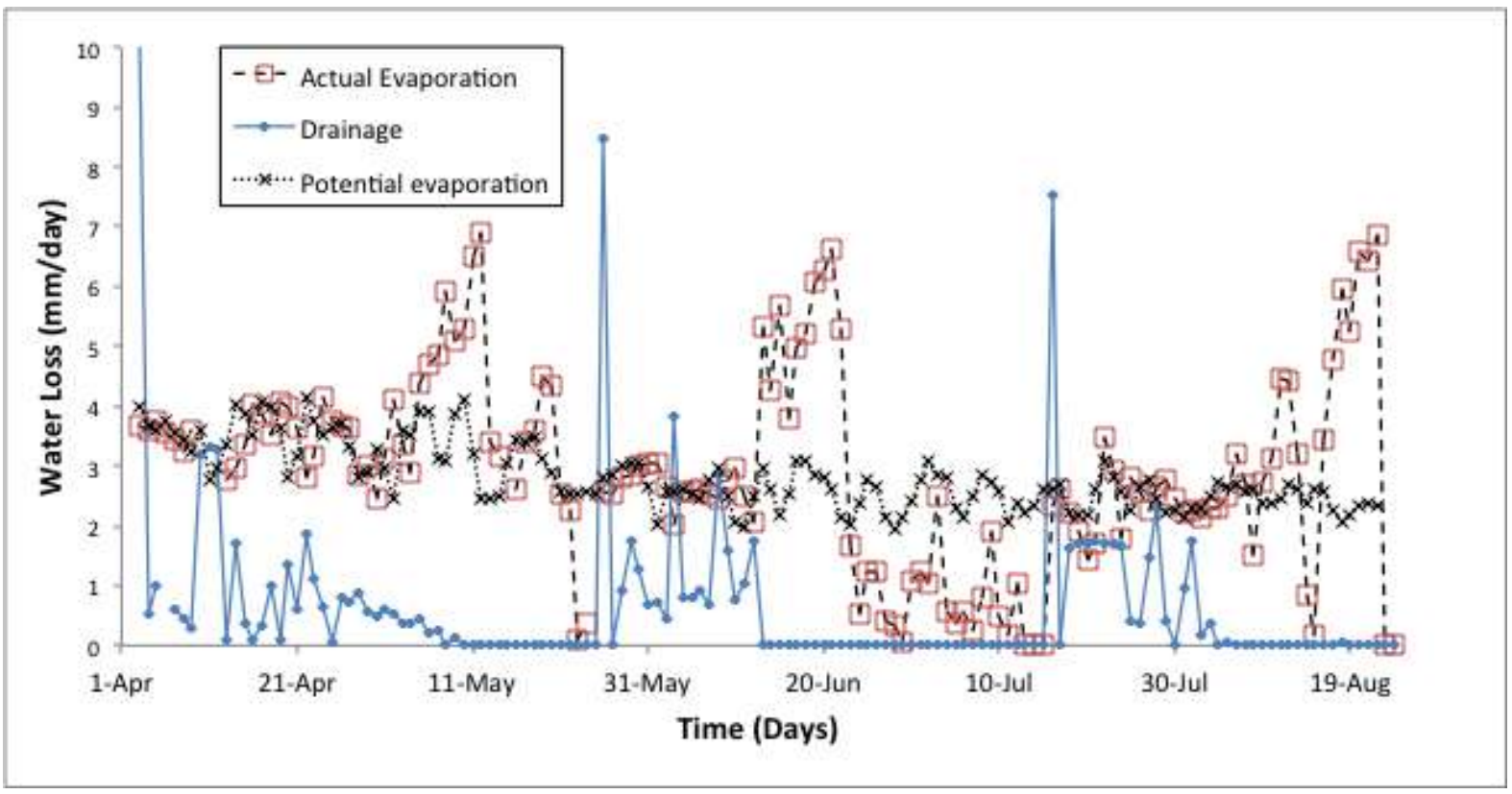

Figure 4.1-78. AE, PE and drainage - Overall

The start of this period correlates with the commencement of cracking, and ends when crack development stops. Figure 4.1-79 shows the evolution of crack geometry and evaporation is compared to crack volumes. 


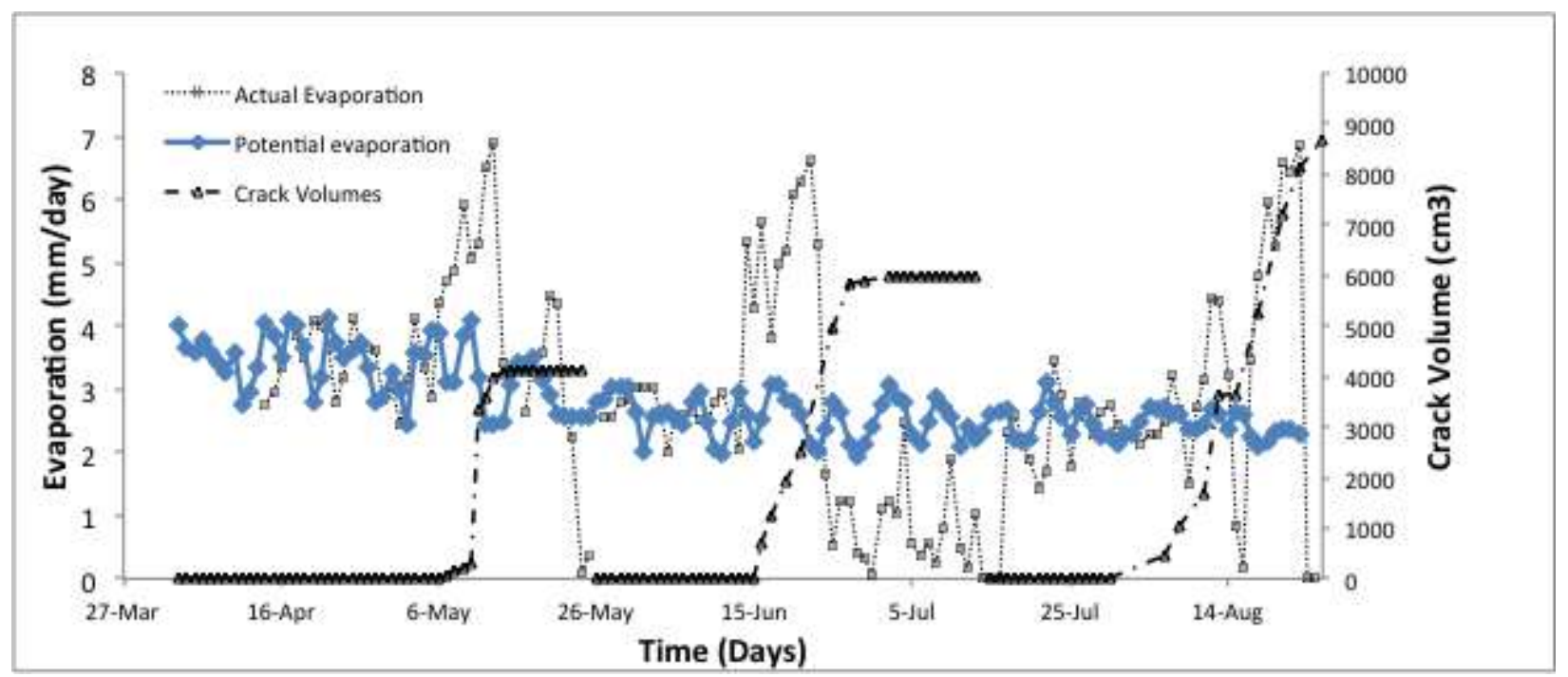

Figure 4.1-79. Evaporation vs. cracking - Overall

The evaporative behaviour can be divided into three phases

1) $A E$ is close to the $P E$;

2) $A E$ exceeds $P E$ and is co-incident with crack growth; and

3) $\mathrm{AE}$ decreases below the PE, coincident with termination of crack growth.

The crack depths reached the bottom of the dry box in each of the layers and stopped growing shortly after. The third stage is also characterized by the development of high total suctions (> $1 \mathrm{MPa}$ ) at the surface of the tailings (section 4.1.4.5). This behaviour is expected and is similar other oil sand tailings streams and hard rock tailings (Innocent-Bernard et al. 2013, Daliri et al. 2013). This trend suggests that the formation of fresh new cracks is exposing wet material to the atmosphere, increasing the surface area of the tailings and therefore the $\mathrm{AE}$ rate.

\subsubsection{Settlement}

Figure 4.1-80 shows the expected height of the tailings for each layer, if the tailings were added instantaneously (vertical lines), and the actual heights of the tailings over time. As they are were not added instantaneously, the height at the end of Day 1 is somewhat smaller than this height, and there is much more of a difference in the 
second and third layers. For the latter layers, this is due to capacity of the underlying layers to absorb moisture.

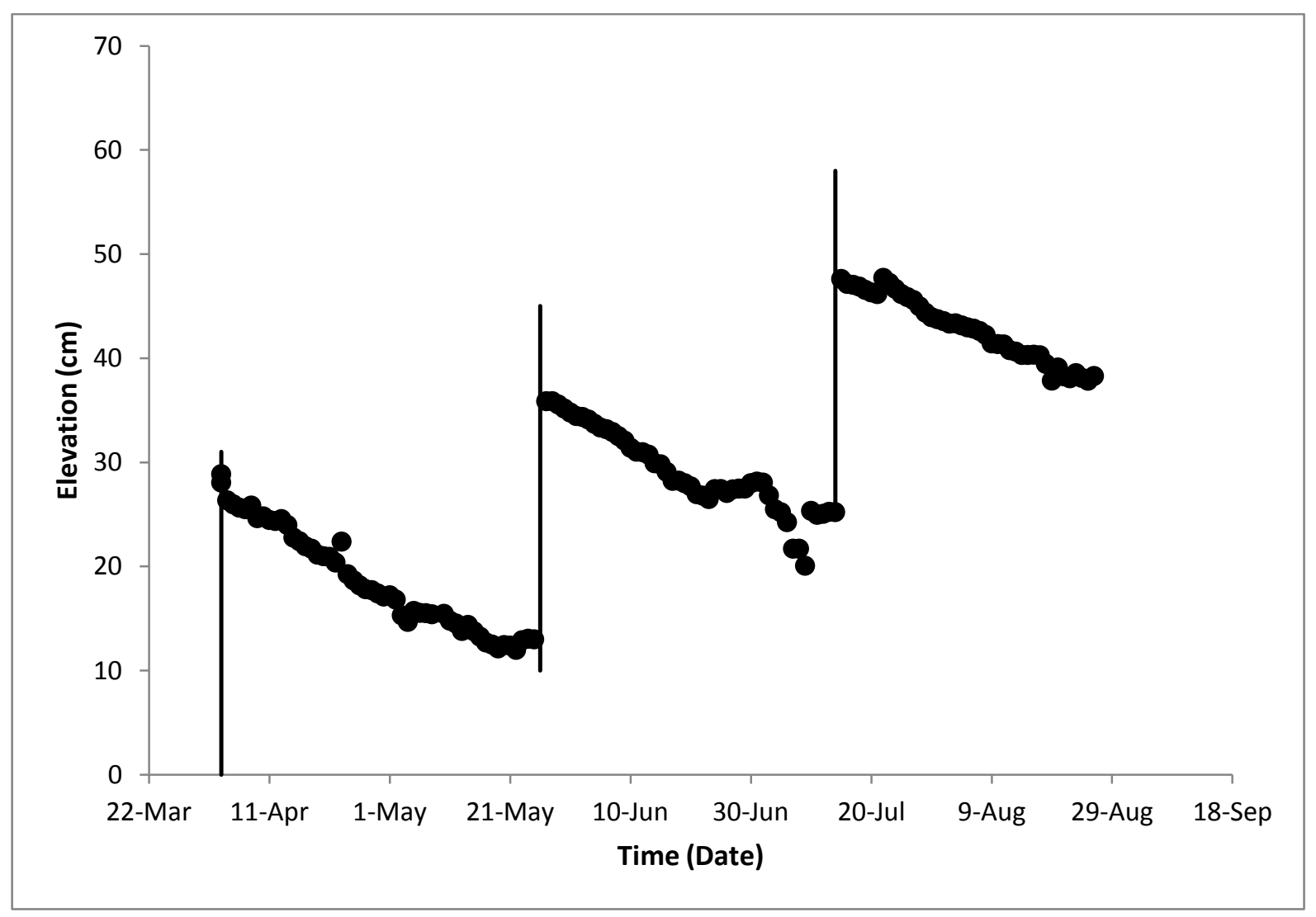

Figure 4.1-80. Settlement of the tailings - Overall

Based on the settlement and water loss results, the overall void ratio was calculated and plotted in Figure 4.1-81. This figure shows the change in void without considering cracks, and considering the influence of cracks. There is no considerable difference in both sets of data at the beginning, but as cracks began to appear and grow in size, there is a difference of about 0.2 . 


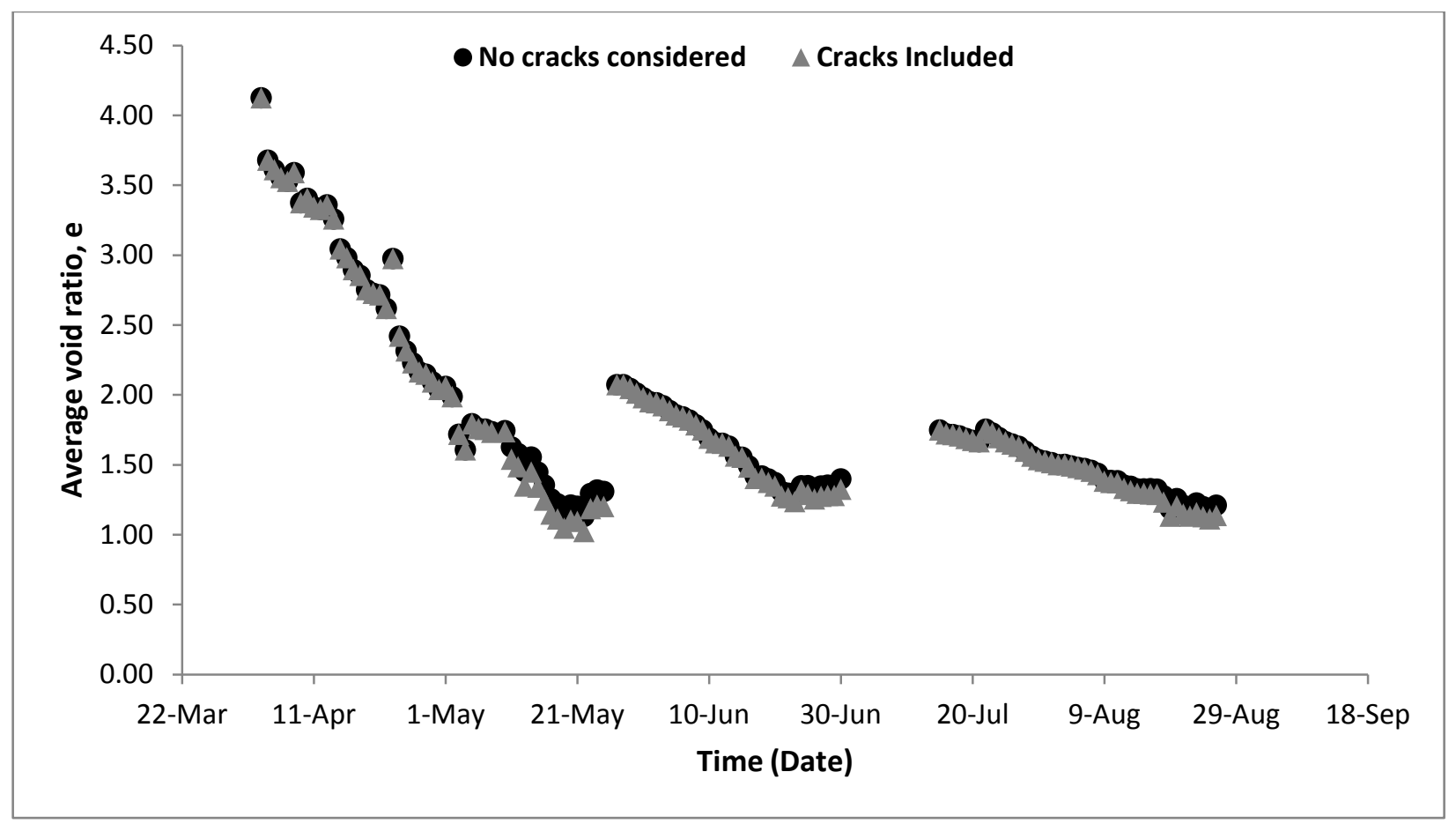

Figure 4.1-81. Average void ratio - Overall

\subsubsection{Volume Change}

The volume change in individual layers was differentiated using the VWC sensors. The VWC in layer 1 is shown in Figure 4.1-82. At the beginning of dewatering, the sensors show a variation of water content with depth, lower water content and therefore higher density at the bottom, which would be expected from self-weight consolidation. The top sensors ratcheted out of the tailings and had to be re-positioned. Once drying sets in, the water contents sensors show lower water contents at higher elevation sensors. After placement of the new layers, the VWC of layer 1 settles down to about 0.35 . One sensor rises in VWC value, but this sensor was in contact with fresh tailings. 


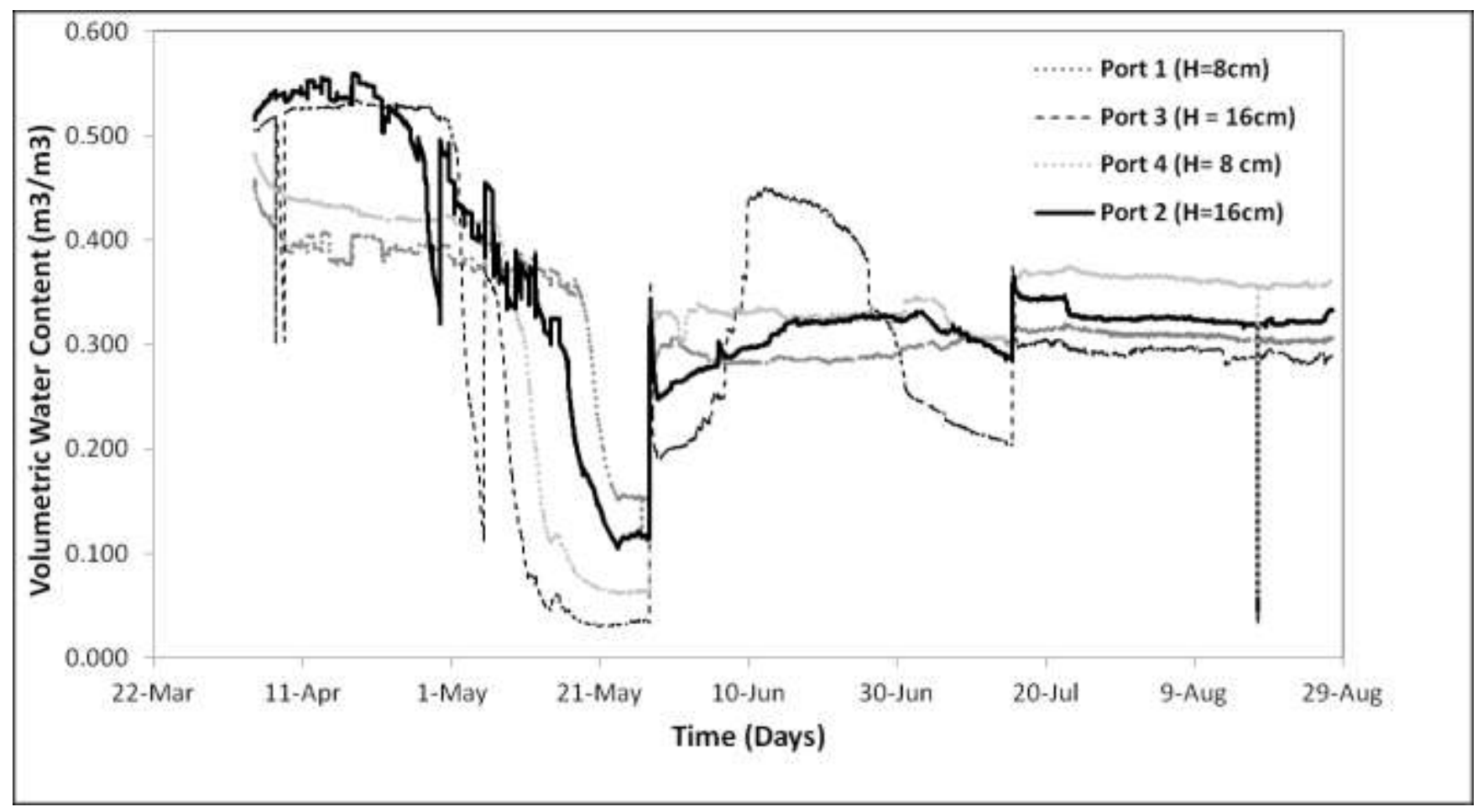

Figure 4.1-82. Volumetric water contents at various heights - Overall

The WWC in the two other layers is shown in Figure 4.1-83. The sensor at the top of layer 2 is exposed to fresh tailings during placement of layer 3 . 


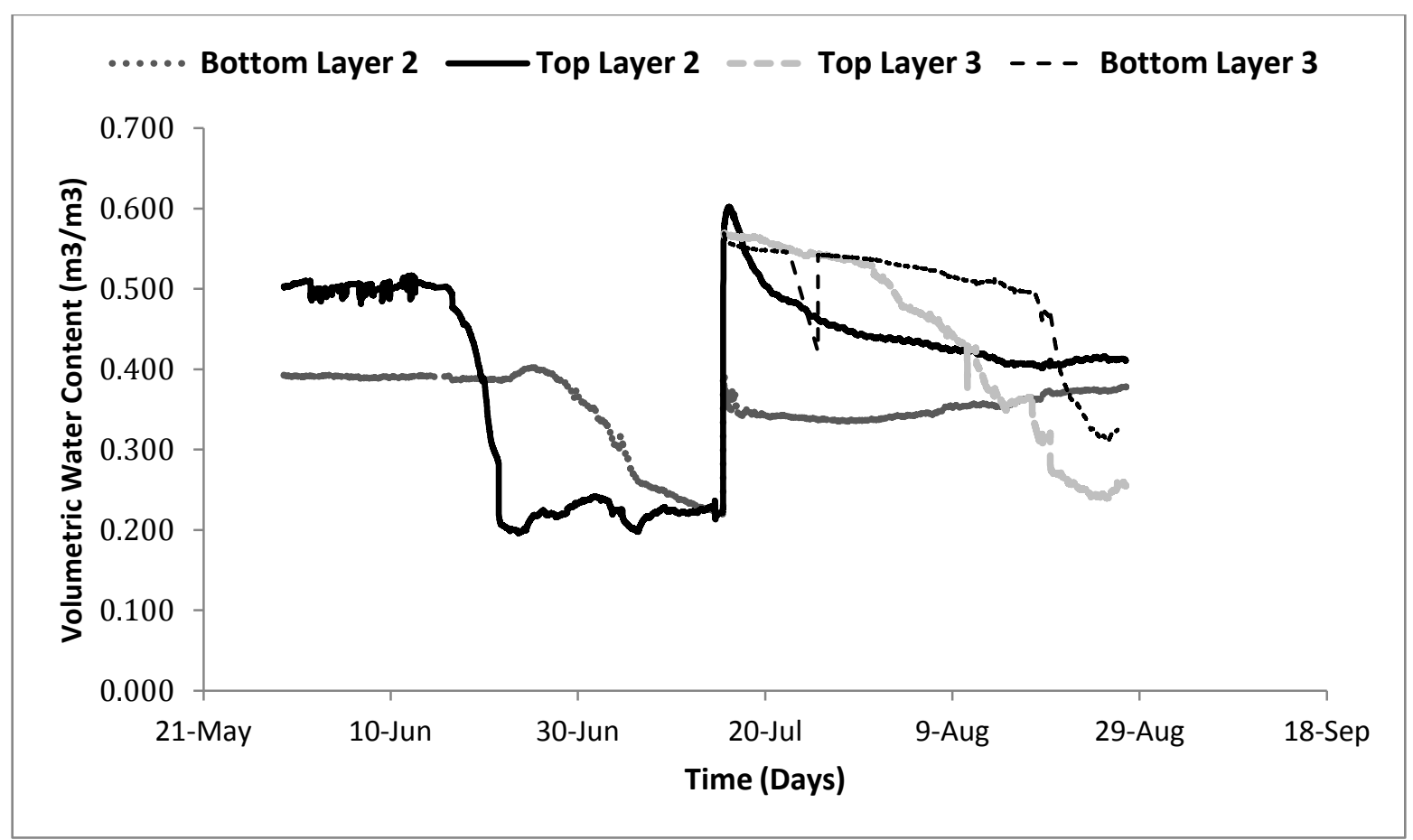

Figure 4.1-83. Volumetric water contents at various heights in top layers - Overall

The VWC values in Figures 4.1-82 and 4.1-83 are not calibrated. After calibration, the VWC in layer 1 tailings after rewetting was equivalent to a GWC of about $47 \%$. Constructing a shrinkage curve from measured void ratio and GWC data from Layer 1, it is clear that $47 \%$ GWC is the shrinkage limit of the material, corresponding to a void ratio of 1 , as shown in Figure 4.1-84. Thus the tailings resaturate, but do not swell appreciably upon rewetting. Figure 4.1-84 also shows the results for shrinkage curve obtained from a small sample in a ring. The resulting shrinkage curves for both cases are very similar. 


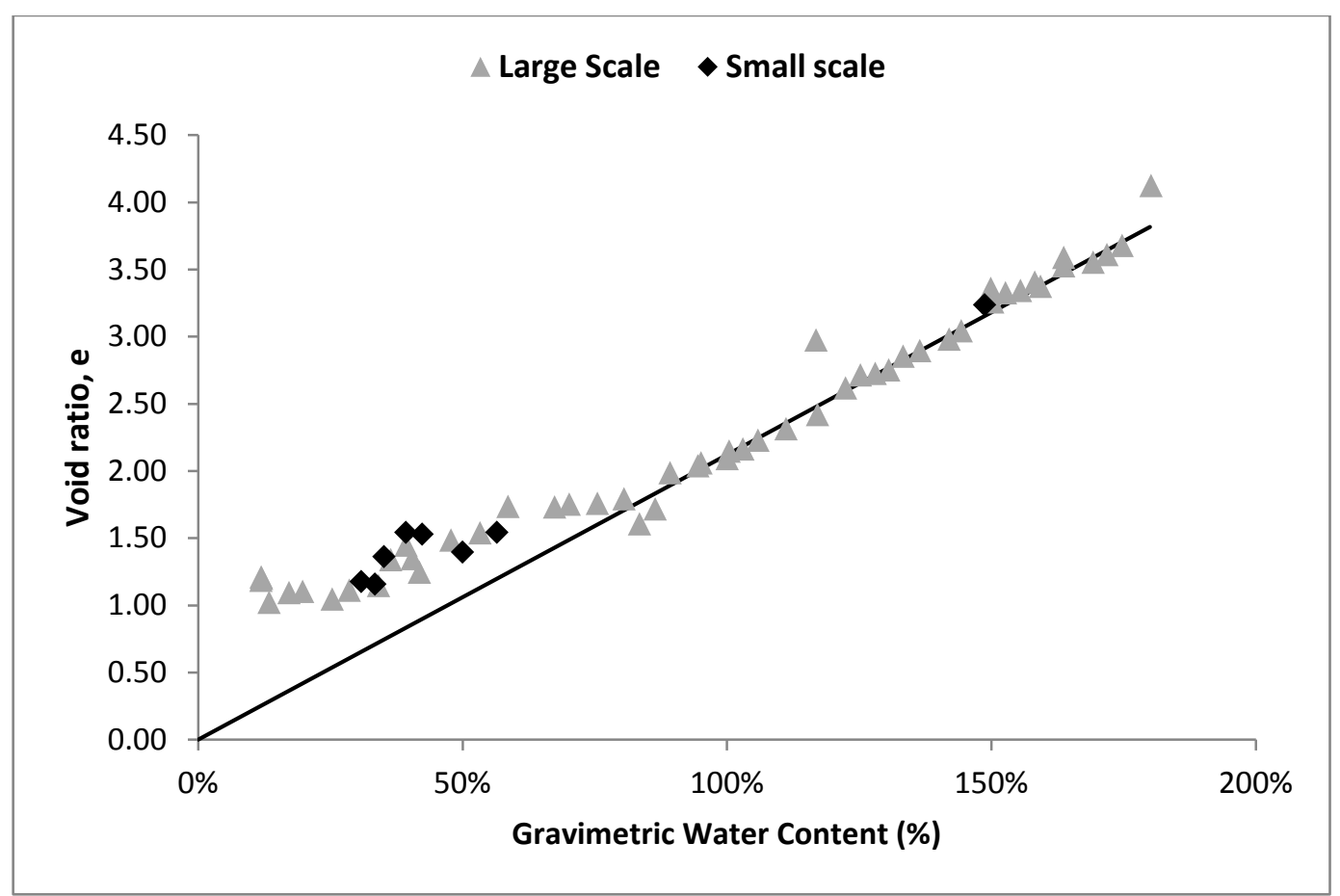

Figure 4.1-84. Thin lift dry box shrinkage curve

\subsubsection{Water Content}

The overall GWC (Figure 4.1-85) was calculated based on weight measurements obtained with the load cells and the water loss through evaporation and drainage. Surface measurements within the top $1 \mathrm{~cm}$ were also taken after the supernatant water that had collected at the top of the tailings had evaporated. The overall GWC takes the supernatant water into account. There is a steady decrease in overall GWC from $180 \%$ to $12 \%$ while the surface GWC decreases from $59 \%$ to $9 \%$. 


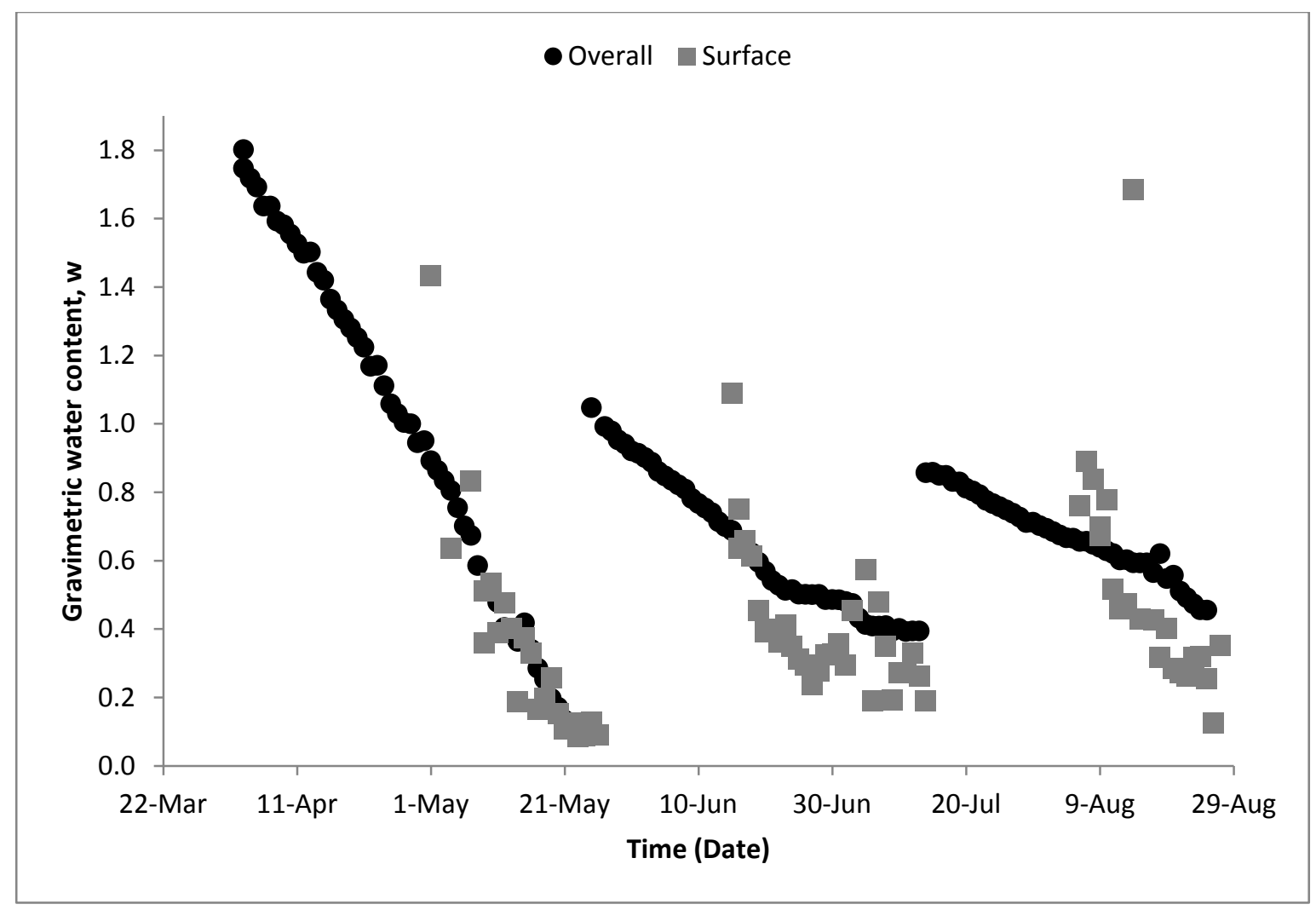

Figure 4.1-85. Gravimetric water contents - Overall

Surface samples were also taken at various locations once cracks began to form. They were taken from the surface (between cracks), at the CE and IC. The IC measurements were stopped as soon as the tailings became so dry that extraction of samples would significantly damage the integrity of the crack formations. The GWC for these samples is shown in Figure 4.1-86. 


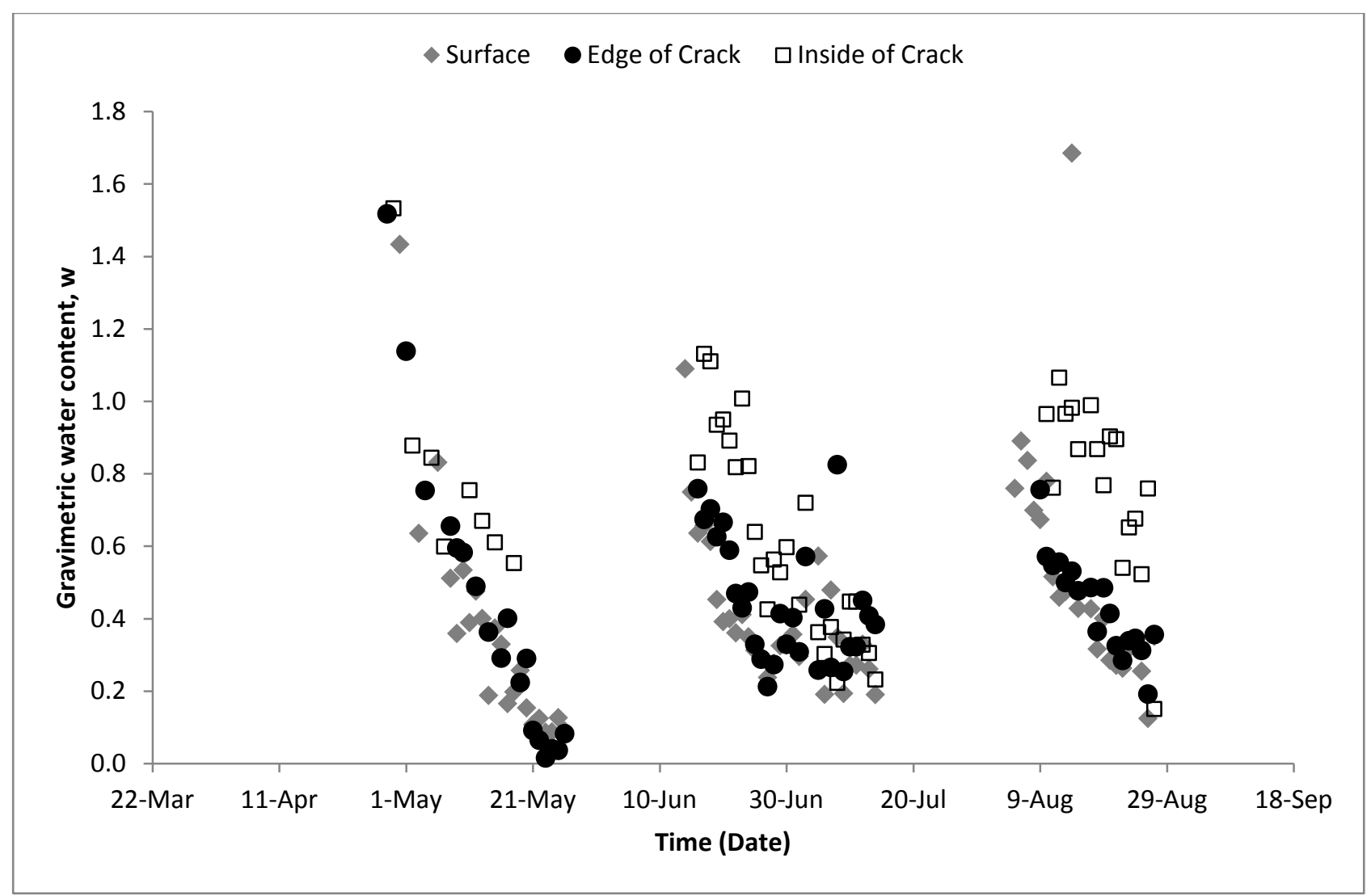

Figure 4.1-86. Surface sample gravimetric water contents - Overall

Generally, the GWC inside the cracks was highest, followed by the surface, and the CE had the lowest GWC, and were found to be the driest.

SCs were calculated using three different methods. The overall SC was based on the load cell measurements and water loss. The SC of the top layer was based on the readings obtained by the VWC sensors. The surface SC was obtained by measuring SC from samples extracted from the top $1 \mathrm{~cm}$ of the top layer. Results are presented in Figure 4.1-87. 


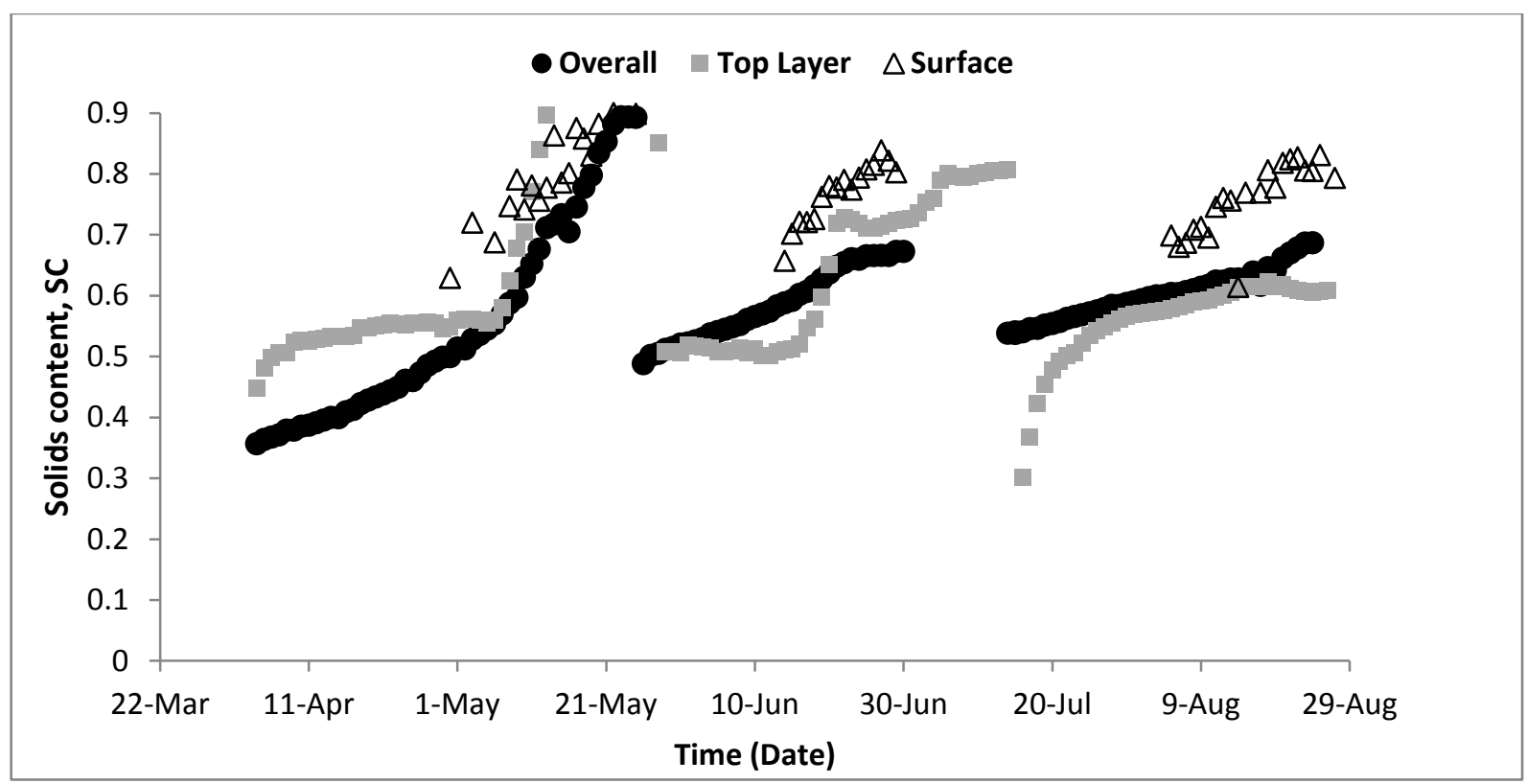

Figure 4.1-87. Solids contents - Overall

Figure 4.1-88 provides a breakdown of the SCs at the surface, CE and IC surface samples.

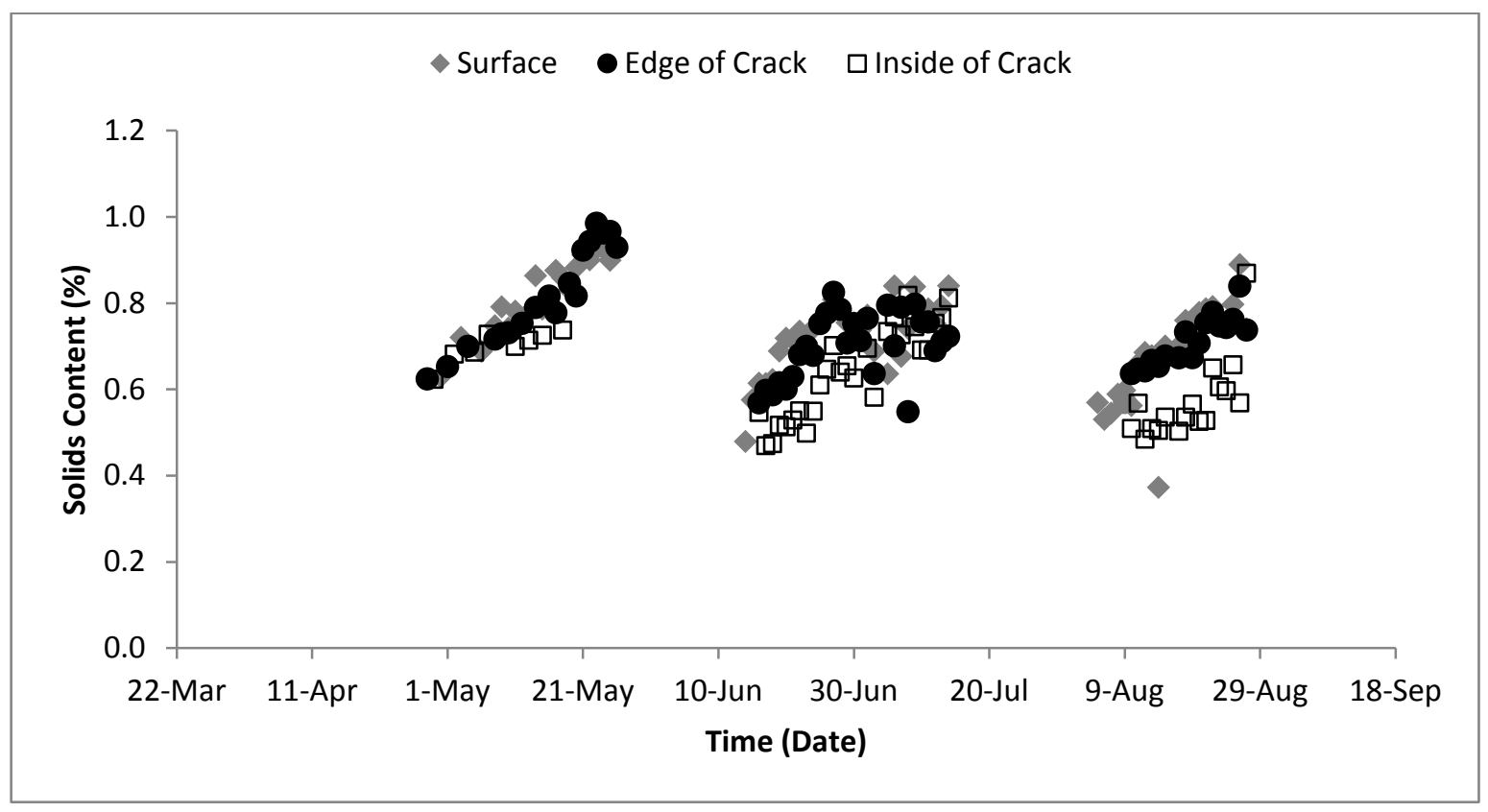

Figure 4.1-88. Surface sample solids contents - Overall 
Figure 4.1-89 shows the variation in overall degree of saturation throughout the test. The degree of saturation begins to fall appreciably below 1 on May $4^{\text {th }}$, June $17^{\text {th }}$, and August $21^{\text {st }}$ at about $80 \%$ GWC and $55 \%$ solids for the average water content of the top layer.

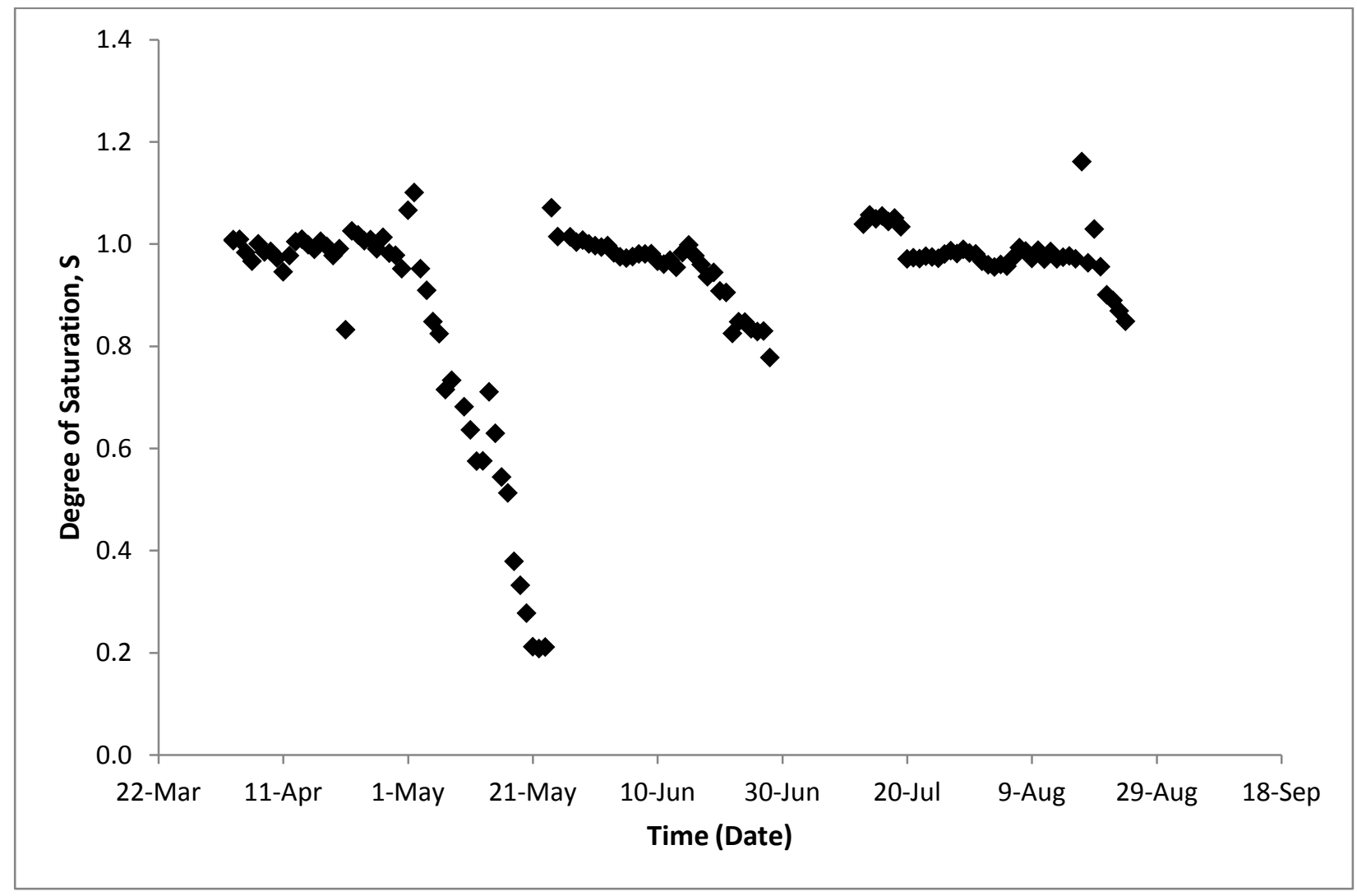

Figure 4.1-89. Degree of saturation - Overall

\subsubsection{Suction}

This section provides results related to matric, osmotic and total suctions for all three layers of the thin lift dry box experiments. 


\subsection{Matric Suction}

The tensiometer readings over the course of the experiment are shown in Figure 4.1-90. These reading were problematic, as tensiometers became exposed to air when cracking started to develop, or were even ratcheted out of the tailings during consolidation. However, the tensiometers provide good data passing from the positive to the negative pore-pressure range.

For all layers, crack initiation was correlated with one or more tensiometers registering suction (negative pore-water pressure), which occurred almost immediately when supernatant water disappeared.

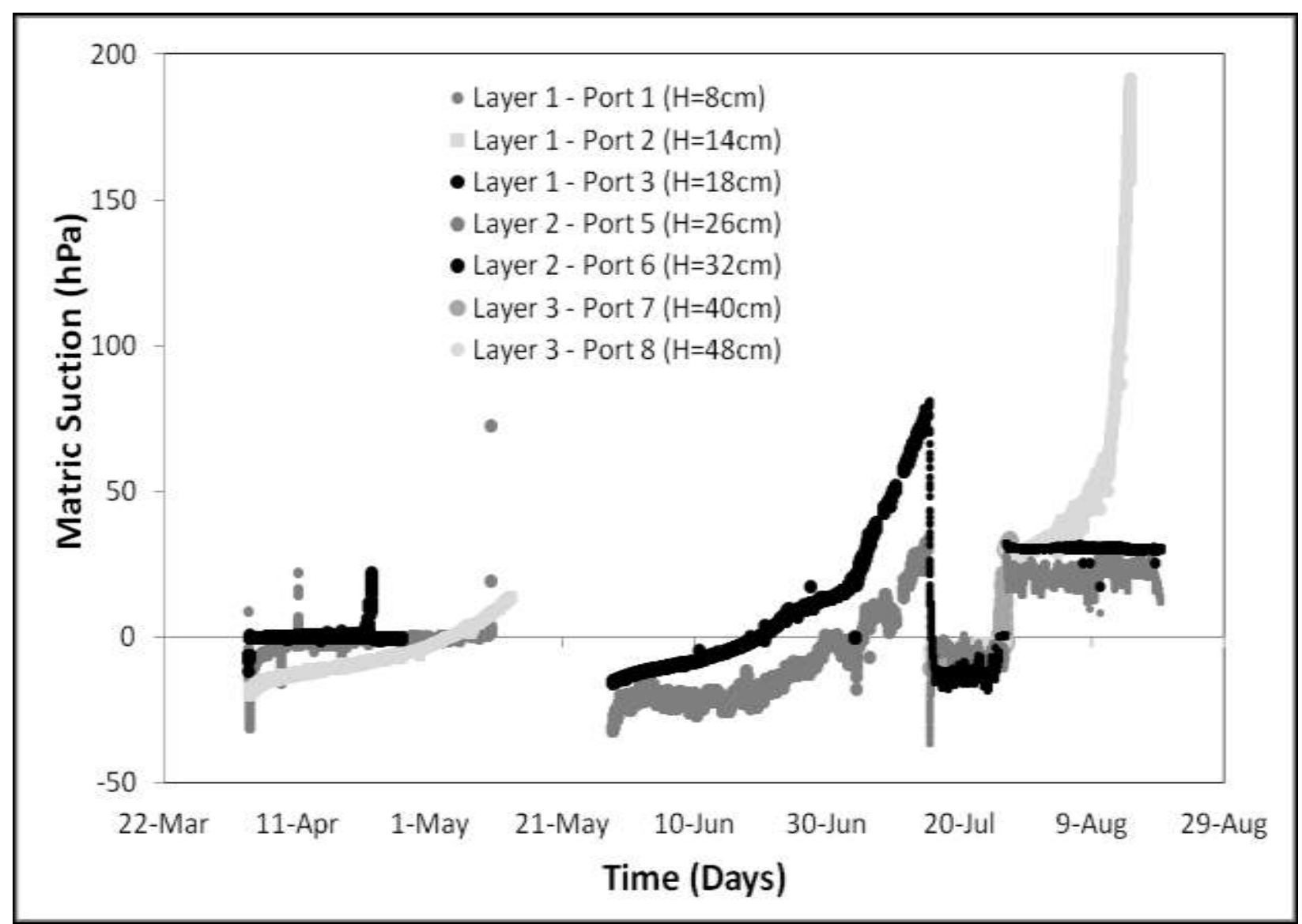

Figure 4.1-90. Matric Suction at various heights - Overall 
Figure 4.1-91 provides matric suction profiles constructed from tensiometer data shown in Figure 4.1-90, for Layer 3 at $60 \%$ SC (May $8^{\text {th }}$ ), and $70 \%$ SC (May $12^{\text {th }}$ ). In both cases, matric suction increases with elevation. For $70 \%$ SC, matric suctions are higher, and are parallel to the $60 \% \mathrm{SC}$, except at the very top.

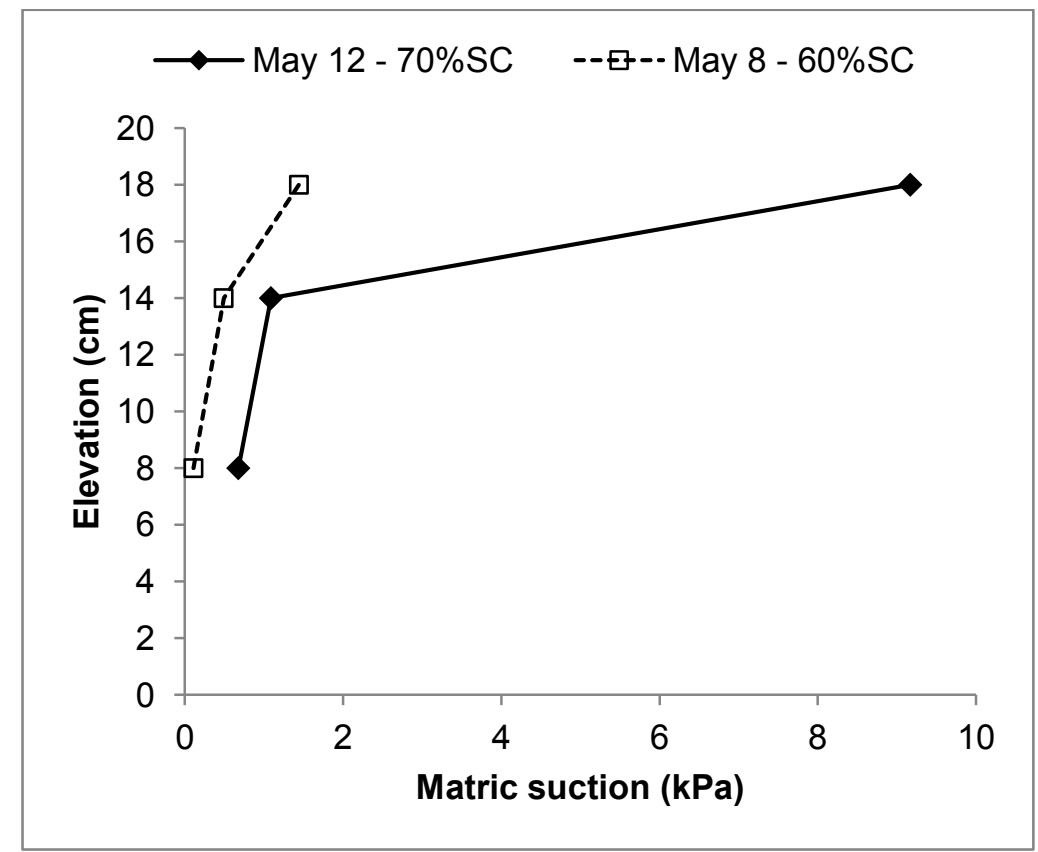

Figure 4.1-91. Thin lift dry box matric suction profiles

\subsection{Osmotic Suction}

Figure 4.1-92 shows a comparison of osmotic suction to total suction for all three layers. Note that the suction values above $4 \mathrm{MPa}$ were truncated in this figure, in order to provide a better idea of the relationship of osmotic to total suction, since the osmotic values were very low. 


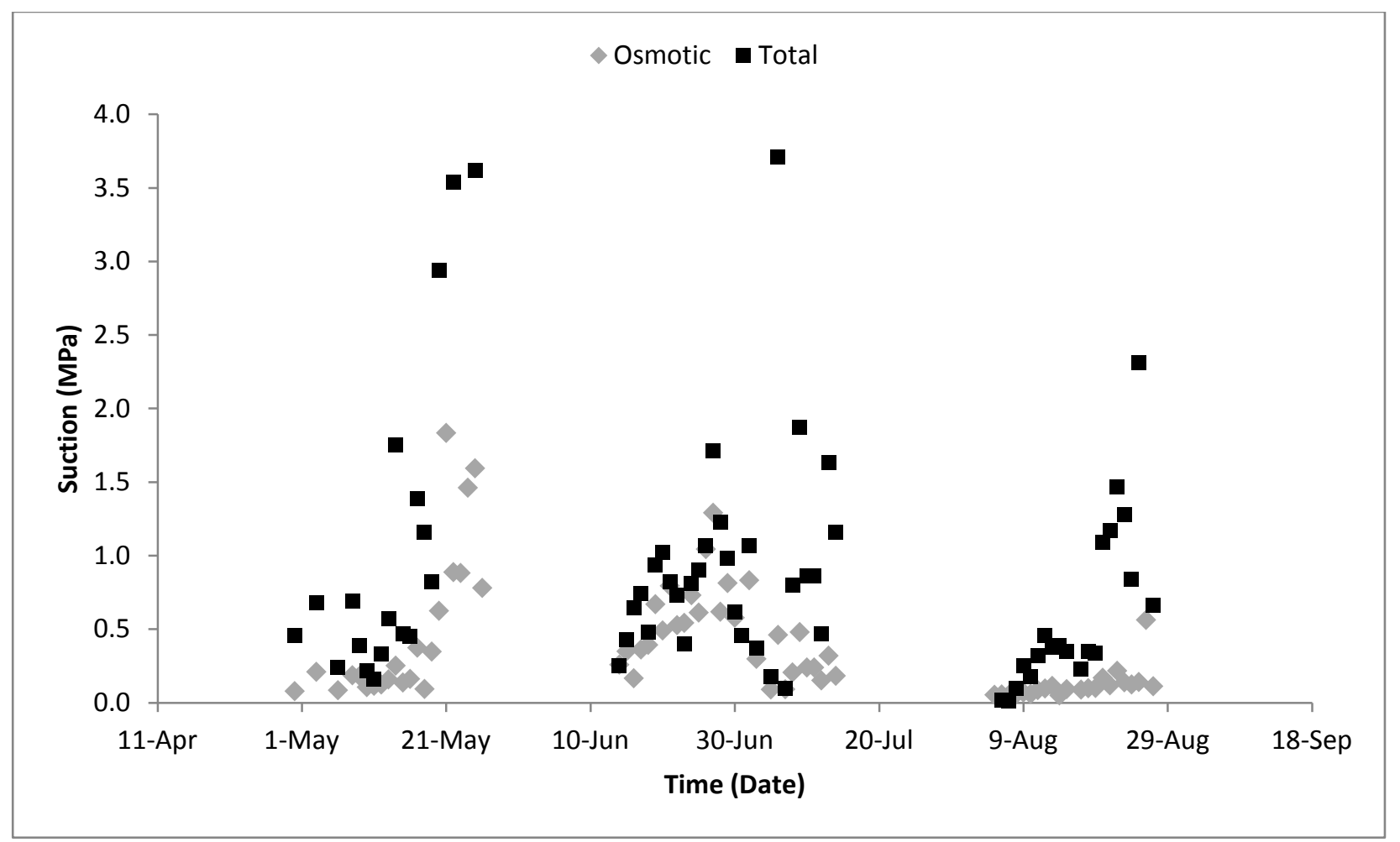

Figure 4.1-92. Surface sample total and osmotic suctions - Overall

\subsection{Total Suction}

Samples extracted from the top $1 \mathrm{~cm}$ of the surface of the tailings, CE and the IC were measured for total suction using a WP4-C potentiometer. These results are shown in Figure 4.1-93.

Overall, suction values at the surface increased as water escaped the tailings. Initially, suction values along the CE were wetter than those at the surface, but as the tailings dried out and the crack volumes remained constant, the edges also dried out, and in some instances surpassed the values at the surface. The values IC were generally lowest. 


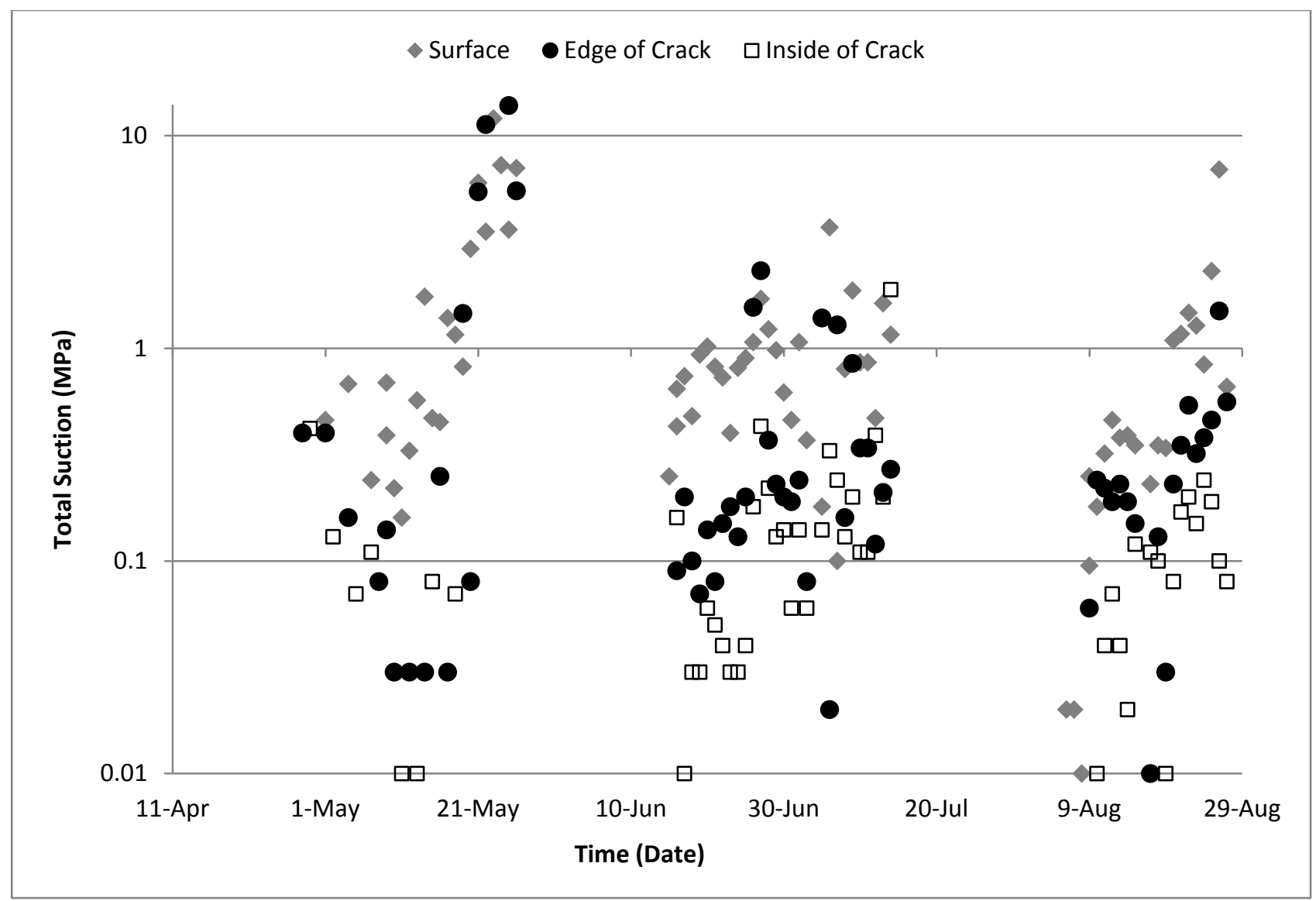

Figure 4.1-93. Surface sample total suctions (Log scale)- Overall 


\subsection{Thick-Lift Dry Box Test}

The thick-lift dry box test was conducted approximately one year after the thin lift dry box from March $2^{\text {nd }}-$ June $22^{\text {nd }}, 2015$. Two $50 \mathrm{~cm}$ layers were added approximately six weeks apart.

\subsubsection{Layer 1}

Tailings were remixed with a drum mixer at a speed of $180 \mathrm{rpm}$ for approximately $6 \mathrm{hr}$ in forward and reverse modes. The material was then dosed with a polymer at 650 $\mathrm{mg} / \mathrm{kg}$ using the method described in Mizani et al. (2013). The average initial SC of the tailings was $33 \%$. The flocculated tailings were deposited in 108 buckets of $3.6 \mathrm{~kg}$ into a drying box on March $2^{\text {nd }}$ and allowed to dry to a final SC of $60 \%$.

Core samples were taken before the deposition of layer \#2, on April $23^{\text {rd }}$ to provide a history of the drying process with depth. The data collected for the first layer is presented in this section.

\subsubsection{Mass Loss, Evaporation and Drainage}

Figure 4.2-1 shows the overall mass loss in the dry box in Layer 1, which occurred due to the combination of evaporation and drainage. Note that the dip in the figure occurs due to the drainage of water from the top by hand over two days. Figure 4.2-2 presents a breakdown of the mass loss due to the two components. In this layer, overall mass loss occurs gradually, but constantly. 


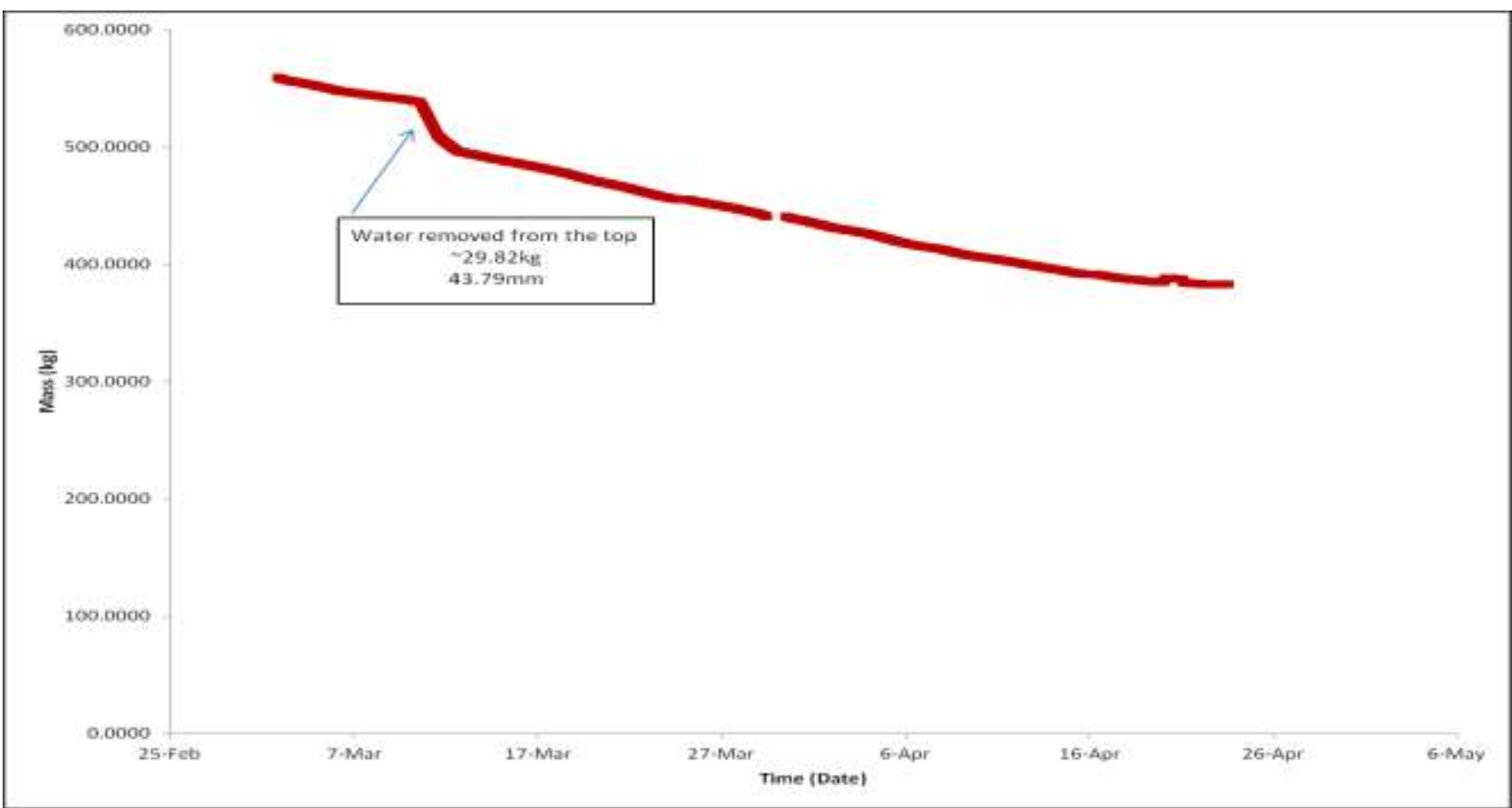

Figure 4.2-1. Total mass of tailings - Layer 1

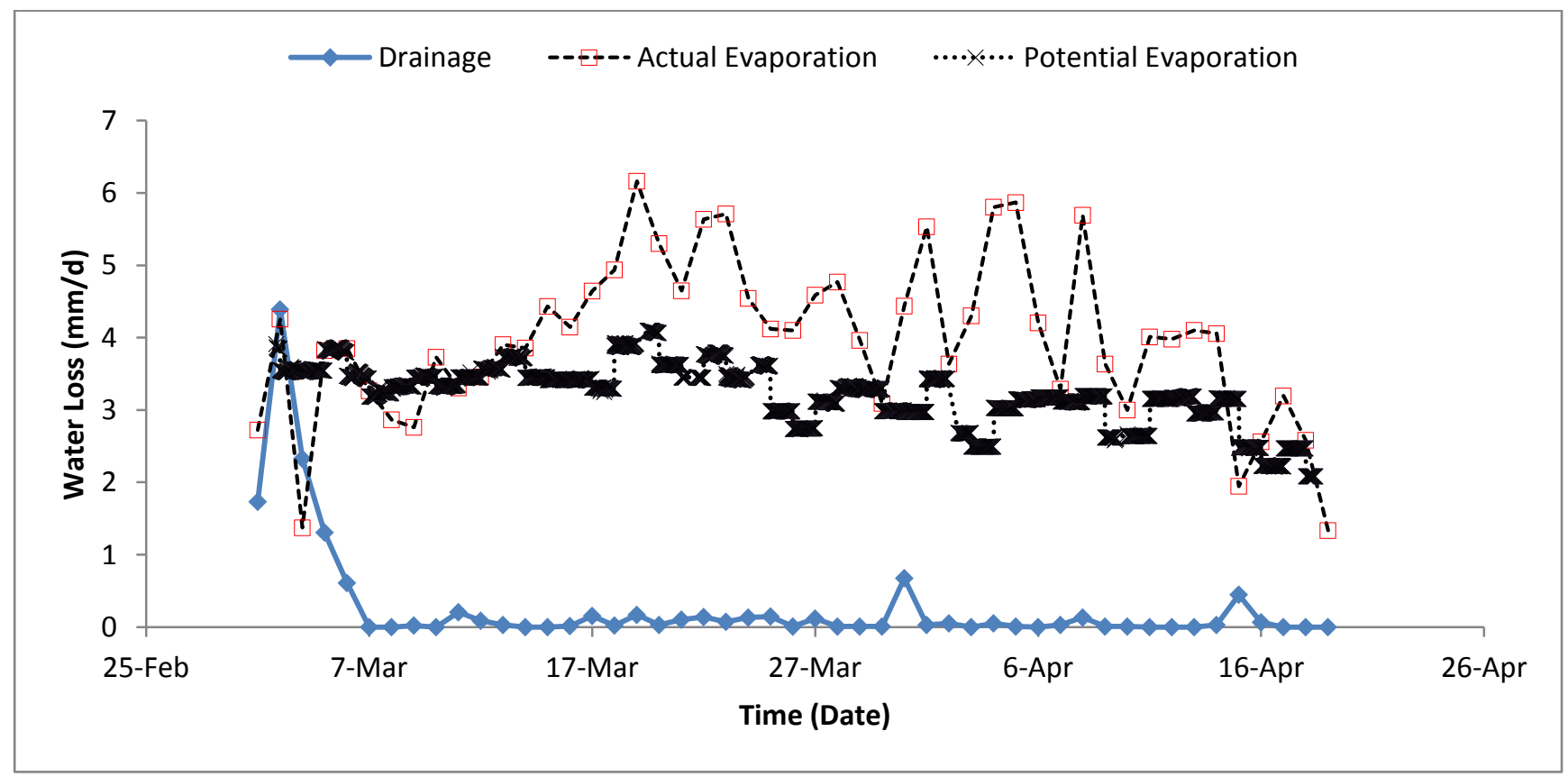

Figure 4.2-2. AE, PE and drainage - Layer 1 
As shown in Figure 4.2-2, the AE rate was found to vary from approximately 2 to $6 \mathrm{~mm} /$ day. The PE was calculated by filling the box up with water prior to tailings deposition, to calculate the effective wind speed using the Penman-Monteith equation, and measured values of $\mathrm{RH}$ and temperature at the surface of the tailings, shown in Figure 4.2-3.

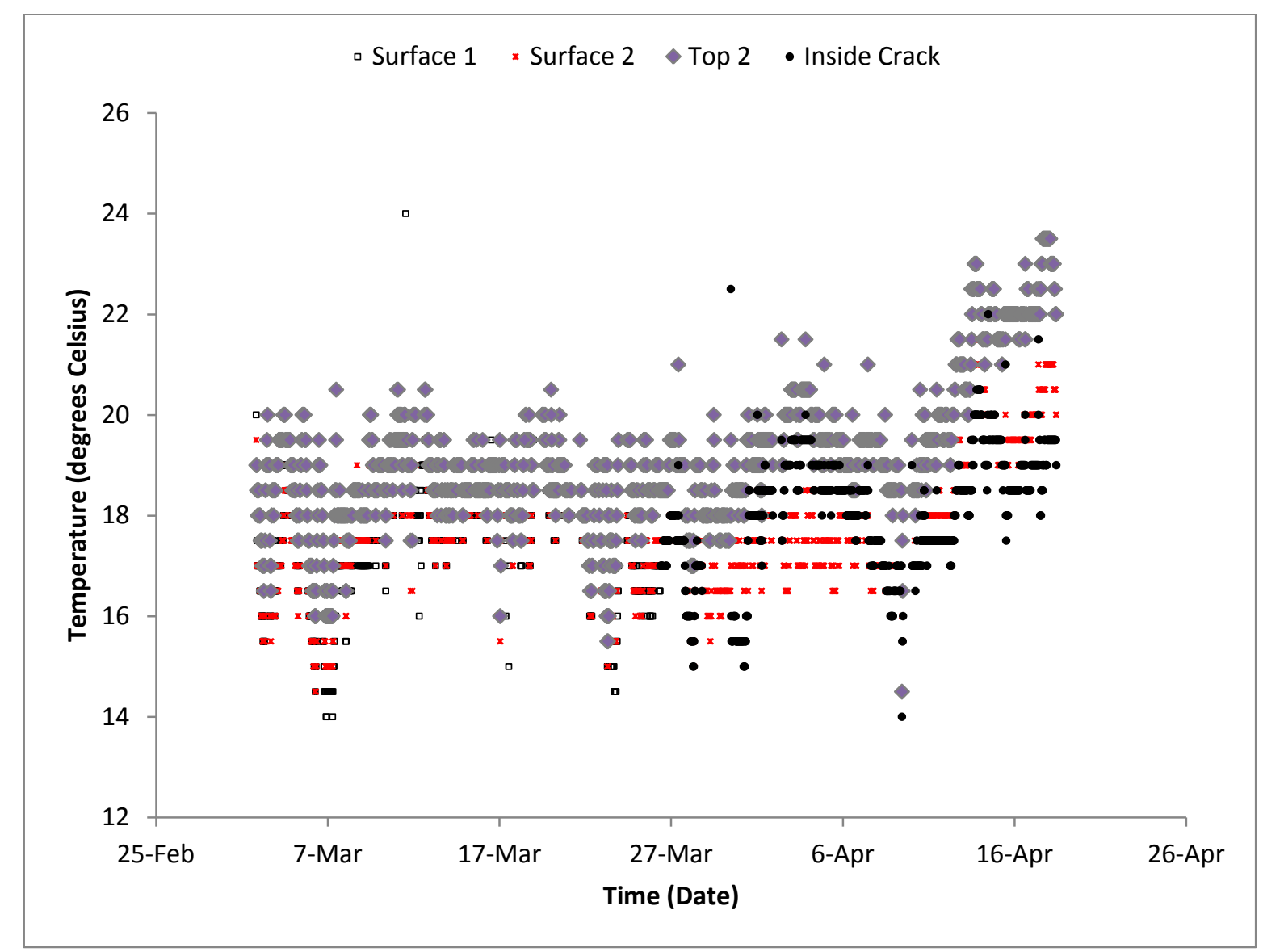

Figure 4.2-3. Surface temperatures - Layer 1

During this experiment, three additional RH sensors were added. Two sensors were placed on the beams holding the senix sensors, and the other two were placed at the surface of the tailings. Once cracks were large enough, one of the sensors from the surface was placed into a crack. Figure 4.2-4 shows the $\mathrm{RH}$ variations as recorded by 
these sensors. Generally, the RH is higher inside the crack, and more or less constant at the surface and top.

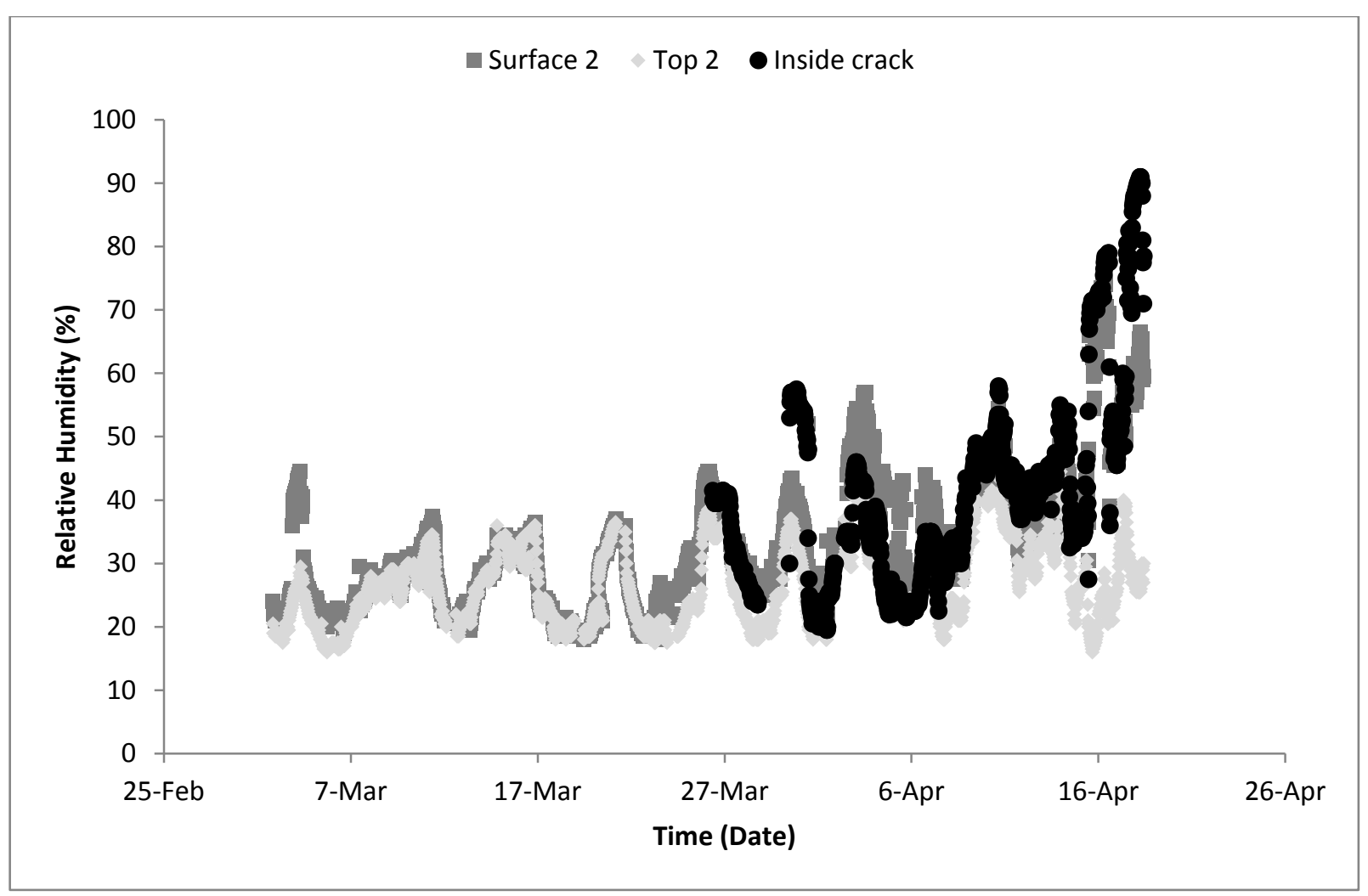

Figure 4.2-4. RH profile at the surface - Layer 1

Figure 4.2-5 shows the variation of temperature inside the tailings, as measured by the VWC sensors. The temperature was found to vary from approximately 9-20 degrees Celsius in Layer 1. 


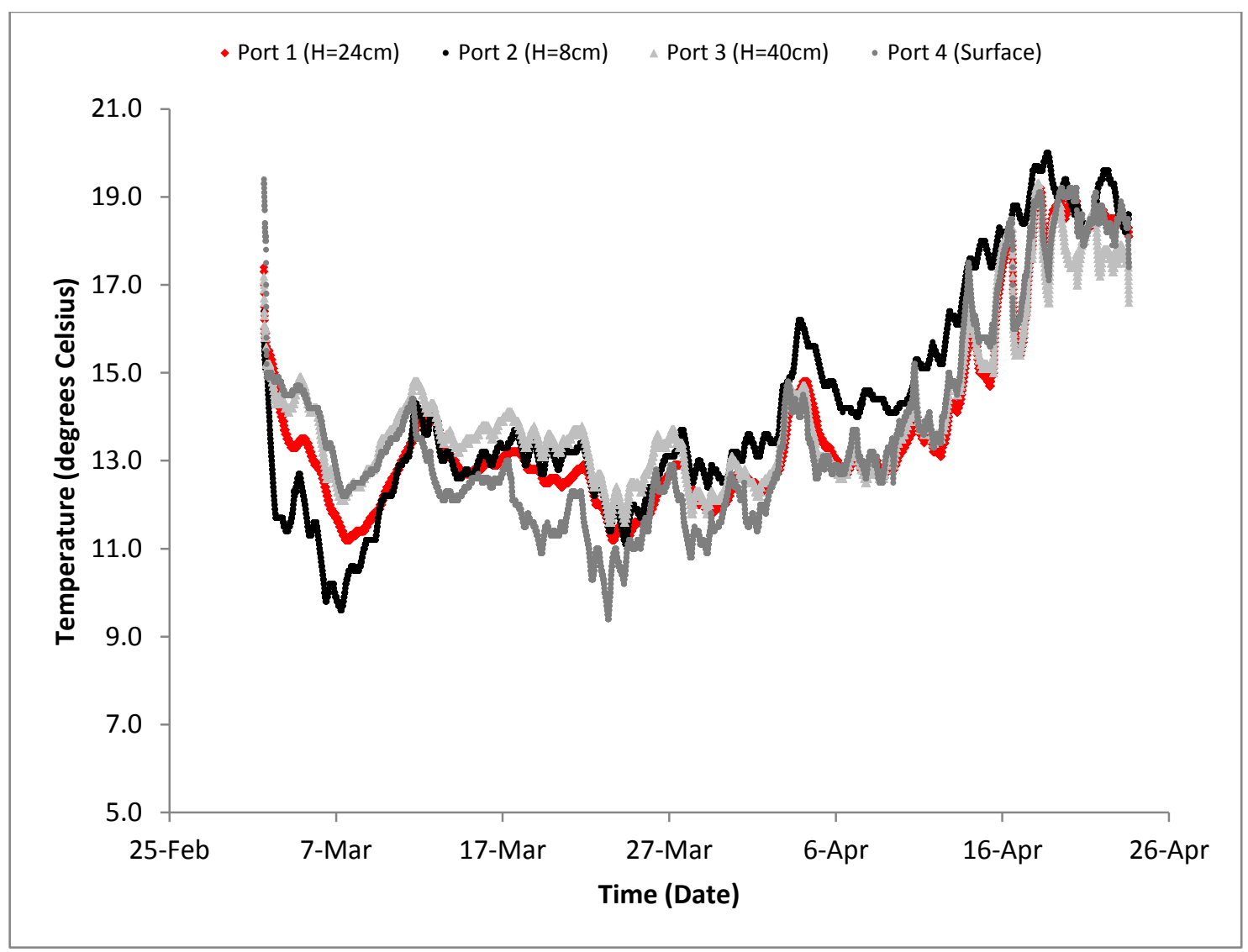

Figure 4.2-5. Temperatures at various heights - Layer 1

Based on the conditions shown in these figures the PE was found to vary from approximately $2.0 \mathrm{~mm}$ to $4.0 \mathrm{~mm}$ per day. In the first layer, the PE closely matches the $A E$ until about March $15^{\text {th }}$, when cracking was first observed. After that date, although the $A E$ should in theory be decreasing with increasing suction values, the $A E$ exceeds the PE, and continues to do so until almost the end of drying. This behavior is almost mirroring the progression of cracking in the tailings as shown in Figures 4.2-6 and 4.2-7. 


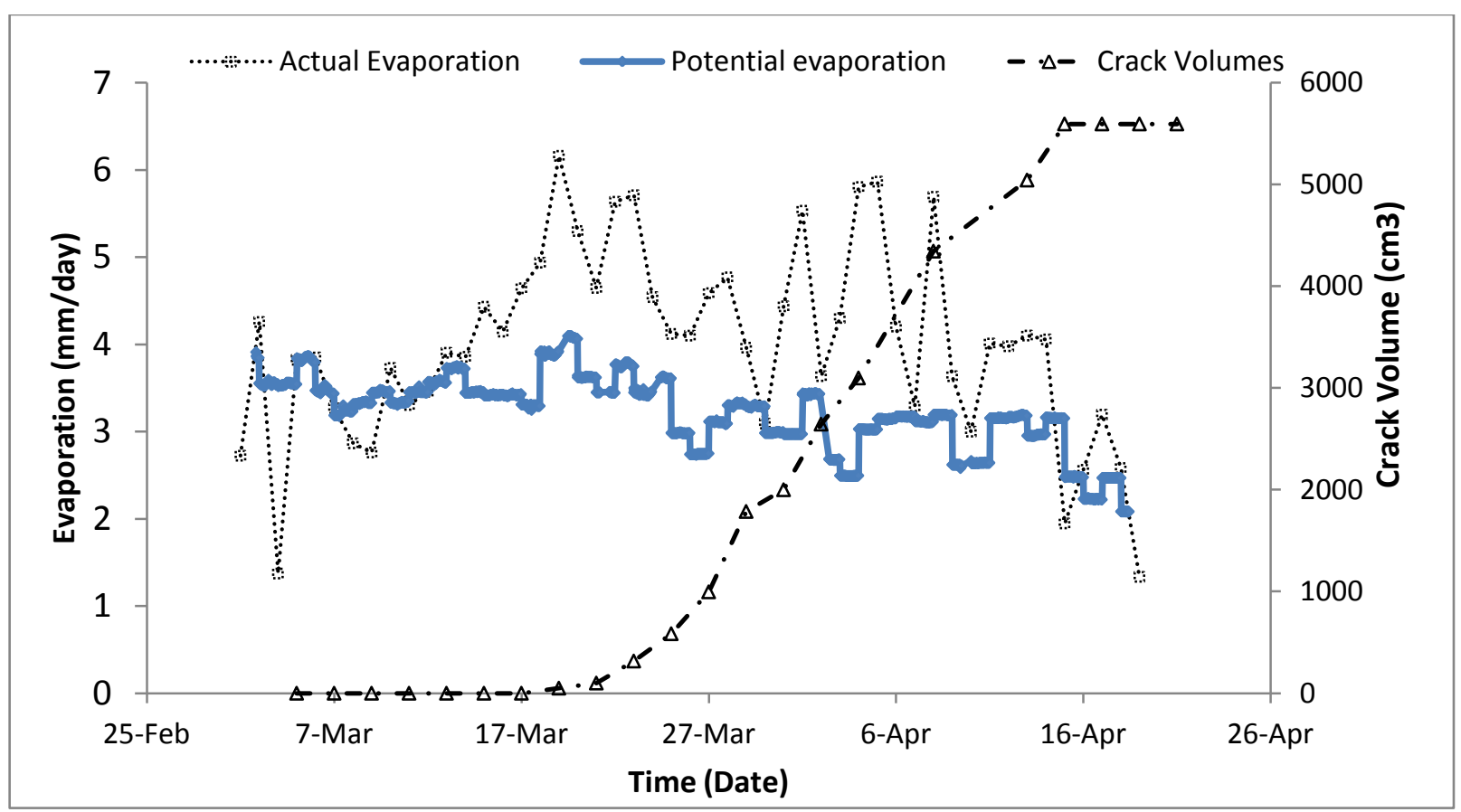

Figure 4.2-6. Evaporation vs. cracking - Layer 1

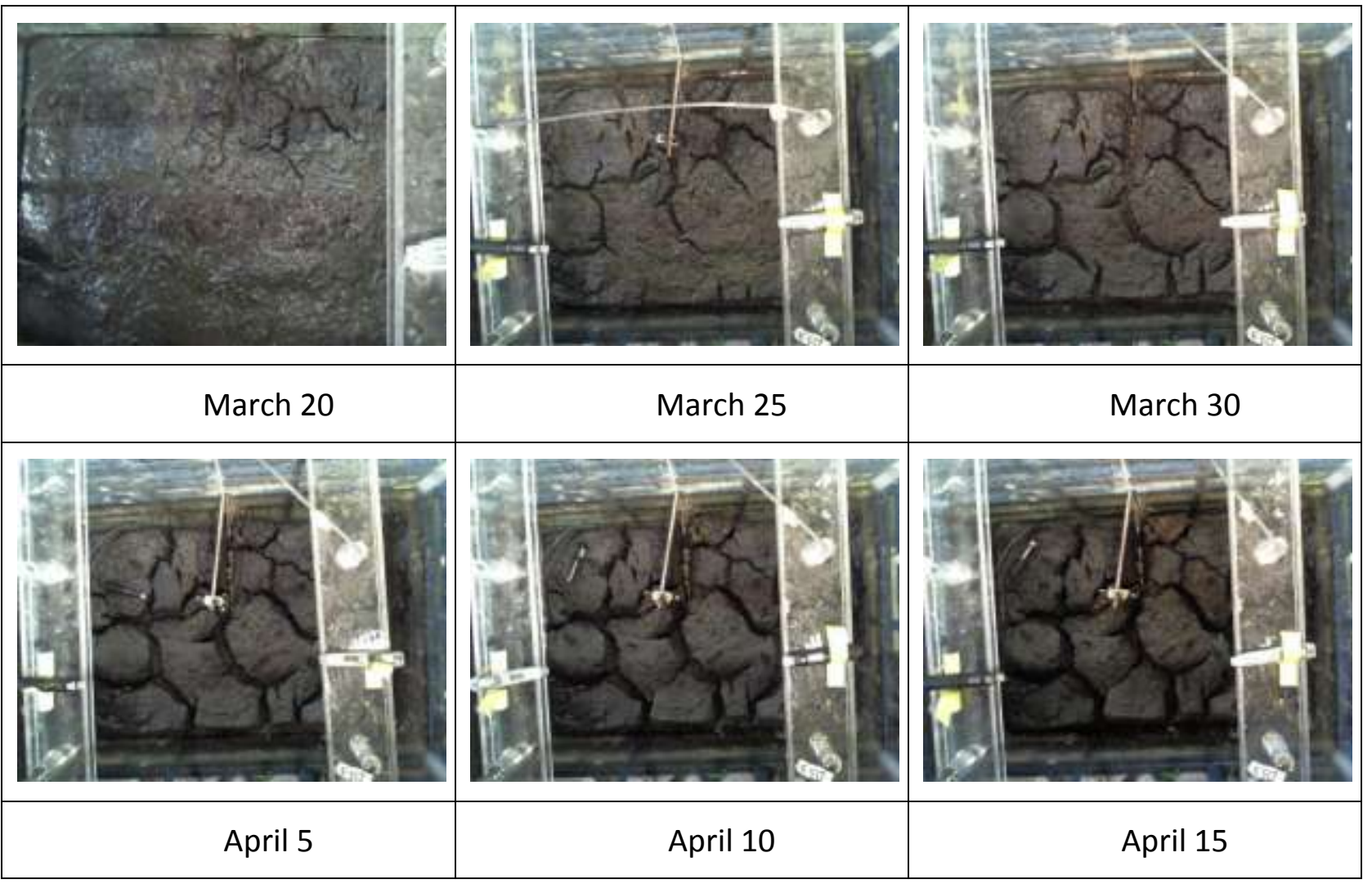

Figure 4.2-7. Progression of cracking - Layer 1 


\subsubsection{Settlement}

A few hours after deposition, the tailings separated into two visible layers, the heavier MFT at the bottom and a layer of turbid water at the top. The distance between the top of the water and the MFT interface was measured at five points daily, and averaged. The MFT settled due to self-weight consolidation, and the water at the top evaporated. Figure 4.2-8 shows the settlement of the MFT and the height of the water on top. There is a sharp drop in the figure since water was drained by hand once the MFT had sufficiently settled.

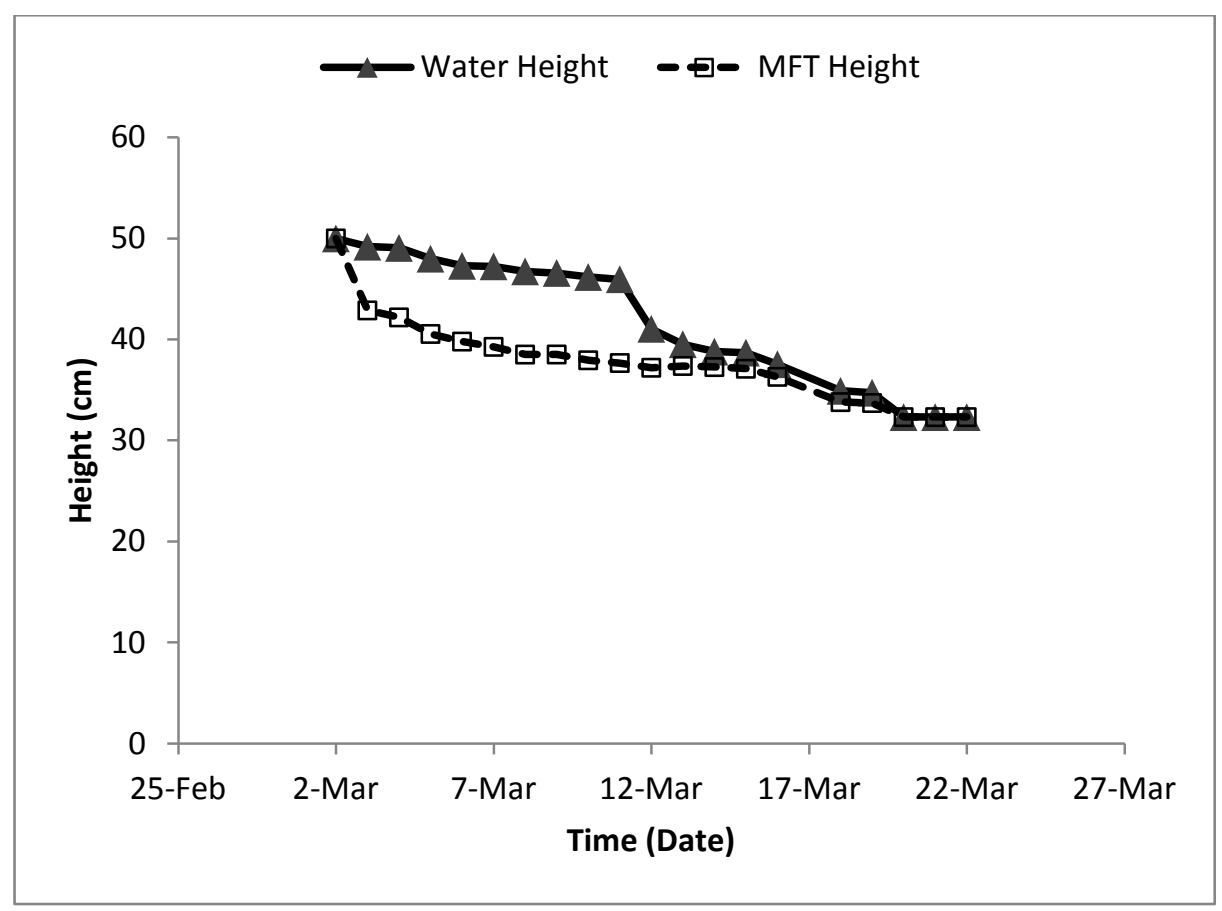

Figure 4.2-8. Water and MFT heights - Layer 1

Figure 4.2-9 shows the expected height of the tailings for this layer, if the tailings were added instantaneously (vertical lines), and the actual heights of the tailings over time. Of course, as they are not added instantaneously, the height at the end of Day 1 is somewhat smaller than this height. 


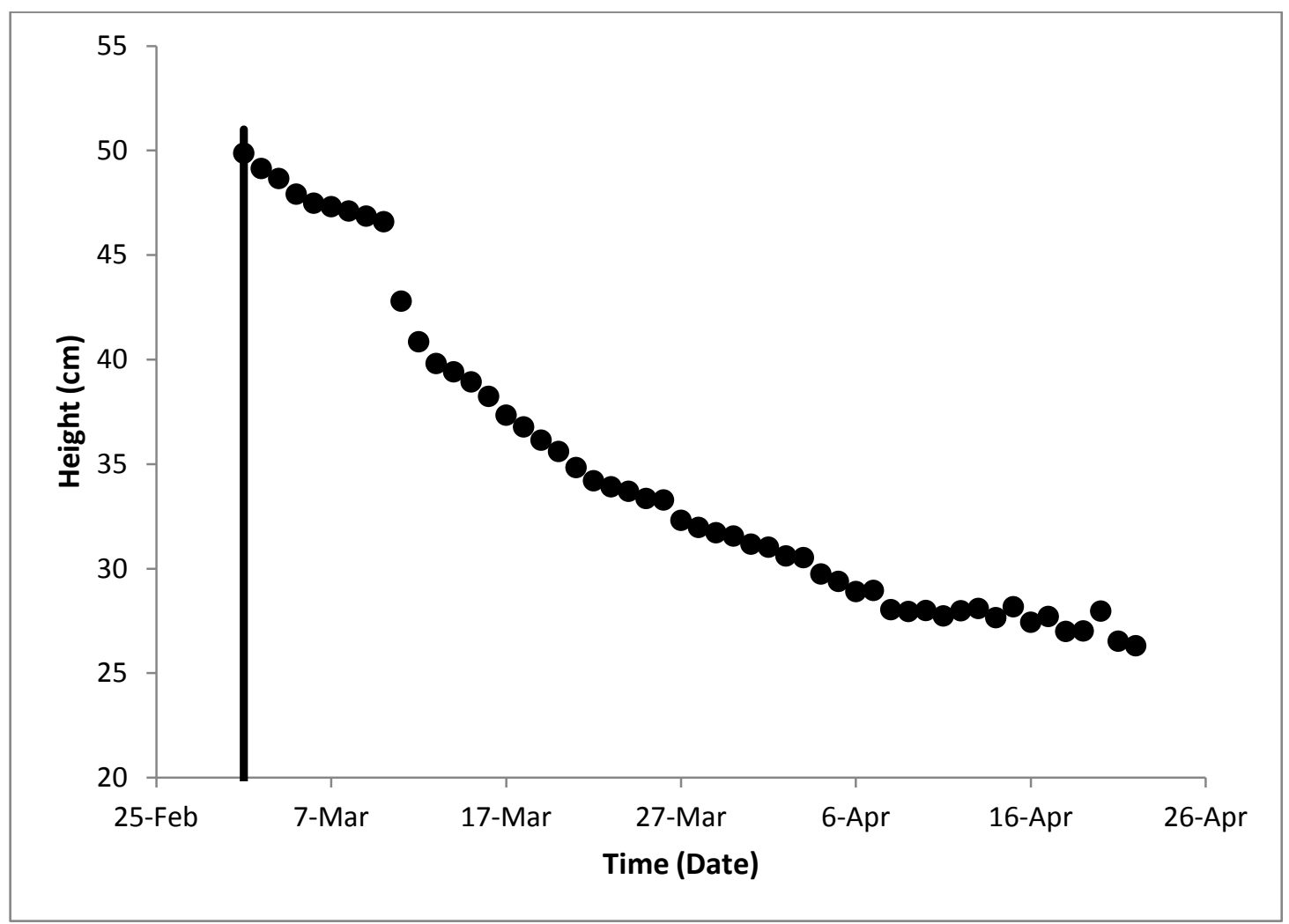

Figure 4.2-9. Settlement of tailings - Layer 1

Based on the settlement and water loss results, the overall void ratio was calculated and plotted in Figure 4.2-10. This figure shows the change in void without considering cracks, and considering the influence of cracks There is no considerable difference in both sets of data at the beginning, but as cracks began to appear and grow in size, there is a difference of about 0.05 . 


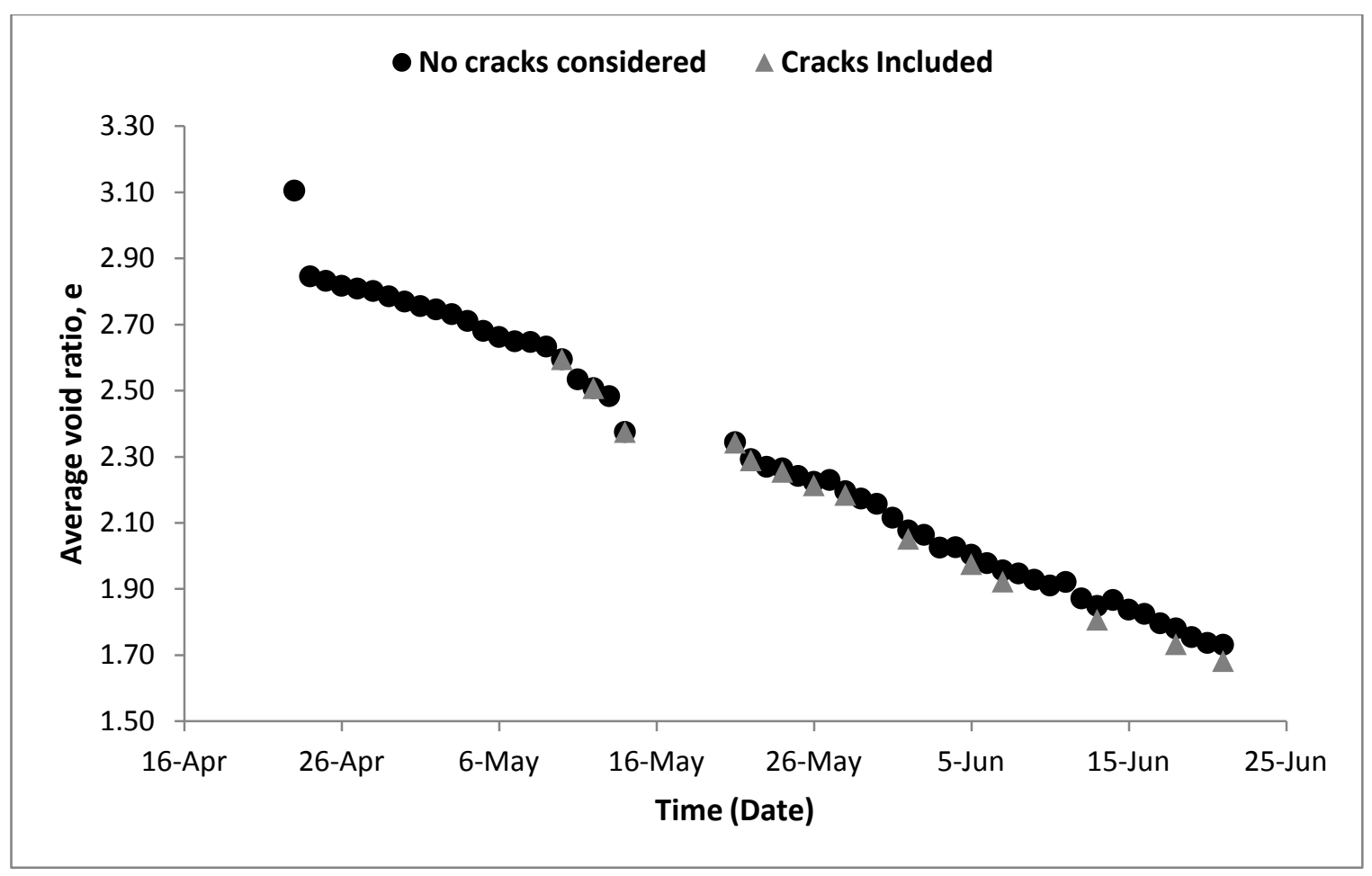

Figure 4.2-10. Average void ratio - Layer 1

\subsubsection{Volume Change}

Volume change was measured by VWC sensors placed at varying heights in each layer in the dry box and processed using calibration curves for each sensor. Uncalibrated VWC data for layer 1 is shown in Figure 4.2-11. On the onset of dewatering, the readings vary with depth. Lower water contents are at the bottom, indicating higher densities, as expected, due to self-weight consolidation. Once drying sets in, the water contents sensors show lower water contents at higher elevation. 


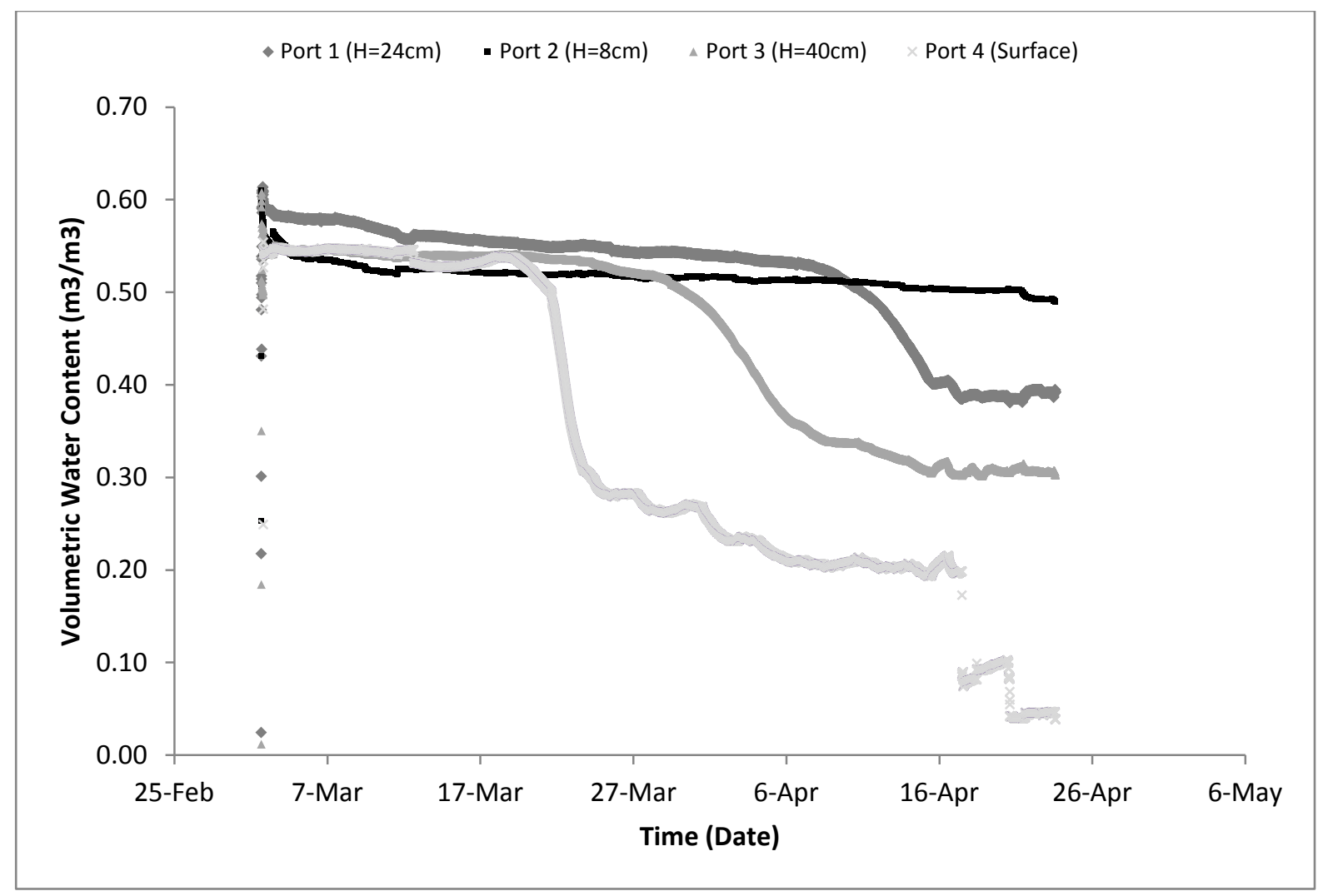

Figure 4.2-11. Volumetric water contents at various heights - Layer 1

\subsubsection{Water Content}

The overall GWC (Figure 4.2-12) was calculated based on weight measurements obtained with the load cells and the water loss through evaporation and drainage. Surface measurements within the top $1 \mathrm{~cm}$ were also taken after the supernatant water that had collected at the top of the tailings had evaporated. The overall GWC takes the supernatant water into account. There is a steady decrease in overall GWC from $199 \%$ to $50 \%$ while the surface GWC decreases from $120 \%$ to $10 \%$. 


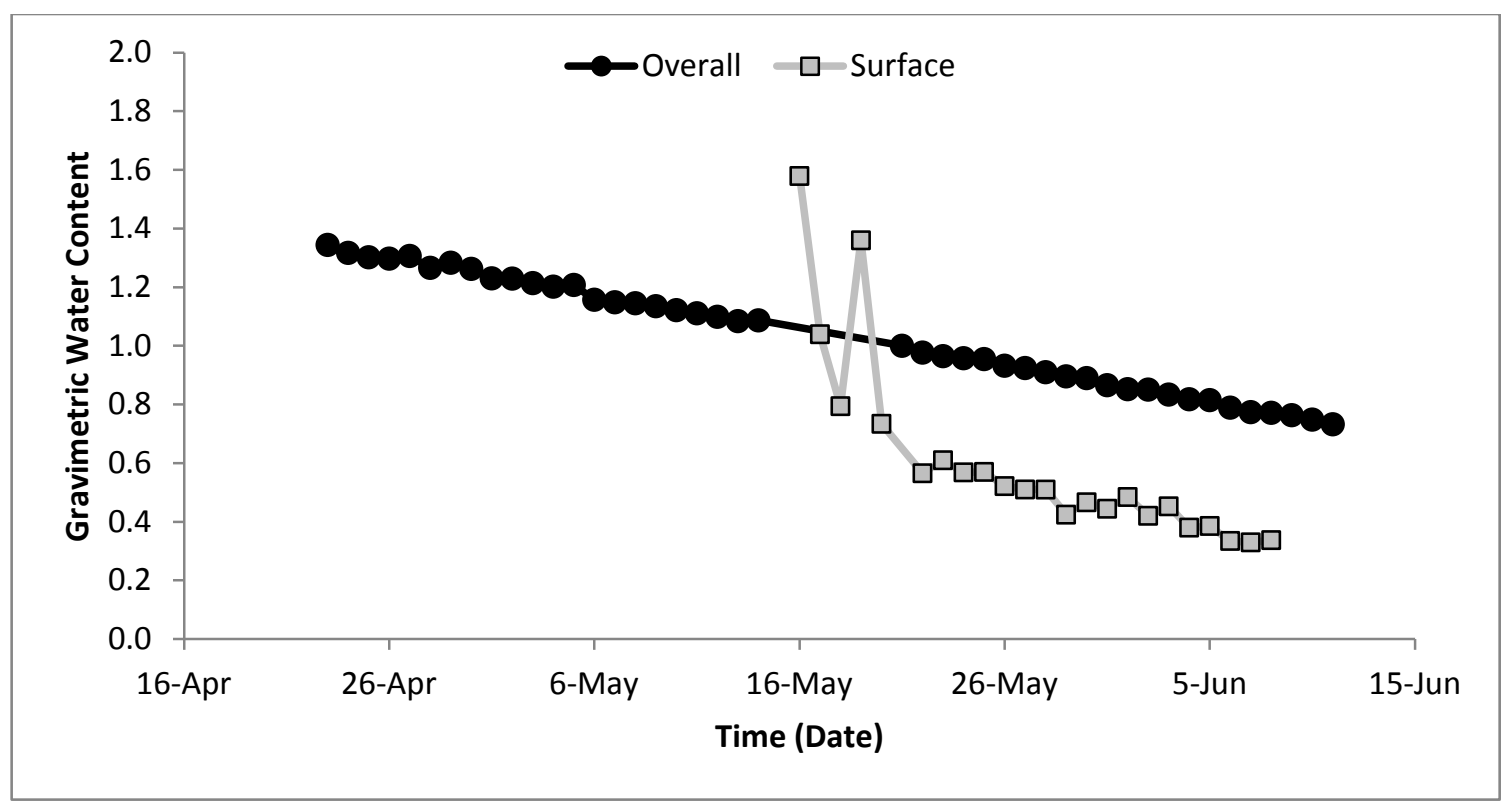

Figure 4.2-12. Gravimetric water contents - Layer 1

Surface samples were also taken at various locations once cracks began to form. They were taken from the surface (between cracks), at the CE and IC. The results are shown in Figure 4.2-13.

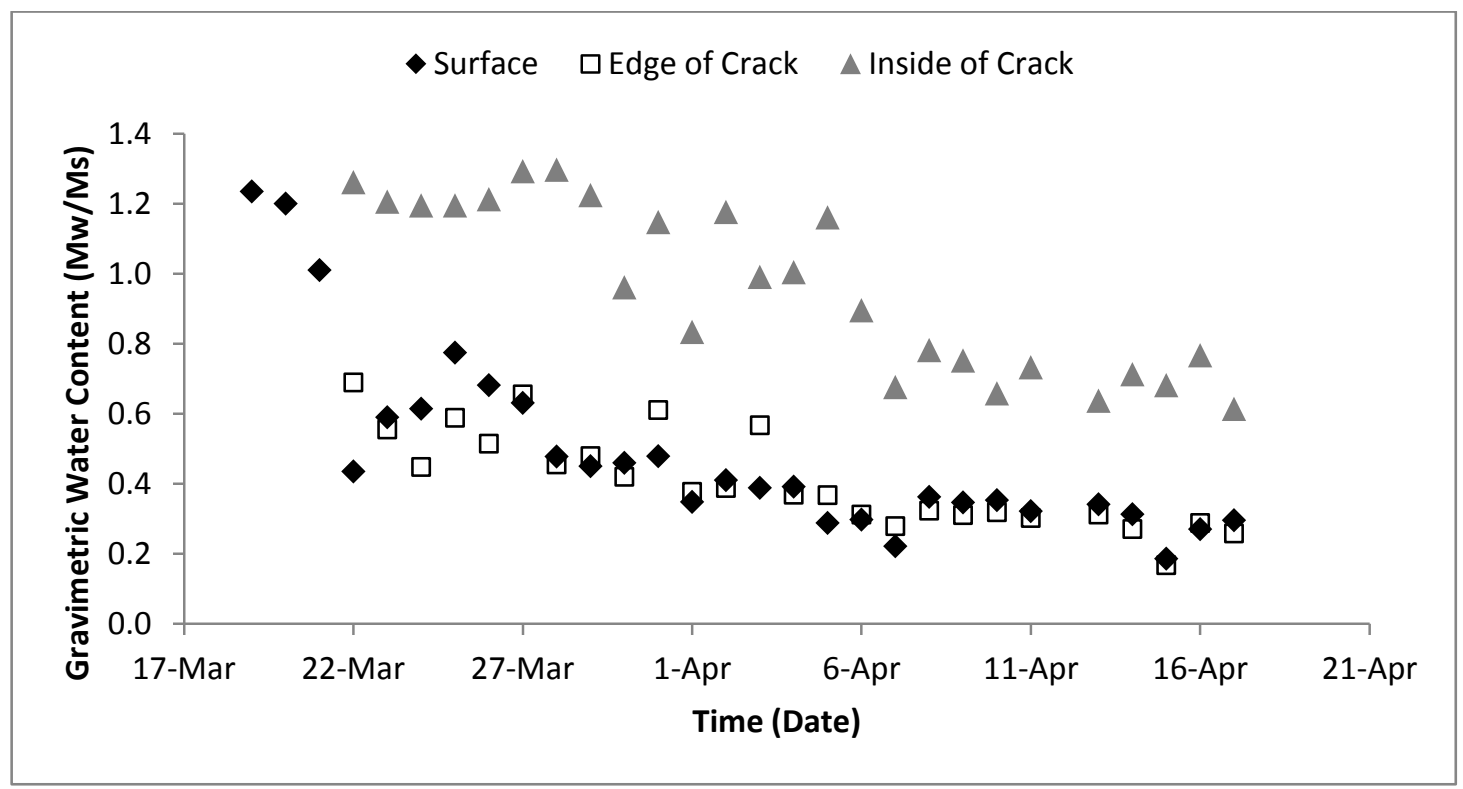

Figure 4.2-13. Surface sample gravimetric water contents - Layer 1 
Generally, the GWC inside the cracks was highest, followed by the surface, and the CE had the lowest GWC, and were found to be the driest.

SCs were calculated using two different methods for the first layer. The overall SC was based on the load cell measurements and water loss. The surface SC was obtained by measuring $\mathrm{SC}$ from samples extracted from the top $1 \mathrm{~cm}$ of the top layer. Results are presented in Figure 4.2-14.

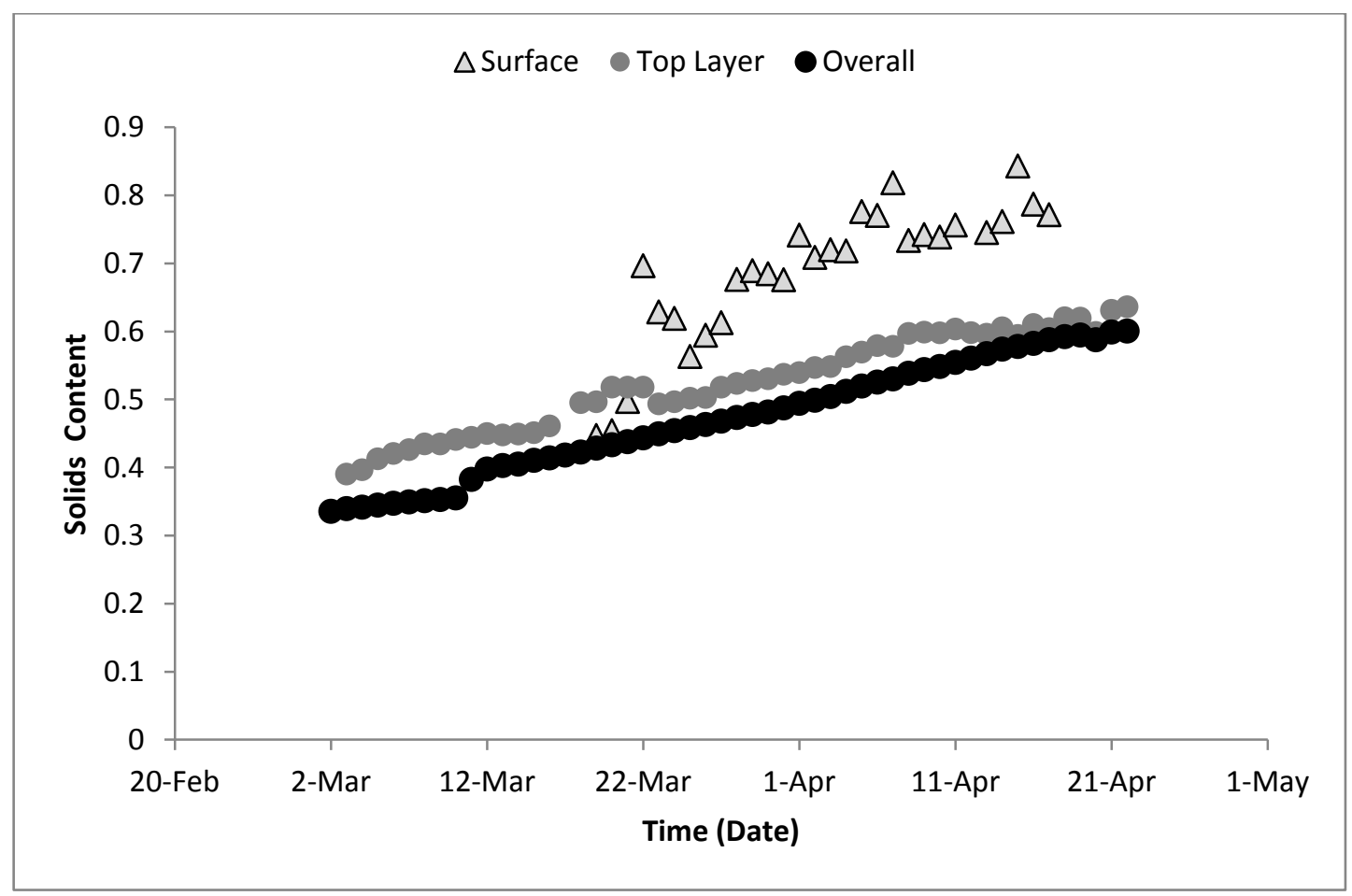

Figure 4.2-14. Solids contents - Layer 1

Figure 4.2-15 provides a breakdown of the SCs at the surface, CE and IC surface samples. 


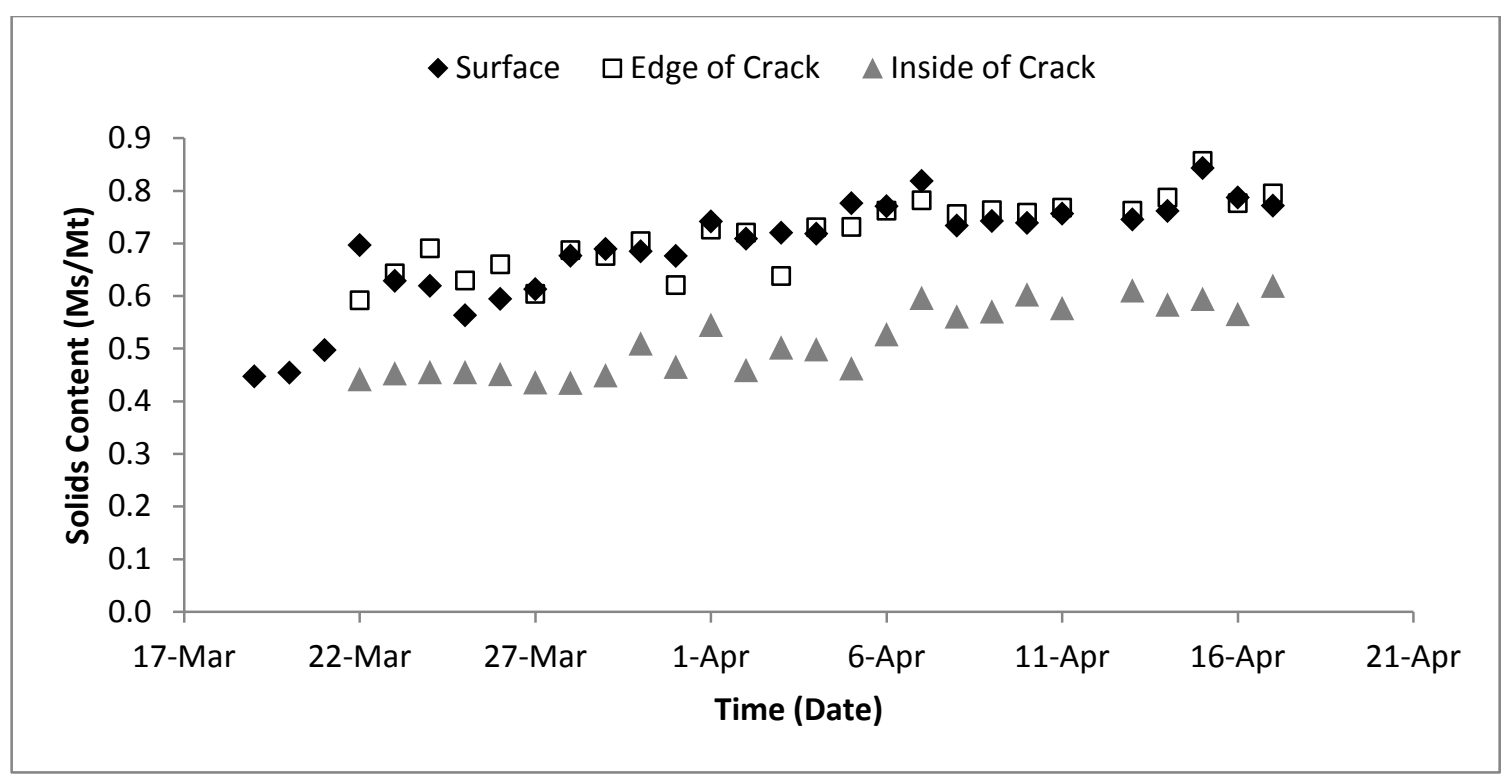

Figure 4.2-15. Surface sample solids contents - Layer 1

Figure 4.1-16 shows the variation in overall degree of saturation in Layer 1 throughout the test.

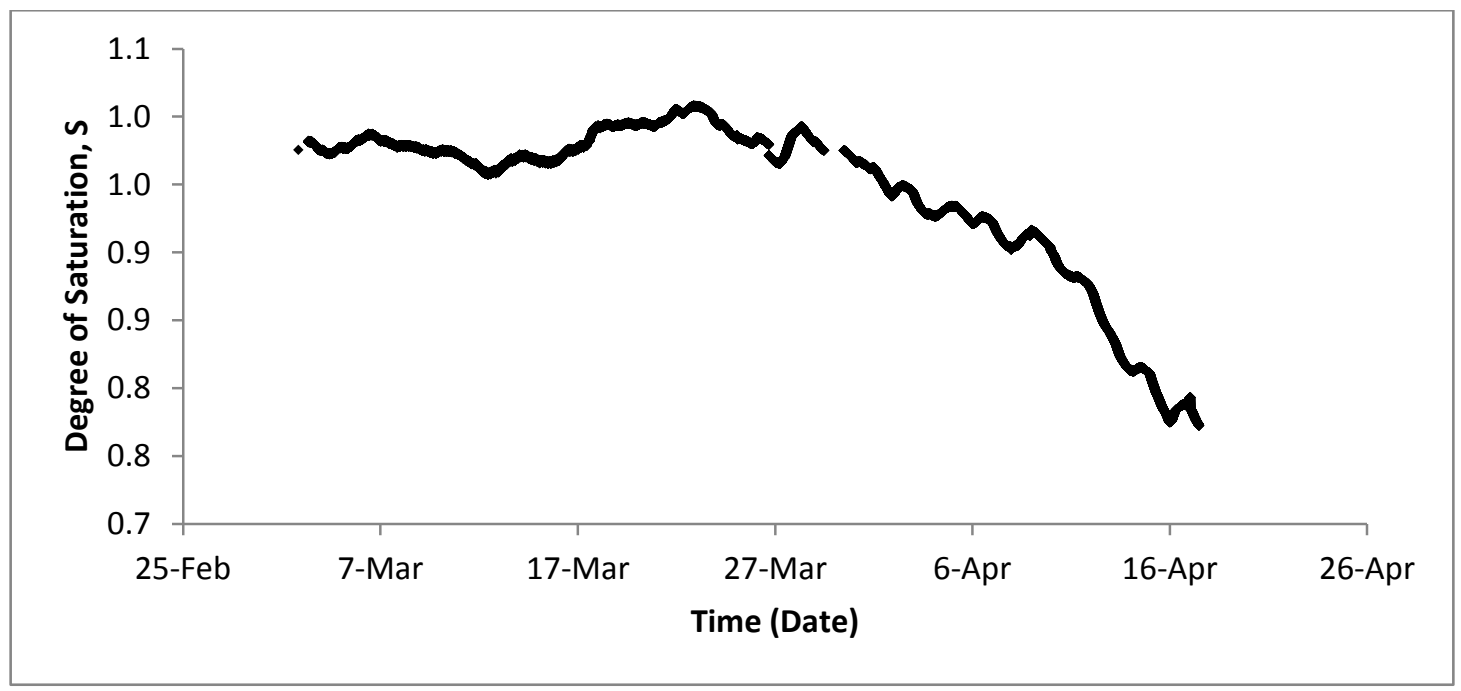

Figure 4.2-16. Overall degree of saturation - Layer 1 


\subsubsection{Suction}

This section provides results for measurements for matric, osmotic, and total suctions in various locations for Layer 1.

\subsection{Matric Suction}

Matric suction was measured with tensiometers placed at varying heights in each layer. The results obtained for layer 1 are shown in Figure 4.2-17. The top tensiometer reached suctions of $790 \mathrm{hPa}$ and cavitated. The other two tensiometers did not cavitate before the addition of Layer 2, however there are some oscillations due to the addition of tensiometers to the logger.

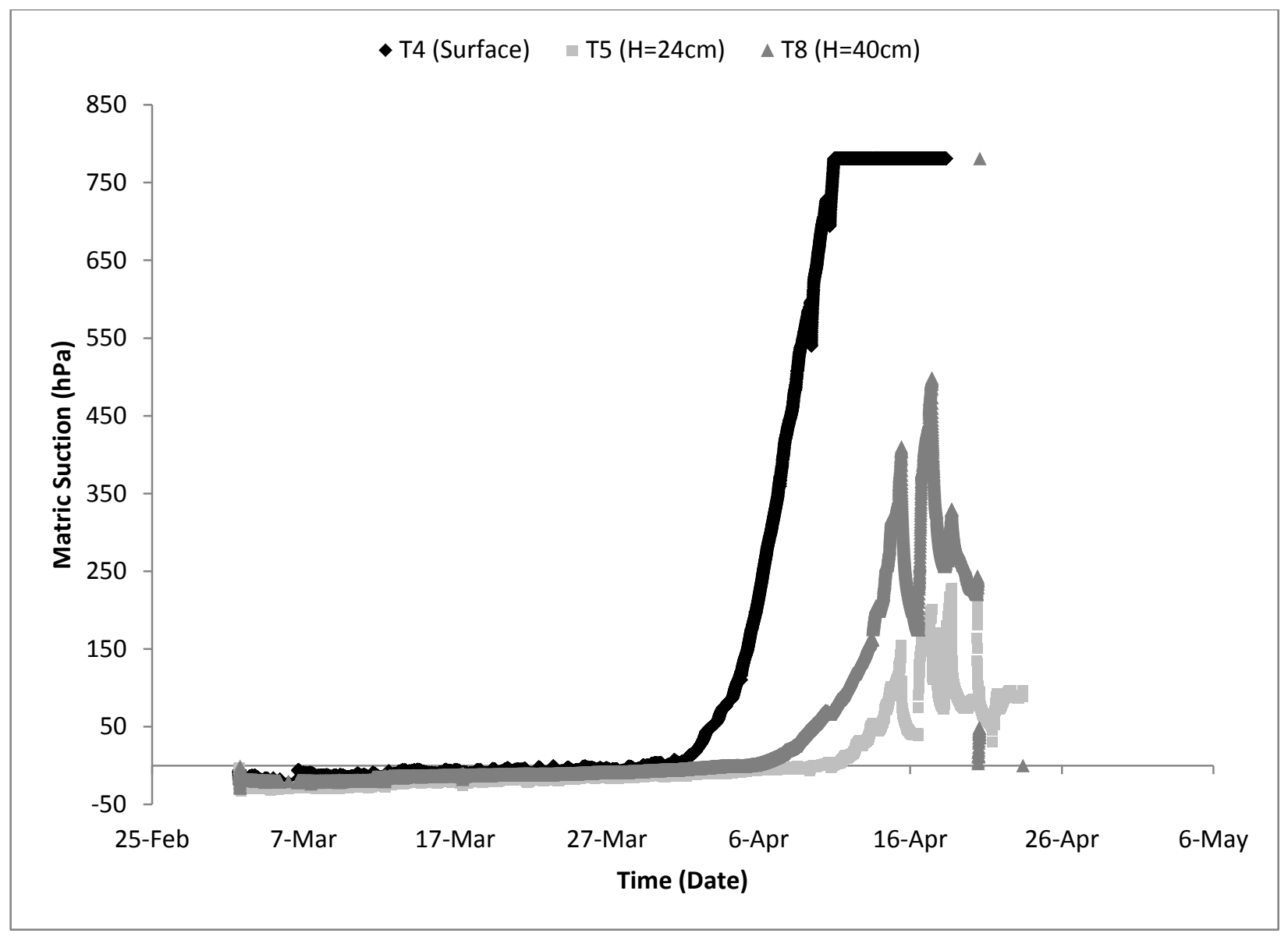

Figure 4.2-17. Matric suction at various heights - Layer 1 


\subsection{Osmotic Suction}

Daily EC measurements at the surface, CE and IC are shown in Figure 4.2-18. These values begin increasing significantly around April $6^{\text {th }}$. These values are much greater than previously seen in the thin lift dry box, especially at the CE.

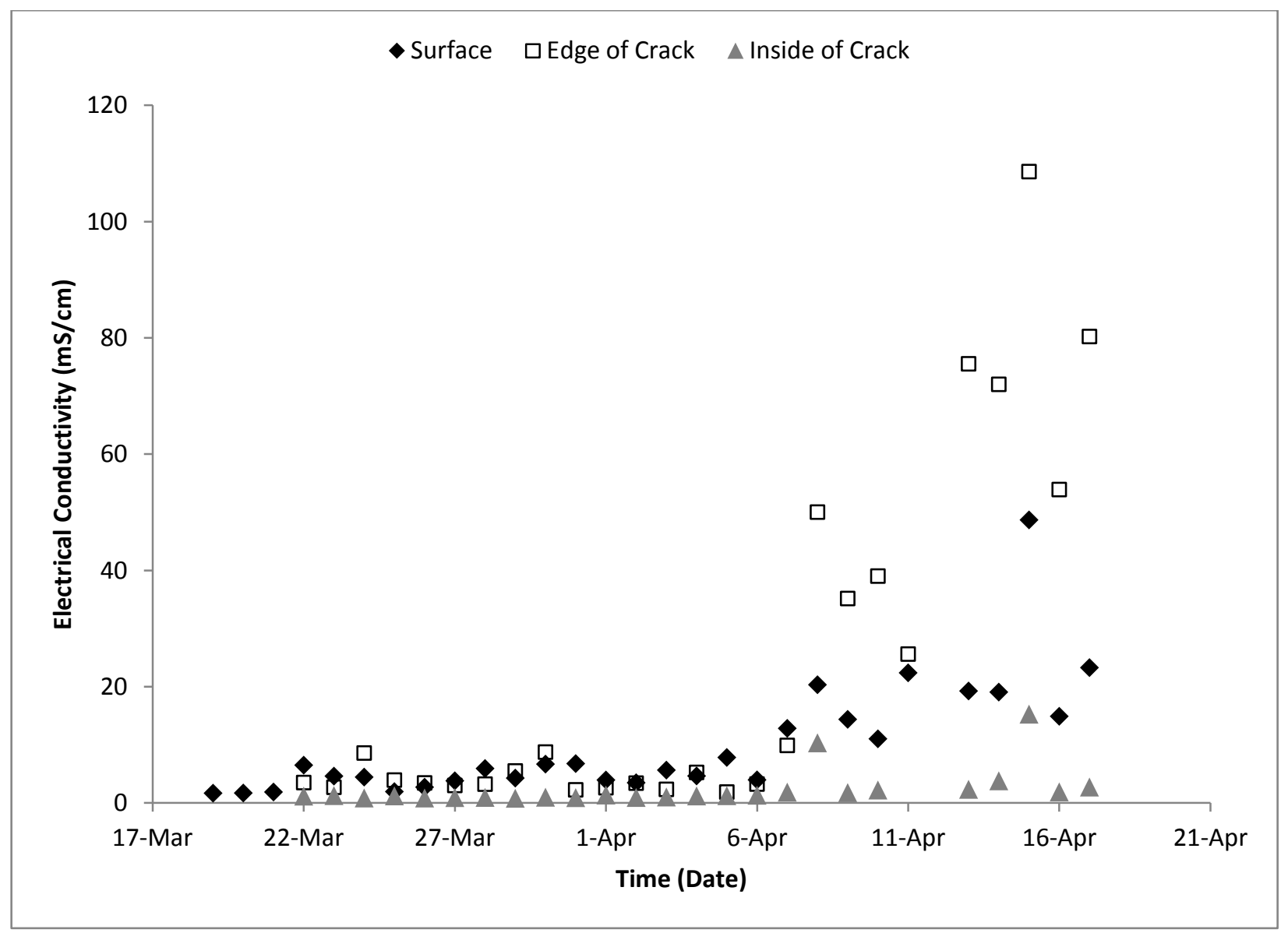

Figure 4.2-18. Surface sample electrical conductivity - Layer 1

A comparison of osmotic suction to total suction is shown in Figure 4.2-19. The total suction is always greater than the osmotic component. 


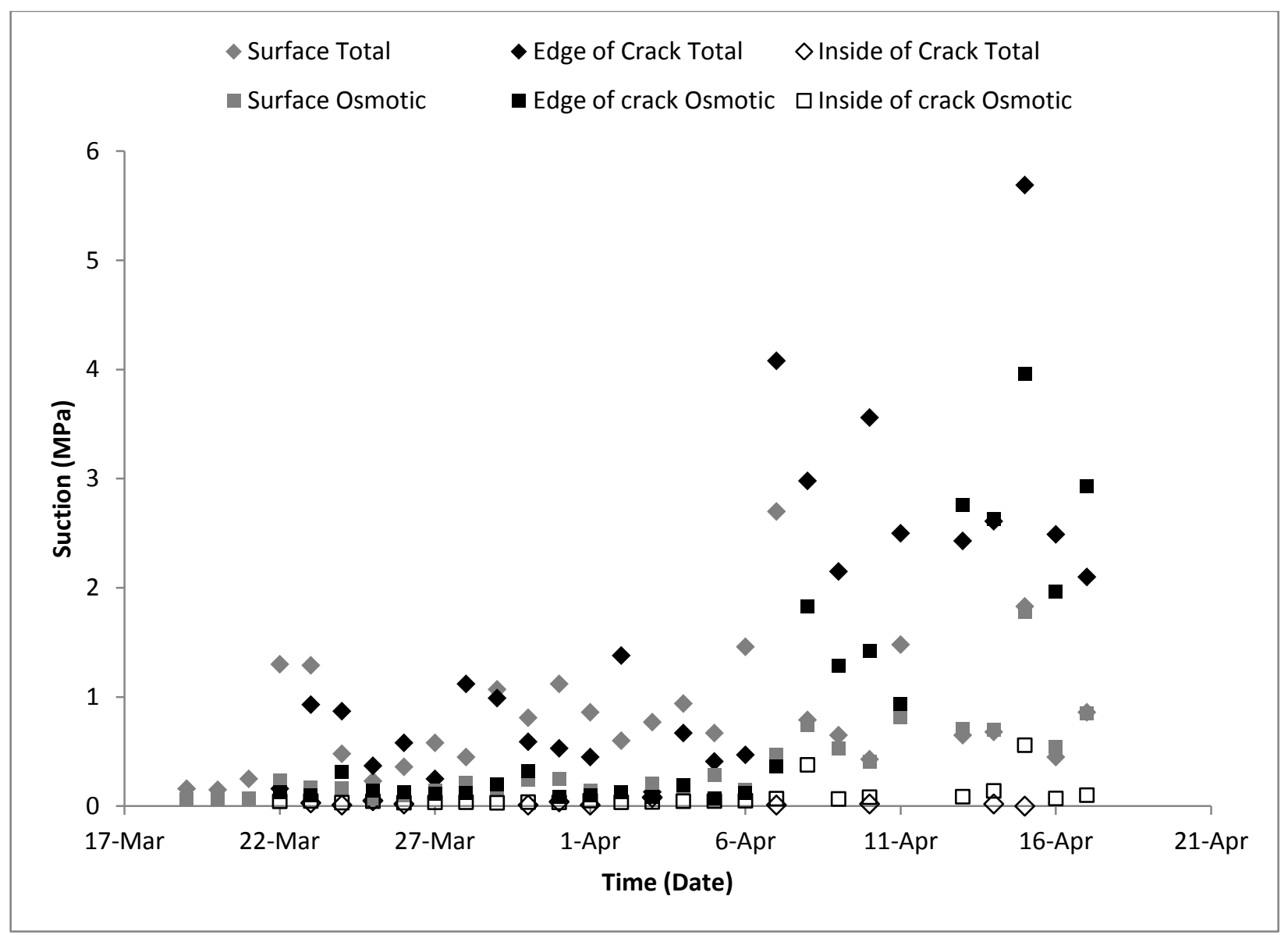

Figure 4.2-19. Surface sample total and osmotic suctions - Layer 1

\subsection{Total Suction}

Samples extracted from the top $1 \mathrm{~cm}$ of the surface of the tailings, crack edges and the ICs were measured for total suction using a WP4 potentiometer. These results are shown in Figure 4.2-20. Figure 4.2-21 is the same set of measurements on a log scale.

Overall, suction values at the surface increased as water escaped the tailings. Initially, suction values along the crack edges were wetter than those at the surface, but as the tailings dried out, the edges also dried out, and in some instances surpassed the values at the surface. The values inside the cracks were always lowest, and more or less the same, since the cracks were always expanding down wise and exposing fresh wet tailings from the bottom. 


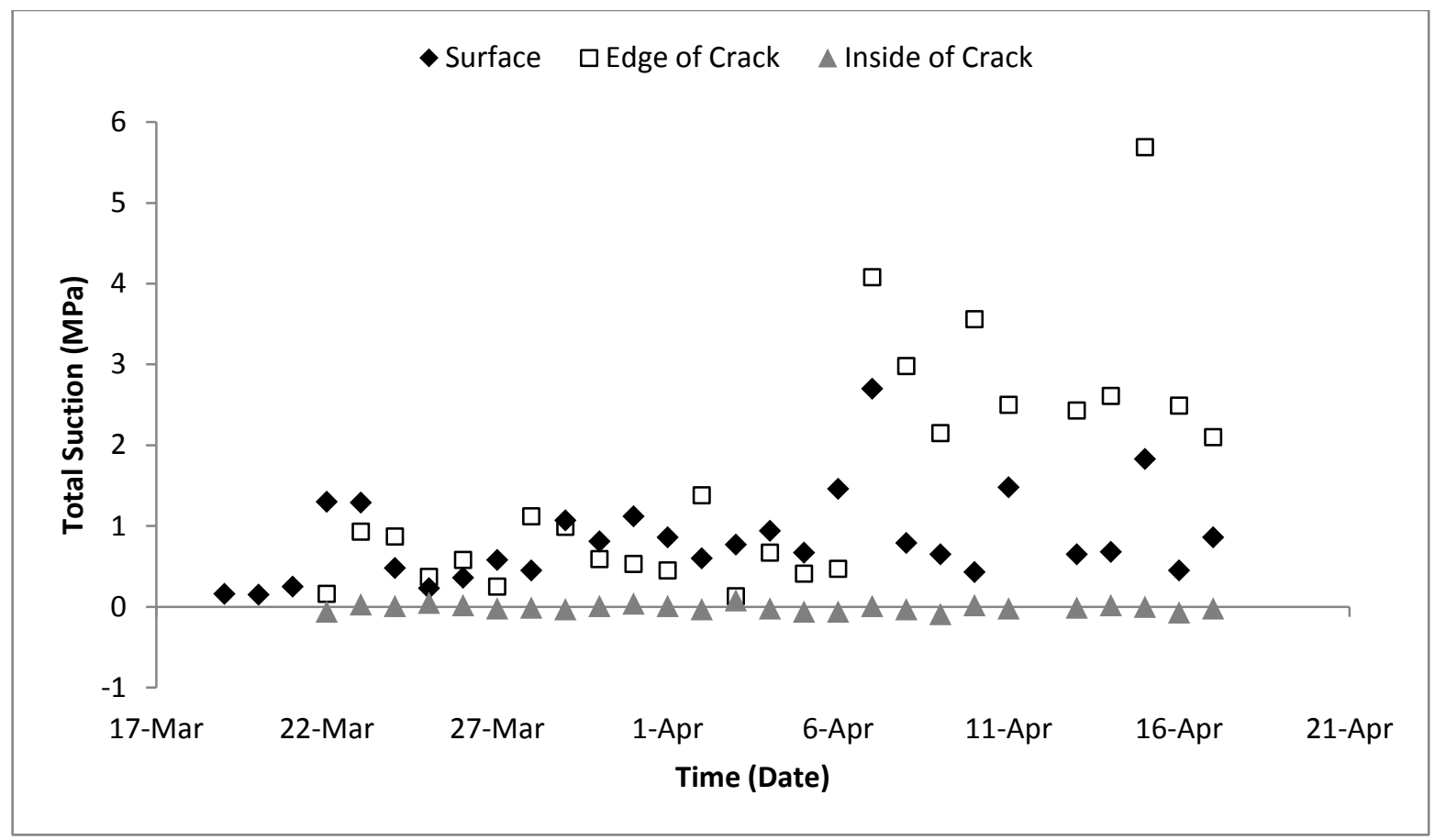

Figure 4.2-20. Surface sample total suctions - Layer 1

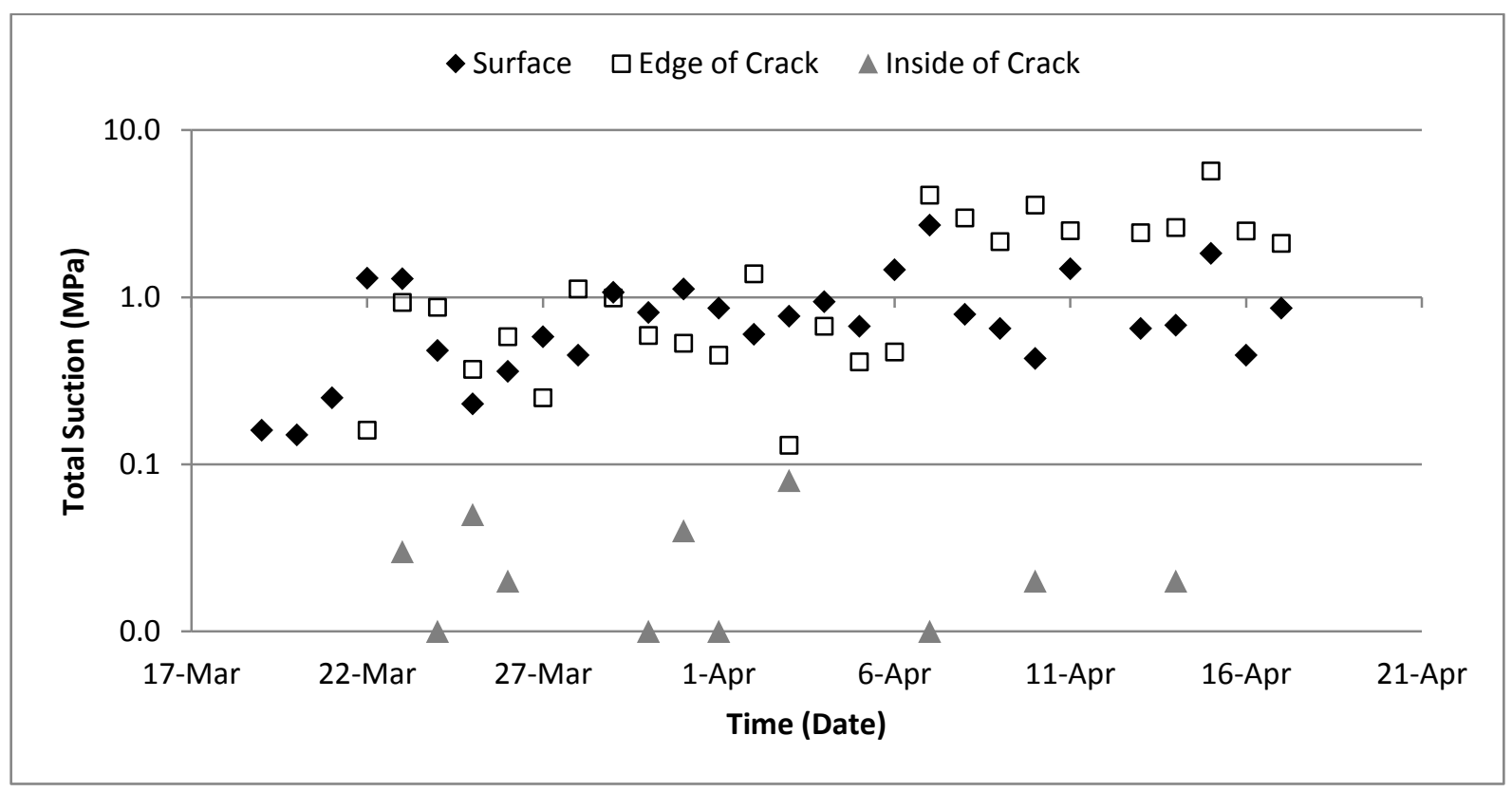

Figure 4.2-21. Surface samples total suctions on log scale - Layer 1 


\subsubsection{Core Samples}

A core sample was extracted once the layer had reached $60 \%$ SC on April $18^{\text {th }}$. The location for sample is shown in Figure 4.2-22, where the core extraction caused some cracking.

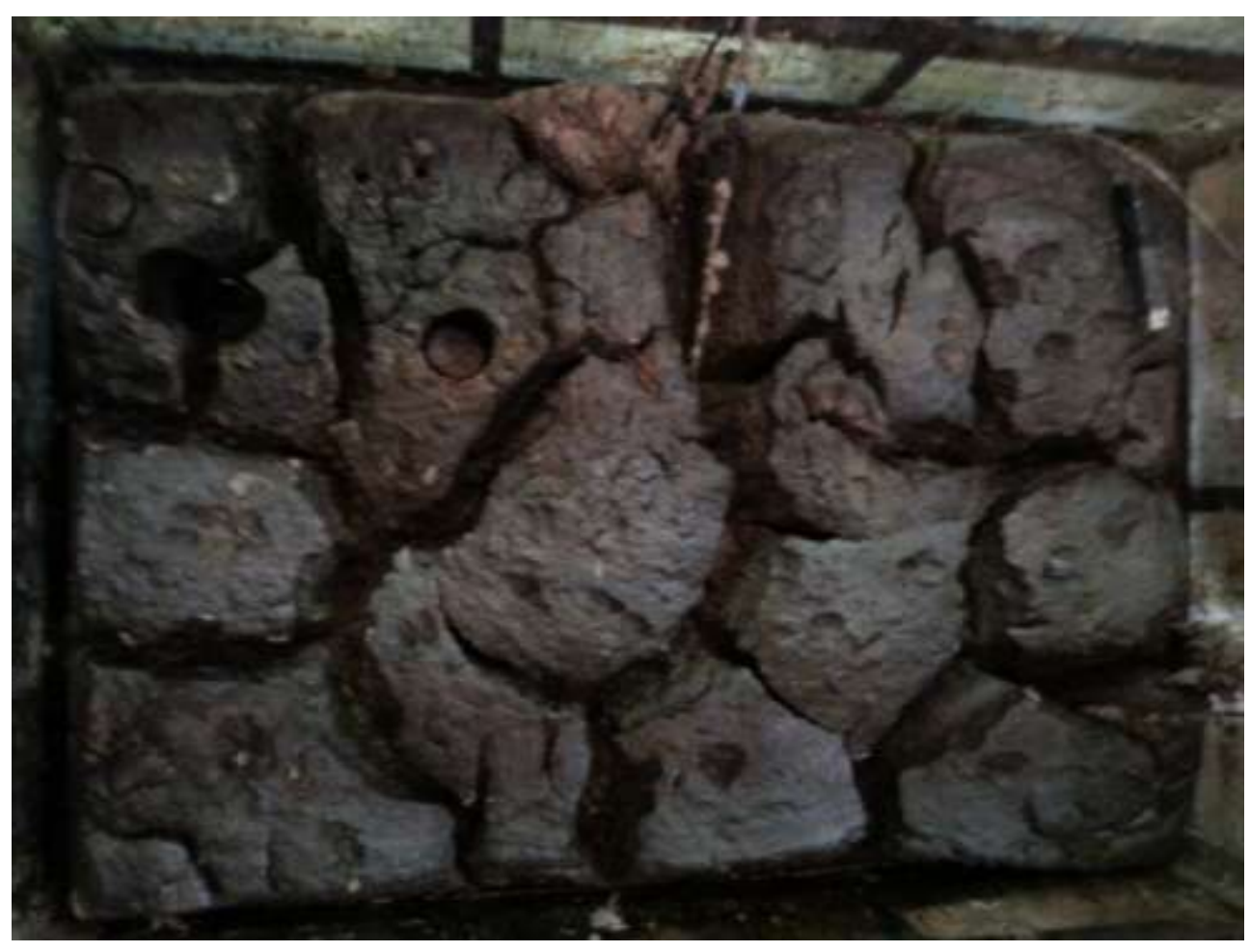

Figure 4.2-22. Core sample location - Layer 1

The core was analysed for GWC, SCs, osmotic suction, total suction and TOC every $1 \mathrm{~cm}$.

\subsubsection{Core Sample Results}

The extracted core sample is shown in the following figure, along with the pushed in and extracted depths. The pushed in depth was $26 \mathrm{~cm}$, while the extracted depth was $21 \mathrm{~cm}$. The surface of the layer is the disk on top of core, since it had broken off during extraction. The bottom $10 \mathrm{~cm}$ was scooped out of the core location using a spoon, since 
the very bottom of the dry box was still very wet, and the core tube could not extract the wet material. Therefore the measurements with depth for the bottom $10 \mathrm{~cm}$ are ambiguous, the material was uniform upon analysis.

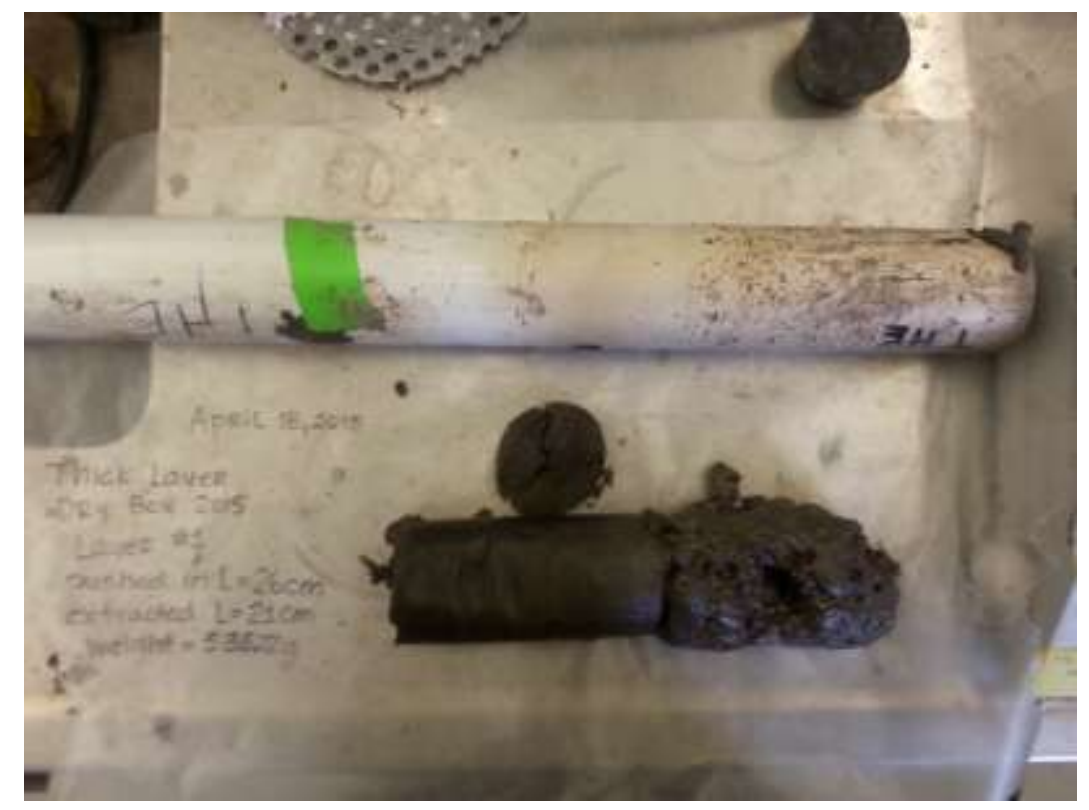

Figure 4.2-23. Core sample - Layer 1

The following figure is related to water content with depth, as well as the SC and TOC. 


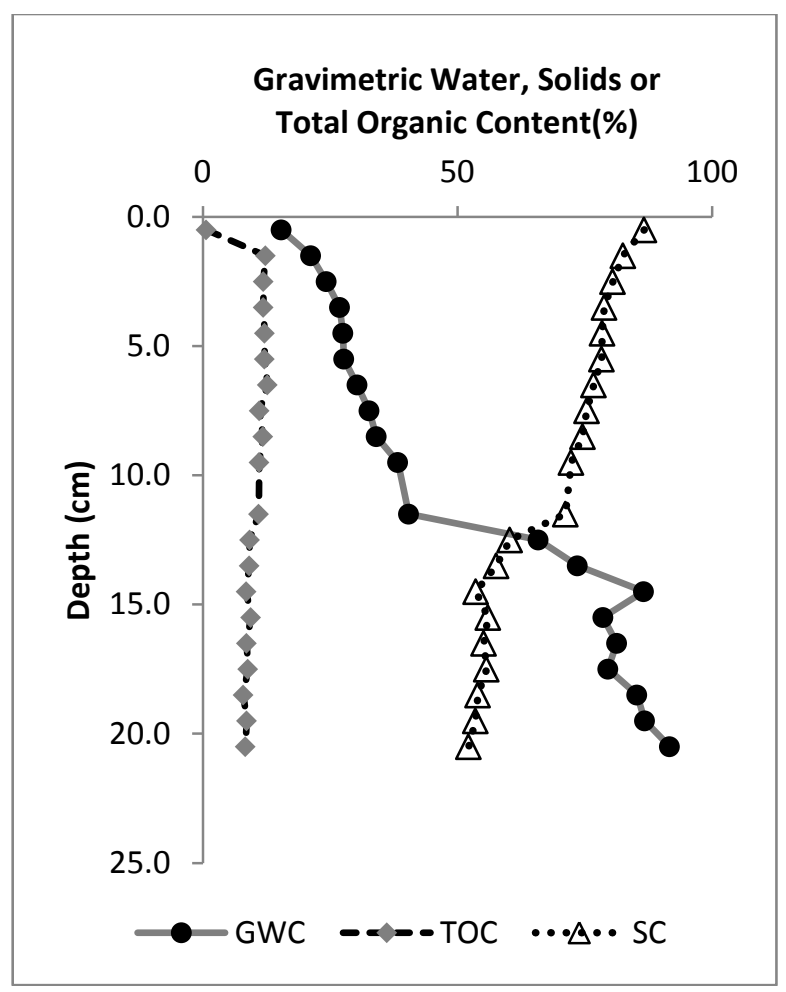

Figure 4.2-24. Core GWC, and SC profile - Layer 1

The following figures are related to osmotic and total suction with depth.

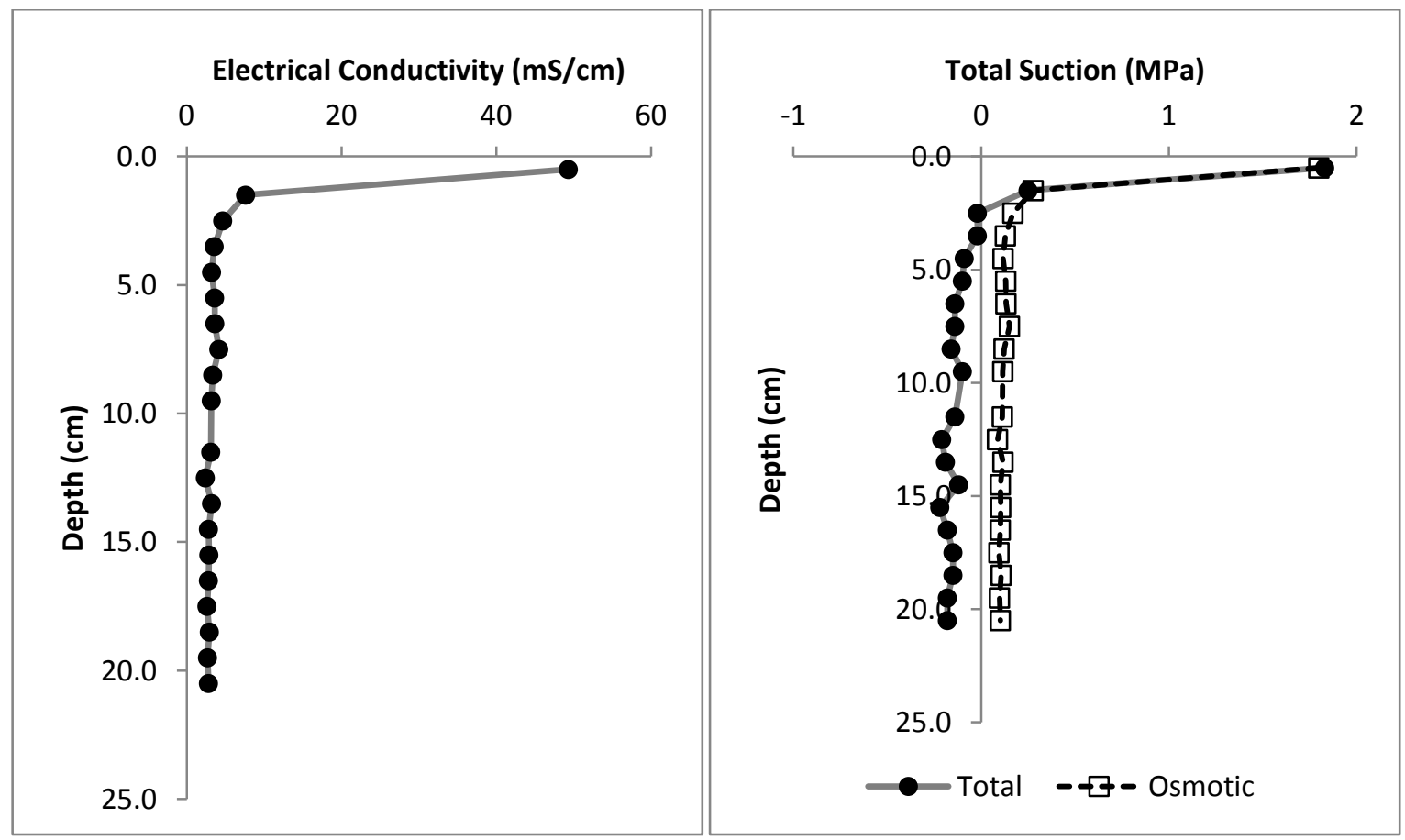

Figure 4.2-25. Core EC, osmotic and total suction profiles - Layer 1 


\subsubsection{Undrained Shear Strength}

Vane shear tests were conducted in conjunction with core extraction. The locations of these tests are right next to the locations of the core extraction. Figure 4.2-26 shows the results from these tests.

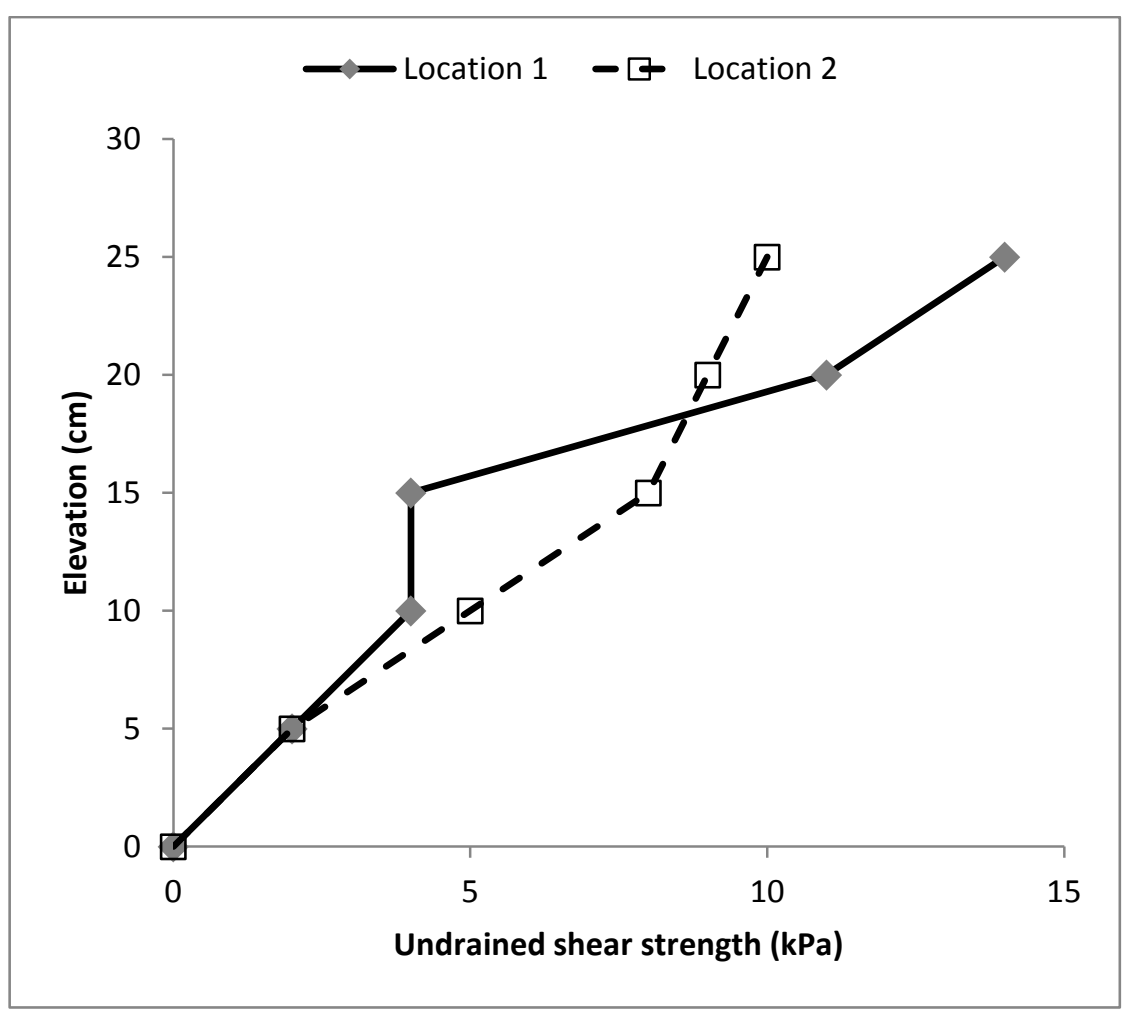

Figure 4.2-26. Undrained shear strength profiles - Layer 1

\subsubsection{Layer 2}

Once layer 1 had attained an overall SC of $60 \%$, layer 2 was deposited on April $23^{\text {rd }}$. The same process was used as for layer 1 . The average initial SC of the tailings was $35 \%$. Then the flocculated tailings were deposited in 106 buckets of $3.6 \mathrm{~kg}$ and allowed to dry to overall $60 \%$ and $70 \%$ SC. Core samples were taken once the top layer reached these SCs. The data collected for the second layer is presented in this section. 


\subsubsection{Mass Loss, Evaporation and Drainage}

Figure 4.2-27 shows the overall mass loss in the dry box after the deposition of the second layer. Figure 4.2-28 provides a breakdown of the evaporation and drainage. In this layer, the mass loss is slower than layer 1 , because of the dry underlying layer.

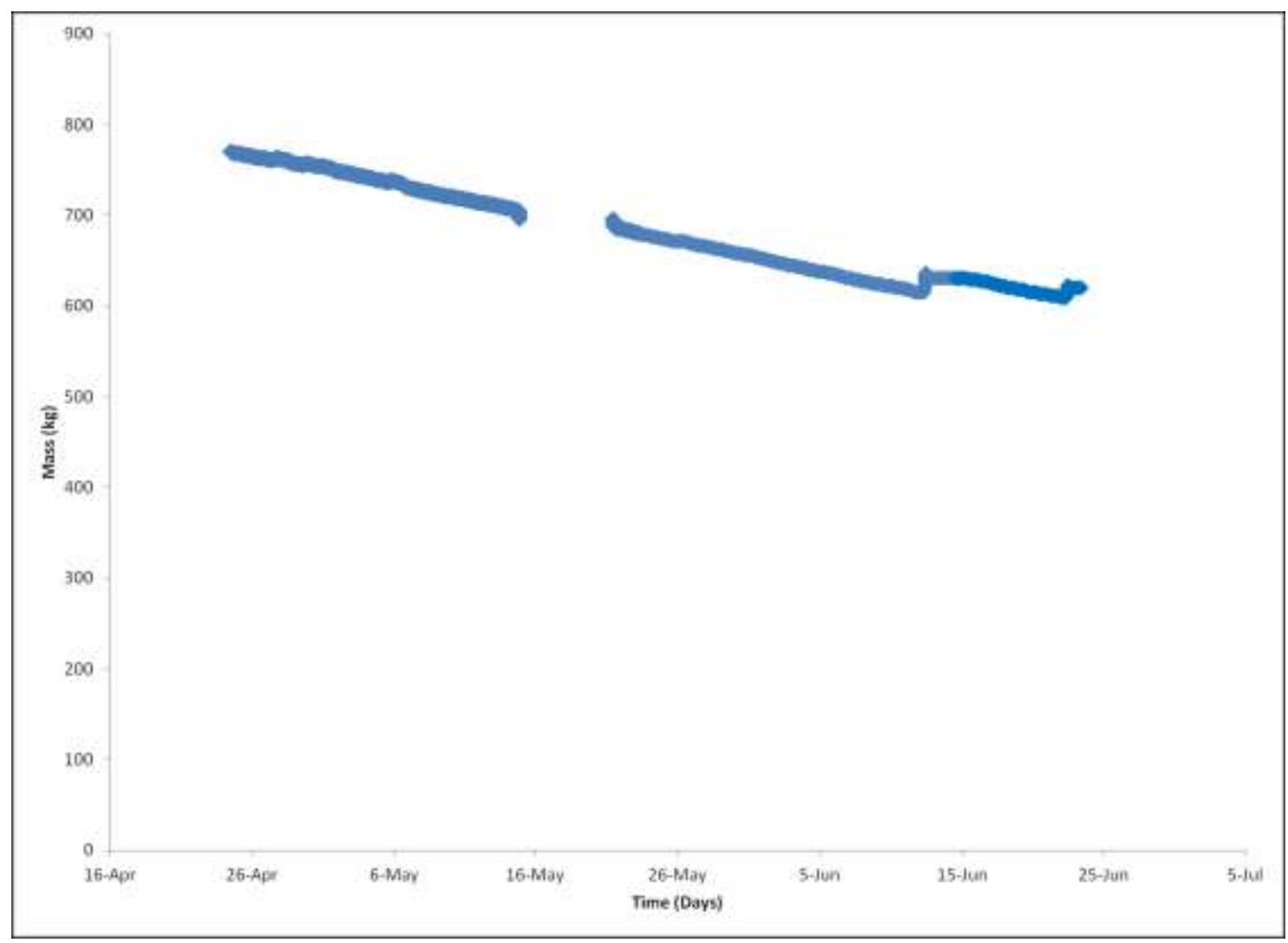

Figure 4.2-27. Total mass of tailings - Layer 2

The $A E$ rate was found to vary from approximately 2 to $6 \mathrm{~mm} /$ day, which is generally in agreement with layer 1. 


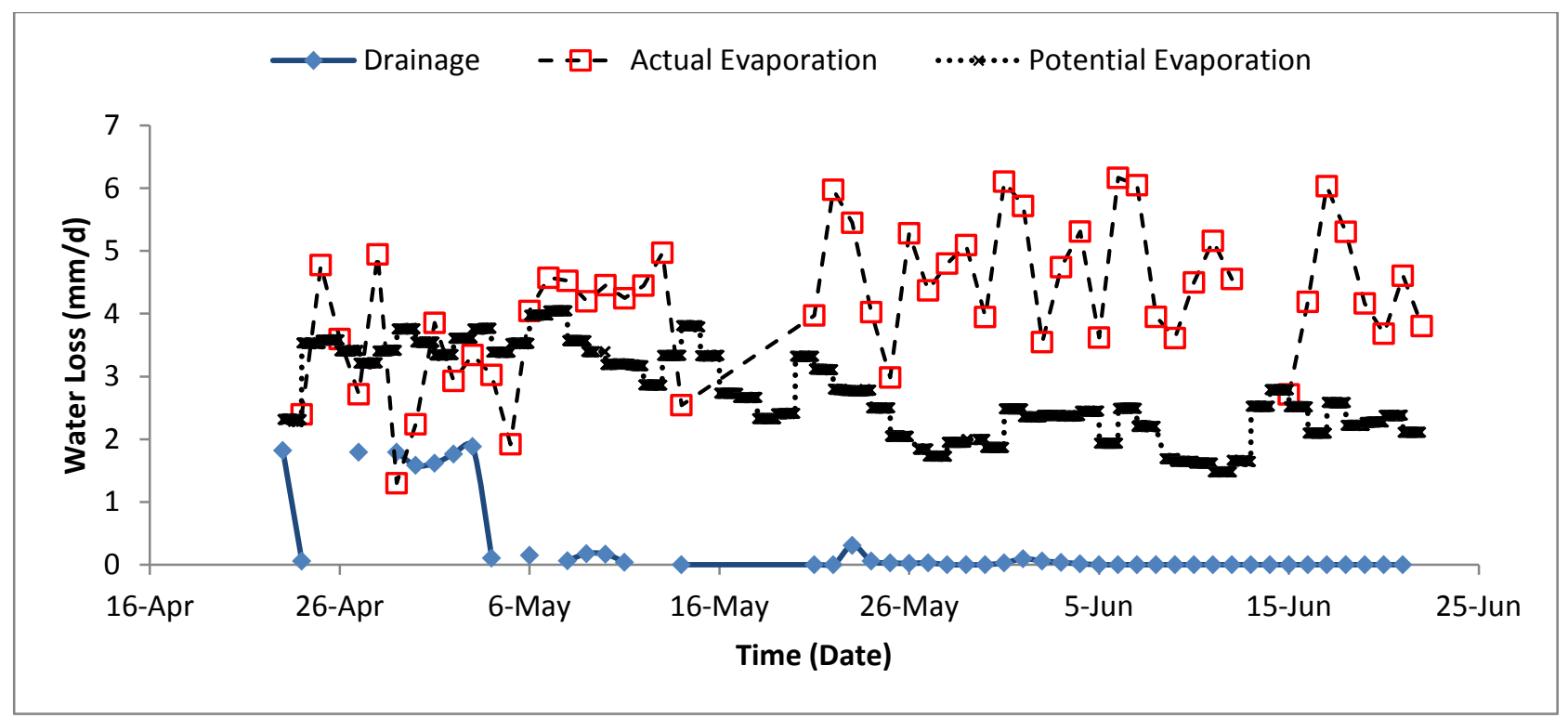

Figure 4.2-28. AE, PE and drainage - Layer 2

Figure 4.2-29 shows the temperature variation, above the tailings, at the surface and inside a crack after the deposition of Layer 2. Temperatures varied from 18-30 degrees Celsius.

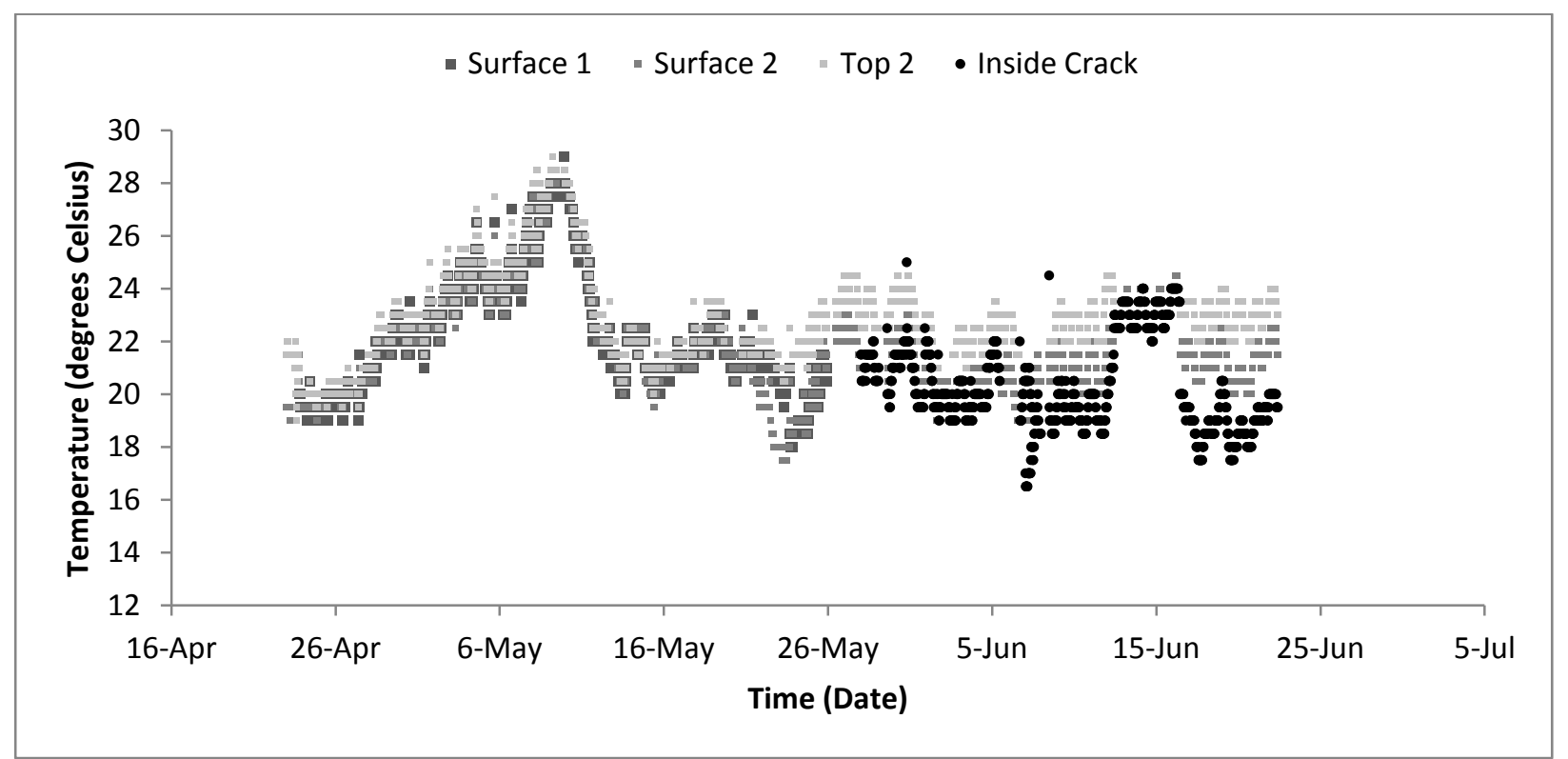

Figure 4.2-29. Temperatures at the surface - Layer 2 
Figure 4.2-30 shows the temperature inside the bottom layer of the tailings as recorded by VWC sensors placed at various heights. Temperatures were found to have increased once the second layer was added in the bottom layer.

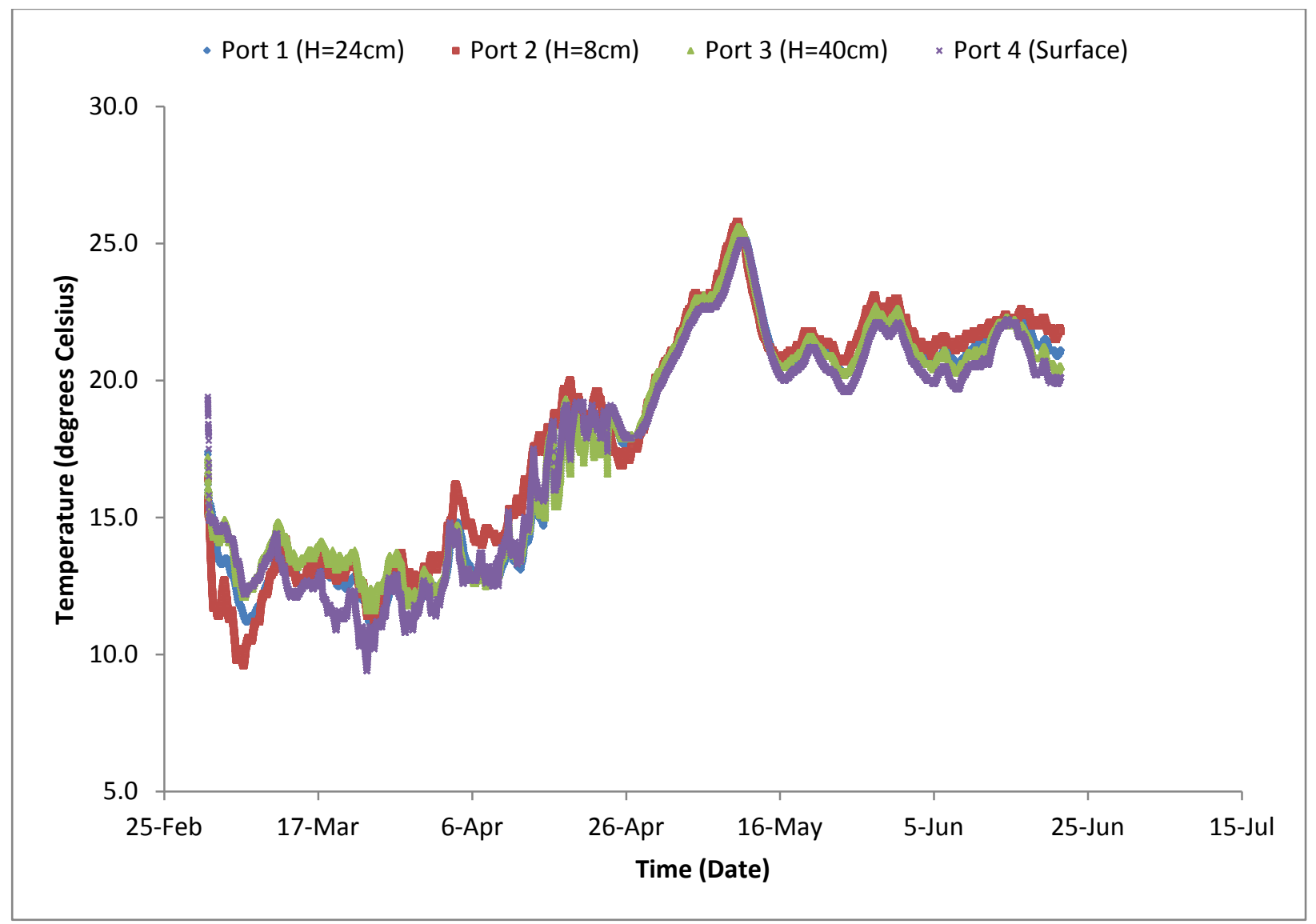

Figure 4.2-30. Temperatures at various heights in bottom layer - Layer 2

Figure 4.2-31 shows the temperature inside the top layer of the tailings as recorded by VWC sensors. In this Layer, temperatures were found to be cooler at the top than at the bottom. 


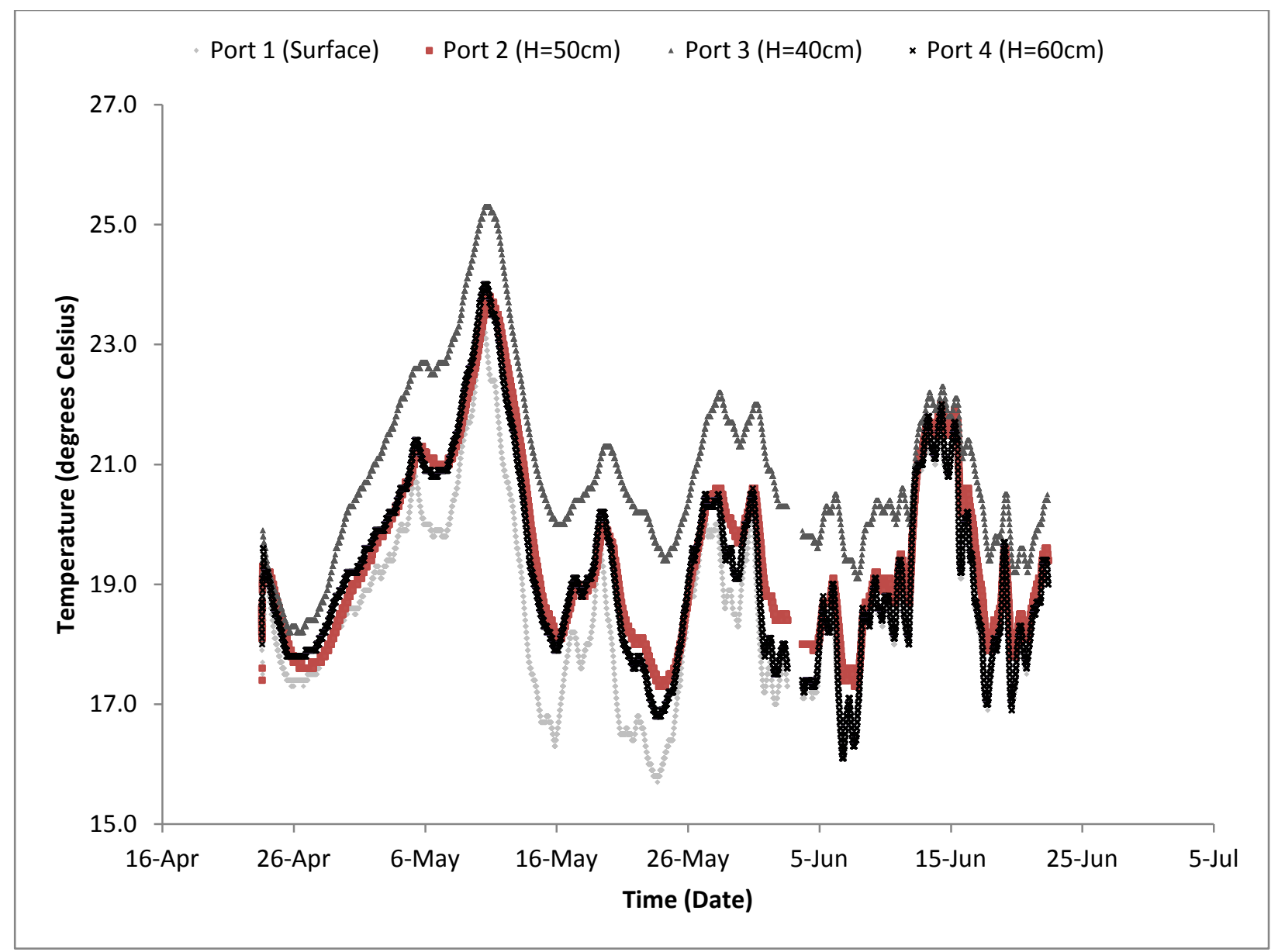

Figure 4.2-31. Temperatures at various heights in top layer - Layer 2

Figures 4.2-32 shows the variations in $\mathrm{RH}$ above the tailings, at the surface, and inside a crack. There is an overall increasing trend in the $\mathrm{RH}$ values as the seasons changed from late spring to summer; generally the values of $\mathrm{RH}$ are higher inside the crack. Based on the conditions shown in these figures the PE was found to vary from approximately $2 \mathrm{~mm}$ to $4 \mathrm{~mm}$ per day. 


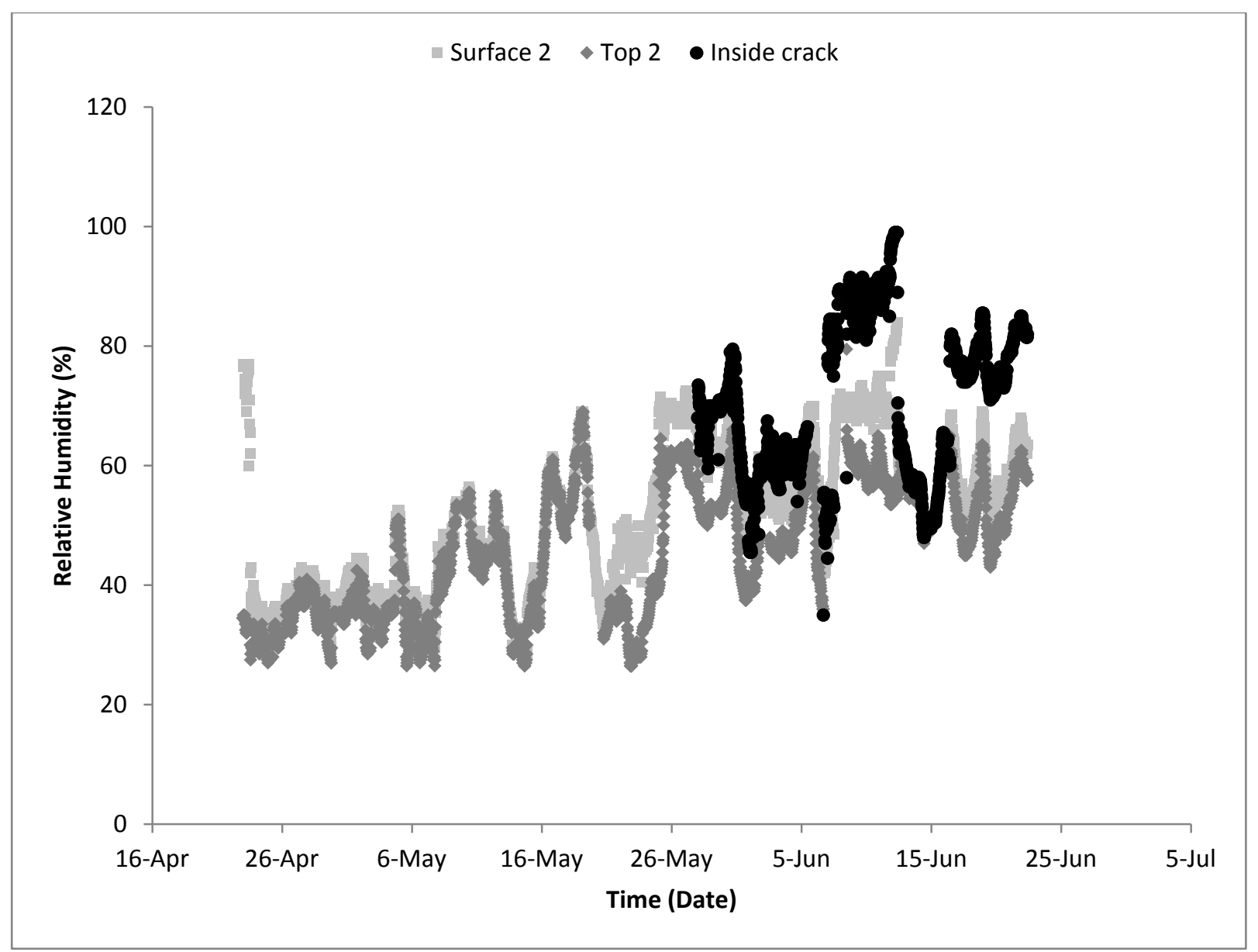

Figure 4.2-32. RH profiles at the surface - Layer 2

After the deposition of the second layer, the AE generally matches the PE until approximately May $10^{\text {th }}$, when cracking was first observed (Figures 4.2-33 and 4.2-34). After that date, the $A E$ increased beyond PE values. In this case, the cracks did not stop growing, since thick lifts were implemented and the crack depths never reached the bottom of the dry box. 


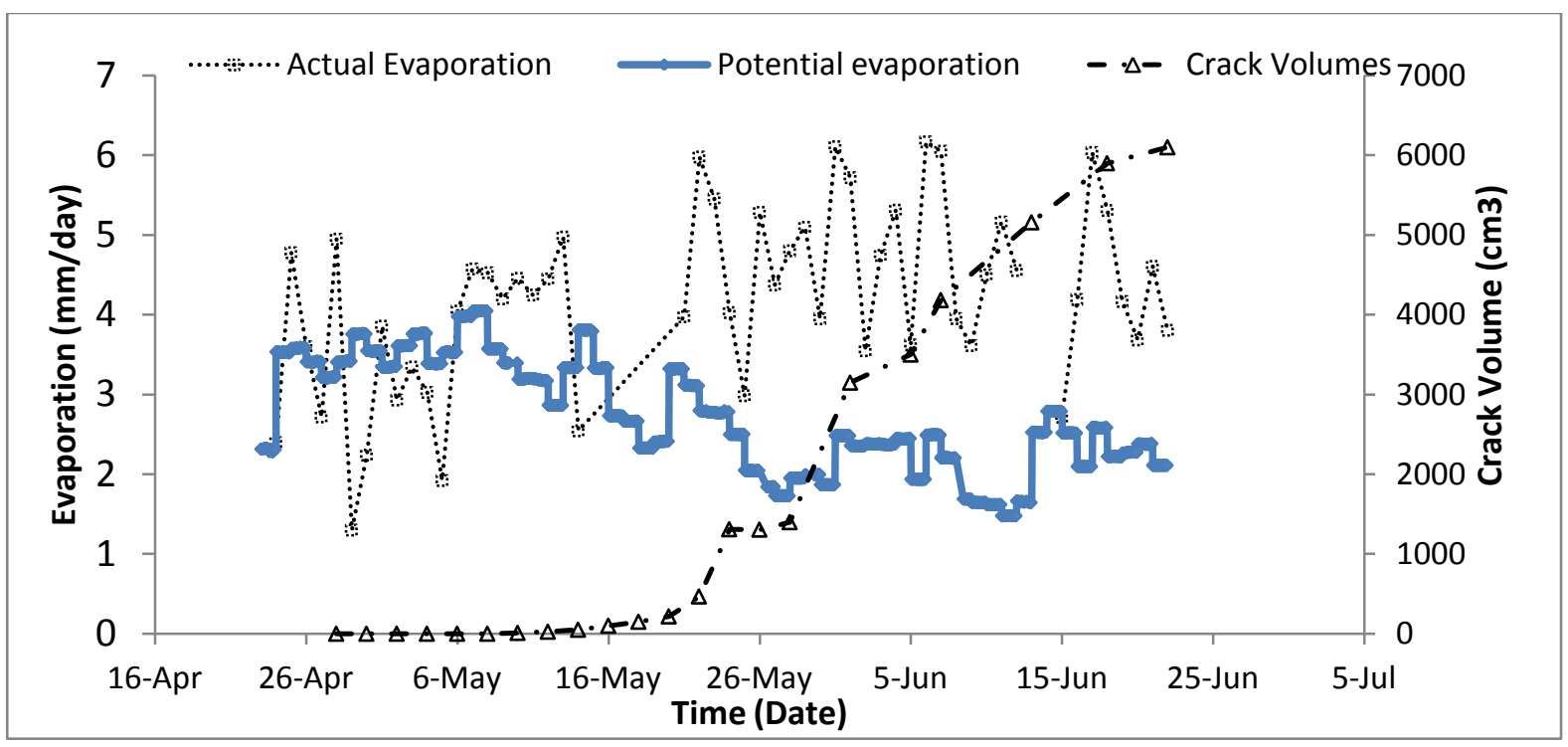

Figure 4.2-33. Evaporation vs. cracking - Layer 2

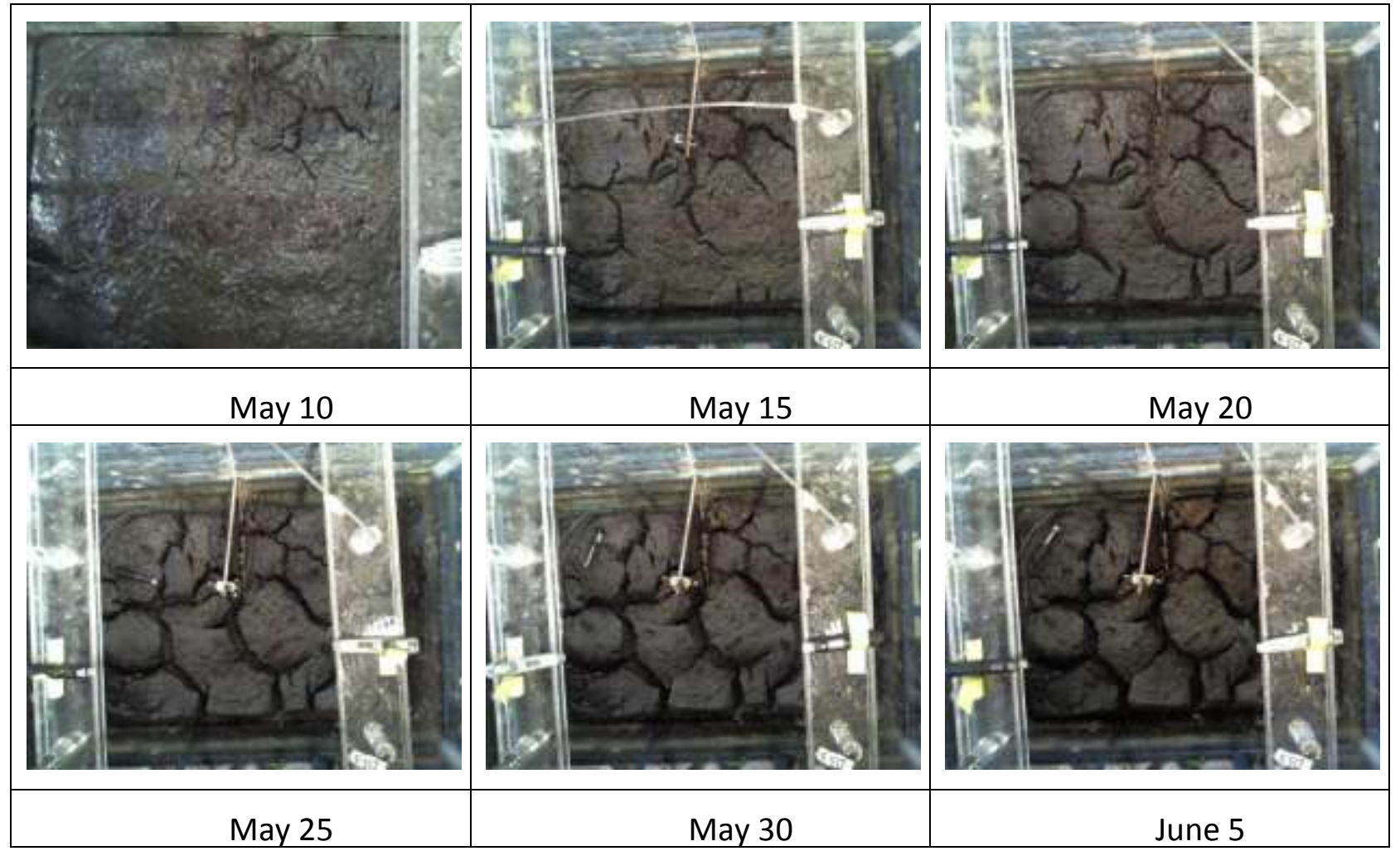

Figure 4.2-34. Progression of cracking - Layer 2

\subsubsection{Settlement}

A few hours after deposition, the tailings separated into two visible layers, the heavier MFT at the bottom and a layer of clear water at the top. The distance between 
the top of the water and the MFT interface was measured at 5 different points daily, and averaged. The MFT settled due to self-weight consolidation, and the water at the top evaporated. Figure 4.2-35 shows the settlement of the MFT and the evaporation of the top water before that point.

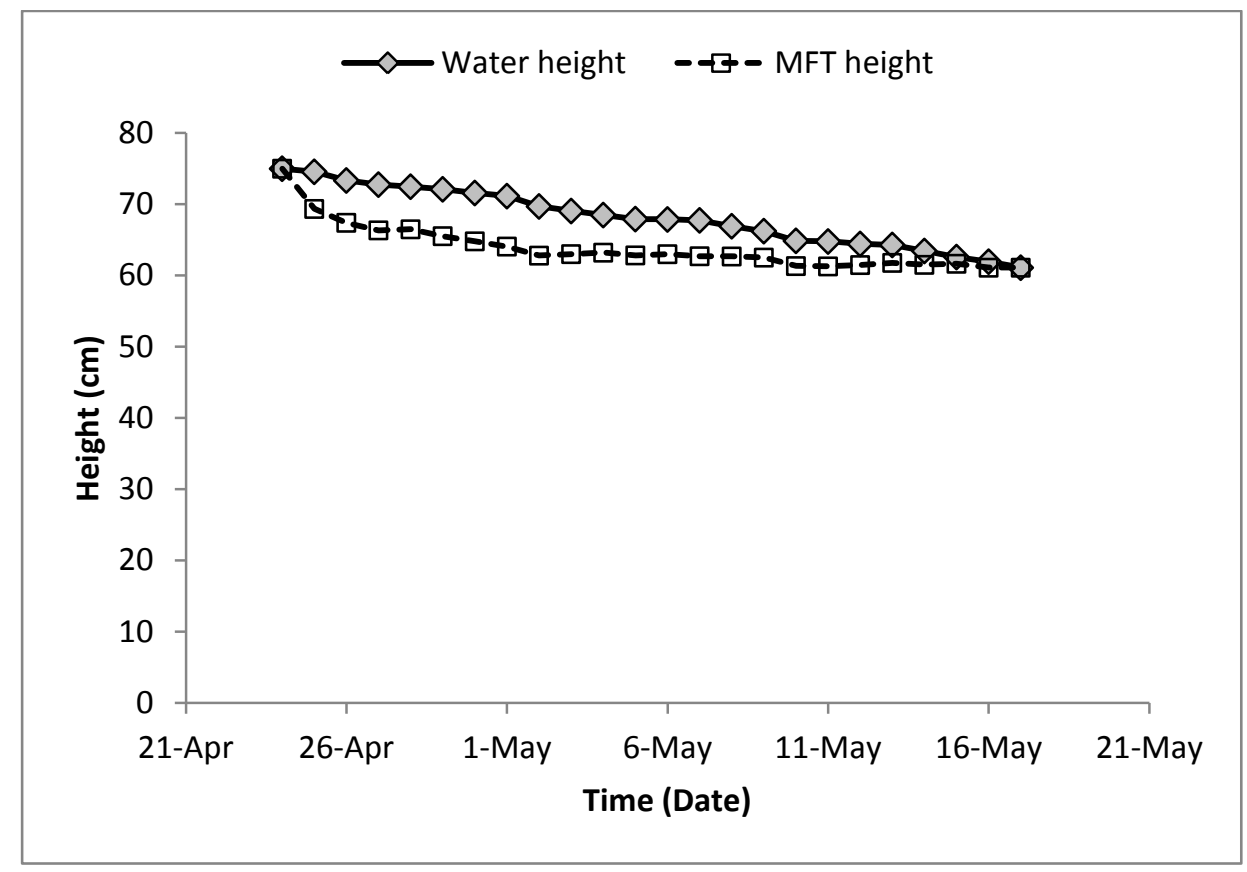

Figure 4.2-35. Water and MFT heights - Layer 2

Figure 4.2-36 shows the expected height of the tailings for this layer, if the tailings were added instantaneously (vertical lines), and the actual heights of the tailings over time. Of course, as they are not added instantaneously, the height at the end of Day 1 is somewhat smaller than this height. In the second layer, this is due to the ability of the drier material at the bottom to absorb moisture. 


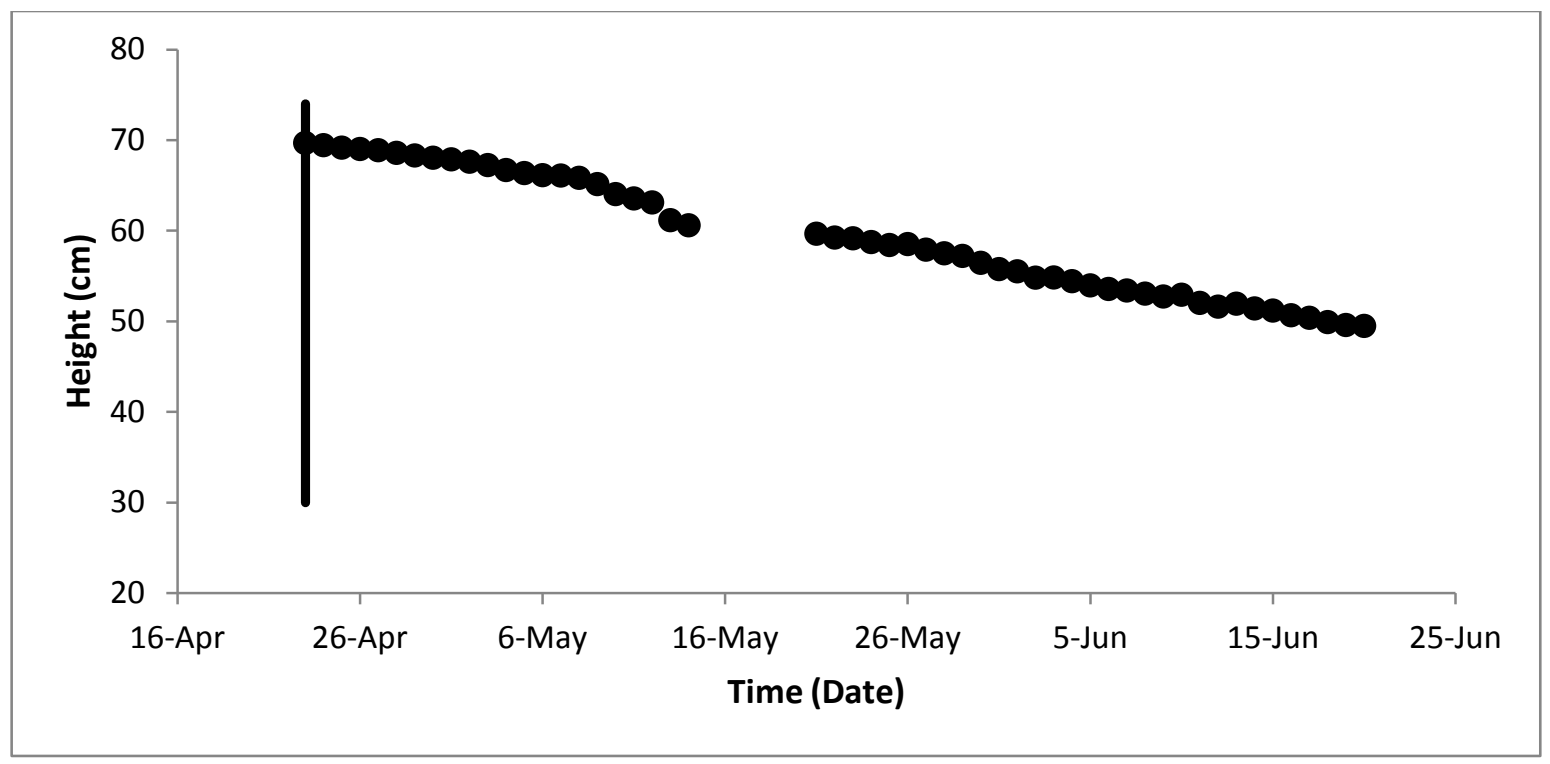

Figure 4.2-36. Settlement of tailings - Layer 2

\subsubsection{Volume Change}

After placement of the second layer, the VWC of layer 1 settles down to about 0.4 (uncalibrated) as seen in Figure 4.2-37, about 0.55 calibrated.

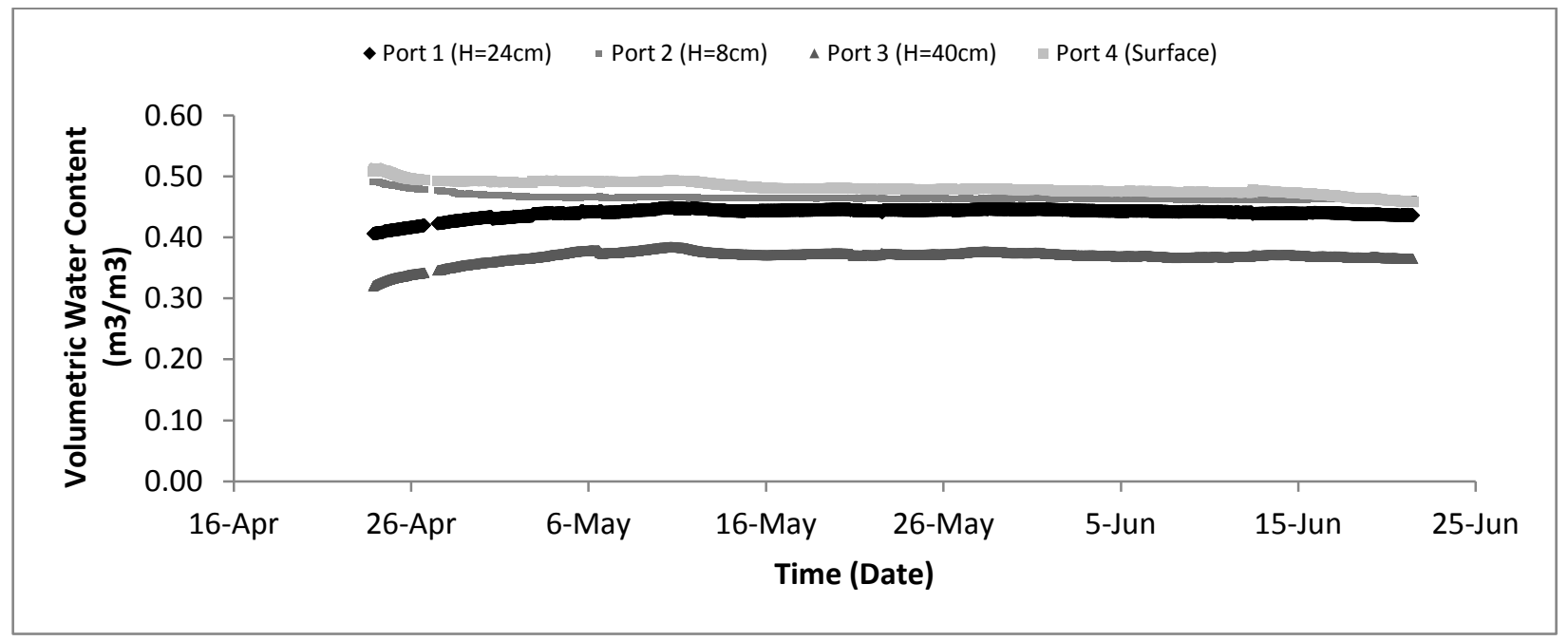

Figure 4.2-37. Volumetric water contents at various heights - Layer 2 
Upon the addition of layer 2, four more VWC sensors were placed, about $10 \mathrm{~cm}$ apart. Figure 4.2-38 presents the data collected by these sensors for the drying time of layer 2. The trends in the data are similar to those seen on the onset of drying and the end of drying as in layer 1 , where there is variance in elevation due to higher densities at the bottom at the beginning and then the lower water contents seen in the top sensor after drying settles in.

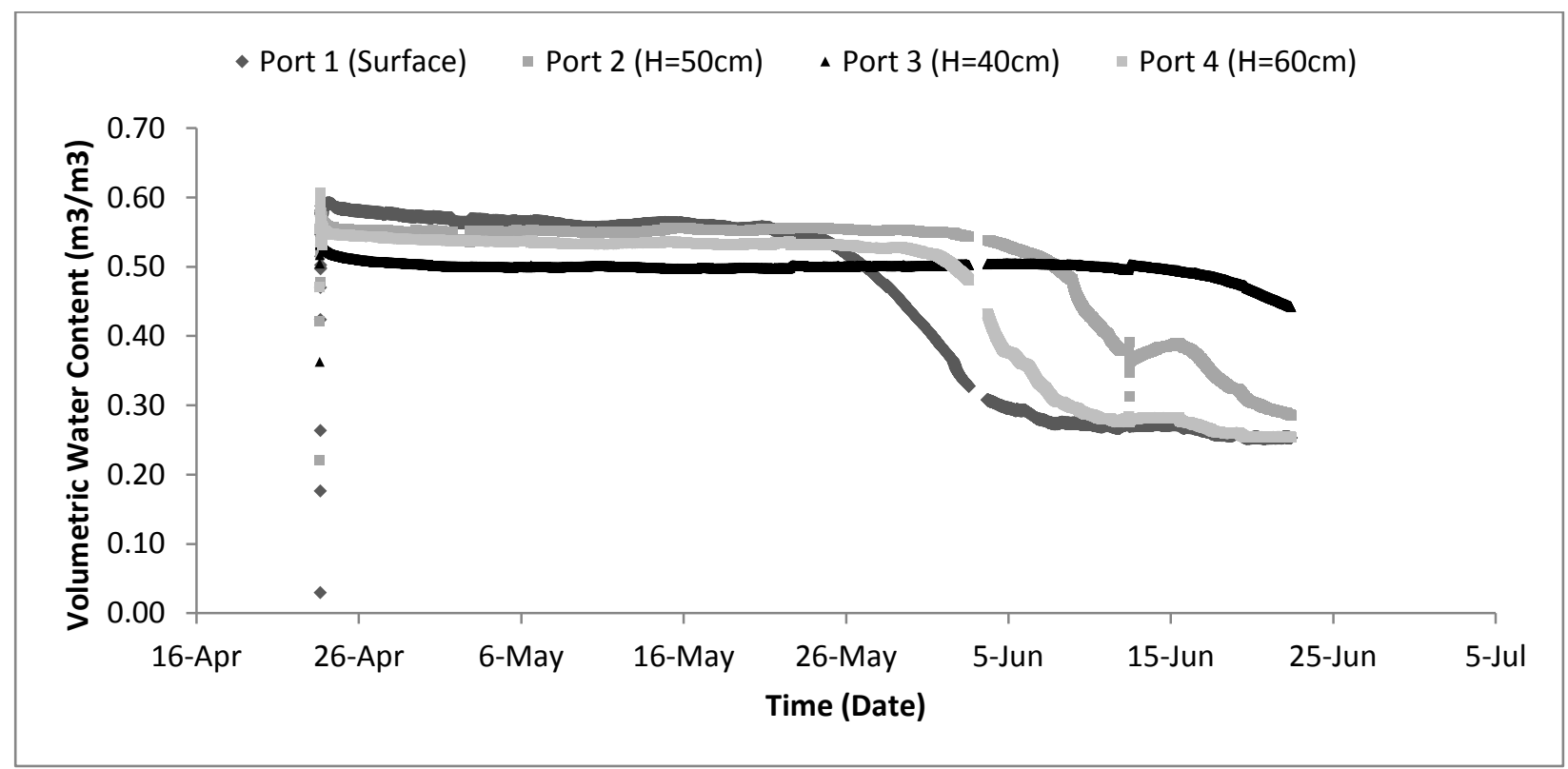

Figure 4.2-38. Volumetric water contents at various heights in top layer - Layer 2

\subsubsection{Water Content}

The overall GWC in layer 2 is shown in Figure 4.2-39, as well as results for surface measurements within the top $1 \mathrm{~cm}$ after the supernatant water that had collected at the top of the tailings had evaporated. There is a steady decrease in overall GWC from $130 \%$ to $75 \%$ while the surface GWC decreases from $150 \%$ to $30 \%$. 


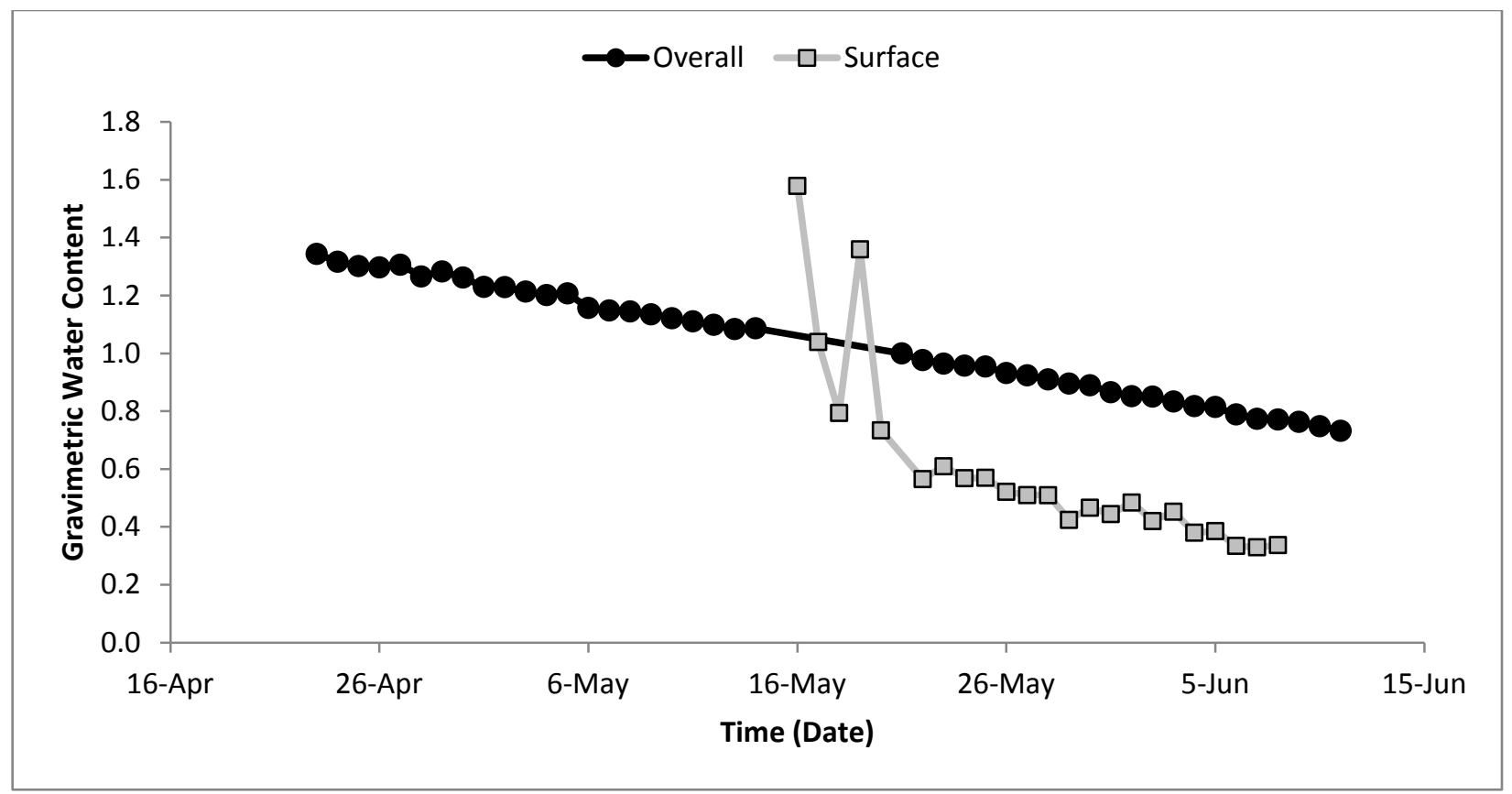

Figure 4.2-39. Gravimetric water contents - Layer 2

Surface samples taken at various locations once cracks began to form are shown in Figure 4.2-40.

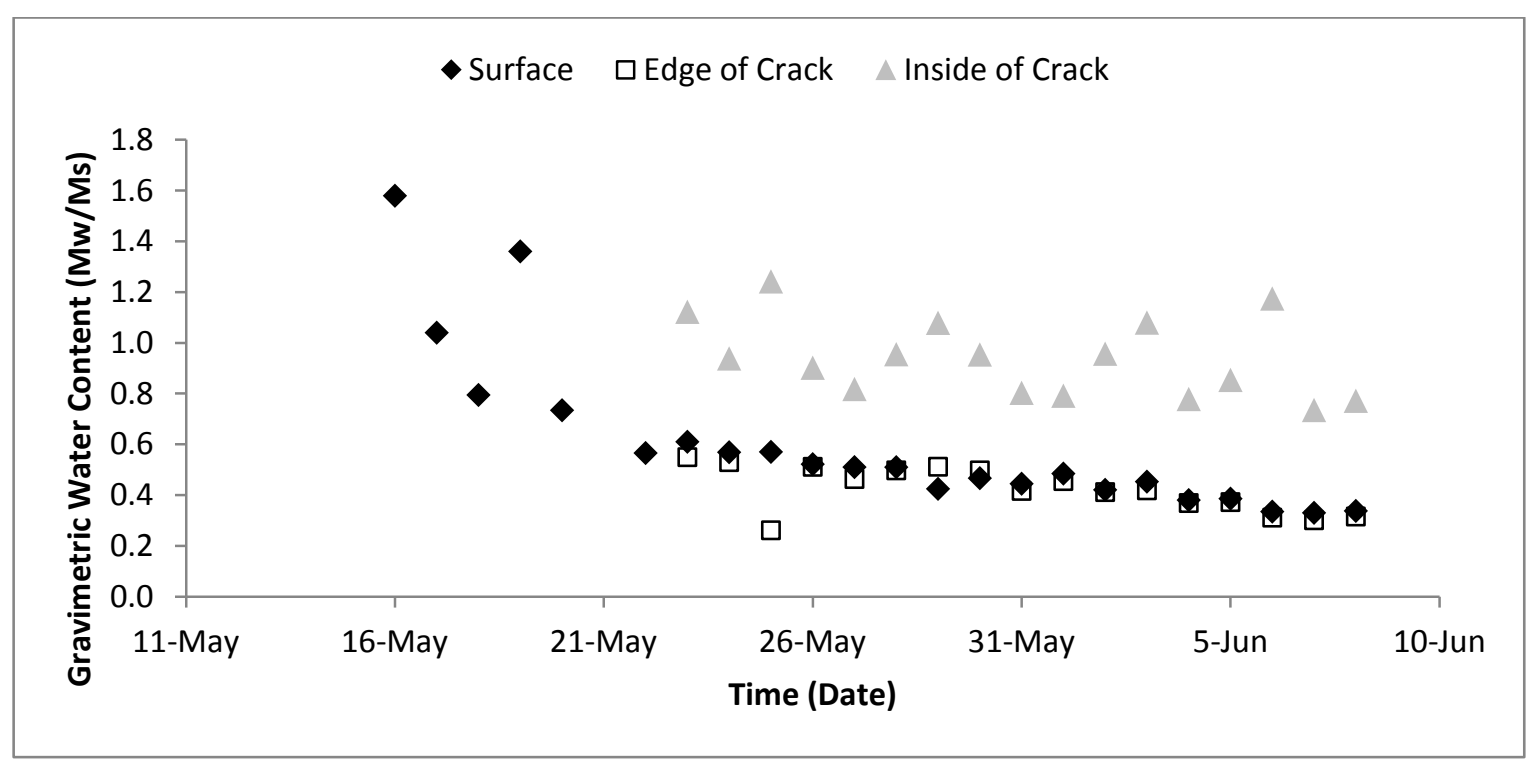

Figure 4.2-40. Surface sample gravimetric water contents - Layer 2 
Generally the IC measurements once again show the greatest GWC, but the figure shows that the surface and CE GWCs are decreasing at the same rate.

SC measurements are shown in Figure 4.2-41. The overall SC increased from $43 \%$ to $57 \%$. The initial SC is greater than that of the added tailings since it takes into account the underlying tailings.

From the data regarding water retention obtained from the sensors in layer 1 , it was possible to determine the SC in the second layer at the top. This information is also shown in Figure 4.2-41.

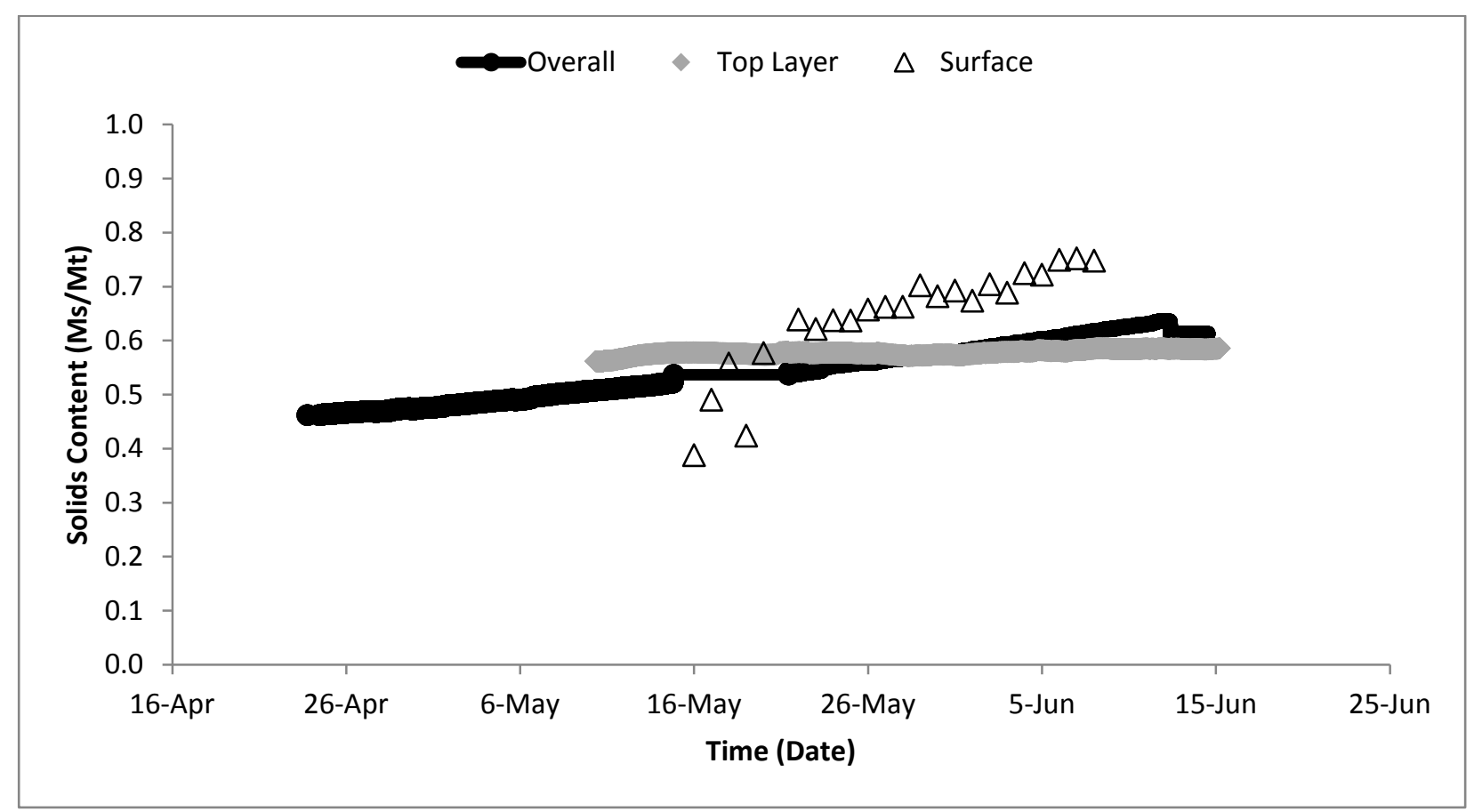

Figure 4.2-41. Solids contents - Layer 2

Figure 4.2-42 provides a breakdown of the SCs at the surface, CE and IC surface samples. 


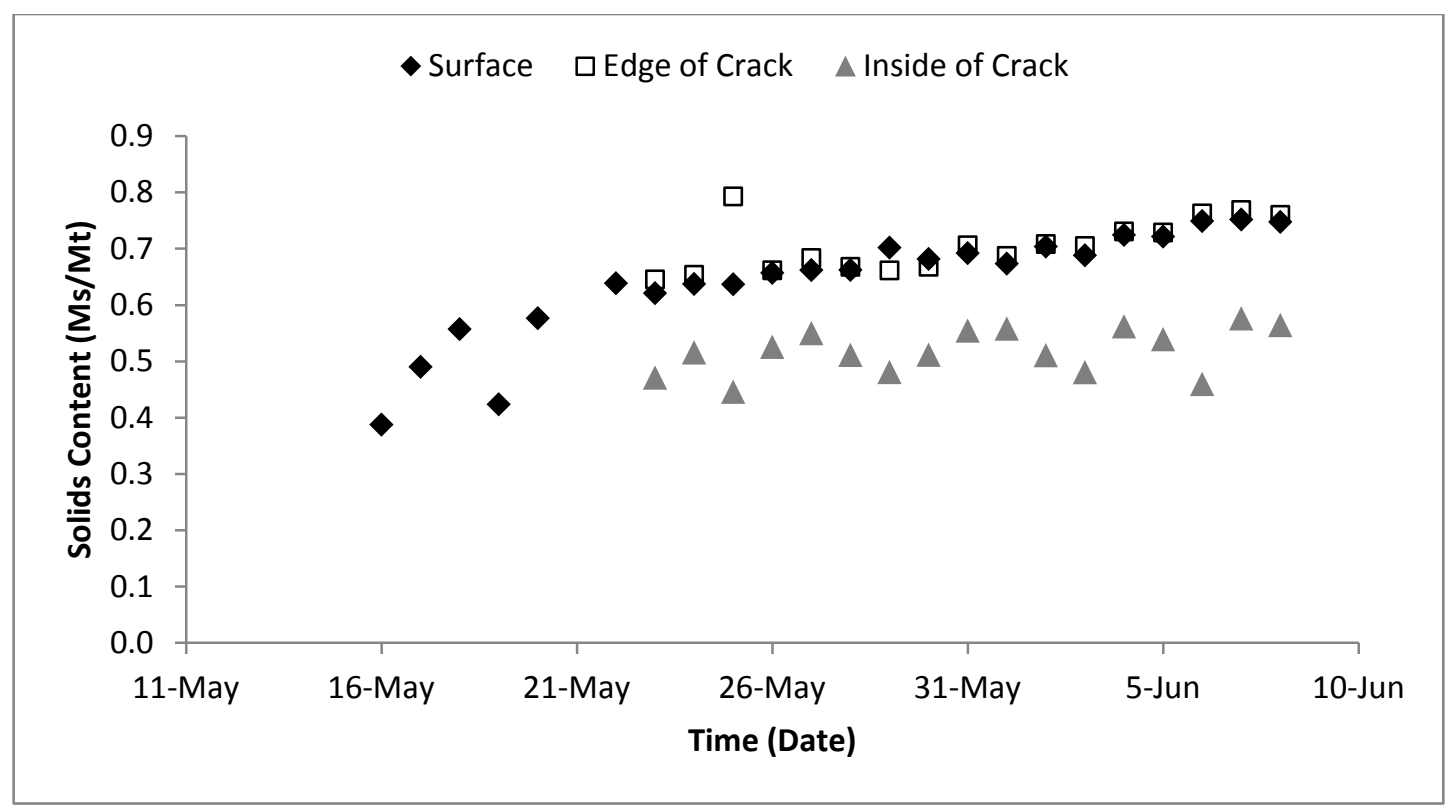

Figure 4.2-42. Surface sample solids contents - Layer 2

Figure 4.2-43 shows the variation in overall degree of saturation after the deposition of Layer 2 throughout the test.

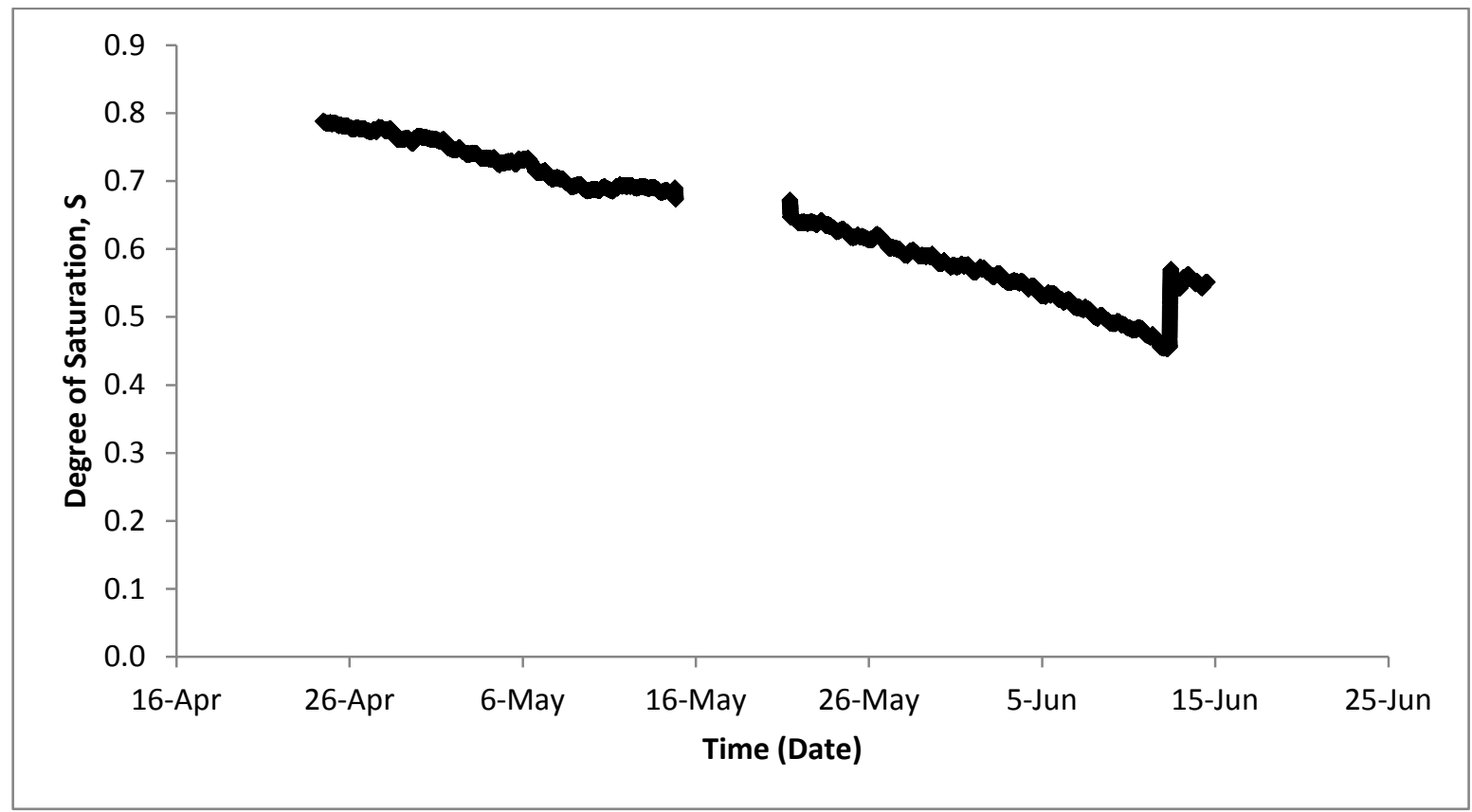

Figure 4.2-43. Overall degree of saturation - Layer 2 


\subsubsection{Suction}

This section provides results for measurements for matric, osmotic, and total suctions in various locations for Layer 2.

\subsection{Matric Suction}

Two more tensiometers were added to layer 2 upon deposition, as shown in Figure 4.2-44. The tensiometer at the surface of Layer 1 (T4), which had previously cavitated, was also replaced as shown in the same figure. Both tensiometers show increasing values of matric suctions, with similar rates of increase. The readings became noisy once the logger had been tampered with, by other experiments. T5, for instance, was disconnected.

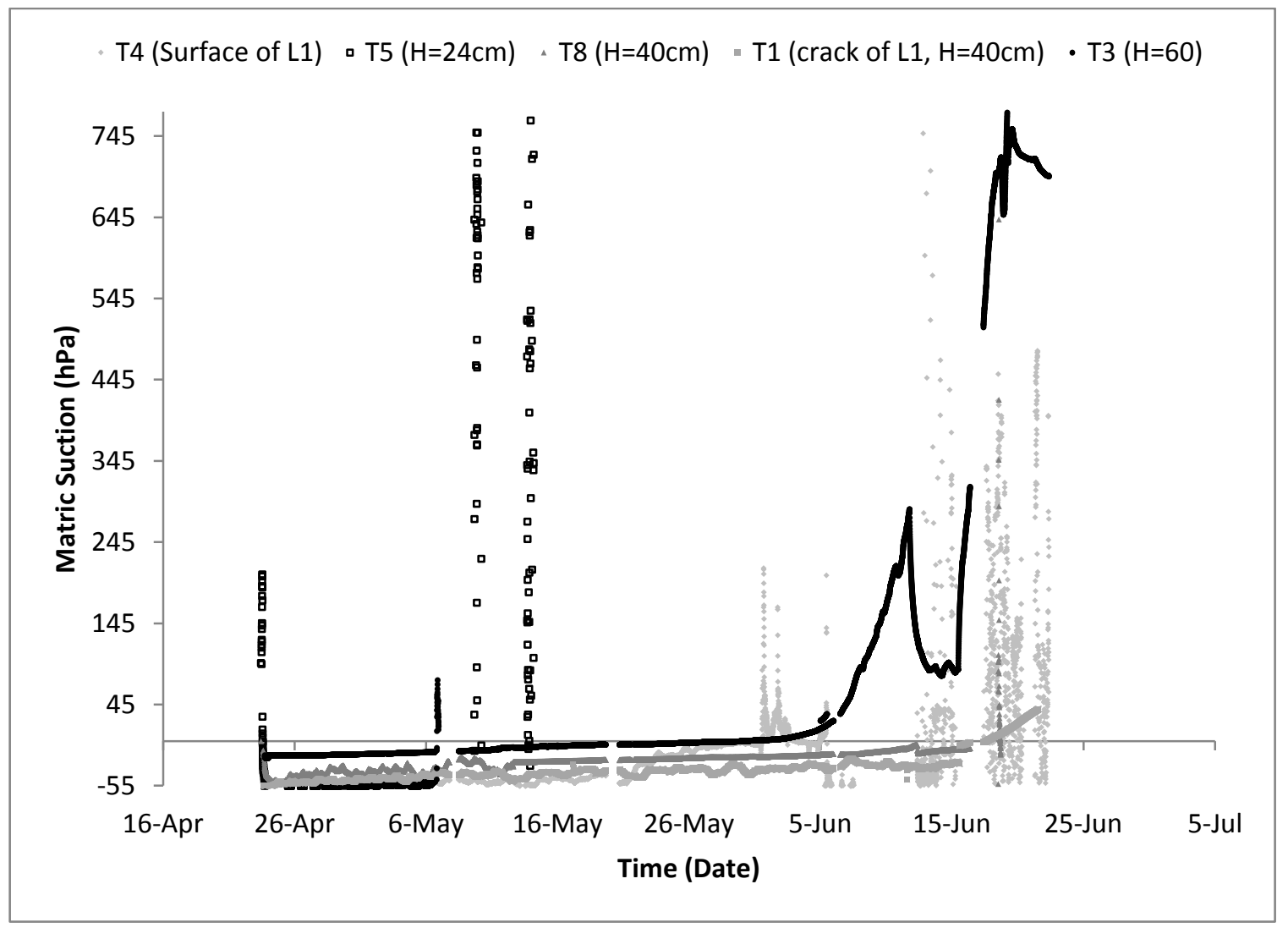

Figure 4.2-44. Matric suction at various heights - Layer 2 


\subsection{Osmotic Suction}

Daily EC measurements at the surface, CE and IC are shown in Figure 4.2-45.

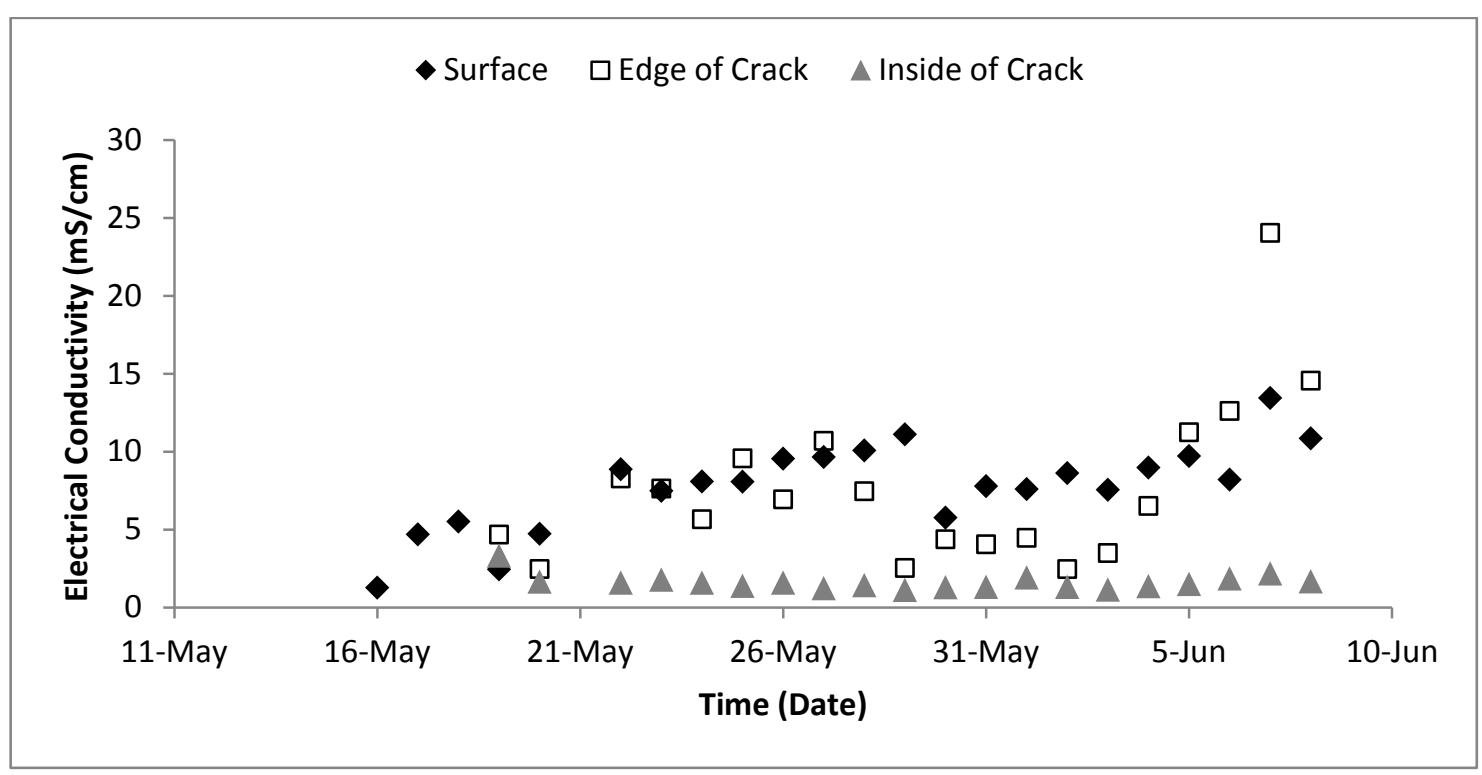

Figure 4.2-45. Surface sample electrical conductivity - Layer 2

A comparison of osmotic suction to total suction is shown in Figure 4.2-46.

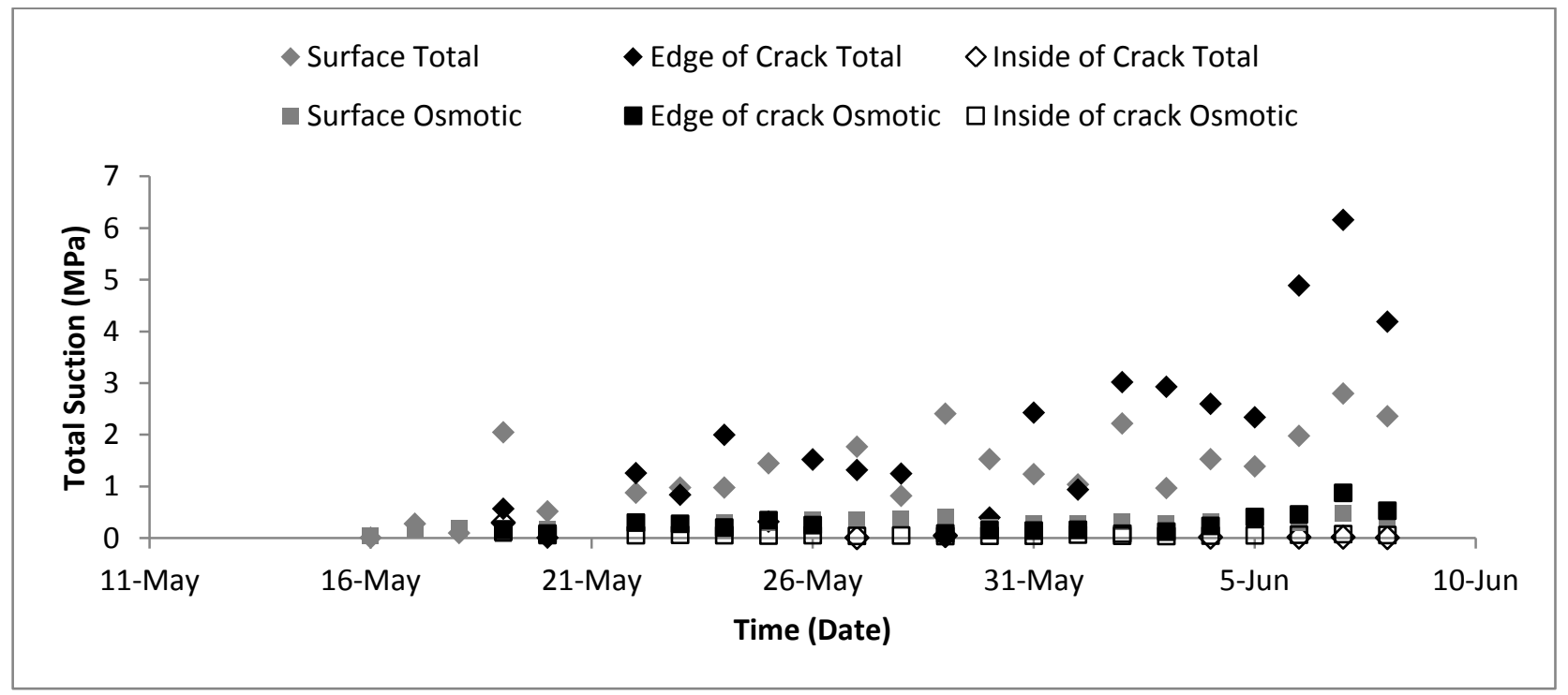

Figure 4.2-46. Surface sample total and osmotic suctions - Layer 2 


\subsection{Total Suction}

Samples extracted from the top $1 \mathrm{~cm}$ of the surface of the tailings, crack edges and the ICs were measured for total suction using a WP4-C potentiometer. These results are shown in Figures 4.2-47 and 4.2-48.

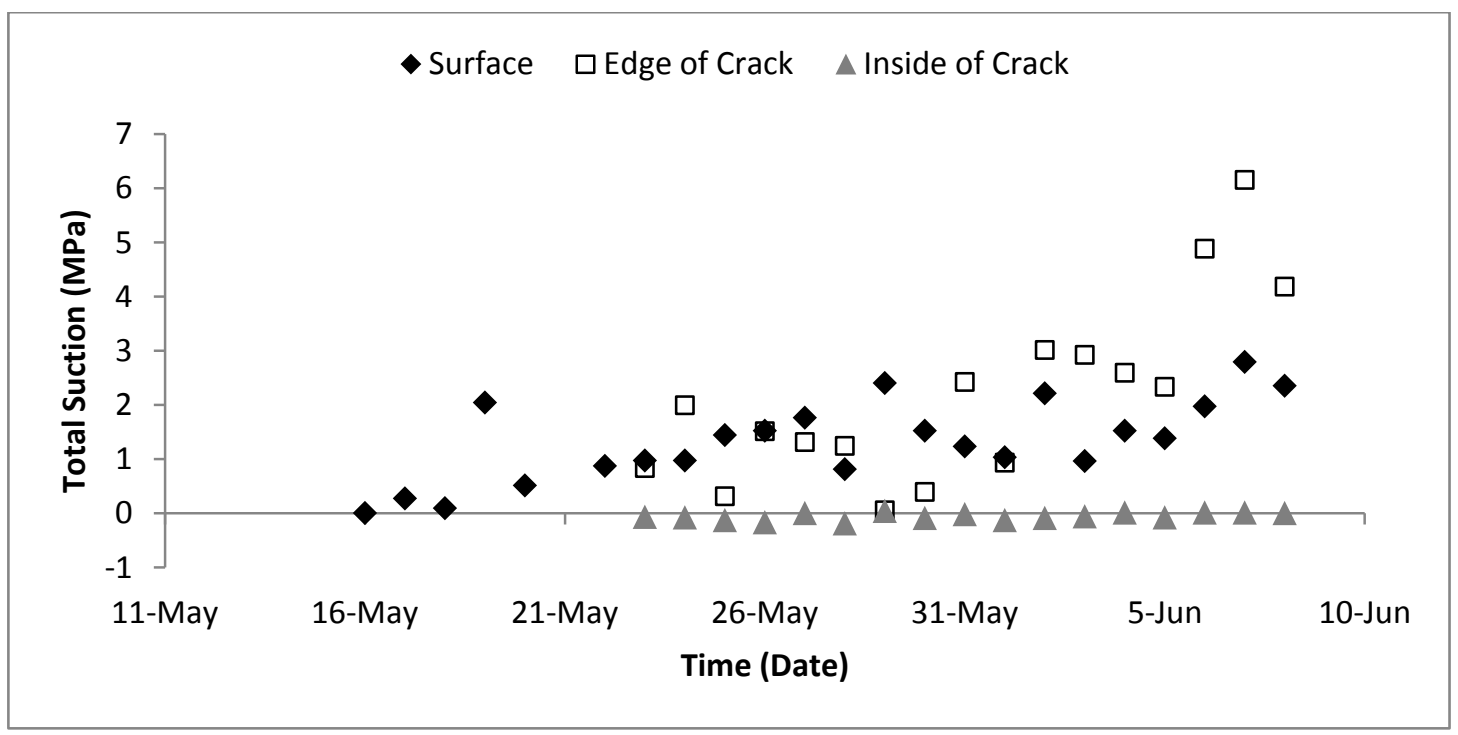

Figure 4.2-47. Surface sample total suctions - Layer 2

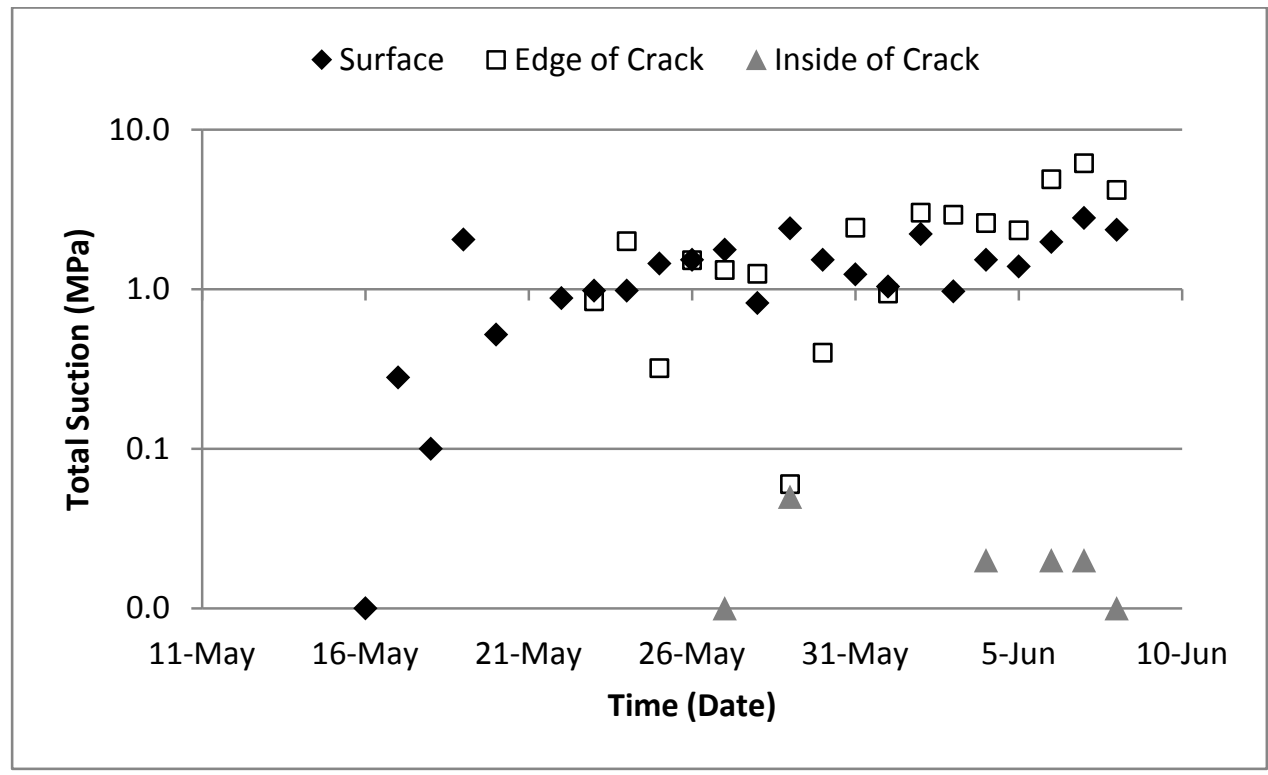

Figure 4.2-48. Surface samples total suctions on log scale - Layer 2 
Overall, suction values at the surface increased as water escaped the tailings. Initially, suction values along the crack edges were wetter than those at the surface, but as the tailings dried out and the crack volumes remained constant, the edges also dried out, and in some instances surpassed the values at the surface. The values inside the cracks were always lowest, and remained approximately the same during the duration of the test.

\subsubsection{Core Sample \#1}

A core sample was extracted once the layer had reached $60 \%$ overall SC on June $11^{\text {th }}$. The location for the core sample is shown in Figure 4.2-49.

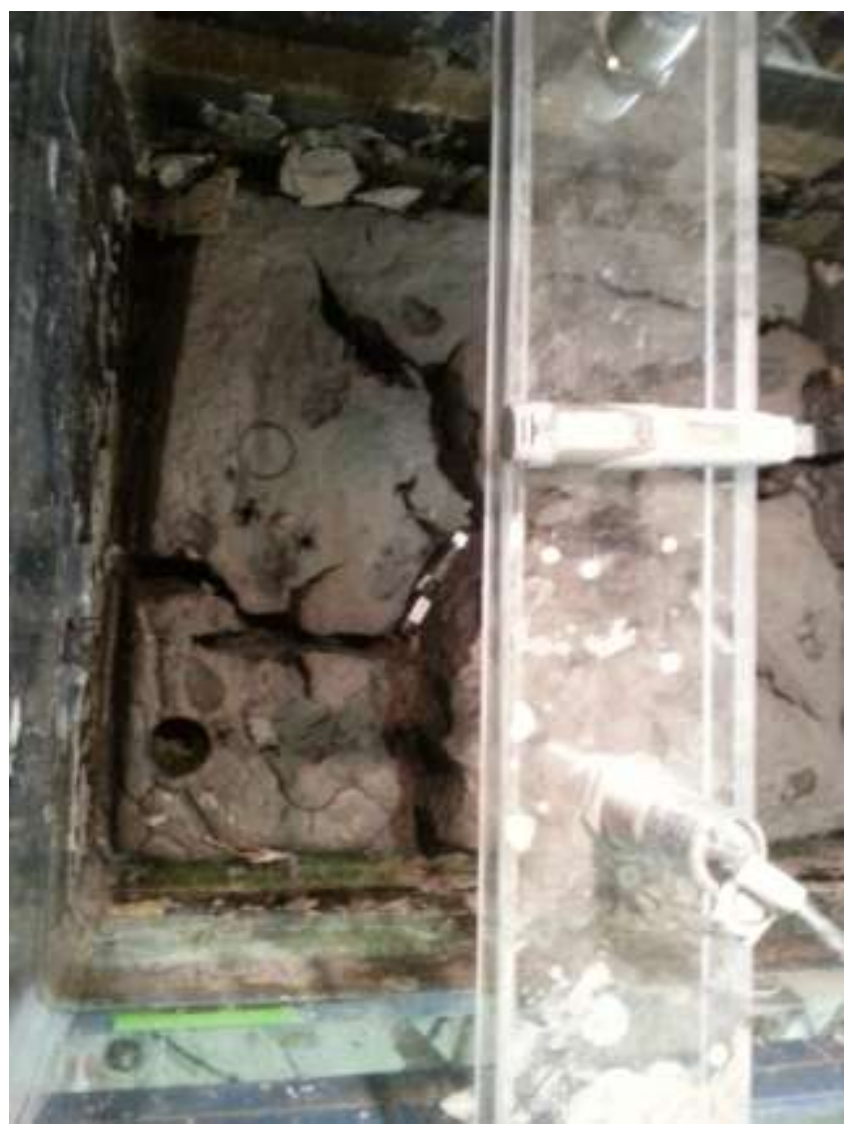

Figure 4.2-49. Core sample \#1 location - Layer 2 
The extracted core sample is shown in the following figures, along with the pushed in and extracted depths. The pushed in depth was $50 \mathrm{~cm}$, while the extracted depth was $39 \mathrm{~cm}$. The bottom $19 \mathrm{~cm}$ was scooped out of the core location using a spoon, since the very bottom of the dry box was still very wet, and the core tube could not extract the wet material. Therefore the measurements with depth for the bottom $19 \mathrm{~cm}$ are ambiguous, the material was uniform upon analysis.

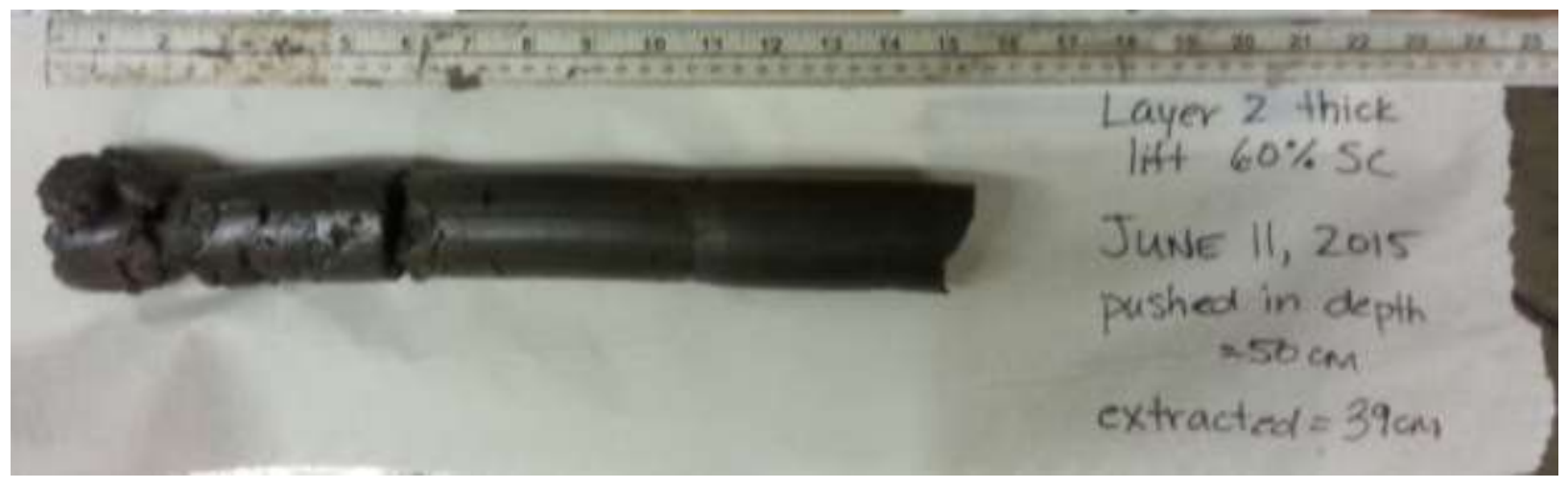

Figure 4.2-50. Core \#1 sample - Layer 2

The core was analysed for GWC, SCs, osmotic suction, total suction and TOC every $1 \mathrm{~cm}$. The core sample is shown in the following figure, along with the extracted depth. The bottom $19 \mathrm{~cm}$ of the core was scooped out using a spoon after the actual core was extracted.

. The following figures are related to water content with depth. The sample is very dry at the top, but gets wetter with greater depth. 


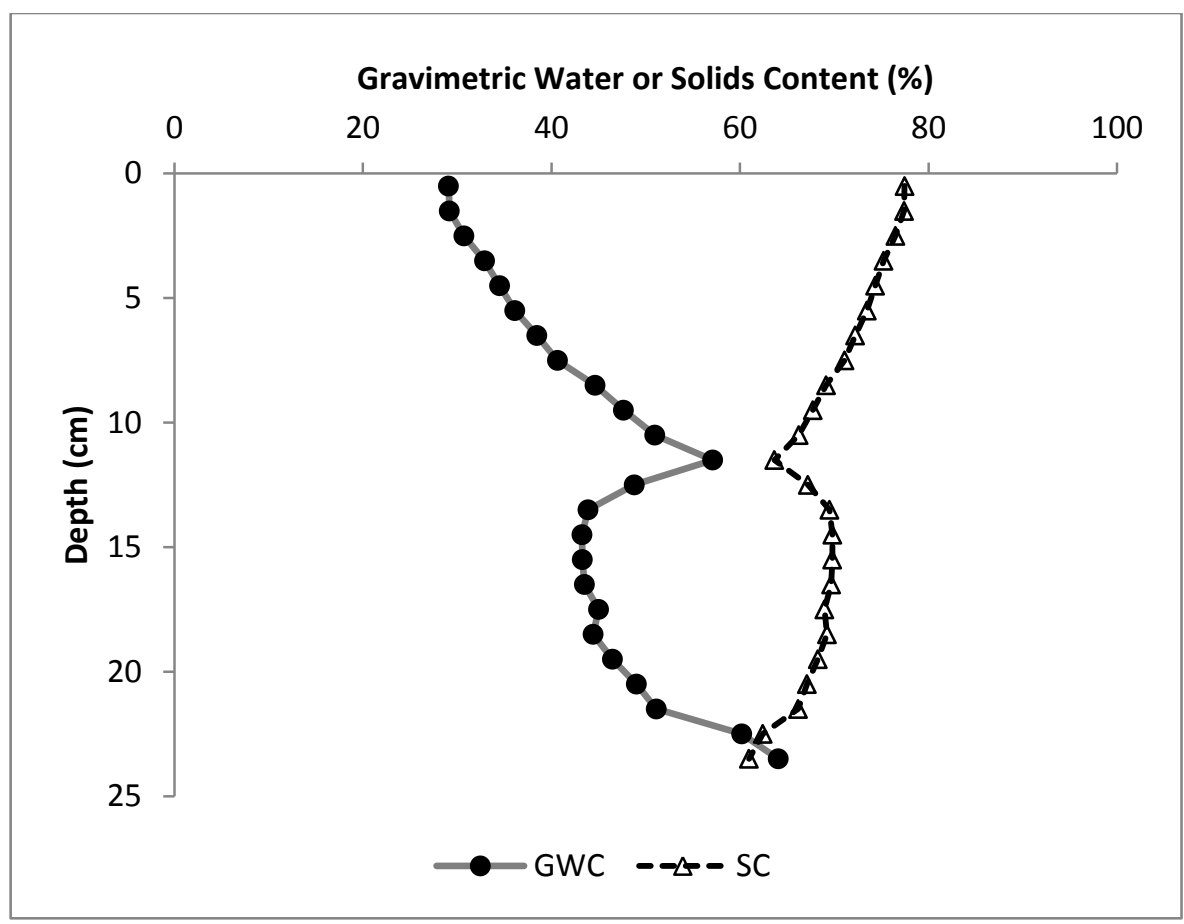

Figure 4.2-51. Core \#1 GWC and SC profiles - Layer 2

The following figures are related to osmotic and total suction with depth. In this sample, the total suction is great at the top, and uniform with depth.
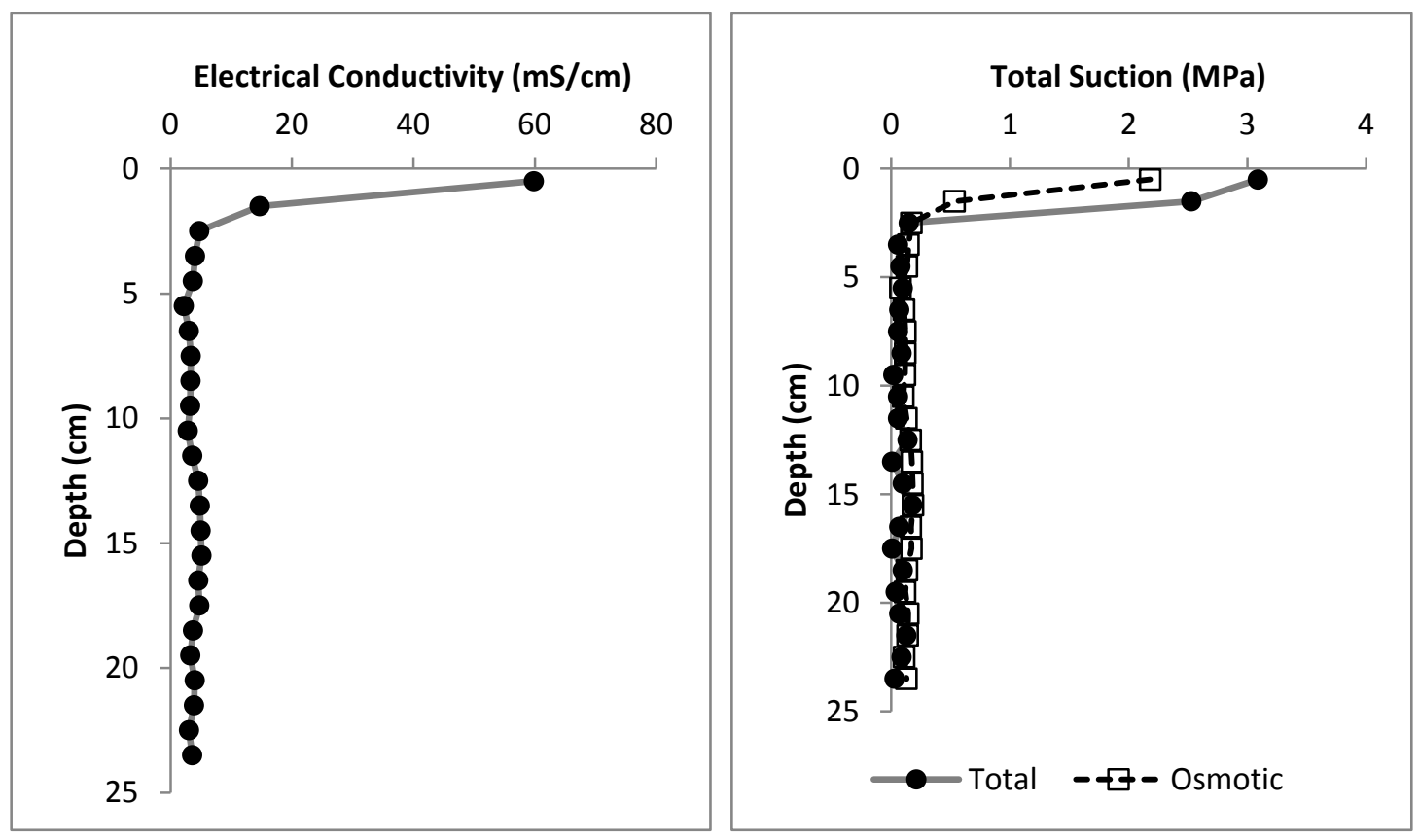

Figure 4.2-52. Core \#1 EC and total and osmotic suction profiles - Layer 2 


\subsubsection{Undrained Shear Strength}

Vane shear tests were conducted in conjunction with core extraction. The locations of these tests are right next to the locations of the core extraction. Figure 4.2-53 shows the results from these tests.

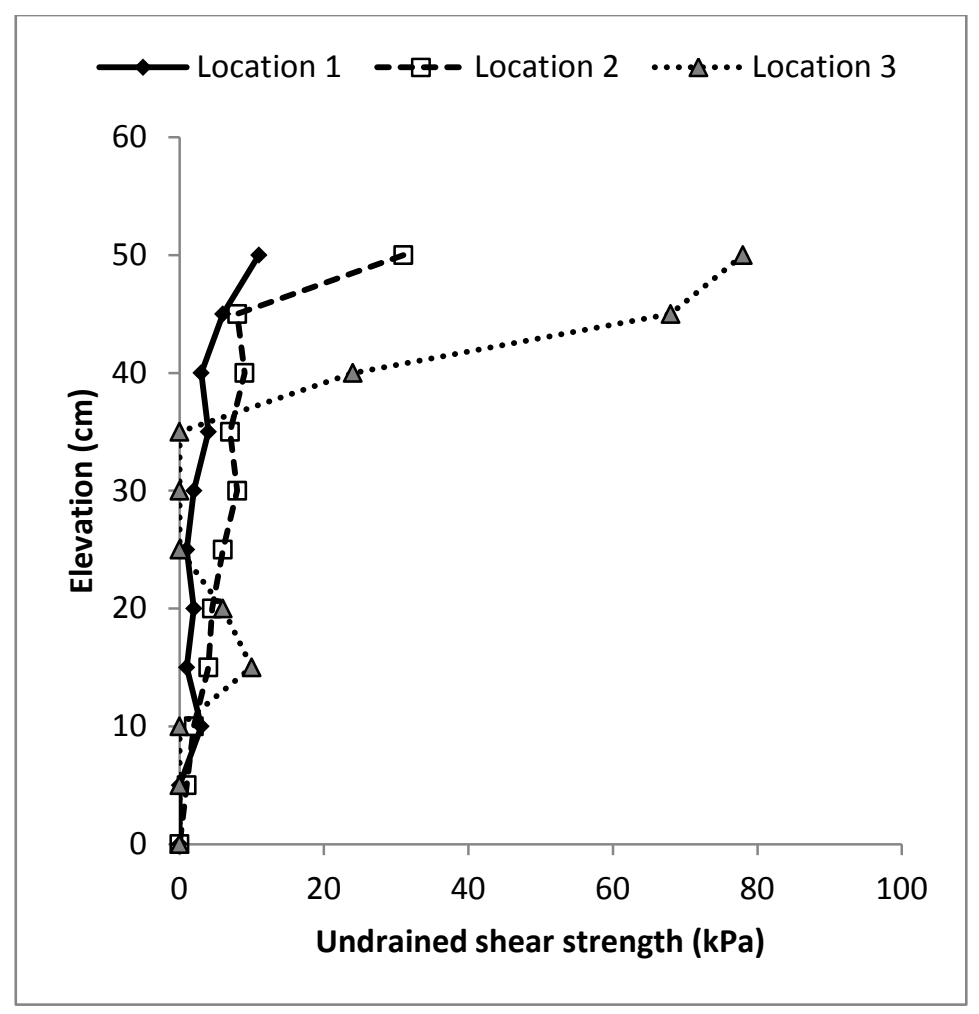

Figure 4.2-53. Core \#1 undrained shear strength profiles - Layer 2

\subsubsection{Core Sample \#2}

Another core sample was extracted once the layer had reached $70 \%$ overall SC on July $1^{\text {st }}$. The location for the core sample is shown in Figure 4.2-54. It is the hole at the bottom of the figure, very near the location of the core sample extracted at $60 \%$ SC. 


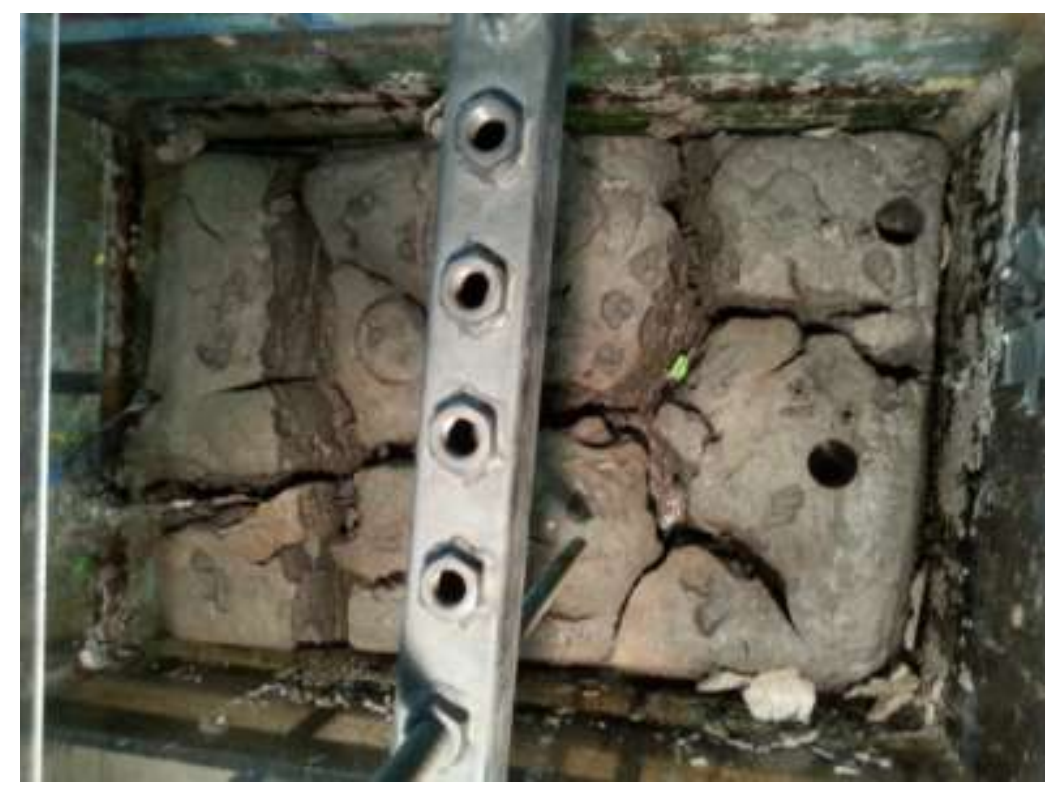

Figure 4.2-54. Core \#2 sample location - Layer 2

The extracted core sample is shown in the following figure, along with the pushed in and extracted depths. The pushed in depth was $45 \mathrm{~cm}$, while the extracted depth was $20 \mathrm{~cm}$.

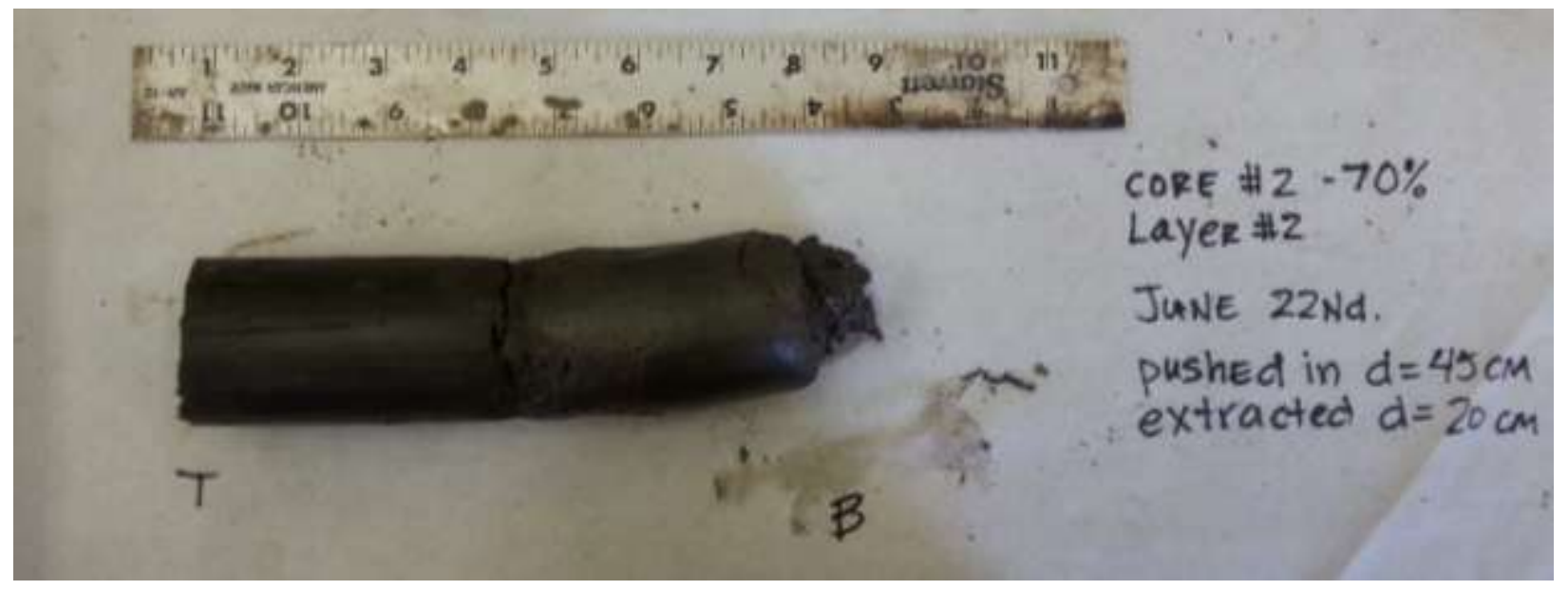

Figure 4.2-55. Core \#2 sample - Layer 2 
The core was analyzed for GWC, SCs, osmotic suction, total suction and TOC every $1 \mathrm{~cm}$. The core sample is shown in the following figure, along with the extracted depth. The bottom $19 \mathrm{~cm}$ of the core was scooped out using a spoon after the actual core was extracted.

. The following figures are related to water content with depth. The sample is very dry at the top, but gets wetter with greater depth.

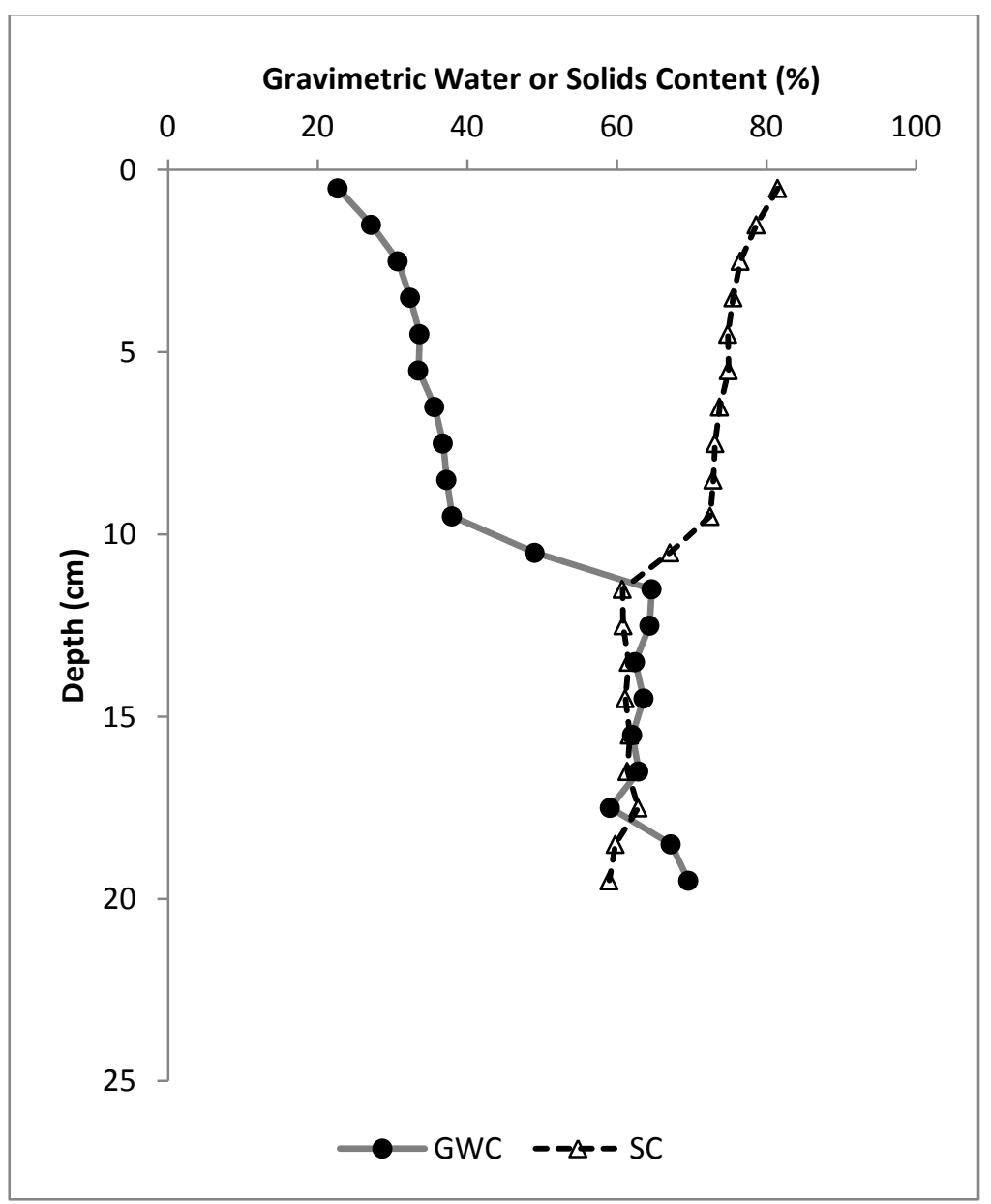

Figure 4.2-56. Core \#2 GWC and SC profiles - Layer 2 
The following figures are related to osmotic and total suction with depth. In this sample, the total suction is great at the top, and uniform with depth.
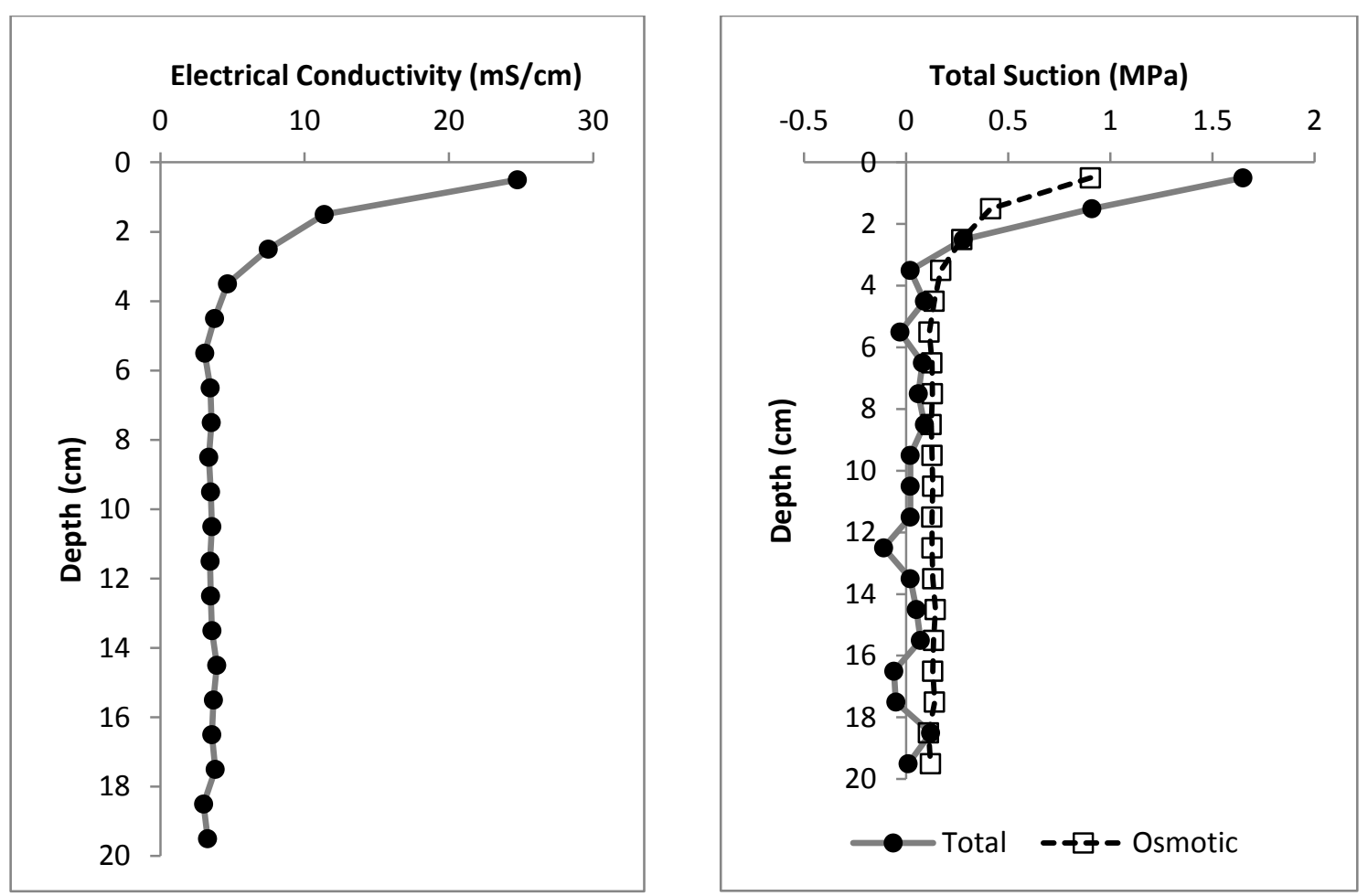

Figure 4.2-57. Core \#2 EC, and total and osmotic suction profiles - Layer 2

\subsubsection{Undrained Shear Strength}

Vane shear tests were conducted in conjunction with core extraction. The locations of these tests are right next to the locations of the core extraction. Figure 4.2-58 shows the results from these tests. 


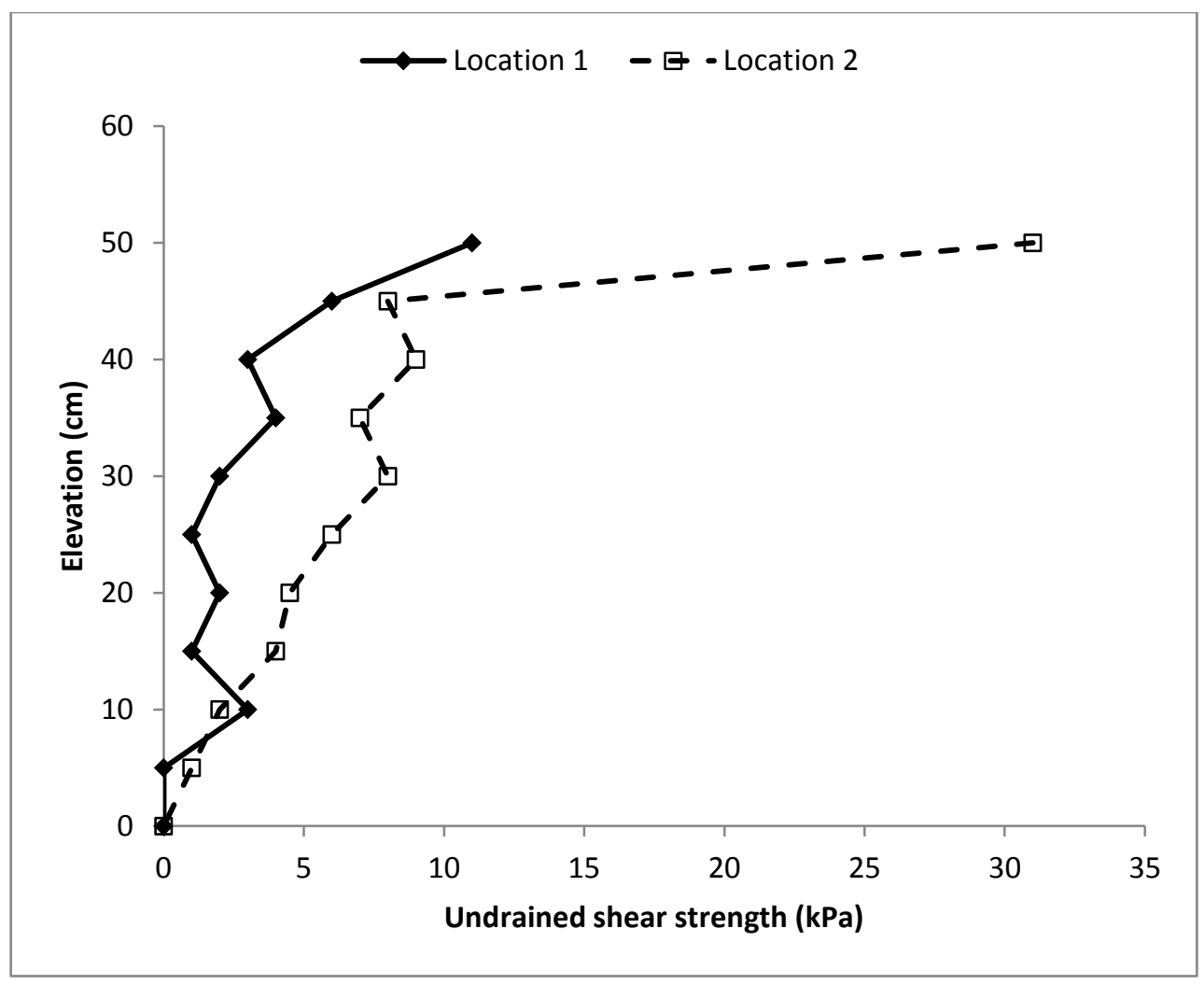

Figure 4.2-58. Core \#2 undrained shear strength profiles - Layer 2

\subsubsection{Thick-Lift Dry Box Overall Results}

This section shows results that were compiled together for Layer 1 and 2 of the thick lift dry box experiment.

\subsubsection{Mass Loss, Evaporation and Drainage}

The evolution of $\mathrm{RH}$, and temperature are shown in Figures 4.2-59 to 4.2-60. Two sensors were placed on the beams holding the senix sensors, and the other two were placed at the surface of the tailings. Once cracks were large enough, one of the sensors from the surface was placed into a crack. Temperatures varied from 15-28 degrees Celsius throughout the experiment. The $\mathrm{RH}$ shows a gradual but substantial increase from March to July, as the seasons change from spring to summer. The change in the 
$\mathrm{RH}$ is reflected in the variation of the predicted PE rate, shown in Figure 4.2-62, which gradually decreases from $4 \mathrm{~mm} /$ day to $2 \mathrm{~mm} /$ day.

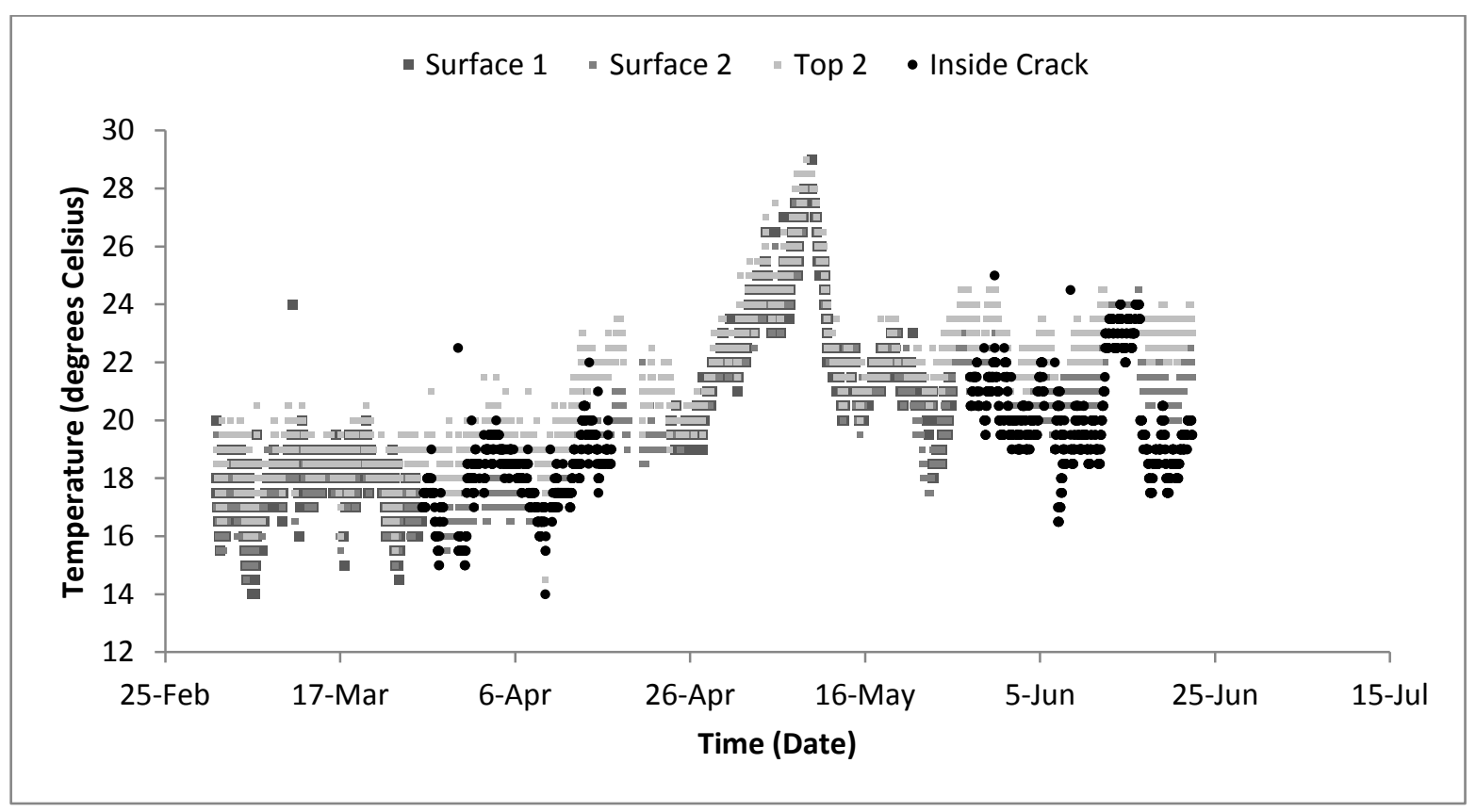

Figure 4.2-59. Temperature profiles at the surface - Overall

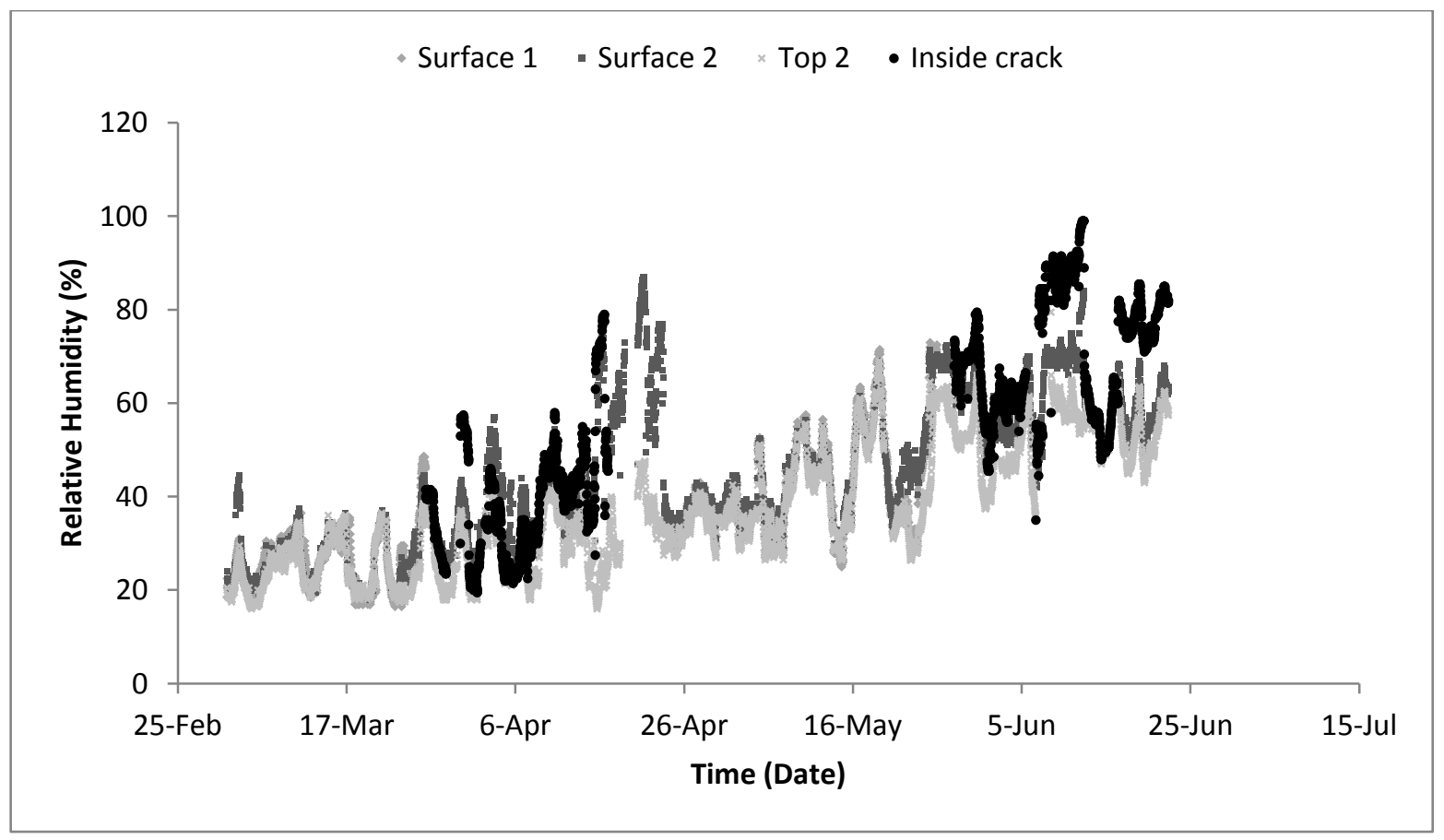

Figure 4.2-60. RH profiles at the surface - Overall 
Figure 4.2-61 provides a distribution of temperature with elevation plotted shortly before the end of drying for Layers 1 and 2. The temperature is always highest at the bottom and generally gets lower at the top of the tailings.

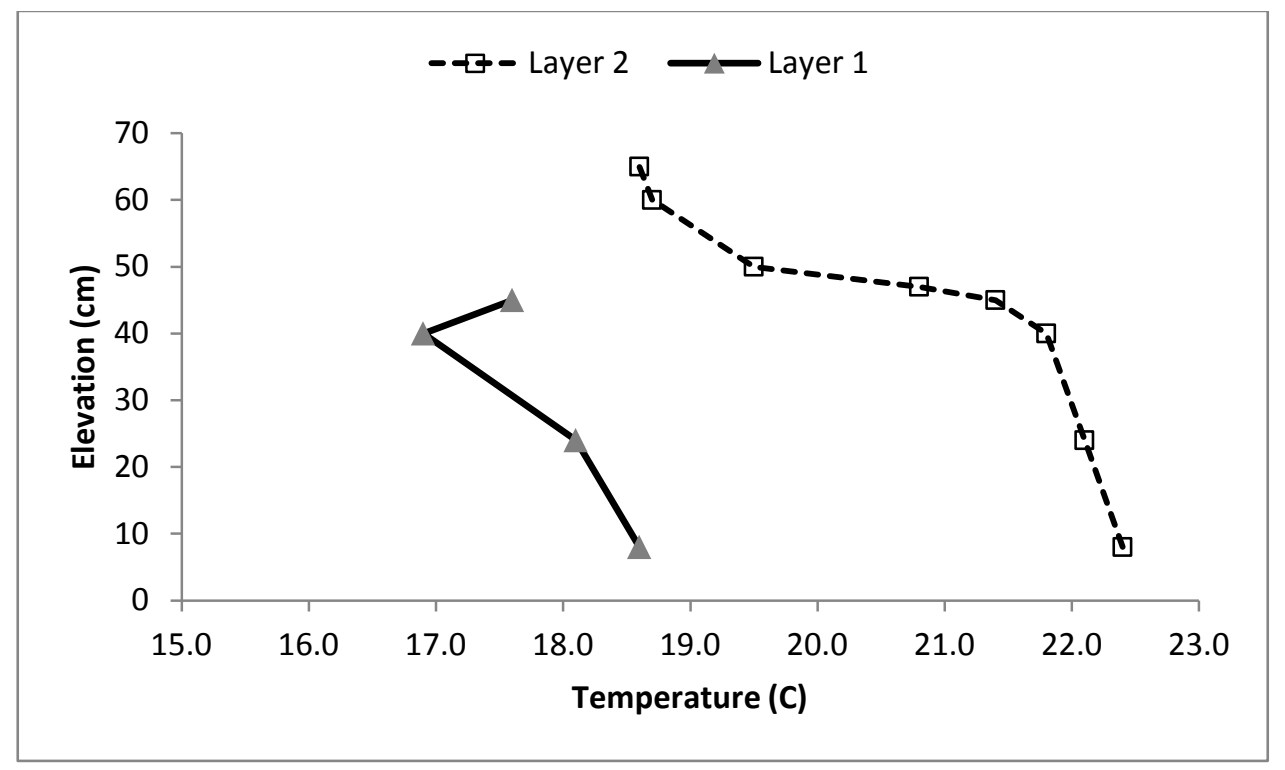

Figure 4.2-61. Thick lift dry box temperature profiles

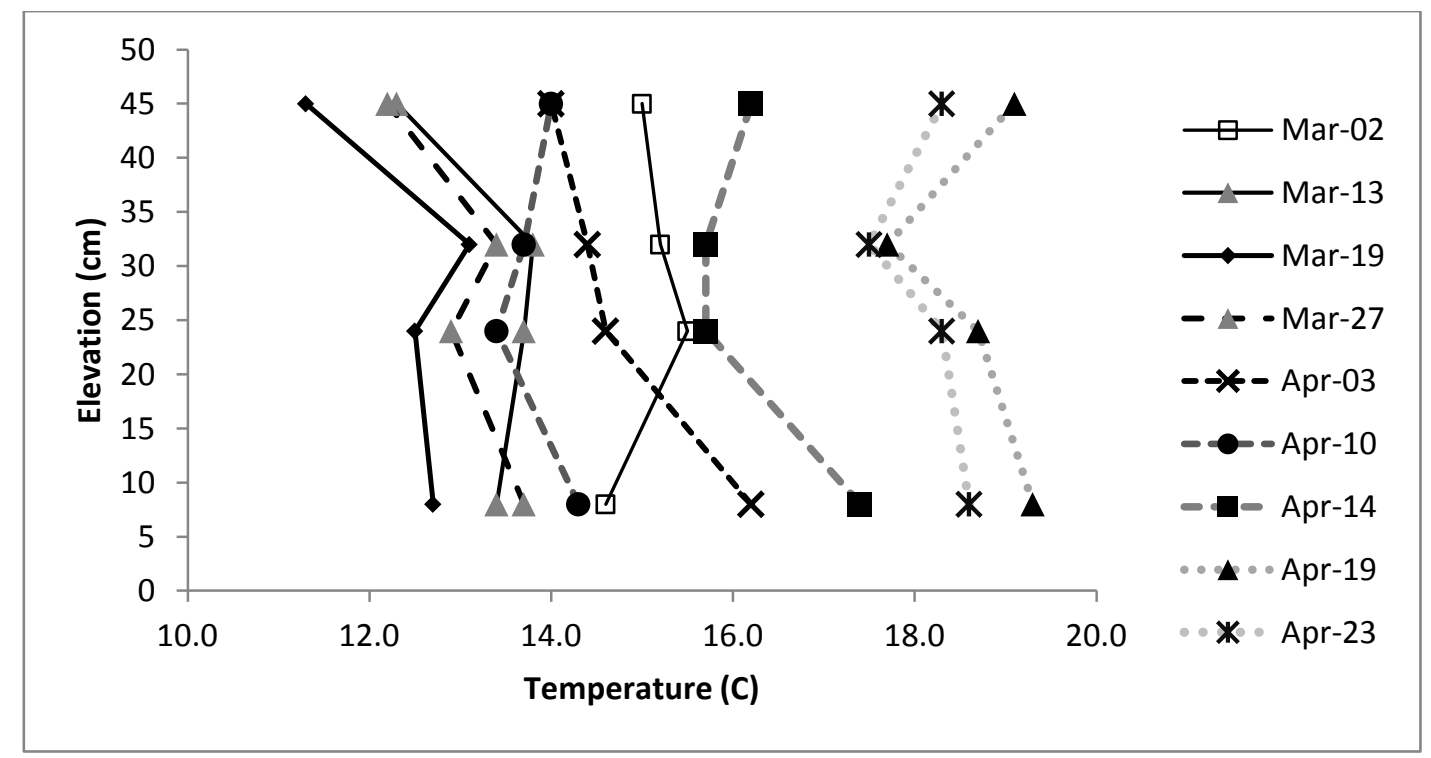

Figure 4.2-62. Thick lift dry box temperature profiles over time - Layer 1 
Figure 4.2-62 provides a distribution of temperature with elevation for layer over time. Similar to the thin lift dry box, the tailings start with a higher temperature near the surface and lower at the bottom. As time progresses, lower temperatures are seen near the top and higher at the bottom.

Figure 4.2-63 shows drainage and AE. Deposition of each lift occurred on March $2^{\text {nd }}$ and April $23^{\text {rd }}$. AE matches closely with the predicted $P E(P E)$ values from after deposition until March $15^{\text {th }}$, and May $10^{\text {th }}$ for each layer, after which AE substantially exceeds PE.

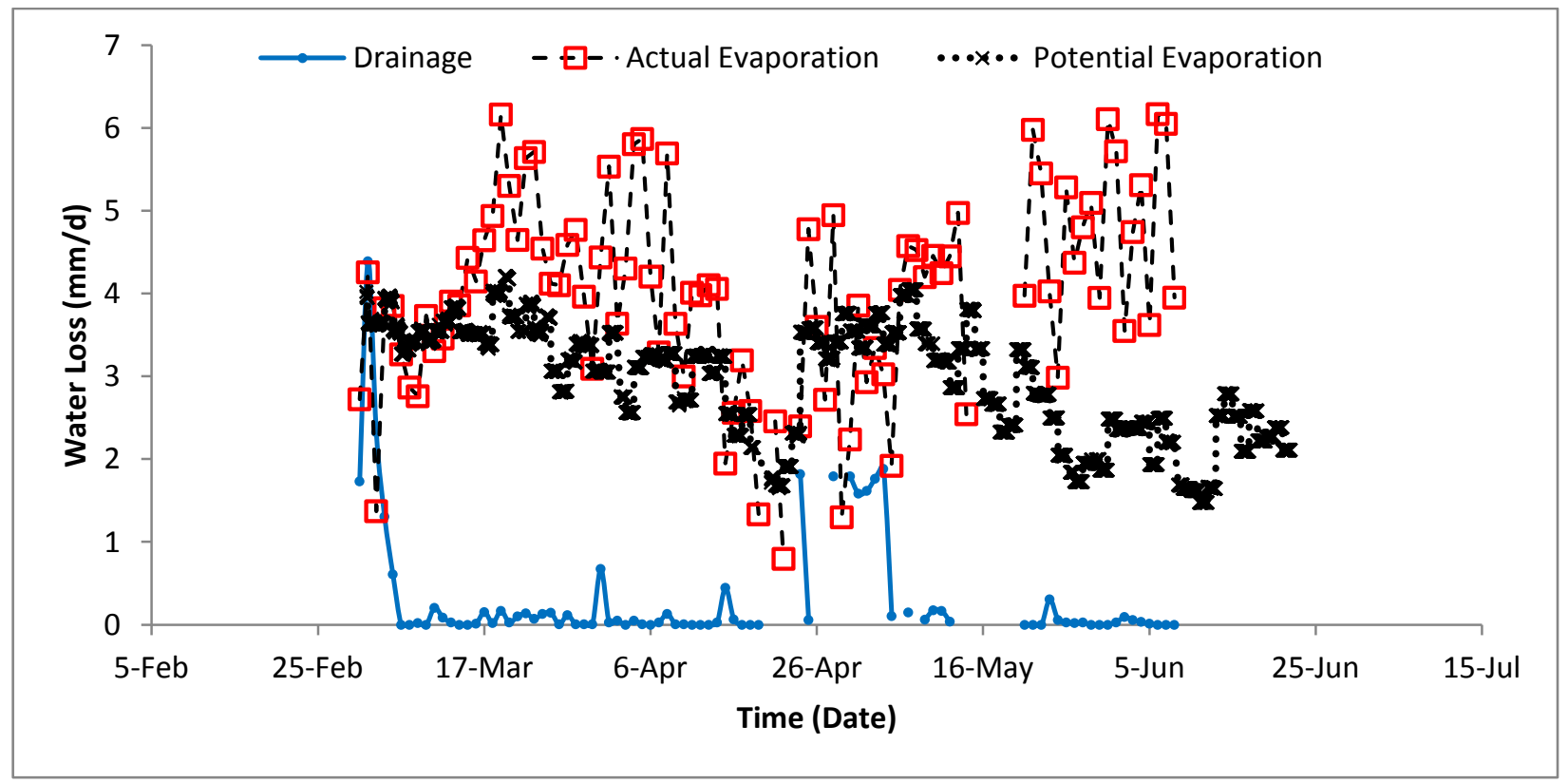

Figure 4.2-63. AE, PE, and drainage - Overall

The start of this period correlates with the commencement of cracking, and ends when crack development stops. Evaporation is compared to crack volumes in Figure 4.2-64. 


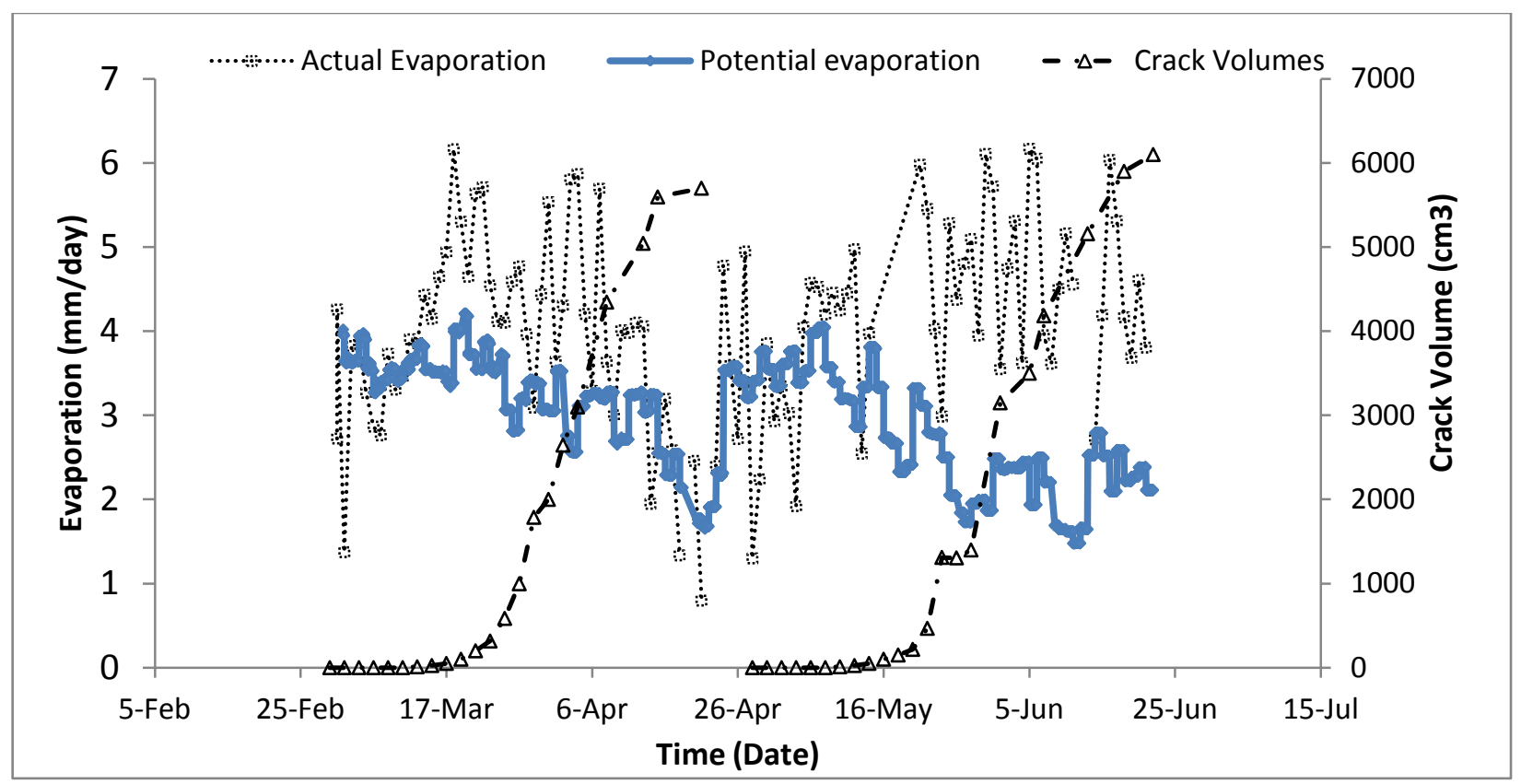

Figure 4.2-64. Evaporation vs. cracking - Overall

Similar trends to the thin lift dry box are seen here. In the case of the thick lifts, the evaporative behaviour can be divided into two phases

1) $A E$ is close to the $P E$; and

2) $A E$ exceeds $P E$ and is co-incident with crack growth.

There is no phase 3 in this case, as observed in the thin lift dry box. The cracks do not stop growing as they did in the thin lift dry box. The crack depths never reached the bottom of the dry box either.

\subsubsection{Settlement}

Figure 4.2-65 shows the expected height of the tailings for each layer, if the tailings were added instantaneously (vertical lines), and the actual heights of the tailings over time. Of course, as they are not added instantaneously, the height at the end of 
Day 1 is somewhat smaller than this height. For the second layer, this is due to capacity of the older layers to absorb moisture.

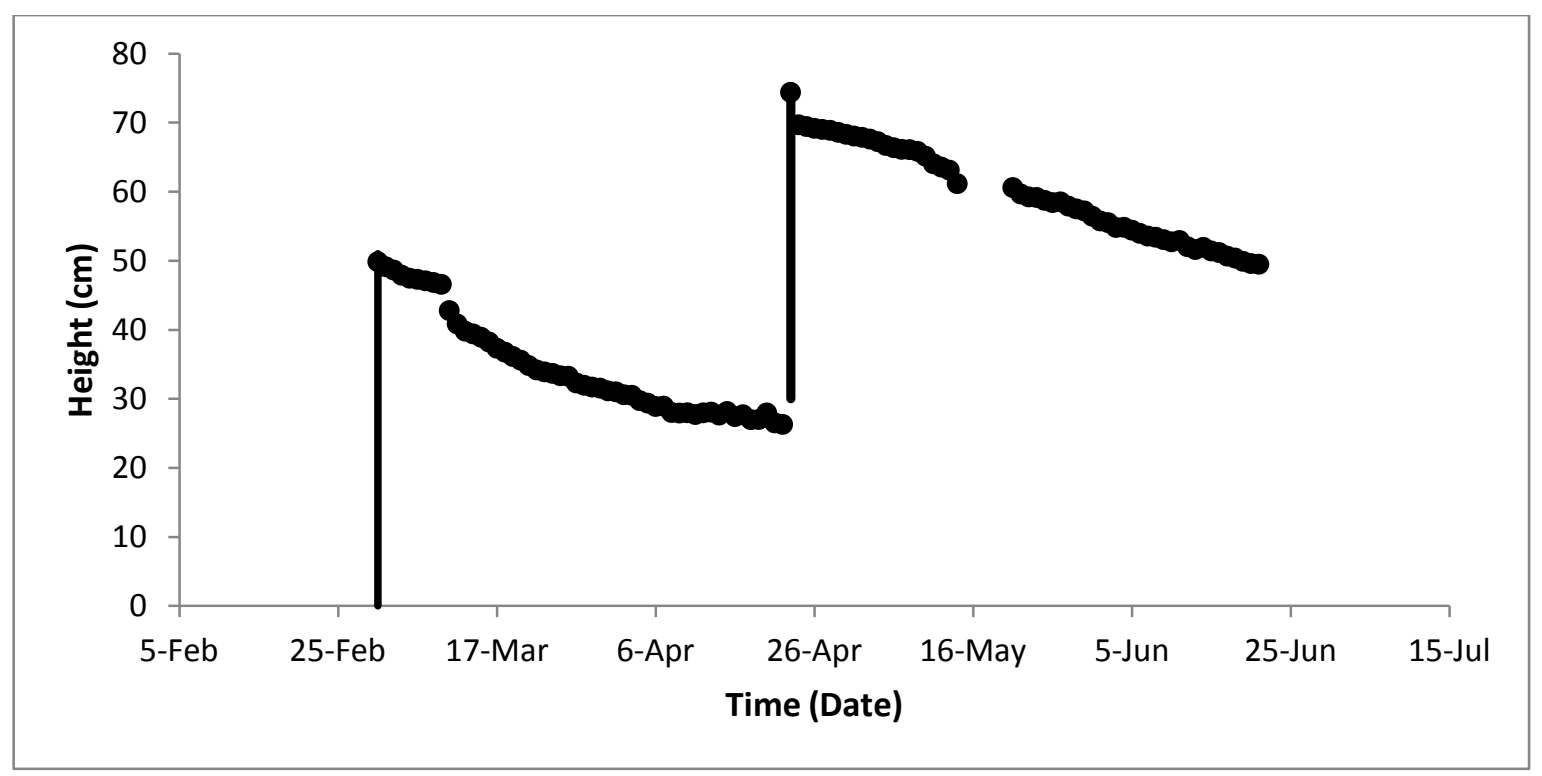

Figure 4.2-65. Settlement of tailings - Overall

Based on the settlement and water loss results, the overall void ratio was calculated and plotted in Figure 4.2-66. This figure shows the change in void without considering cracks, and considering the influence of cracks There is no considerable difference in both sets of data at the beginning, but as cracks began to appear and grow in size, there is a difference of about 0.05 at the most. 


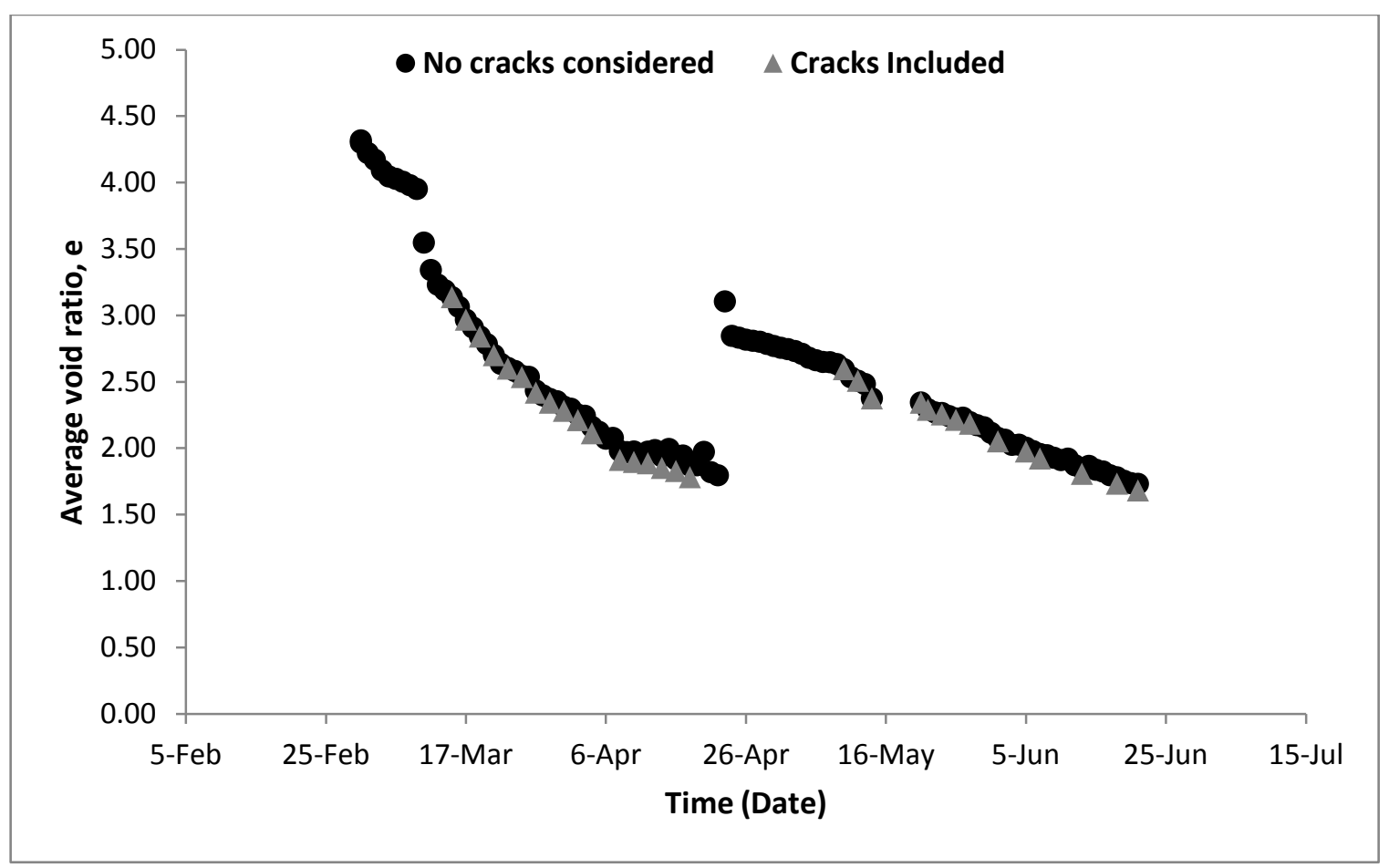

Figure 4.2-66. Average void ratio - Overall

\subsubsection{Volume Change}

The volume change in individual layers was differentiated using the VWC sensors. The VWC in layer 1 is shown in Figure 4.2-67. At the beginning of dewatering, the sensors show a variation of water content with depth, lower water content and therefore higher density at the bottom, expected from self-weight consolidation. Once drying sets in, the water contents sensors show lower water contents at higher elevation sensors. After placement of the new layers, the VWC of layer 1 settles down to about 0.4 . 


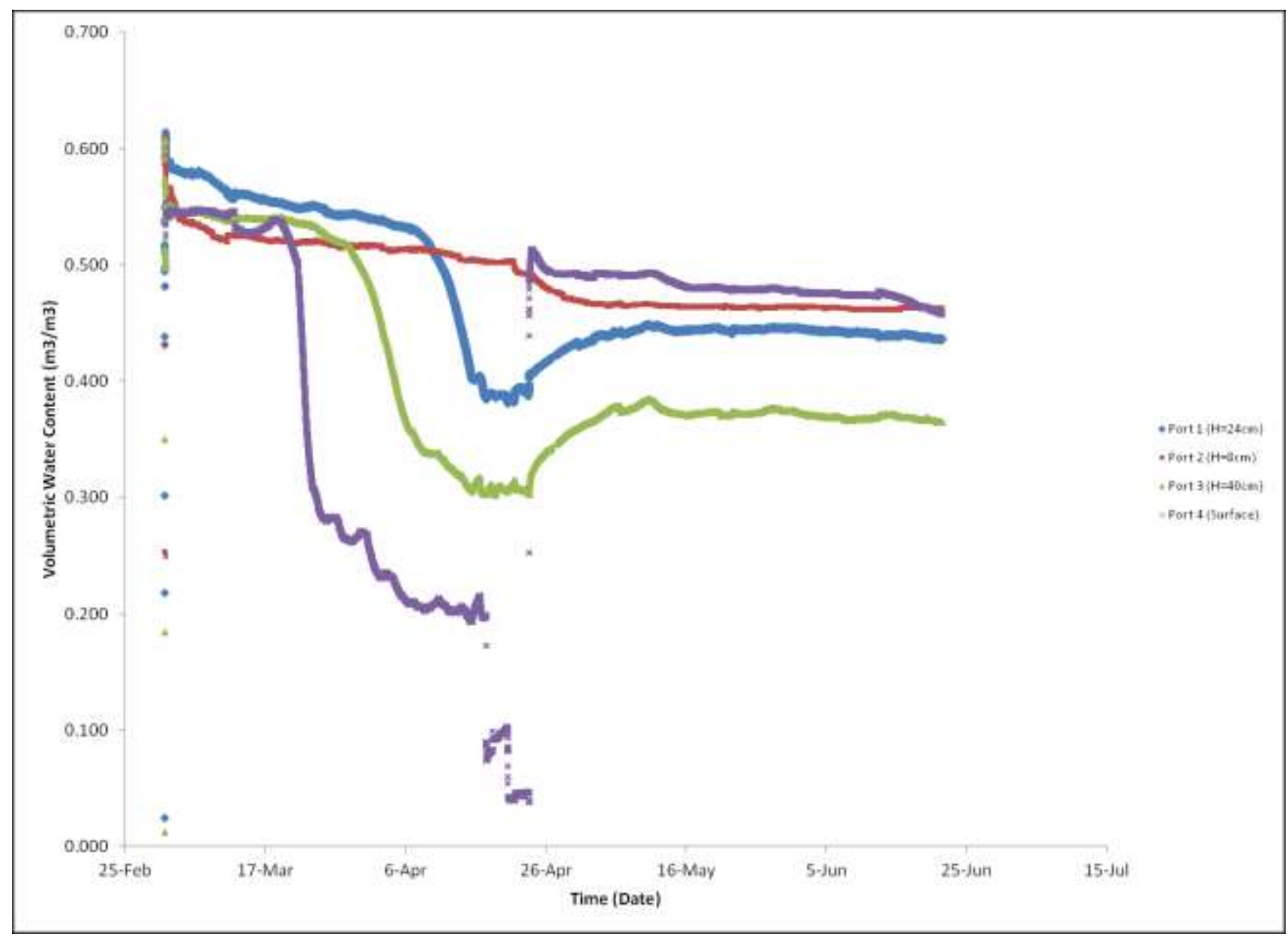

Figure 4.2-67. Volumetric water contents at various heights in bottom layer Overall 


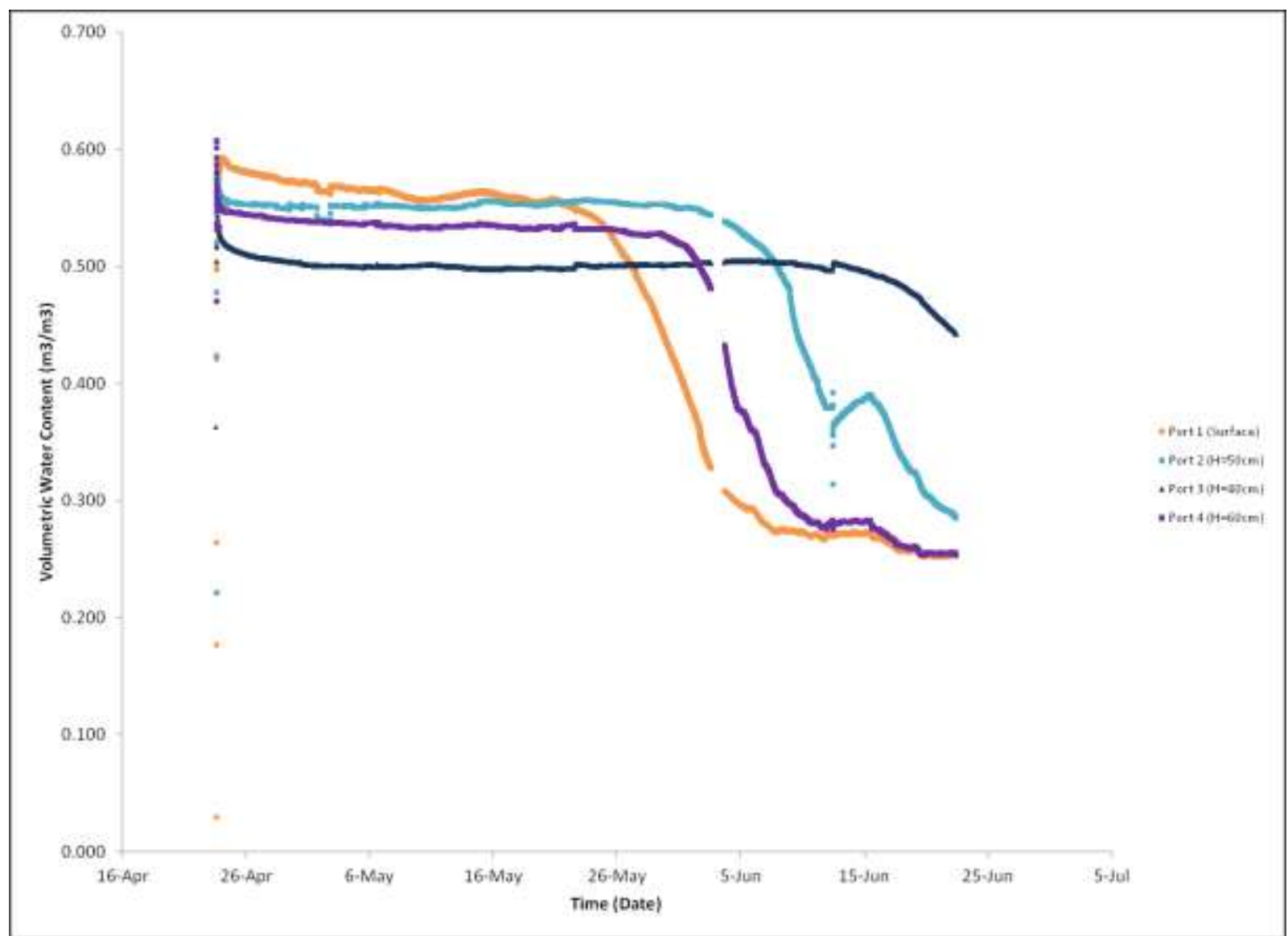

Figure 4.2-68. Volumetric water contents at various heights in top layer - Overall

The VWC in the second layer is shown in Figure 4.2-68. The VWC values in Figures 4.2-67 and 4.2-68 are not calibrated. After calibration, the VWC in layer 1 tailings after rewetting was equivalent to a GWC of about $47 \%$. Constructing a shrinkage curve from measured void ratio and GWC data from Layer 1, it is clear that $47 \%$ GWC is the shrinkage limit of the material, corresponding to a void ratio of 1 , as shown in Figure 4.2-69, which is in agreement to the thin lift dry box. 


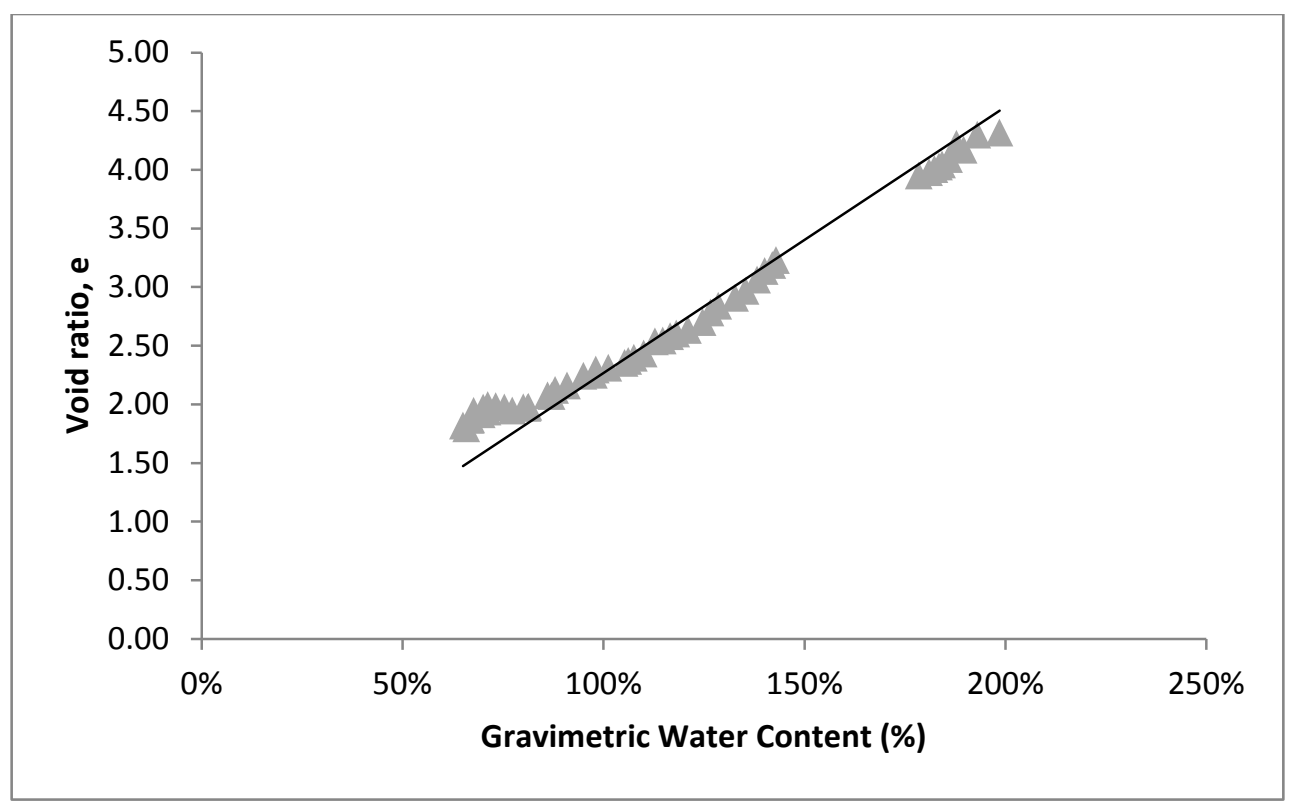

Figure 4.2-69. Shrinkage curve for thick lift dry box

\subsubsection{Water Content}

The overall GWC (Figure 4.2-70) was calculated based on weight measurements obtained with the load cells and the water loss through evaporation and drainage. Surface measurements within the top $1 \mathrm{~cm}$ were also taken after the supernatant water that had collected at the top of the tailings had evaporated. The overall GWC takes the supernatant water into account. There is a steady decrease in overall GWC from $190 \%$ to $65 \%$ while the surface GWC decreases from $120 \%$ to $30 \%$. 


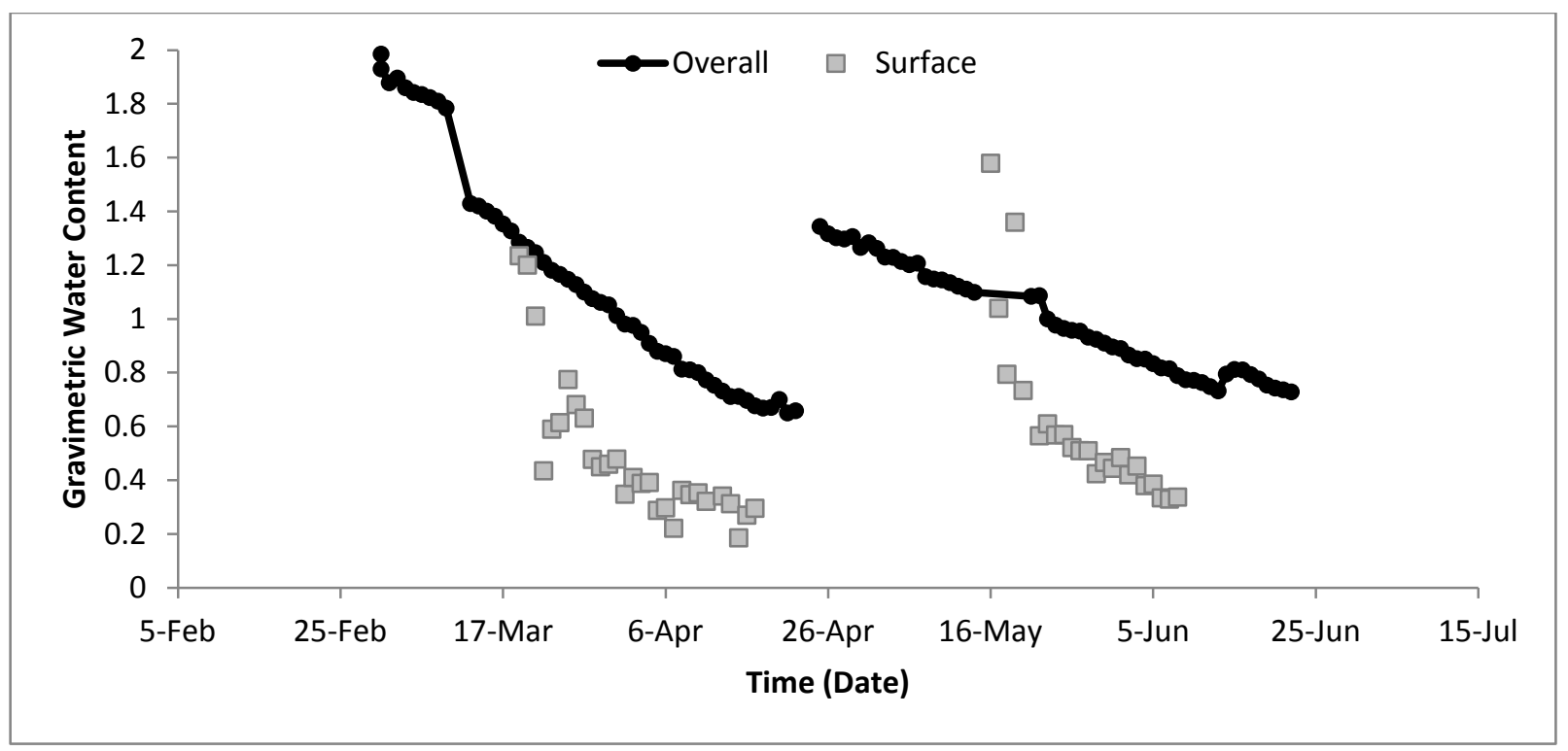

Figure 4.2-70. Gravimetric water contents - Overall

Surface samples were also taken at various locations once cracks began to form. They were taken from the surface (between cracks), at the CEs and inside the cracks. The GWC for these samples is shown in Figure 4.2-71.

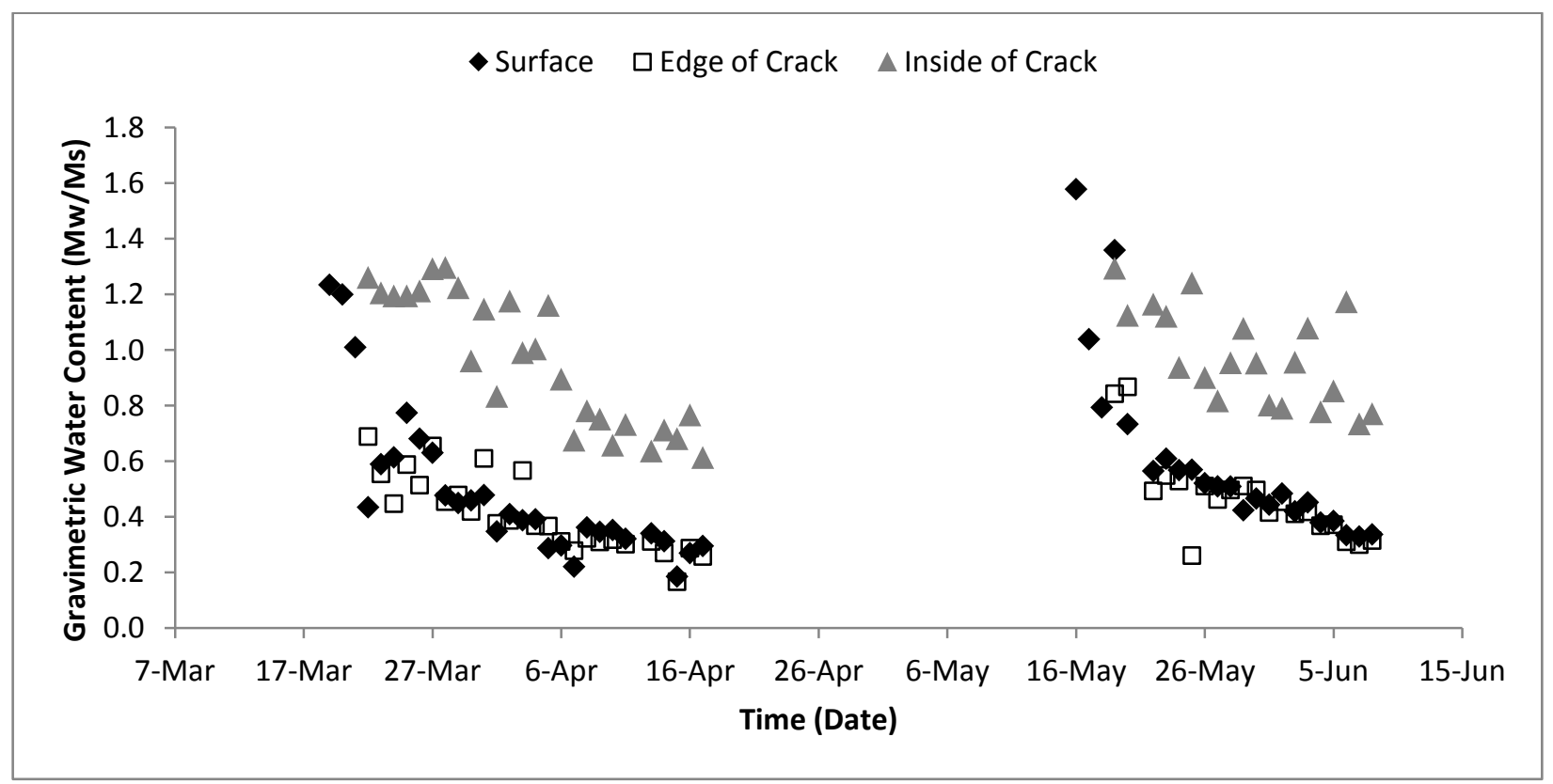

Figure 4.2-71. Surface sample gravimetric water contents - Overall 
SCs were calculated using three different methods. The overall SC was based on the load cell measurements and water loss. The SC of the top layer was based on the readings obtained by the VWC sensors. The surface SC was obtained by measuring SC from samples extracted from the top $1 \mathrm{~cm}$ of the top layer. Results are presented in Figure 4.2-72.

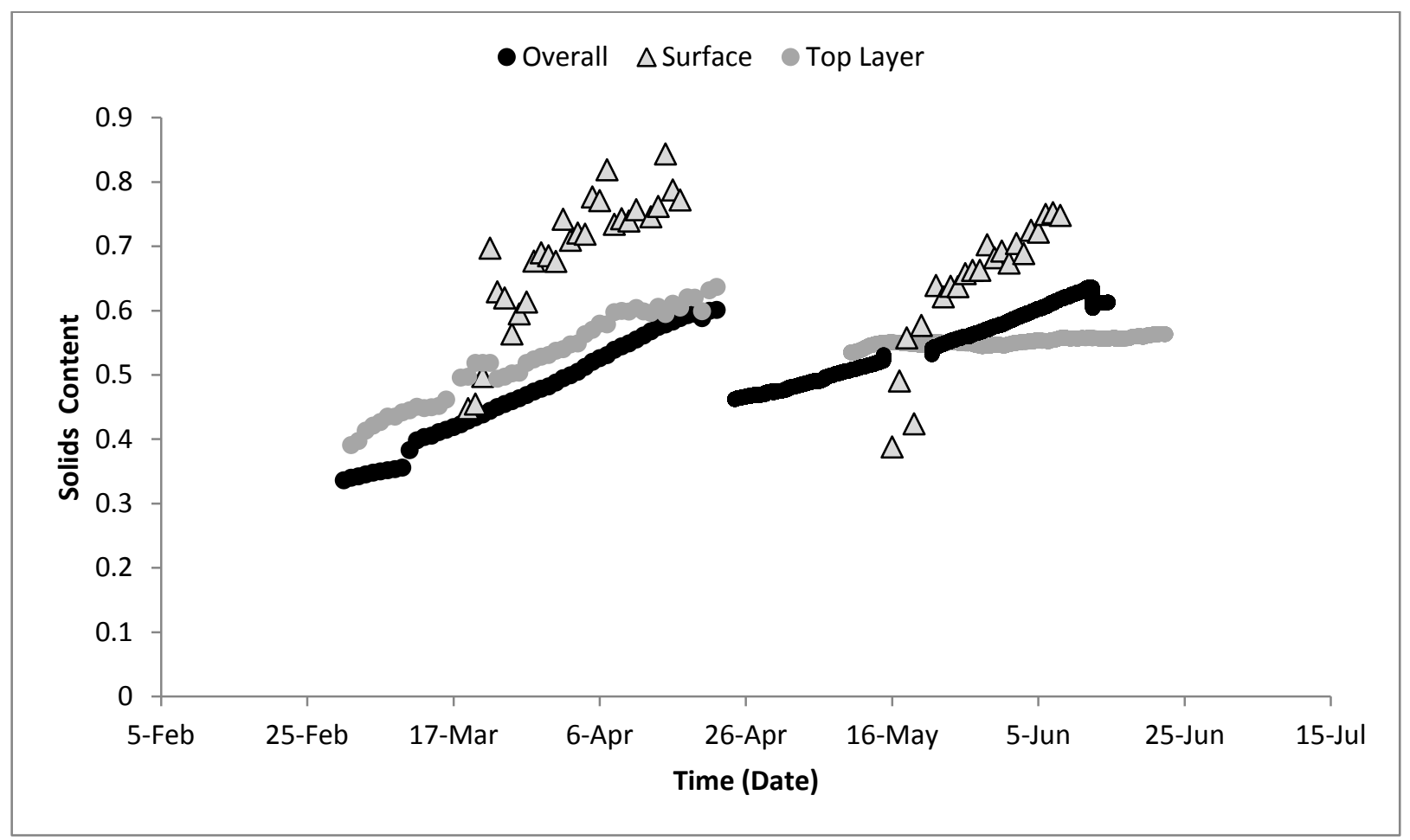

Figure 4.2-72. Solids contents - Overall

Figure 4.2-73 provides a breakdown of the SCs at the surface, CE and IC surface samples. 


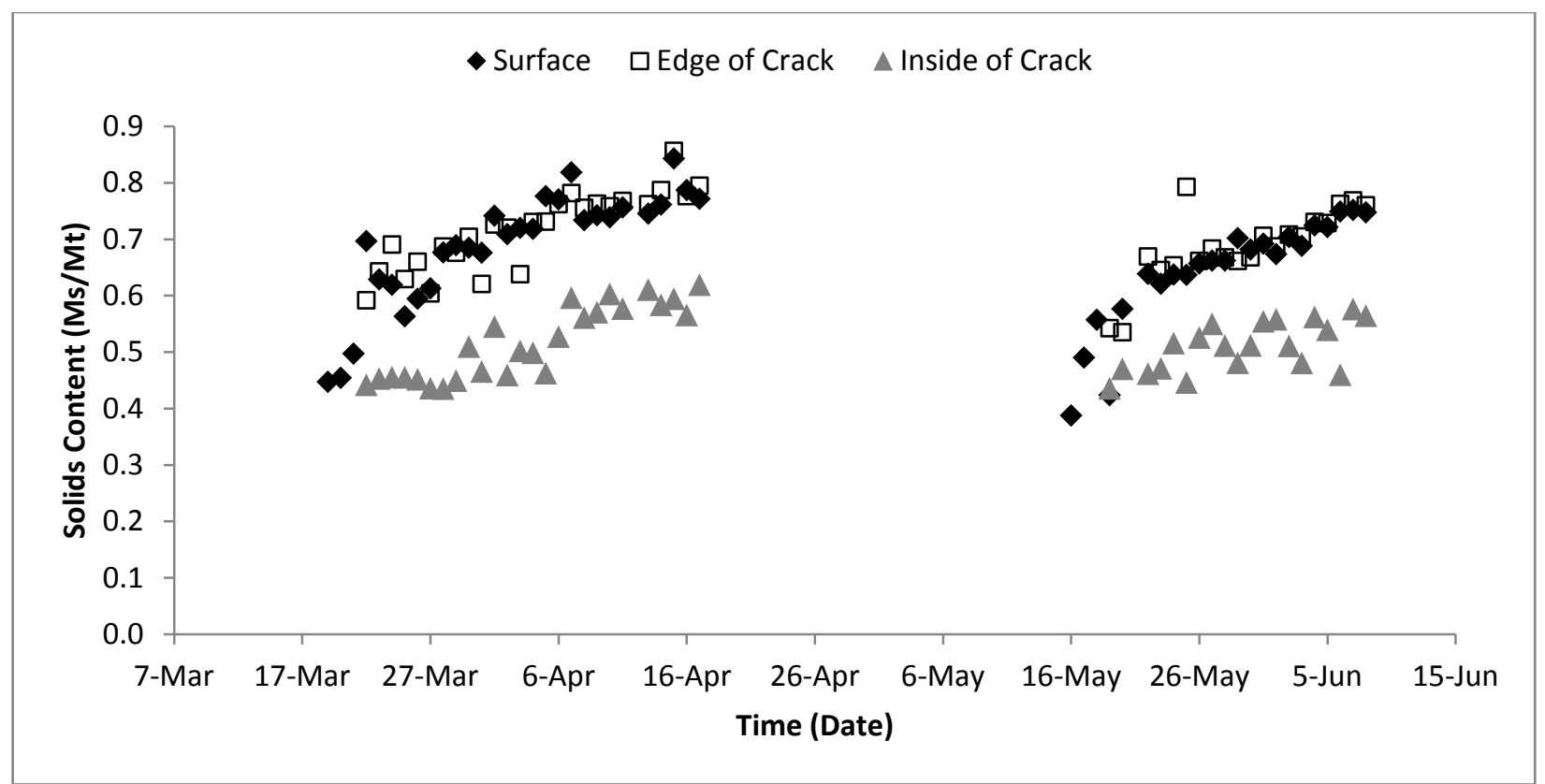

Figure 4.2-73. Surface sample solids contents - Overall

Figure 4.2-74 shows the variation in overall degree of saturation throughout the test. The degree of saturation begins to fall appreciably below 1 on April $1^{\text {st }}$ for the first layer at about $80 \%$ GWC and $55 \%$ solids for the average water content.

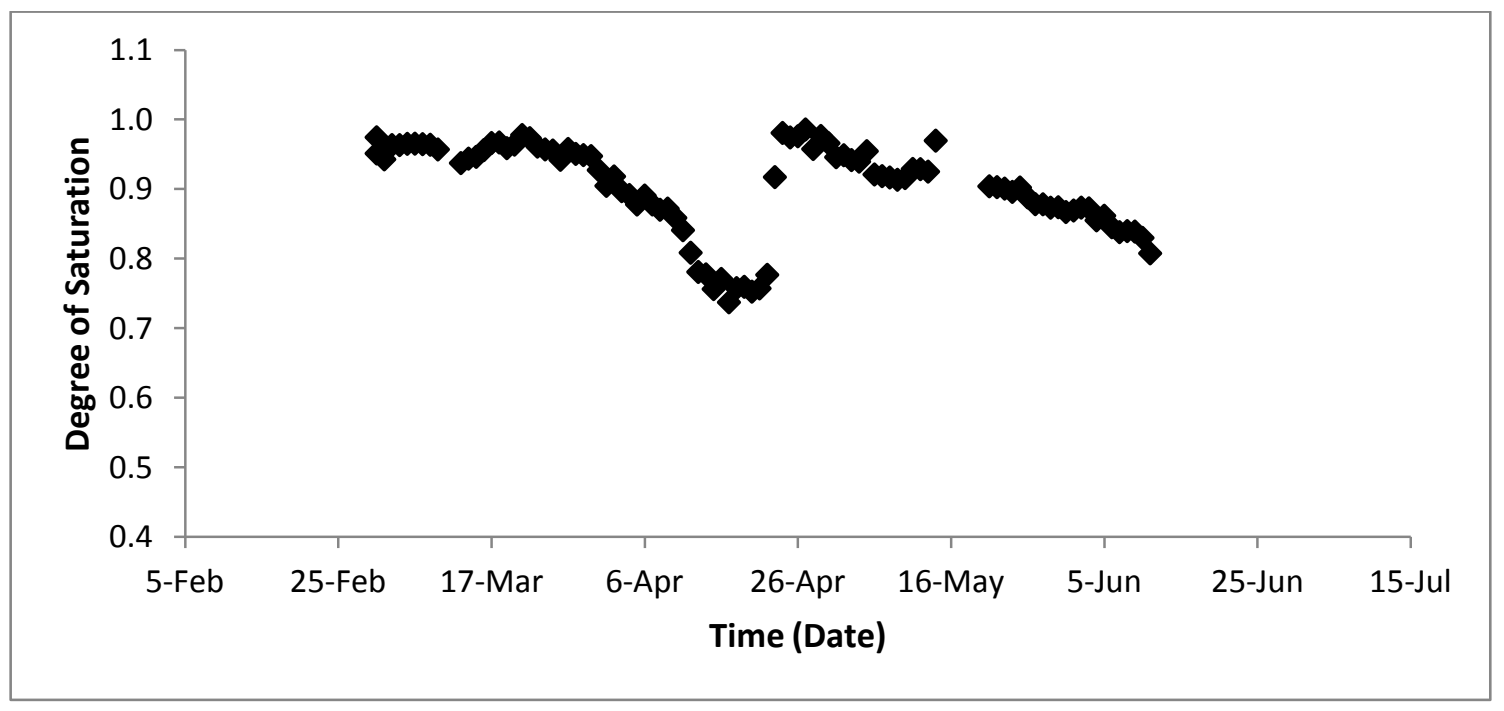

Figure 4.2-74. Degree of saturation - Overall 


\subsubsection{Suction}

This section provides results for measurements for matric, osmotic, and total suctions in various locations for the test.

\subsection{Matric Suction}

The tensiometer readings over the course of the experiment, are shown in Figure 4.2-75. These reading were problematic, as tensiometers became exposed to air when cracking started to develop, or were even ratcheted out of the tailings during consolidation. However, the tensiometers provide good data passing from the positive to the negative pore-pressure range.

For all layers, crack initiation was correlated with one or more tensiometers registering suction (negative pore-water pressure), which occurred almost immediately when supernatant water disappeared.

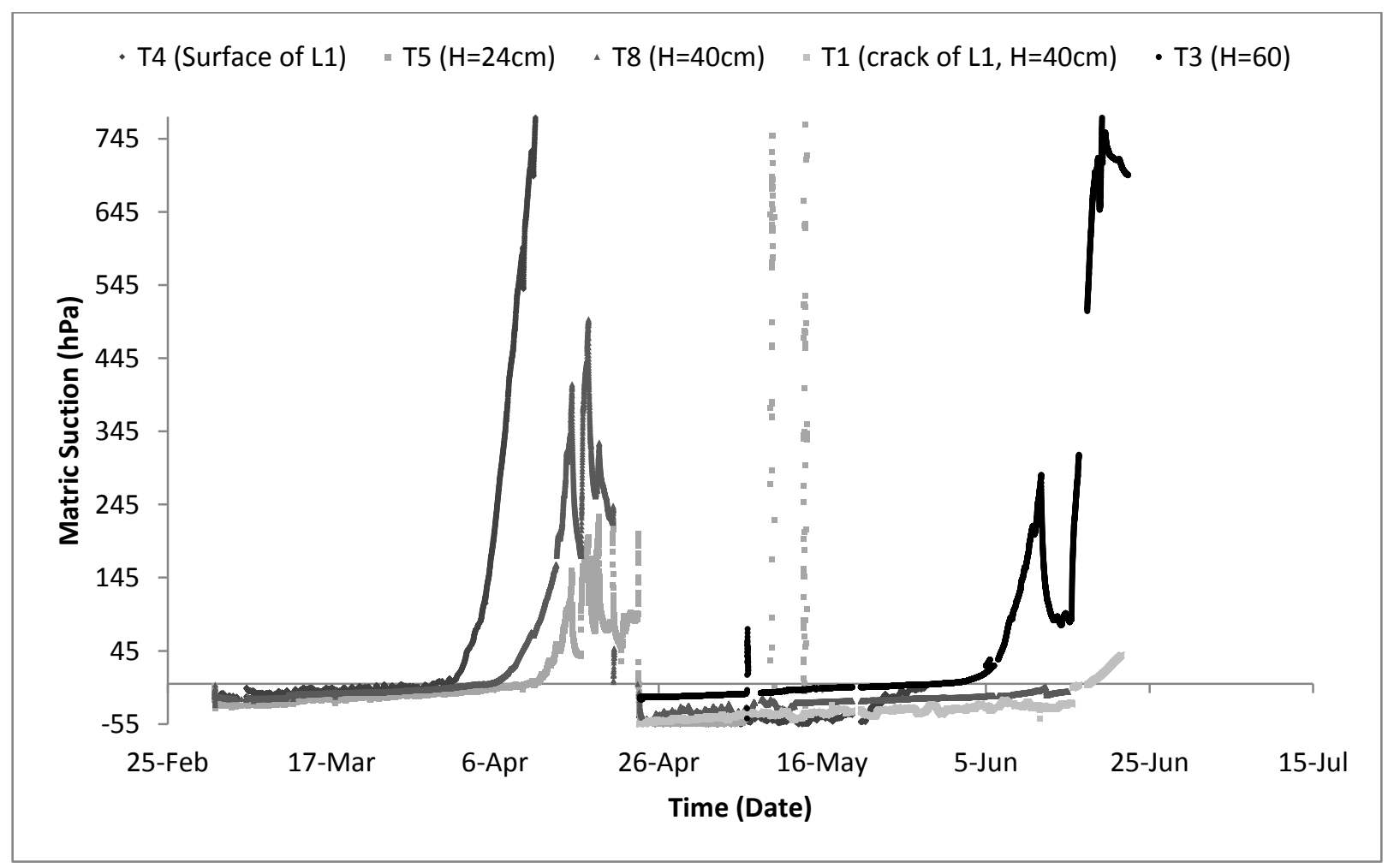

Figure 4.2-75. Matric suction at various heights - Overall 
Figure 4.1-76 provides matric suction profiles constructed from tensiometer data shown in Figure 4.2-75 and interpolated values from the SWCC in section 4.4-13 (Figure 4.4-9), for Layer 1 at $60 \%$ SC and Layer 2 at 55\% SC. In both cases, matric suction decreases with depth. In the second layer, the matric suction at the top is equal to the matric suction at the top for layer 1 . However, matric suctions are higher for layer 2 in the top $10 \mathrm{~cm}$.

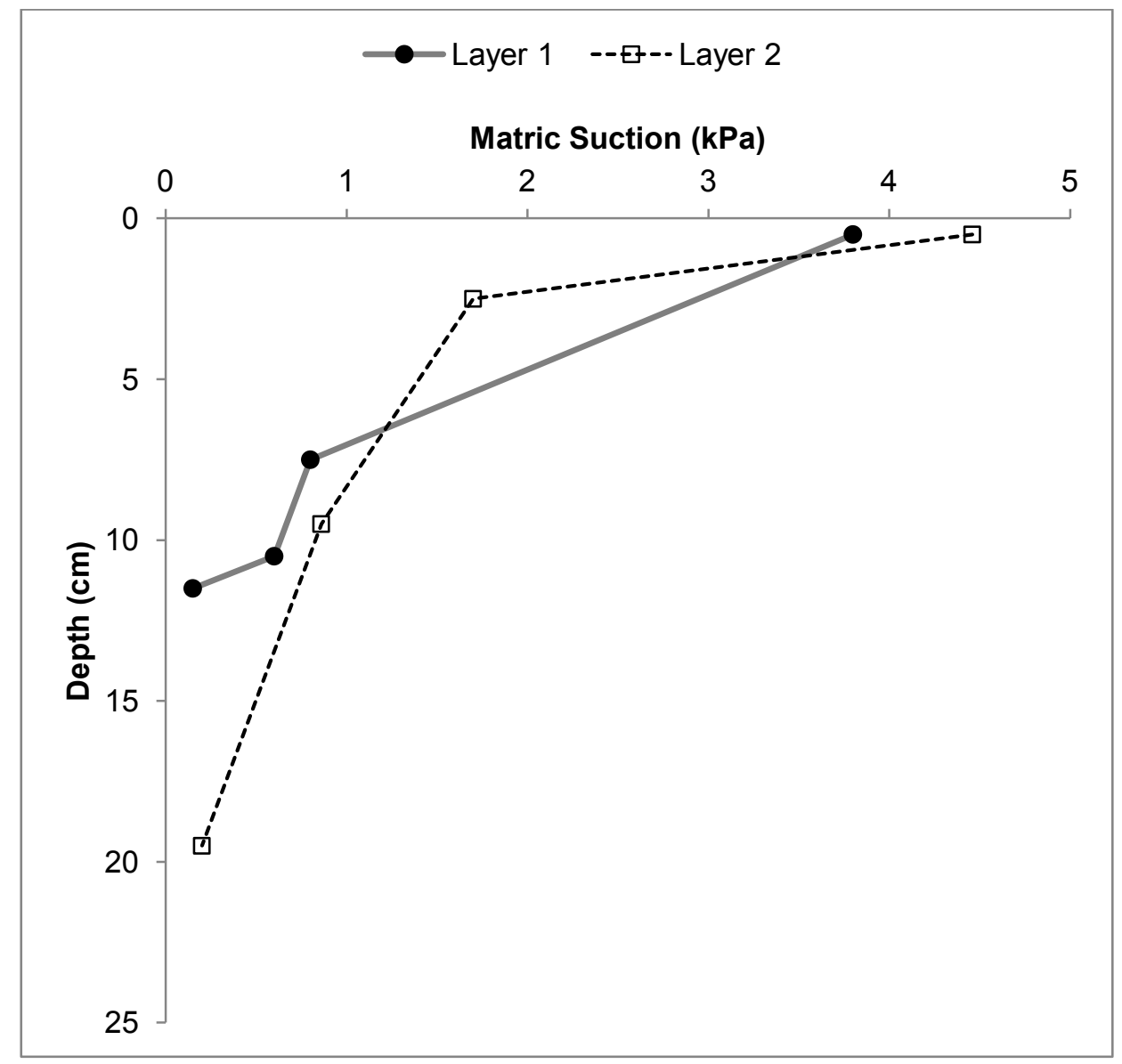

Figure 4.2-76. Thick Lift dry box matric suction profiles 


\subsection{Osmotic Suction}

Osmotic suction measurements over the course of the experiment are shown in Figure 4.2-77.

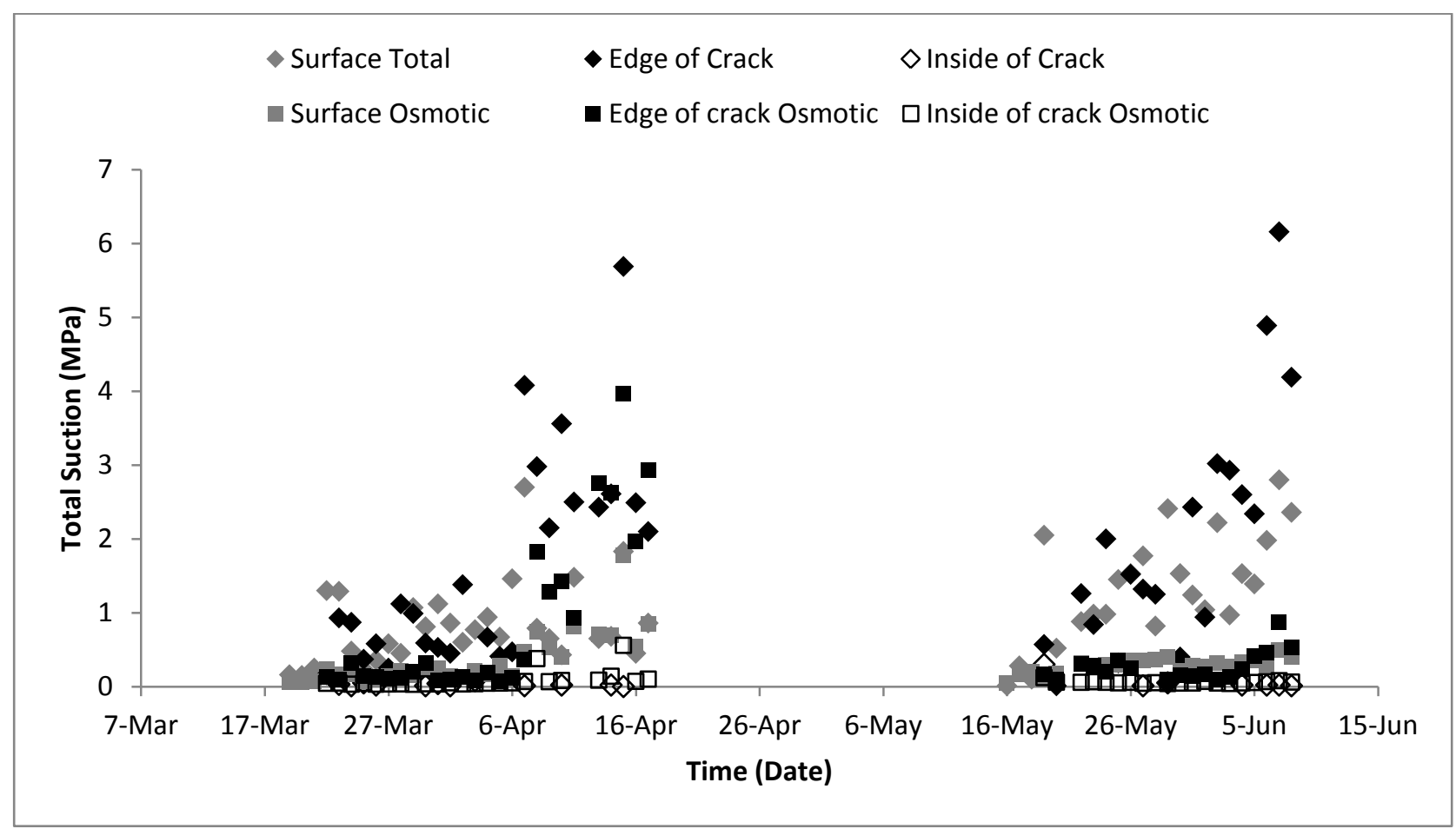

Figure 4.2-77. Surface sample total and osmotic suctions - Layer 2

\subsection{Total Suction}

Samples extracted from the top $1 \mathrm{~cm}$ of the surface of the tailings, crack edges and the ICs were measured for total suction using a WP4-C potentiometer. These results are shown in Figure 4.2-78.

Overall, suction values at the surface increased as water escaped the tailings. Initially, suction values along the crack edges were wetter than those at the surface, but as the tailings dried out and the crack volumes remained constant, the edges also dried out, and in some instances surpassed the values at the surface. The values inside the cracks were generally lowest. 


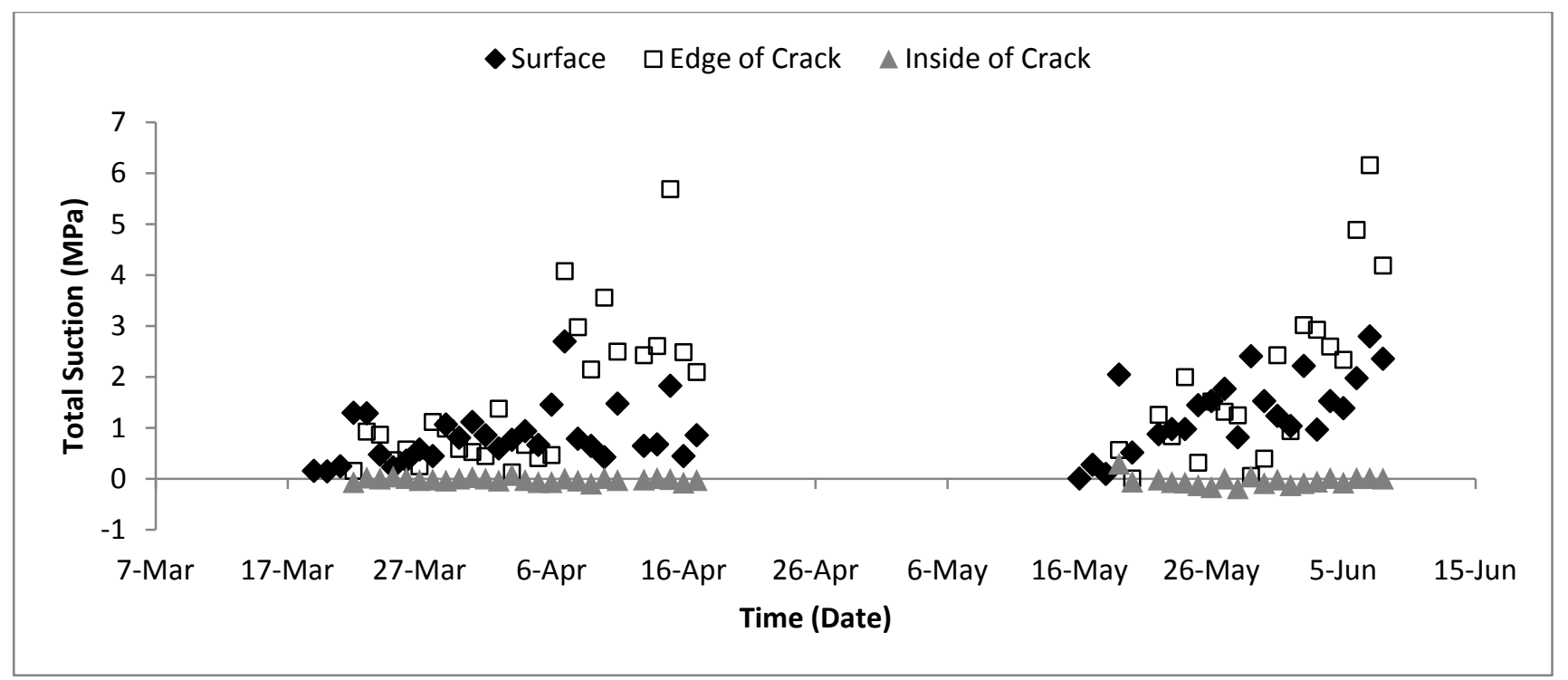

Figure 4.2-78. Surface sample total suctions - Overall

\subsection{Cracking: Dry Box vs. Field}

The extension of crack contribution to $A E$ to the field from the dry box tests may not be applicable due to differences in crack geometry, frequency of cracking, and crack volumes. This section provides a brief discussion of crack geometry, and total suction observed in the dry box tests and the crack patterns observed in the AFD trial, described in section 2.5.4.1.

Figures 4.3-1 and 4.3-2 show a comparison of crack patterns from the dry box test on the left, and a picture from the AFD trial on the right. Note that the scale may differ in each image. In Figure 4.3-1, both tailings are at approximately $60 \%$ SC, and in Figure 4.3-2 both tailings are at approximately $70 \%$ SC. In both cases, there are noticeable differences. The tailings from the dry box seem to be wetter at the surface than the field tailings. It appears as if the AFD tailings experienced more shrinkage. In the AFD tailings, occur more frequently. It is hard to tell whether the field cracks or the dry box cracks have a larger surface area that may have an impact on the evaporation rate. 


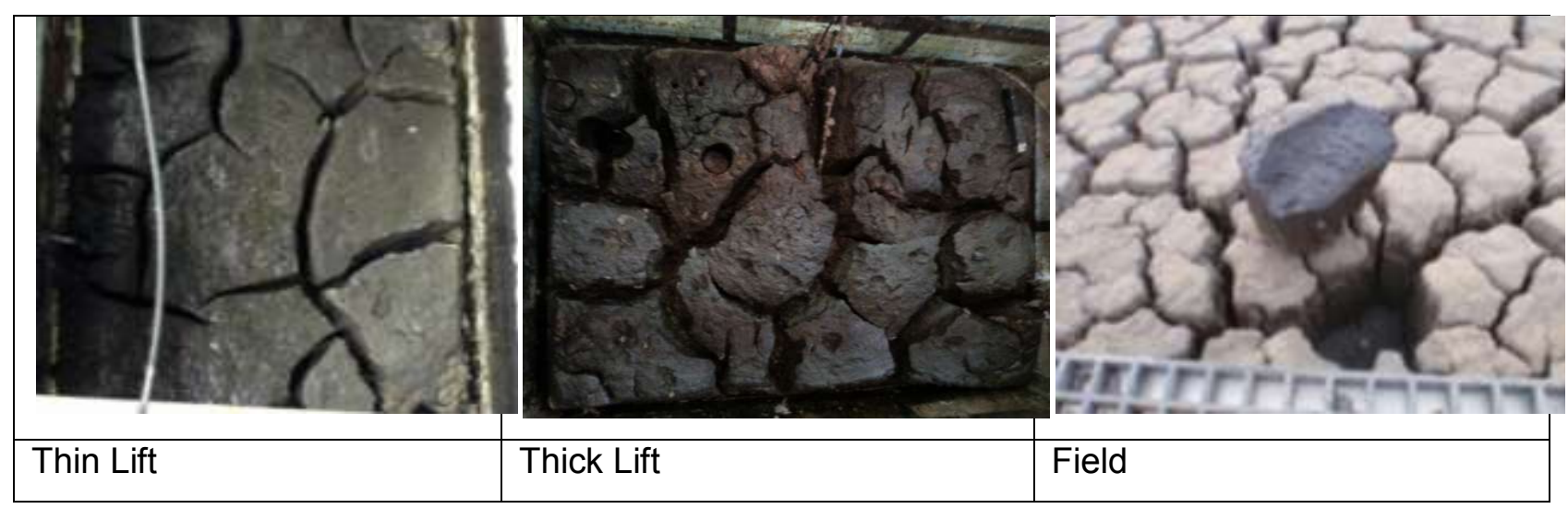

Figure 4.3-1. Dry box thin and lift tailings and AFD tailings dried to approximately $60 \%$ SC

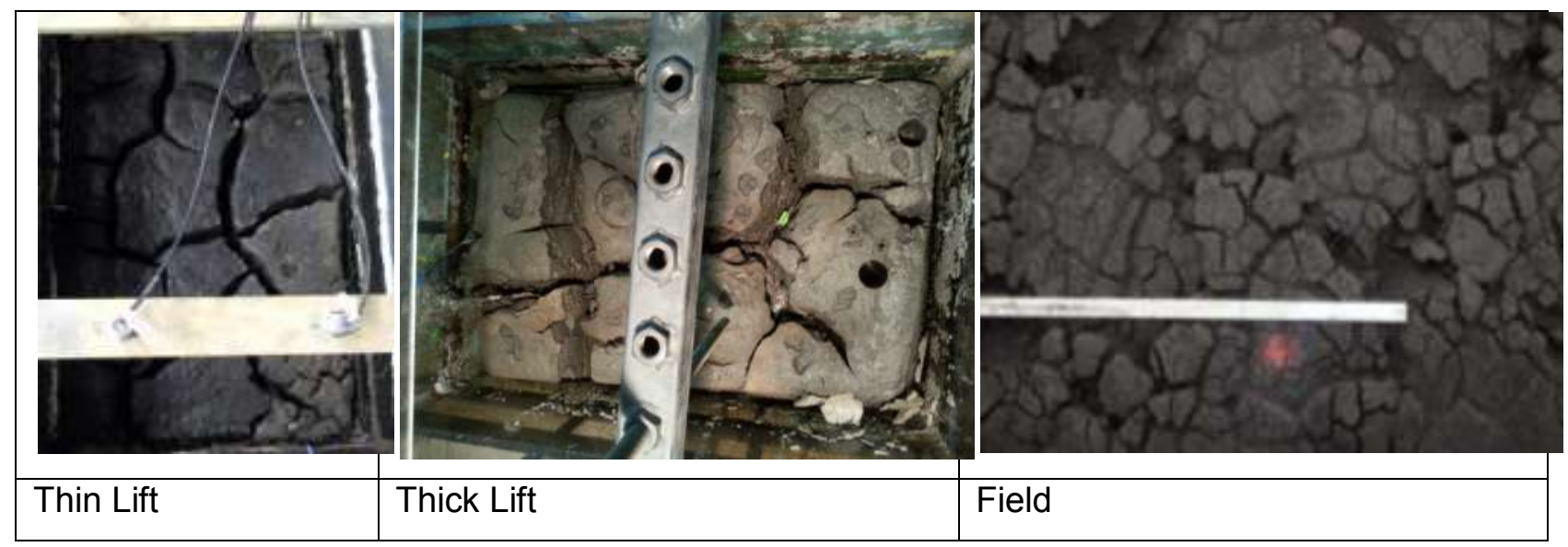

Figure 4.3-2. Dry box thin lift tailings (left) and AFD tailings (right), both dried to approximately $70 \%$ SC 

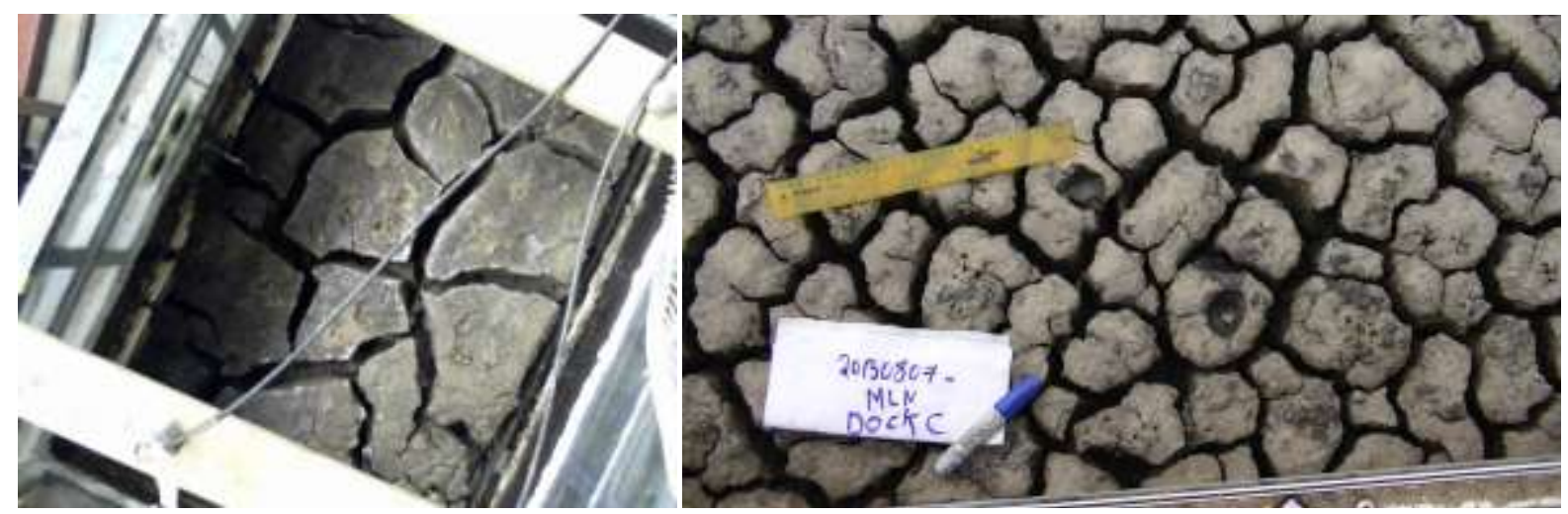

Figure 4.3-3. Dry box thin lift tailings (left) and AFD tailings (right), with dry box tailings dried to approximately $90 \%$ SC

The dry box tailings appear to be as dry as the AFD tailings once they reach a SC of approximately 90\%, shown in Figure 4.3-3.

Figure 4.3-4 shows a comparison between the total suction distribution across a crack transect from a multi-layer thick deposition field trial, and one side of a crack transect from the thick lift dry box Layer 1 . The values are lower at the surface and the IC but are almost identical at the CE.
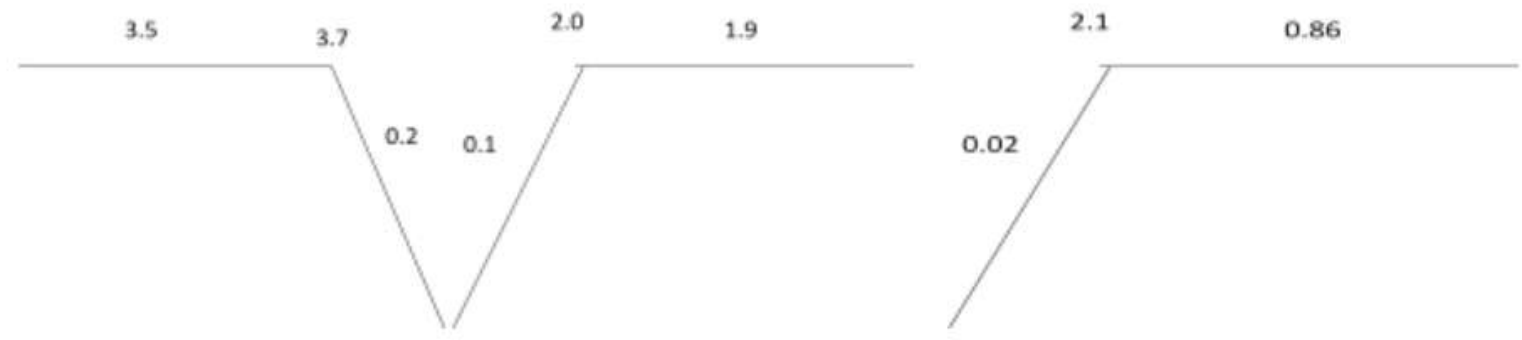

Figure 4.3-4. Transect of total suctions (MPa) across a multi-layer thick lift crack from the field (left), and thick lift layer 1 crack (right) 


\subsection{Thin-Lift vs. Thick Lift Tests}

In this section, overall dewatering, and evaporation behaviours in the thin-lift and thick-lift dry box experiments are compared.

\subsubsection{Overall Dewatering}

The following figure shows the overall increase in solids content for Layer 1 of the thin lift and thick lift dry box tests. The increase in the thick lift dry box is more gradual than that of the thin lift dry box. The SC increase is more abrupt in the thin lift dry box after 40 days, while the thick dry box seems to converge to approximately $55 \%$ SC.

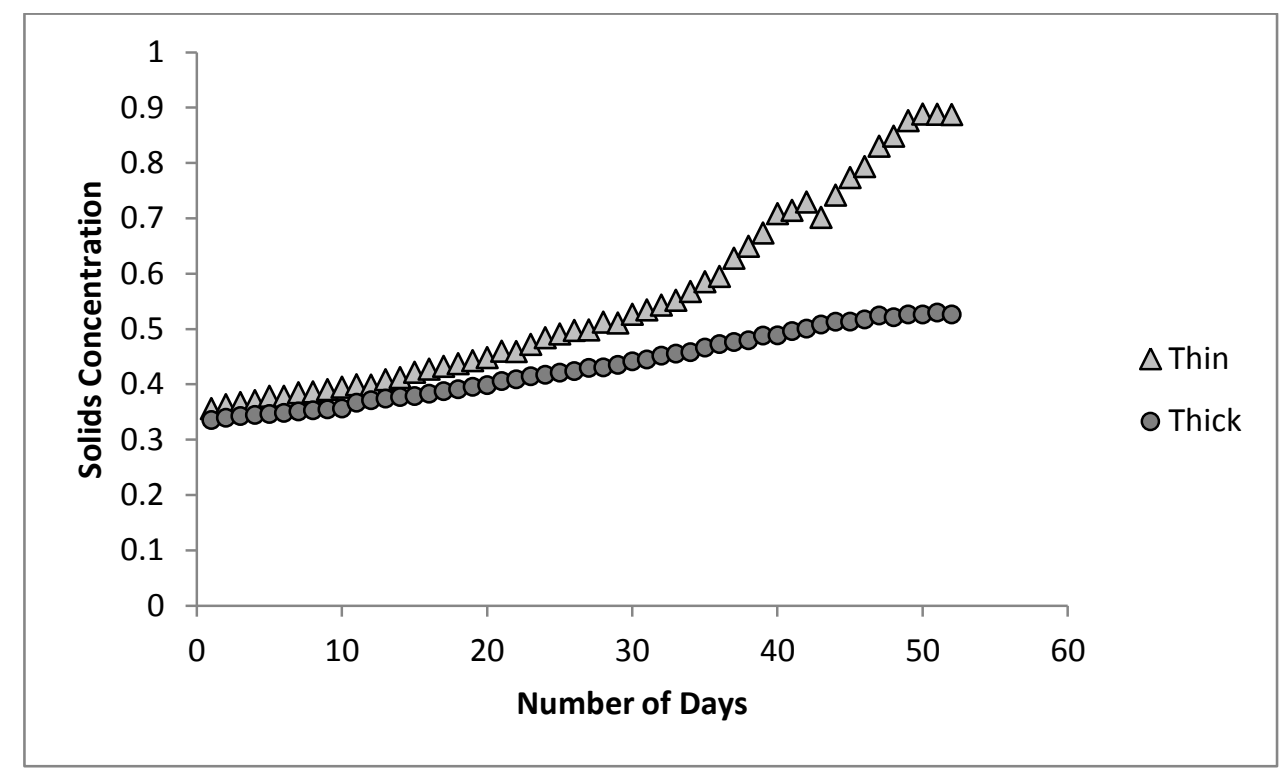

Figure 4.4-1. Comparison of solids content in thin and thick lift tests

These results can also be compared to modeling results for a thin layer $(35 \mathrm{~cm})$, as shown in Figure 4.4-2 to Layer 1 of the thin lift dry box and Figure 4.4-3 for the thick lift 
(Simms et al., 2015). The progression of SC in the top layer, calculated by the values measured by the VWC sensors is found to closely mimic the results of the modeling. Modeling software, FSConsol and SoilVision were used to model dewatering (Simms et al., 2015)

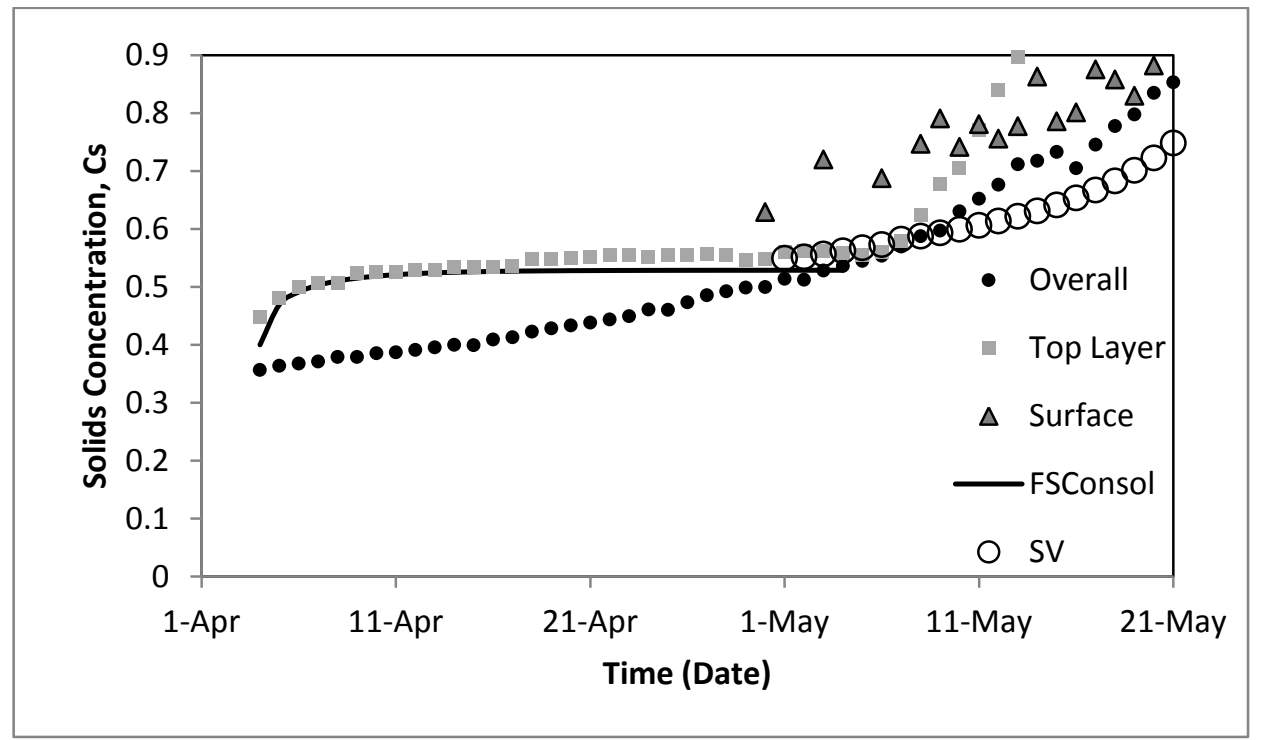

Figure 4.4-2. Comparison of solids content to modeling results - Thin lift dry box 


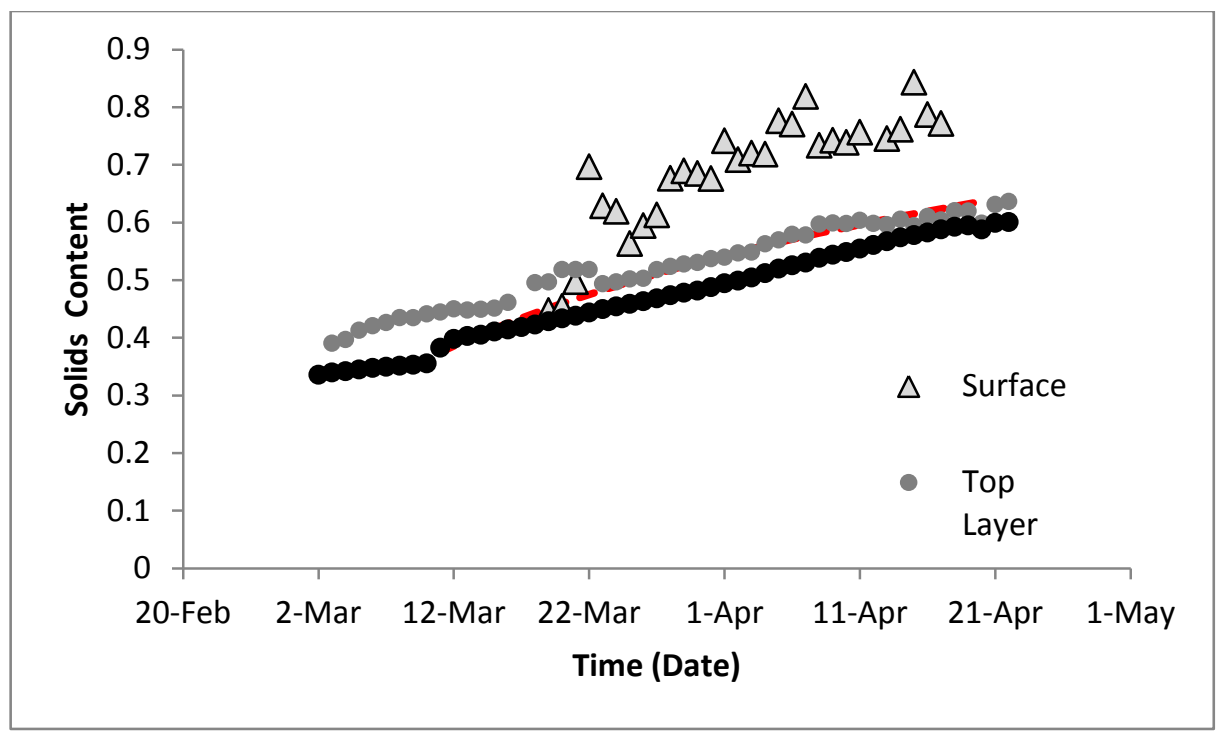

Figure 4.4-3. Comparison of solids content to modeling results - Thick lift dry box 4.4.2 Evaporation

To compare the evaporation in both dry box experiments, the cumulative $A E$ and PE were divided by the original thickness of the tailings. Figure 4.4-4 shows the results.

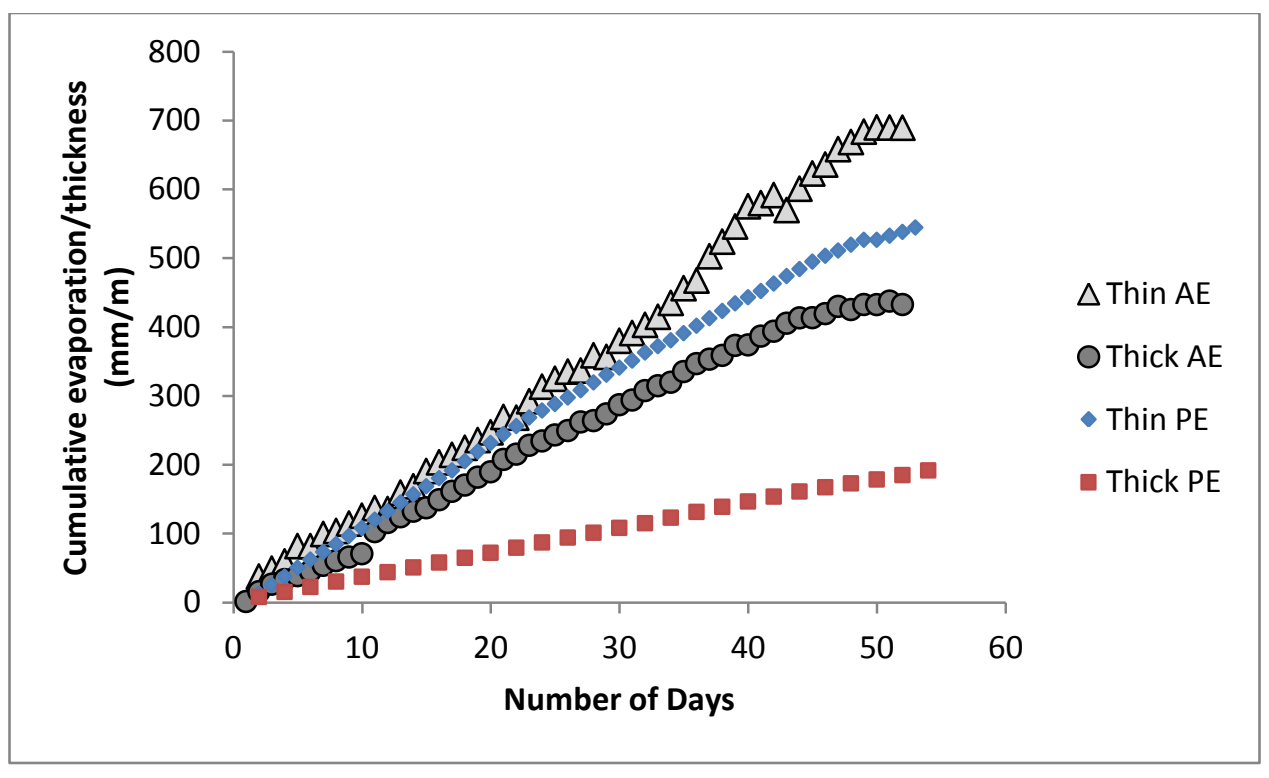

Figure 4.4-4. Evaporation for thin and thick lift dry box experiments 
Figure 4.4-6 shows the cumulative RE (cumulative AE divided by the cumulative $\mathrm{PE})$ normalized over the thickness of each dry box experiment. From this figure it is apparent that cracking is more beneficial for the thin lift dry box, rather than the thick.

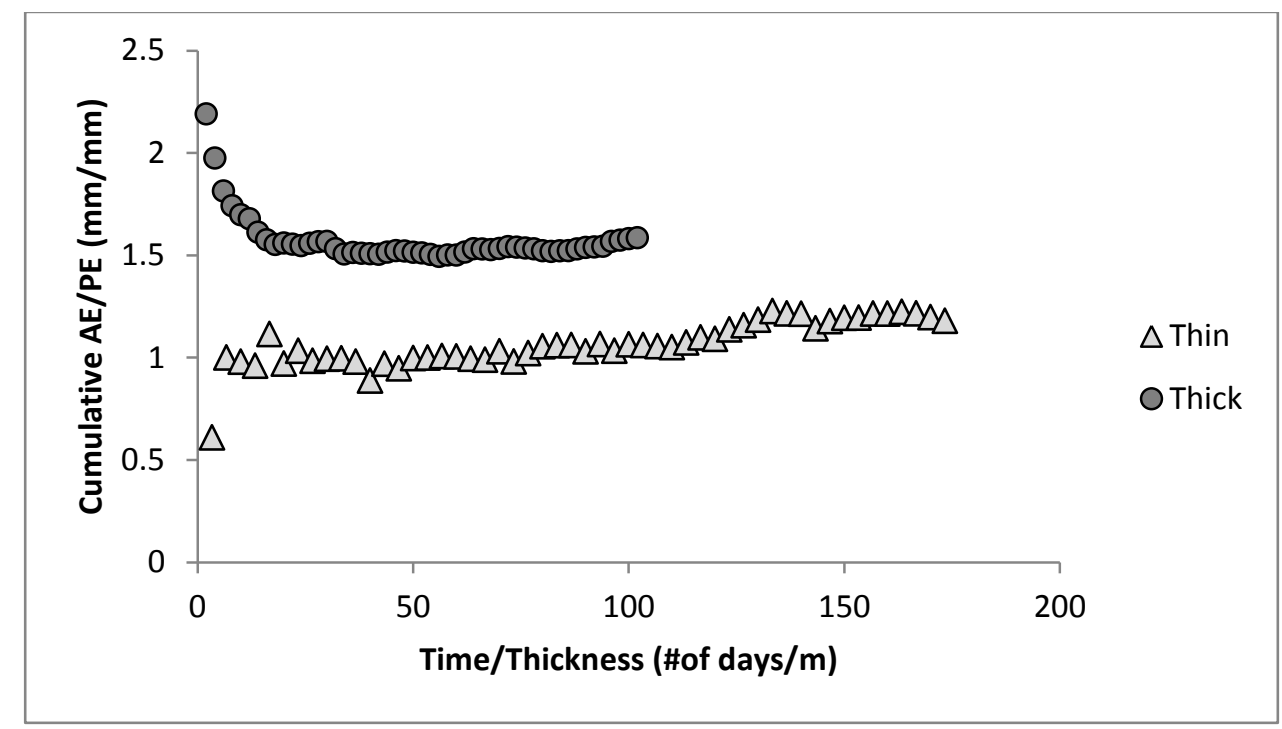

Figure 4.4-5. RE for thin and thick lift dry box experiments

\subsubsection{Implications for the Industry}

It was found that for these tailings, a $5 \mathrm{kPa}$ shear strength, is achieved for solids content between $55 \%$ and $60 \%$, at least when pore-pressures are reduced to near zero or negative values. If this requirement needs to be accomplished within 1 year after deposition, it is likely that no more than $55 \%$ SC needs to be achieved before placement of the second layer.

For the scenario of thin lift deposition (30-35 cm), $5 \mathrm{kPa}$ would be achieved by 1 month, or sooner if supernatant water would drain off due to placement of tailings on a slope. Considering a 4 month summer season (mid-May to mid-September), a summer rate of rise of $1.2 \mathrm{~m}$ is possible. Coupled with a $1 \mathrm{~m}$ lift placement prior to the winter for freeze-thaw, a rate of rise of $2.2 \mathrm{~m}$ a year is possible. 
For the scenario of thick lift deposition $(50 \mathrm{~cm}), 5 \mathrm{kPa}$ would be achieved by 2 months. A summer rate of rise of $1.0 \mathrm{~m}$ would is possible. Coupled with a $1 \mathrm{~m}$ lift placement prior to the winter for freeze-thaw, a rate of rise of $2.0 \mathrm{~m}$ a year is possible. Table 4.4-1 provides a comparison of rate of rise possibilities for thin and thick lifts.

Table 4.4-1. Estimated drying times for various lift thicknesses

\begin{tabular}{clcccc}
\hline & Drying Time & 1 Month & 2 Months & Summer & Year \\
\hline Rate of Rise & Thin Lift & $0.30-0.35$ & - & 1.2 & 2.2 \\
$(\mathrm{~m})$ & Thick Lift & - & 0.50 & 1.0 & 2.0 \\
\hline
\end{tabular}

Thin lifts would require a footprint of $4 \mathrm{~km}$ by $4 \mathrm{~km}$ for an operation generating $100,000 \mathrm{~m}^{3}$ of mature fine tailings per day. The rate of rise is comparable to that suggested by the experience with thin lift drying at Suncor (Caldwell et al. 2014).Thick lifts would require a footprint of $4.5 \mathrm{~km}$ by $4.5 \mathrm{~km}$ at a minimum.

From these results, it appears that thin lifts are more beneficial over thick lifts for the contribution of cracking to evaporation, the rate of rise over the span of one year, and the footprint.

However, there are certain assumptions made when extrapolating these results to the field that may not hold true in this case. The flocculated tailings mix achieved in the field may not always be consistent with the mix in the laboratory. Environmental factors, such as wind, rain, $\mathrm{RH}$, and season change may either help with the rate of evaporation, or diminish it. The deposition method itself is also different, since tailings are deposited from a pipeline, onto a larger area, therefore the initial thickness of the tailings could not be as uniform as the thicknesses achieved in the laboratory. 


\subsection{Bearing Capacity}

As discussed in Chapter 2, for the prediction of bearing capacity in saturated soils, equation (15) given in section 2.9 .1 can be used. In unsaturated soils however, the bearing capacity is influenced by matric suction, requiring some modifications to equation (15) to consider this factor. Oloo et al. (1997) proposed a simple technique, given by equation (19), which considers saturated shear strength parameters c' and ' and the SWCC, in order to predict the variation of bearing capacity with respect to matric suction. Furthermore, Vanapalli and Mohamed (2007) proposed equation (20) to deal with uniform fine-grained soils.

This section begins by an in-depth analysis of the SWCC obtained from the dry box experiments, and past studies. Since a factor in the bearing capacity equation is the AEV, shrinkage curves are also presented, to help predict the parameter more accurately.

Bearing capacity estimates, using the methods outlined in Oloo et al. (1997), Vanapalli and Mohamed (2007), and Oh and Vanapalli (2013) are then presented. These estimates are compared to results obtained by plate load tests. This chapter concludes with a discussion of possible implications of these results on trafficability.

\subsubsection{Shrinkage Curves and SWCCs inferred from dry box measurements}

This section presents a shrinkage curve and SWCCs inferred from thin and thick lift dry box experiment measurements. SWCCs are presented in terms of GWC, and degree of saturation, plotted against total and matric suctions. 


\subsubsection{Shrinkage Curve}

A shrinkage curve was constructed for both dry box experiments using GWC and void ratio measurements for both dry boxes, as shown in Figure 4.5-1. Void ratio results do not include crack volumes. From this figure, approximately $47 \%$ GWC is the shrinkage limit of the material, corresponding to a void ratio of 1 . Therefore, the tailings resaturate, but do not swell appreciably upon rewetting. In this figure, the dry box results are also compared to a small scale results from a small sample in a ring. Results seem to agree closely in all three cases.

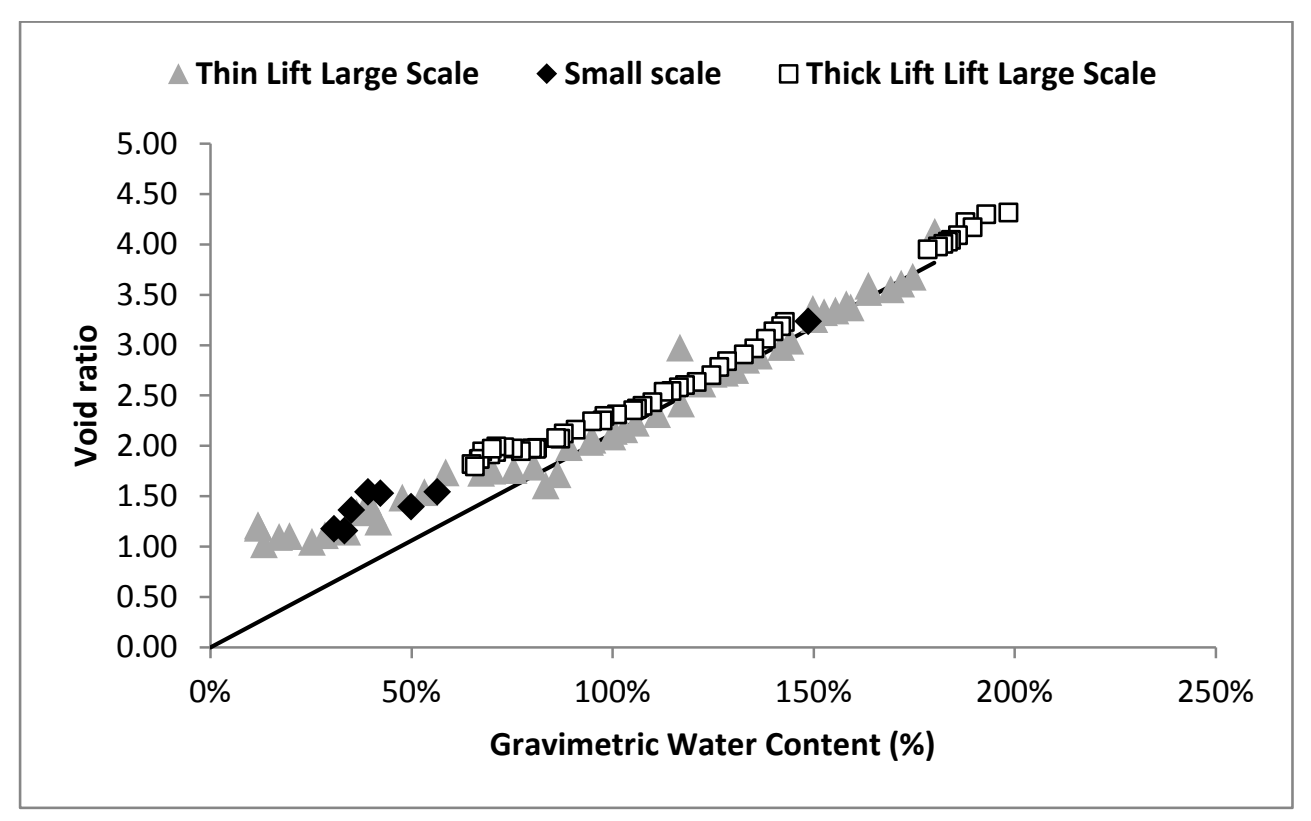

Figure 4.5-1. Shrinkage Curve

\subsubsection{SWCC - GWC versus Total Suction}


SWCCs were constructed from surface total suction and GWC measurements. The SWCC obtained by samples from the three layers of the thin lift dry box and two layers of the thick lift dry box are shown in Figure 4.5-2 below.

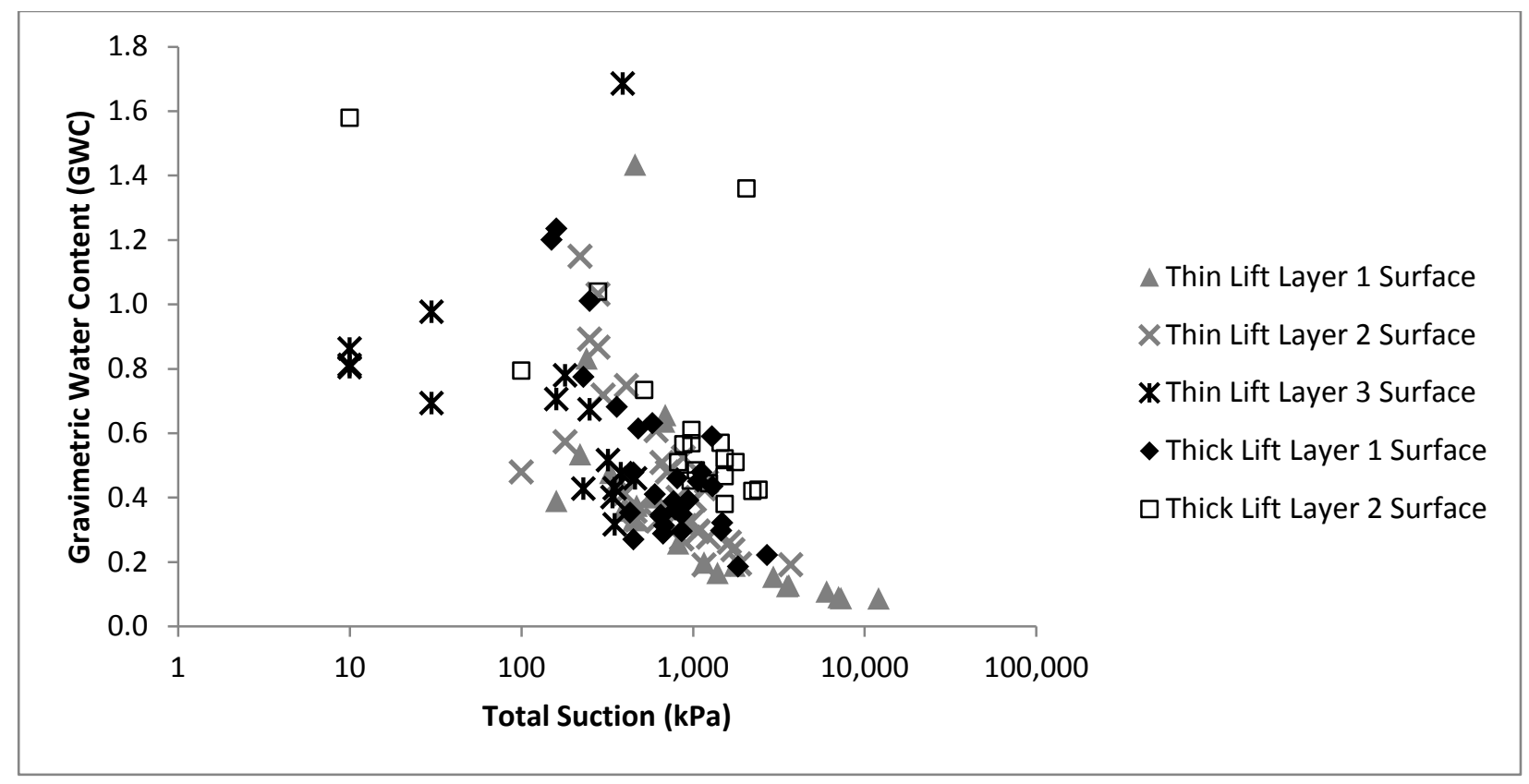

Figure 4.5-2. SWCC in terms of GWC and total suction from surface samples

Alternatively, the relationship between total suction and GWC could also be plotted using results from the extracted cores as shown in Figure 4.5-3 below. 


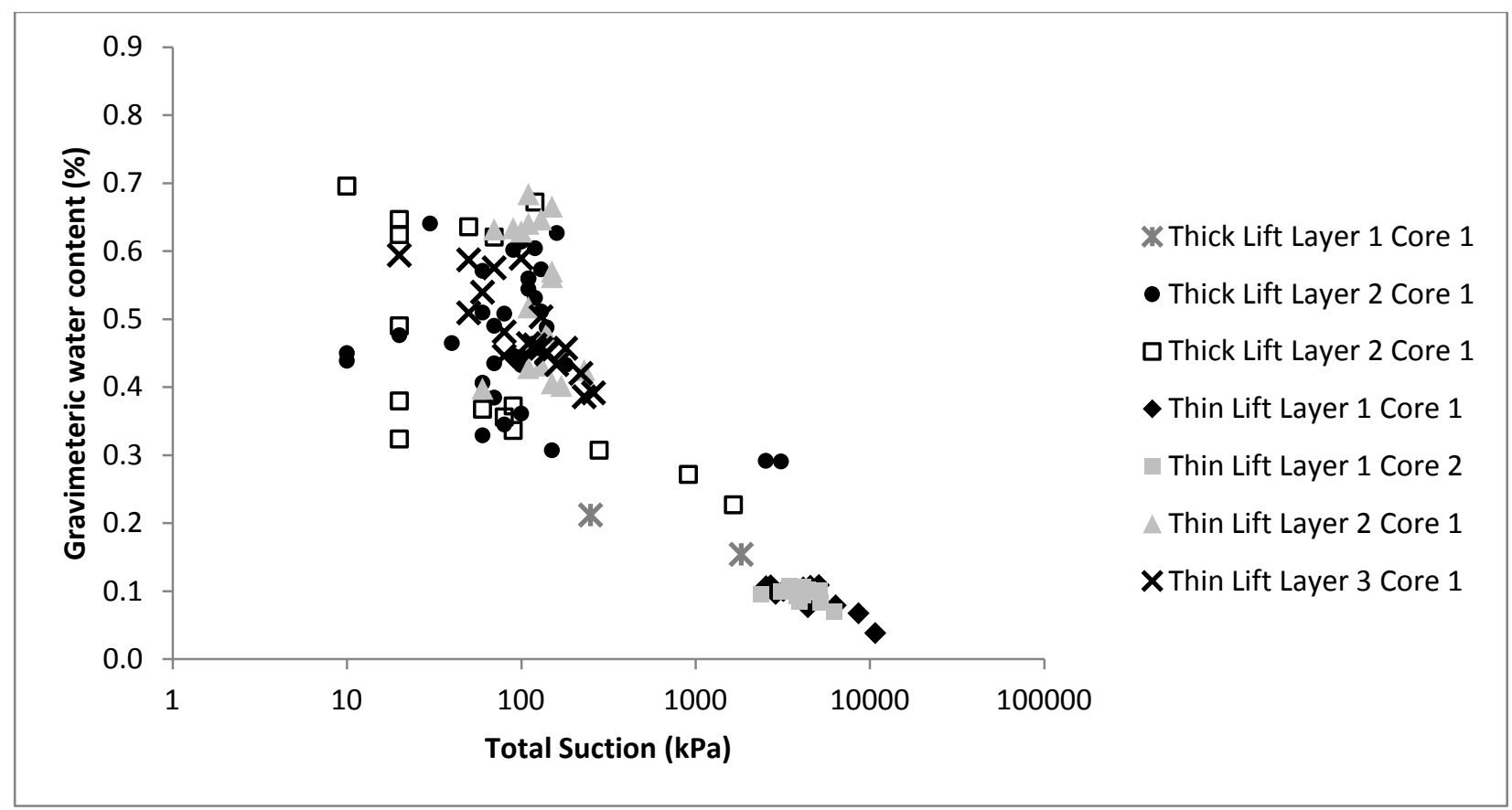

Figure 4.5-3. SWCC in terms of GWC and total suction from core samples

The SWCCs obtained by the cores and the surface samples seem to agree overall. The SWCC for the surface is more dependable than the one from the cores, since the core samples did not achieve great degrees of saturation. Since the accuracy of the potentiometer is $+-0.1 \mathrm{MPa}$, it is more reliable at greater suctions.

\subsubsection{SWCC - GWC versus Matric Suction}

Figure 4.5-4 shows the SWCC in terms of GWC to matric suction for the thin lift experiment. The matric suction from the surface samples in these figures is obtained by subtracting the osmotic suction values shown in sections 4.1 and 4.2 from the total suctions shown in the same sections. The other set of data is collected by the tensiometers. 


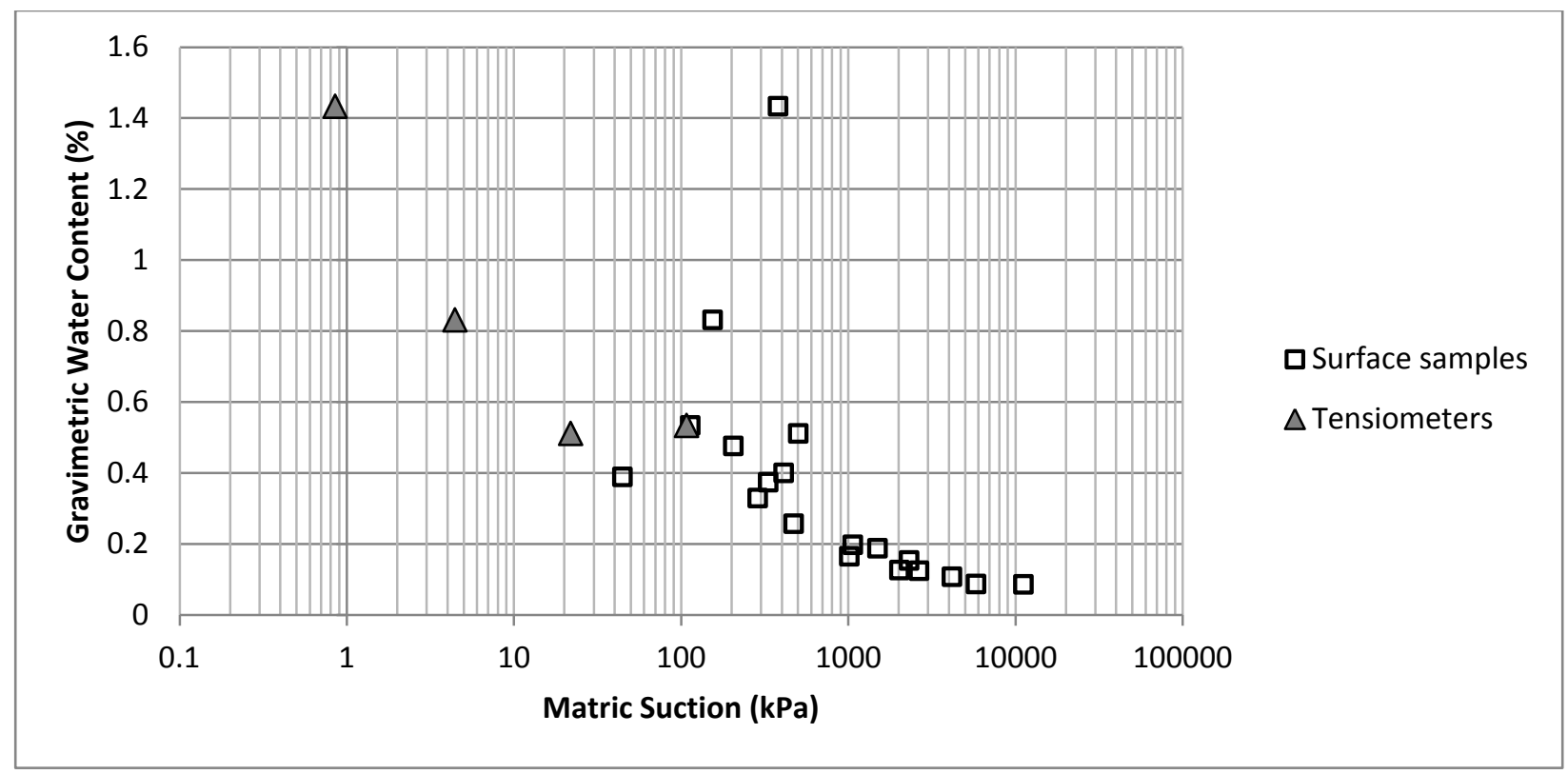

Figure 4.5-4. SWCC in terms of GWC and matric suction for thin lift dry box

Figure 4.5-5 presents the same relationship, for the thick lift dry box. Both sets of measurements are for Layer 1.

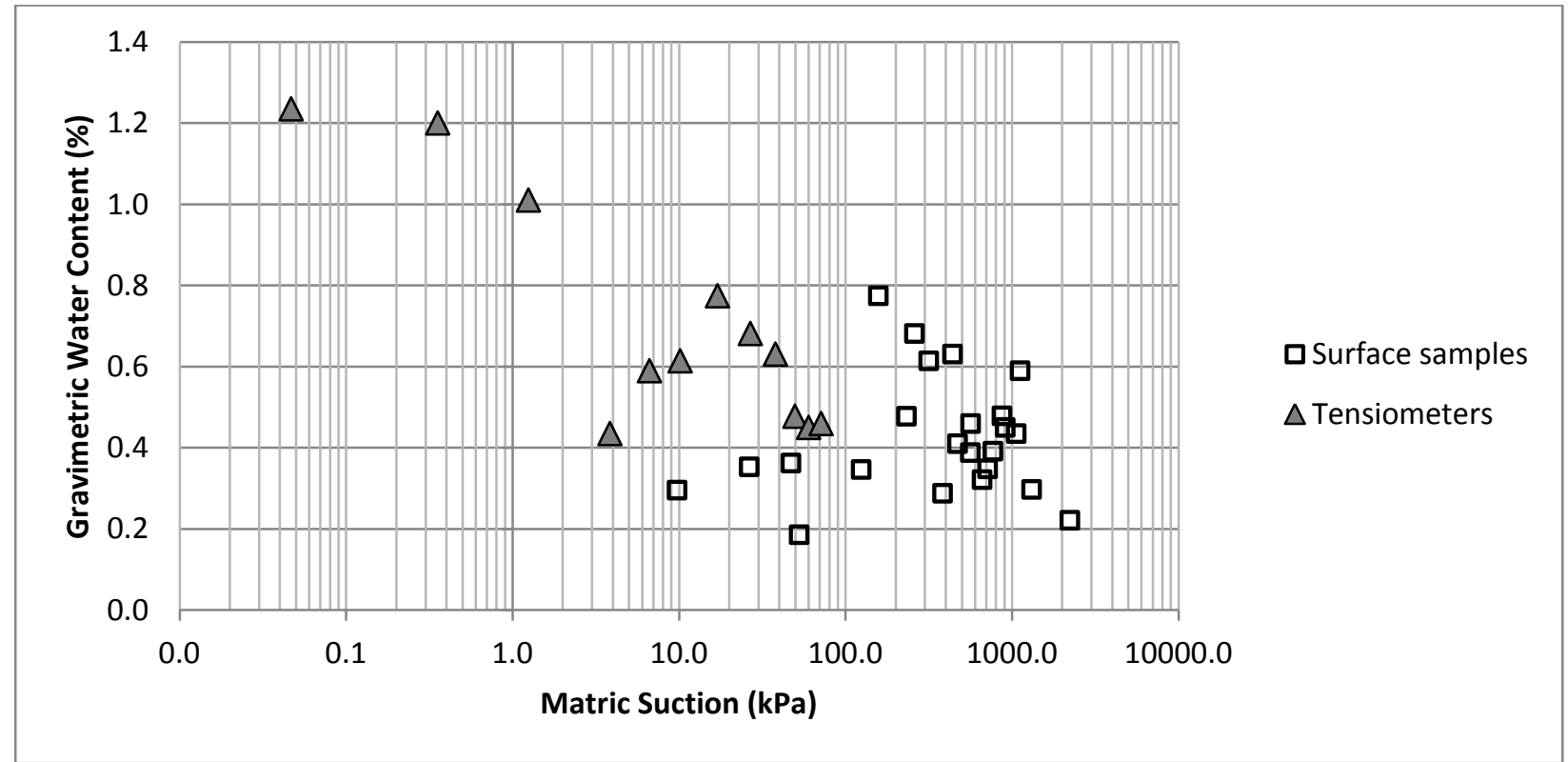

Figure 4.5-5. SWCC in terms of GWC and matric suction for thick lift dry box 
Figure 4.5-6 is a relationship of SC to matric or total suction from surface samples obtained from the field. These samples are compared to the SC to suction relationship at the surface from Layer 1 of the thin lift dry box. In the dry box, the GWC values were higher, because the layer was very dry. The corresponding values of total and matric suctions were smaller, however, the relationship follows a similar overall trend.

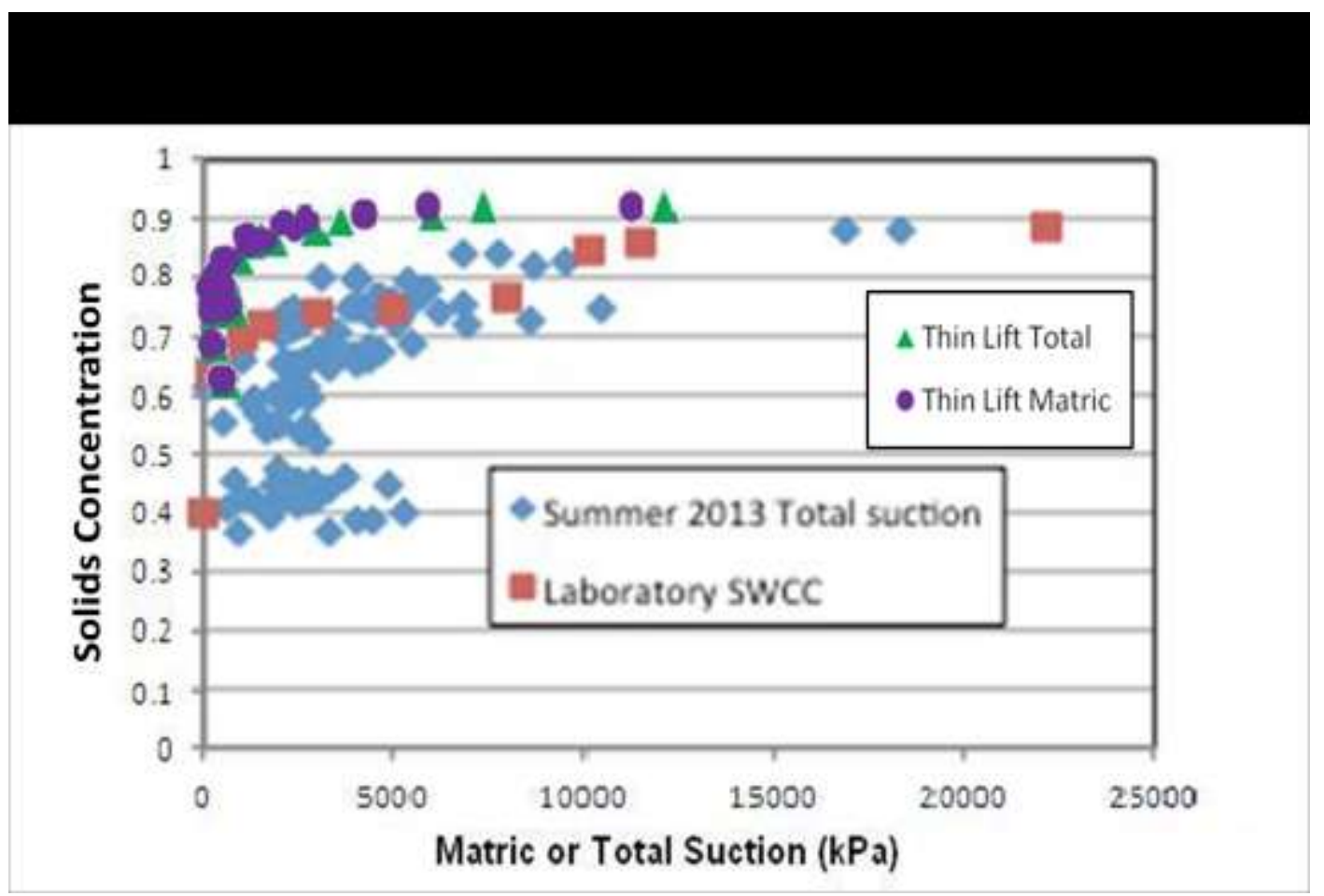

Figure 4.5-6. Comparison of SWCC from thin lift dry box experiment to field data

Figure 4.5-7 is also a comparison of field data to dry box results, this time for the Layer 1 of the thick lift dry box. This time, the surface samples were not so dry, and did not achieve very high values of suction. 


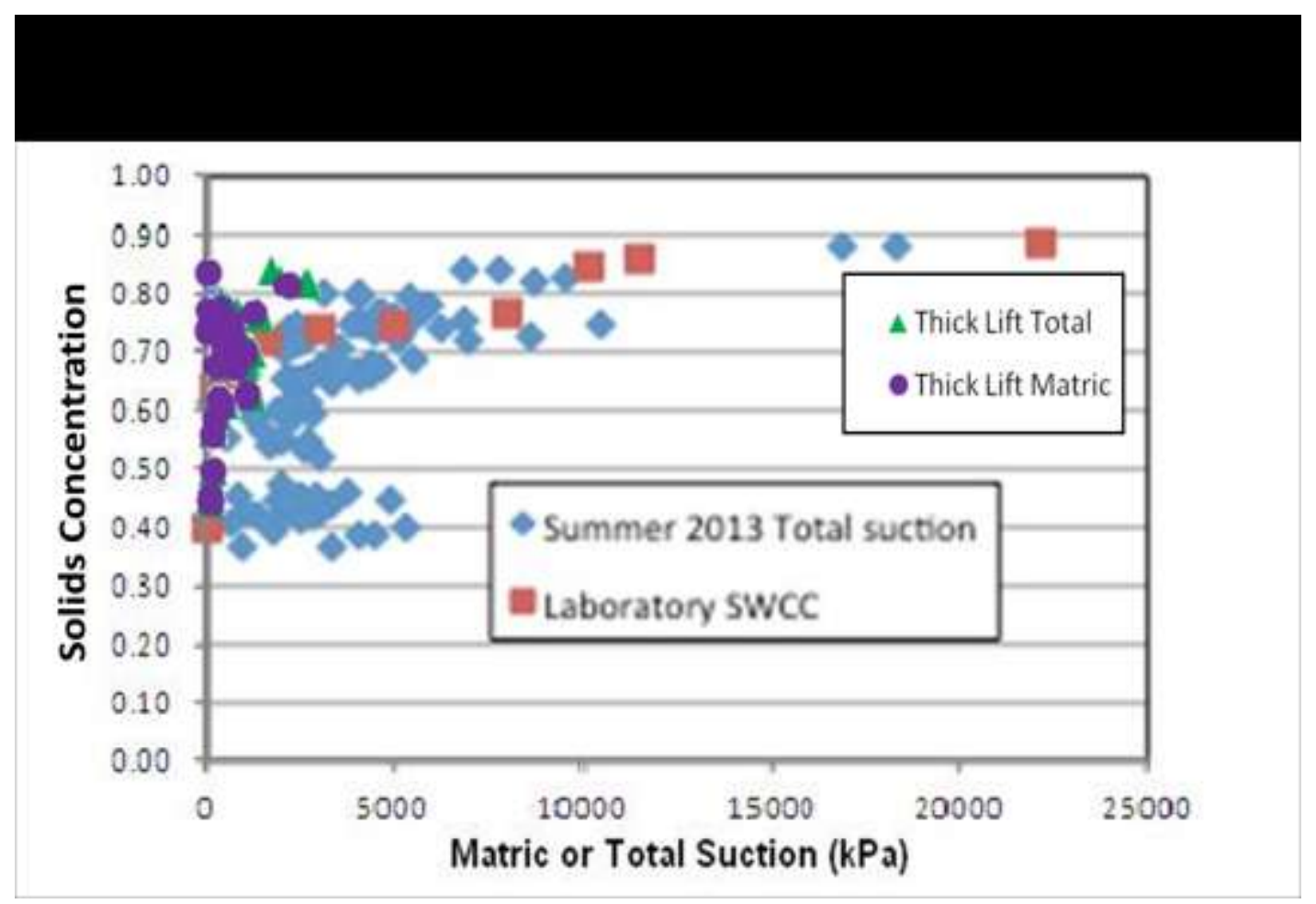

Figure 4.5-7. Comparison of SWCC from thick lift dry box experiment to field data

Unfortunately, the technique used to measure the total suction at these low GWC values provides unreliable results for the suction values. Only values $1 \mathrm{MPa}$ and greater provided reliable results. Therefore the AEV from the study conducted by Soleimani and Simms (2014) was used for estimated bearing capacity calculations.

Several tensiometers were installed at various intervals in the dry box to monitor the variation of matric suction in the tailings. Matric suction distribution profiles with depth are provided in sections 4.1 and 4.2 for thin and thick lift dry box experiments as the tailings became unsaturated.

The SWCC was established using the axis-translation method with volume change measurement for low suctions, and with the use of a dewpoint hygrometer to measure total suction in the high range by Soleimani and Simms (2014). According to Figure 4.5-8, the AEV is approximately $50 \mathrm{kPa}$ From the shrinkage curve shown in Figure 4.5-1, it is clear that there are two AEVs. The first is at a void ratio of 1.8 , and the 
second at a value of 1.2. Referring to the curve from Soleimani and Simms (2014), the inference is that the AEV is either less than $20 \mathrm{kPa}$ or between 100 and $150 \mathrm{kPa}$.

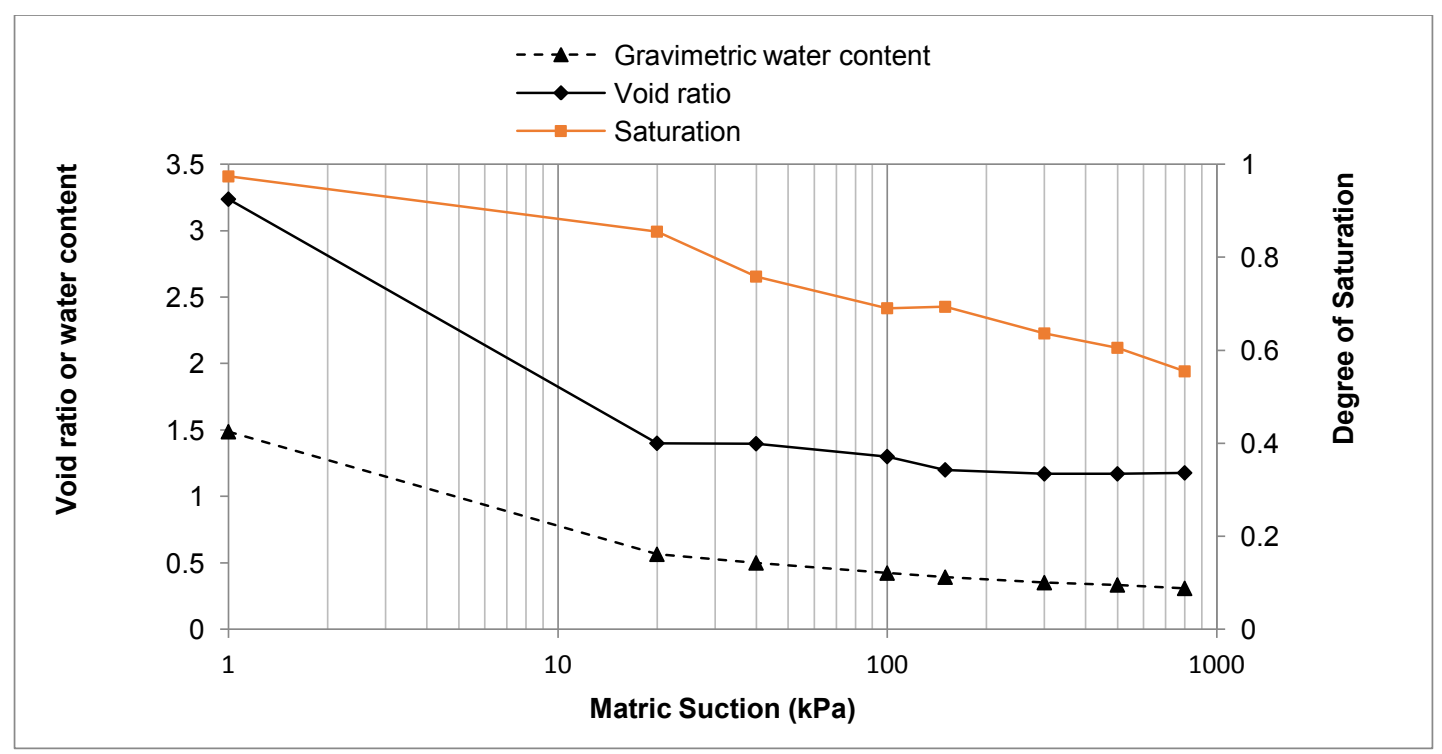

Figure 4.5-8. SWCC for oil sands tailings (Soleimani and Simms, 2014)

\subsubsection{SWCC - Degree of Saturation versus Suction}

Figure 4.5-9 shows the SWCC in terms of degree of saturation to total/matric suction for the thin lift experiment. The matric suction from the surface samples in these figures is obtained by subtracting the osmotic suction values shown in section 4.1 from the total suctions. The other set of matric suction data is collected by the tensiometers. 


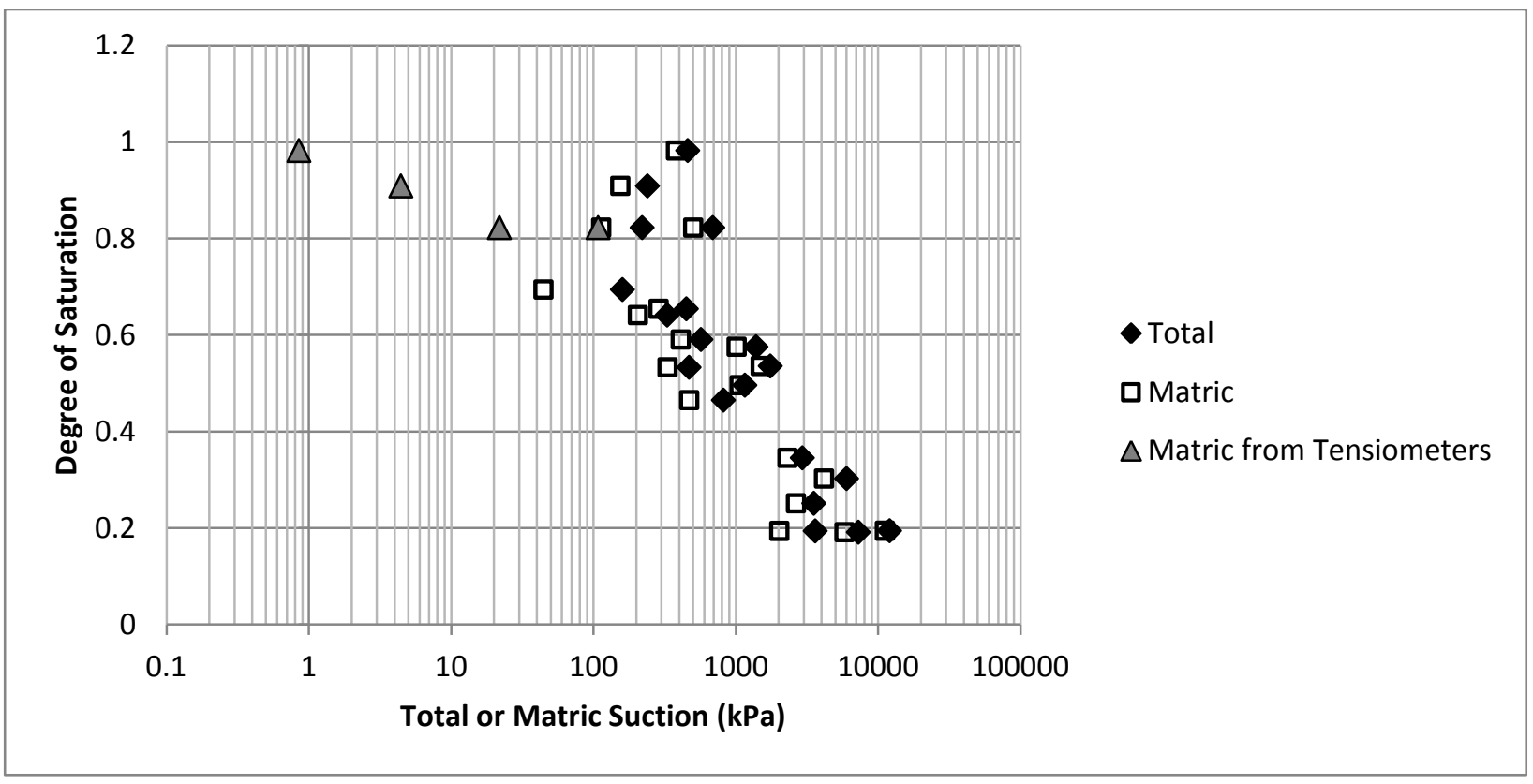

Figure 4.5-9. SWCC in terms of degree of saturation for thin lift dry box

Figure 4.5-10 presents the same relationship, for the thick lift dry box. Both sets of measurements are for Layer 1.

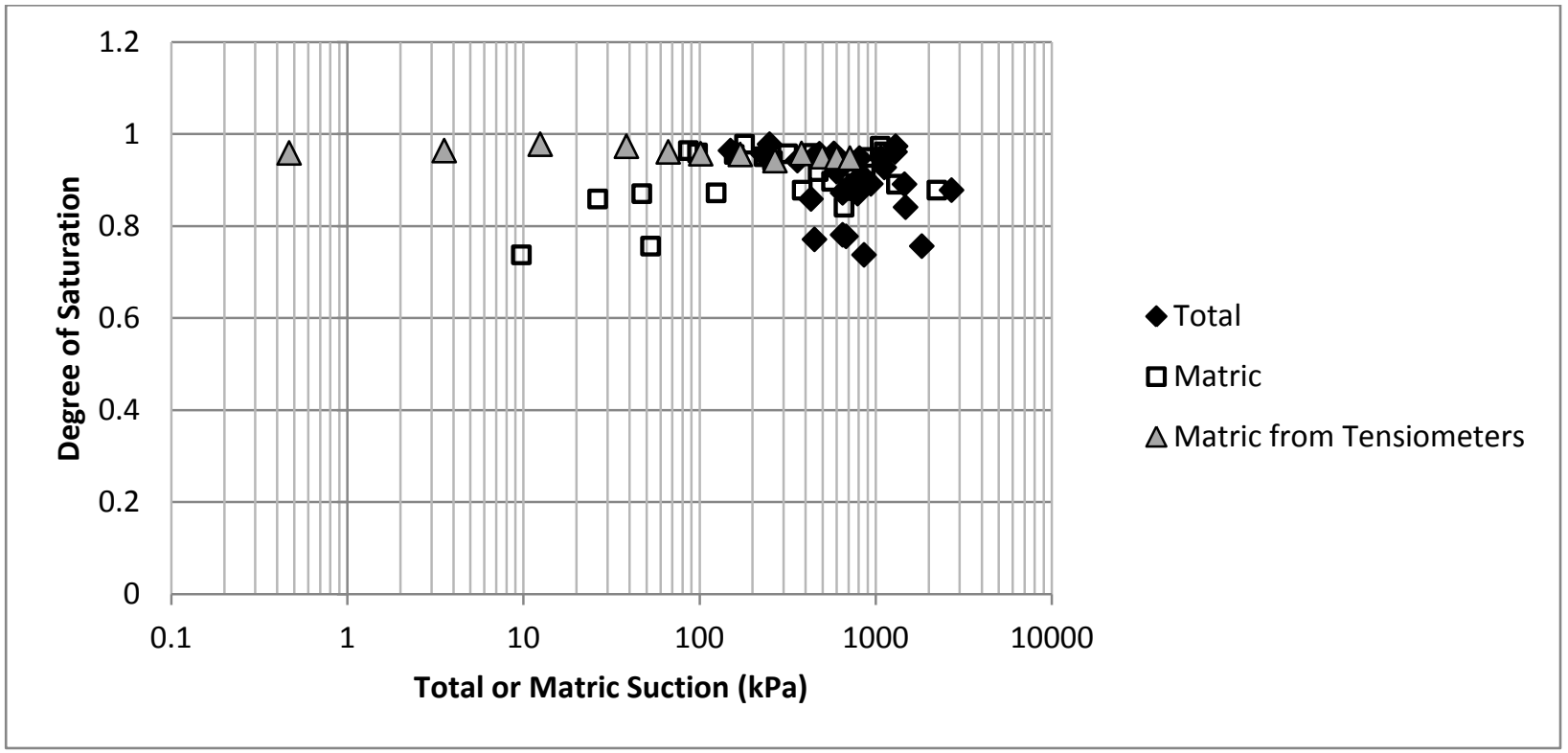

Figure 4.5-10. SWCC in terms of degree of saturation for thick lift dry box 


\subsubsection{Estimation of Bearing Capacity}

The tailings used in the present study were assumed to have a cohesion value of zero degrees, and a friction angle of 30 degrees (Qiu and Sego, 2001).

From the soil water characteristic curve, the AEV of these tailings is approximately $125 \mathrm{kPa}$.

\subsubsection{Thin Lift Dry Box}

The bearing capacity was estimated using the TSA, ESA, and MESA methods (equations 15, 19 and 20). The bearing capacity was estimated without the contribution of matric suction and with it for Layer 3 at $60 \%$ SC and $70 \%$ SC respectively. The reduction factor approach, (equations 22 and 23), was also applied to the MESA to account for punching shear failure. This approach was used to account for the observations made during the plate load test (section 4.6), where the plate load punched through the top layer and into the weaker bottom layer, and the result of ultimate load was not well defined. The values obtained are shown in Table 4.5-1.

The average matric suction was obtained by calculating the matric suction at the centroid of the matric suction profile, as described in section 2.9.3.1. The matric suction profiles for the thin lift dry box were obtained using tensiometer data and are shown in Figure 4.1-90. The reduction factor approach was also applied to the MESA values in the last column.

For the thin lift dry box, the contribution of matric suction increased the estimated bearing capacity significantly in both cases. With $60 \%$ SC, the bearing capacity was increased by nearly $30 \%$ compared to the value without the contribution of matric suction (ESA). In the case of $70 \% \mathrm{SC}$, the contribution was even greater, resulting in $138.25 \mathrm{kPa}$ as opposed to $8.39 \mathrm{kPa}$ without considering matric suction. 
Table 4.5-1. Bearing capacity estimates - Thin lift dry box

\begin{tabular}{|c|c|c|c|c|c|c|c|c|}
\hline \multirow[b]{2}{*}{ SC (\%) } & \multirow[b]{2}{*}{ GWC(\%) } & \multirow[b]{2}{*}{$\begin{array}{c}\text { Degree of } \\
\text { Saturation } \\
\text { (from Dry } \\
\text { Box) }\end{array}$} & \multirow[b]{2}{*}{$\begin{array}{c}\text { Unit } \\
\text { Weight } \\
\left(\mathrm{kN} / \mathrm{m}^{3}\right)\end{array}$} & \multirow[b]{2}{*}{$\begin{array}{c}\text { Average } \\
\text { Matric } \\
\text { suction } \\
(\mathrm{kPa})\end{array}$} & \multicolumn{4}{|c|}{ Estimated Bearing Capacity (kPa) } \\
\hline & & & & & TSA & ESA & MESA & $\begin{array}{l}\text { MESA with reduction } \\
\text { factors }\end{array}$ \\
\hline 60 & 66.7 & 0.802 & 12.5 & 0.9 & 36.84 & 8.96 & 27.17 & 12.12 \\
\hline 70 & 42.9 & 0.515 & 13.4 & 6.1 & 78.29 & 8.39 & 138.25 & 69.05 \\
\hline
\end{tabular}

\subsubsection{Thick Lift Dry Box}

The bearing capacity for the thick lift dry box at $60 \%$ SC and $55 \%$ SC was estimated without the contribution of matric suction and with it, using the same equations as for the thin lift dry box. Punching shear failure was again observed during the plate load tests, therefore the reduction method was also applied to the MESA. The values obtained are shown in Table 4.5-2.

The average matric suction was obtained by calculating the matric suction at the centroid of the matric suction profile, as described in section 2.9.3.1. The matric suction profiles for the thick lift dry box were obtained using tensiometer data and are shown in Figure 4.2-75.

For the thick lift dry box, the contribution of matric suction also increased the estimated bearing capacity significantly in both tested cases. In the thick lift test, the plate load test was conducted once the first layer had reached $60 \% \mathrm{SC}$, and once the second layer reached $55 \%$ SC. With $60 \%$ SC in Layer 1 , the bearing capacity was increased by $82 \%$ compared to the value without the contribution of matric suction. In the case of Layer 2 at $55 \%$ SC, the bearing capacity increased by $85 \%$ once the contribution of matric suction was taken into account. 
Table 4.5-2. Bearing capacity estimates - Thick lift dry box

\begin{tabular}{|c|c|c|c|c|c|c|c|c|}
\hline \multirow[b]{2}{*}{ Layer } & \multirow[b]{2}{*}{ GWC(\%) } & \multirow[b]{2}{*}{$\begin{array}{c}\text { Degree of } \\
\text { Saturation } \\
\text { (\%) }\end{array}$} & \multirow[b]{2}{*}{$\begin{array}{c}\text { Unit } \\
\text { Weight } \\
\left(\mathrm{kN} / \mathrm{m}^{3}\right)\end{array}$} & \multirow[b]{2}{*}{$\begin{array}{c}\text { Average } \\
\text { Matric } \\
\text { suction } \\
\text { (kPa) }\end{array}$} & \multicolumn{4}{|c|}{ Estimated Bearing Capacity (kPa) } \\
\hline & & & & & TSA & ESA & MESA & $\begin{array}{l}\text { MESA with reduction } \\
\text { factors }\end{array}$ \\
\hline 1 & 66.7 & 0.709 & 11.6 & 2.9 & 55.26 & 8.52 & 69.71 & 33.98 \\
\hline 2 & 81.8 & 0.835 & 12.9 & 4.0 & 49.12 & 9.11 & 93.83 & 46.20 \\
\hline
\end{tabular}

\subsection{Plate Load Test Results}

Plate load tests were undertaken for both dry box experiments once the tailings had reached undrained shear strength of at least $5 \mathrm{kPa}$. The results are presented in this section.

\subsubsection{Thin Lift Dry Box}

As shown in Figures 4.6-1 and 4.6-2, the material was found to fail in the "punching shear" mode in the attempted tests, similar to an unsaturated fine-grained soil (Oh and Vanapalli, 2013). 


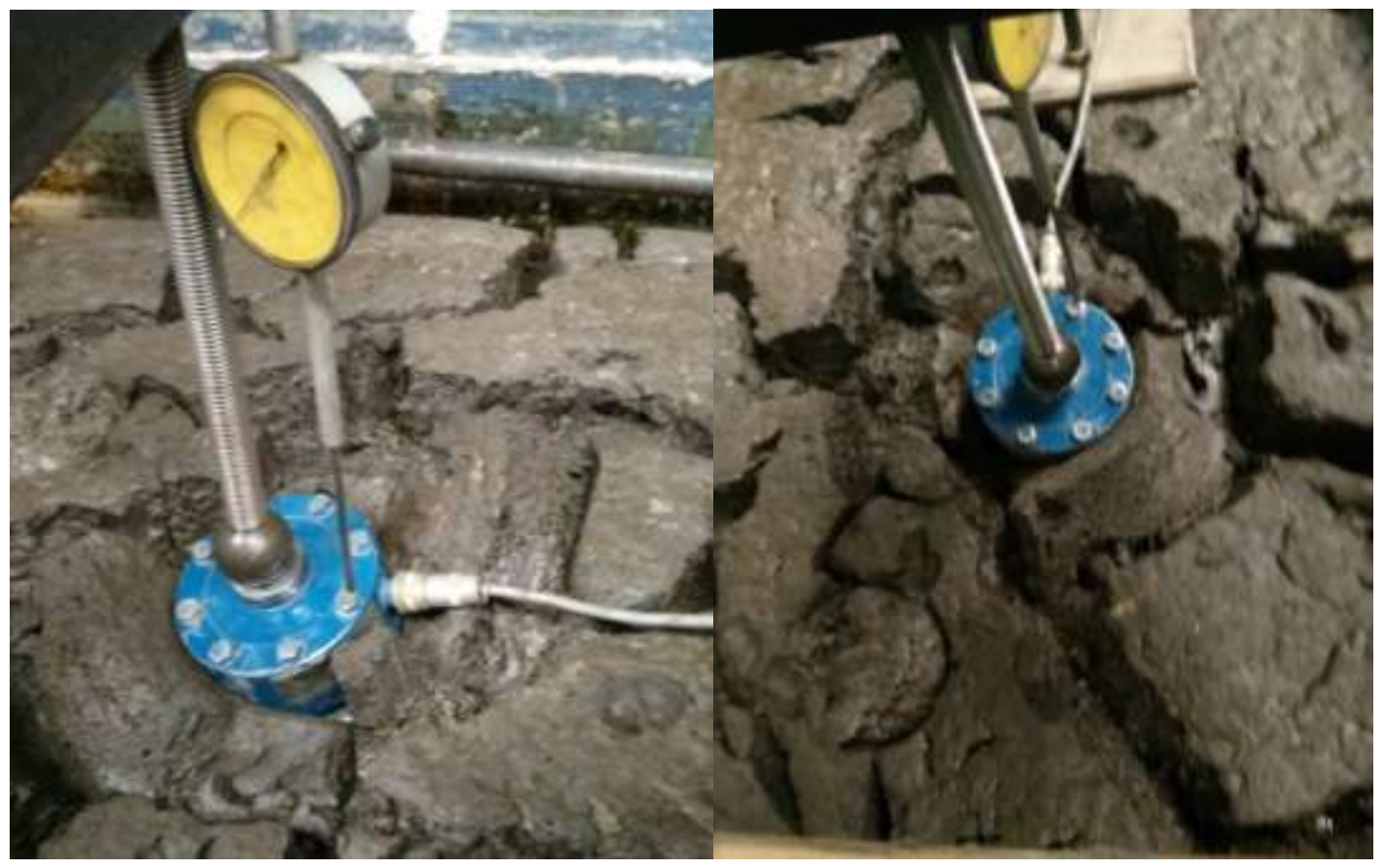

Figure 4.6-1 "Punching Shear" failure mechanism after the $60 \%$ SC bearing capacity test on Thin Lift box

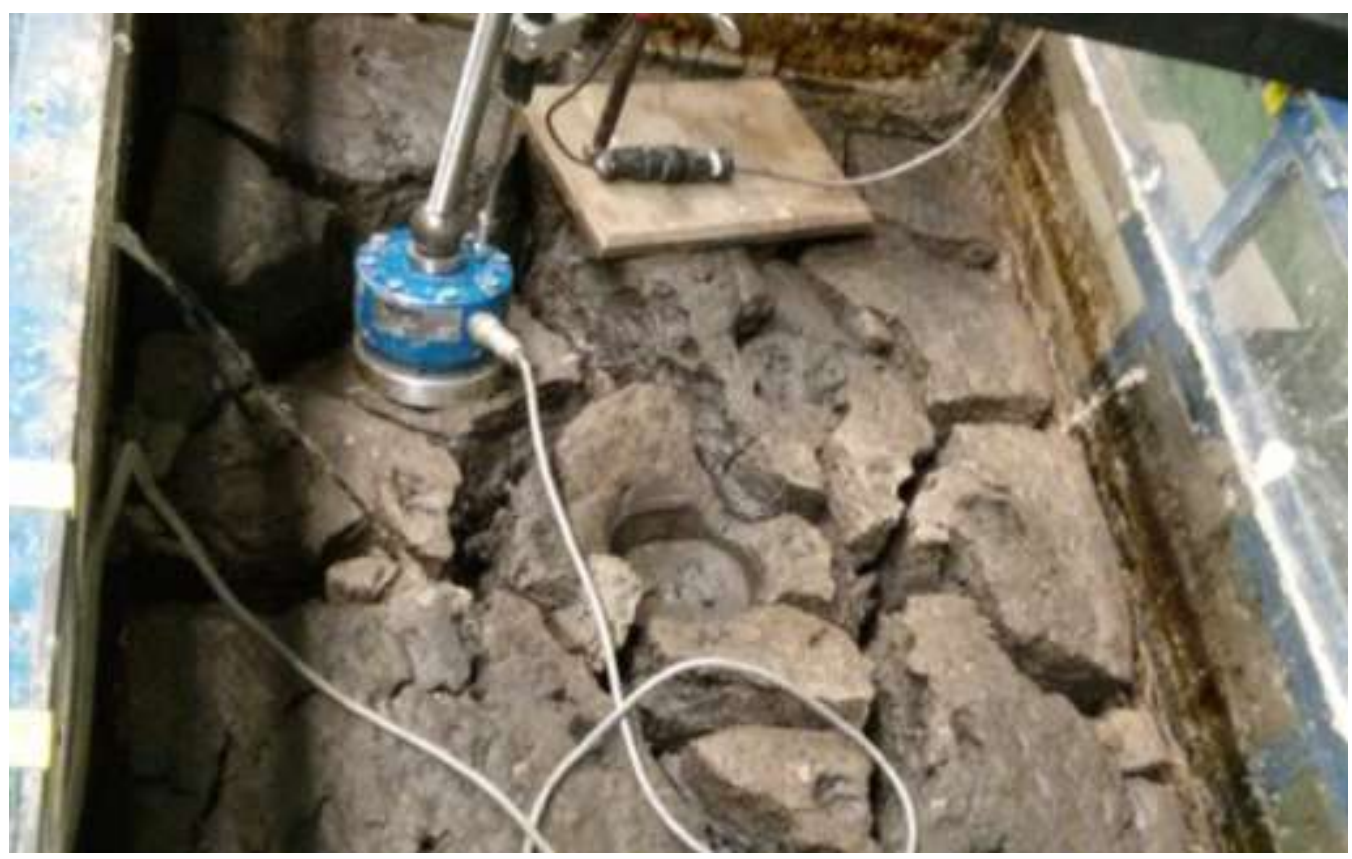

Figure 4.6-2. Failure after the $70 \%$ SC bearing capacity test on Thin Lift box 
The results for each of the plate load tests for the thin lift dry box are shown in Figure 4.6-3 below. All tests completed on the thin lift dry box were conducted once the third layer had reached the SCs shown. The shape of the load versus settlement figure, the indentations in Figure 4.6-3, and the picture in Figure 4.6-1 taken right after failure demonstrate punching shear failure (Vesic 1973).

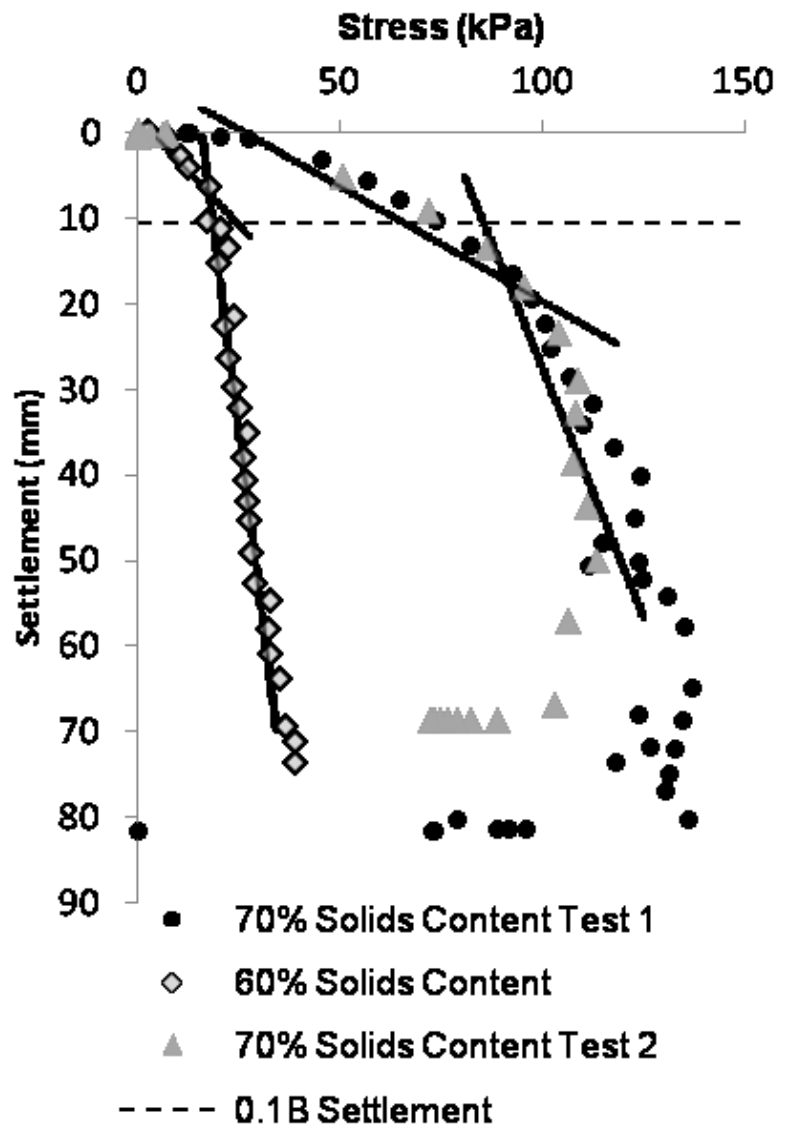

Figure 4.6-3. Plate load test results for thin lift dry box

Where the point of failure of the soil is ambiguous, the ultimate bearing capacity can be estimated as the stress coinciding with either: 
1) A settlement corresponding to $10 \%$ of the footing width (0.1B settlement method) (Cerato and Lutenegger 2007; Oh and Vanapalli 2013); or

2) The intersection of the tangents to the initial and latter portions of the stress-settlement curve (slope tangent method) (Consoli et al. 1998; Costa et al. 2003; Oh and Vanapalli 2013).

According to the $0.1 \mathrm{~B}$ settlement method, the bearing capacity from these plate load tests is approximately $18 \mathrm{kPa}$ for $60 \% \mathrm{SC}$ and $82 \mathrm{kPa}$ for $70 \% \mathrm{SC}$ which are almost in agreement the estimated bearing capacities considering the contribution of matric suction as summarized in Table 4.6-1. From the same table, it can be seen that the estimate considering the contribution of matric suction is in more agreement to the values from the plate load tests.

As shown in Figure 4.6-3, the slope tangent method, corresponding to a value of approximately $20.7 \mathrm{kPa}$, is also in agreement with the estimated bearing capacity considering the contribution of matric suction at $60 \%$ SC, . However, this method overestimates the bearing capacity at $70 \%$ as shown in Figure $4.6-3$, corresponding to a value of approximately $100 \mathrm{kPa}$.

Table 4.6-1. Summary of experimental bearing capacity values for Thin Lift Dry Box

\begin{tabular}{cccc}
\hline $\begin{array}{c}\text { Solids Content } \\
(\%)\end{array}$ & $\begin{array}{c}\text { Gravimetric Water } \\
\text { Content (\%) }\end{array}$ & $\begin{array}{c}\text { 0.1B Settlement Method } \\
\mathbf{( k P a )}\end{array}$ & $\begin{array}{c}\text { Slope Tangent Method } \\
\mathbf{( k P a )}\end{array}$ \\
\hline 60 & 66.7 & 18 & 21 \\
70 & 42.9 & 82 & 100 \\
\hline
\end{tabular}




\subsubsection{Thick Lift Dry Box}

For thick lift layers, it was found that the crust had to be drier than that of the thin lift layers before the top layer achieved the same SC. For instance at $60 \%$ SC for a 30 $\mathrm{cm}$ layer, the GWC measured at the surface was in the range of $27.8-52 \%$, while the surface GWC for a $50 \mathrm{~cm}$ layer that had reached the same SC was in the range of 15.4$22.7 \%$. This is demonstrated in the core samples in section 4.2 . The core samples also show that for the thin layer, the GWC is more uniform with depth, while the thick layer samples are drier at the surface, and become wetter at greater depths. The failure of the tailings deposited in a $50 \mathrm{~cm}$ lift and dried to $60 \%$ SC is shown in Figure $4.6-4$.

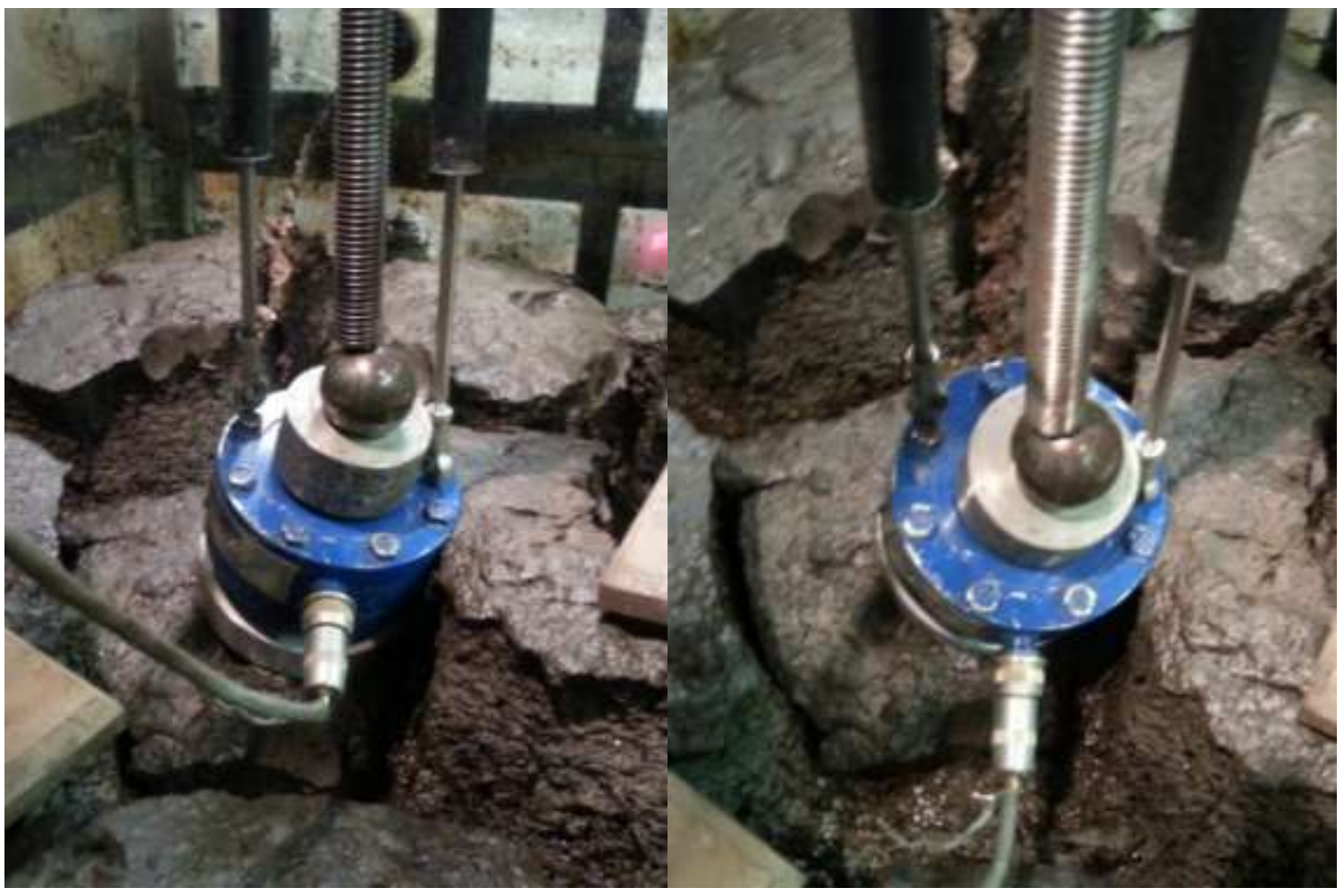

Figure 4.6-4 Failure after the $60 \%$ SC bearing capacity test on Thick Lift box Layer 1 
The results for each of the plate load tests for the thick lift dry box are shown in Figure 4.6-5 below. The shapes of the load versus settlement curves are similar to the thin lift test at $70 \%$ SC, even though all the tests for the thick lift dry box were conducted once the top layer had reached $55-60 \%$ SC.

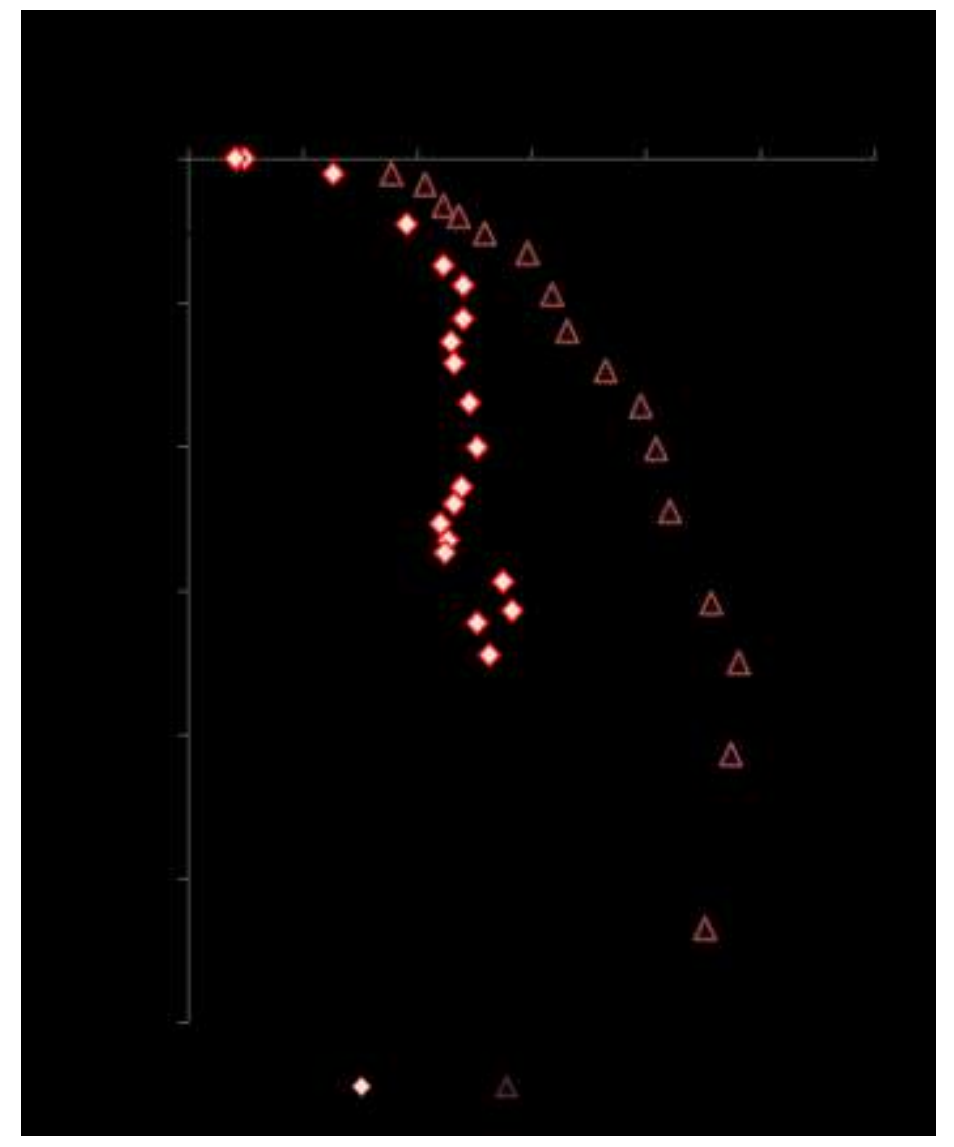

Figure 4.6-5. Plate load test results for thick lift dry box

According to the $0.1 \mathrm{~B}$ settlement method, the bearing capacity from these plate load tests is approximately $39 \mathrm{kPa}$ for layer 1 at $60 \% \mathrm{SC}$ and $53 \mathrm{kPa}$ for layer 2 at $55 \%$ SC which are almost in agreement the estimated bearing capacities considering the contribution of matric suction as summarized in Table 4.6-2. From the same table, it can 
be seen that the estimate considering the contribution of matric suction is in more agreement to the values from the plate load tests.

As shown in Figure 4.6-5, using the slope tangent method results in a bearing capacity of $40 \mathrm{kPa}$ for layer 1 and $60 \mathrm{kPa}$ for layer 2.

Table 4.6-2. Summary of experimental bearing capacity values for Thick Lift Dry Box

\begin{tabular}{ccccc}
\hline Layer & $\begin{array}{c}\text { Solids } \\
\text { Content (\%) }\end{array}$ & $\begin{array}{c}\text { Gravimetric } \\
\text { Water Content }\end{array}$ & $\begin{array}{c}\text { 0.1B Settlement } \\
\text { Method (kPa) }\end{array}$ & $\begin{array}{c}\text { Slope Tangent } \\
\text { Method (kPa) }\end{array}$ \\
\hline 1 & 60 & 66.7 & 39 & 40 \\
2 & 55 & 81.8 & 53 & 60 \\
\hline
\end{tabular}

A comparison between estimated and measured values is provided in Figure 4.66. Results comparing the MESA and TSA are only shown. The ESA was found to significantly underestimate the bearing capacity in all cases. 


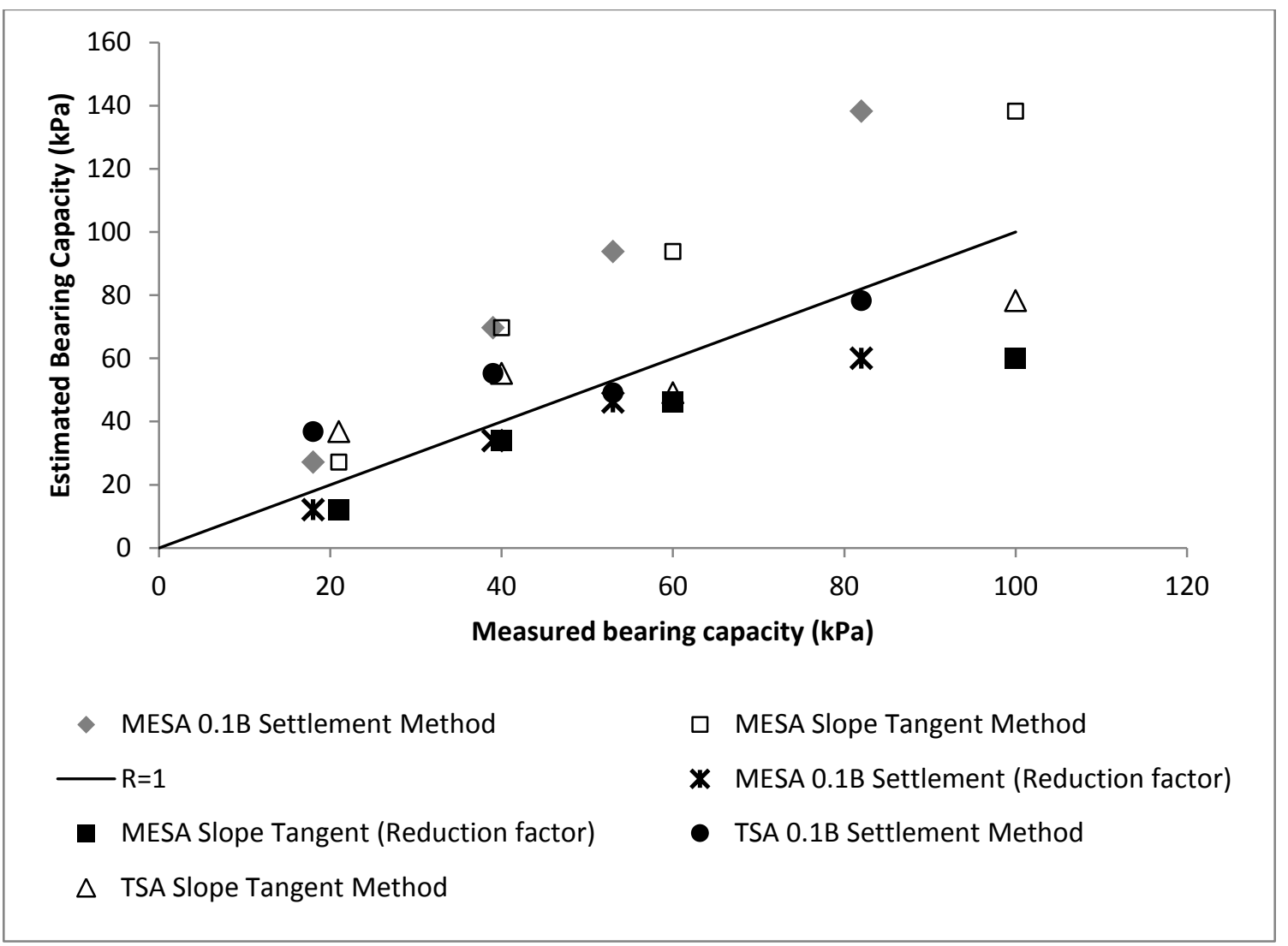

Figure 4.6-6. Comparison of estimated and measured bearing capacity values

There is more variance between measured and estimated values at greater suctions. The reduction factor method and TSA provided the best agreement with measured values, while the MESA overestimated the bearing capacity when compared to measured values using both the $0.1 \mathrm{~B}$ settlement and slope tangent methods. The measured values are compared to a wheel load from earth moving equipment in the next section.

\subsubsection{Trafficability}

Trafficability bearing capacity is focused on the capability of the soil to support the vehicle without significant settlement. Trafficability traction capacity is the resistance between the wheels of the vehicle and the soil required to develop the forward thrust to overcome the rolling resistance. The combination of these capacities is considered to 
be adequate trafficability for a given vehicle, as discussed in Chapter 2. (Lutton et al, n.d.). Similar to the assumption made in Chan and Law's (2006) study, trafficability was considered to solely depend on bearing capacity in the early stage.

The wheel load of a vehicle was estimated using the process described by Tannant and Regensburg (2001). The wheel load can be calculated using manufacturer's specifications. To determine wheel load, the loaded vehicle weight over each axle should be divided by the number of tires on that axle, and the greatest wheel load should be used in design applications. For wheels mounted on tandem axles, the wheel load should be increased by $20 \%$ (Kaufman and Ault, 1977).

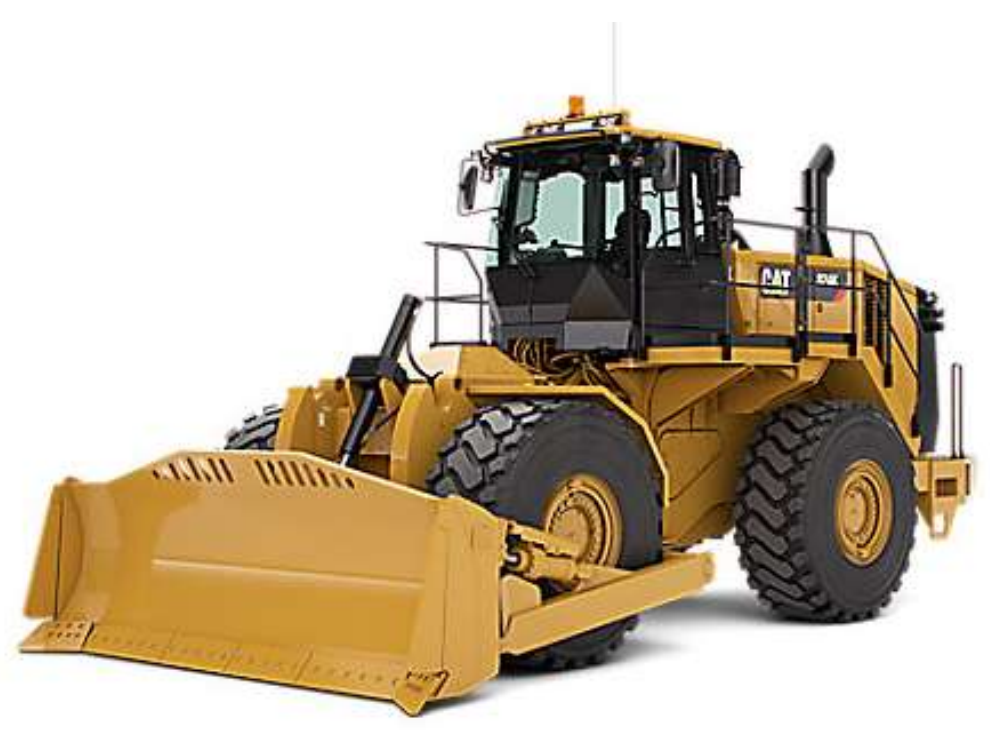

Figure 4.6-7. Caterpillar 824K medium wheel dozer

The bearing capacity results were compared to the wheel load of a Caterpillar $824 \mathrm{~K}$ medium wheel dozer, shown in Figure 4.6-6. The operating weight of this machine is $34004 \mathrm{~kg}$, resulting in a $73.8 \mathrm{kPa}$ stress exerted by each tire.

In this study, bearing capacity tests were done once the tailings had reached an undrained shear strength of $5 \mathrm{kPa}$ or higher, which for the ERCB regulations are considered to be "on the road" to trafficability. The percentage of the wheel load of the 
Caterpillar $824 \mathrm{~K}$ that these tailings would be able to support based on these tests are shown in Table 4.6-3.

Table 4.6-3. Comparison of plate load tests to $824 \mathrm{~K}$

\begin{tabular}{cccccc}
\hline Test & $\begin{array}{c}\text { Solids } \\
\text { Content } \\
\mathbf{( \% )}\end{array}$ & $\begin{array}{c}\text { 0.1B Settlement } \\
\text { Method } \\
\mathbf{( k P a )}\end{array}$ & $\begin{array}{c}\text { \% of 824K } \\
\text { wheel load }\end{array}$ & $\begin{array}{c}\text { Slope Tangent } \\
\text { Method } \\
\mathbf{( k P a )}\end{array}$ & $\begin{array}{c}\text { \% of 824K } \\
\text { wheel load }\end{array}$ \\
\hline Thin Layer 3 & 60 & 18 & 24.4 & 21 & 28.5 \\
Thin Layer 3 & 70 & 82 & 100 & 100 & 100 \\
Thick Layer 1 & 60 & 39 & 52.8 & 40 & 54.2 \\
Thick Layer 2 & 55 & 53 & 71.8 & 60 & 81.3 \\
\hline
\end{tabular}

From this table, once the third layer of flocculated oil sands tailings in thin lifts $(30 \mathrm{~cm})$ reach $60 \%$ SC and undrained shear strengths of $5 \mathrm{kPa}$, and are considered "on the road" to trafficability, they are only able to support approximately $24.4 \%$ of a $824 \mathrm{~K}$ dozer. Once the same tailings reach $70 \%$ SC, and an even greater undrained shear strength at the surface, this percentage increases by approximately $75 \%$, resulting in the support of $100 \%$ of the same vehicle.

In the case of the thick lift, the second layer is seen to have the capability of supporting a greater percentage of the dozer. Layer 1, at $60 \%$ SC, can support approximately a maximum of $52.8 \%$ of the dozer, while Layer 2 , at the same SC can support $71.8 \%$, resulting in an increase of $18 \%$.

\subsubsection{Implications for the Industry}

There are several factors that limit the extension of these bearing capacity results to the field as presented in section 4.6.3. These factors include: footing size, and shape, cracking, and environmental considerations. 
The load used in the bearing capacity test was circular, with a $10.5 \mathrm{~cm}$ diameter. In the field, the load would originate from earthmoving equipment, such as the wheel dozer discussed in section 4.6.3. A wheel load would be larger and elliptical in shape. For instance, if the contact area of a dozer wheel is simplified to dimensions of $255 \mathrm{~mm}$ $x 635 \mathrm{~mm}$, and the matric suction profiles shown in sections 4.1 and 4.2 are extended to an effective area of $1.5 \mathrm{~B}$, constructed from the SWCC shown in section 4.5 , the resulting bearing capacities are shown in Table 4.6-4 for each case.

Table 4.6-4. Bearing capacity estimates for dozer wheel

\begin{tabular}{|c|c|c|c|c|c|c|}
\hline \multirow[b]{2}{*}{ Case } & \multirow[b]{2}{*}{$\begin{array}{c}\text { Unit } \\
\text { Weight } \\
\left(\mathrm{kN} / \mathrm{m}^{3}\right)\end{array}$} & \multirow[b]{2}{*}{$\begin{array}{c}\text { Average Matric } \\
\text { suction } \\
(\mathrm{kPa})\end{array}$} & \multicolumn{4}{|c|}{ Estimated Bearing Capacity (kPa) } \\
\hline & & & TSA & ESA & MESA & $\begin{array}{l}\text { MESA with } \\
\text { reduction } \\
\text { factors }\end{array}$ \\
\hline Thin Lift 60\%SC & 12.5 & 0.75 & 33.3 & 36.3 & 42.9 & 16.0 \\
\hline Thin Lift $70 \%$ SC & 13.4 & 6.0 & 70.8 & 34.0 & 153.8 & 73.1 \\
\hline Thick Lift $60 \%$ SC & 11.6 & 2.1 & 50.0 & 34.5 & 70.5 & 30.4 \\
\hline Thick Lift 55\%SC & 12.9 & 3.1 & 44.4 & 36.9 & 93.7 & 41.9 \\
\hline
\end{tabular}

The only case where the bearing capacity estimate is lower than the laboratory plate is the TSA. The calculated average matric suction is also lower, since the effective depth is greater. This would decrease the influence of matric suction on the bearing capacity. Overall, however, the values obtained from the MESA are higher than for the test plate due to the shape.

The stress bulbs are different when loads are applied to different footing sizes, and the stress bulb for a smaller footing is shallower than that of a larger footing. (Oh and Vanapalli, 2013). If the matric suction were uniform over depth, the value for the average matric suction would not be affected, but since the matric suction profile is not uniform, the average matric suction depends on the footing size. Additionally, for a 
wheel load, the tire footprint area, load per tire, and tire pressure, are all factors that determine the stress distribution in the soil under the tire. This factor poses a limitation on the extension of laboratory results to the field.

The influence of cracking on the bearing capacity must also be taken into account. In the dry box, bearing capacity tests were carried out on a crack island, where the plate was placed so as not to be on top of any cracks. In the field however, it is impossible to avoid placing wheel loads over cracks. Lozada et al. (2015) found that the crack depths have an influence on the bearing capacity failure mechanisms. The study found that the highest bearing capacity was demonstrated by a sample with cracks $5 \mathrm{~m}$ deep and was lowest when cracks were $8 \mathrm{~m}$ deep. The sample with no cracks attained values in the middle. All of these cases, however, demonstrated different mechanism failures (Figure 4.6.8). The crack-free surface experienced a failure of a shallow circular footing, and the $5 \mathrm{~m}$ and $8 \mathrm{~m}$ crack experienced shear failure of the column and failure of the soft soil, respectively. However, the desiccation in the cracks was shown to increase bearing capacity (Lozada et al., 2015).

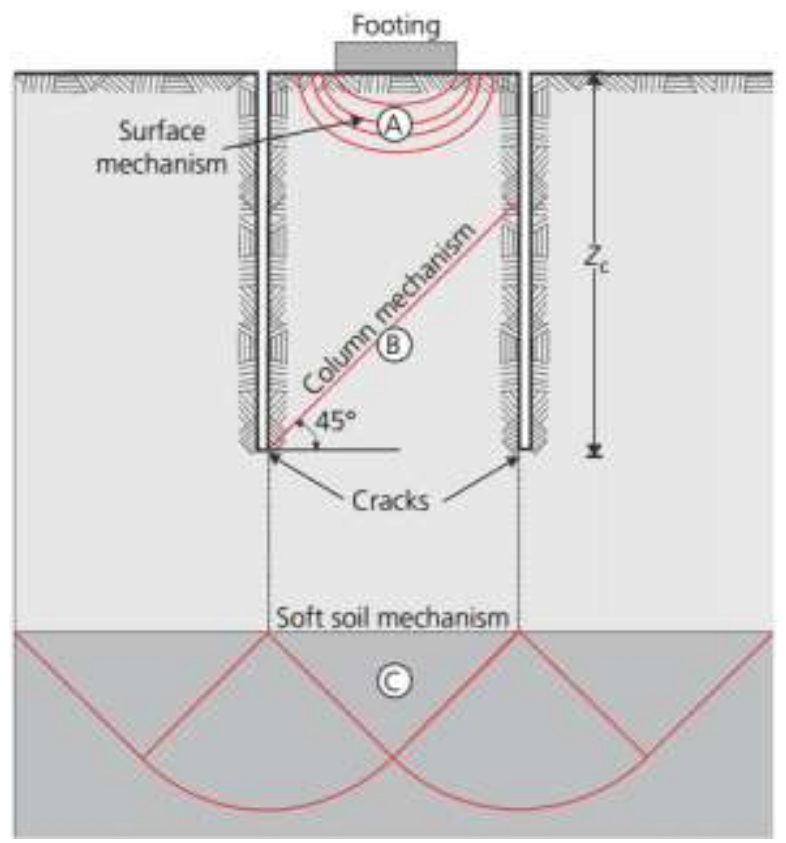

Figure 4.6-8. Cracking and bearing capacity failures (Lozada et al., 2015) 
An environmental factor that could influence the bearing capacity of unsaturated soil is rainfall. Rain fall could change the water table, which has a significant effect on the bearing capacity of a soil. A water table at a depth less than the width of the footing will reduce the bearing capacity. Furthermore, negative pore-water pressure will dissipate with the infiltration of rain, therefore the matric suction would dissipate. In terms of the bearing capacity calculation, the matric suction component would be set to zero, also reducing bearing capacity. 


\section{CONCLUSIONS}

Oil sands tailings management is a great challenge in the mining industry, since the tailings exhibit poor consolidation and settling properties when conventional deposition methods are used. The objectives of this research were gain an in-depth understanding of the dewatering behavior of in-line multi-layer deposits, and to study the bearing capacity of these tailings.

In order to meet these objectives, the following laboratory work was carried out; polymer amended MFT that imitates field samples was generated and two dry box tests: thin $(0.30 \mathrm{~m})$ and thick $(0.50 \mathrm{~m})$ layer multilayer deposition dry box tests were performed. The goal of the dry box testing was to study how dewatering behaviors progress as layers are dried and more layers are added, and how cracking influences the evaporation rates in these tests. Core samples were extracted before the addition of each layer in each dry box experiment to investigate the history of dewatering with respect to GWC, total suction, osmotic suction, and TOC. Thin lift and thick lift core sample results were compared. Shear strength and plate load tests were performed to determine undrained shear strength; and bearing capacity respectively between the additions of each new layer for each dry box test. Thin lift and thick lift strength results were also compared.

In terms of dewatering in the thin lift dry box, it was found that all three layers exhibited a consolidation phase, followed by a lag in dewatering due to the presence of supernatant water, followed by drying and crack development. Consolidation brought the top layer to about $53 \%$ solids. Consolidation was accelerated in the case of the second layer, due to the first layer having a low degree of saturation upon placement of the second layer. After crack initiation, AE increased substantially over the PE rate.

In terms of dewatering in the thick lift dry box, both layers exhibited similar phases to the thin lift dry box, but within a greater timeframe. Consolidation brought the top layer to approximately $50 \%$ SC. It took approximately 6 weeks for the top layer to achieve $60 \%$ SC in the top layers, which is twice as long as the necessary time in the thin lift dry box. 
Once results for overall dewatering were compared between the thin lift and thick lift dry box experiments, it was found that cracking was more advantageous in thin lift depositions.

For the bearing capacity tests conducted on the thin lift dry box, from the $0.1 \mathrm{~B}$ settlement method, the bearing capacity from these plate load tests was approximately $18 \mathrm{kPa}$ for $60 \%$ SC and $82 \mathrm{kPa}$ for $70 \%$ SC which are almost in agreement the estimated bearing capacities considering the contribution of matric. It was also seen that the estimate considering the contribution of matric suction is in more agreement to the values from the plate load tests. The slope tangent method, corresponded to a value of approximately $20.7 \mathrm{kPa}$, is also in agreement with the estimated bearing capacity considering the contribution of matric suction at $60 \%$ SC. However, this method overestimated the bearing capacity at $70 \%$ corresponding to a value of approximately $100 \mathrm{kPa}$.

For the bearing capacity tests conducted on the thick lift dry box, from the $0.1 \mathrm{~B}$ settlement method, the bearing capacity from these plate load tests is approximately 39 $\mathrm{kPa}$ for layer 1 and $53 \mathrm{kPa}$ for layer 2, both at $60 \%$ SC, which were almost in agreement the estimated bearing capacities considering the contribution of matric suction. From the The estimate considering the contribution of matric suction was also found to be in more agreement to the values from the plate load tests. Using the slope tangent method resulted in a bearing capacity of $40 \mathrm{kPa}$ for layer 1 and $60 \mathrm{kPa}$ for layer 2 .

The strong influence of matric suction on bearing capacity could imply two consequences. Firstly, dry weather will facilitate trafficability, but secondly, and more importantly, measuring undrained strength or bearing capacity in unsaturated deposits can over-predict the reliable long term bearing capacity of a deposit, as dissipation of suction will greatly lower strength.

The bearing capacity tests values were compared to the operating weight of a Caterpillar $824 \mathrm{~K}$ wheel dozer, which could be used in land reclamation applications. Once the third layer of flocculated oil sands tailings in thin lifts $(30 \mathrm{~cm})$ reach $60 \%$ SC and undrained shear strengths of $5 \mathrm{kPa}$, and are considered "on the road" to 
trafficability, they were only able to support approximately $24.4 \%$ of a $824 \mathrm{~K}$ dozer. Once the same tailings reach $70 \% \mathrm{SC}$, and an even greater undrained shear strength at the surface, this percentage increases by approximately $75 \%$, resulting in the support of $100 \%$ of the same vehicle. In the case of the thick lift, the second layer was seen to have the capability of supporting a greater percentage of the dozer. Layer 1 , at $60 \%$ SC, can support approximately a maximum of $52.8 \%$ of the dozer, while Layer 2 , at the same SC can support $71.8 \%$, resulting in an increase of $18 \%$. However, there are strict limitations that would impact this comparison, including footing size, shape and cracking. 


\section{RECOMMENDATIONS}

For the dewatering portion of the research, it would be beneficial to compare the dry box results to another dry box experiment, but this time to suppress cracking that may occur. Suppressing the cracks would help determine the extent to which cracking influences evaporation in terms of a percentage or fraction. The same mix of tailings would have to be achieved, in order to allow a good comparison. An effective method to suppress cracking would need to be developed, such as filling the cracks with a material that would prevent evaporation in the cracks only.

The drainage system in the dry box should be replaced in order to simulate field conditions more accurately. In the current study, it was found that the valve could be clogged up, or precipitates would form around it, limiting drainage. The bottom of the box could be replaced by a grid system. This could have the potential to increase the amount of drainage as well.

In terms of bearing capacity, the research presented in this thesis is only a beginning. Since there was a limited amount of crack island formation in each box (i.e. crack islands that did not touch the edge of the box), plate load tests were only conducted once for each situation presented in the thesis. It would be useful to be able to repeat the tests multiple times for each situation to ensure accurate results.

Tests to determine the strength parameters (cohesion and friction angle) specific for these tailings should also be carried out in order to validate the results.

Plate load tests should also be carried out in the field and compared with laboratory results. Plates that are more representative of the earthmoving equipment (same scale). The size of the plate can have a significant effect on the bearing capacity as shown in the study conducted by Oh and Vanapalli (2013). The effect of the plate size should be investigated in the case of oil sands tailings. 


\section{REFERENCES}

Adams, M. T., and Collin, J. G. (1997). Large model spread footing load tests on geosynthetic reinforced soil foundations, Journal of Geotechnical and Geoenvironmental Engineering. ASCE. 123: 66-72.

Adams JE., and Hanks R.J. (1964). Evaporation from soil shrinkage cracks, Soil Science Society of America Journal. 28 (2): 281-28.

Adams, J.E., Ritchie, J.T., Burnett, E., and Fryrear, D.W. (1969) Evaporation from a Simulated Soil Shrinkage Crack. Soil Science Society of America Journal 1969 33:609-613.

Alberta Energy. (2014). Quick Facts. Retrieved August 30, 2015 from http://www.energy.alberta.ca/oilsands/791.asp.

Alberta Energy Regulator. (2015). Bulletin 2015-11. Retrieved August 23, 2015 from http://www.aer.ca/rules-and-regulations/bulletins/bulletin-2015-11

Anderson, W. G. (1986) Wettability literature survey-part 1: rock/oil/brine interactions and the effects of core handling on wettability. Journal of Petroleum Technology, 38(11) 1125-1144.

ASTM. (2003). Standard Test Method for Bearing Capacity of Soil for Static Load and Spread Footings. D 1194 - 94. West Conshohocken, PA, USA.

Barbour, S.L., Fredlund, D.G., Wilson, G.W. (1997), The effect of soil suction on evaporative fluxes from soil surfaces, Canadian Geotechnical Journal, 31(2): 151-161.

Barr Engineering Report (2012). Atmospheric Fines Drying (AFD) Deposition Optimization: Multi-lift versus Deep Stacking. 2012 Program - Interim Project Report

Beier, N.A., and Sego, D.C. (2008). The oil sands tailings research facility. Geotechnical News, June 2008, pp. 72-77. 
Beier, Nicholas, Ward Wilson, Adedeji Dunmola, and David Sego. (2013). Impact of Flocculation-Based Dewatering on the Shear Strength of Oil. NRC Research Press 1007 (July 2012): 1001-1007.

Bera, A. K., Ghosh, A., and Ghosh, A. (2007). Behaviour of model footing on pond ash. Geotechnical and Geological Engineering. 25: 315-325.

BGC Engineering Inc. (2010). Oil Sands Tailings Technology Review. Oil Sands Research and Information Network (Vol. OSRIN Repo, p. OSRIN Report No. TR-1. 136 pp.). Edmonton, Alberta.

Bitelli, M., Ventura, F., Campbell, G.S., Snyder, R.L., Gallegati, F., Pisa, P.R. (2008). Coupling of heat water vapor and liquid water to compute evaporation in bare soils. Journal of Hydrology. 362: 191-205.

Boratynec, D.J. (2003). Fundamentals of Rapid Dewatering of Composite Tailings. M.A.Sc. thesis. Department of Civil and Environmental Engineering. University of Alberta.

Caldwell, J., Revington, A., McPhail, G. and Charlebois, I. 2014. 'Optimized Seasonal Deposition for successful management of treated mature fine tailings', in Proceedings of the Eighteenth International Conference on Paste and Thickened Tailings (Paste2014), June 2014, Vancouver, Canada, pp. 1-18.

Calgary Herald. (2015). Strong oilsands growth still forecast despite low oil prices. Retrieved September 5, 2015 from http://calgaryherald.com/business/energy/strongoilsands-growth-still-forecast-despite-low-oil-prices.

Canadian Geotechnical Society. (2006). Canadian Foundation Engineering Manual. $4^{\text {th }}$ edition.

Canadian Association of Petroleum Producers, CAPP, (2015). Retrieved September 3, 2015 from http://www.oilsandstoday.ca/topics/Tailings/Pages/default.aspx

Caterpillar Inc. (2015). Products and Services - North America. Retrieved July 10, 2015 from http://www.cat.com/en_US.html 
Chalaturnyk, R.J., Scott, J.D. and Ozum, B. (2004). Environmentally Acceptable Deposition of Oil Sands Tailings, SWEMP 2004, 8 International Symposium on Environmental Issues and Waste Management in Energy and Mineral Production May 17-20, 2004 Antalya, Turkey.

Chalaturnyk, R.J., Scott, J.D., and Ozum, B. (2002). Management of oil sands tailings. Petroleum Science and Technology, 20 (9-10): 1025-1046.

Chen, X. (1992). Evaporation from a salt-encrusted sediment surface:Field and laboratory studies. Australian Journal of Soil Research, 30:429-442.

Costa, Y. D., Cintra, J. C., and Zornberg, J. C. (2003). Influence of matric suction on the results of plate load tests performed on a lateritic soil deposit. ASTM Geotechnical Testing Journal, 2(2), 219-226.

Daliri, F. Simms, P. and Sivathayalan. S. (2012). Contribution of desiccation to monotonic and cyclic strength of thickened gold tailings- not the same as overconsolidation, in Proceedings of the Fifteenth International Seminar on Paste and Thickened Tailings (Paste2012), April 2012, Sun City, South Africa, pp. 73-84.

Dash, S. K., Sireesh, S., and Sitharam, T. G. (2003). Model studies on circular footing supported on geocell reinforced sand underlain by soft clay. Geotextiles and Geomembranes, 21:197-219.

Decagon. (2007). WP4 Potentiameter- Operators Manual version 5. Pullman, WA: Decagon Devices, Inc. Retrieved July 17, 2015 from http://www.decagon.com/assets/Manuals/Inside-Pages-WP4.pdf

Decagon. (2015). 5TE Soil Moisture, Temperature and EC Sensor. Retrieved August 5, 2015 from http://www.decagon.com/products/soils/volumetric-water-contentsensors/5te-soil-moisture-temperature-and-electrical-conductivity-sensor/

Djalal, K., (2014). The effect of cracks and geo-morphology on evaporation from clay soils. M.A.Sc. thesis, Department of Civil and Environmental Engineering, Carleton University, Ottawa, On. 
Dunmola, A. (2012). Predicting evaporative fluxes in saline soil and surfacedeposited thickened mine tailings. PhD Thesis. Ottawa: Carleton University.

Edlefsen, N. E., and Anderson, A. B. (1943). Thermodynamics of soil moisture. Hilgardia, 15(2), 31-298

Energy Resources Conservation Board. (2009). Directive 074: Tailings Performance Criteria and Requirements for Oil Sands Mining Schemes Directive 074. Calgary, Alberta.

ESS Earth Sciences. (2015). Shear Vane Tester Portable Field Kit. Retrieved July 16, 2015 from http://www.essearth.com/product/shear-vane-tester/.

FTFC. (1995). Clark hot water extraction for fine tailings. In Advances in oil sands tailings research. Fine Tailings Fundamentals Consortium (FTFC), Oil Sands and Research Division, Alberta Department of Energy, Edmonton, Alberta. 1:79-84.

Fredlund, D. G., and Rahardjo, H. (1993). Soil Mechanics fo r Unsaturated Soils. New York: John Wiley and Sons, Inc.

Fredlund, DG, Jeff Stone, Jason Stianson, and Andrea Sedgwick. (2011). Determination of Water Storage and Permeability Functions for Oil Sands Tailings. Proceedings Tailings and Mine Waste 2011, Vancouver, Canada. Retrieved June 3, 2015 from https://circle.ubc.ca/handle/2429/38765.

Fredlund, D G., and Houston, S.L. (2013). Interpretation of Soil-Water Characteristic Curves When Volume Change Occurs as Soil Suction Is Changed. In Advances in Unsaturated Soils, c:15-31. London: Caicedo et al.

Fredlund,D.G. and Xing, A. (1994). Equations for the soil-water characteristic curve. Canadian Geotechnical Journal, 31(3): 521-532.

Fujimaki, H., Shimano, T., Inoue, M., and Nakane, K. (2006). Effect of a Salt Crust on Evaporation from a Bare Saline Soil. VadoseZone Journal, 5:1246-1256 
Fujiyasu, Y., and Fahey, M. (2000). Experimental study of evaporation from saline tailings. Journal of Geotechnical and Geoenvironmental Engineering, 18- 27.

Fujiyasu, Y., Fahey, M., and Newson, T. (2000). Field investigation of evaporation from freshwater tailings. Journal of geotechnical and geoenvironmental engineering, 126(6): 556-567.

Gibson, R. E., England, G. L., and Hussey, M. J. L. (1967). The theory of onedimensional consolidation of saturated clays. Geotechnique, 17(3): 261-273.

Hall, A. C., Collins, S. H., and Melrose, J.C. (1983) Stability of Aqueous Wetting Films in Athabasca Tar Sands. Society of Petroleum Engineers Journal, 23(2) 249-258.

Hanna, A., and Abdel-Rahman, M. (1998).Experimental investigation of shell foundations on dry sand. Canadian Geotechnical Journal, NRC. 35: 847-857.

Hatano, R., Nakamoto H., Sakuma, T., and Okajima, H. (1988) Evapotranspiration in cracked clay field soil, Soil Science and Plant Nutrition, 34:4, 547-555.

Hoskin Scientific Ltd. (2015). WP4-C Dewpoint Potentiometer. Retrieved August 5, 2015 from http://www.hoskin.ca/catalog/index.php?main_page=product_info\&products_id=340

Hossain, M.S., and a. Fourie. (2013). Stability of a Strip Foundation on a Sand Embankment over Mine Tailings. Géotechnique 63 (8) (June 1): 641-650.

Hyndman, A., and Sobkowicz, J. (2010). Oil sands tailings: reclamation goals and the state of technology. In Proceedings of the 63rd Canadian Geotechnical Conference, Calgary, Alta., 12-16 September 2010. Canadian Geotechnical Society, pp. 642-655.

Innocent-Bernard, T. (2013). Evaporation, cracking, and salinity in a thickened oil sands tailings. M.A.Sc. thesis, Department of Civil and Environmental Engineering, Carleton University, Ottawa, Canada. 
Jakubick, Alex. T., McKenna, Gord, Robertson, Andy. (2003). Stabillisation of Tailings Deposits: International Experience. In Mining and the Environment III, 9. Sudbury, Canada.

Jeeravipoolvarn, S. 2005. Compression behavior of oil sands tailings. M.S.c. thesis, Department of Civil and Environmental Engineering, University of Alberta, Edmonton, Alberta.

Jeeravipoolvarn, S., Scott, D., Chalaturnyk R., Shaw B., (2014). Effect of Shear on Consolidation Properties of Oil Sands Fine Tailings. Tailings and Mine Waste 2014 Conference.

Jeeravipoolvarn, S. (2010). Geotechnical behavior of in-line thickened oil sands tailings. Ph.D. thesis, Department of Civil and Environmental Engineering, University of Alberta, Edmonton, Alberta.

Kaminsky, H. A. (2008). Characterization of an Athabasca Oil Sands Ore and Process Streams. Ph.D thesis, Department of Chemical and Materials Engineering, University of Alberta, Edmonton, Alberta.

Kaufman, W. W., \& Ault, J. C. (2011). Design of Surface Mine Haulage Roads - A Manual.Pittsburch: Bureau of Mines, United States Department of the Interior.

Kirkham, D., and Selim, H. M., (1970). Soil temperature and water content changes during drying as influenced by cracks: A laboratory experiment. Soil Science Society of America Journal, 34(4), 565-569.

Kolstad, D., Dunmola, A., Dhadli, N., O'Kane, M., Song, J., and Masala, S. 2012. Towards the improvement in geotechnical performance of atmospheric fines drying (AFD) deposits at Shell's Muskeg River Mine. In Proceedings of the 3rd International Oil Sands Tailings Conference, Edmonton, Alta., 3-5 December 2012. pp. 411-420.

Krahn, J., and Fredlund, D. G. (1972). On total, matric and osmotic suction. Soil Science, 116(5). 
Kumbhokjar, A.S. (1993). "Numerical evaluation of Terzaghi's $N_{y}$." Journal of Geotechnical Engineering, 119(3), 598-607.

Lal, R., and Shukla, M. K. (2004). Principles of Soil Physics. Basel, Switzerland: Marcel Dekker, Inc.

Liu, C., Tang, C., Shi, B., Zhao, L., and Wang, B. (2008). Influencing factors of geometrical structure of surface shrinkage cracks in clayey soils. Engineering Geology, 101(3), 204217.

Lozada, C., Caicedo, B., and Thorel, L. (2015). Effects of cracks and dessication on the bearing capacity of soil deposits. Géotechnique Letters 5, 112-117, http://dx.doi.org/10.1680/geolett.15.00021

Majid, A., and Sparks, B. D. (1983). Determination of residual organic matter in extracted oil sands using a low temperature ashing method. FUEL, 62(1), 772-774.

Masliyah, Jacob, Zhiang Joe Zhou, Zhenghe Xu, Jan Czarnecki, and Hassan Hamza. (2004). Understanding Water-Based Bitumen Extraction 82 (August): 628-654.

Matthews, J. G., Dhadli, N., House, P., (2011). Field trials of thin-lift deposition of amended mature fine tailings at the Muskeg River Mine in Northern Alberta Shell Canada, In Proceedings of Paste 2011, Perth, Australia.

Mizani, S., Soleimani, S., and Simms, P. (2013). Effects of polymer dosage on dewaterability, rheology, and spreadability of polymer-amended mature fine tailings. In Proceedings of the Sixteenth International Seminar on Paste and Thickened Tailings (Paste13), 20 June 2013, Belo Horizonte, pp. 117-131.

Monteith, J. L. (1965). Evaporation and Environment. In: Foff, G.E. (ed.) The state and movement of water in living organisms. 19th Symposium Society of Experimental Biology. 205-234.

Monteith, J. L. (1981). Evaporation and surface temperature. Quarterly Journal of the Royal Meteorological Society, 707(451), 1-27 
Mossop, G. D. (1980). Geology of the Athabasca Oil Sands, Science 207,145152.

Natural Resources Canada (NRCan). (2013). Oil Sand Processes. Retrieved September 15, 2015 from http://www.nrcan.gc.ca/energy/oil-sands/5853

Oh, Won Taek, and Sai K Vanapalli. (2013). Interpretation of the Bearing Capacity of Unsaturated Fine-Grained Soil Using the Modified Effective and the Total Stress Approaches 13.

Oil Sands Discovery Centre. (2009). Facts about Alberta's oil sands and its $\begin{array}{lllll}\text { industry. } & \text { Retrieved } & \text { September } & 25, & \end{array}$ http://history.alberta.ca/oilsands/resources/docs/facts_sheets09.pdf

Oloo, S. Y. (1994). A bearing capacity approach to the design of low volume traffics roads. Ph.D. thesis, University of Saskatchewan, Saskatoon, SK, Canada.

Oloo, S. Y., Fredlund, D. G., and Gan, J. K.M. (1997). Bearing capacity of unpaved roads. Canadian Geotechnical Journal. 34(3), 398-407.

Owolagba, J., and Azam, S. (2013). Unsaturated Soil Properties of Centrifuged Oil Sands Fine Tailings. In Geo-Montreal. Retrieved October 30, 2014 from http://www.soilvision.com/downloads/docs/pdf/research/2013-66-CGC-IVMONTREAL.pdf.

Pembina Institute (n.d.). Oilsands 101: Tailings. Retrieved September 15, 2015 from http://www.pembina.org/oil-sands/os101/tailings\#footnote1_pcush9s

Qiu, Yunxin, Sego, D.C. (2001). Laboratory Properties of Mine Tailings. Canadian Geotechnical Journal 38 (1): 183-190.

Rassam, D.W., and Williams, D.J. (1999). Bearing Capacity of Desiccated Tailings. Journal of Geotechnical and Geoenvironmental Engineering 125 (7): 600-609

Richards, B. G. (1965). Measurement of the free energy of soil moisture by the psychrometric technique using thermistors. Moisture equilibria and moisture changes in 
soils beneath covered areas. A symposium in print convened by Soil Mechanics Section, CSIRO, in collaboration with the National Building Research Institute and National Institute for Road Research CSIR (pp. 39-46). South Africa: Butterworths, Sydney, N.S.W.

Rojas, J. C., Salinas, L. M., and Seja, C. (2007). Plate-load tests on an unsaturated lean clay. In Proceedings of the 2nd International Conference on Unsaturated Soils, Weimar, 445-452.

Schumacher, B. A. (2002). Methods for the determination of total organic carbon (TOC) in soils and sediments. Las Vegas: Ecological Risk Assessment Support Center, USEPA.

Scott, J.D., Jeeravipoolvarn, S., Kabwe, L., Wilson G.W., (2013). Properties Which Affect the Consolidation Behaviour of Mature Fine Tailings. In Proceedings of the $17^{\text {th }}$ International conference on Tailings and Mine Waste, November 3-6, 2013, Banff, Alberta.

Shimojima, E., Yoshioka, R., and Tamagawa, I. (1996). Salinization owing to evaporation from bare-soil surfaces and its influences on evaporation. Journal of Hydrology, 178, 109-136.

Simms, P., Grabinsky, M., and Zhan, G. (2007). Modelling evaporation of paste tailings from the Bulyanhulu mine. Canadian Geotechnical Journal, 1417-1432.

Skempton. A. (1948) The $\varnothing=0$ analysis of stability and its theoretical basis. In Proceedings of the 2nd International Conference on Soil Mechanics and Foundation Engineering, vol 1, 1948, pp 72-78

Sobkowicz, J.C. (2010). History and development in the treatment of oil sands fine tailings. In Proceedings of the 14th International Conference on Tailings and Mine Waste, Vail, Colo., 17-20 October 2010. Taylor Francis Group. pp. 11-30.

Sobkowicz, J.C. (2012). Oil Sands Tailings Technolody Deployment Roadmap Project Report - Volume 1, Component Results. 
Takamura, K. (1982), Microscopic structure of athabasca oil sand. Canadian Journal of Chemical Engineering, 60: 538-545.

Tannant, D. D., and Regensburg, B. (2001). Guidelines for Mine Haul Road Design. Retrieved September 16, 2015 from https://circle.ubc.ca/bitstream/handle/2429/26992/Haul_Road_Design_Guidelines.pdf.

Simms, P., Soleimani, S., Rozina, L., and Mizani, S., (2015). Dessication and consolidation modeling of oil sands fine tailings deposits. In electronic proceedings of Geoquebec 2015, September 20-23 $3^{\text {rd }}$, Quebec City, Quebec.

Soleimani, S., Simms, P. Dunmola A., Freeman, G., Wilson, W. (2014), Desiccation and consolidation in thin-lift deposition of polymer amended MFT. In Proceedings of the Seventeenth International Seminar on Paste and Thickened Tailings (Paste 2014), 3-9 June 2014, Vancouver, Canada, pp. 75-86.

Terzaghi K. (1923). "Die Berechnung der Durchlassig Keisziffer des Tones ans dem Verlauf der Hydrodynamischen Spannungserscheinungen Reproduced in Terzaghi K. (1960), From Theory to Practice in Soil Mechanics", John Wiley and Suns. New York

Terzaghi, K. (1943) Theoretical Soil Mechanics. J. Wiley and Sons, inc., 1943. $\begin{array}{llll}\text { Retrieved September } & 10, & & \end{array}$ http://onlinelibrary.wiley.com/book/10.1002/9780470172766

Thorburn, P.J., Walker, G.R., and Woods, P.H., (1992). Comparison of diffuse discharge from shallow water tables in soils and salt flats. Journal of Hydrology. 136, 253-274.

Total. (2014). Extra Heavy Oil and Oil Sands: Composition. Retrieved August 30, 2015 from http://www.total.com/en/energies-expertise/oil-gas/explorationproduction/strategic-sectors/heavy-oil/focus-oil-sands/oil-sands/what-are-oilsands?\%FFbw=kludge $1 \% \mathrm{FF}$

Tuk-Ki, M. and Nhat, V.D., (2008). Kelvin-Voigt model for dynamics of crack opening in shrinkage cracking. KSCE journal of civil engineering. (12)3, 149 - 154. 
UMS. (2009). T5/T5X Pressure Transducer Tensiometer User Manual. Retrieved July 17 2015 from http://www.umsmuc.de/fileadmin/produkt_downloads/Tensiometer/T5_Manual.pdf

United States Department of Agriculture, USDA (1954). Saline and Alkali Soils. Agriculture Handbook No. 60. Washington, D.C. Retrieved September 15, 2015 from http://www.ars.usda.gov/sp2UserFiles/Place/20360500/hb60_pdf/hb60complete.pdf

Van de Griend A. A., Owe M., Vugts H.F., and Prince, S.D. (1989). Water and Surface Energy Balance Modeling in Botswana. Bull. Amer. Meteor. Soc., 70, 14041411.

Vanapalli, S.K., Fredlund, D. G., Pufahl, D. E., and Clifton, A. W. (1996). Model for the prediction of shear strength with respect to soil suction. Canadian Geotechnical Journal, Vol. 33, No. 3, pp. 379-392.

Vanapalli, S.K., Eigenbrod, K.D., and Garven, E.A. (2003). Measurement of capillary stress in three compacted granular soils. Proceedings of the 56th Canadian Geotechnical Conference, Winnipeg. 127-135.

Vanapalli, S.K. and Mohamed, F. O. (2007). Bearing capacity of model footings in unsaturated soils. Proceedings of the Experimental Unsaturated Soils Mechanics, Ed. Schanz, T. Springer Proceedings in Physics \# 112, pp. 483-494.

Vesic, A. B. (1973). "Analysis of ultimate loads of shallow foundations." Journal of the Soil Mechanics and Foundations Division, 99(1), 45-73.

Wells, P.S., Revington, A., and Omotoso, O. (2011). Mature fine tailings drying technology update. In Proceedings of Paste 2011. Edited by R.J. Jewel and A.B. Fourie, 5-7 April 2011. Australia Centre for Geomechanics, Perth, Australia. pp. 155-166.

Wells, P. S. (2011). Long term in-situ behaviour of oil sands fine tailings in Suncor's Pond 1A. Proceeding of the Conference on Tailings and Mine Waste 2011. Vancouver, BC 
Williams, D.J. (2013). The Mystery of Unsaturated Soil Mechanics - Some Mining Applications. Australian Geomechanics Society. Adelaide, Australia. Retrieved September 15, 2015 from http://slidegur.com/doc/26058/presentation---australiangeomechanics-society.

Wilson, G. W., Fredlund, D. G., and Barbour, S. L. (1994). Coupled soilatmosphere modeling for soil evaporation. Canadian Geotechnical Journal, 151-161.

Wilson, G. W., Fredlund, D. G., and Barbour, S. L. (1997). The effect of soil suction on evaporative fluxes from soil surfaces. The Canadian Geotechnical Journal, 34(4), 145-155

Zawislanski, P. T.; Tokunaga, T. K.; Benson, S. M.; Oldfather, J. M.; Narasimhan, T.N., (1992) Bare Soil Evaporation and Solute Movement in Selenium-Contaminated Soils of Kesterson Reservoir. Journal of Environmental Quality, 21 (3), 447-457 


\section{APPENDICES}

\section{APPENDIX A: Thin Lift Dry Box - Layer 1}

The following tables are a summary of measurements taken during the deposition and right after deposition of the first layer in the thin lift dry box.

Table A1. Initial Conditions (Empty Box vs. Layer 1)

\begin{tabular}{|l|r|r|r|}
\hline \multicolumn{1}{|c|}{ Layer \#1 } & $\begin{array}{c}\text { Pre-deposition } \\
\text { [Senix Readings] }\end{array}$ & $\begin{array}{c}\text { Post-deposition } \\
\text { [Senix Readings] }\end{array}$ & $\begin{array}{c}\text { Initial Conditions (Post- } \\
\text { deposition) } \\
\text { [Actual Heights] }\end{array}$ \\
\hline Date & 03/04/2014 & $03 / 04 / 2014$ & $03 / 04 / 2014$ \\
\hline Time & $4: 56: 29$ PM & $9: 21: 25$ PM & $9: 21: 25$ PM \\
\hline Mass $\mathbf{( k g )}$ & 124.821526 & 358.059627 & 233.238101 \\
\hline Sensor 1 (cm) & 64.45441 & 34.938321 & 29.516089 \\
\hline Sensor 2 (cm) & 64.894497 & 35.272181 & 31.220614 \\
\hline Sensor 3 (cm) & 65.143169 & 33.922555 & 30.237694 \\
\hline Sensor 4 (cm) & 65.50314 & 35.265446 & 30.14917825 \\
\hline Average $\mathbf{( c m )}$ & 64.998804 & 34.84962575 & \\
\hline
\end{tabular}

Table A2. Quality Control and Initial Solids Content

\begin{tabular}{|c|r|r|r|r|}
\hline $\begin{array}{c}\text { Mdish } \\
\mathbf{( g )}\end{array}$ & $\begin{array}{c}\text { mdish+sample } \\
\mathbf{( g )}\end{array}$ & $\begin{array}{c}\text { mdish+dry } \\
\mathbf{( g )}\end{array}$ & \multicolumn{1}{c|}{ w\% } & $\begin{array}{c}\text { slump } \\
\mathbf{( c m})\end{array}$ \\
\hline 1.63 & 33.44 & 13.07 & 1.78 & \\
\hline 1.65 & 36.00 & 14.03 & 1.77 & \\
\hline 1.63 & 37.20 & 14.48 & 1.77 & 9.0 \\
\hline 1.63 & 42.63 & 16.46 & 1.76 & 9.0 \\
\hline 1.63 & 44.00 & 16.89 & 1.78 & \\
\hline 1.67 & 45.83 & 17.57 & 1.78 & \\
\hline 1.63 & 54.19 & 20.46 & 1.79 & 8.2 \\
\hline 1.66 & 51.64 & 18.27 & 2.01 & \\
\hline 1.63 & 51.58 & 18.22 & 2.01 & 7.8 \\
\hline 1.62 & 37.92 & 14.57 & 1.80 & 8.0 \\
\hline 1.63 & 62.04 & 21.78 & 2.00 & 7.9 \\
\hline 1.64 & 45.41 & 17.50 & 1.76 & \\
\hline 1.64 & 37.15 & 14.41 & 1.78 & 7.4 \\
\hline 1.62 & 41.74 & 15.09 & 1.98 & \\
\hline & & & 1.84 & \\
\hline & & average & 0.35 & \\
\hline
\end{tabular}


The figures below show the height of the tailings recorded by the senix sensors, and the bulk electrical conductivity recorded by VWC sensors in Layer 1 of the thin lift dry box.

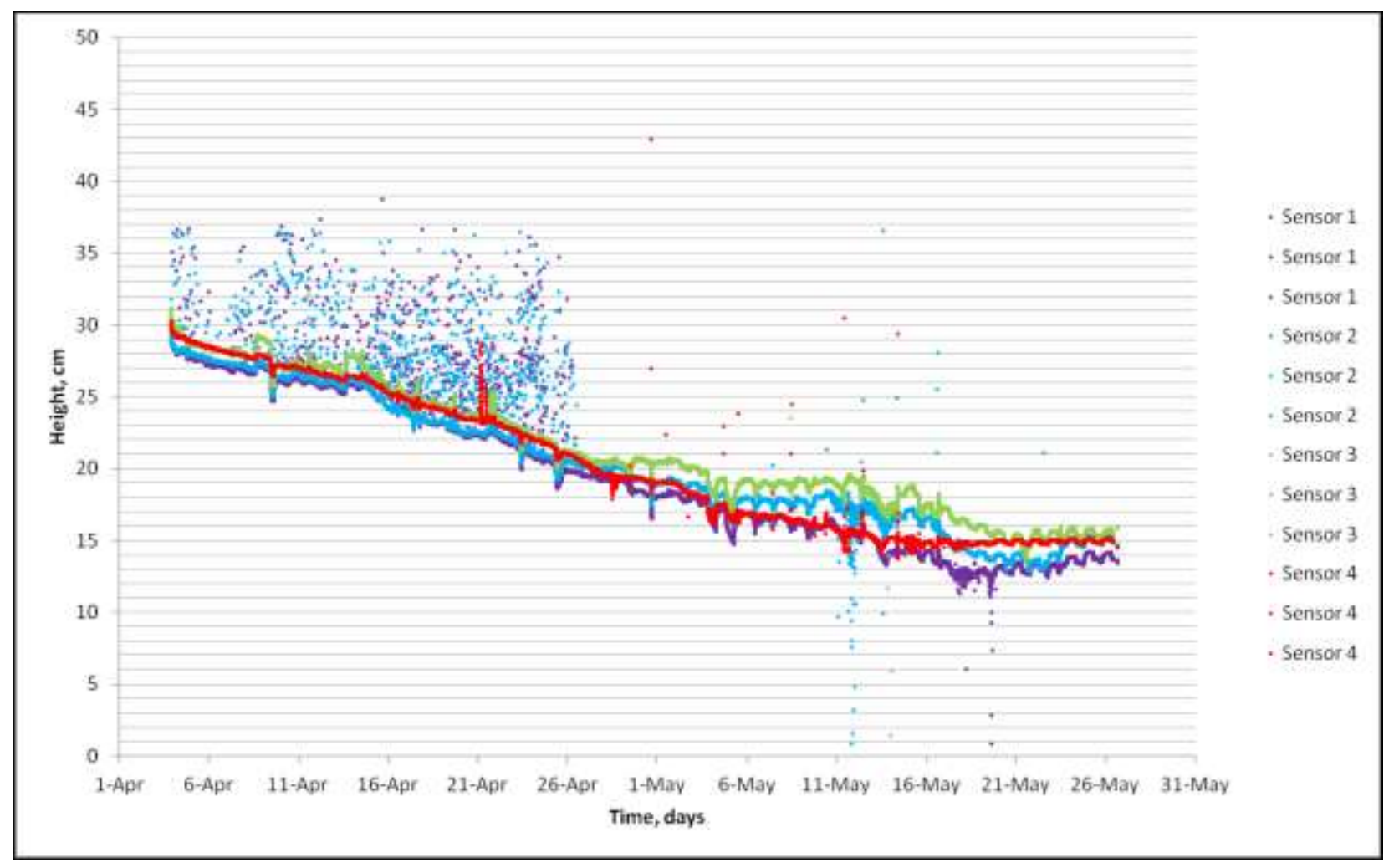

Figure A4.6-1. Height of Tailings from Senix Sensors - Thin Layer 1 


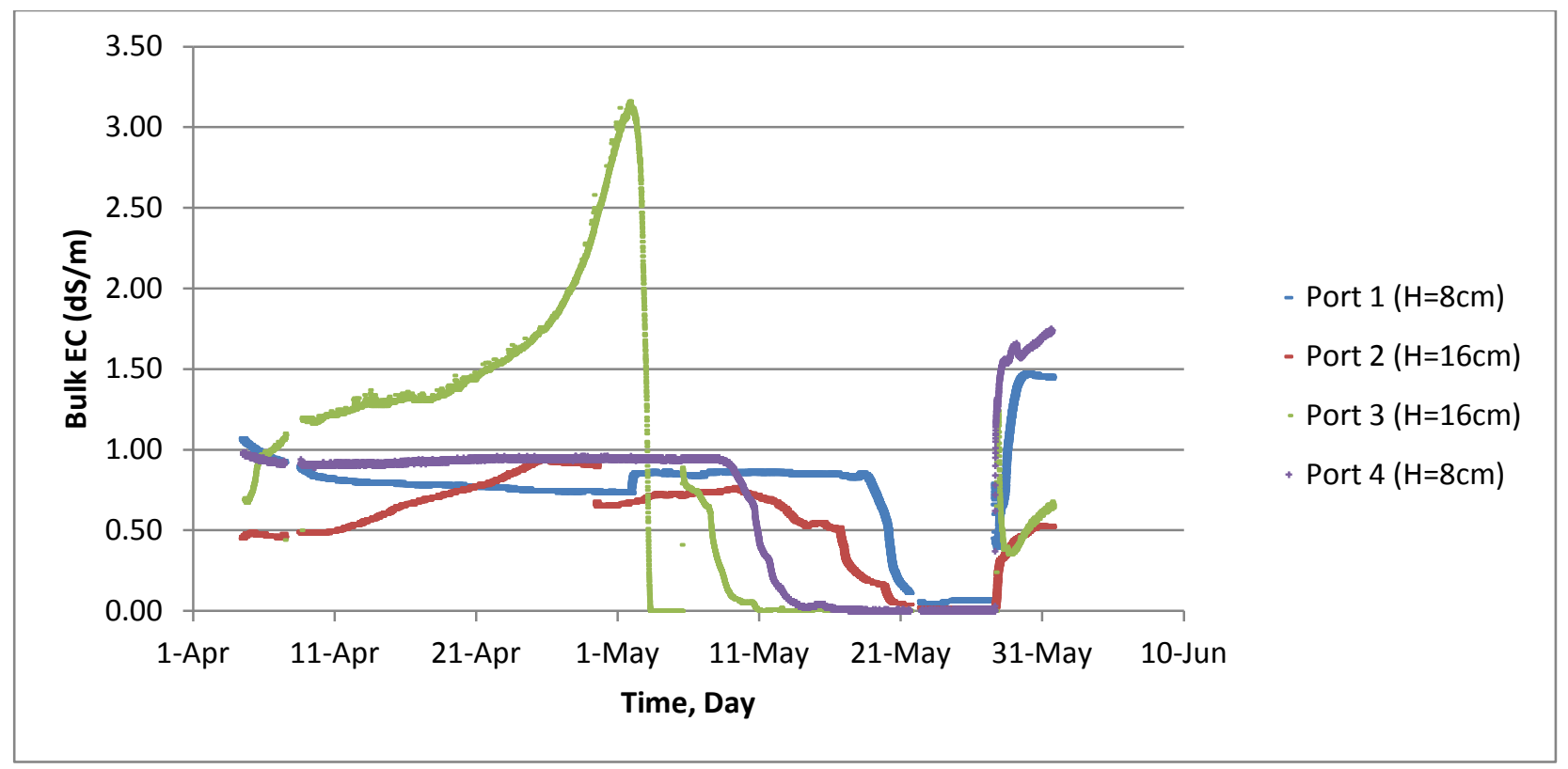

Figure A4.6-2. Bulk Electrical Conductivity - Overall

The tables below provide a summary of the height and mass measurements recorded before, during and after the deposition of Layer 1.

Table A3. Pre-deposition and post-deposition heights and masses - Thin Layer 1

\begin{tabular}{|l|r|r|r|r|}
\hline & $\begin{array}{c}\text { Pre- } \\
\text { deposition }\end{array}$ & Post-deposition & $\begin{array}{c}\text { Initial Conditions (Post- } \\
\text { Leposition) }\end{array}$ & $\begin{array}{c}\text { Final (Pre-deposition } \\
\text { of Layer 2) }\end{array}$ \\
\cline { 2 - 5 } & $\begin{array}{c}\text { [Senix } \\
\text { Readings] }\end{array}$ & [Senix Readings] & [Actual Heights] & [Actual Heights] \\
\hline Date & $03 / 04 / 2014$ & $03 / 04 / 2014$ & $03 / 04 / 2014$ & $26 / 05 / 2014$ \\
\hline Time & $4: 56: 29$ PM & $9: 21: 25$ PM & $9: 21: 25$ PM & $3: 22: 46$ PM \\
\hline Mass $\mathbf{( k g )}$ & 124.821526 & 358.059627 & 233.238101 & 86.949451 \\
\hline Sensor 1 (cm) & 64.45441 & 34.938321 & 29.516089 & 13.425604 \\
\hline Sensor 2 (cm) & 64.894497 & 35.272181 & 29.622316 & 14.649682 \\
\hline Sensor 3 (cm) & 65.143169 & 33.922555 & 31.220614 & 15.852973 \\
\hline Sensor 4 (cm) & 65.50314 & 35.265446 & 30.237694 & 14.524988 \\
\hline Average $\mathbf{( c m )}$ & 64.998804 & 34.84962575 & 30.14917825 & 14.61331175 \\
\hline
\end{tabular}


Table A4. Initial and final solids contents - Thin layer 1

\begin{tabular}{|l|r|r|}
\hline & \multicolumn{1}{|c|}{ Initial } & \multicolumn{1}{c|}{ Final } \\
\hline \multicolumn{1}{|c|}{ Solids Content } & 0.352 & 0.944 \\
\hline Mass of Solids $(\mathrm{kg})$ & 82.099 & 82.099 \\
\hline Mass of Water $(\mathrm{kg})$ & 151.139 & 4.850 \\
\hline Mass of Water Lost $(\mathrm{kg})$ & 0.000 & 146.289 \\
\hline
\end{tabular}

Figure A3 provides a breakdown of the TOC of the surface samples. At the beginning, the TOC is approximately the same in the different sample locations. As drying continues, the surface begins to have a greater TOC, and as the layer gets even drier, the CE surpasses the TOC of the surface.

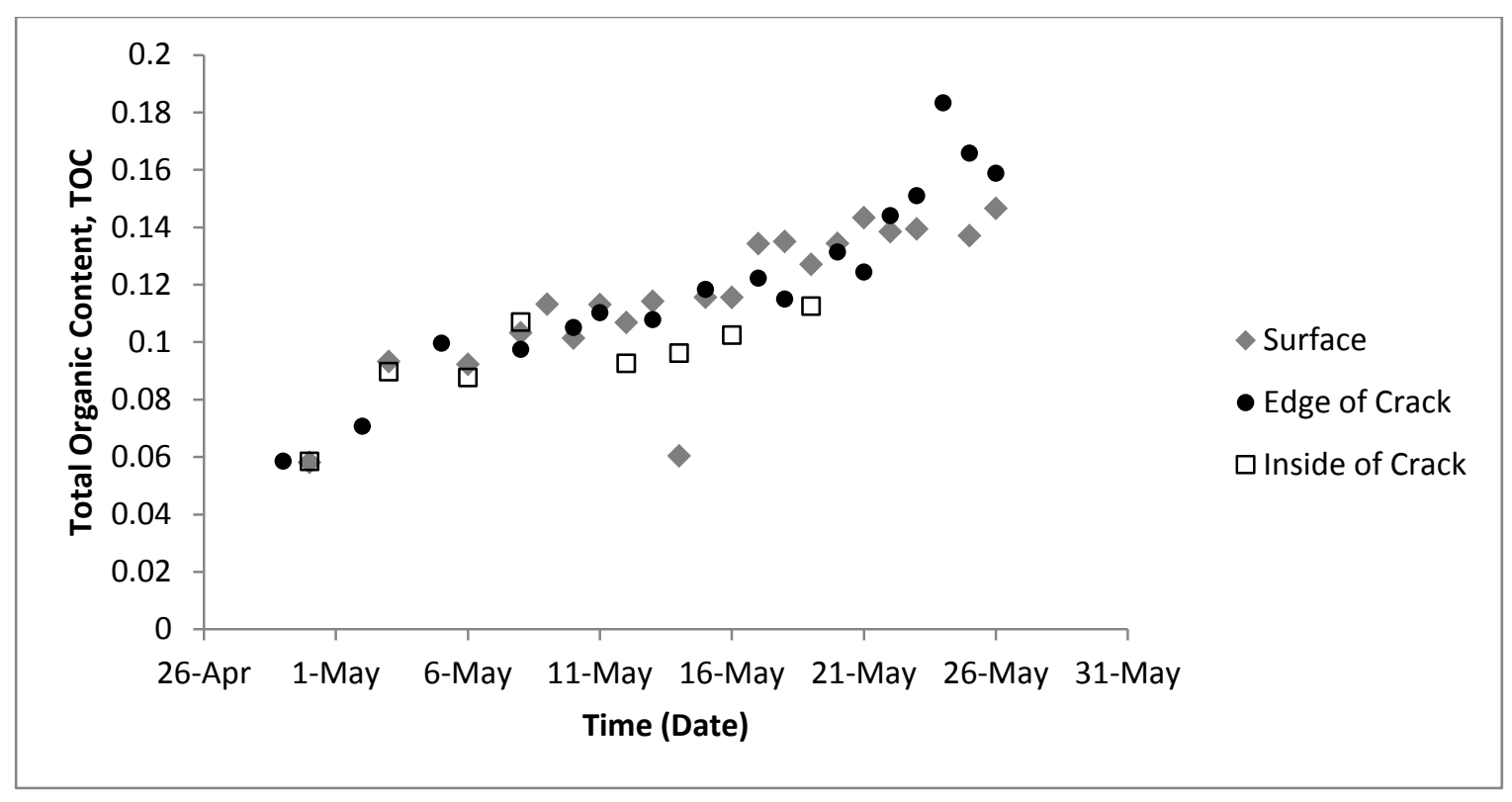

Figure A4.6-3. Surface sample total organic contents - Layer 1 


\section{APPENDIX B: Thin Lift Dry Box - Layer 2}

The following tables are a summary of measurements taken during the deposition and right after deposition of the second layer in the thin lift dry box.

Table B1. Original Conditions (Box+Layer1)

\begin{tabular}{|l|r|r|r|}
\hline \multicolumn{1}{|c|}{ Layer \#2 } & $\begin{array}{c}\text { Pre-deposition } \\
\text { [Actual] }\end{array}$ & $\begin{array}{c}\text { Post-deposition } \\
\text { [Actual] }\end{array}$ & New Material Added \\
\hline Date & $26 / 05 / 2014$ & $27 / 05 / 2014$ & $27 / 05 / 2014$ \\
\hline Time & $3: 22: 46 \mathrm{PM}$ & $7: 54: 47 \mathrm{PM}$ & $7: 54: 47 \mathrm{PM}$ \\
\hline Mass $\mathbf{( k g )}$ & 86.949451 & 340.166043 & 253.216592 \\
\hline Sensor 1 (cm) & 13.425604 & 38.265486 & 24.839882 \\
\hline Sensor 2 (cm) & 14.649682 & 37.969208 & 23.319526 \\
\hline Sensor 3 (cm) & 15.852973 & 39.079745 & 23.226772 \\
\hline Sensor 4 (cm) & 14.524988 & 41.069895 & 26.544907 \\
\hline Average $\mathbf{( c m )}$ & 14.61331175 & 39.0960835 & 24.48277175 \\
\hline
\end{tabular}

Table B2. Quality Control and Initial Solids Content

\begin{tabular}{|c|c|c|c|c|}
\hline $\begin{array}{l}\text { Mass of dish } \\
\text { (g) }\end{array}$ & $\begin{array}{c}\text { Mass of dish + wet sample } \\
(\mathrm{g})\end{array}$ & $\begin{array}{c}\text { Mass of dish + dry } \\
\text { sample } \\
(\mathrm{g})\end{array}$ & $\begin{array}{c}\text { Water Content } \\
(\%)\end{array}$ & $\begin{array}{c}\text { Slump } \\
(\mathrm{cm})\end{array}$ \\
\hline 1.63 & $\begin{array}{r}39.4 \\
\end{array}$ & 14.32 & 1.976359338 & 6.7 \\
\hline 1.63 & 52.5 & 18.89 & 1.947276941 & 6.9 \\
\hline 1.64 & 26.86 & 10.18 & 1.953161593 & 7.1 \\
\hline 1.65 & 37.64 & 13.84 & 1.952420016 & 6.7 \\
\hline 1.64 & 25.67 & 9.8 & 1.944852941 & 7.4 \\
\hline 1.64 & 31.44 & 11.75 & 1.947576657 & 7.2 \\
\hline 1.63 & 32.98 & 12.23 & 1.95754717 & 7.2 \\
\hline 1.62 & 29.1 & 10.96 & 1.942184154 & 7.3 \\
\hline 1.63 & 29.66 & 11.17 & 1.938155136 & 7.1 \\
\hline 1.63 & 28.83 & 10.82 & 1.959738847 & 7 \\
\hline 1.64 & 42.87 & 15.55 & 1.964054637 & 7.3 \\
\hline 1.64 & 29.22 & 11.02 & 1.940298507 & 7.1 \\
\hline \multirow[t]{3}{*}{1.64} & 29.48 & 11.08 & 1.949152542 & 6.9 \\
\hline & & Average & 1.951752191 & \\
\hline & & Solids Content & 0.338781827 & \\
\hline
\end{tabular}

The figures below show the bulk electrical conductivity recorded by VWC sensors in Layer 1 and 2 of the thin lift dry box. 


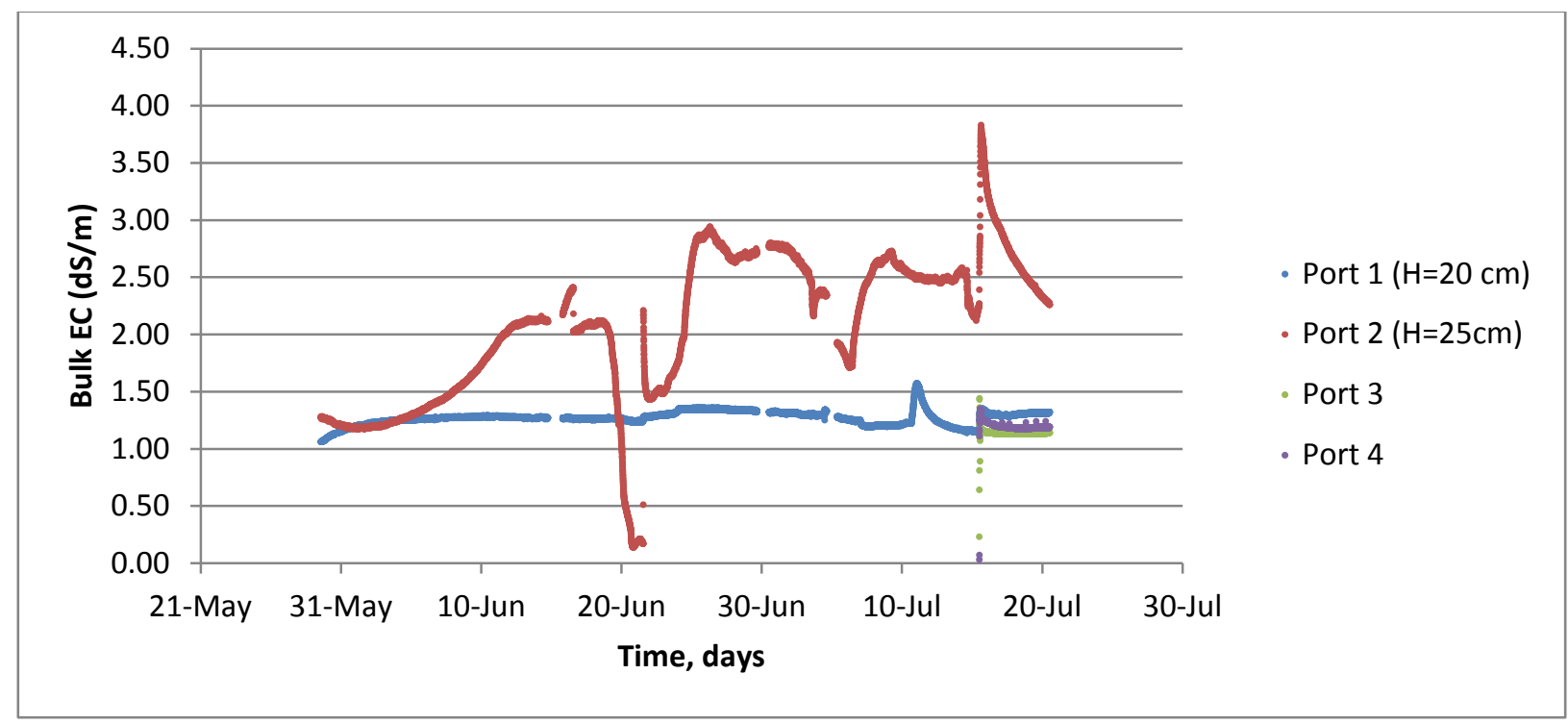

Figure B1. 5TE Bulk EC Readings - Layer 2

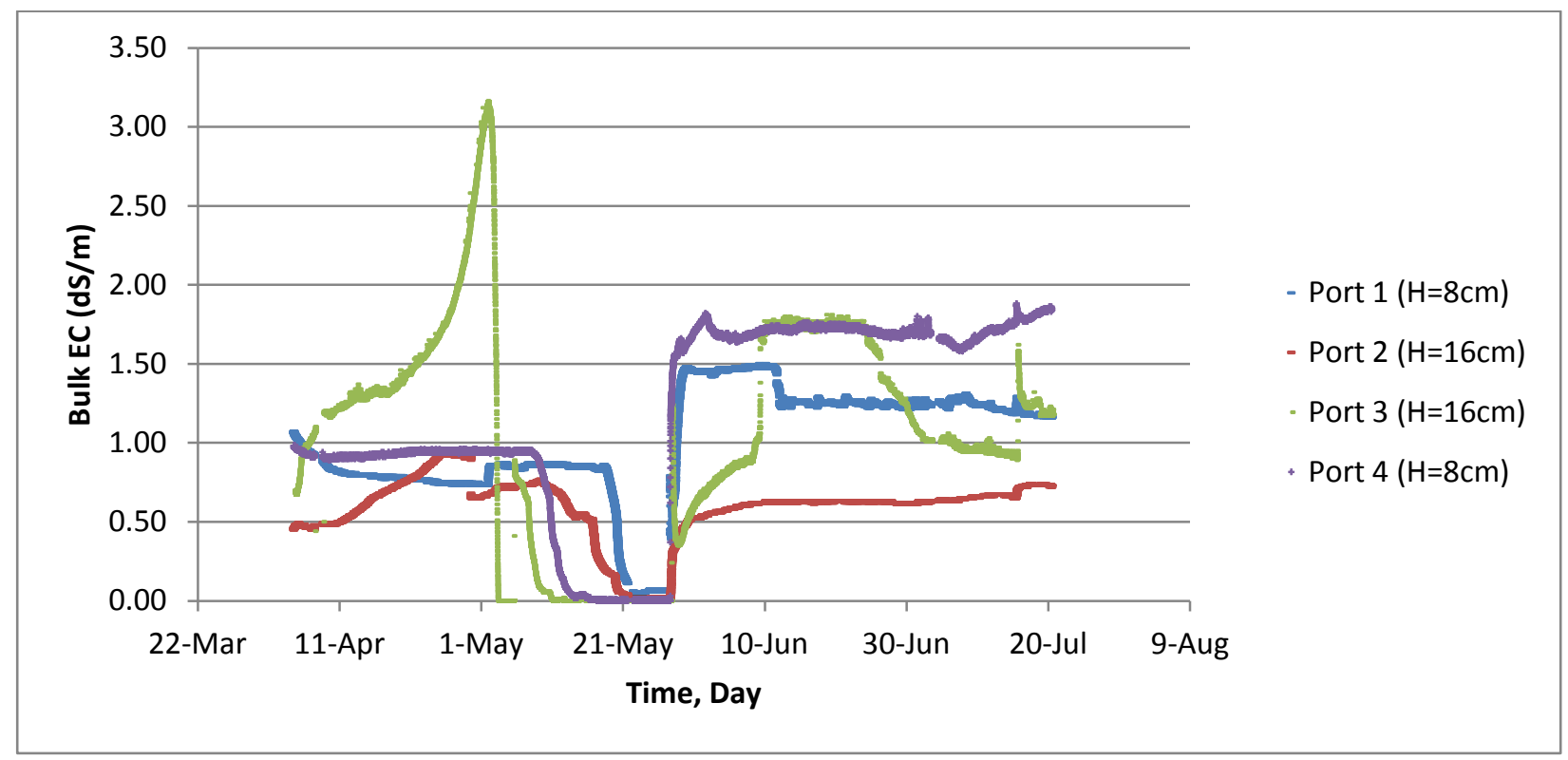

Figure B2. 5TE Bulk EC Readings - Bottom Sensors

The tables below provide a summary of the height and mass measurements recorded before, during and after the deposition of Layer 2. 
Table B3. Pre-deposition and post-deposition heights and masses - Thin Layer 2

\begin{tabular}{|c|c|c|c|c|}
\hline \multirow{2}{*}{ Layer \#2 } & $\begin{array}{c}\text { Pre- } \\
\text { deposition }\end{array}$ & Post-deposition & $\begin{array}{l}\text { Initial Conditions } \\
\text { (Post-deposition) }\end{array}$ & $\begin{array}{c}\text { Final (Pre-deposition of } \\
\text { Layer 3) }\end{array}$ \\
\hline & $\begin{array}{c}\text { [Senix } \\
\text { Readings] }\end{array}$ & $\begin{array}{c}\text { [Senix } \\
\text { Readings] }\end{array}$ & [Actual Heights] & [Actual Heights] \\
\hline Date & $26 / 05 / 2014$ & $27 / 05 / 2014$ & $27 / 05 / 2014$ & 15/07/2014 \\
\hline Time & 3:22:46 PM & 7:54:47 PM & 7:54:47 PM & 12:08:02 PM \\
\hline Mass (kg) & 86.949451 & 340.166043 & 253.216592 & 232.564054 \\
\hline Sensor $1(\mathrm{~cm})$ & 13.425604 & 38.265486 & 24.839882 & 26.289764 \\
\hline Sensor $2(\mathrm{~cm})$ & 14.649682 & 37.969208 & 23.319526 & 26.655186 \\
\hline Sensor $3(\mathrm{~cm})$ & 15.852973 & 39.079745 & 23.226772 & 27.959147 \\
\hline Sensor $4(\mathrm{~cm})$ & 14.524988 & 41.069895 & 26.544907 & 26.527492 \\
\hline Average (cm) & 14.61331175 & 39.0960835 & 24.48277175 & 26.85789725 \\
\hline
\end{tabular}

Table B4 Initial and final solids contents - Thin layer 1

\begin{tabular}{|l|r|r|r|r|r|}
\cline { 2 - 6 } \multicolumn{1}{c|}{} & \multicolumn{2}{c|}{ Layer 1 } & \multicolumn{1}{c|}{ Layer 2 } & \multicolumn{2}{c|}{ Total } \\
\hline & \multicolumn{1}{c|}{ Initial } & \multicolumn{1}{c|}{ Final } & \multicolumn{1}{l|}{ Initial } & \multicolumn{1}{c|}{ Initial } & \multicolumn{1}{c|}{ Final } \\
\hline \multicolumn{1}{|c|}{ Solids Content } & 0.352 & 0.944 & 0.339 & 0.494 & 0.722 \\
\hline Mass of Solids $(\mathrm{kg})$ & 82.099 & 82.099 & 85.785 & 167.884 & 167.884 \\
\hline Mass of Water $(\mathrm{kg})$ & 151.139 & 4.850 & 167.431 & 172.282 & 64.680 \\
\hline $\begin{array}{l}\text { Mass of Water Lost } \\
(\mathrm{kg})\end{array}$ & 0.000 & 146.289 & 0.000 & 0.000 & 107.602 \\
\hline
\end{tabular}

Figure 4.1-66 provides a breakdown of the TOC of the surface samples. At the beginning, the TOC is greater at the surface. As drying continues, the measurements at the IC surpass those at the surface. 


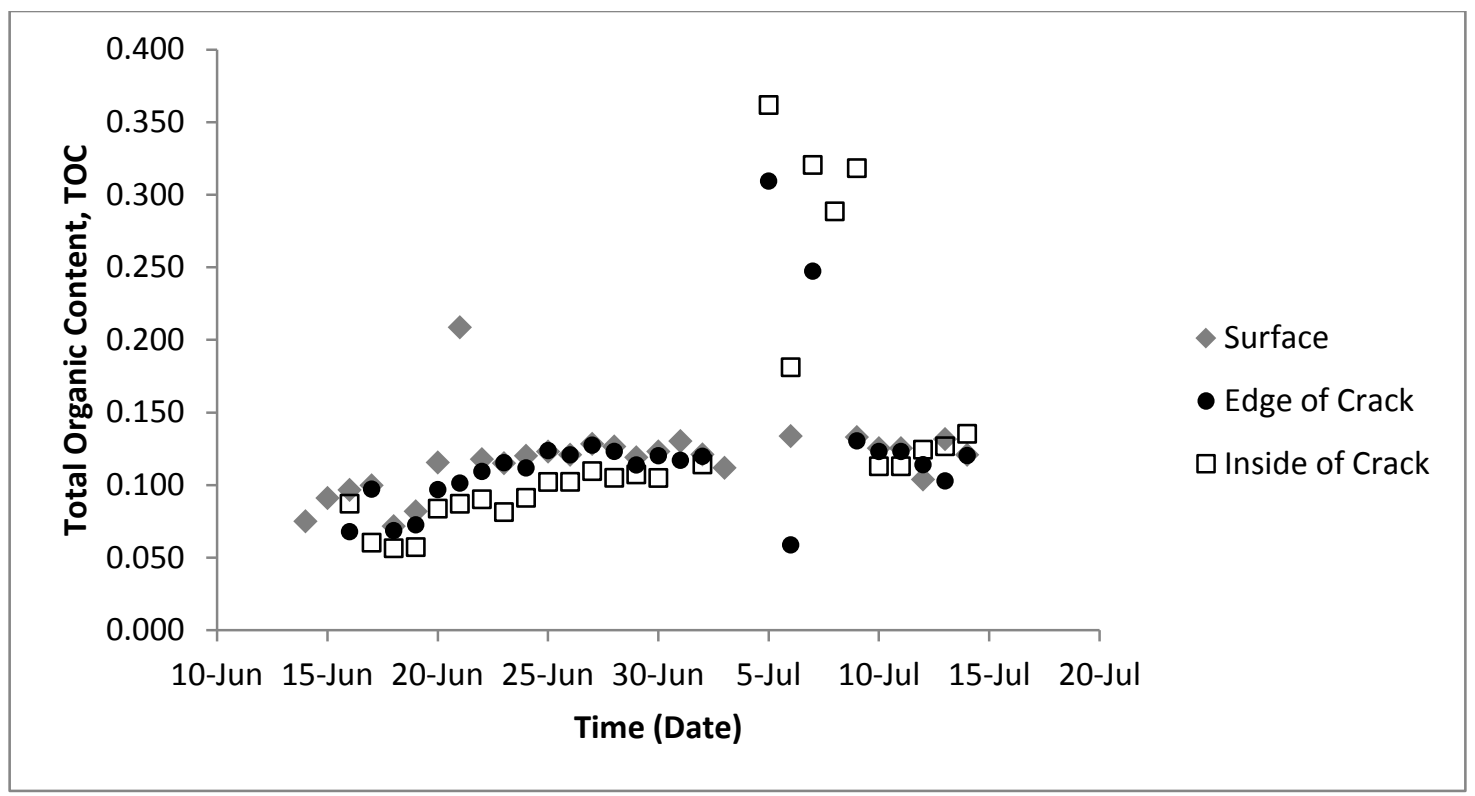

Figure B3. Surface sample total organic contents - Layer 2 


\section{APPENDIX C: Thin Lift Dry Box - Layer 3}

The following tables are a summary of measurements taken during the deposition and right after deposition of the third layer in the thin lift dry box.

Table C1. Original Conditions (Box+Layer1+Layer2)

\begin{tabular}{|l|r|r|r|}
\hline \multicolumn{1}{|c|}{ Layer \#3 } & $\begin{array}{c}\text { Pre-deposition } \\
\text { [Actual] }\end{array}$ & $\begin{array}{c}\text { Post-deposition } \\
\text { [Actual] }\end{array}$ & $\begin{array}{c}\text { New Material Added } \\
\text { (Post-deposition) }\end{array}$ \\
\hline Date & $15 / 07 / 2014$ & $15 / 07 / 2014$ & $15 / 07 / 2014$ \\
\hline Time & $12: 08: 02 \mathrm{PM}$ & $2: 07: 02 \mathrm{PM}$ & $2: 07: 02 \mathrm{PM}$ \\
\hline Mass $\mathbf{( k g )}$ & 232.564054 & 460.891245 & 228.327191 \\
\hline Sensor 1 $\mathbf{( c m )}$ & 26.289764 & 44.345993 & 17.056229 \\
\hline Sensor 2 $\mathbf{( c m )}$ & 26.655186 & 44.199465 & 17.371228 \\
\hline Sensor 3 (cm) & 27.959147 & 45.330375 & 24.80318 \\
\hline Sensor 4 (cm) & 26.527492 & 51.330672 & 19.443729 \\
\hline Average $\mathbf{( c m )}$ & 26.85789725 & 46.30162625 & \\
\hline
\end{tabular}

Table C2. Quality Control and Initial Solids Content

\begin{tabular}{|c|c|c|c|c|}
\hline $\begin{array}{l}\text { Mass of dish } \\
(\mathrm{g})\end{array}$ & $\begin{array}{c}\text { Mass of dish + wet sample } \\
(\mathrm{g})\end{array}$ & $\begin{array}{c}\text { Mass of dish + dry } \\
\text { sample } \\
(\mathrm{g})\end{array}$ & $\begin{array}{c}\text { Water Content } \\
(\%)\end{array}$ & $\begin{array}{l}\text { Slump } \\
\text { (cm) }\end{array}$ \\
\hline 1.63 & 49.82 & 18 & 1.943799633 & 8.4 \\
\hline 1.61 & 40.59 & 14.87 & 1.939668175 & 8.8 \\
\hline 1.6 & 36.64 & 13.52 & 1.939597315 & 8.8 \\
\hline 1.61 & 41.03 & 15.04 & 1.935219657 & 7.6 \\
\hline 1.66 & 41.83 & 15.29 & 1.947175348 & 8.1 \\
\hline 1.63 & 39.8 & 14.61 & 1.940677966 & 8.5 \\
\hline 1.67 & 37.52 & 13.86 & 1.940935193 & 8.3 \\
\hline 1.55 & 38.22 & 14.06 & 1.931254996 & 8.8 \\
\hline 1.64 & 31.67 & 11.87 & 1.935483871 & 8.1 \\
\hline 1.68 & 40 & 12.62 & 2.50274223 & 8.1 \\
\hline 1.69 & 42.66 & 15.62 & 1.941134243 & 8.4 \\
\hline \multirow[t]{3}{*}{1.65} & 33.81 & 12.62 & 1.931631723 & 8.9 \\
\hline & & Average & 1.985776696 & \\
\hline & & Solids Content & 0.334921229 & \\
\hline
\end{tabular}

The figures below show the bulk electrical conductivity recorded by VWC sensors in Layers 1, 2 and 3 of the thin lift dry box. 


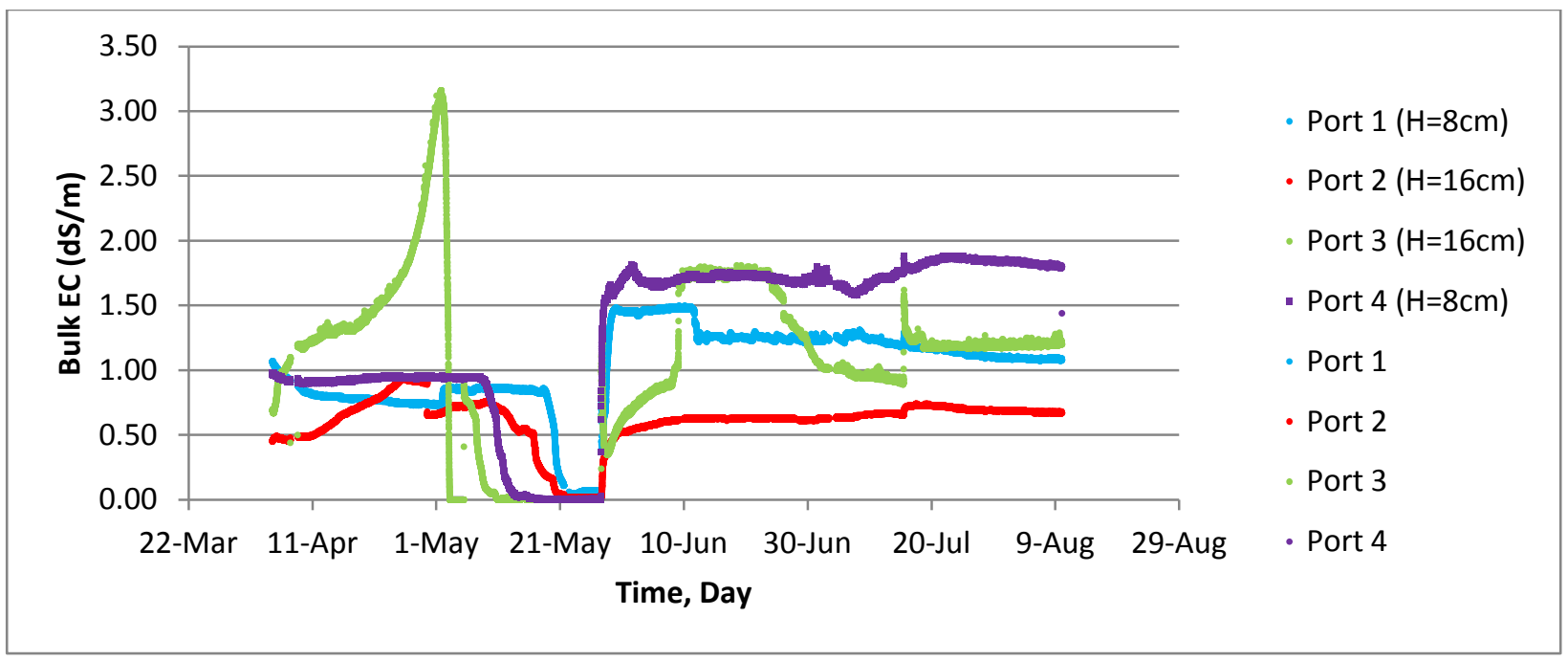

Figure C1. Bulk EC from 5TE from 5TE Probes in Layer 1

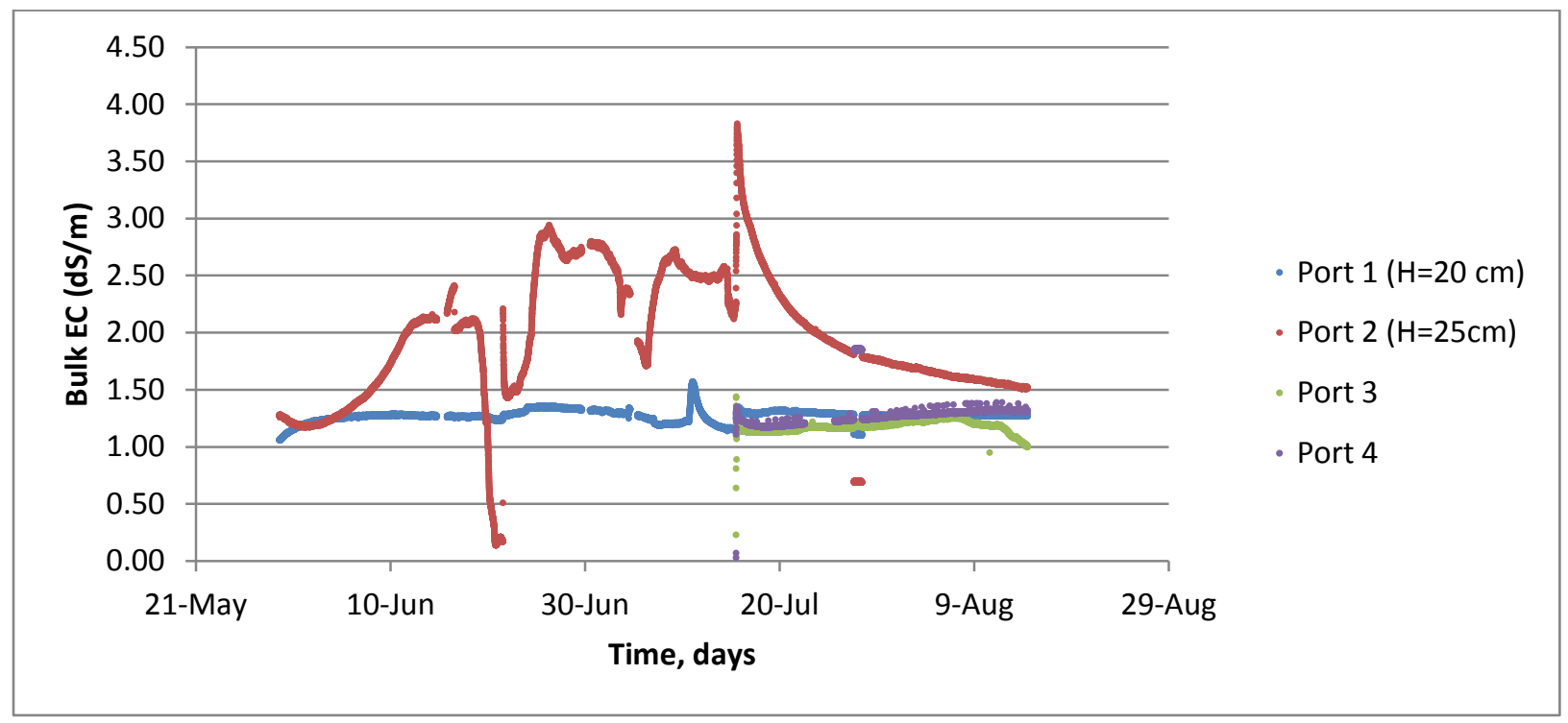

Figure C2. Bulk EC from 5TE Probes in Layers 2 and 3

The tables below provide a summary of the height and mass measurements recorded before, during and after the deposition of Layer 2. 
Table C3 Initial and final solids contents - Thin layer 1

\begin{tabular}{|c|c|c|c|c|c|c|}
\cline { 2 - 7 } \multicolumn{1}{c|}{} & \multicolumn{2}{c|}{ Layer 1 } & Layer 2 & \multicolumn{2}{c|}{ Total } & Layer 3 \\
\hline & Initial & Final & Initial & Initial & Final & Initial \\
\hline Solids Content & 0.352 & 0.944 & 0.339 & 0.494 & 0.722 & 0.334921 \\
\hline Mass of Solids (kg) & 82.099 & 82.099 & 85.785 & 167.884 & 167.884 & 76.47162 \\
\hline Mass of Water (kg) & 151.139 & 4.850 & 167.431 & 172.282 & 64.680 & 151.8556 \\
\hline $\begin{array}{c}\text { Mass of Water Lost } \\
\text { (kg) }\end{array}$ & 0.000 & 146.289 & 0.000 & 0.000 & 107.602 & 0.000 \\
\hline
\end{tabular}

Figure C3 provides a breakdown of the TOC of the surface samples. At the beginning, the TOC is approximately the same in the different sample locations. As drying continues, the surface begins to have a greater TOC, and as the layer gets even drier, the CE values surpass the TOC of the surface.

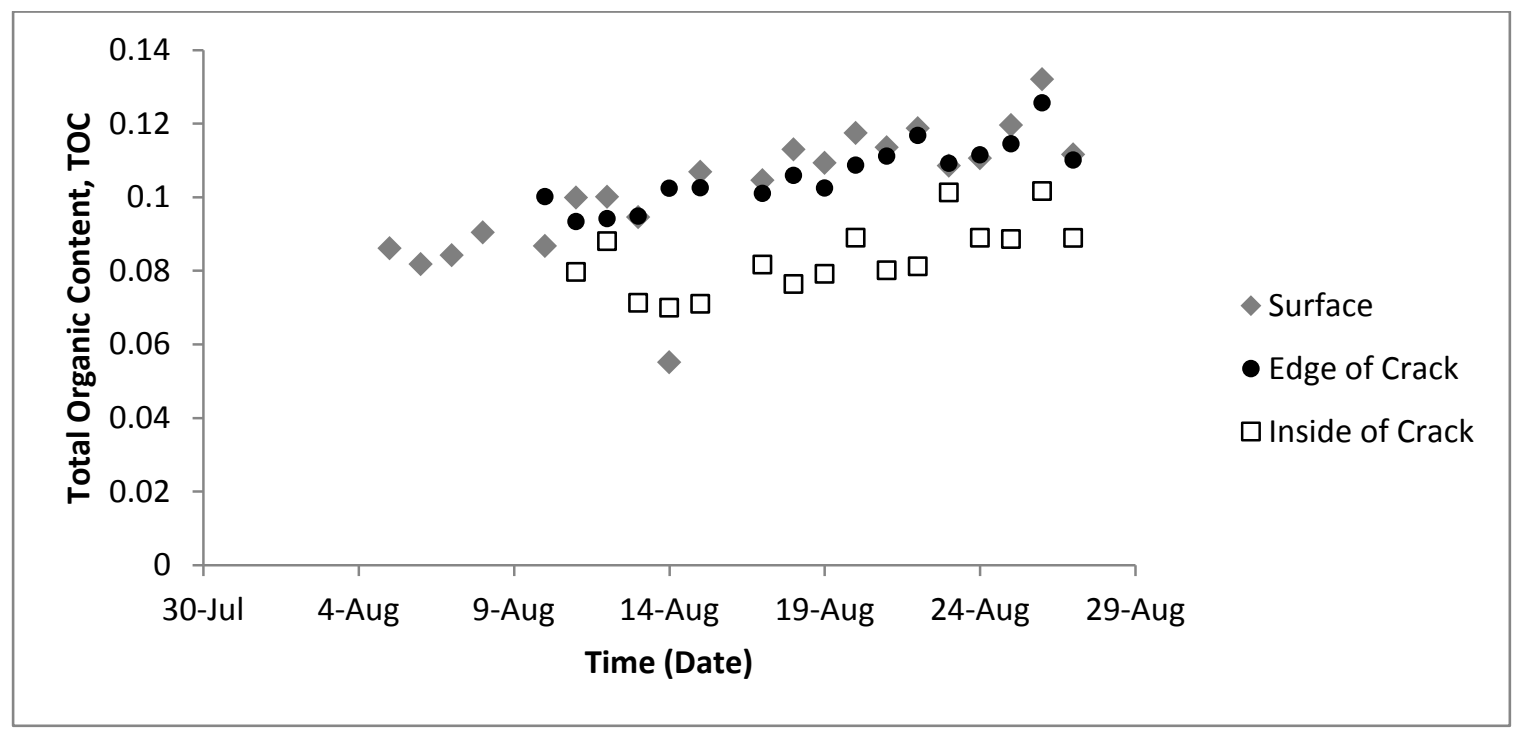

Figure C3. Surface sample total organic contents - Layer 3 


\section{APPENDIX D: Thick Lift Dry Box - Layer 1}

The following tables are a summary of measurements taken during the deposition and right after deposition of the third layer in the thin lift dry box.

Table D1. Quality Control and Initial Solids Content

\begin{tabular}{|r|r|r|r|r|}
\hline \multicolumn{1}{|c|}{ mdish } & mdish+sample & \multicolumn{1}{|c|}{ mdish+dry } & w\% & slump \\
\hline 2.2 & 35.4 & 13.3 & 1.990991 & 7.8 \\
\hline 2 & 28.7 & 11 & 1.966667 & 7.8 \\
\hline 2.1 & 46.3 & 16.9 & 1.986486 & 7.8 \\
\hline 2.1 & 37.2 & 13.9 & 1.974576 & 7.7 \\
\hline 2 & 30.4 & 11.7 & 1.927835 & 8 \\
\hline 2.1 & 38.9 & 14.4 & 1.99187 & 7.9 \\
\hline 2.1 & 22.8 & 9.1 & 1.957143 & 7.7 \\
\hline 2.1 & 19.4 & 7.8 & 2.035088 & 6.3 \\
\hline 2.1 & 32 & 12.1 & 1.99 & 7.6 \\
\hline 2.1 & 21.4 & 8.6 & 1.969231 & 7.4 \\
\hline 2.1 & 28 & 10.6 & 2.047059 & 7.4 \\
\hline & & & 1.985177 & \\
\hline & & solids content & 0.334989 & \\
\hline
\end{tabular}

The following figure shows the dewpoint profile at various locations at the surface of the tailings for layer 1 of the thick lift dry box.

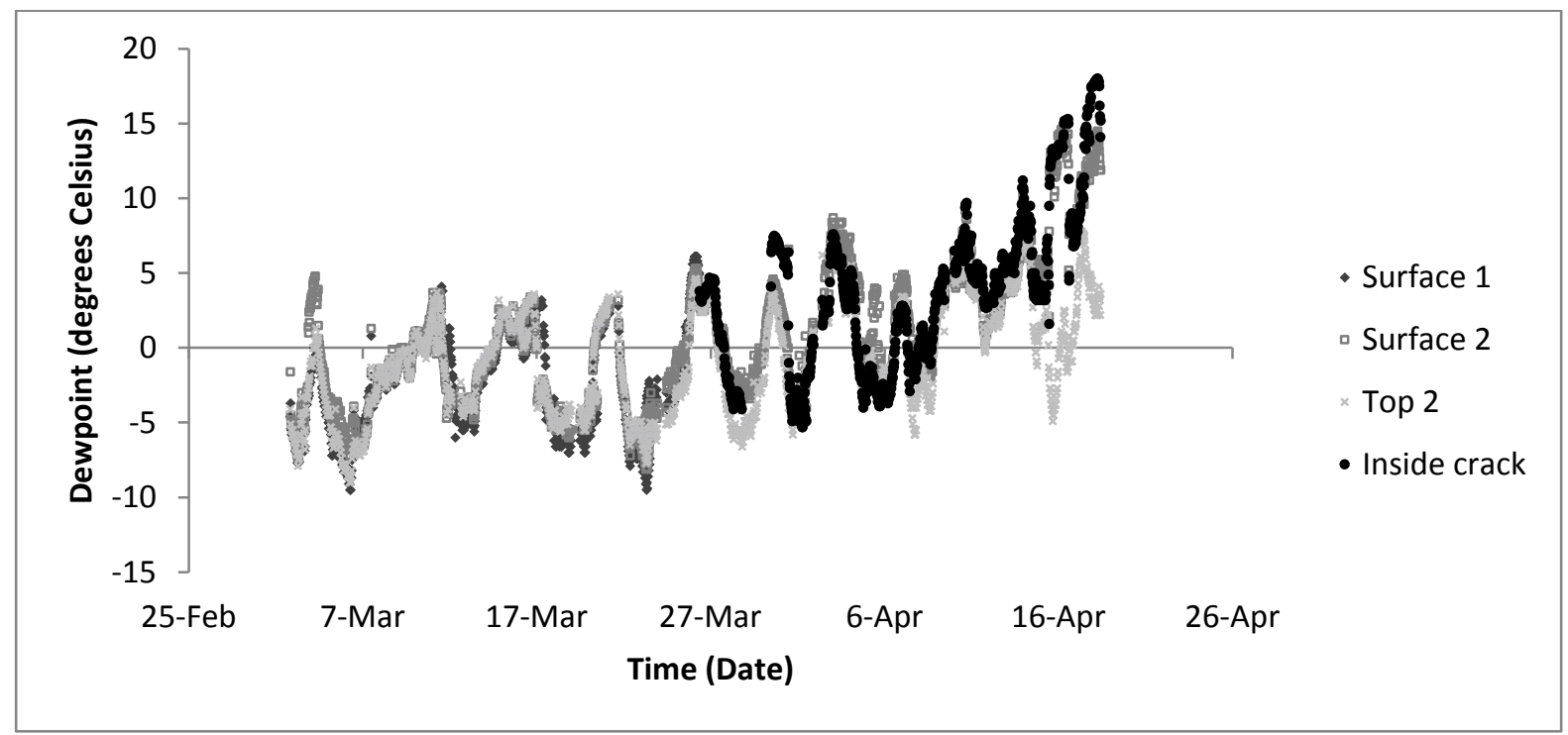

Figure D1. Dewpoint profile at the surface - Layer 1 
Figure D2 shows the senix readings obtained during Layer 1.

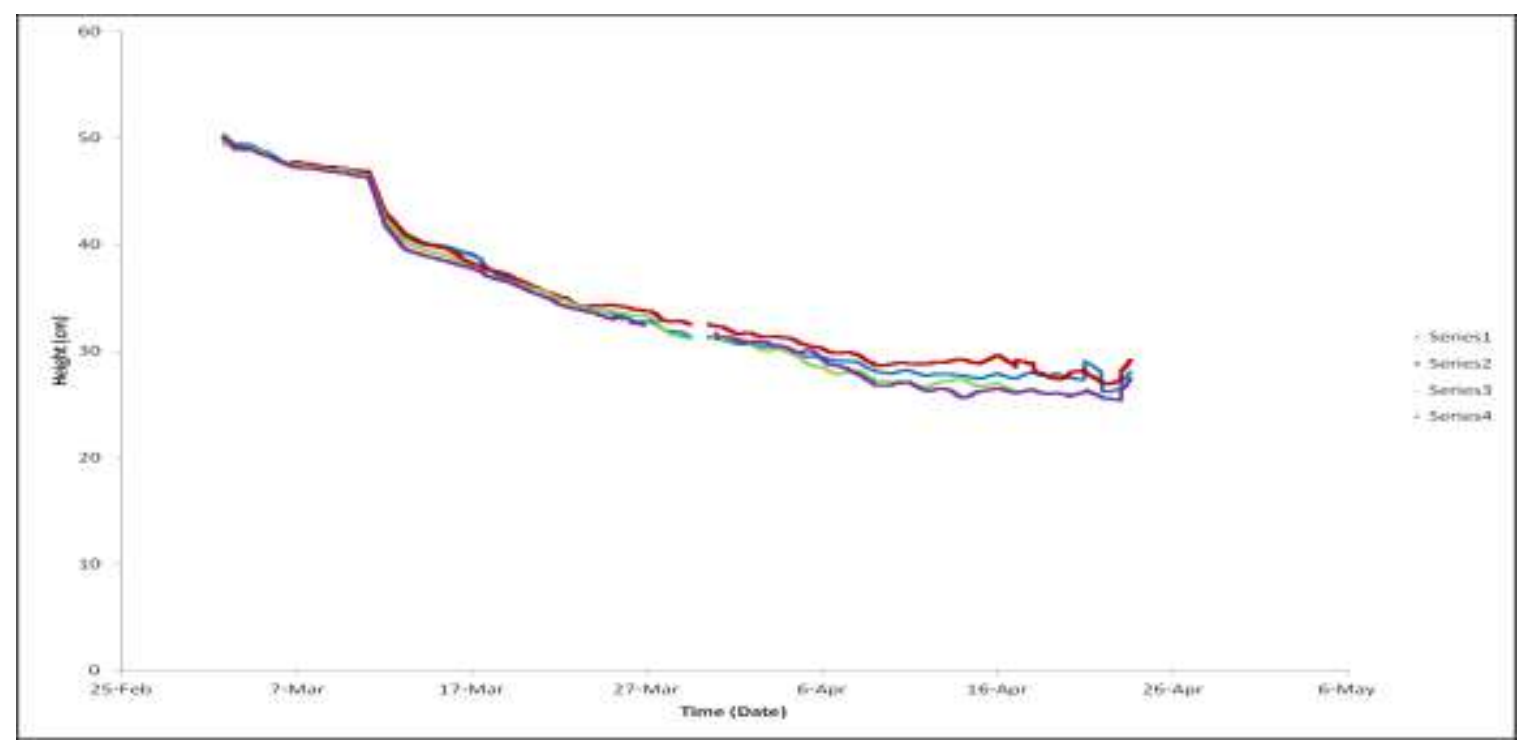

Figure D2. Overall tailings thickness from Senix sensors (Note: some data recorded during plate load test, core removal, and sensor placement still needs to be deleted)

The figures below show the bulk electrical conductivity recorded by VWC sensors in Layers 1 of the thick lift dry box.

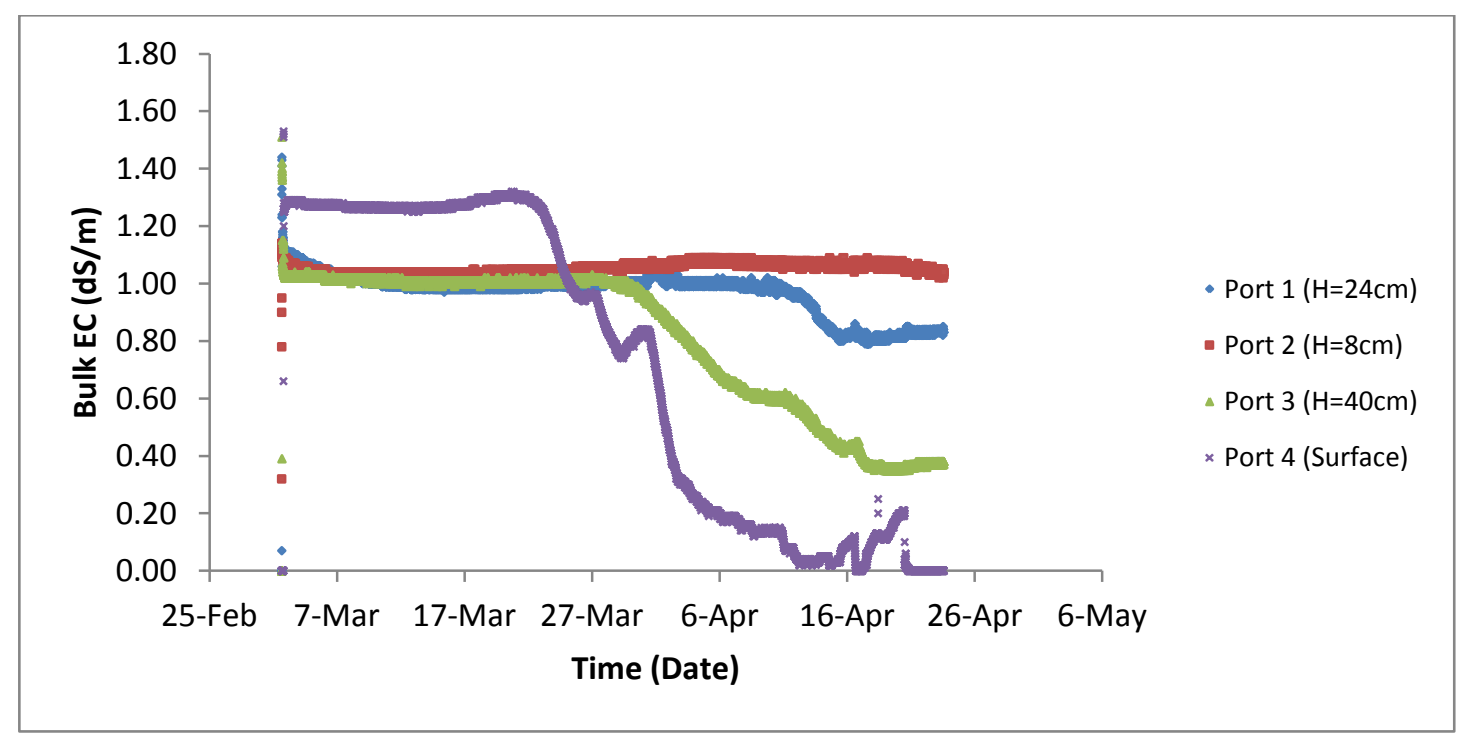

Figure D3. Bulk EC in the tailings - Layer 1 
Figure D4 provides a breakdown of the TOC of the surface samples. At the beginning, the TOC is approximately the same in the different sample locations. As drying continues, the surface begins to have a greater TOC, and as the layer gets even drier, the CE surpasses the TOC of the surface.

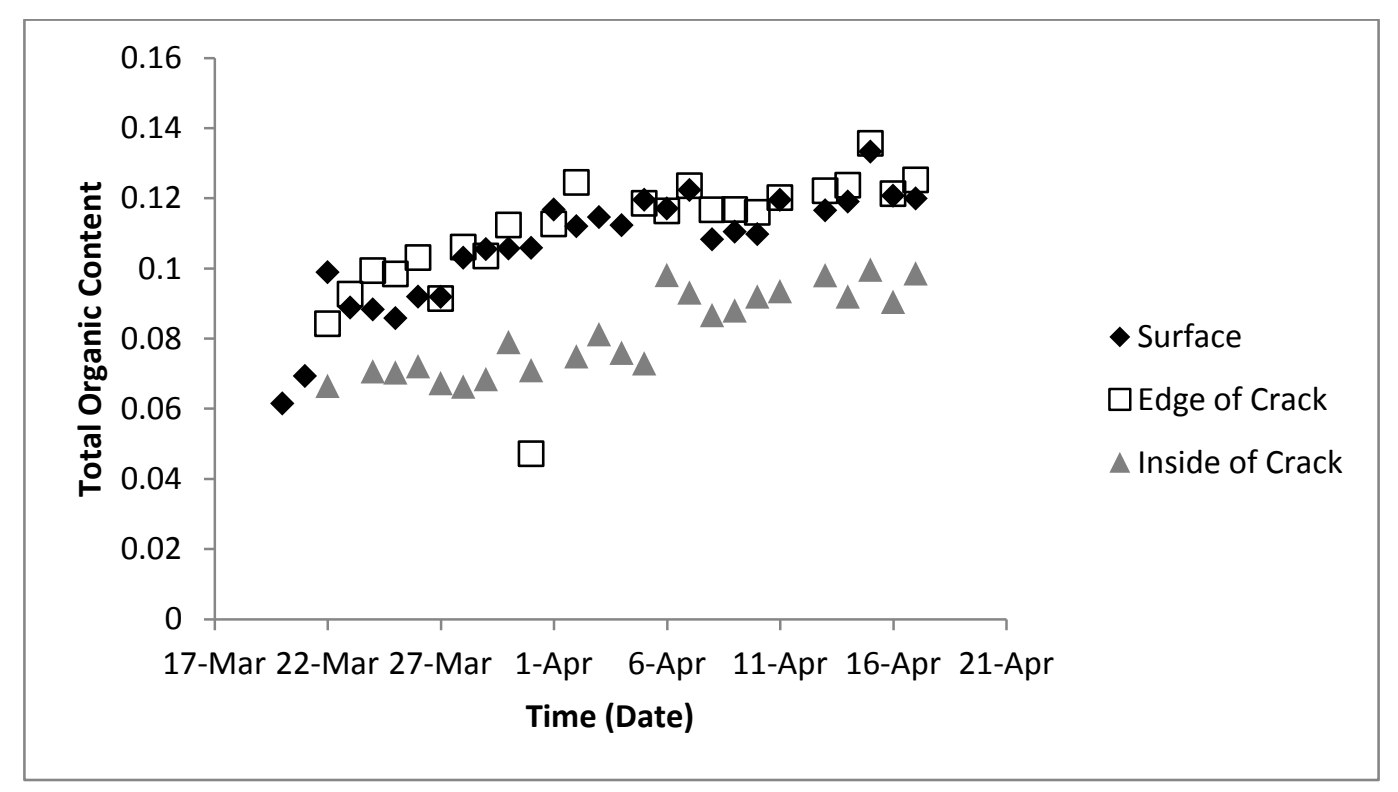

Figure D4. Surface sample total organic contents - Layer 1 


\section{APPENDIX E: Thick Lift Dry Box - Layer 2}

The following tables are a summary of measurements taken during the deposition and right after deposition of the third layer in the thin lift dry box.

Table E1. Quality Control and Initial Solids Content

\begin{tabular}{|r|r|r|c|r|}
\hline \multicolumn{1}{|c|}{ mdish } & mdish+sample & \multicolumn{1}{|c|}{ mdish+dry } & w\% & slump \\
\hline 2 & 24.7 & 9.9 & 1.873418 & 7.5 \\
\hline 2 & 17.6 & 7.4 & 1.888889 & 7.8 \\
\hline 2.1 & 24.3 & 9.7 & 1.921053 & 8 \\
\hline 2.1 & 30.5 & 11.8 & 1.927835 & 7.5 \\
\hline 2 & 14.5 & 6.3 & 1.906977 & 8.2 \\
\hline 2.1 & 20.6 & 8.4 & 1.936508 & 8 \\
\hline 2 & 15.1 & 6.6 & 1.847826 & 7.7 \\
\hline 2 & 27.8 & 10.9 & 1.898876 & 8.4 \\
\hline 2.1 & 15.2 & 6.6 & 1.911111 & 8.1 \\
\hline 2.1 & 21.4 & 8.7 & 1.924242 & 7.8 \\
\hline 2 & 34.3 & 13.1 & 1.90991 & 7.8 \\
\hline & & & 1.90424 & \\
\hline & & solids content & 0.344324 & \\
\hline
\end{tabular}

Figure E1 provides dewpoint profiles at various locations at the surface of the tailings for Layer 2 of the thick lift dry box.

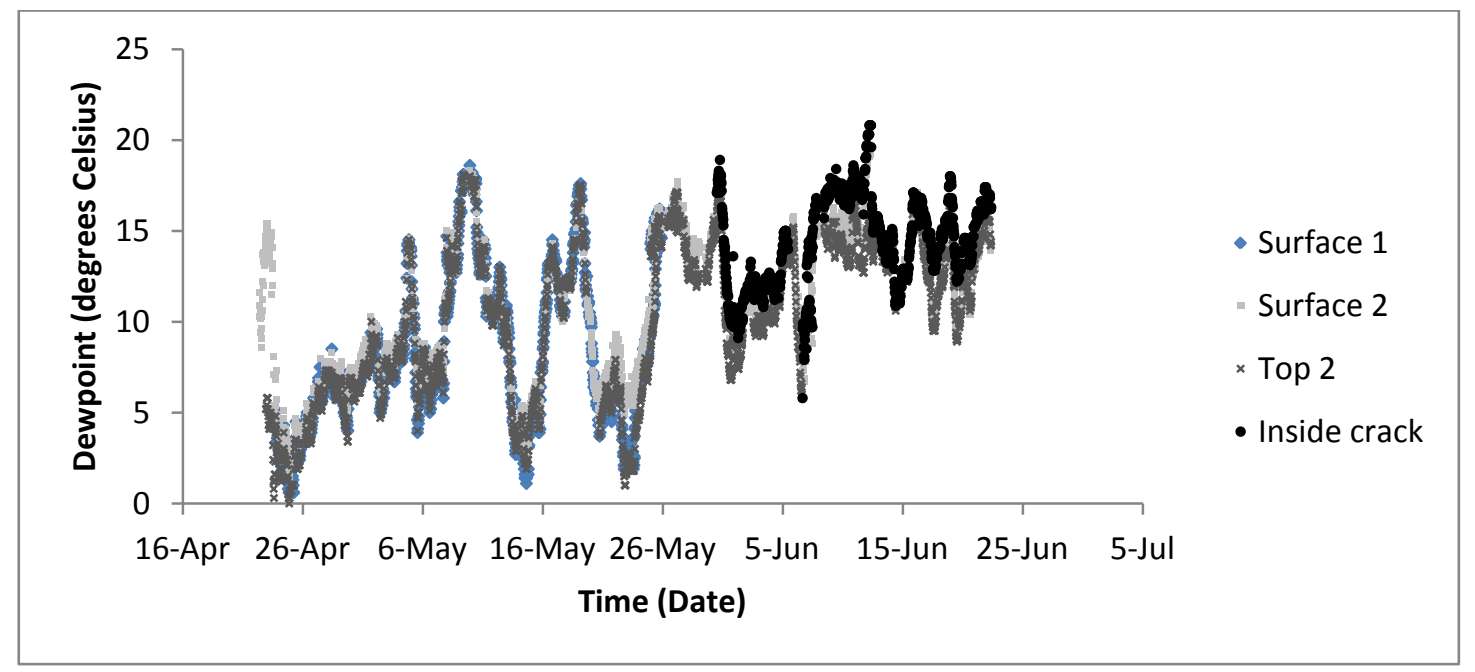

Figure E1. Dewpoint profiles at the surface - Layer 2 
Figure E2 demonstrates the settlement of the tailings recorded by the senix sensors for the second layer of the thick lift dry box.

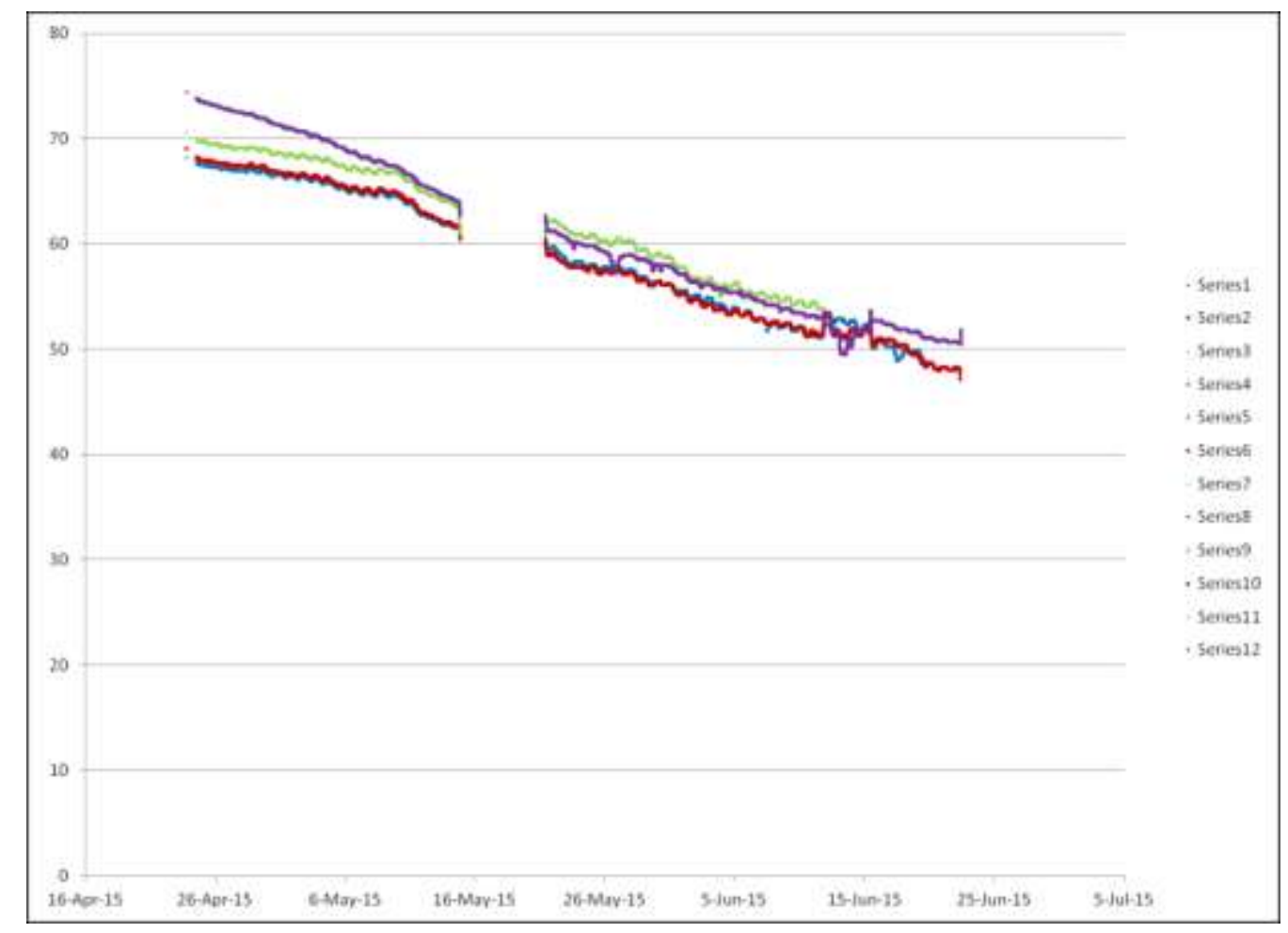

Figure E2. Overall tailings thickness from Senix sensors - Layer 2

The following figure shows the bulk EC recorded by the VWC sensors in layer 1 after the addition of layer 2 in the thick lift dry box. 


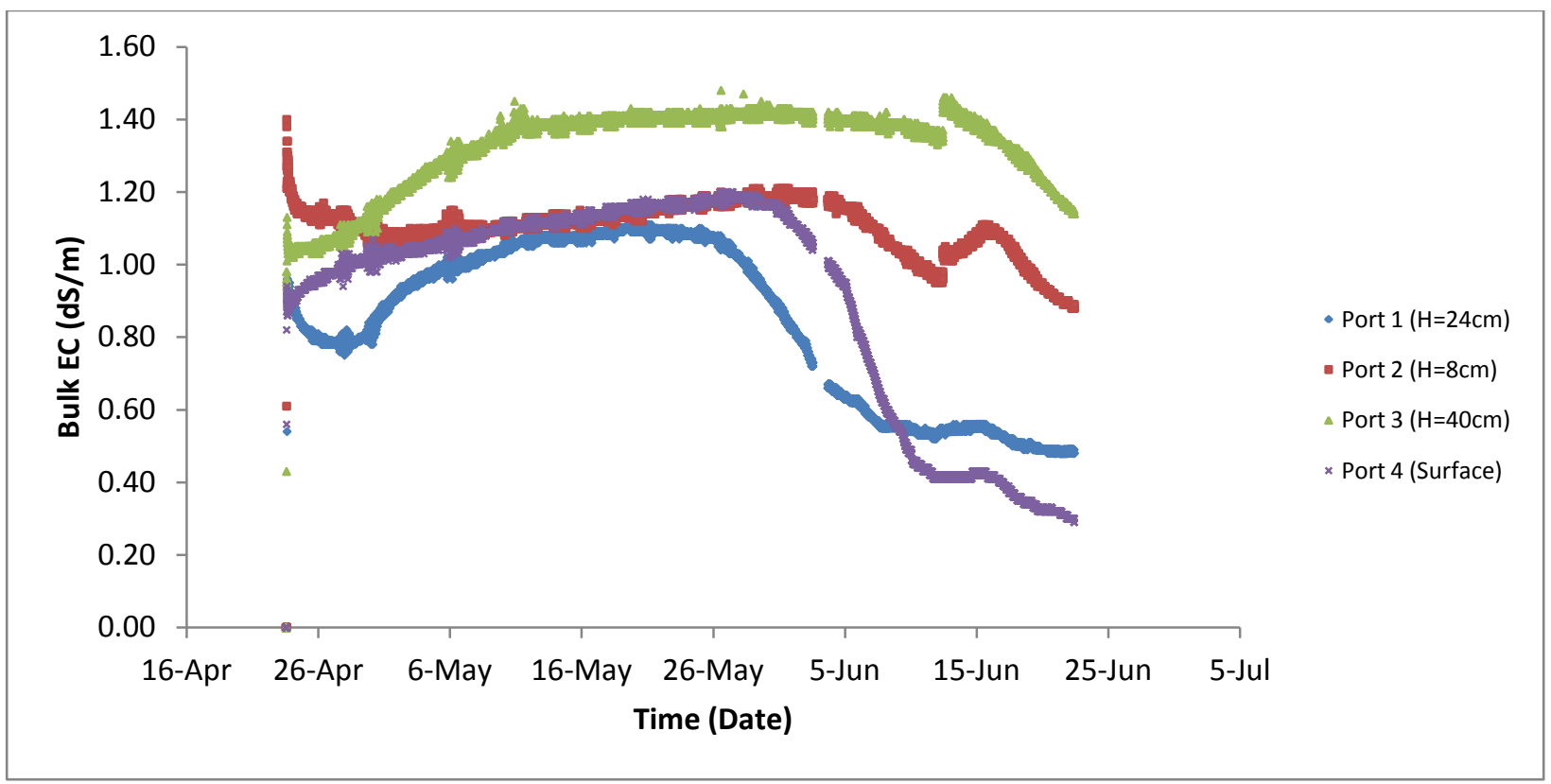

Figure E3. Bulk EC in bottom layer - Layer 2

Figure E4 provides a breakdown of the TOC of the surface samples. At the beginning, the TOC is greater at the surface. As drying continues, the measurements at the IC surpass those at the surface.

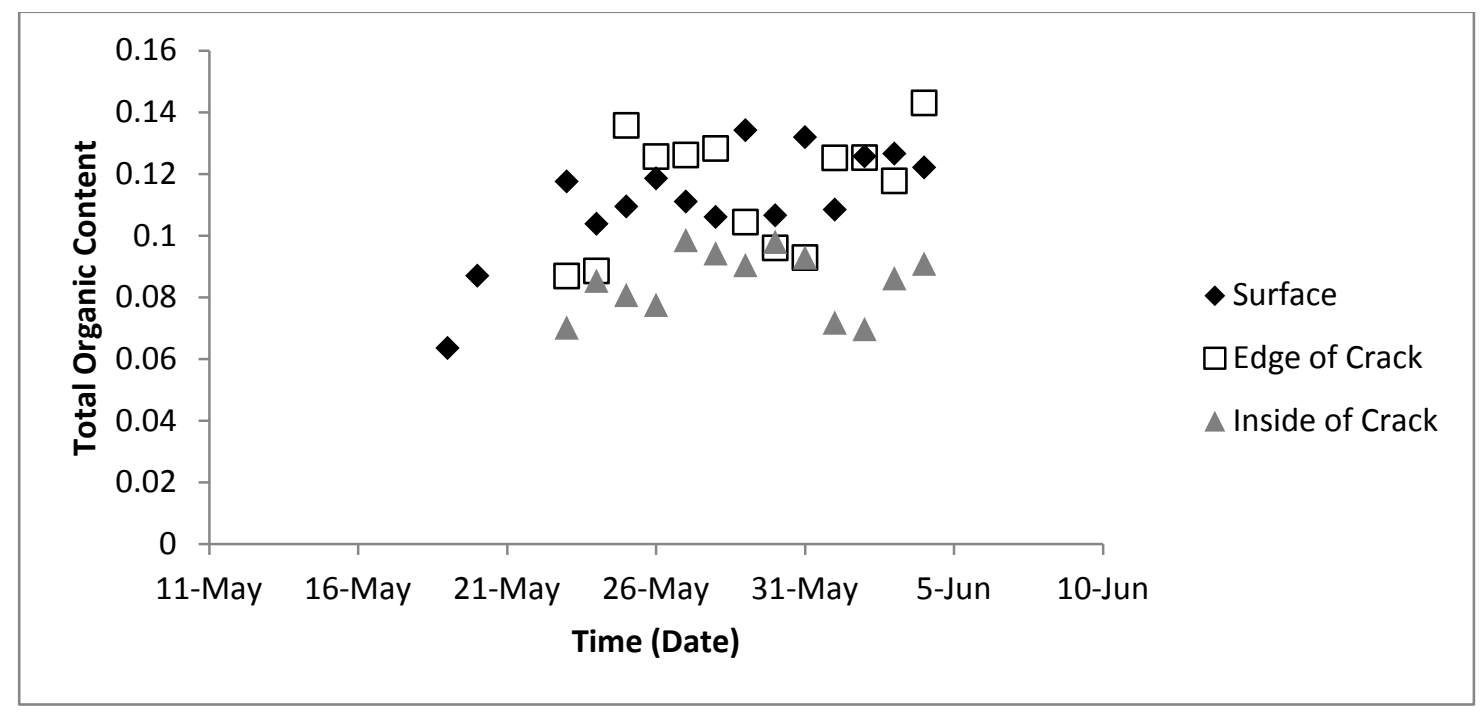

Figure E4. Surface samples total organic contents - Layer 2 


\section{APPENDIX F: Overall Dry Box Results}

Figure F1 provides a breakdown of the TOC of the surface samples for the thin lift dry box. At the beginning, the TOC is approximately the same in the different sample locations. As drying continues, the surface begins to have a greater TOC, and as the layer gets even drier, the CE surpasses the TOC of the surface.

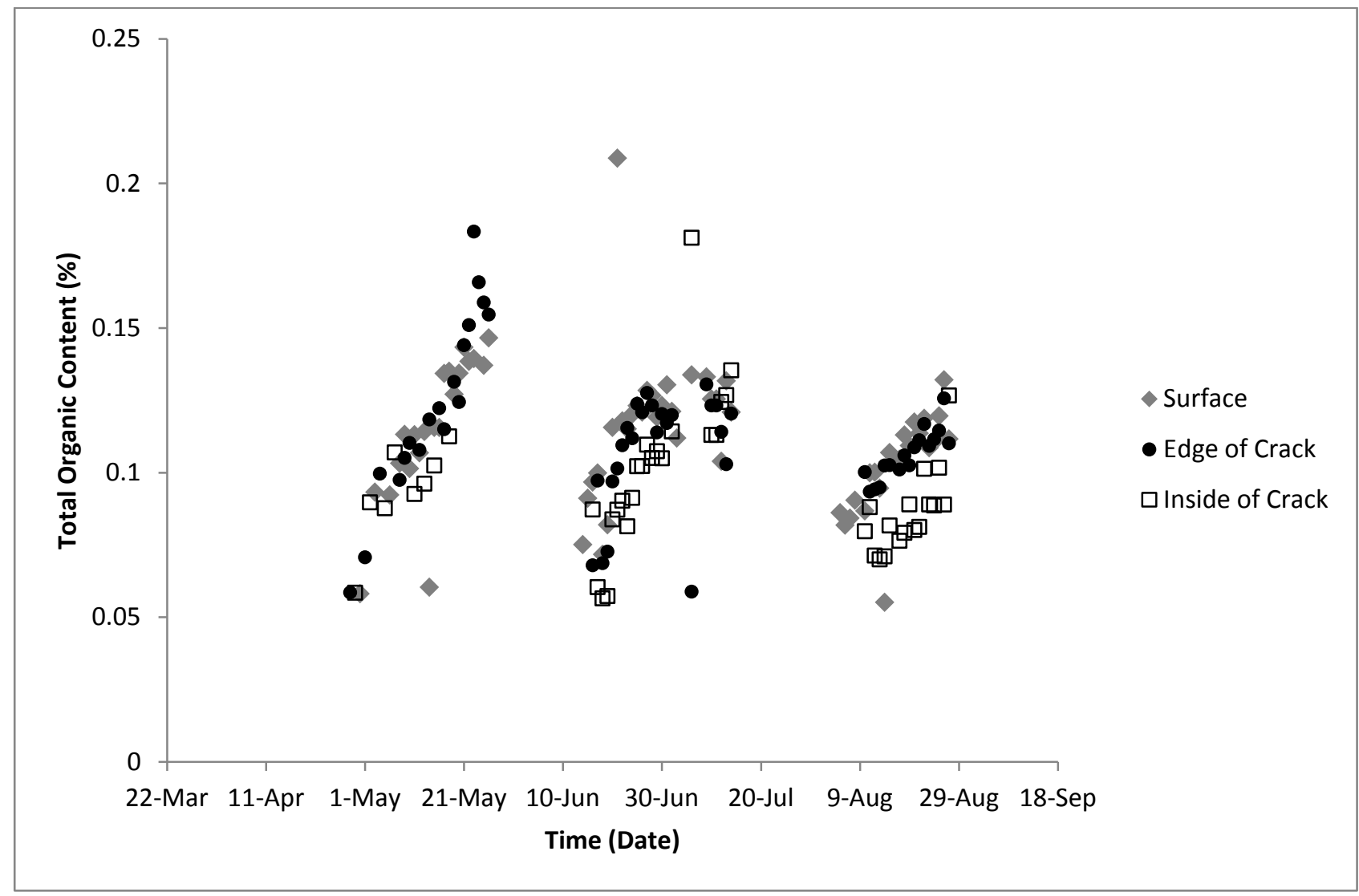

Figure F1. Thin Lift surface sample total organic contents - Overall

Figure F2 provides a dewpoint profile for various locations at the surface for the thick lift dry box throughout the during of the entire test. 
- Surface 1 "Surface 2 × Top 2 •Inside crack

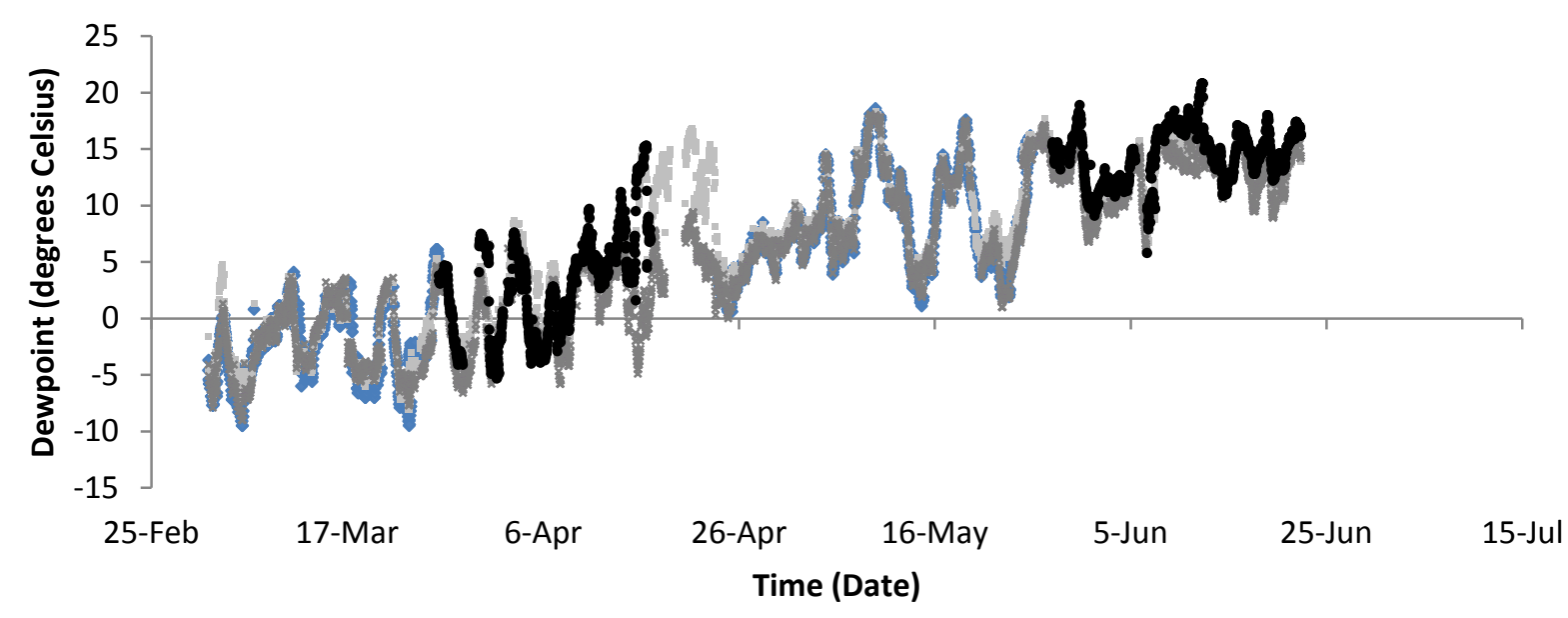

Figure F2. Dewpoint profiles at the surface - Overall

Figure F3 provides a breakdown of the TOC of the surface samples for the thick lift dry box. At the beginning, the TOC is approximately the same in the different sample locations. As drying continues, the surface begins to have a greater TOC, and as the layer gets even drier, the CE surpasses the TOC of the surface.

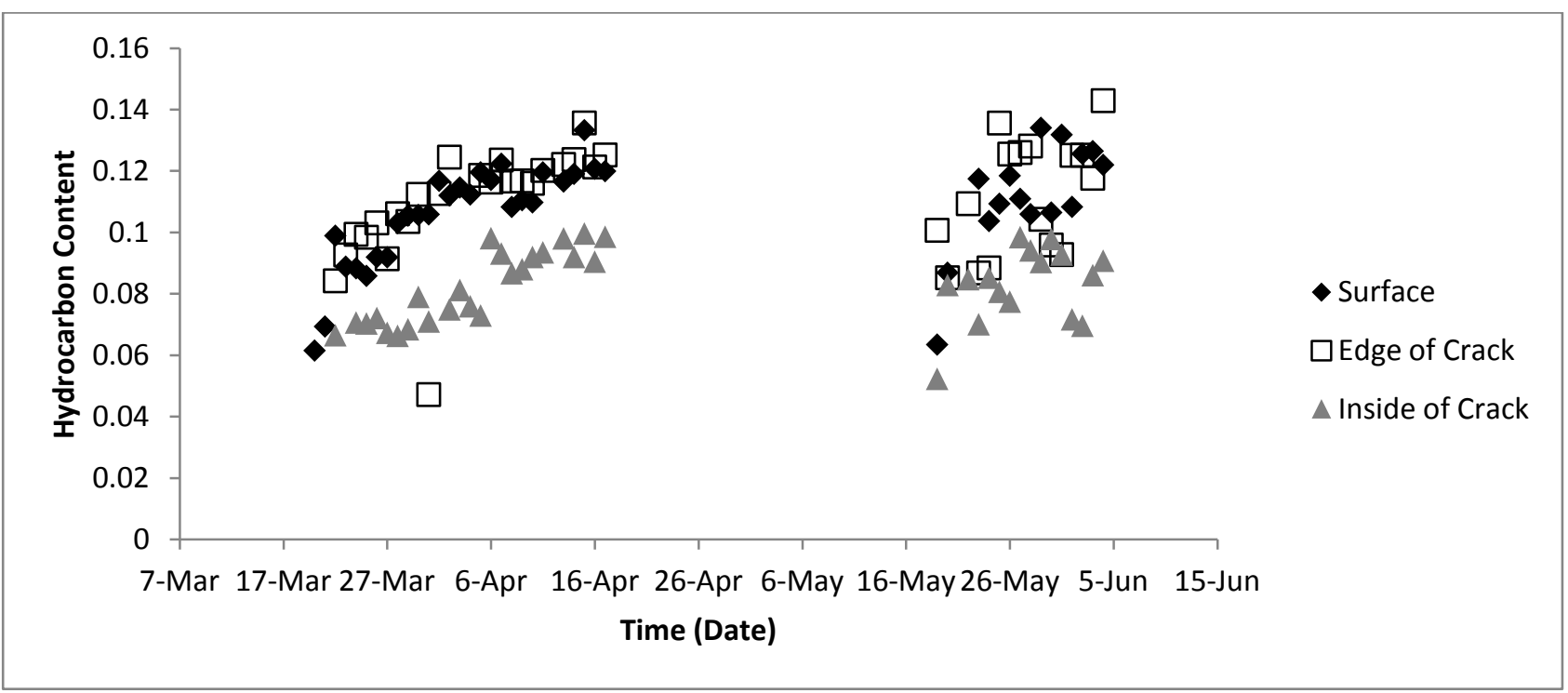

F3. Surface sample total organic contents - Overall 


\section{APPENDIX G: Crack Island Analysis for Thick Lift Dry Box}

After the thick layer dry box, and plate load tests were completed, two crack islands were extracted from the dry box. The first one was extracted right after the tests, on July 1st. Then, water was added to another crack island that remained in the box, in an attempt to bring the degree of saturation of the crack island back to 1.0. The island was left to absorb the added water for 24 hours. Then the rewetted crack island was extracted on July 2 nd. The results are detailed in the following sections.

\section{Dry Crack Island}

The location of the extracted dry crack island is shown in Figure G1. At this point, the solids content was calculated to be approximately $70 \%$ in the top layer.

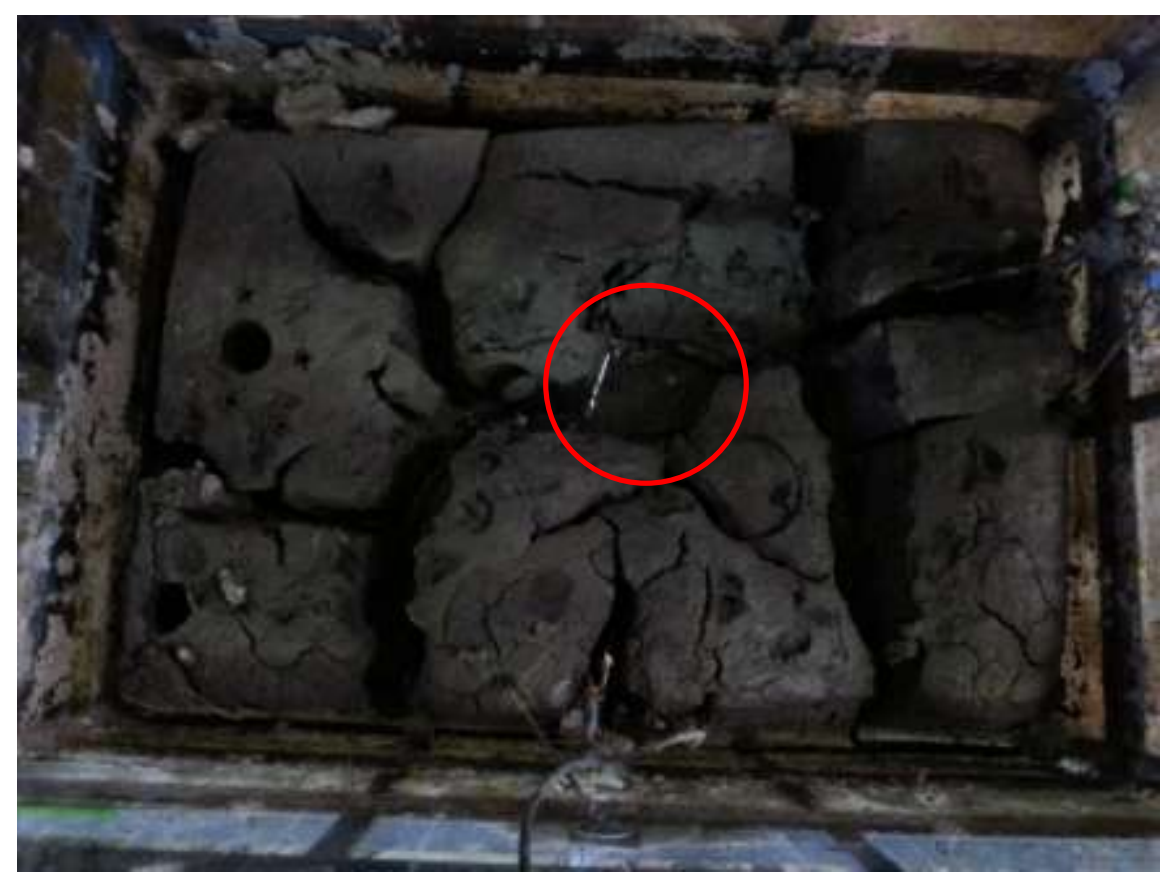

Figure G1. Dry crack island sample location 
A side/top view of the extracted sample is shown in Figure G2.

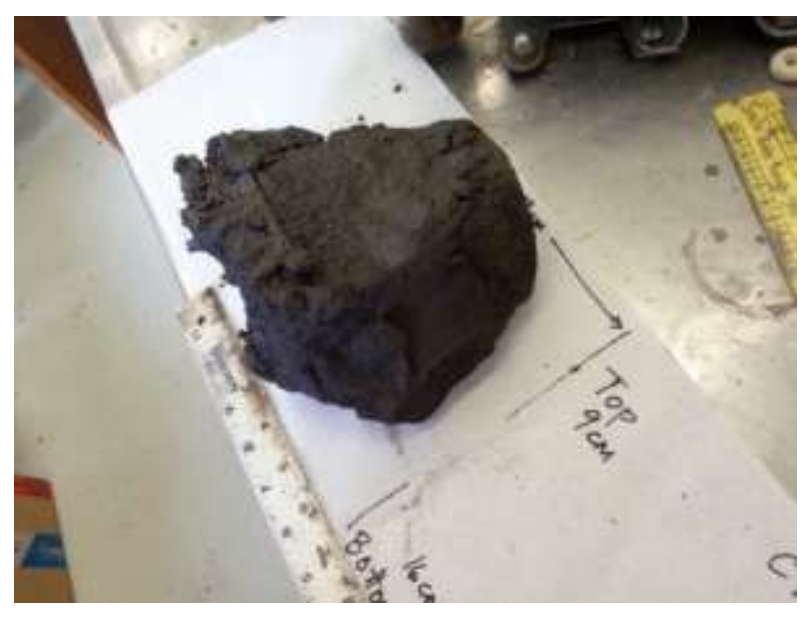

Figure G2. Dry crack island sample

The approximate dimensions of the sample were $16.7 \mathrm{~cm} \times 9 \mathrm{~cm} \times 16 \mathrm{~cm}(\mathrm{~L} \times \mathrm{W} \times$ D). The sample was divided into sections of $1 \mathrm{~cm} \times 1 \mathrm{~cm} \times 2 \mathrm{~cm}$ as shown in Figure $\mathrm{G} 3$, providing 3D samples to measure GWC, total, and osmotic suctions.

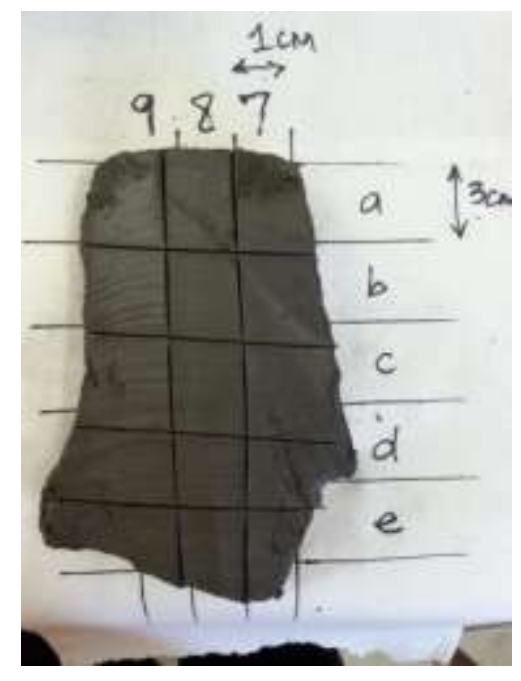

Figure G3. Mid-section of dry crack island 
Profiles for GWC, total suction and osmotic suction are compared along the vertical and horizontal axes along the middle of the section as shown by the dissections in Figure G4.

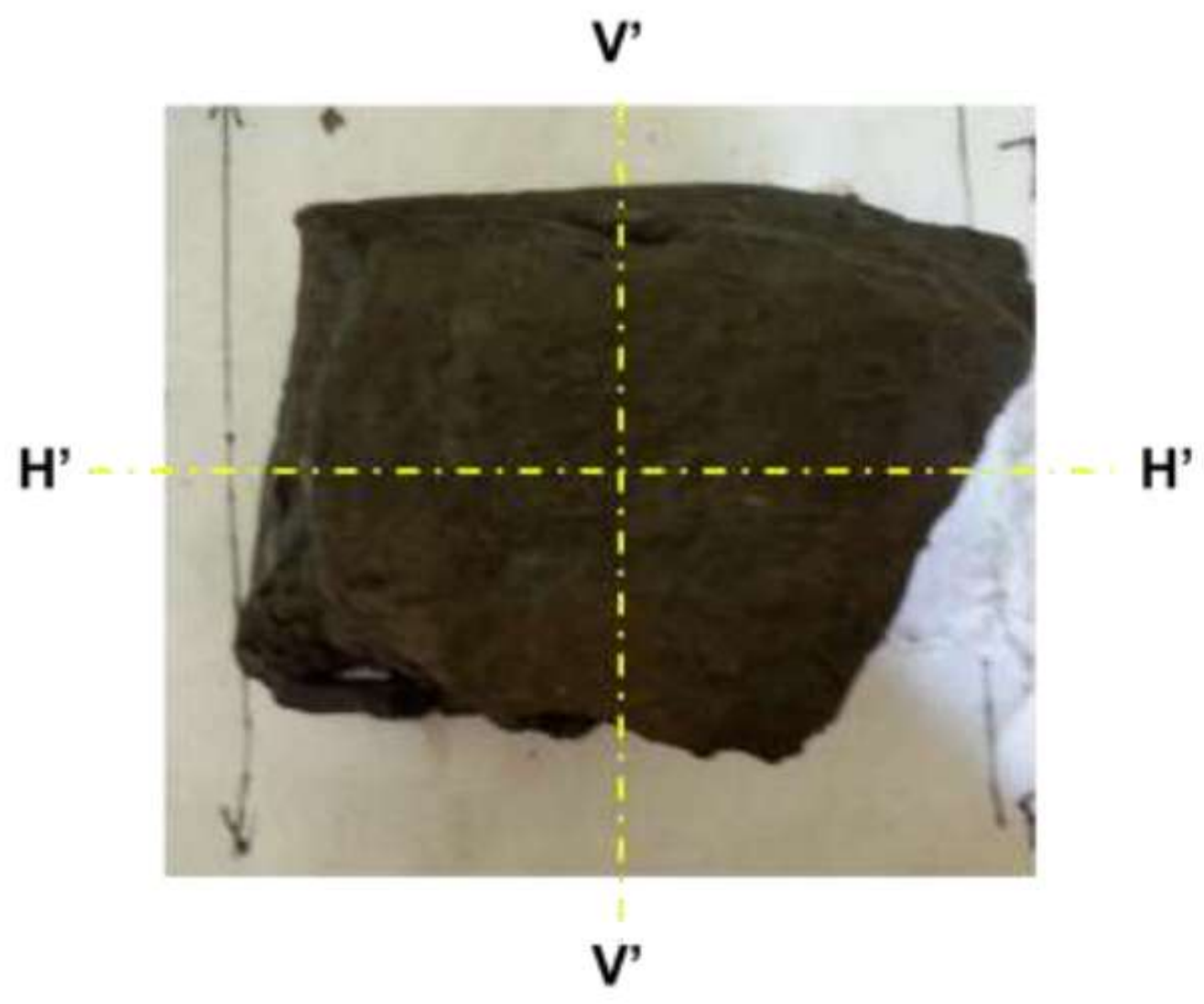

Figure G4. Vertical and horizontal axes for dry crack island

The profiles are shown in Figures G5 to G7. The axis and depth of each row of samples is indicated in the legend of the figure. The GWC and suctions are plotted in terms of distance of each sample from the middle of the section. 


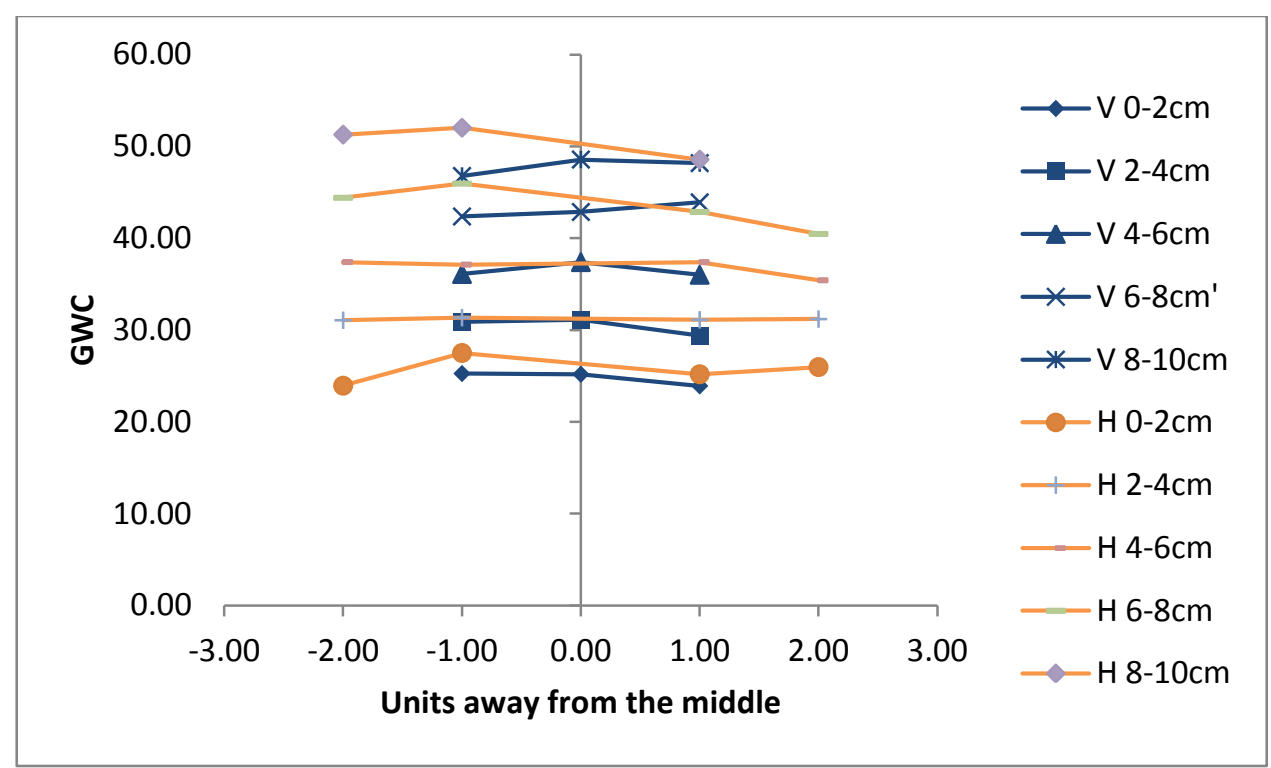

Figure G5. GWC profile of dry crack island mid-section

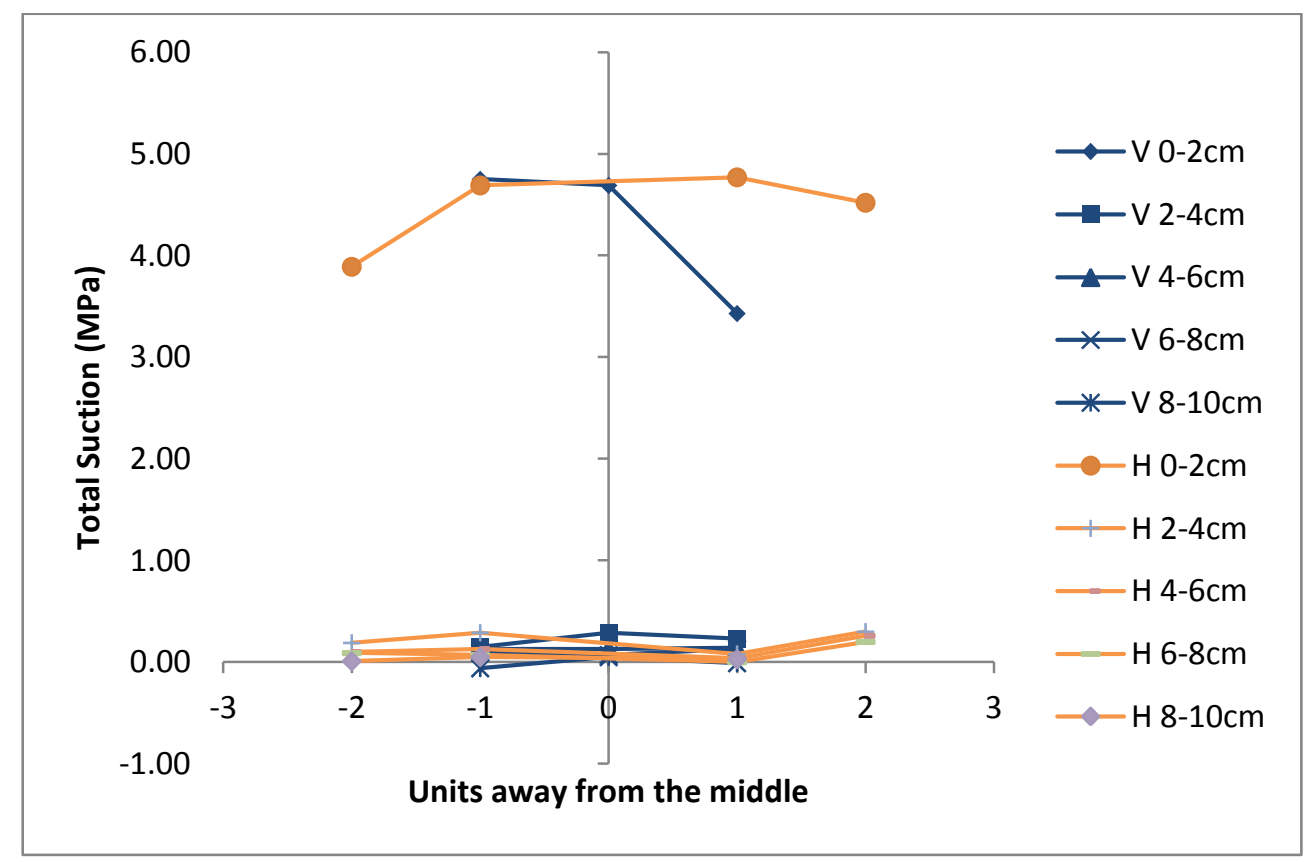

Figure G6. Total suction profile of dry crack island mid-section 


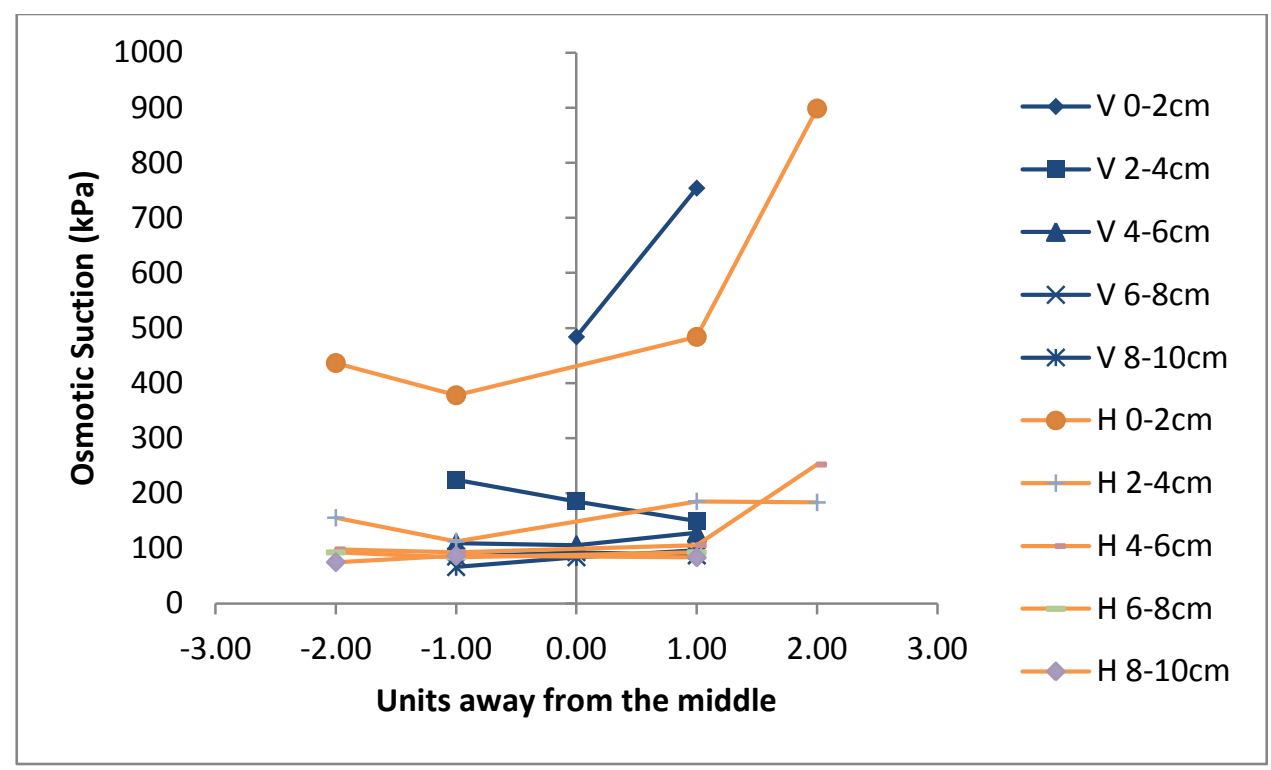

Figure G7. Osmotic suction profile of dry crack island mid-section

\section{Rewetted Crack Island}

The location of the extracted dry crack island is shown in Figure G8. At this point, the solids content was calculated to be approximately $70 \%$ in the top layer.

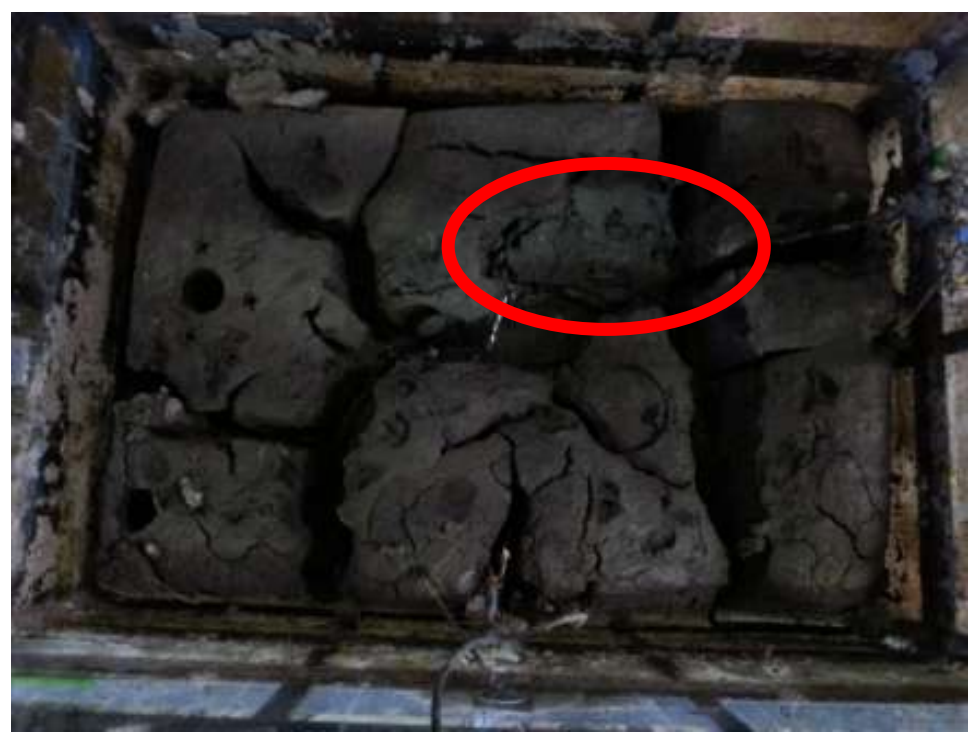

Figure G8. Rewetted crack island sample location 
A side/top view of the extracted sample is shown in Figure G9.

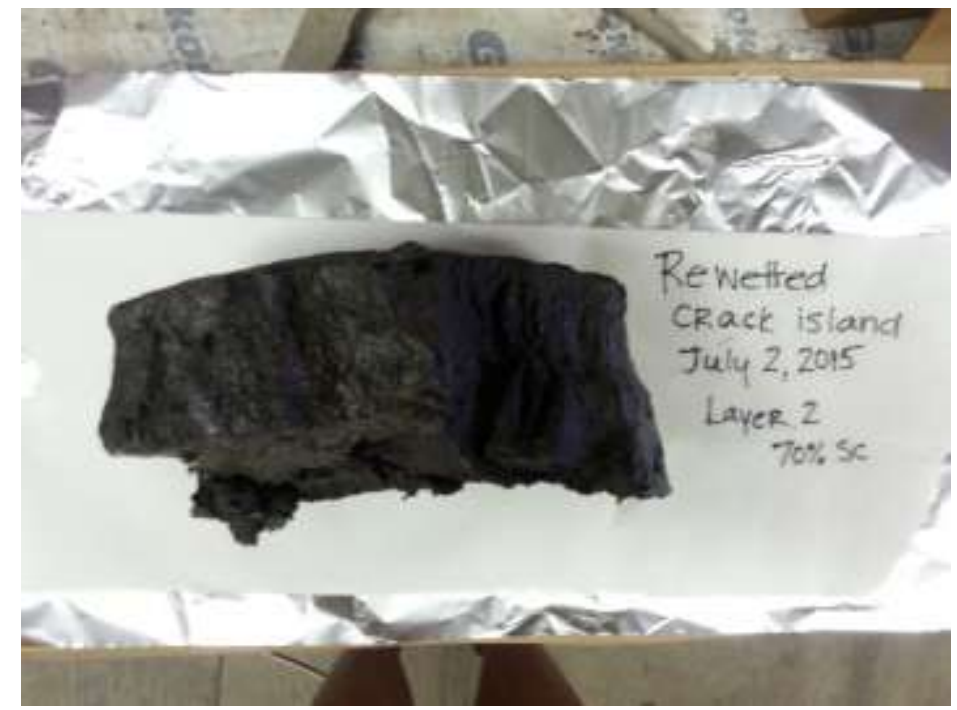

Figure G9. Rewetted crack island sample

The approximate dimensions of the sample were $24 \mathrm{~cm} \times 10 \mathrm{~cm} \times 9 \mathrm{~cm}(\mathrm{~L} \times \mathrm{W} \times \mathrm{D})$. The depth of the rewetted sample was shorter since a great percentage of added water was not absorbed by the crack island itself, but ran over the edges of the sample, and into the cracks, rendering the bottom wetter. The sample was divided into sections of $2 \mathrm{~cm} \times 2 \mathrm{~cm} \times 3 \mathrm{~cm}$ as shown in Figure G10, providing 3D samples to measure GWC, total, and osmotic suctions.

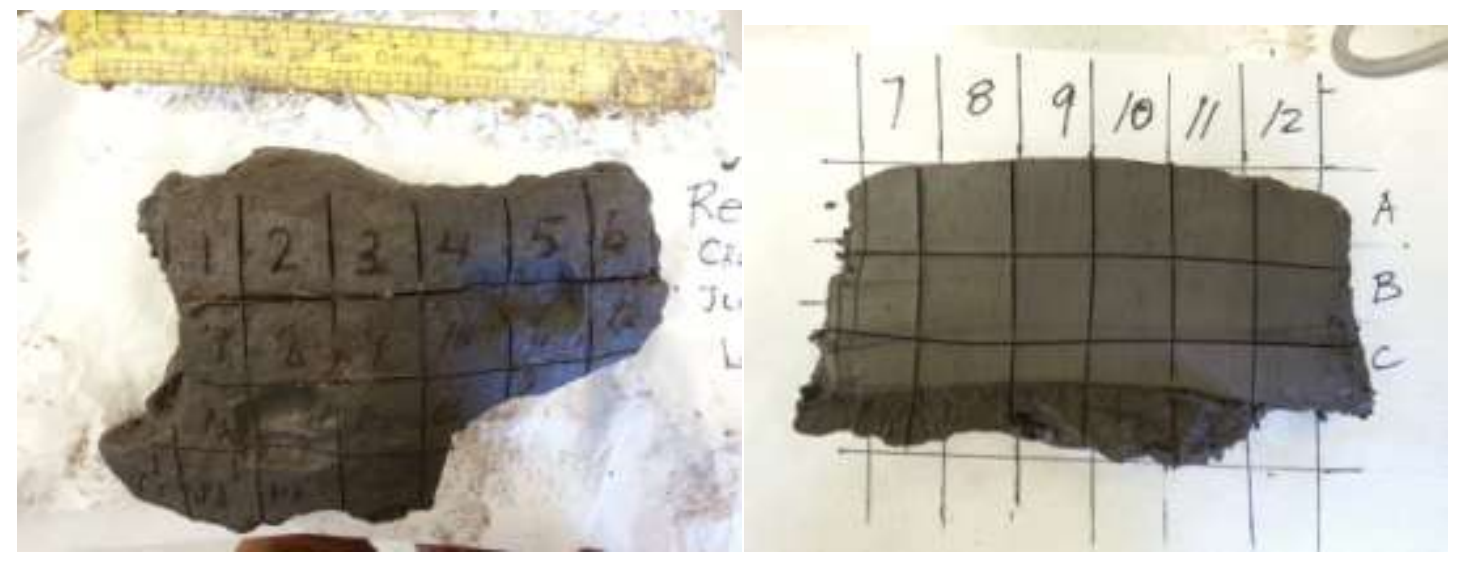

Figure G10. Rewetted crack island dimensions and mid-section 
Profiles for GWC, total suction and osmotic suction along the vertical and horizontal axes shown by the dissections in Figure G11.

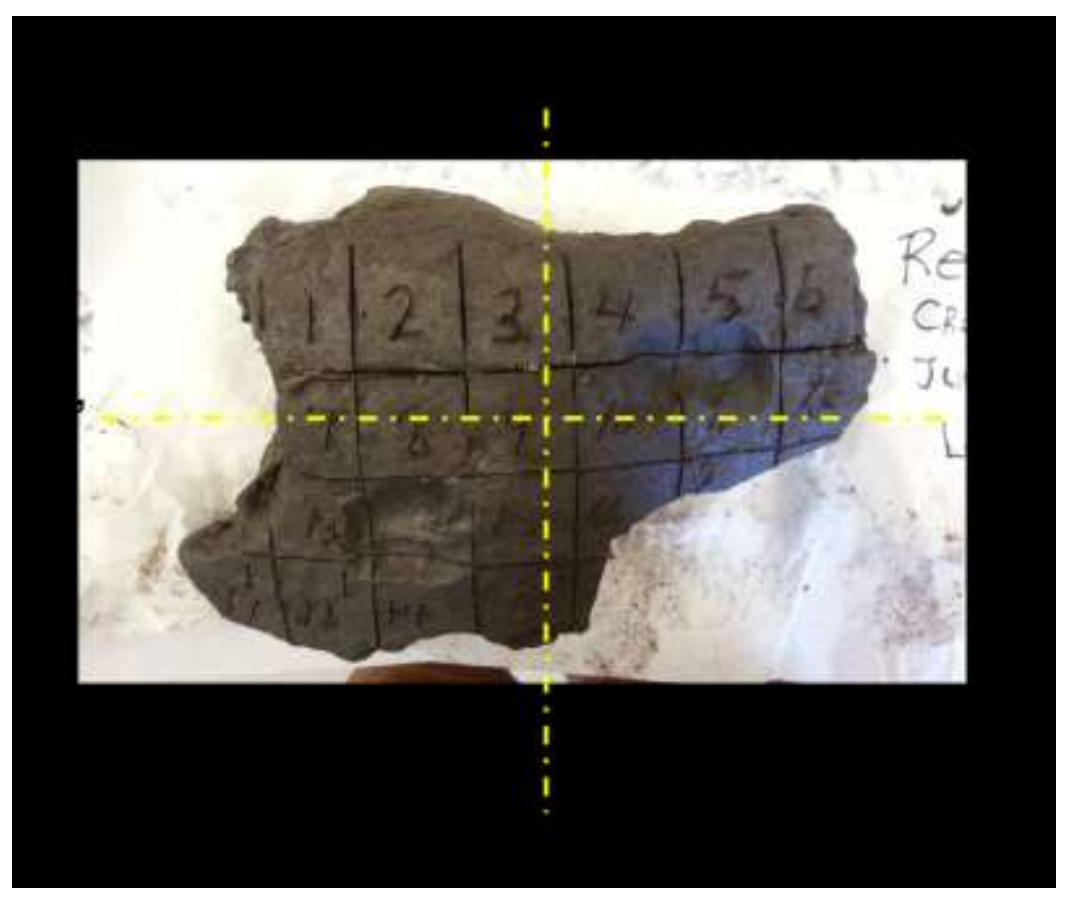

Figure G11. Vertical and horizontal axes for rewetted crack island

The profiles are shown in Figures $\mathrm{G} 12$ to $\mathrm{G} 14$. The axis and depth of each row of samples is indicated in the legend of the figure. The GWC and suctions are plotted in terms of distance of each sample from the middle of the section. 


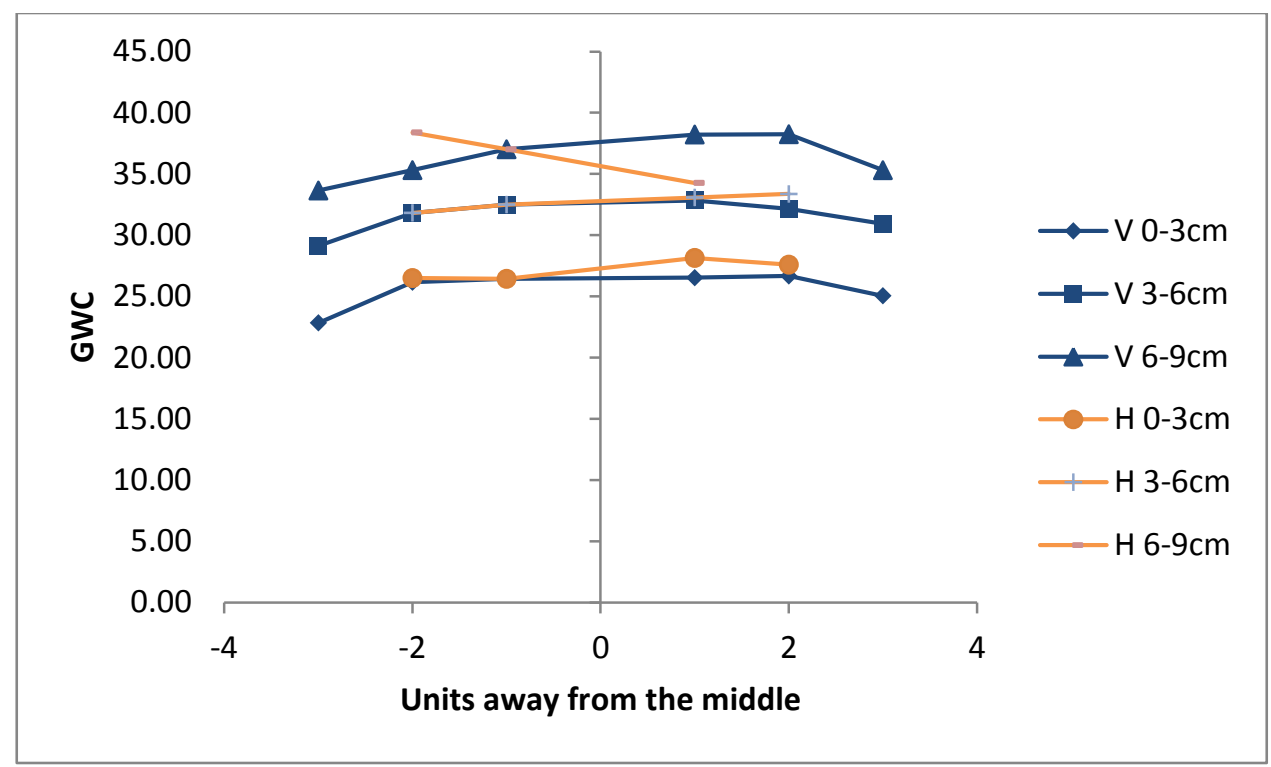

Figure G12. GWC for rewetted crack island mid-section

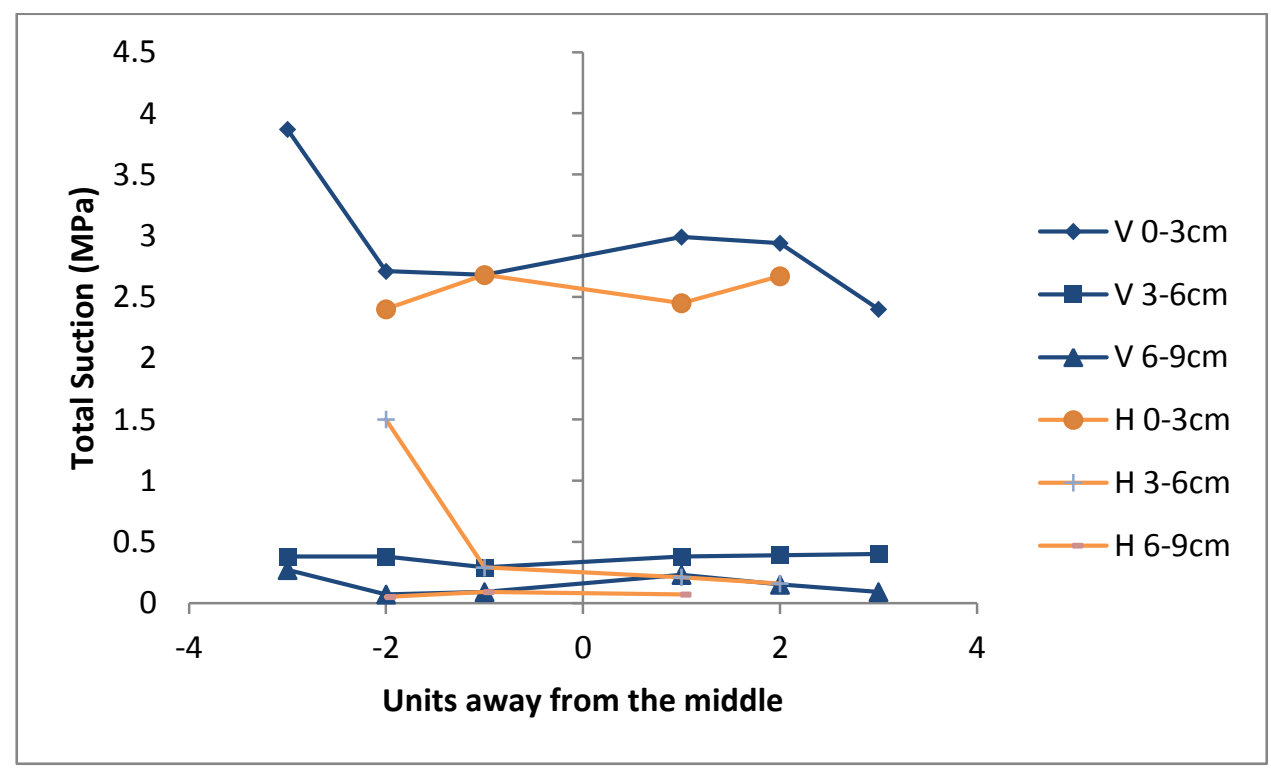

Figure G13. Total suction profile for rewetted crack island mid-section 


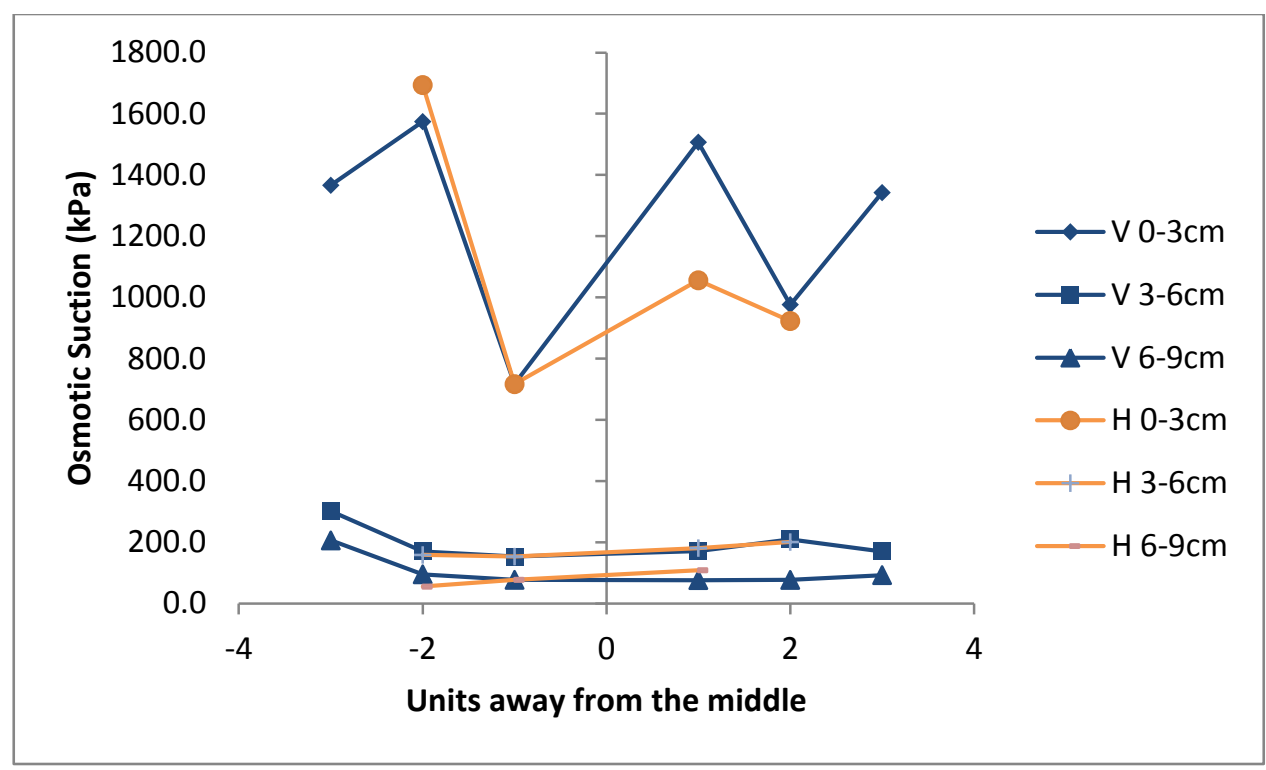

Figure G14. Osmotic suction profile for rewetted crack island mid-section 